\title{
ECLAC
}

Economic Commission for Latin America and the Caribbean

\section{POVERTY Statistics}

SANTIAGO SEMINAR, 7-9 May, 1997

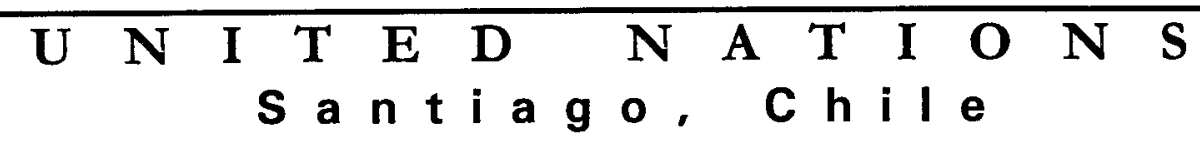



Distr.

RESTRICTED

LC/R.1814

17 April 1998

ORIGINAL: ENGLISH

$\begin{array}{lllll}\mathbf{E} & \mathbf{C} & \mathbf{L} & \mathbf{A} & \mathbf{C}\end{array}$

Economic Commission for Latin America and the Caribbean

\section{POVERTY STATISTICS}

Santiago Seminar, 7-9 May, 1997

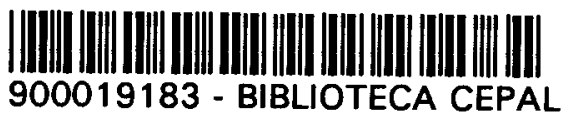

98-4-324 



\section{PReface}

Within the framework of the Statistical Commission of the United Nations, its Working Group in its session of April 1996, created an Expert Group on Poverty Statistics. It was decided that the Expert Group would be chaired by Brazil and that ECLAC (Economic Commission for Latin America and the Caribbean) would act as its Secretariat.

A Seminar on Poverty Statistics was organized by ECLAC from 7-9 May 1997, as a starting point of activities. At the end of the Seminar, the Expert Group met for the first time and identified a group of topics to guide the participants in their common research in the area of poverty statistics. A Second Meeting of the Expert Group (Rio Group) will be held in Rio de Janeiro from 13-15 May, 1998.

The Seminar helped to confirm that "de facto" in many countries of the regions, the government (meaning the Statistical Office or other official department) is engaged in the measurement of poverty. The pressure towards reducing and targeting expenditures gives an operational character to the measurement and identification of the poor. This is, therefore, a field in which user demand is strong and will continue to be so at least in the medium term.

In the measurement of poverty, a clear distinction should be established between synthetic indexes and poverty statistics. The former plays a similar role to other synthetic indexes such as the rate of growth or level of GDP, the unemployment rate, the current account deficit of the balance of payments as a percentage of GDP, etc. The latter includes a broader set of data and indicators related to the design and evaluation of policy measures oriented to alleviate poverty. They pursue the identification of socio-economic groups that suffer poverty. Normally, these groups are heterogeneous and, therefore, their characteristics call for different sets of policies.

For practical reasons associated with the establishment of a working programme for the Rio Group on Poverty Statistics, the experience of the countries was classified in what was related to the estimation of poverty and to the establishment of profiles of poverty groups. In measurement, three areas of work were identified: the income or consumption insufficiency method (poverty lines), the unmet basic needs method and relative measures of poverty. 
In all of these areas of work, papers were presented during the Seminar and they constitute an important gathering of experience of institutions involved in measuring poverty. Therefore, this document contains a valuable collection of experiences and is aimed at helping countries that are measuring or starting to measure poverty. It is hoped that it will encourage institutions or technicians that are measuring poverty to share their experience with participants of the Group and to follow-up research in the topics identified as suitable for international cooperation in the area of poverty statistics.

Pedro Sáinz

Director

Division of Statistics

and Economic Projections

ECLAC 


\section{TABLE OF CONTENTS}

Page

Agenda 7

POVERTY MEASUREMENT. PRESENT STATUS OF CONCEPTS AND

METHODS. Luis Beccaria, Juan Carlos Feres, Pedro Sáinz (ECLAC) 9

EXPERT GROUP ON POVERTY STATISTICS. Simón Schwartzman (IBGE -

BRAZIL)

I. METHOdology ASPECTS AND INFORMATION REQUIREMENTS FOR THE MEASUREMENT

OF ABSOLUTE AND RELATIVE POVERTY

TOPIC 1: Income or Consumption Insufficiency Methods

CHANGING THE WAY THE UNITED STATES MEASURES INCOME AND

POVERTY: A PROGRESS REPORT. DRAFT. Charles Nelson, Daniel H.

Weinbert (USA)

POVERTY MEASUREMENT IN BOTSWANA. Dabilani Buthali

(BOTSWANA)

CONCEPTUALISATION. MEASUREMENT AND DIMENSIONAL ASPECTS

OF POVERTY IN INDIA. P.D. Joshi (INDIA)

POVERTY DEFINITIONS AND POVERTY IN TURKEY. Güzin Erdogan.

(TURKEY)

MEASUREMENT OF POVERTY IN URUGUAY. María Dolores Fernández,

Marcia Rama (URUGUAY)

POVERTY MEASUREMENT AND POVERTY STATISTICS IN AUSTRALIA.

Maureen K. Mc Donald (Australian Bureau of Statistics - AUSTRALIA) 125

POVERTY MEASUREMENT IN AUSTRALIA: THE EFFECT OF GOVERNMENT NON-CASH BENEFITS AND LOCCATION. David Wilson (Australian Institute of Health and Welfare - AUSTRALIA). 145

ANALYSES OF HOUSEHOLD INCOME STATISTICS IN THE UNITED

KINGDOM. Dennis Roberts (UNITED KINGDOM). 163 
INCOME DISTRIBUTION AND POVERTY IN EU12 - 1993. Teresa Bento (EUROSTAT).

POVERTY MEASUREMENT IN INDONESIA. Agus Sutanto (INDONESIA) 183

MEASURING INCOME DYNAMICS: THE EXPERIENCE OF CANADA'S

SURVEY OF LABOUR AND INCOME DYNAMICS. Maryanne Webber

(CANADA).

TOPIC 2: The Unmet Basic Needs (UBN) Method

MONITORING LIVING CONDITIONS AND POVERTY IN SOUTH AFRICA.

Ros Hirschowitz, Mark Orkin (SOUTH AFRICA).

POVERTY IN THE HUMAN DEVELOPMENT PERSPECTIVE: CONCEPT AND MEASUREMENT. (UNDP).

ON STATISTICAL MAPPING OF POVERTY: SOCIAL REALITY, CONCEPTS AND MEASUREMENT. Sonia Rocha (IPEA - BRAZIL)

MEASUREMENT OF POPULATION'S LIVING STANDARDS BY APPLYING DIFFERENT METHODOLOGIES: THE MEXICAN EXPERIENCE. Miguel Cervera (MEXICO)

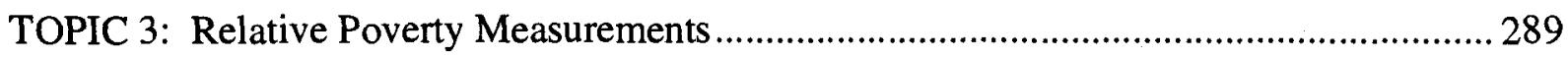

POVERTY MEASUREMENT IN FRANCE. Madior Fall (FRANCE) …….................. 291

STATISTICAL SOURCES FOR THE STUDY OF POVERTY AND

INEQUALITY. Paloma Seoane (SPAIN). 305

II. POVERTY PRofiles AND IMPROVEMENTS IN NATIONAL STATISTICAL CAPACTTY AND INFORMATION DISSEMINATION.

DIMENSIONS OF POVERTY AND DIRECTIONS OF MEASUREMENT.

TALKING POINTS FOR DISCUSSION. Michael Ward (WORLD BANK)

THE PROFILE OF POVERTY: GENDER INDICATORS. (ECLAC, UNSD) ................... 339

GOALS FOR CHILDREN, EXCLUSION AND VULNERABILITY: EXPANDING THE USEFULNESS OF HOUSEHOLD SURVEYS. Alberto Minujin (UNICEF) 
NUTRITIONAL STATUS INDICATORS AND INSTRUMENTS FOR

MEASURING AND MONITORING POVERTY AND EQUITY. Beverley Carlson

(ECLAC).

A BRIEF OVERVIEW OF UNFPA EXPERIENCE IN LATIN AMERICA AND THE CARIBBEAN IN POVERTY STATISTICS AND MEASUREMENT. José Miguel

Guzmán (UNFPA).

POVERTY STATISTICS: IMPLICATIONS FOR LINKAGES BETWEEN HEALTH POLICY AND TO REDUCE POVERTY. Edward Greene (PAHO)

POVERTY STATISTICS AND MEASUREMENT IN AFRICA. Siddig A. Salih (ECA).

POVERTY ALLEVIATION THROUGH ECONOMIC GROWTH AND SOCIAL DEVELOPMENT. Khalid Siddiqui (ESCAP)

POVERTY IN TRANSITION IN EASTERN EUROPE AND THE COMMONWEALTH OF INDEPENDENT STATES. Wolf Scott (ECE) 427

List of Participants 449 



\section{AGENDA}

I. Measurements of poverty prepared at present in countries and international or regional organizations. Typology following conceptual frameworks used. Relation between measurements, present development scenarios and policy design and monitoring.

II. Methodology aspects and information requirements for the measurement of absolute and relative poverty.

A. The income or consumption insufficiency method. Poverty Income Lines.

1. Establishment of standards. Food, housing, health, etc.

2. Measurement of standards. Basic Food Basket, and other non food expenditures.

3. Conceptual and operative problems associated with the measurement of households income and consumption.

4. Public social expenditures.

5. Equivalencies in consumption and scaled economies.

6. Poverty measurements.

7. Sources of information.

8. Requirements for the dynamic analysis of poverty.

B. The Unmet Basic Needs (UBN) method.

1. Selection of social indicators and thresholds definitions.

2. The aggregation problem: construction of the UBN index.

3. Comparison in time and space.

4. Sources of information.

5. The UBN maps and the Geographical Information Systems (GIS).

C. Relative Poverty measurements.

III. Poverty groups profiles as a basis for the design and evaluation of antipoverty policies.

1. Scope and limitations for diagnosis purposes and poverty analysis.

2. Improvement of the national statistical capacity in this area.

3. Results reports and dissemination of information.

4. Towards a basic set of information and social indicators at the national level. 



\section{POVERTY MEASUREMENT}

\section{Present status of concepts and methods}

by

Messrs. Luis Beccaria, Juan Carlos Feres and Pedro Sáinz

ECLAC 


\section{CONTENTS}

I. Approaches to the measurements of poverty in national and international organizations

II. Methodology aspects and information requirements for the measurement of poverty

A. The income or consumption insufficiency method. Poverty income lines

1. Establishment of standards

2. Measurement of standards

3. Conceptual and operative problems associated to the measurement of household income and consumption

4. Public social expenditures

5. Equivalencies in consumption and scale economies

6. Poverty measurement

7. Sources of information

8. Requirements for the dynamic analysis of poverty

B. The unmet basic needs (UBN) method

1. Selection of social indicators and threshold definitions

2. The aggregation problem

3. Comparison in time and space

4. Sources of information

5. UBN maps and Geographical Information Systems (GIS)

C. Relative measures of poverty

III. Poverty groups profiles as a basis for the design and evaluation of antipoverty policies

1. Scope and limitations for diagnosis purposes and poverty analysis

2. Improvement of the national statistical capacity in this area

3. Reporting results and disseminating information

4. Towards a basic set of information and social indicators at the national level 


\section{POVERTY MEASUREMENT Present status of concepts and methods}

Poverty is, and for quite a long time has been, a main issue in most countries, particularly in LDCs but also DCs., since antipoverty efforts usually have a high priority among economic and social policy objectives. In many countries of the world poverty has recently acquired new dimensions and magnitudes as well as considerable political significance. As a consequence, some countries are devoting important resources to the production of statistical data on the extent and characteristics of poverty in their midst, data considered a significant input in policy design. International organizations are also working in this field, sometimes directly supporting national activities, sometimes producing data needed to program and execute work programs required by countries, sometimes investigating methodological questions. However, these efforts have been so far relatively uncoordinated. The purpose of this seminar is, precisely, to take advantage of the disseminated progress attained by countries and organizations with experience in poverty measurement.

Identifying poor persons or households and building synthetic indices of poverty incidence and intensity --the main topics of this seminar-- are obviously not enough for understanding the social situation or for the design of public policy. However, the experience of many countries shows that --as in other fields with a variety of synthetic indicators, such as GDP or the open unemployment rate-- the discussion about poverty incidence or poverty intensity indicators has played an important role in the debate on social questions. Therefore, the Working Group of the Statistical Commission considered that improving the methodological bases of these indicators and taking steps towards facilitating a better understanding of similarities and differences between measurement criteria is a worthwhile effort. It is hoped that this seminar, and the other activities proposed by the Commission will contribute to this objective.

The origins or causes, characteristics, and also political and social pressure regarding poverty alleviation, differ among countries, specially between LDCs and DCs. It is, therefore, worth stressing that these present efforts aimed at intensifying international discussion on poverty measurement do not pretend to reach internationally agreed recommendations.

\section{Approaches to the measurements of poverty in national and international organizations}

In general, a person is considered poor if he or she does not have access to (or lacks the capability of accessing) a normatively established package of goods, services and rights. The establishment of the standard(s) allowing the identification of poor persons has followed alternative approaches reflecting both conceptual differences and data availability. The differences stem from different views regarding some of the dimensions which need to be considered. One of them relates to the absolute or relative character of poverty. No attempt will be made here to summarize the vast literature on the conceptual aspects of this subject and on the controversies about the comparative advantages of each of the two approaches. It should be mentioned, however, that --as indicated above and regardless of theoretical considerations-- 
national characteristics play an important part in deciding on the more appropriate approach. The level of development appears to be a key factor, since increasing the satisfaction of basic needs is a pressing goal in the LDCs. Therefore, it seems convenient to measure the size and characteristics of poverty by establishing standards in terms of definite quantities of goods and services allowing the satisfaction of a set of basic needs. In many of the more advanced nations, absolute poverty may be a minor problem, but reducing gaps among population groups is increasingly becoming a high priority goal. This is one of the reasons why standards are in some cases established considering the population's average level of need satisfaction.

Differences in poverty measures also arise because in some cases actual consumption of or access to goods and services are considered, while in others the capability --in terms of resources-- of a person or household to obtain them is the variable considered for identifying poor persons.

National and international agencies resort to poverty indices --together with other indicators-- for policy monitoring. However, not all the usual measures are equally appropriate to this task. A given poverty index may not consider those aspects and dimensions that are to be monitored which deserve a high priority in the policies aimed at improving the standard of living. As it will be mentioned below, the effect of a housing improvement program may not be reflected in the poverty incidence based on income measurement. And if these do take into account some such dimensions, the degree of sensitivity to policy changes may be low (the basic need approach is scarcely sensitive to money transfers). In order to get a clearer picture of a given situation it seems necessary to analyze a combination of indices.

The types of data used in poverty measurement are closely related to the statistical capabilities of each nation. Household surveys and population censuses are usually the main sources, but they differ in scope, frequency and quality from one country to another. Few countries resort to administrative records. ${ }^{1}$ However, data employed in estimating poverty indices also depend on the demands posed by the main users of such data. In relatively stable and high income economies the principal objective is the analysis of the structural characteristics of poverty and in those cases it does not seem necessary to produce frequent measurements. In such cases, detailed information on several dimensions to facilitate in-depth analyses is of particular interest. In countries undergoing ample macroeconomic fluctuations and/or structural adjustments, the living conditions of large portions of the population may vary substantially even in the short run. In such cases frequent measures are in order.

Hitherto, no specific mention was made of the unit considered in poverty measurements since we have referred without further discussion to "poor persons" or "poor households" indistinctly. The international experience shows, however, that households are, almost

\footnotetext{
${ }^{1}$ The Scandinavian countries used tax and social security records, see Epland, J. The combination of survey data and register data. The case of Norway, Paper presented at the Meeting of the United Nations Expert Group on Household Income Statistics, Canberra, 1996.
} 
exclusively, the units classified according to the poor / non-poor dichotomy. In countries using tax records, income units are usually considered ${ }^{2}$

\section{Methodology aspects and information requirements for the measurement of poverty}

This section includes a description of the poverty measurement methods most frequently adopted by national and international agencies. Following generally agreed typologies, they were grouped in three classes. In each of the first two headings the more usual procedures followed to assess absolute poverty will be discussed; in the third one, the relative approach will be considered.

As is many other classifications, it is not always possible to include some of the specific methodologies used to produce a given poverty indicator in one of the above three classes. For example, those using an approach termed as "absolute" may resort to certain "relative" considerations at some stage of the estimation procedure. Therefore, the distinction - even if drawn on the basis of conceptual considerations-- has been adopted chiefly to facilitate the presentation of the experiences during the Seminar.

\section{A. The income or consumption insufficiency method. Poverty income lines}

This is perhaps the more widely used method and the one adopted in the first attempts to attain quantitative assessments of poverty. ${ }^{3}$ According to this approach, a household --the unit generally considered, as mentioned before-- is classified as poor if its income or aggregate expenditure is less than the value of a given "poverty line". The poverty line is a normative concept: it represents the aggregate value of all the goods and services considered necessary to satisfy the unit's basic needs. Therefore, this approach requires, in the first place, determining the poverty line and, secondly, obtaining data on households income or expenditures distribution. Afterwards, one or more dimensions of poverty can be synthesized using alternative indices.

Since they are less often used, our discussion will not focus on methods identifying poor households as those with a certain expenditure structure; specifically, those with a ratio of food expenditures to total expenditures higher than a certain value. ${ }^{4}$

This heading will discuss precisely the more important methodological aspects involved in the process of poverty measurement estimation using income or expenditures. The possibility

\footnotetext{
${ }^{2}$ In Australia the "family" is also employed, see McLennan, W. A provisional framework for household income, consumption, saving and wealth, ABS Catalogue $\mathrm{N}^{\circ}$ 6549.0, Australian Bureau of Statistics, Canberra ACT, June 1995.

${ }^{3}$ For a brief description of the studies carried out in the thirties and fifties in England, see Atkinson, A. Poverty and social security, London: Harverster Wheatsheaf, 1989, Chapters 3 and 4.

${ }^{4}$ The cutoffs of Canada are established according to this approach.
} 
of using alternative procedures in many of the specific questions explains the differences found between particular indices calculated by different nations and/or international agencies. This international experience will be taken into consideration to exemplify the available options as well as certain of their implications.

Besides discussing the methodological aspects, reference will be made to the statistical data used to estimate poverty indicators. This is not a subject to be dealt with separately from the methodological questions, since these are influenced --and in some cases fully determined-- by the availability and quality of information. Recent experience has shown that intensive use of available information to produce timely indicators has lead to significant increases in resources and in the quality of information.

\section{Establishment of standards}

The definition of a poverty line is the first required task when adopting this procedure. As indicated above, it is the amount of money that a household has to receive or spend in order to buy all the goods and services necessary to attain a minimum level of living or to satisfy the basic needs. In computing this normative value several decisions and procedures are required: i) to define the set of basic needs; ii) to determine the thresholds of satisfaction; iii) to select the kinds and quantities of goods and services required to satisfy each identified need; iv) to price the resulting package of goods and services.

In most of the known experiences the establishment of the poverty line has not followed closely these successive steps. The value of the normative set of goods has been directly estimated only in the case of one or --most rarely-- a few basic needs, while for all the other needs an aggregate value corresponding to the normative budget has been calculated indirectly. This means that no specific efforts are made to define thresholds for many basic needs. Such procedures are adopted chiefly because of practical considerations but they also reflect, on one hand, the difficulties in reaching widespread consensus on what should be reputed as basic needs and their level of satisfaction, and, on the other, the relevance of an aggregated income value where substitution possibilities might allow the satisfaction of basic needs.

In a few countries, the poverty line estimation procedure differs from that indicated above because there is no intention of defining a line based on expert opinion of specific thresholds. Instead, the perception of people about what is the minimum necessary household budget is considered the best standard of comparison for actual incomes or expenditures. In these cases, a survey of a representative sample of the population is carried out to ask what values are considered to define a poverty line. No further discussion of this approach will be made here; in what follows, the analysis will be restricted to aspects related to the determination of a poverty line following basically the steps mentioned in the first two paragraphs of this subheading.

When estimating directly the normative basket of goods and services, thresholds are generally (but not always) fixed in a non-product basis and only then the package of goods and 
services allowing the threshold to be reached is established. The most typical case is that of food, where the threshold is determined in terms of nutritional requirements (generally, calories and proteins, see next section). In order to translate the minimum quantity of, e.g., calories into quantities of different foods, two factors are considered: on one hand, the actual consumption patterns of the population (strictly, of a reference population), on the other, costs. Consequently, the normative food basket (generally referred to as the Basic Food Basket) must satisfy nutritional requirements but exclude the less frequent consumed items as well as the most expensive ones, i.e. the basket includes cheap available foods which are the usual ones in the actual diet of the reference population. The price of the cheaper varieties of the selected foods, purchased in the outlets where the reference population usually buy food ${ }^{5}$, are used to value the normative basket in order to establish to the normative food budget.

There are a few examples of poverty lines that include independent estimations of housing requirements. In such cases, the threshold is, to a certain extent, also fixed in non-product terms (e.g. square meters or rooms per person, sewage disposal, water supply).

The non-directly estimated components values of the normative budget are calculated by assuming that their ratios in the poverty line are the same as those registered in the actual average expenditure structure of a given population group. For example, many countries follow the Orshansky criterion used in the United States: the total poverty line is computed by applying the ratio total expenditures / foods expenditures to the normative food budget, which is the only component independently estimated.

Different households require different quantities of goods and services to satisfy their basic needs, due to differences in size and composition. Sometimes, this aspect can be dealt with in a relatively simple way as in the case of food, since the nutritional norms used to estimate requirements (see next section) are established for different type of persons. In general, these problems can be solved (albeit partially) when establishing specific thresholds. A serious difficulty arises in the case of indirectly fixed standards. This subject will be analyzed in subheading 5 .

As it was mentioned above, reference populations should be identified as representative of the consumption patterns (in order to define the normative package) and also to calculate the ratio of food (or food plus housing plus other components) expenditures to total expenditures. The reference groups sometimes include strata of low income households: in those cases, these strata can comprise some households barely complying with minimum nutritional standards, implicitly assuming that those units satisfying the nutritional requirements are also able to satisfy other needs.

\footnotetext{
${ }^{5}$ At least in many LDCs, the buying patterns --and, consequently, the prices paid-- may be quite varied among different economic strata. Poor families usually buy at around-the-corner shops where they may sometimes benefit from informal credits, but pay higher prices.
} 


\section{Measurement of standards}

Direct estimation of thresholds is almost restricted to the value of an assortment of foods satisfying various nutritional requirements: energy, proteins and other micronutrients. In most cases energy is the dimension chiefly involved in the basic estimation, and some of the other requirements are taken into account afterwards when defining the food basket. This means that international $^{6}$ or national standards are employed to establish the minimum calorie requirement. These standards vary according to --among other things-- the individual height, weight, age, sex, health status, eventual pregnancy, and the activities he or she usually performs. Since some of this information --especially, height, weight, health conditions, pregnancy-- is not usually available in the data bases used to estimate poverty indices, nutritional requirements are generally defined for groups of persons which are defined in terms of age brackets, sex and type of main activity. The average heights and weights of the population under study are considered when deciding the standards.

Once the energy requirements are established, the food basket satisfying them is computed considering both actual consumption patterns and relative prices. Basically, the approach can be seen as an exercise in minimizing the cost of a budget having as a restriction the actual expenditure patterns. Various specific procedures have been considered to take into account these two factors, some of them emphasizing cost while the rest focus on expenditure pattern.

The protein and other nutrient content in the first-round basket is then evaluated; as a consequence, adjustments are introduced if minimum nutritional standards are not satisfied.

Consumption patterns are generally approached using expenditure data obtained from income and expenditure surveys. This source is also used to estimate the rate of food expenditure to total expenditure for a reference population group, which, as we have already mentioned, is used to establish the normative value of the non-food components of the poverty line. Sometimes, a low (but not the lowest) income bracket is considered; in other cases, the reference group includes households with a food basket slightly exceeding minimum energy requirements. Since this last group is relatively small --especially when sample size is taken into account-- it is increased by considering households with slightly higher incomes. ${ }^{7}$

It must be taken into account that expenditure data are not always a fully adequate input in the process of estimating food (or other component) normative basket. In some countries surveys are only carried out with low periodicity and/or may be restricted to a part of the country (i.e. the larger cities).

${ }^{6}$ Such as the experts' recommendations forwarded at a consulting meeting convened by FAO, WHO and UNU.

${ }^{7}$ Actual food supply should also be taken into account when defining the normative food basket, since, e.g., shortages for some commodities may have appeared/disappeared between the reference period of the expenditure survey and that of the poverty indices. 
Prices defining a low cost basket as well as the value of the resulting food basket are also aspects requiring careful consideration because of the already mentioned market segmentation affecting many products. The prices surveyed for Consumer Prices Indices are usually considered. Different food varieties and qualities should be defined when establishing the basket, because the identification of products in the income and expenditure surveys is not always as detailed as would be necessary. Sometimes the prices considered when assessing the value of the food basket are those obtained from the type of outlets where low income households usually do their shopping.

The food expenditure / total expenditure ratio used to compute the aggregate non food value of the poverty line reflects the average for a reference population. However, using such an average may introduce a certain bias when identifying poor households, due to the level of diversity existing in several aspects. ${ }^{8}$ In particular, two aspects have sometimes deserved specific attention: housing and publicly provided goods and services. The latter will be specifically analyzed in subheading 4 . In regards to housing, the rent value implicitly included in the non-food portion of the poverty line is that resulting from averaging the actual values paid by households actually renting their dwelling and a zero value assigned to those not paying rent (owner-occupants and other situations). Therefore, this factor needs to be taken into account when estimating the non-food portion. One alternative is to impute a rent value to the owner-occupant households; as a consequence, the value of the non-food component of the poverty line will rise. Symmetrically, an imputed income equivalent to this rent has to be added to the actual incomes of these households. Alternatively, different poverty lines for those facing a different situation in regards to housing may be calculated. Similar criteria may be applied to other non food components in some respects analogous to housing.

\section{Conceptual and operative problems associated to the measurement of household income and consumption}

In order to identify poor households, the poverty line is compared to either total current income or total expenditure. Both conceptual and empirical reasons are used to favor one or the other of these alternative. As for theoretical questions, it is sometimes argued that the relevant variable is the household's capacity to purchase goods and services, which is best reflected by income. For example, a given unit may be spending above the poverty line but only as a consequence of borrowing; this household should be considered poor as it is not clear whether it will be able to maintain the acquisitive power. Conceptual considerations are also advanced to argue in favor of the use of expenditure as it would be a better proxy for "permanent income" which is the adequate variable for medium and long term poverty analysis as it reduces the impact of temporary fluctuations in current income.

\footnotetext{
${ }^{8}$ Bias derived from differences between the average and each household's size and composition will be discussed in subheading 5 .
} 
On the empirical side, it is usually emphasized that in household surveys --the most generalized source used for this purpose ${ }^{9}$-- expenditure estimates are of higher quality than income estimates: different non-sampling errors usually affect the latter, basically un- and underreporting. Many studies have shown that this problem is present in most countries although with varying intensity. ECLAC has been working in this topic and will publish a document towards the end of 1997. Using data from National Accounts as a norm, overall underestimation has been estimated in $15 \%$ in some $\mathrm{DC}^{10}$ or between $15 \%$ and $40 \%$ in some Latin American countries. ${ }^{11}$ However, household spending data are not free from problems when used in poverty assessments. Also affected by un-and underreporting, the short reference period used in surveys on food and other commodities spending, total expenditures for a individual household could be abnormally high or low.

Moreover, expenditure data seems to be adequately measured only through a disaggregated inquiry into the various goods and services bought and received by household members, i.e. through a traditional expenditure survey. However, we have already mentioned that in most countries such surveys are carried out only sporadically --once every ten or at best five years--. Consequently, in many countries income data --collected in multipurpose household surveys-appear to be as the only alternative for a follow up of the poverty situation. In addition, increasingly more disaggregated methods have been put into practice to evaluate the reliability of income measurement in these surveys, especially in urban areas, thus helping to reduce errors.

Income estimation from household surveys may incur in particularly large errors in rural areas, specially in those where small producers are an important proportion of the total population. Seasonality, lack of adequate registers, barter transactions, subsistence activities are some of the factors that make it difficult to gather good quality income data from such surveys. However, some of these same factors also lead to larger errors in measuring expenditures through household survey. Only more expensive and operatively complicated surveys on goods and services actually consumed could reduce the level of errors.

When income is employed, the disposable version should be used, i.e. all money and in kind components net of taxes and personal contributions to social security. According to the treatment applied to housing (as seen in the previous subheading) and to publicly provided goods and services in the poverty line, it may be also necessary to impute these items.

\footnotetext{
${ }^{9}$ As mentioned, income and social security records are used as main source only in a few DCs.

${ }^{10}$ Data for the Netherlands coming from van der Laan, $\mathrm{P}$ and $\mathrm{H}$. van Tuinen, Increasing the relevance of income statistics: experiences and plans in the Netherlands, Presented at the first Meeting of the UN Expert Group on Household Income Statistics, Canberra, 1996.

${ }^{11}$ Data from work underway at ECLAC.
} 


\section{Public social expenditures}

It was implicitly assumed in the previous section that consumption is totally financed by households, without considering that portion which is partly or wholly subsidized by the state. Again, this situation does not introduce any particular difficulty in the estimation of the poverty line when thresholds are directly computed. In such cases, minimum requirements in terms of goods and services are determined irrespectively of sources of financing. Household incomes to be compared to the poverty line have to be increased in order to take into account these inkind transferences received from the government.

However, when non-food components are indirectly estimated, the existence of publicly provided or financed products is sometimes a source of complications, not always recognized in the process of poverty line estimation. These difficulties appear only when subsidies are not generalized to the entire reference population under consideration. For example, if all the school age children in all households of the reference stratum attend state-run schools ${ }^{12}$, the poverty line computed using the total expenditure / food expenditures ratio is an adequate ${ }^{13}$ value to be compared to actual household incomes. Changes need not to be introduced in the poverty line estimation procedure above discussed nor should incomes be imputed for the totally subsidized school fees. However, for other types of analysis, such as those which resort to the Engel coefficient as an indicator of welfare, such amounts should be added on both sides.

The situation becomes more complicated when public social expenditures are unequally distributed between households of the reference population, i.e. some of them do not have access to subsidies and/or the benefit level varies. In these cases, a circumstance similar to that commented when discussing the estimation of the housing component of the poverty line arises. Average recorded actual expenditures in goods and services benefiting from targeted subsidies is actually the average of households with different level of subsidies (i.e., ranging from those fully paying for the product to those receiving them freely). Under these conditions, the poverty line calculated by the indirect method is biased. A solution to this problem would be to establish different total expenditure / food expenditure coefficients for the various groups. The actual and final level of the bias also depends on the treatment given to incomes, i.e., to what extent these in-kind subsidies were added to total registered income.

To take into account such circumstances, it is necessary to add to the recorded expenditures a value equivalent to the subsidies provided to households. Continuing with the example used above, an imputed fee should be added to the actual expenditures of households with children attending state schools. Practical --and also conceptual-- problems arise when trying to implement such an approach for some of the subsidies. Health is a good example of such

${ }^{12}$ Or receive a voucher for the same tuition value to be used either in public or private establishments.

13 "Adequate" in terms of the assumptions of the indirect approach, i.e. incurring the problems indicated in previous subheadings. 
difficulties, since it is not clear how to define the benefit received by each household, specially because many health services are not frequently used. Perhaps, an equivalent value for a health insurance premium covering a basic package could be considered for those eligible for subsidies. In this case, actual payments for those services (covered by the insurance) registered in the expenditure survey should not be considered when estimating the poverty line. The total (or partial) value of the insurance premium should also be added as an imputed component to the income of those households receiving free (or low cost) care. However, such an alternative is not immune to other complications. For instance, it is not always possible to know whether a given household member benefits from the access to free (or partly subsidized) care. Furthermore, household surveys (the source of income distribution data used to estimate poverty indices) do not always record access to subsidized health care, consequently, it is not always possible to identify those units in the set of households for which in-kind subsidies have to be imputed.

These comments are intended to illustrate the difficulties and restrictions facing the indirect measurement of poverty line components when public social expenditures are targeted ${ }^{14}$ (at least, within the reference population). Programs of a more universal character (such as primary education in most countries) do not pose any difficulty. How to take into account such a factor depends mostly not only on data availability but also on institutional arrangements. It is necessary to stress that they should be carefully considered in cases where public expenditure of a non-universal character are important and/or where changes have been introduced in the level and characteristics of public expenditures. For example, the increasing efforts made by many LDCs in targeting their social policies may lead to biased assessments of poverty evolution if no consideration is made of the impact of public expenditure.

\section{Equivalencies in consumption and scale economies}

It was already mentioned (subheading II.A.2) that thresholds should be household specific because they depend on household size, age-sex composition and specific circumstances of those living in the unit. Hence, minimum requirements and, consequently, poverty lines, should be computed (or equivalencies calculated) for as many household types as need to be defined in order to capture differences stemming from the relevant dimensions.

Concentrating in the first two above mentioned aspects (i.e., size and age-sex composition -those more oftenly considered--) it is clear, on the one hand, that households of different compositions should have different thresholds, since the set of goods and services satisfying basic need varies with age and sex. On the other hand, the influence of household size is obvious and in principle should not lead to theoretical and practical problems, since --for a given composition-- proportionality in the value of the poverty line would be enough. However, household size does introduce (at least potentially) a major practical problem:

\footnotetext{
${ }^{14}$ It must be stressed that this applies strictly to subsidies which do not reach all members of the reference population; this could be the result of programs being targeted or simply to an inadequate implementation of policies intended to be universal in scope.
} 
proportionality is only a rough approximation, given the existence of consumption scale economies in several budget components. It must be stressed that these two phenomena -equivalence among households of different composition and scale economies-- are linked. For example, scale economies in education (if they exist) would depend on the total number of students and not on the overall household size. In the following discussion both phenomena will be treated separately for the sake of clearness.

Differences in composition may be accounted for in a manageable way when thresholds are directly computed. The above description of the steps usually taken to estimate a normative food basket reveals that equivalencies between the demands of individuals of with different age and sex can be calculated. ${ }^{15}$ This is actually done in some countries where the requirements of energy are estimated for different population groups, thus allowing the calculation of equivalencies scales in food consumption. ${ }^{16}$

On the contrary, the effect of composition is difficult to consider for indirectly estimated poverty line components. In principle, it would be possible to compute total expenditures / food expenditure ratios for each household composition. However, this exercise would surely pose sample size problems. Because of this and other reasons, only one such ratio is considered in some cases; it is applied to the value of normative food baskets corresponding to different age-sex composition groups, in order to define a poverty line for each of these different groups. This procedure rests on the implicit assumption that the nutritional equivalencies are representative of non-food equivalencies. In other cases, even if equivalencies are available for food, only one poverty line is calculated using the average composition of the reference population to establish the basic food basket (average per capita poverty line).

There is scarce experience with scale economies when estimating poverty lines, and the influence of household size is considered exclusively through the use of equivalence defined on the basis of the total number of household members. There are several exercises, developed with other purposes, which estimate total budget scale economies; however, they lead to widely varying results. Therefore, more research is needed before establishing practical approaches to quantify the impact of this dimension. It must be emphasized that this is an aspect of considerable relevance to certain groups, specifically to large and small (in particular, one member) households. Thus, the influence of considering scale economies on poverty profiles could be of some importance. Nonetheless, simulations carried out by ECLAC for one country proved that it was of no relevance to the aggregate incidence indicator, but still, the profile of the poor could be influenced.

\footnotetext{
${ }^{15}$ As indicated, not only sex and age but the type of activities usually carried out by adult households' members are also considered.

${ }^{16}$ See, for example, ECLAC, Magnitud de la pobreza en América Latina en los años ochenta, ECLAC Studies and Reports $N^{\circ} 81$, Santiago de Chile, 1991.
} 
Again, it would be relatively simple to take into account the impact of equivalencies scales for (at least some) specific necessities. For nutritional needs, practically the only one to be directly evaluated --as it has been repeatedly indicated-- experience shows that it is possible to establish equivalencies scales on more objective bases.

To sum up, neither composition equivalencies nor scale economies are considered in some methodologies used in poverty line estimation. In these cases, only one per capita normative budget is used on the basis of a per capita basic food basket reflecting the average age and sex structure of the reference population and the total expenditures / food expenditure ratio of this same group. This per capita poverty line is compared to incomes of all households, regardless of age and sex composition. In other cases, nutritional equivalencies are taken into account and, therefore, per capita basic food baskets are computed for household of different types; scale economies are not accounted for. Thus, poverty lines are usually estimated using only one total expenditures / food expenditure ratio, using implicitly the assumptions already indicated. Anyhow, it should be remembered that adopting a global ratio for no-food expenditures allows substitution in the way that the reference group uses -de facto- its budget possibilities. Adding normative standards for different needs would introduce a certain rigidity in expenditures.

\section{Poverty measurement}

Hitherto, the discussion has dealt with procedures usually followed to distinguish poor households or other units from non-poor households or persons. However, this is only the first stage in the process of quantitative poverty analysis because this classification is an input commonly used to build up two sets of information. On the one hand, to compute indices summarizing one or more dimensions of poverty. On the other hand, to prepare comparative profiles of poor and non-poor groups --in terms of variables such as education, sex, age or occupation-- which could be of interest in analyzing causes and origins of poverty and in policy design.

We shall briefly discuss here synthetic indicators because references to profiles will be dealt with in section III.

The head-count ratio showing poverty incidence is the most widely used indicator. It informs on the proportion of total households classified as poor (i.e. with incomes below the poverty line) or the ratio of persons living in poor households to the total population. It is used chiefly for comparisons between different periods and areas, it often being the starting point for social policies programming since it is sometimes used to obtain rough figures about the target population for some anti-poverty programmes. However, this indicator, does not take into account other changes or differences that are relevant in assessing poverty: in particular, it may show no variation while the degree of poverty -i.e., poverty intensity-- is rising or declining. Therefore, an intensity index is also produced in some cases; it is defined as the average difference between the poverty line and the actual income of each poor household. 
It was also pointed out that neither of these two indicators --i.e. incidence and intensity-allows for changes or differences in income distribution below the poverty line; hence, it is possible that both of them remain unchanged while inequality varies. Those who point out these objections propose indicators taking into account the three dimensions considered. The alternative indices combine these dimensions in various ways and consider, implicitly or explicitly, different functions to assess income distribution. The latter is an already well known situation when choosing between income distribution synthetic indicators. For example, the Sen poverty index resort to the Gini coefficient to assess inequality, while that developed by Foster, Greer and Thorbecke uses the approach earlier proposed by Atkinson of explicitly incorporating the degree of inequality aversion.

It is necessary to insist on the practice of presenting a menu of different indicators; when they are used together, a more comprehensive picture of poverty emerges and a more accurate analysis of changes through time and of differences between countries or regions can be performed.

\section{Sources of information}

In the previous headings, when discussing specific aspects of the procedures used to estimate poverty indices, it was necessary to refer to some characteristics of data regularly considered. It is worth summarizing here, in a more systematic fashion than before, the statistical sources employed, their main shortcoming as well as their strengths.

When calculating the poverty line, expenditures surveys play a major role in the direct estimation of thresholds, because they provide information on consumption patterns used to establish the minimum requirements in terms of goods and services. Such surveys are also the source of total expenditure / food expenditure ratios used to indirectly estimate the non-food components. Regarding this last point, eventual differences in un- and underreporting of expenditures for the various components may affect those ratios and, hence, bias the total poverty line estimation. Also, when targeted subsidies are important, the structure of expenditures may not adequately reflect actual consumption structure. If access to (some of) these subsidies is recorded --as it occurs in many surveys-- such expenditures may be imputed in order to minimize this problem.

Expenditure surveys and general household surveys are the most frequently used sources of households expenditure or income data which are compared to the poverty line in order to estimate the different poverty indices. In general, since they are integrated into permanent programs --particularly general or employment household surveys-- time series of these indicators are produced. The reasons for preferring either income or expenditure were already discussed in subheading 3 . It was also indicated there that data on income (and also to a lesser extent on expenditure) are generally un-or underreported. The extent of these errors is generally assessed by comparing, for each type of income source, the aggregate survey estimate to that obtained from the system of national accounts. The difference thus computed is then used to correct survey data. The procedure usually followed poses a major problem in poverty --and 
also income distribution-- analysis because the average error --i.e., the overall difference just mentioned-- is used to adjust incomes of a given type for all individuals answering the survey, irrespectively of income size or other variables; it is therefore assumed that every person register the same degree of error. This alternative is used because there are no reliable indications about underreporting distribution; however, possible effects of such procedures should always be taken into account when using poverty indices. In many cases, the possible bias is diminished because underreporting distribution of property incomes does not follow that procedure --i.e., it is not evenly distributed-- but takes into account the distribution of assets. It should also be remembered that progress in household surveys data and national accounts are not independent. Measurements on poverty and income distribution constitute a challenge for these sources of information that normally derived in progress for both.

From the perspective of poverty studies, improving income data should be a major goal for those in charge of household surveys. Experience can be gained from efforts already made by other countries in questionnaire design, training and imputation techniques. These subjects were also chief matters of concern at the Canberra Group's first meeting in December 1996. It is necessary to recognize, however, that reasons for underreporting do not only depend on inappropriate surveying, specially in LDCs. A large non-registered economy and the importance of certain items which are difficult to record are two relevant reasons leading to normally high errors. Regarding the latter case, a portion of some households' income in many developing countries is the remittance of money by relatives working and living abroad. This has proved to be a difficult component to inquire about, although improvements could be made. The problem of measuring income in backwards rural areas is perhaps the major challenge for those countries with a large rural population.

It is also necessary to produce other changes in the current surveys in many LDCs, in order to produce more meaningful data. These changes do not refer to income measurement aspects but to sampling and operative questions. In many cases, the survey cover only part of the country, while in others data are produced with a complete lack of timeliness.

In a few countries (e.g., in Brazil, Canada, and Mexico), population censuses are another source of income distribution data which could be used to derive poverty indicators. The difficulties already mentioned in the case of household surveys are also present in census. Moreover, it seems it would be more difficult to inquire about income with the same care --in terms of disaggregation of items, for example-- as in surveys.

It has already been indicated that in a few DCs, administrative records are used as a source of income distribution data, showing a lower degree of error than surveys. This source will surely, for some time yet, remain restricted to statistically advanced countries. The possibility of combining different records and also of matching records with surveys on very specific aspects provides those nations with very rich statistical basis. In other countries, records can -and are actually beginning to-- be employed either as partial source for income distribution but mainly for assessing the quality of survey data. Some of them, such as the social security records, could even be considered when analyzing difference in underreporting across groups. 


\section{Requirements for the dynamic analysis of poverty}

In order to study poverty evolution, it is not always enough to analyze series of some of the above mentioned indices. An important aspect shown by different studies, mainly carried out in DCs (USA and Germany, for example) but also in some developing country, is the existence of high turnover, i.e. many households classified as poor in one period change their status (become non-poor) in the following period, and viceversa. It is therefore frequent that households cross to and from this border constituted by the poverty line and, consequently, the head count ratio may not register any change between two successive periods while relatively intense movements across the poverty line are actually occurring.

This is in part due to the effect of using current income which, for some households, may exhibit seasonal or short term variations. But it also results from more important changes in, say, labor market conditions or relative prices. Thus, it would be highly convenient to follow poverty evolution through the use of indicators based on panel data. In many permanent surveys, households are interviewed several times making it possible to produce panel type information. It would be, therefore, highly convenient to fully exploit this possibility in order to generate data on poverty turnover. It could be argued, however, that since the same household remains in the panel for only a relatively short period of time (one or, at most two years) information coming from regular household inquires is not completely adequate. Longitudinal surveys following the same panel of units is the necessary instrument to track the evolution of poverty. Some DCs carry out this type of efforts aimed at measuring not just the poverty indices and poverty turnover but also other social questions, including structural determinants of poverty, which are best assessed employing dynamic data. One must keep in view that these surveys are relatively more expensive and perhaps do not have at present a high priority in those LDCs which are setting up or consolidating their permanent household surveys.

\section{B. The Unmet Basic Needs (UBN) method}

While the income or consumption method identifies poor households as those without the capacity of acquiring all goods and services needed to satisfy basic needs ${ }^{17}$, the unmet basic need (UBN) approach inquires whether the household is actually satisfying those needs by asking about the products actually consumed. A unit is then regarded as poor if the thresholds for all or some of the different basic needs are not reached.

The UBN method has been widely adopted in Latin America to estimate poverty incidences and profiles using mainly data from population censuses about access to necessary goods and services. In fact, probably the main reason for the widespread acceptance of this approach during the eighties has been the possibility of obtaining geographically dissagregated

\footnotetext{
17 This also applies when expenditures instead of incomes are used (see subheading A.3), since total expenditure is compared to the poverty line.
} 
indicators, i.e., the possibility of obtaining "poverty maps". As a consequence, a synthetic index to characterize social conditions in small areas was relatively easy to calculate at a moment where targeted social policies became increasingly considered in the region. As it will be seen in the next subheading, this more detailed geographical disaggregation is obtained at the cost of considering only a restricted set of needs. While the income or consumption approach implicitly covers every needs, the UBN method as it is usually applied in the region considers only a few of them.

The specific methodology developed in Latin America is only remotely related to some studies performed in DCs (particularly in the UK) where households are classified as poor if they do not actually attain certain level of consumption of given products and/or do not usually carry out specific activities (e.g., receive/invite friends at home). ${ }^{18}$

Even if the discussion between the absolute and the relative approach is not usually explicit in this methodology, the indices estimated in Latin America have been considered as reflecting situations of absolute poverty because of the dimensions and thresholds actually used. However, relative considerations should be --and have been-- incorporated when defining these limits. This is clearly seen in the European studies where an explicitly relative stance was adopted and the most frequent practices --in terms of access to products and social habits-were used as thresholds. In Latin America because of the dimensions selected, poverty identified through the UBN tended to be considered of a more structural character than that identified by means of the income / expenditure approach.

Before analyzing specific aspects of this method, it should be taken into account that both approaches are not, in fact, alternative ways to describe the same phenomenon; they are depicting different phenomena or, at best, partial aspects of a comprehensive notion of poverty.

\section{Selection of social indicators and threshold definitions}

Conceptual arguments were not considered in the selection of the basic needs nor in choosing the set of goods and services used to assess the level of satisfaction. Both decisions were almost exclusively determined by the subject coverage of the population censuses and the specific variables there included. As a consequence, housing was the main dimension taken into account: three or four out of the five or six variables used to reflect access to goods and services were related to this dimension. Only when defining thresholds for each of these variables the association with income (usually analyzed by resort to a household survey) was sometimes considered.

In general, indicators of access refer to three basic aspects: quality of building materials, availability of basic services (water supply and sewage disposal) and overcrowding.

\footnotetext{
${ }^{18}$ The best known is probably Townsend, P., Poverty in the United Kingdom, Harmondsworth: Penguin, 1979.
} 
In many cases it can be seen that the value adopted as threshold implies extremely low minima, i.e., the limits are scarcely demanding. The reason for such a decision has to do probably with the aggregation criterion chosen (see next subheading). In some few cases no difference was established in the thresholds used for rural and urban areas, and those adequate to the former (and hence less demanding) were used in evaluation of urban households.

In the study on Chile which probably inspired the use of the UBN method throughout the region $^{19}$, the adequacy of household equipment (e.g. some electrical appliances) was also considered. Other countries' censuses did not inquire on the existence of these assets. For this practical reason and other theoretical considerations, the estimation of poverty incidence in Latin America during the 80 s and the 90 s did not include that indicator.

Another dimension usually included was education, which is estimated through school attendance by household children of primary school age.

The argument sometimes adduced to support the selection of indicators is that the enjoyment of adequate housing and the other dimensions considered is highly correlated to income, or that such a situation reveals a more favorable and stable social condition than when using income. It is believed, too, that they are also associated to the satisfaction of other basic needs, i.e. they operate as tracing indicators. Unfortunately, this correlation is far from perfect (see next subheading); however, it is reasonable to assume that households living in inadequate housing --especially when scarcely demanding thresholds are applied-- and with children not receiving basic education, should be considered poor. However, more restrictive limits seem to reflect more aptly the satisfaction of housing needs. Moreover, there are other significant dimensions, such as nutrition or access to health services, whose insatisfaction may coexist with adequate housing and school attendance as assessed in usual poverty indices based on the UBN method.

An "economic capacity" dimension was also considered in most Latin American exercises; it tries to reflect the households' income generating potential. This dimension is, however, somewhat extraneous to the UBN approach since it attempts to measure capacity and not actuality. This capacity is measured by combining the dependency ratio (household size / number of its income-earning members) and the household head's educational status. In most countries, the marginal contribution of this factor to the overall incidence indicator has proved to be small.

In the above mentioned European studies, the list of indicators was established by the analyst since in these cases specific household surveys were carried out. In some cases, even the indicators to be used in the definition of poverty were selected on the basis of the population's opinion. ${ }^{20}$

\footnotetext{
${ }^{19}$ ODEPLAN-IEUC, Mapa de extrema pobreza, Santiago de Chile, 1975; and Mapa de extrema pobreza en Chile: 1982, Santiago de Chile, 1986.

${ }^{20}$ Brownlee, H. Measuring living standards, Australian Living Standard Study Paper $\mathrm{N}^{\circ}$ 1, AIFS: Melbourne, 1990.
} 


\section{The aggregation problem}

From a conceptual point of view, the main problem with the UBN approach is connected with the aggregation question. Since different indicators of access to satisfactors are used, it is necessary to establish criteria to classify households that comply with some of the thresholds but not with the others. This situation is not unusual: furthermore, it has proved to be the most frequent one. ${ }^{21}$ Hence, the idea of how to weight the different indicators rapidly arises.

The method used in all the Latin American estimations is the so-called co-realization: a household is classified as poor if it does not reach the threshold of at least one indicator. Hence, registering an adequate access to all but one of the goods and services is sufficient to class a unit as poor. In fact, between 20 and $30 \%$ of all households (and between 30 and $50 \%$ of all households identified as poor following this method) in seven Latin American countries registered such a situation. ${ }^{22}$ This criterion seems especially appropriate if thresholds are very low and reflect extreme deprivation. The study on Chile referred to in the previous subheading followed basically the co-realization criterion, but imposed the combination of more than one indicator in certain cases in order to classify a household as poor.

The idea behind this approach rests on two basic assumption: all needs are equally important and all of them are basic, i.e., critical in reflecting poverty. The latter implies that the impossibility of satisfying any one necessity --irrespectively of what happens to the others-will suffice to classify a household as poor. It must be taken into account, however, that the procedure employed in the region does not lead to co-realization of needs but of indicators; in particular (see Table 1) three or more individual indicators are being used for housing. Again, the idea of co-realization, even of indicators, turns out to be less strong given the hardly demanding thresholds.

Alternatively to this view, methods could be designed assigning different importance to each considered need and/or requiring that more than one need must be satisfied. For example, in an study of the UK which uses a list of over 20 indicators, poverty was defined as a situation where three or more indicators exhibit inadequate levels (i.e., do not reach the threshold). ${ }^{23}$

${ }^{21}$ Data for five large Argentine cities (coming from a survey) show that the proportion of households simultaneously failing to reach the thresholds of the five indicators considered was no significantly different from zero.

22 PNUD, Desarrollo sin pobreza, Bogotá, 1990: Cuadro 3.9.

${ }^{23}$ In the already quoted study, Townsend generates a household score which aggregates the satisfaction / insatisfaction situation of the individual indicators for each household. He then correlates it to income in order to reach an overall threshold. 


\section{Comparison in time and space}

Poverty incidence figures calculated by means of the UBN method were basically used, as we mentioned before, to characterize geographic areas, specially small ones. This implies that estimates for different regions should be comparable, a situation that has been questioned on occasions because the same indicator threshold is sometimes used for urban and rural regions. This seems to be a shortcoming in the case of housing indicators, especially those related to access to basic services. In fact, comparisons among different countries of incidences for the same type of regions (i.e. rural) may be less problematic than those among widely varying regions of a given country insofar as minima take into account national patterns.

Even if this purpose of obtaining regional data was the driving force leading to a rapid spread of poverty indices estimation in Latin America, the aggregate figures on poverty incidence were also used to assess poverty evolution. In particular, this situation arose when the results of the 1990 round population censuses were published and comparisons to the 1980s' figures were made; it also occurs when series from survey data are analyzed. However, comparison over time of estimates obtained by the UBN method --as employed in Latin America-- is not straightforward. On one hand, incidence figures tend to be unresponsive to the worsening of the general social situation; on the other, even a constant government investment in social infrastructure --e.g. water supply and sewage-- may be reflected in a continuous reduction of the indicator. These are perhaps the main reasons behind the conflicting evolution of overall incidence figures obtained from the two described method in those countries of the region with available data: a large increase in the proportion of poor households when the income method is applied but a reduction when the UBN approach is used. ${ }^{24}$ In part, at least, the updating of thresholds would reduce this problem since changes in overall conditions would be reckoned. The experience in the region was, precisely, that of maintaining the same limits used in the previous measurement exercise. However, this would lead to discussions about the relative/absolute character of the measurement.

\section{Sources of information}

We have already mentioned the data sources used when the UBN method is applied. Population censuses are the most frequent ones, and in fact the type of source defines to a large extent the characteristics of the overall approach. Because of the more structural character of poverty identified through this procedure, the fact that census are carried out every ten years is not a major restriction.

Once a poverty map is produced with information from a population census, the usual development is that poverty incidence begins to be estimated on a more frequent basis using data from household surveys. In many Latin American countries these surveys regularly collect housing and educational variables. In some cases, however, they do not include the same set of

\footnotetext{
${ }^{24}$ For a thorough discussion of these questions, including comparative figures for several countries, see Katzman, R. "Virtudes y limitaciones de los mapas censales de carencias críticas"; in Revista de la CEPAL, N 58, 1996.
} 
questions as the population censuses and this leads to the introduction of partial changes in the indicators used and, consequently, in the thresholds. Hence, data from surveys cannot be strictly compared to those of poverty maps, although the main goal of these survey based estimates is to monitor the evolution during the intercensal period. It goes without saying that incidence data derived from household surveys refer only to relatively large geographical areas (regions, large metropolitan areas, provinces, etc.).

Household surveys are also useful in comparing the income or expenditure approaches and the UBN method: it has become relatively frequent to find tables where households are simultaneously classified according to both procedures, as it will be discussed in the next section.

Household surveys are also used --as mentioned-- to define thresholds (and to a lesser extent indicators) since they make it possible to associate census variables to income.

\section{UBN maps and Geographical Information Systems (GIS)}

The UBN method is frequently used as a synthetic indicator to characterize small areas; this is perhaps a more important objective than the estimation of overall poverty incidence figures. In some countries at least, such was the demand posed to the central statistical office, which led to the production of poverty maps, since there were requirements for the ranking certain administrative units (e.g., municipalities, counties, districts) in order to define appropriate criteria for the allocation of specific social programs. However, it was rapidly realized that poverty incidence estimates could be calculated at an even more detailed level: for example, in urban areas, at neighborhood level and even block level. This was observed precisely at a moment of rapid developments in hardware and software allowing a more intense use and interrelation of statistical data and geographical data bases.

Geographical Information Systems (GIS) are potentially very helpful to a variety of institutions dealing with aspects as diverse as fiscal matters or social policy design. In particular, they are extremely useful to local authorities in policy planning and execution. Poverty incidence figures are actually demanded to be incorporated as one of the basic indicators, because of their (already mentioned) role as synthetic indicator of a region's living conditions.

The possibility of relatively easy manipulation of an interrelated set of indicator for very small areas is also relevant to the process in many countries whereby all or much of their social and fiscal policies are being decentralized.

\section{Relative measures of poverty}

The income or consumption method (see heading A) was basically developed to measure absolute poverty. Even if it takes into account relative considerations --e.g. to define the set of products which must be consumed by the household to satisfy a given need-- the conceptual 
basis seems to rest on the idea that thresholds (e.g., the quantity of calories) are established independently of the distribution of actual consumption (e.g., of actual distribution of calorie intakes). To some extent --and because of many of the aspects described in the previous section-- the UBN approach, as widely used in Latin America, should also be regarded as a method for assessing absolute poverty.

A different approach to measure this phenomenon, used in many countries and by international agencies as well, is entirely founded on a relative perspective. Contrary to the methods mentioned in the previous paragraph, poor households are directly identified by comparing each household situation to the mean or to other moment of the distribution.

The most usual relative procedures resort --as in the absolute poverty income- or expenditure-based approach-- to the comparison of household incomes to a poverty line. In this case, however, the normative budget is not derived from an analysis of the requirements to satisfy basic needs but is defined as a given percentage of the mean household income. Changes in poverty indicators based on this approach depend only on variations in income distribution but not on the mean ${ }^{25}$; it must be remembered that both parameters are determinants of poverty changes under the absolute criterion. Another relative procedure defines as poor those units which make up the bottom portion of the income distribution --e.g. the poorest $40 \%$ percent of households according to their per capita income--. This procedure is useful only as a way to identify poor households; the head-count ratio has no interest (it is always equal to the fraction chosen to define poverty) and no normative value is considered to define intensity.

These relative methods are particularly relevant to developed countries, where --as already indicated-- the most pressing forms of absolute poverty do not represent main social problems. Even when some of those countries are experiencing high unemployment rates, the extended safety net resulting from the interplaying of various social policies ensures the access to a minimum basket of products for the great majority of the population. A central objective in these societies is, hence, the reduction of existing gaps in incomes and assets among population groups, gaps that from a different conceptual perspective are originating a process of social exclusion.

In such context, the knowledge of the characteristics of the lower incomes groups --even if they are actually meeting absolute thresholds-- have much importance in gaining insight into the associated poverty factors, and hence in designing economic and social policies. The evolution of head-count ratios and intensity indices (when a poverty line defined as a percentage of mean income) seems quite useful in monitoring gap changes.

${ }^{25}$ Ravallion, M. , Poverty comparisons, Living Standards Measurement Study Working Paper $\mathrm{N}^{\circ} 88$, Washington: The World Bank, 1992. 
III. Poverty groups profiles as a basis for the design and evaluation of antipoverty policies

\section{Scope and limitations for diagnosis purposes and poverty analysis}

It has been already pointed out that a main objective of the process of quantitative assessment of poverty is to produce synthetic indices of the type presented in II.A.6. These are useful in providing indications on some poverty dimensions and as overall indicators of the level of and changes in social conditions. Again, it must be emphasized that the dissemination of these aggregate social indices has proved to be an important element in promoting an open discussion of such an important issue both in developed and underdeveloped countries.

As is the case with most social indicators, those on poverty face the limitations imposed by the implicit conceptual bases and the decisions adopted to make the theoretical definitions operative. Specifically, usual poverty indices are highly dependent on the delimitation of poor units. As discussed in the previous section, the two approaches generally used are only imperfect empirical procedures to capture a complex phenomenon. Hence, they surely incur in errors of type I and II. Consequently, both methods are sometimes used simultaneously in order to minimize errors of type I and also to characterize "types" of poverty situations. Specifically, a table such as the following is frequently produced.

\begin{tabular}{|l|l|l|}
\hline \multirow{2}{*}{ UBN method } & \multicolumn{2}{|c|}{ Income or expenditure method } \\
\cline { 2 - 3 } & Poor & Non-poor \\
\hline With UBN & & \\
\hline Without UBN & & \\
\hline
\end{tabular}

It is clear, however, that synthetic indicators are not enough for understanding poverty and that more disaggregated information is needed. Precisely, useful evidences for this purpose can be obtained, using any of the discussed methods, once poor households are identified. As mentioned elsewhere, profiles of poor households and of their members are usually produced characterizing poor units and persons from different viewpoints. These tables show the distribution of households according to such dimensions as size and composition; and also the distribution of persons according to, e.g., age, occupation, education, migration or access to certain social services. Consequently, by associating poverty to different variables, evidence can be obtained to analyze alternative hypotheses on the main direct and indirect determinants of incidence and/or intensity levels and/or their changes.

Profiles are also relevant to social policy planning; for example, by identifying population groups with disproportionately high incidence of poor members, priorities can be established. As an example, gender, children and youth considerations have become important features of studies as those reported in the ECLAC's series of the Social Panorama. By looking at certain characteristics of members of such groups --e.g., labor market variables, access to health service and education-- it is also possible to obtain useful evidence to decide on the types of 
interventions best suited to the problems of different groups with high poverty incidence. Proxy variables for the implementation of targeting strategies may also be selected by analyzing poverty profiles. Since household surveys provide data for large areas, target populations in the field can be identified by the use of certain traits associated to poverty (or to certain forms of poverty) which are easily observed --such as type of neighborhood or housing qualities-- or relatively simple to inquire --such as education and family size.

\section{Improvement of the national statistical capacity in this area}

Poverty measurement has been carried mostly out with data coming from general purposes surveys and population censuses. As it has been mentioned, this tends to restrict the selection of variables considered in defining poor households according to the UBN method. Similarly, the use of these sources limits the production of profiles because variables of analytical interest --i.e., those relevant to the understanding of poverty and/or the evaluation of social policies and programs-- cannot be taken into account since they are not captured by such instruments.

It is therefore necessary to consider the possibility of introducing in some rounds of general purpose surveys those variables demanded for poverty analysis and policy assessment. If not all the required variables can be included in these surveys --i.e., when this entails a significant increase in questionnaire size--, special surveys aimed at gathering information on dimensions relevant to these goals might be designed and carried out with certain periodicity. In fact, in some countries such surveys are included --or are intended to be included-- as part of a system of multipurpose and/or expenditure surveys.

When analyzing the effect of different policies, data regarding access of population to social services and programs are important in assessing how targeting actually works. Evidence from this type of information is also useful to analyze certain policy consequences. The need to improve access to administrative information is a challenging dimension in LDC's.

In order to better understand the influences affecting poverty, data on assets must needs be recorded. Even if human capital variables are usually collected, the same does not apply to those concerning physical assets, especially for peasants and small-size urban producers. They are included in many of the analytical models used to explain poverty.

The possibility of gathering data on still other variables through the statistical system increases the ability to answer the questions usually posed by those engaged in poverty analysis. However, in order to obtain adequate information, it is not only necessary to enlarge the range of dimensions to be measured but also to improve their quality. For the specific case in hand, it is of the highest priority to design methods aimed at correcting income un- and underreporting: in particular, to obtain estimates of differentials between income size groups (and/or between groups defined according to other variables). 


\section{Reporting results and disseminating information}

One of the conclusions stemming from the previous discussion is that notwithstanding the subject's long tradition, poverty measurement faces various challenges regarding both conceptual and data quality aspects. At the same time, however, it seems that much work is being done in many countries, by both public and private agencies, on the production of poverty measurement and/or methodological questions, which is not being adequately disseminated. This situation limits, even within a given country, the possibility of an open discussion which would help in dealing and trying to cope with those challenges.

Moreover, in many cases statistical reports are not clear enough regarding the methodological bases of the data presented and only inform on synthetic indicator without making comprehensive use of all available data. In particular, profiles taking into account different perspectives are seldom produced.

It seems therefore necessary to improve the dissemination of poverty measurement efforts. This means, on one hand, to expand the set of information presented: regarding synthetic indicators, by including those that capture the different dimensions which appear to be analytically relevant and by regularly presenting profiles together with the synthetic indices. On the other hand, given the different perspectives for a quantitative approach to poverty, a clear and detailed description of the applied criteria must be included in statistical reports. It is also convenient to describe the criteria applied --if any-- in adjusting income figures when poverty measurements using the income or expenditure methods are presented. In the latter case, it would also be convenient to include in the same report complementary data on income distribution and average income --which are regularly produced from the same source-- since they are helpful in trying to understand changes in poverty indicators and profiles.

\section{Towards a basic set of information and social indicators at the national level}

The idea of designing and regularly producing a set of social indicators providing a comprehensive view on the main social dimensions, and helping to assess changes in time and comparisons to other countries, has been repeatedly put forward in many countries as well as by international agencies. The latter have been proposing --or sponsoring works aimed at proposing -- indicators allowing countries to monitor goals agreed by them regarding specific social questions. For example, after the World Summit for Children, UNICEF established a list of indicators for the measurement of progress towards the goals targeted on that occasion; in the eighties, WHO identified a set of indicators for monitoring and evaluating the strategy of Health For All; others were defined to follow the Population Program goals established at the 1989 International Forum on Population organized by UNFPA. Moreover, these and other institutions have been working together trying to coordinate their efforts and to produce a set of common social indicators. Recently, the Statistical Commission approved a minimum national social data set of social indicators, following the recommendations of an ad hoc Expert Group created to study the data requirements for monitoring implementation of the social programmes agreed in the recent major United Nations Conferences. 
It is becoming increasingly clear that indicators related to poverty should be included among those sets of national social indicators. As indicated, some of them provide a synthetic view on how those more in needs are sharing the benefits of (or suffering from) economic growth (or decline).

In addition to the convenience of producing synthetic indicators on poverty, it would be useful to disaggregate some of the other social indicators --e.g., school attendance, malnourishment, access to a clean water supply-- according to the poor/non-poor criterion. This would certainly offer a clearer insight into the implications of improvements registered by those indicators at an aggregate level. 


\section{EXPERT GROUP ON POVERTY STATISTICS}

by

Simon Schwartzman

Instituto Brasileiro de Geografía e Estatística (IBGE)

Brazil 


\section{Expert Group on Poverty Statistics}

\section{Background}

The Working Group of the United Nations Statistical Commission, in its last session in April, 1996, approved the recommendation to establish an Expert Group on poverty statistics to be chaired by Brazil, through the Brazilian Institute for Geography and Statistics - IBGE, with the U.N. Economic Commission of Latin America - ECLAC - acting as a Secretariat. Australia, Mexico, South Africa, the United States of America, the UNDP and the World Bank manifested their interest in participating, and representatives of other countries and institutions are welcomed to join. The Statistical Commission, during its Twenty Ninth Session held on February 10-14, 1997, took note of this initiative, under the expectation that the expert group could provide the Commission with specific suggestions for guidelines on this matter.

The Working Group, in the same session, approved also the recommendation to hold a seminar on poverty statistics at the ECLAC headquarters in Santiago, Chile, during the first semester of 1997. With the support of the statistical divisions of the other Regional Commissions, ECLAC will be the Secretariat of the meeting.

The Seminar on Poverty Statistics is scheduled for May 7,8 and 9, and it was agreed that this would be also a convenient time to hold the first meeting of the Expert Group. A provisional agenda for the seminar was prepared and included in the invitation sent to statistical offices and international organizations.

\section{The ECLAC Seminar}

The main goal of the ECLAC seminar will be to compile the different measurements of poverty now being used in different countries of the world. A reference document, "Poverty Measurement - Present Status of concepts and methods" was prepared by ECLAC, reviewing the main methodologies used by different countries in the measurement of poverty, and highlighting their strengths and limitations.

\section{The Expert Group meeting}

The expert group meeting will convene on the last day of the ECLAC Seminar, and the first subject of the agenda will be to discuss whether the constitution of such expert group is really justified, on the light of the discussions occurred during the ECLAC seminar. If it is agreed that the expert group should be maintained, it will necessary to define its goals and a time schedule for its activities; the end product of its work should be a written recommendation to the United Nations Statistical Commission about recommended practices and standards for the improvement of poverty statistics. Participation in the meeting and in the expert group is open to countries present or not at ECLAC's event, and 
representatives of international organizations. The Brazilian Institute of Geography and Statistics will be pleased to host a meeting of the expert group in Rio de Janeiro later in 1997, if considered useful.

\section{The issues}

The condition of poverty is as old as mankind, but the way it is perceived by society, and the ways governments and policy makers have strived to deal with it has changed enormously. In the past, poverty was often considered a natural and unavoidable condition of large parts of the population. The tendency, today, is to consider poverty as an unacceptable condition, requiring positive action to eliminate it.

Poverty is a relatively new subject in the realm of public statistics, or rather a renewed one, since it was a central concern in the earlier days of the European statistical offices in England and other countries ${ }^{1}$. More recently, however, the issues of poverty came to be treated in terms of income distribution and unemployment, and also as a condition derived from personal handicaps, rather than as poverty as such. The assumption was that in a well organized and modern economy everybody should have a stable employment and a "satisfactory" income, and it was the task of statistical agencies to monitor deviations to this general expectation, in order to prompt for the necessary corrective measures. For the developed countries, social welfare policies were called for; in the poorer parts of the world, economic development was to be the answer.

The renewed interest on the subject of poverty started already in the 1950's with the severe problems of famine afflicting large population groups in Asia and Africa, and studies showing the worldwide problems of malnutrition and their long-term consequences. The relevance of poverty as an issue increased as it became clear that economic development was not being successful in many countries, and, even when it was successful, it often left large groups at the margins, suffering the impact of social, economic and political change on traditional patterns of social and economic organization. Finally, it became clear that the exclusion of significant segments of the population from the benefits of a modern economy was not something limited to the less developed economies, but a something that occurred at the very core of highly industrialized and developed societies.

Whatever the determinants and explanations of poverty, it is always associated with income deprivation, which, in extreme conditions, has direct and observable consequences for the health, life expectancy and quality of life of specific groups, which could be compared and monitored through time and space. The standard procedures are either to

'For the surveys of Charles Booth, Seebown Rowntree and Arthur Bowley in $19^{\text {th }}$ Century England, see Hennock, E. P., "The Measurement of Poverty: from Metropolis to the Nation, 1880-1920", Economic History Review $2^{\text {nd }}$ series, XL, 2, 1987, p. 208-227, quoted by Alain Desrosières, "Les pauvres: comment les décrire, qu'en faire?", La politique des grands nombres (Paris, La Découverte, 1993), $271 \mathrm{ff}$. 
make a direct evaluation of the population's health conditions, or to measure the number of people who are above or below a minimum income threshold, considered necessary for the satisfaction of basic needs. Income inequality is also amenable to fairly straightforward measurements, if income data are available.

The technical problems associated with the measurement of poverty are well analyzed in ECLAC's paper, but it is worth stressing two complicating factors which might be relevant for the consideration of the expert group. The first is that income in monetary terms may not be an adequate measurement of living conditions of poor populations. Besides the known problems with the measurement of household income, there is often a significant amount of non-monetary transactions, out-of-the-market transfers, access to public services and production for self-consumption which may become more important than straightforward income, as measured in standard household surveys. Secondly, access to specific products and services can be associated with extreme levels of poverty in one place, but not in others. For instance, to live in a shanty-town in a big Latin American city is not necessarily an indication of extreme poverty, in contrast to the absence of a heated living place in cold regions. Distance from clean water wells may be a measure of poverty in some areas, equivalent in others to the presence or absence of tap water in households. Cultures vary in the way they value specific conditions, like clothing and living standards, access to education for women, exposure to violence, or access to public transportation, public health and public justice. The issue here is whether some of these "cultural variations" should be taken as such, or measured against some "objective" (and often value-loaded) standard.

Because of these problems, the notion that the international statistical community should attempt to develop cross-national, comparative poverty measurements, which could be used to rank countries in terms of their poverty levels, is often questioned, and should be the subject of an evaluation. The same question should be raised about the establishment of "poverty lines", not only for international comparisons, but even for national studies. The usefulness of reliable and internationally comparable poverty figures seems unquestionable, but this usefulness should be weighted in relation to the loss of information and reliability which are implied in the sequence of ad hoc and arbitrary decisions which are taken during this process, and also in terms of other possible alternatives to respond to the need to quantify and monitor the conditions of the poor.

\section{Poverty levels and poverty syndromes}

An alternative approach to the issues of poverty is to consider it not just as a matter of a position in a continuum of income, needs satisfaction or deprivation, but as a condition deriving from complex social conditions that are specific of some groups and societies, requiring specific policy actions and well differentiated social policies. Standard multivariate analysis can be used to measure the impact of specific variables in the conditions of poverty, and to generate policy recommendations. For instance, Ricardo Paes e Barros and José Márcio Camargo have shown that education and productivity are the most important variables explaining poverty levels in Brazil, which places educational policies at the top 
priority in the poverty reduction agenda ${ }^{2}$. This kind of study requires complex data sets combining information on poverty with other variables, and are different in scope and methods from the efforts to generate extensive and detailed poverty measurements.

Multivariate analysis may not be sufficient, however, to understand the full extent and implications of poverty conditions occurring in different social contexts, and to generate the corresponding policy recommendations. To think in terms of "syndromes of poverty", as complex conditions associated with the language, ethnicity, culture, economic institutions, education and history of the affected communities and their social environment and afflicting specific groups, can be more useful from a policy point of view, and closer to common sense. For instance, although it is true that lack of formal education is associated with poverty everywhere, the impact of investing in educating the unskilled urban worker can be greater than the same investment, with the same approach, on the education of rural ethnical minorities. This is not to deny the importance and relevance of multivariate analysis, but only to stress that it should be combined with other ways of organizing, interpreting and presenting the information.

A list of such conditions and contexts, or poverty syndromes, would necessarily include. among others:

- Poverty associated with low salaries in an organized economy. This is the classic condition of economic exploitation, and it is relatively easy to identify and measure, since it is above all a matter of income distribution.

- Poverty associated with traditional social and economic conditions. This is the situation of the Brazilian poor in the Northeastern region, and applies, more generally, to the rural poor; it also applies, more forcefully, to the native, rural populations in countries like Bolivia, Paraguay and Peru. A special and aggravating condition occurs when the social and economic organization of these sectors are shattered in the contact with the modern side, or with conditions of local violence, generating extreme cases of social deprivation and potential conflict.

- Poverty associated with lack of access to the organized economy. This is a very broad category, which can affect special groups and conditions. It includes, for instance,

- the inner-city ghettos;

- specific age groups, like the old age cohorts in societies with inadequate provisions for social security;

- non-educated, "unemployable" youths in modern, urban societies;

2"As causas da pobreza no Brasil", in João Paulo dos Reis Velloso and Roberto Cavalcanti de Albuquerque, eds., Modernidade e Pobreza, Rio de Janeiro, Fórum Nacional, editora Nobel, 1994, 81-112. 
- population living in the periphery of the large metropolitan areas.

- women;

- specific ethnic groups;

- specially deprived groups, such as the physically handicapped, unwed mothers

- economic and political refugees

- professional groups displaced by the obsolescence of their professional skills.

- Poverty associated with chronic unemployment. Unemployment, measured according to the standards of the International Labor Organization, refers to a short-term condition (persons who had been recently laid off and are actively looking for a job). There are other conditions, however, which are not captured by these data - adults who have never entered the labor market, or who have ceased to look for jobs, or who are marginally or "under-employed".

The analysis and measurement of complex social conditions require specific approaches and methodologies which are usually not part of the working tradition of statistical offices, or my resemble a step back in the direction of old, qualitative studies an anthropological kind. The Living Standards Measurement Survey, supported in many countries by the World Bank, gathering a large amount of information on a limited sample of households, and applying user-friendly data processing procedures for their interpretation, is an attempt to analyze complex situations making use of modern survey and data analysis facilities. Other governmental agencies and research institutions may have approaches of which statistical offices may not be aware, and should be taken into consideration. Whatever the approaches, the end result of this effort to develop better poverty statistics could be the publication of typologies of poverty situations, associated with the usual figures on income, employment, education, household conditions, demographic characteristics, and so forth.

\section{Issues for the expert group}

If the expert group agrees to continue its work, it should take a long-term view of the current efforts to measure inequality along the lines described in ECLAC's "state of the art" paper, and take into consideration other approaches which might be closer to the typological perspective suggested here. After this examination, it should prepare a document making recommendations about what the countries should do to improve the quality and the policy relevance of their poverty statistics. The Santiago meeting should identify countries, persons or organizations willing to prepare review papers of these and similar topics, for discussion in the group's next meeting in Rio de Janeiro. 


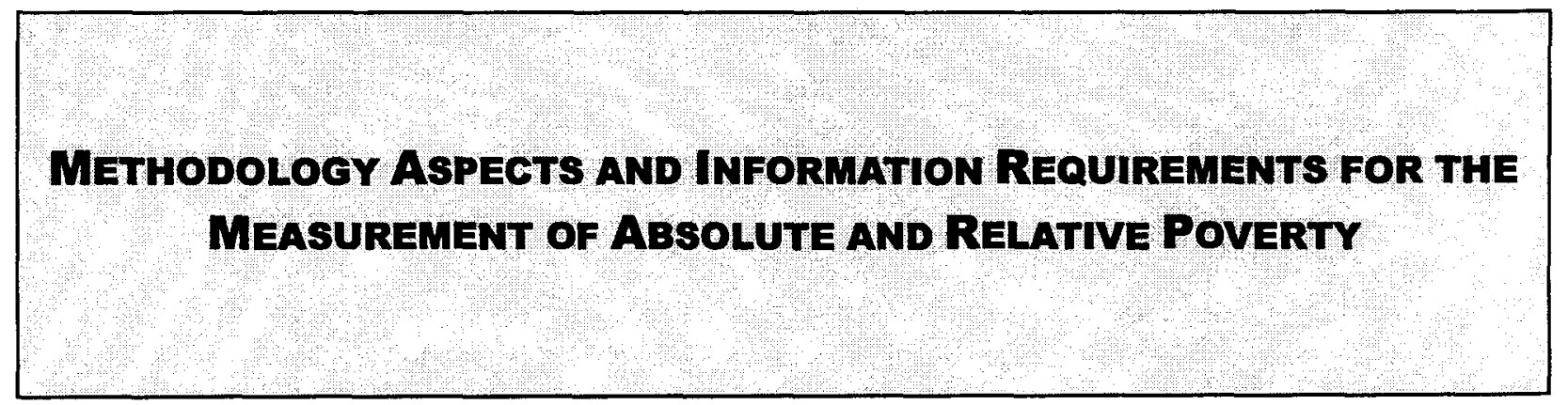



TOPIC 1

INCOME OR CONSUMPTION INSUFFICIENCY METHODS 



\section{CHANGING THE WAY THE UNITED STATES MEASURES INCOME AND POVERTY: A PROGRESS REPORT (DRAFT)}

by

Charles Nelson and Daniel H. Weinberg

U.S. Bureau of the Census 


\section{Changing the way the United States measures income and poverty: A progress report}

\section{BACKGROUND -- THE OFFICIAL DEFINITION}

The United States Census Bureau has been compiling income estimates annually since 1947. These estimates are from the Current Population Survey (CPS), a nationwide random sample of households, whose primary purpose is to collect labor force information monthly. In March of each year (April prior to 1956), data are collected on the household's income for the previous calendar year.

The official definition of income is not specified in law or regulation. In effect, what is included in income depends on the questions asked. As survey researchers know, the more questions one asks about income by source, the better able respondents are to identify all income. initially, there were only two questions asked of each adult: (1) "How much did ... earn in wages and salaries in 1947?" and (2) "How much income from all sources did ... receive in 1947?". In 949, self-employment income was asked separately and in 1950 farm and nonfarm self-employment income was asked separately. In 1962, the Census Bureau began systematically assigning values to missing income items (based on reported characteristics using the "hot deck" method). In March 1967, the number of income questions was again expanded, from four to eight categories. These additional items dealt with Social Security, interest, dividends, and rent. In 1968, interest, dividends, rents, and royalties were combined into one question and separate questions were added on public assistance and on unemployment and workers' compensation. In 1975, the number of income questions increased from eight to eleven through addition of a question on the supplemental Security Income program, a question on Aid to Families with Dependent Children and general assistance, and private and government pension income. A major change took place in 1980 -- the questionnaire was expanded to identify over 50 sources of income and recording of up to 27 different income amounts, including receipt of numerous noncash benefits, such as food stamps (coupons used as cash for

qualified food purchases), and housing assistance. Except for minor wording changes, those questions are still in use today. The survey was converted to a computer-assisted interviewing mode in 1994.

The data on income thus cover money income received (exclusive of certain money receipts such as capital gains) before payments for items such as personal income taxes, Social Security payroll taxes, and union dues. Money income does not reflect the fact that some families receive part of their income in the form of noncash benefits, such as food stamps, health benefits, rent-free or subsidized housing, and goods produced and consumed on the farm. In addition, money income does not reflect the fact that noncash benefits are also received by some as fringe benefits, e.g. the use of company cars, and full or partial payments by business for retirement programs, medical insurance, and educational expenses.

Moreover, for many different reasons, there is a tendency in household surveys for respondents to underreport their income. From an analysis of independently derived income estimates, it has been determined that income earned from wages or salaries is much better 
reported than other sources of income and is nearly equal to independent estimates of aggregate earnings (Coder and Scoon-Rogers, 1996). Among the least well-reported sources are interest and dividends. The detailed components of money income are presented in the Appendix.

\section{ALTERNATIVE MEASURES OF INCOME}

Because money income is but one measure of economic well-being, the Census Bureau also reports on 14 other definitions of income (the series begins in 1979). While not exhaustive, they do illustrate different perspectives on what could be included.

Definition 1. Money income excluding capital gains before taxes. This is the official definition described above.

Definition 2. Definition 1 less government cash transfers. Government cash transfers include nonmeans-tested transfers such as Social Security payments, unemployment compensation, and government educational assistance (e.g., Pell Grants), as well as means-tested transfers such as Aid to Families with Dependent Children (AFDC), Temporary Assistance to Needy Families, and Supplemental Security Income (SSI).

Definition 3. Definition 2 plus capital gains. Realized capital gains and losses are simulated as part of the Census Bureau's Federal individual income tax estimation procedure. While the Census Bureau has access to some income information on individual tax returns that can be matched (with substantial time lag) to survey data, actual capital gains or losses or tax liability are not known.

Definition 4. Definition 3 plus imputed health insurance supplements to wage or salary income. Employer-paid health insurance coverage is treated as part of total worker compensation; no other benefits paid for or provided by employers are estimated.

Definition 5. Definition 4 less payroll taxes. Payroll taxes are payments for Social Security old age, survivors, and disability insurance, and for hospital insurance (Medicare).

Definition 6. Definition 5 less Federal income taxes. The effect of the Earned Income Tax Credit, targeted to low-income workers, is shown separately in Definition 7.

Definition 7. Definition 6 plus the Earned Income Tax Credit.

Definition 8. Definition 7 less state income taxes.

Definition 9. Definition 8 plus nonmeans-tested government cash transfers. Nonmeans-tested government cash transfers include Social Security payments, unemployment compensation, workers' compensation, nonmeans-tested veterans' payments, U.S. railroad retirement, Black lung payments, and Pell Grants and other government educational assistance. (Pell Grants are income-tested but are included here because they are very different from the assistance programs included in the means-tested category.)

Definition 10. Definition 9 plus the value of Medicare. Medicare is counted at its fungible value.

Definition 11. Definition 10 plus the value of regular-price school lunches.

Definition 12. Definition 11 plus means-tested government cash transfers. Means-tested government cash transfers include AFDC, SSI, other public assistance programs, and meanstested veterans' payments.

Definition 13. Definition 12 plus the value of Medicaid. Medicaid is counted at its fungible value.

Definition 14. Definition 13 plus the value of other means-tested government noncash transfers. Including food stamps, rent subsidies, and free and reduced-price school lunches. 
Definition 15. Definition 14 plus net imputed return on equity in one's own home. This definition includes the estimated annual benefit of converting one's home equity into an annuity, net of property taxes.

Table 12 is a reproduction of a table from U.S. Bureau of the Census (1996a) illustrating the different distributions of income that these definitions imply. Table 5 (U.S. Bureau of the Census, 1996b) illustrates this effect on poverty estimates.

These alternative definitions illustrate the dilemma faced by official statisticians when presenting income statistics. Different definitions serve different purposes. Money income has its uses - it represents command over the resources available to purchase the necessities of life in the open market, including meeting the obligations of citizenship (taxes). Definition 4 probably comes closest to measuring what resources would be available in the absence of government, except that some benefits paid for or provided by employers are not included and others are mandated by the government, some benefits are not provided by employers because they are provided by the government, and work effort is presumably reduced by the existence of a tax on earnings. Definition 8 is closest to after-tax income. Disposable income tries to take account of the effect of taxes and transfers on the household's command of resources -definition 14 probably comes closest to that approach. Finally, in definition 15 there is an attempt to include the income equivalent value of owning one's own home in that such an asset reduces the need for additional expenditures on shelter.

\section{CONSIDERATIONS IN MEASURING POVERTY}

Formal measurement of poverty in the United States is less than three decades old. Not since the adoption of official poverty thresholds by the Federal government in the late 1960's has there been such a great interest as now in examining and possibly respecifying the thresholds and the income compared with them. The official poverty thresholds in use today by the U.S. Bureau of the Census to measure poverty have their basis in work by Orshansky $(1963,1965)$. Orshansky started with a set of minimally adequate food budgets calculated for families of various sizes and composition by the U.S. Department of Agriculture for 1961. Based on evidence from the 1955 Household Food Consumption Survey, she determined that expenditures on food represented about one-third of after-tax income for the typical family. This relationship yielded a "multi- plier" of three, that is, the minimally adequate food budgets were multiplied by a factor of three to obtain 124 poverty thresholds that differed by family size, number of children, age and sex of head, and farm or nonfarm residence (ad hoc adjustments were made for families of size one and two).

In 1969, the U.S. Bureau of the Budget (now the U.S. Office of Management and Budget -OMB) adopted the Orshansky measure using pre-tax income as the standard government poverty measure, mandating that thresholds be adjusted for inflation using the Consumer Price Index (CPI) published by the U.S. Bureau of Labor Statistics. With only minor modifications since then (mostly reducing the number of categories, now 48), the Orshansky thresholds still form the basis for the official poverty statistics.

When considering the adequacy of the official poverty thresholds, it is critical to realize that one cannot separate the issue of income measurement from poverty definition. When one 
defines the level of resources needed to be non-poor, one must also determine which resources are to be counted. Therefore, the discussion below covers both income measurement and poverty definition issues; income measurement is discussed first.

Whatever poverty thresholds are chosen should be the result of a carefully specified process that cannot be changed arbitrarily from year-to-year, and should be capable of being updated at reasonable intervals as the economic circumstances of the society and the behavior of its demographic and economic components change.

\section{A. DEFINING INCOME FOR MEASURING POVERTY}

The key measurement issues are three -- valuing and counting noncash income, subtracting taxes, and reducing survey underreporting and nonsampling errors. Also of interest is whether to continue to publish official estimates based on the CPS or switch to a newer survey designed to collect better income information, the Survey of Income and Program Participation (SIPP).

\section{A.1. Noncash income}

The issue of valuing noncash income spans the income distribution. A more comprehensive income measure, such as definition 14 above, would place a value not only on noncash government transfers, such as food stamps, which typically go to low-income families, but also on elements of nonwage compensation (from employer-paid health insurance to company cars) that typically go to earners at all income levels or only at high levels. The noncash income of U.S. families has grown substantially in the past 25 years. In the 1990's, over half of government transfer spending for the poor is in the form of noncash benefits (U.S. Bureau of the Census, 1996a), whereas the only noncash benefit program that predated the 1960's "War on Poverty" was subsidized (public) housing. This growth of benefits to the poor has been paralleled by a growth of nonwage compensation to wage earners, induced in part by tax laws exempting such compensation from income and payroll taxes, and by growth in health benefits for the elderly. By 1996, employer costs for nonwage compensation had grown to over onequarter (28.4 percent) of total compensation costs, up from 19.4 percent in 1966 . Further, nearly two-thirds of households own homes, which provide them with additional noncash income in the form of housing services.

Of key concern to understanding the well-being of U.S. households is the valuation of medical benefits, both the government health programs--Medicare (medical aid to the elderly and severely disabled) and Medicaid (medical aid to a portion of the poor)--and employer-paid health insurance. The valuation of medical benefits is particularly difficult since coverage of high medical expenses for people who are sick does nothing to improve their poverty status (although the benefits clearly make them better off). Even if one imputes the value of an equivalent insurance policy to program participants, these benefits (high in market value due to large medical costs for the fraction who do get sick), and cannot be used by the recipients to meet other needs of daily living. Accordingly, the Census Bureau developed a not-altogethersatisfactory method, termed fungible value (described in footnote 2), to avoid giving too high a value of these benefits to those toward the low end of the income scale. Note that this is not a problem for countries with universal health care systems. 


\section{A.2. Disposable income}

Even though Orshansky's original calculations were based on post-tax income, poverty has always been calculated for the official statistics using pre-tax income because of the limited information collected on the CPS. After-tax income is a better measure of the ability to meet the daily necessities of life than is money income. Also important, in calculating disposable income though, is to address the advisability of deducting work expenses for wage earners such as child care, uniforms, and transportation costs.

\section{A.3. Other issues}

As noted earlier, research matching household survey responses to Federal income tax returns and comparing them with national income accounts has revealed substantial areas where the level and receipt of certain income sources is underreported. Attempts to reduce underreporting were made by revising the language used in the CPS questionnaire (and using a shorter reference period) when the SIPP was launched. This was only partially successful, and response errors remain.

While current procedures of the Census Bureau reweight the data for full interview nonresponse and impute appropriate income responses for individual unanswered questions (item nonresponse), these corrections are insufficient to fully resolve the problem. Procedures to enhance the data through microsimulation or other means are being investigated, along with continued improvement in imputation for nonresponse.

In most societies, "underground," "nonmarket," or "black market" income from legal or illegal activities is typically poorly reported by household respondents to government surveys (or not even collected) and consequently is substantially omitted from official income statistics. This income ranges from barter transactions to home production (e.g., home gardens) to illegal income. Researchers are a long way from measuring this activity accurately, however, so including this income in official statistics would be quite difficult.

It has been suggested that consumption is a better measure of well-being than income (see Cutler and Katz, 1991, and Slesnick, 1993). If a family can maintain its consumption through judicious use of assets when income falls, is it truly poor? Unfortunately, it is difficult to collect accurate annual data on consumption or even expenditures. Further, consumption reflects choices on how to allocate resources, rather than need. Nevertheless, fuller investigation of a consumption-based measure would be useful.

A final issue of income measurement is the choice of surveys to use. As mentioned briefly above, the SIPP questionnaire design, as crafted to reduce income underreporting, does succeed for almost all income sources. Yet, when compared with the CPS, it has historically had several drawbacks--a smaller sample size (one-third as large) and necessarily slower data release because of its much greater complexity. These defects are compensated for by the SIPP having greater income detail, both in number of sources and in time segments (by having monthly as opposed to the CPS's annual statistics,) and lower underreporting. The new version of the SIPP, as implemented in 1996, increased the sample size substantially (to 36,700 households) and oversampled low-income households. National estimates from the SIPP will then be 
comparable to or better than (in terms of sampling error) those from the CPS (reduced to 48,000 households but inefficient for national estimates because it uses a state-based design). One drawback for obtaining a consistent time series of annual national income or poverty estimates from the SIPP, though, will be sample attrition and time-in-sample bias as current plans call for only one SIPP panel to be in the field during any one four-year period. The CPS sample is constantly refreshed by new households.

While the timeliness issue may never be resolved fully in SIPP's favor, the SIPP can provide a preliminary estimate on much the same schedule as the CPS. Still, it is desirable to view the surveys complementarily. If modeling using administrative records can correct underreporting errors in both surveys, they would then give the same aggregate statistics. The CPS could be used for a quick snapshot, consistent with data collected since 1947 (the SIPP began in 1983), while the SIPP would be used for more detailed estimates, for subannual and multiyear estimates, and for understanding other dimensions of poverty (assets, disability, gross flows, and other dynamic aspects).

\section{B. SETTING THRESHOLDS TO DEFINE POVERTY}

With an absolute measure of poverty, there are key decisions to be made about determining the appropriate level for poverty thresholds. The key research issues addressed here are minimal consumption levels for specific commodities, ways of correcting for differences in family size and composition, and ways of correcting for cost-of-living differences across time and among areas.

\section{B.1. Minimal consumption standards}

Minimal consumption standards for all necessary commodities could in theory be established, perhaps by an expert panel, but doing so would raise difficult ethical issues about which commodities to include (e.g., is a telephone a necessity?). One alternative is to define minimal consumption standards for a limited number of necessities (e.g. food, clothing, shelter) and obtain a poverty threshold by using a multiplier to account for necessities not measured.

\section{B.2. Equivalence scales}

The relationship embodied in the current U.S. poverty thresholds among families of different sizes (termed the equivalence scale) is supposed to represent the different relative costs of supporting those families at a minimally adequate levels. In fact, the relationship is based solely on the relative food costs as they existed in 1961 and include some unfortunate anomalies (see Ruggles, 1990, pp. 64-68). While it is possible to develop minimal budgets for every type and size of family separately and thus eliminate the need for equivalence scales entirely, in practice it is difficult to do so. No one scale now exists that is generally accepted. Issues in developing equivalence scales include which distinctions in family circumstances (e.g. owner/renter) should lead to different thresholds, how resources are shared within the family or household, and whether a more useful basis for determining poverty is the household (those living in one housing unit) rather than the family (those in one household related by blood or marriage). See Betson (1996) for a further discussion of these issues. 


\section{B.3. Cost-of-living differences}

In as large and diverse a country as the U.S., there are significant differences in the cost of living among localities. Unfortunately, there are no currently available data upon which to estimate interarea price differences reliably. (See Kokoski et al., 1992, and Moulton, 1992, for some work in this area.)

A related price issue is how to adjust for inflation. The U.S. poverty thresholds now use the CPI to adjust thresholds over time. If the measurement of minimal consumption is used as the basis for new thresholds, presumably this should be the basis every year, with components, prices, and multipliers reestimated as often. Clearly this is not practical. A reasonable compromise might

be to respecify and reestimate the minimal consumption bundle at prespecified intervals as market baskets become outdated, say every ten years, and use the CPI for interim adjustments. The market basket used for the CPI itself is typically reviewed and respecified once every ten years or so.

\section{THE COMMITTEE ON NATIONAL STATISTICS REPORT}

The National Academy of Sciences' Committee on National Statistics (CNStat) released a report in May 1995 entitled Measuring Poverty: A New Approach (Citro and Michael, 1995). In that report, the committee recommended that the Federal government redefine the way it measures poverty. OMB has requested that experts from the Census Bureau and other agencies examine technical methods for doing so.

The key changes they recommend are threefold: change the income measure, change the poverty thresholds, and change the survey used. To change the income measure from the current money income definition, they propose to add noncash benefits, subtract taxes, subtract work expenses, subtract child care expenses, subtract child support paid, and subtract medical out-ofpocket expenses (MOOP). The poverty thresholds are to be based on food, clothing, shelter, and "a little bit more" (75-83\% of median expenditures on these items multiplied by 1.15-1.25), a new equivalence scale, an allowance for geographic variation, and are to be updated annually based on growth in median expenditures. Finally, the panel recommended that the government use the SIPP instead of the March CPS to collect the basic income and poverty-related data.

Among the technical issues to be resolved before implementing such a new measure are the following:

1. Reestimating the valuation methodologies for government noncash transfer programsincluding school lunches, food stamps, and housing benefits; developing new estimation methodologies for additional programs and possibly developing a new methodology for valuing Medicare and Medicaid (depending on whether the subtraction of MOOP is adopted or not);

2. Completing development of a tax simulation model for SIPP; 
3. Developing a methodology for estimating MOOP (e.g. a statistical match of the National Medical Expenditures Survey to SIPP) or reestimation of employer contributions to health insurance using more recent data;

4. Estimating and imputing work and child care expenses;

5. Redesigning the SIPP sampling scheme to maximize reliability of a time series of cross-section estimates while maintaining some longitudinal estimation capabilities, taking account of the need for state-level estimates, and minimizing the attrition bias;

6. Reviewing the Consumer Expenditure Survey to improve its effectiveness for its new dual role (defining the market basket for the Consumer Price Index and the poverty thresholds) and possibly preparing for consumption-based rather than income-based poverty estimates in the future;

7. Creating a time series of poverty estimates from the SIPP and developing methods to impute additional variables to the CPS to develop comparable time-series data for that survey;

8. Doing substantial further work on income underreporting and imputation models;

9. Adding child support and alimony paid questions to CPS; and

10. Developing and adding "medical care risk" and possibly medical expenditures questions to SIPP to supplement the poverty measure if medical care costs and benefits are excluded from the measure.

Even if these technical issues can be resolved expeditiously, there are still policy issues that must be debated and resolved before a new measure is adopted. These include:

1. Including or excluding medical costs and benefits. On the one hand, the CNStat recommended excluding MOOP, employer contributions to health insurance, and benefits from medical transfer programs from income. On the other hand, adopting as official the current (experimental) practice of including them would require improving the current method for valuing medical transfer program benefits, measuring medical needs more accurately, and updating the methodology for imputing employer contributions to health insurance.

2. Basing thresholds on a pre-specified fraction of median expenditures. How might the public and Congress react to a new poverty threshold that showed millions more poor persons than the current measure? Are we confident enough about the quality of (i.e. lack of biases in) the Consumer Expenditure Survey data to use it as the arbiter of the poverty level? It may be that the likely acceptance of any new definition would be enhanced if the new index were "chained" to the old by matching the overall poverty rate obtained (but allowing the distribution to vary).

3. Developing geographical cost-of-living variations. It is clear that the cost of living differs substantially from place to place, and different choices of methodology to reflect this fact would have different implications. If geographic variation is to be incorporated, some method for periodically updating the thresholds for relative price changes among areas would also need to be established. 
4. Annual inflation updating. The panel proposed using the rate of growth in expenditures to index the thresholds. This is an attempt to introduce some deliberate "relativity" into the measure and would have quite different ramifications from using the Consumer Price Index.

5. Choosing the equivalence scale. Choice of the scale would inevitably alter the distribution of the poor.

6. Underreporting. If the technical issues about how to do so are resolved, should the income statistics from the survey be adjusted for underreporting based on administrative data and modeling?

7. Review and Revision. Should any new definition include a regular cycle of review and revision based on pre-specified criteria (CNStat recommended once a decade)?

Open debate of these issues seems the most likely way to resolve them, potentially leading to a

new way of measuring poverty that OMB would approve and that other policy makers would accept as an improved methodology for measuring poverty in the United States.

\section{CENSUS BUREAU POVERTY REDEFINITION RESEARCH}

In order to provide a basis on which some of these issues can be resolved, the Census Bureau and other U.S. government agencies have begun research studies.

\section{D.1. Census Bureau-Bureau of Labor Statistics Study}

The CNStat report on redefining poverty contained sweeping recommendations for changing the way poverty is defined in the U.S. Recent joint research by the Bureau of the Census and the Bureau of Labor Statistics (BLS) (Garner et al., 1997) examined two of these issues changing the income definition and modifying the poverty thresholds.

In formulating poverty thresholds, BLS researchers started by implementing the basic recommendations from the CNStat report. Some of the CNStat panel recommendations regarding thresholds were given as ranges. Thus, some simplifying assumptions were made. First, the panel recommended a range of thresholds, with a lower bound based on 78 percent of median expenditures for food, clothing, and shelter and a multiplier of 1.15 to account for other needs. The upper bound was based on 83 percent of the median and a multiplier of 1.25 . In the Garner et al. paper the midpoint of this range was used. The other simplifying assumption was for the equivalence scale (the relationship between thresholds for different family sizes). The panel recommended a range of economy scale factors of 0.65 to 0.75 and again they choose the midpoint -- 0.70. Thresholds were computed for the years 1990 through 1995.

On the resource side, the panel's recommendations were followed to the extent possible. The only recommendation not followed (because of a lack of data) was their recommendation to subtract child support paid from income when computing a poverty resource measure. Though the panel recommended changing the official source of poverty statistics in the U.S. from the 
CPS to the SIPP, the initial work was based on the CPS. At this time, the CPS is the only survey with a working tax simulation model and in-kind benefit valuation procedures, both necessary ingredients for producing a resource measure based on the panel's recommendations.

The report found that the threshold computation methods as recommended by the panel result in relatively stable thresholds over time (at least over the 1990-1995 period measured in this study), and the resulting poverty rates based on applying the panel's basic resource definition to these thresholds also showed relatively stable results. In fact, though the panel's recommendations result in significantly higher poverty rates than the U.S. official estimates, the trends based on the official estimates and the panel's recommended method show very similar trends over the 1990-1995 period. Differences across subgroups were also found to be stable over time. However, the key change under the proposed definition of poverty is in the composition of the poverty population. Consistent with the panel's findings, poverty rates under the recommended poverty measure are significantly higher among groups with relatively low official poverty rates (for example, Whites or those living in married-couple families). Groups with relatively high poverty rates, on the other hand, did not tend to have very different poverty rates under the revised measure. Thus, an effect of moving to the recommended poverty measure would be to narrow the gaps that now exist in the U.S. between high- and low-poverty groups (married-couple and single-parent families, Whites and Blacks, etc.). Put another way, under the revised measure, the poverty population looks more like the total population in terms of demographic and socioeconomic characteristics. (See Table 1 and Figures 1-4.)

Table 1. Poverty Rates: Official and Experimental by Race, Hispanic Origin, Family Type and Age: 1992

\begin{tabular}{|lccc|}
\hline & Official & Experimental & Percent Difference \\
\hline All Persons & & & 34.5 \\
White & 14.8 & 19.9 & 43.7 \\
Black & 11.9 & 17.1 & 11.1 \\
Hispanic Origin & 33.4 & 37.1 & 40.2 \\
(of any race) & & & \\
& 29.6 & 41.5 & 77.9 \\
Married Couple & 7.7 & 13.7 & 9.7 \\
Female Household & 39.0 & 42.8 & 21.0 \\
& & & 37.0 \\
Under 18 Years Old & 22.4 & 27.1 & 74.4 \\
18-64 Years Old & 11.9 & 16.3 & \\
65 Years Old and Over & 12.9 & 22.5 & \\
& & & \\
\hline
\end{tabular}


Figure 1. Poverty Rates: Official and Experimental: 1990-1995

\begin{tabular}{ccc}
\multicolumn{2}{c}{ Official } & Experimental \\
\hline 1990 । & 13.5 & 18.3 \\
1991 । & 14.2 & 19.1 \\
1992 । & 14.8 & 19.9 \\
1993 । & 15.1 & 20.6 \\
1994 । & 14.5 & 19.2 \\
1995 । & 13.8 & 18.4 \\
\hline
\end{tabular}

Figure 2. Composition of the Poverty Population, Official and Experimental, by Race: 1992

Pie 1 Pie 2

Official Experimental

\begin{tabular}{llll}
\hline White & I & 66.45 & 71.16 \\
Black & 1 & 28.48 & 23.54 \\
Other & 1 & 5.07 & 5.30 \\
\hline
\end{tabular}

Figure 3. Composition of the Poverty Population, and Experimental, by Family Type: 1992

Pie $1 \quad$ Pie 2

Official Experimental

\begin{tabular}{lcc}
\hline Married & 45.94 & 57.10 \\
Female Householder & 49.05 & 37.62 \\
Other & 5.01 & 5.28 \\
\hline
\end{tabular}

Figure 4. Composition of the Poverty Population, Official and Experimental, by Age: 1992

Pie 1 Pie 2

Official Experimental

\begin{tabular}{lll}
\hline Children (under 18 years) & $40.23 \quad 36.23$
\end{tabular}

Age 18-64 years $\quad 49.44 \quad 50.40$

Elderly (over 64 years) $\quad 10.33 \quad 13.36$ 
Other, slightly different poverty thresholds were also examined in the Census-BLS study. One modification, which was suggested by the panel, was to define shelter costs by their rental equivalent value. This technique resulted in higher poverty thresholds (and higher poverty rates), and appeared to have some effect on the composition of the poverty population (further narrowing the gaps, for example, between high-and low-poverty groups). Another set of thresholds was based on alternative multipliers that were computed more precisely than those used in the Panel's report. This modification resulted in little change in the composition of the poverty population.

\section{D.2. Other Census Bureau Poverty Research}

The panel recommended changing the source of official U.S. poverty estimates from the March CPS to the SIPP. As noted earlier, the SIPP is a longitudinal survey with: 1) a more detailed set of questions than the CPS, 2) a shorter reference period (4 months versus 12 months for the CPS), and 3 ) increased flexibility sufficient to add the questions required to measure poverty based on the broadened resource definition recommended by the panel. Questions have already been added to SIPP to collect some of this additional information, and a sample design change, in order to make SIPP a better cross-sectional survey (a requirement for measuring annual poverty changes) has been proposed, though not yet adopted.

The Census Bureau has also examined the panel's recommendations on work-related and child-care expenses (the panel recommended subtracting these costs from income when computing the poverty resource measure and has suggested alternative methods for imputing such costs). This research showed that using a definition of resources that excludes child care and other work-related expenses has a significant effect on poverty rates. In both CPS and SIPP-based analyses, the effect of using a resource definition that excluded these expenses was to raise children's poverty rates by about 3 percentage points. (See Short et al., 1996.)

Another area of research at the Census Bureau is on the housing subsidy valuation method. The value of public or subsidized housing is included in the recommended poverty measure, and the current Census Bureau method for imputing such subsidies (on the CPS) is badly outdated. Current methods are being reviewed, and ways to implement this imputation on SIPP are being explored. A paper is planned for presentation in August (Eller and Naifeh, forthcoming).

The one major element of the panel's recommended resource measure not included in the Census Bureau-BLS study was the subtraction of child support paid, since this information was not available in the CPS. Data from SIPP indicate that the inclusion of such payments would increase the poverty rate by 0.3 to 0.5 . Questions were added to the April 1996 CPS Supplement on child support to examine the feasibility of capturing this information on a regular basis on the March CPS. Data on child support paid are regularly collected on SIPP.

As already noted, the treatment of medical benefits and expenditures in defining poverty is a difficult one. Staff are currently examining the treatment of medical out-of-pocket expenditures in the definition of poverty (see Doyle, forthcoming(a)). To come up with a definition of income that excludes these expenditures, our current thinking is that statistically matching SIPP to another Federal government survey that includes detailed information about these 
expenditures (the Medical Expenditure Panel Survey) holds the most promise. In addition, staff are working on a proposed medical care risk index to complement the new poverty measure (to address another recommendation of the panel). (See Doyle, forthcoming(b).)

Since the panel recommended an after-tax income definition for its poverty measure, one problem with transferring the official poverty measure from the CPS to SIPP is the lack of a working tax simulation model based on the SIPP (since the early 1980's, the CPS has employed a model to estimates taxes). The Census Bureau, along with several other Federal agencies, supported the development of a SIPP-based tax model, and we are now in the process of exploring how to best incorporate this model into the Census Bureau's processing system.

Equivalence scales are an important issue in the formulation of poverty thresholds. Betson (1996) provides compelling evidence that the choice of equivalence scales has a significant effect on the composition of the poverty population. He also pointed to the need for continued research in this area.

In another paper, Betson (1995) examined the issue of home ownership and whether the flow of housing services from owner-occupied homes should be taken into account when defining poverty status. He found that counting the value of housing services would change the distribution of the poor, primarily by counting fewer of the elderly as poor.

\section{E. CONCLUDING REMARKS}

We believe that prospects for developing a consensus around a new measure of poverty in the United States are the highest since the current measure was adopted in the 1960's. Converting the measure to the SIPP is not costless, though, and budgetary pressures may cause a delay even if a broad methodological consensus is reached. Furthermore, delicate negotiations over broad policy issues must ensue before any change is made.

Readers are welcome to follow further developments as they happen. Visit the special poverty measurement web site at http://www.census.gov/hhes/www/povmeas.html. 


\section{APPENDIX: DEFINITION OF MONEY INCOME}

The current official U.S. definition of income is based on questions which are asked of each person in the CPS sample household 15 years old and over. These questions cover the amount of money income received in the preceding calendar year from each of the following sources.

Earnings from longest job (or self-employment) and other employment earnings can be classified into three types: (1) Money wage or salary income is the total received for work performed as an employee during the income year. This category includes wages, salary, Armed Forces pay, commissions, tips, piece-rate payments, and cash bonuses earned, before deductions were made for items such as taxes, bonds, pensions, and union dues; (2) Net income from nonfarm self-employment is the net money income (gross receipts minus expenses) from one's own business, professional enterprise, or partnership. Gross receipts include the value of all goods sold and services rendered. Expenses include items such as costs of goods purchased, rent, heat, light, power, depreciation charges, wages and salaries paid, business taxes (not personal income taxes); and (3) Net income from farm self-employment is the net money income (gross receipts minus operating expenses) from the operation of a farm by a person on their own account, as an owner, renter, or sharecropper. Gross receipts include the value of all products sold, payments from government farm programs, money received from the rental of farm equipment to others, rent received from farm property if payment is made based on a percent of crops produced and incidental receipts from the sale of items such as wood, sand, and gravel. Operating expenses include items such as the cost of feed, fertilizer, seed, and other farming supplies; cash wages paid to farmhands; depreciation charges; cash rent; interest on farm mortgages; farm building repairs; and farm taxes (not state and Federal personal income taxes). The value of fuel, food, or other farm products used for family living is not included as part of net income.

Unemployment compensation includes payments received from government unemployment agencies or private companies during periods of unemployment and any strike benefits received from union funds.

Workers' compensation includes payments received periodically from public or private insurance companies for injuries received at work.

Social Security includes Social Security (old age) pensions and survivors' benefits and permanent disability insurance payments made by the Social Security Administration prior to deductions for medical insurance. Medicare reimbursements for health services are not included.

Supplemental Security Income includes payments made by Federal, state, and local welfare agencies to low income persons who are 65 years old or over, blind, or disabled.

Public assistance or welfare payments include public assistance payments made to lowincome persons, such as Aid to Families With Dependent Children, Temporary Assistance for Needy Families, and general assistance. 
Veterans' payments include payments made periodically by the Department of Veterans Affairs to disabled members of the Armed Forces or to survivors of deceased veterans for education and on-the-job training, and means-tested assistance to veterans.

Survivor benefits include payments from survivors' or widows' pensions, estates, trusts, annuities, or any other types of survivor benefits. Payments can be reported from ten different sources: private companies or unions; Federal government (Civil Service); military; state or local governments; railroad retirement; workers' compensation; "Black lung" (miners') payments; estates and trusts; annuities or paid-up insurance policies; and other survivor payments.

Disability benefits include payments received as a result of a health problem or disability other than those from Social Security. Payments can be reported from ten sources: workers' compensation; companies or unions; Federal government (Civil Service); military; state or local governments; railroad retirement; accident or disability insurance; Black lung payments; state temporary sickness; or other disability payments.

Pension or retirement income includes payments reported from eight sources: companies or unions; Federal government (Civil Service); military; state or local governments; railroad retirement; annuities or paid-up insurance policies; withdrawals from special (tax-favored) retirement accounts such as Individual Retirement Account (IRA's); or other retirement income.

Interest income includes payments received (or credited to bank accounts), from bonds, treasury notes, IRA's, certificates of deposit, interest-bearing savings and checking accounts, and all other investments that pay interest.

Dividends include income received from stock holdings and mutual fund shares. Capital gains from the sale of stock holdings are not included as income.

Rents, royalties, and estates and trusts include the net income from the rental of a house, store, or other property, receipts from boarders or lodgers, net royalty income, and periodic payments from estate or trust funds.

Educational assistance includes Pell Grants; other government educational assistance; any scholarships or grants; or financial assistance from employers, friends, or relatives not residing in the student's household.

Child support includes all periodic payments made by parents for the support of children, even if these payments are made through a state or local government office.

Alimony includes all periodic payments to ex-spouses. One-time property settlements are not included.

Financial assistance from outside of the household includes periodic payments from nonhousehold members. Gifts or sporadic assistance is not included. 
Other income includes all other regularly received payments that are not included elsewhere on the questionnaire. Some examples are state programs such as foster child payments, military family allotments, and income received from foreign government pensions.

Receipts not counted as income include capital gains received (or losses incurred) from the sale of property, including stocks, bonds, a house, or a car (unless the person was engaged in the business of selling such property, in which case the net proceeds would be counted as income from self-employment); withdrawals of bank deposits; money borrowed; tax refunds; gifts; and lump-sum inheritances or insurance payments. 


\section{REFERENCES}

Betson, David M. 1996. '"Is Everything Relative?' The Role of Equivalence Scales in Poverty Measurement." University of Notre Dame. March.

Betson, David. 1995. "Effect of Home Ownership on Poverty Measurement." Unpublished paper. November.

Citro, Constance F. and Graham Kalton (eds.). 1993. The Future of the Survey of Income and Program Participation. Washington, DC: National Academy Press.

Citro, Constance F. And Robert T. Michael (eds.). 1995. Measuring Poverty: A New Approach. Washington, DC: National Academy Press.

Coder, John and Lydia Scoon-Rogers. 1996. "Evaluating the Quality of Income Data Collected in the Annual Supplement to the March Current Population Survey and the Survey of Income and Program Participation." Working Paper. U.S. Bureau of the Census. July.

Cutler, David M. and Lawrence F. Katz. 1991. "Macroeconomic Performance and the Disadvantaged." Brookings Papers on Economic Activity No. 2, pp. 1-74.

Doyle, Pat. Forthcoming (a). "How Can We Deduct Something We Do Not Collect? The Case of Out-of-Pocket Medical Expenditures." U.S. Bureau of the Census.

Doyle, Pat. Forthcoming (b). "Who's at Risk? Designing a Medical Care Risk Index." U.S. Bureau of the Census.

Eller, T.J. and Mary Naifeh. Forthcoming. "Housing Subsidies: Effect of Estimates on Poverty." U.S. Bureau of the Census.

Fisher, Gordon M. 1992. "The Development and History of the Poverty Thresholds." Social Security Bulletin vol. 55 No. 4 (Winter), pp. 3-14.

Garner, Thesia I., Geoffrey Paulin, Stephanie Shipp, Kathleen Short, Charles Nelson. 1997. "Experimental Poverty Measurement for the 1990's." Prepared for the Allied Social Science Meetings, session sponsored by the Society of Government Economists, January 1997; and the SGE Session: Measures of Well-Being From the Consumer Expenditures Survey, January 1997.

Kokoski, Mary, Patrick Cardiff, and Brent Moulton. 1992. "Interarea Price Indices for Consumer Goods and Services: An Hedonic Approach Using CPI Data." U.S. Bureau of Labor Statistics, January.

Moulton, Brent R. 1992. "Interarea Indexes of the Cost of Shelter Using Hedonic Quality Adjustment Techniques." U.S. Bureau of Labor Statistics, October. 
Orshansky, Mollie. 1963. "Children of the Poor." Social Security Bulletin v. 26 (July), pp. 3-13.

Orshansky, Mollie. 1965. "Counting the Poor." Social Security Bulletin v. 28 (January), pp. 3-29.

Ruggles, Patricia. 1990. Drawing the Line. Washington, D.C.: Urban Institute Press.

Short, Kathleen, Martina Shea, and T.J. Eller. 1996. "Work-Related Expenditures in a New Measure of Poverty." Prepared for the 1996 Meetings of the American Statistical Association.

Slesnick, Daniel T. 1992. "Gaining Ground: Poverty in the Postwar United States." Journal of Political Economy Vol. 101 No. 1 (February), pp. 1-38.

U.S. Bureau of the Census, Money Income in the United States: 1995, Current Population Reports P60-193, Washington, DC: U.S. Government Printing Office, September 1996[a].

U.S. Bureau of the Census, Poverty in the United States: 1995, Current Population Reports P60-194, Washington, DC: US Government Printing Office, September 1996[b].

Watts, Harold W. 1993. "A Review of Alternative Budget-Based Expenditure Norms." Prepared for the Panel on Poverty Measurement and Family Assistance of the Committee on National Statistics, revised (May).

Welniak, Edward J., Jr. 1990. "Effects of the March Current Population Survey's New Processing System on Estimates of Income and Poverty." Prepared for American Statistical Association annual meeting, August.

Weinberg, Daniel H. 1996. "Changing the Way the U.S. Measures Income and Poverty." Prepared for the Canberra Group on Income Statistics, December. 



\section{POVERTY MEASUREMENT IN BOTSWANA}

by

Dabilani Buthali

Central Statistical Office

Botswana 


\section{Poverty measurement in Botswana}

\section{Introduction}

1. A lot is documented about the protracted debate regarding the definition of poverty and its dimensions. In spite of the debate, there is however overwhelming consensus that poverty does exist and is indeed undesirable. In recognition of the latter concern many governments are making concerted efforts to counter poverty. This is important because any development initiatives aimed at the socio-economic welfare of a country's total population must embody a poverty reduction strategy.

2. Poverty and poverty alleviation have long been issues of major concern to the Government of Botswana. The development plans pursued at the dawn of independence bear testimony to that. Having taken a conscious decision to focus on the productive mining sector with the idea that other sectors will be developed through the "trickle down effect", it was expedient to put in place, at the earliest stages of development, programmes to aid the redistribution of revenues accruing to that sector. The trickle down strategy of development may not necessarily ensure an equitable distribution of the nation's income. In recognition of that, the 1970-75 National Development Plan (NDP) stated that one of the Government objective was "the promotion of an equitable distribution of income, in particular by reducing income differentials between the urban and the rural sectors".

3. The concern of the disparities in development between urban and rural was further echoed by the late President Sir Seretse Khama in a message marking the fifth anniversary of independence in 1971 when he stated:

"Unless we introduce clear and consistent policies which provide for social justice, development will enrich a minority of our citizens and leave the lives of the majority practically untouched.... We must make every effort to ensure that our strategy is based on social justice and this means that rural development must have a high priority."

4. In view of the demand for baseline data for planning purposes in the mid-70s, the Central Statistics Office (CSO) conducted the Rural Income Distribution Survey (RIDS) in 1974/5 with financial assistance from the World Bank. Data from the survey were used to assess the sources and level of incomes of rural households.

\section{Poverty Studies in Botswana}

5. The results of the 1974/5 RIDS enabled a first attempt to study poverty in Botswana. The results of the poverty analysis were presented as an appendix to the RIDS report. In 1976 another study was conducted, with coverage restricted to the four main towns. Although the 1976 study adopted the same method as the earlier one, the point of departure was in the assessment of what constituted the minimum levels of sustenance.

6. During the period between the RIDS and the 1985/6 HIES there were no reliable benchmark data for poverty assessment purposes. Consequently, it took eleven years to update the $1974 / 5$ poverty datum line. While in 1978/79 a HIES was conducted alongside a migration survey, the results of 
the survey were not satisfactory and hence were not published. The third poverty study was conducted in 1989 following the release of the 1985/6 Household Income and Expenditure Survey (HIES) results. The 1989 study covered urban and rural areas and divided the country into six regions to allow for regional comparison of the extent of poverty. It must be noted, however, that the boundaries for these regions were rather arbitrary though.

7. All the poverty studies surveys mentioned above were conducted by the Central Statistics Office. The fourth poverty study was done late 1996 following the release of the 1993/4 HIES report earlier the same year. The Rural Development Co-ordination Division of the Ministry of Finance and Development Planning contracted the Botswana Institute for Development Policy Analysis (BIDPA) to update the 1989 poverty datum line, and also review the effectiveness of poverty alleviation policies. The results of the study, conducted in collaboration with the CSO, have just been released. To the extent that some poverty alleviation policies had to evaluated, the BIDPA study not only looked at the characteristics of the poor but also made an effort to enumerate the underlying causes of poverty.

8. The first three poverty studies used total income per household to derive the percentage of households below the poverty datum line. However, because of the concern that income is more susceptible to under-reporting than consumption, the BIDPA study used consumption per household instead. Apart from the concern about under-reporting of income, consumption is considered to enable a comparison of actual consumption with the threshold consumption level as reflected by the PDL. In spite of the concern relating to under-reporting of income, results show that poverty is less when using income than with consumption. Perhaps this may be due to the fact that some high income households have low consumption because they are saving - therefore being wrongly misclassified as being poor.

\section{Poverty Method}

9. Poverty studies carried out in Botswana adopted the absolute poverty measurement approach; putting more emphasis on capabilities rather than basic needs or basic rights. The premisse ${ }^{1}$ was essentially that individuals should have the capability to feed and clothe themselves; should be able to work if they wish; should be housed in a manner not prejudicial to health; should be able to enjoy education; and should be able to take their place in society. All these must be achieved at a very minimum cost. Suffice it to note that in deriving what was considered to be the core dimensions of poverty, CSO was quite aware of the problems of objectively measuring the implicit basket.

\subsection{Poverty Basket}

10. On the basis of the capabilities cited above, a basket of goods and services for individuals and the household (as an entity) was established. The Botswana poverty basket broadly comprises; food, clothing, personal items, household goods, shelter, and a few other items. Determining the specific requirements for each individual was not an easy task since that depended on the age and sex of each person. The household requirements depended on the household size and age groups of members.

\footnotetext{
' The BIDPA study rephrased the premisse to read "Poverty is the inability to meet basic nutritional, health, education, shelter, social and recreational needs, and is closely related to choice. In spite of the BDPA working definition, they have however used the same basket and methodology adopted by the CSO.
} 


\subsubsection{Food Items}

11. Food is usually the least contentious component of the poverty basket. However, this does not presuppose that the calculation of the requirements is a straight forward matter. The amount allocated to an individual was the minimum necessary to maintain physical health. A table of the food requirements was prepared with assistance from nutritionists in the Ministry of Health. The table provides what is considered the ideal diet - balanced in terms of calories and other nutrients. Analysing the food consumption pattern from the HIES showed that the food households consumed was often different from the ideal diet. Not only was the actual food consumed different, but in some instances it turned out to be more expensive and nutritionally deficient. For example among the commodities consumed by the low income groups (1985/6 HIES) beer of some form stood out as being of major importance. Similarly, the consumption of fizzy drinks was high in the desert $\operatorname{areas}^{2}$. Neither of the two items is part of the ideal diet.

12. The issues noted above raises the dilemma as to whether to impose the cheap ideal diet which may not be available in some regions, or to use the actual (albeit expensive) diet. The final food table was essentially a compromise between the consumption pattern from the HIES and the ideal diet. For instance, while the food table gives the requirement for meat, the relative expenditure for beef, goat/mutton, chicken and fish from the HIES were used to arrive at a kilogram of meat.

\subsubsection{Non-Food items.}

13. The treatment of the non-food component of the poverty basket is not usually an easy matter. It is for this very reason that many studies derive the component indirectly, by multiplying the food cost by some factor. Notwithstanding the simplicity of the indirect method, the rather crude estimate of the non-food tends to undermine the importance of some commodities. To the extent that food is considered the baseline for the basket, this may suggest that households or individuals have more appreciation of food over other items. While food may be necessary for survival, a healthy diet may not prevent a person from falling ill. For instance shelter from rain and cold is also necessary for health.

14. CSO's approach in dealing with the non-food items was to consider the level below which it was impractical to live in a society - a bare minimum level. For all the items considered here, quality is not of any importance at all but something very basic. A question which immediately comes to mind is "what is basic?" The bottom line was simply that it must be a level below which it is practically impossible to live.

15. It stands to reason that a person living in a civilised society must dress in a way which allows him/her to take part in social life. Putting aside the legal part of clothing, there are some cultural dimensions attached to clothing. For instance, the setswana culture dictates that a man must wear a jacket at a funeral or to be allowed to speak at a public meeting (Kgotla). Taking all these issues into consideration, the poverty studies made an allowance for basic clothing. With regard to the quantity, the bottom line was that "there must be one to wash and one to wear/repair".

16. The treatment of housing was to cost a basic house from among those considered to be the norm in a given area. For instance in the rural areas of Botswana thatched huts with reeds, poles or mud walls (or a combination of these) are the norm. Apart from the cost of the builder, building

\footnotetext{
2 There is no acute shortage of water in the desert and therefore it should not be assumed that fizzy drinks were used as substitutes for water.
} 
materials could be gathered from the veld for free, implying zero cost for materials. For a given household the number of huts depended on the household size, treating young children as half adults. With regard to housing in towns, thatched huts are not common despite there being no legislation against such cheap structures. Rather than impose a mud hut to town households, rental of single room or a basic $2 \frac{1 / 2}{\text { roomed house }}{ }^{3}$ (depending on the household size) was assumed.

17. The requirement for household goods (e.g. cooking utensils) was a function of the household size, again taking young children as half adults. With regard to personal items, the allocation followed the same rationale of bare minimum. Personal items included all items that are neither food nor clothing and could be conveniently allocated to an individual. Included in the list of personal items are health, hygiene, and personal household goods (bathing soap, toothbrush, plats, etc.).

18. Among the exclusions from the poverty basket were things like toys, soft drinks, snacks, beds, socks, furniture, electricity, entertainment, saving, etc. to list just a few. Also there is no allowance for travelling; it is assumed that all journeys are made on foot. Some of the exclusions are indeed important for a meaningful life. The general opinion in Botswana is that the basket is very harsh. However, poverty studies in the region feel that the basket is too generous.

19. One major issue relating to non-food items is the life span in terms of the number of months they are expected to last. It was important to establish the life span as accurately as possible since it is the factor upon which the monthly cost of a commodity largely depends. Increasing (decreasing) the life of an item decreases (increased) the cost. Average life spans obtained from sample of households interviewed were used. Indeed there is a lot of subjectivity in the estimation process.

20. Although deciding the constituent items of the basket is not entirely an objective exercise, it is hoped that the criteria employed draw as close to an objective as possible. Furthermore, maintaining the same basket over time should enable a fair assessment of the poverty level since the results are based on the same scale. To that extent, therefore, the subjectivity of the basket should not be a major concern.

\subsubsection{Pricing the basket}

21. Items in the basket are priced through a country-wide exercise designed specially for the PDL. This is important, primarily because prices from the cost-of-living index are not sufficiently detailed for PDL purposes. In pricing the PDL basket, small quantities are priced, because it is assumed that poor people can not afford large quantities. Furthermore, the lowest reasonable prices or the lowest price at which an item is readily available is used. The reasoning was that at the low income level people behave more rationally and hence do care about prices.

22. In view of the short time frame within which results were required, the 1996 poverty study could not collect prices for the PDL basket. Instead, the 1989 PDL prices were adjusted using the Consumer Price Index (CPI). The food index was used to adjust the food basket while for non-food items the overall index was used. Having noted that the CPI index is not sufficiently detailed for PDL purposes, at best this was just a crude estimation.

23. Suffice it to say that in the 1989 poverty study, prices for the PDL basket were collected in 1989 whereas the incomes were from the 1985/6 HIES (February 1986 was the mid period).

\footnotetext{
${ }^{3}$ These have neither a bathroom nor a flush toilet. A pit latrine is assumed to be sufficient although not quite hygienic.
} 
Incomes were adjusted using the CPI to equate them to the 1989 level. Some users argue that perhaps it was more appropriate to deflate the 1989 prices to 1986 level. Whichever option is chosen, one has to accept the inherent deficiencies in the data.

\section{Source of Data}

24. Apart from prices, which are collected through a separate exercise, the HIES provides benchmark data for poverty analysis. Having mentioned that the poverty threshold is compared with income (or consumption as a proxy for income), there is a need to look at the reliability of the income data. This is very important because an underestimation of income overstates the percentage of poor households.

25. The concept of income includes both cash and income in kind. Cash income includes earnings, unearned cash, business profit, gifts and cash remittances. On the other hand income in kind covers non-cash earnings, own produce, goods from gathering, non-cash gifts (e.g. food rations) and remittances. Households do not only receive but also give out goods to other households. In view of that, income outgoing (which includes tax) is deducted from the total income to derive what is termed "disposable income", the income to compare with the threshold poverty level. The two HIES made no attempt to estimate the income from owner-occupied dwellings. However, this part of income should not affect the incomes of the poor significantly moreover that most households who own houses reside in rural areas where thatched huts are the norm. It must be noted that there is increasing pressure to estimate the income from owner-occupied dwellings especially for national accounting purposes

26. For most practical purposes, the HIES data are fairly reliable. The level of under-reporting of income and expenditure is that expected in a survey of the same nature. However the underreporting of commodities such as alcohol and tobacco needs some mention. Reported expenditure on alcohol in the 1993/4 HIES was less than that for soft drinks; this was just not true. This may have emanated from the fact that smoking and drinking are social habits for which participation is viewed negatively in the society. Therefore the likelihood for under-reporting of such items is quite high. While these may be the main candidates for under-reporting, there are many more. Using imports and local production figures it was possible to estimate fairly accurately the level of consumption of many commodities.

27. Pricing of non-marketed commodities especially those acquired from hunting or gathering may lead to an upward bias. The usage or consumption of some of the items (e.g. firewood) is not consistent with the reported value in money terms. An upward bias may result due to the fact that the value reported is that for the nearest market rather than the specific area where the commodity may be over abundant to the extent that it is almost valueless.

28. Botswana is a drought prone country and therefore the fragile subsistence agriculture, the backbone for rural households, is frequently affected by drought spells. Changes in the incomes of poor households (predominantly in rural areas) is closely linked to the performance of the agricultural sector. The effect of the drought on the income levels of the rural households is often very immense. As a result, if an income and expenditure survey is conducted during a drought period incomes for rural households may be very low. The 1985/6 HIES was conducted at the tail end of a long drought period. Whether the resulting income could be considered to be an underestimation or just low figures (albeit accurate) is another matter. The important thing is that comparing the poverty threshold with such incomes could be misleading especially when poverty 
studies are not conducted frequently. To the extent that it is not always easy to establish the level of poverty resulting just from the drought, this is indeed a matter deserving some attention.

\section{Living Conditions}

29. Statistics for monitoring living conditions or the quality of life are closely linked and play a complementary role to poverty studies. In 1996 the CSO took the initiative to analyse the two HIES (1993/4 and 1985/6) and 1991 Census results to assess changes in living conditions in Botswana between 1986 and $1994^{4}$. Among the subjects covered were household income and consumption; household resources for production and income earning; health, education; household size and relations; housing conditions and amenities; and transport and communications. Other areas to be explored in future include victimisation by crime, medical care, and nutrition. With the current plans of conducting a HIES at six year intervals, the assessment of living conditions will be more frequent.

\section{Poverty measurement in SADC Region}

30. In an effort to address poverty in the sub-region, the Southern Africa Development Community $\left(\mathrm{SADC}^{5}\right)$ took a major step to synthesise the individual initiatives of member countries. A workshop was held in Namibia in July 1996, the main aim being to share experiences on poverty measurement and living conditions assessment. A major achievement of the workshop was the establishment of core dimensions for statistics on poverty and living conditions in the region. In regard to poverty measures, the workshop agreed that the baseline for comparison should be the food component of the basket. There was no consensus reached about what should constitute the non-food component of the basket. Member countries are to decide on the scope of the non-food component depending on their needs.

\section{Poverty Alleviation Policies}

31. As mentioned in the introductory note, Botswana's development strategy focuses more on the mining sector, with the idea that the resulting revenues will develop other sectors. In order to address the issue of equity in income distribution, a number of policies have been put in place. While most of the programmes are aimed at the ordinary citizen (not necessarily the poor), in some respect they implicitly address poverty. Only a few programmes were designed specifically for the poor and thus explicitly address poverty. Among the first group is the Financial Assistance Policy (for small scale citizen enterprises), Basic Education programme, Adult Literacy Programme, and Vulnerable groups (e.g. remote area dwellers programme). The objective of these programmes was to build sustainable income-earning opportunities for low income households. Programmes which are directly aimed at alleviating poverty include the Arable Lands Development Programme (for subsistence agriculture), Destitutes Programme, drought Labour Based Public Works (employment creation for a basic wage during drought spells). In October 1996 the government introduced the old age pensions for all elderly citizens aged 65 and above. Through such programmes the government commitment to alleviate poverty is clearly manifested.

\footnotetext{
"The results are contained in the report "Living Conditions In Botswana: 1986 to 1994" published in 1996.

5 SADC comprise Angola, Botswana, Lesotho, Malawi, Mauritius, Mozambique, Namibia, South Africa, Swaziland, Tanzania, Zambia and Zimbabwe.
} 


\section{Appendix}

Poverty Indicators (based on consumption per household)

$\begin{array}{llll} & \mathbf{P}_{\mathbf{0}} & \mathbf{P}_{1} & \mathbf{P}_{2} \\ 1985 / 6 & 0.49 & 0.22 & 0.13 \\ 1993 / 4 & 0.37 & 0.16 & 0.09\end{array}$

Poverty Indicators (based on income per household)

$\begin{array}{llll} & \mathbf{P}_{\mathbf{0}} & \mathbf{P}_{1} & \mathbf{P}_{2} \\ 1985 / 6 & 0.46 & 0.23 & 0.18 \\ 1993 / 4 & 0.33 & 0.14 & 0.08\end{array}$

GINI Coefficient by strata

\begin{tabular}{lcccc}
\multicolumn{1}{c}{ Cash income } & \multicolumn{3}{c}{ Cash + In kind income } \\
& $1985 / 6$ & $1993 / 4$ & $1985 / 6$ & $1993 / 4$ \\
\hline Towns & 0.563 & 0.548 & 0.536 & 0.539 \\
Urban villages & - & 0.552 & - & 0.451 \\
Rural & 0.674 & 0.599 & 0.477 & 0.414 \\
\hline All & 0.703 & 0.638 & 0.556 & 0.537 \\
\hline Source: $1985 / 6$ and 1993/4 HIES reports, CSO & & &
\end{tabular}

Income enjoyed poorest, middle and richest households/persons in Botswana

$$
\text { Poorest } 40 \% \text { Middle 40\% Richest 20\% }
$$

$\begin{array}{lrrr}1985 / 6 \text { (based on households } & 10.7 & 27.8 & 61.5 \\ 1993 / 94 \text { (based on persons) } & 11.6 & 29.1 & 59.3 \\ 1993 / 4 \text { (based on households) } & 9.4 & 29.4 & 61.2\end{array}$

Source: 1985/6 and 1993/4 HIES reports, CSO 


\section{References}

1. CSO (1988), Household Income and Expenditure Survey: 1985/86, Gaborone.

2. CSO (1996), Household Income and Expenditure Survey: 1993/94, Gaborone.

3. CSO (1996) Living Conditions In Botswana: 1986 to 1994, Gaborone.

4. CSO (1991), A Poverty Datum Line For Botswana November 1989, Gaborone.

5. CSO (1976), The Rural Income Distribution Survey In Botswana 1974/75, Gaborone.

6. BIDPA (1996), Study Of Poverty and Poverty Alleviation In Botswana, Gaborone.

7. CSO (1976) Poverty Datum Line For Urban Areas Of Botswana, Gaborone. 


\title{
CONCEPTUALISATION, MEASUREMENT AND DIMENSIONAL ASPECTS OF POVERTY IN INDIA
}

\author{
by
}

P.D. Joshi

Department of Statistics

India 


\title{
Conceptualisation, measurement and dimensional aspects of poverty in India
}

\author{
National Sample Survey Organisation
}

Department of Statistics, New Delhi

\begin{abstract}
This paper focuses mainly on the conceptual and measurement aspects of poverty and describes the methods of estimating the incidence of poverty in India. The sensitivity of movements in poverty to the methods used employing National Sample Survey data on consumer expenditure as available from different rounds at the all India level separately for the rural and urban sector has been presented for (a) judging the robustness in the pattern of poverty to the manner in which poverty is measured and (b) for drawing conclusion about progress in poverty alleviation. Trend in relative poverty employing different inequality measures has been presented. Lastly, efforts made on pilot basis for obtaining profile of the poor utilising National Sample Survey data on consumer expenditure and identification of poor families through below poverty line (BPL) census have been reported.
\end{abstract}

\section{Introduction}

Poor and poverty are historical in nature and their concern appears to be as old as human history. Generally, the terms are used as if their meanings are clear, but this is not so. The word "poor" is adjectival to the word "Poverty" and is realised as economic and or social difference between the human beings.

A poor person is one who does not have command over or access to the basic physical needs like adequate food, drinking water, clothing and shelter and social needs like education and health.

Poverty is visualised as "The state or condition of having little or no money, goods, or means of support or to a condition of being in want of something that is needed, desired or generally recognised as having value". The meaning of poverty, therefore, not only varies from society to society but it also varies within the same society at different points of time.

Traditionally, poverty had been thought of in terms of relative deprivation. However, it sounds differently depending upon its context. Poverty exists in all countries and in all societies and has various aspects viz., lack of income, productive resources, hunger and malnutrition, illiteracy, homelessness and inadequate housing, unsafe environment, social discrimination and exclusion.

Study on the extent of poverty and a constant watch on it is therefore of great importance for (i) direction of effort required to alleviate poverty (ii) evaluation of the success or failure 
of government programmes and policies and the need for modifications in them and (iii) identification of the poor.

In a developing country like India, the problems of assessing the incidence of poverty are enormous, primarily because poverty is a multi-dimensional concept and the extent of poverty differs from one part of the country to the other. No single symptom of poverty can be relied upon for getting a realistic idea of the true incidence of poverty.

\section{Conceptual and Measurement Approach}

Poverty many be measured either in relative or in absolute terms depending upon whether it is related to the relative or the absolute concept of deprivation. This involves some element of arbitrariness for making it operational. The arbitrariness comes in determining "need" and in specifying the irreducible level of each need. In the absolute concept some absolute norm of income or consumption which determines the cut-off point or the line of demarcation between the poor and the non poor are laid down and all persons below demarcation line are considered as poor. The concept of relative poverty is related to inequality. Thus, whereas an absolute -poverty view point defines poverty as the inability of an individual's income to meet the subsistence needs, a relativist view point defines poverty as a situation in which an individual's income is low relative to some social standard.

Poverty reflects the deficiencies in the essential requirements of individuals. It refers to a situation in which the overall needs of an individual are not satisfied due to lack of adequate purchasing power. Monetary cut-off therefore could be fixed in terms of income or expenditure. Certainly, per capita income indicates the purchasing power of person but the individual utility depends on consumption expenditure. There is no consensus on the definition of poverty in India in terms of minimum per capita per month income. Reliable income data at the household level is not available as may be seen in Joshi (1996a). Further, income (even after correcting for prices) measures the potential consumption of the household or the individual. Poverty is not directly associated with regular cash income flow. On the other hand it is associated with the actual consumption of the individual or household. Consequently, expenditure is more immediate proxy measure than income. Further, income may be generated by individuals but the consumption is shared among the member of the household. It is unlikely that the household will be poor but not the individuals in it. Moreover, expenditure is more stable over time and probably reflects the permanent income of the household. Also, for the agricultural and other self employed households, it is broadly easier to recall expenditure. On the other side, income fluctuates according to season. Actual consumption expenditure determines the living standard and is not always met wholly out of current income and can also come from assets, debt and dissavings. Thus, consumption expenditure is considered to be more appropriate and relevant than income for the purpose of directional idea on the level of poverty. The procedure followed is to define or fix a poverty line in terms of overall monthly per capita consumption expenditure, to update the same over time for price change employing price 
deflator and finally the dimension of poverty in absolute terms utilising the size distribution of Consumer Expenditure.

Several criteria may be used to define the Poverty Line. Important among them include:

i. the proportion of expenditure taken up by specified essential items.

ii. the Calorie value of food.

iii. the cost of balanced diet.

iv. the cost of essentials of a tolerable human existence.

The poverty line determined on the basis of first two criteria is independent of prices and hence comparable over time and space which is not the case with the last two ways of setting the poverty line. Again the monetary cut-off could be explicitly fixed in terms of calorie intake or in terms of balanced diet.

The available literature shows that the definition of poverty line has been viewed from two angles viz., the minimum level of living i.e. the cost of bundle of goods at the relevant prices and the inadequacy in food consumption expressed as the shortage of necessary energy intake in terms of nutritional requirement for healthy living. Given a "balanced" or "minimum" diet, the poverty line may be defined as that expenditure level at which households, on an average seem to have the specified diet which is not easy in practice to follow item by item. Further the cost of the specified diet as poverty line based on value judgement may not necessarily confirm to its prescribed composition. However, it only ensures amount of spending enough to provide balanced diet and it is by no means certain that balanced diet are purchased and consumed.

Poverty needs to be identified with deficiency in the total level of living which not only includes energy requirement but also balanced diet needed for health and the other basic needs essential for human existence at a tolerable level which would be difficult to define in terms of specified quantities and services.

In India, the derivation of the minimum normative absolute living standard in terms of per capita total expenditure (PCTE) or the absolute poverty line has also been focused from two alternative approaches viz., different descriptions of the minimum normative food basket and the calorie norm. However, there is no optimal diet and there is very little correlation between prices and calorie content of different food items as food habits of different individuals differ considerably.

\section{Statistical Dimensions}

The statistical dimension of poverty measured in terms of both absolute and relative employing expenditure approach have been focused from time to time by the national and international organisations, government bodies, social scientists, economists and researchers 
in their individual capacities. But these studies are based on different concepts of poverty line, different methods of estimation and measurement indicators. There has been a difference of opinion on the conceptualisation and measurement of poverty and in turn on the ways of setting the poverty line. The variations in conceptualisation and measurement approaches in defining the poverty line for a geographical area affects the spatial and inter temporal comparison in regard to incidence of poverty. One should therefore be very careful while presenting data on incidence of poverty as the methodology and data used by different agencies/organisations are diverse.

The concepts, measurement and methodological issues relating to estimating of poverty in the Indian Context have been debated by a number of distinguished groups on the subject viz., Working Group (1962), Task Force (1979), Study Group (1984), Expert Group (1993) set up by the Government and also individual researchers. We, therefore present the changes in methodology of poverty estimates employing Head Count Ratio (HCR) and its implication under official and individual approaches. The sensitivity analysis on different measures of poverty has been presented in Joshi (1997).

\section{Official Source}

\section{Concepts, methodologies and dimensions}

Officially, the estimates of poverty are worked out by Planning Commission (PC), an official agency of the Government of India. Accordingly, the first attempt for ensuring a minimum standard of living was made in 1962 through a Seminar on "Some Aspects of Planning and a Study Group" on the subject. The group recommended:

"(i) The national minimum for each household of five persons (4 adult consumption units) should be not less than Rs. 100 per month in terms of 1960-61 prices or Rs.20 per capita per month. For urban areas, this figure will have to be raised to Rs. 125 per month per household or Rs.25 per capita to cover the higher prices of the physical volume of commodities on which the national minimum is calculated.

(ii) This national minimum excludes expenditure on health and education both of which are expected to be provided by the state according to the Constitution and in the light of the commitment.

(iii) An element of subsidy in urban housing will have to be included after taking Rs. 10 per month or 10 percent as the. rent element payable from the proposed national minimum of Rs. 100 per month.

(iv) As a first exercise the target period by which the national minimum should be attained may be taken as fifteen years from 1960-61 to 1975-76". 
The basis of arriving at the monetary norms and the definition of minimum level of living is not available in published form. However a note from Planning Commission (1978) and Pant (1978) point out that the Working Group took into account the recommendations of a balanced diet made by the Nutrition Advisory Committee (NAC) of the Indian Council of Medical Research (ICMR) in 1958 and came to hold the above view. Later, the concept of poverty line was introduced on the recommendation of Task Force on "Minimum Needs and Effective Consumption Demands" as may be seen in Planning Commission (1979). The contribution of the task force was to estimate daily per capita calorie requirement separately for rural and urban areas on the basis of age, sex and activity specific calorie allowance recommended by the Nutrition Expert Group (1968). Accordingly, norms of nutritional requirement for the rural and urban sectors were obtained as $2435 \mathrm{~K}$-cal and $2095 \mathrm{~K}$-cal respectively. These norms were derived by first deriving the age-sex activity specific composition of the rural and urban population by super imposing the census based activity pattern according to the age and sex on the projected rural and urban population.

The official approach to measurement of poverty therefore started by fixing a standard of calorie intake and observing the level of per capita consumption expenditure with which on the average, this calorie intake level is associated. Thus, an allowance for non food consumption also exist in the construction of poverty line through not on normative basis but on a behavioural basis. The poverty line at 1973-74 (base year) prices for the rural and urban sectors were worked out as Rs.49.09 and Rs.56.64 respectively utilising National Sample Survey data on consumer expenditure and using inverse interpolation method. This is incidentally in line with Bhattacharya, Roy Chaudhary and Joshi's (1980) estimate on the sectoral difference to the order of $16.5 \%, 15.2 \%$ in cost of living with Laspeyres, Paasche's and Fisher type indices respectively.

The poverty line so defined was updated over time by taking care of change in the price levels. Initially, the Wholesale price index was used to reflect the price changes for updating the poverty line over time and later shifted to implicit private consumption deflator from National Accounts Statistics for the year 1977-78 and onwards on the basis of the recommendation of a study group on "The Concept and Estimation of Poverty Line" set up by the Planning Commission (1984). In fact the recommendation of the Study Group was for the use of a price index approximately weighted by the consumption basket of the poor as an index for reflecting price changes relevant to the poor which was found, at that time to be very close to implicit private consumption deflator. Further for estimation of incidence of poverty in term of head count ration the use of National Sample Survey (NSS) data on size distribution of consumer expenditure with adjustment for differences in the two sets of estimate as available from National Accounts Statistics (NAS) and NSS was followed. The reason behind this was to have compatibility between the two sets of data in order to ensure consistency between the two important components of the plan model i.e. input - output table (based on NAS) and consumption sub model (based on NSS data). The procedure followed has been to adjust the expenditure level reported by the NSS uniformally across all expenditure classes by a factor equal to the ratio of the total private consumption expenditure obtained from the NAS to that obtained from the NSS. The old NAS series was used for 
deriving the adjustment factor for the estimate up to year 1983 and the new NAS series has been used for the year 1987-88. The population below poverty line was thus estimated by applying the updated poverty line to the corresponding adjusted NSS distribution of population by levels of consumption expenditure. To estimate the incidence of poverty at the state level all India poverty line and the adjustment factor were used on the state specific NSS distribution of population by level of consumption expenditure uniformly across the state. Planning Commission (1981) has also used the NSS $32^{\text {nd }}$ round (July 1972-June 1978) data on consumer expenditure and applied a similar procedure resulting in rural poverty line of Rs.76 per capita per month and urban poverty line of Rs. 88 per capita per month. Table 1 provides poverty line (in Rs) and Head Count Ratio in per cent under different scenarios.

Table 1: Implications of adjustment of NSS distribution on poverty estimates

\begin{tabular}{|c|c|c|c|c|c|c|}
\hline \multirow[t]{2}{*}{$\begin{array}{l}\text { Place of } \\
\text { residence }\end{array}$} & Poverty Line & $\begin{array}{l}\text { Proportion } \\
\text { of poor }\end{array}$ & Poverty Line & $\begin{array}{c}\text { Proportion } \\
\text { of poor }\end{array}$ & Poverty Line & $\begin{array}{l}\text { Proportion } \\
\text { of poor }\end{array}$ \\
\hline & \multicolumn{2}{|c|}{$1977-78$} & \multicolumn{2}{|c|}{$1983-84$} & \multicolumn{2}{|c|}{$1987-88$} \\
\hline \multicolumn{7}{|c|}{ Unadjusted NSS distribution } \\
\hline Rural & 62.10 & 60.19 & 101.70 & 56.33 & 131.60 & 50.87 \\
\hline Urban & 71.65 & 46.55 & 117.34 & 41.94 & 151.83 & 33.25 \\
\hline \multicolumn{7}{|c|}{$\begin{array}{l}\text { Adjusted NSS distribution } \\
\text { A. Using New Series of NAS }\end{array}$} \\
\hline Rural & 62.10 & 45.74 & 101.70 & 32.62 & 131.60 & 30.02 \\
\hline Urban & 71.65 & 33.42 & 117.34 & 21.75 & 151.83 & 17.8 \\
\hline $\begin{array}{l}\text { Adjustment } \\
\text { factor }\end{array}$ & 1.20 & & & 1.33 & & 1.2 \\
\hline \multicolumn{7}{|c|}{ B. Using Old Series of NAS } \\
\hline Rural & 60.60 & 51.20 & 101.80 & 40.40 & 131.80 & 33.40 \\
\hline Urban & 69.90 & 38.20 & 117.50 & 28.10 & 152.10 & 20.10 \\
\hline $\begin{array}{l}\text { Adjustment } \\
\text { factor }\end{array}$ & 1.09 & & & 1.21 & & 1.22 \\
\hline \multicolumn{7}{|c|}{ Adjusted distribution (using commodity specific adjustment factors) } \\
\hline $\begin{array}{l}\text { Rural } \\
\text { Adjustment } \\
\text { factor }\end{array}$ & $\begin{array}{l}62.10 \\
(1.18)\end{array}$ & 46.70 & $\begin{array}{l}101.70 \\
(1.25)\end{array}$ & 37.90 & $\begin{array}{l}131.60 \\
(1.19)\end{array}$ & 35.60 \\
\hline $\begin{array}{l}\text { Urban } \\
\text { Adjustment } \\
\text { factor }\end{array}$ & $\begin{array}{l}71.70 \\
(1.22)\end{array}$ & 32.00 & $\begin{array}{l}117.30 \\
(1.31)\end{array}$ & 22.80 & $\begin{array}{l}151.80 \\
(1.22)\end{array}$ & 20.00 \\
\hline
\end{tabular}

Note: Within brackets are commodity specific adjustment factors. Figures in bracket are adjustment factors.

Source: BANSIL, PC (1996): A Profile of the Visibly Poor, Techno Economic Research Institute, New Delhi.

However, the official method has been examined by several scholars including Sen Gupta and Joshi (1981), Minhas et al (1988, 89, 90, 91), Expert Group (1993) and Dandekar (1996). The grounds of difference include: 
1. Derivation of calorific norms.

2. The procedure of adjustment of consumption expenditure generated by the National Sample Survey with the aggregate private consumption expenditure.

3. The choice of price deflators to represent changes in the poverty line.

4. The ignorance of between state price differences.

5. The uniformity of consumption basket over time.

6. The uniformity of consumption basket among the state.

7. Estimate based on the all India poverty line and the all India size distribution of per capita total expenditure (PCTE) vis-a-vis the population weighted average of state specific head count ratio using state specific poverty lines and state specific size distribution of PCTE.

The Planning Commission constituted an Expert Group in 1989 for looking the methodology of poverty estimation at national and state level and also to go in to the question of re-defining the poverty line. The group in their report submitted in 1993 recommended

(i) Abandonment of NSS-NAS adjustment procedure.

(ii) Derivation and application of state specific poverty lines as against an all India poverty line for rural and urban areas for working out state specific poverty estimates and its aggregation to derive national level poverty estimate.

(iii) Use of state specific cost of living indices for updating the poverty line separately for rural and urban areas.

The recommendation was for the use of consumer price index number for Agricultural Labour (CPIAL) for updating the rural poverty line and a simple average of weighted commodity indices of consumer price index for industrial workers (CPIIW) and urban non manual employees (CPIUNME) for updating the urban poverty line. Recently, the Planning Commission (1997) has accepted the recommendations and the methodology adopted by the Expert Group with a slight modification in adopting the price deflator for updating the poverty line in the urban sector. Accordingly, the most recent official methodology (Modified Expert Group) uses (CPIW) instead of weighted average of CPIIW and CPIUNM along with the other recommendations made by the Expert Group in working out the poverty estimates for the rural and urban areas at the state level and it's aggregation for national level. We have, therefore, presented the trends in incidence of poverty as measured by Head Count Ration under the aforesaid scenario in table 2. 
Table 2: Poverty line (in Rs.0.00) per person per month as available from Planning Commission, Expert Group, and Planning Commission modified recently

\begin{tabular}{rlllllll}
\hline & & \multicolumn{2}{c}{ EG } & \multicolumn{2}{c}{ PC } & \multicolumn{3}{c}{ PCM } \\
\cline { 3 - 8 } Year & Item & R & U & R & U & R & U \\
\hline $1973-74$ & PL & 49.63 & 56.96 & 49.10 & 56.60 & - & - \\
& HCR & 56.44 & 49.23 & 56.44 & 49.23 & 56.64 & 49.01 \\
& & & & & & & \\
$1977-78$ & PL & 56.84 & 72.50 & 62.10 & 71.65 & - & - \\
& HCR & 53.07 & 47.40 & 51.20 & 38.20 & 53.07 & 45.24 \\
& & & & & & & \\
1983 & PL & 89.45 & 117.64 & 101.70 & 117.34 & - & - \\
& HCR & & & & & & \\
$1987-88$ & PL & 115.43 & 165.68 & 131.80 & 152.10 & - & - \\
& HCR & 39.06 & 40.12 & 33.40 & 20.10 & 39.09 & 38.20 \\
$1993-94$ & PL & - & - & - & & & \\
& HCR & 37.27 & 33.66 & 19.24 & 10.11 & 37.27 & 32.36 \\
\hline
\end{tabular}

Source:

GOVERNMENT OF INDIA, PLANNING COMMISSION (1993) Report of the Expert Group on Estimation of Proportion AND NUMBER OF POOR.

GOVERNMENT OF INDIA PLANNING COMMISSION (1997): Press release on Estimate of Poverty, perspective Planning Division, New Delhi, $11^{\text {th }}$ March.

\section{Alternative source}

Several studies on conceptual and measurement aspects pointing dimensional differences in incidence of poverty have been reported as may be seen in Sen Gupta and Joshi (1981) and Joshi (1997). Important among them include Dandekar and Rath (1971), Minhas (1970, 1971), Bardhan (1970, 1973, 1974), Ojha (1970), Bhatty (1974), Rudra (1974), Ahluwalia (1978), Rao (1977), Sen (1973), Srinivasan (1977), Sen Gupta and Joshi (1981).

Minhas $(1970,71)$ assumed the minimum level of consumption i.e. the cut-off point at Rs.200 and Rs.240 per capita per annum for the base year 1960-1961 and obtained the estimated number of poor persons. Bardhan (1970) considered Rs.15 per person per month as the minimum at 1960-61 prices. Dandekar and Rath (1971) utilised nutritional norm of $2250 \mathrm{~K}$.Cal for defining poverty line and the population lying below this level of expenditure was estimated for 1960-61. Sukhatme $(1977,78)$ criticised the use of average nutritional requirement in defining the poverty line and thereby deriving the extent of poverty. He argued for considering the minimum requirement for accounting intra individual variation in calorie requirement in defining the poverty line which has not been supported for working out poverty estimates utilising NSS Consumer expenditure data as may be seen in Sen Gupta and Joshi (1981), Dandekar (1981, 82, 1996).

Minhas etal $(1987,89,90,91)$ constructed the cost of living indices for the middle range of the rural (CPIMR) and urban population (CPIMU) and applied for updating the poverty line for obtaining the Head Count Ratio. The indices relate to the periods of National 
Sample Survey for the year 1970-71 to 1987-88 and are based on retail price data for two alternative weighting diagram relating to the base year or 1970-71 and 1983. Table 3 presents poverty line per person per month and head count ratio under alternative estimation procedure.

Table 3: Poverty line (in Rs.0.00) per month per person and Head Count Ratio (in percent) for selected rounds of NSS based on Minhas and alternative methodology: All India

\begin{tabular}{|c|c|c|}
\hline Year & Rural & Urban \\
\hline \multicolumn{3}{|c|}{ Poverty line* } \\
\hline $1970-71$ & 33.01 & 39.04 \\
\hline 1983 & 93.16 & 111.25 \\
\hline $1987-88$ & 122.63 & 158.31 \\
\hline \multicolumn{3}{|c|}{ Head Count Ratio: Minhas procedure } \\
\hline \multirow[t]{2}{*}{ 1970-71 } & 57.33 & 45.89 \\
\hline & $(58.75)$ & $(46.17)$ \\
\hline \multirow[t]{2}{*}{1983} & 49.02 & 38.33 \\
\hline & $(50.77)$ & (39.74) \\
\hline \multirow[t]{3}{*}{$1987-88$} & 44.88 & 36.52 \\
\hline & $(48.69)$ & . (37.76) \\
\hline & Head Count Ratio: Alternative procedure & \\
\hline \multirow[t]{3}{*}{1983} & $40.40^{*}$ & 28.10 \\
\hline & $(40.50)^{*}$ & $(26.70)^{*}$ \\
\hline & $(56.50)^{* *}$ & $(42.30)^{* *}$ \\
\hline \multirow[t]{3}{*}{$1987-88$} & 32.70 & 19.40 \\
\hline & $(29.33)^{*}$ & $(17.57)^{*}$ \\
\hline & $(51.00)^{* *}$ & $(33.47)^{* *}$ \\
\hline
\end{tabular}

Data source: Minhas, Jain and Tendulkar (1991): Declining incidence of poverty in the 1980s, Evidence Versus Artefacts; EPW July 6-13, pp

- These are based on the Planning Commission poverty lines of monthly per capita total expenditure PCTE of Rs.49.09 and Rs.56.64 for all India rural and urban population at 1973-74 prices.

NB: $\quad$ 1. Figures in bracket are the estimate aggregated for 20 states.

2. Figures with an asterisk mark relate to HCR as officially reported.

3. Figures in bracket with an asterisk mark and double asterisk relate to HCR using official price adjustment with an without prorata adjustment factor.

Sen Gupta and Joshi (1981) estimated the incidence of poverty for the rural and urban sectors of India at the regional level with uniform norm of calorie requirement (2200 k-cal) utilising NSS $27^{\text {th }}$ round (Oct. 1972 - Sept. 1973) data. The choice of $27^{\text {th }}$ round data was on the ground of large sample size (72270 rural households and 52820 urban households) and availability of data for one full year for standardising the Consumer basket at the all India level and to estimate state specific/region specific poverty lines.

Estimates of poverty line over time can be made in two ways: (i) the poverty line as estimated for the base year (1972-73) can be adjusted for changes in prices over time and differences in prices across states; (ii) fresh poverty lines, all India and state specific can be calculated from the latest available consumer expenditure survey data. Method (i) allows only for change in prices which the consumption basket is kept as it was in the base year 1972-73). This makes the poverty line comparable over time and across states in the sense 
in which price index numbers are comparable over time. On the other hand, method (ii) allows for changes in the consumption basket keeping the calorie norm unchanged.

Table 4 and 5 presents the poverty line and incidence of poverty with varying calorie norms (as nutrition recommendations are tentative and subject to variation over time) under the scenario of (a) fixed basket of commodities and (b) varying basket of commodities for inter temporal changes utilising National Sample Survey data of different rounds on consumption expenditure. Consumer price index for Agricultural Labourer and Consumer price index for Industrial Workers have been used as price deflators for updating the poverty lines.

Table 4: Poverty line (in Rs.0.00) at different levels of calorie requirement in the rural and urban sector for selected rounds of NSS under the scenario of (a) fixed basket of commodities and (b) varying basket of commodities: All India

\begin{tabular}{|c|c|c|c|c|c|c|}
\hline $\begin{array}{c}\text { Norm of } \\
\text { calorie } \\
\text { requirement }\end{array}$ & $\begin{array}{c}\text { Basket of } \\
\text { Commodities }\end{array}$ & $\begin{array}{c}27 \\
(\text { Oct72-Sept73) }\end{array}$ & $\begin{array}{c}32 \\
\text { (July77-June 78) }\end{array}$ & $\begin{array}{l}\frac{\text { Round (year) }}{38} \\
\text { (Jan-Dec83) }\end{array}$ & $\begin{array}{c}43 \\
\text { (July83-June84) }\end{array}$ & $\begin{array}{c}50 \\
\text { (July93-June94) } \\
\end{array}$ \\
\hline 2400 & $\begin{array}{l}\text { fixed } \\
\text { varying }\end{array}$ & $\begin{array}{l}44.58 \\
44.58\end{array}$ & $\begin{array}{l}\text { Rural } \\
61.25 \\
60.64\end{array}$ & $\begin{array}{r}96.92 \\
74.27^{*}\end{array}$ & 123.31 & $\begin{array}{l}217.59 \\
324.26\end{array}$ \\
\hline 2200 & $\begin{array}{l}\text { fixed } \\
\text { varying }\end{array}$ & $\begin{array}{l}38.21 \\
38.21\end{array}$ & $\begin{array}{l}52.50 \\
51.36\end{array}$ & $\begin{array}{l}83.07 \\
62.57\end{array}$ & 105.69 & $\begin{array}{l}186.50 \\
262.78\end{array}$ \\
\hline 2000 & $\begin{array}{l}\text { fixed } \\
\text { varying }\end{array}$ & $\begin{array}{l}32.57 \\
32.57\end{array}$ & $\begin{array}{l}44.75 \\
43.29\end{array}$ & $\begin{array}{l}70.81 \\
52.48\end{array}$ & 90.09 & $\begin{array}{l}158.97 \\
209.00\end{array}$ \\
\hline 1800 & $\begin{array}{l}\text { fixed } \\
\text { varying }\end{array}$ & $\begin{array}{l}27.41 \\
27.41\end{array}$ & $\begin{array}{l}37.66 \\
36.02\end{array}$ & $\begin{array}{l}59.59 \\
43.52\end{array}$ & 75.82 & $\begin{array}{l}133.79 \\
191.28\end{array}$ \\
\hline 2200 & $\begin{array}{l}\text { fixed } \\
\text { varying }\end{array}$ & $\begin{array}{l}61.31 \\
61.31\end{array}$ & $\begin{array}{l}\text { Urban } \\
89.21 \\
75.27\end{array}$ & $\begin{array}{r}145.61 \\
99.33\end{array}$ & $\begin{array}{r}204.71 \\
\text { na }\end{array}$ & $\begin{array}{l}356.64 \\
462.30\end{array}$ \\
\hline 2100 & $\begin{array}{l}\text { fixed } \\
\text { varying }\end{array}$ & $\begin{array}{l}55.71 \\
55.71\end{array}$ & $\begin{array}{l}81.06 \\
68.31\end{array}$ & $\begin{array}{r}132.31 \\
88.38\end{array}$ & 186.02 & $\begin{array}{l}324.06 \\
399.96\end{array}$ \\
\hline 2000 & $\begin{array}{l}\text { fixed } \\
\text { varying }\end{array}$ & $\begin{array}{l}50.12 \\
50.12\end{array}$ & $\begin{array}{l}72.92 \\
62.32\end{array}$ & $\begin{array}{r}119.04 \\
79.24\end{array}$ & 167.35 & $\begin{array}{l}291.55 \\
339.55\end{array}$ \\
\hline 1800 & $\begin{array}{l}\text { fixed } \\
\text { varying }\end{array}$ & $\begin{array}{l}38.42 \\
38.42\end{array}$ & $\begin{array}{l}55.90 \\
51.10\end{array}$ & $\begin{array}{l}91.24 \\
62.45\end{array}$ & 128.28 & $\begin{array}{l}223.49 \\
252.55\end{array}$ \\
\hline
\end{tabular}

Data Source:

GOVERNMENT OF INDIA, NATIONAL SAMPLE SURVEY ORGANISATION (1983): Survey results on per capita per diem intake of calories, protein and fat based on NSS $27^{\text {th }}$ round (Oct. 1972-Sept 1973) data.

GOVERNMENT OF INDIA, NATIONAL SAMPLE SURVEY ORGANISATION (1986): Per consumer unit per diem intake of nutrients. Thirty second Round (1977-78), NSS Report N ${ }^{\circ} 329$, Department of Statistics, New Delhi.

GOVERNMENT OF INDIA, NATIONAL SAMPLE SURVEY ORGANISATION (1988a): Per capita and per consumer unit per diem intake of calorie, protein and fat and perception of people on adequacy of food - Thirty Eighth Round (1983), NSS Report N³48, Department of Statistics, New Delhi.

GOVERNMENT OF INDIA, NATIONAL SAMPLE SURVEY ORGANISATION (1996b): Survey Results on Nutrition Intake in India based on NSS $50^{\text {th }}$ Round (July 1993 - June 1994) Report $N^{\circ} 405$ April. 
Table 5: Incidence of Poverty (in per cent) in terms of Head Count Ratio for the poverty line defined at different levels of calorie requirement in the rural and urban sector for selected rounds of NSS under the scenario of (a) fixed basket of commodities and (b) varying basket of commodities: All India

\begin{tabular}{|c|c|c|c|c|c|c|}
\hline $\begin{array}{c}\text { Norm of } \\
\text { calorie } \\
\text { requirement }\end{array}$ & $\begin{array}{c}\text { Basket of } \\
\text { Commodities }\end{array}$ & $\begin{array}{c}27 \\
\text { (Oct72-Sept73) }\end{array}$ & $\begin{array}{c}32 \\
\text { (July77-June78) }\end{array}$ & $\begin{array}{c}38 \\
\text { (Jan-Dec83) }\end{array}$ & $\begin{array}{c}43 \\
\text { (July83-June84) }\end{array}$ & $\begin{array}{c}50 \\
\text { (July93-June94) }\end{array}$ \\
\hline \multirow{3}{*}{2400} & & & Rural & & & \\
\hline & fixed & 64.78 & 59.21 & 51.44 & 45.30 & 42.17 \\
\hline & varying & 64.78 & 58.51 & 30.43 & na & 74.72 \\
\hline \multirow[t]{2}{*}{2200} & fixed & 52.50 & 46.61 & 39.37 & 31.51 & 28.53 \\
\hline & varying & 52.50 & 44.92 & 18.89 & na & 59.01 \\
\hline \multirow[t]{2}{*}{2000} & fixed & 39.88 & 33.83 & 26.91 & 19.26 & 15.88 \\
\hline & varying & 39.88 & 31.31 & 10.46 & na & 38.66 \\
\hline \multirow{2}{*}{1800} & fixed & 26.52 & 19.53 & 16.08 & 10.53 & 6.95 \\
\hline & varying & 26.52 & 19.01 & 5.19 & na & 30.86 \\
\hline \multirow{3}{*}{2200} & & & Urban & & & \\
\hline & fixed & 63.75 & 61.70 & 58.12 & 54.27 & 49.49 \\
\hline & varying & 63.75 & 50.16 & 29.65 & na & 66.53 \\
\hline \multirow{2}{*}{2100} & fixed & 58.70 & 55.75 & 51.14 & 48.04 & 42.42 \\
\hline & varying & 58.70 & 42.99 & 32.45 & na & 57.72 \\
\hline \multirow[t]{2}{*}{2000} & fixed & 50.71 & 47.93 & 43.21 & 40.36 & 34.83 \\
\hline & varying & 50.71 & 36.18 & 15.83 & na & 45.87 \\
\hline \multirow[t]{2}{*}{1800} & fixed & 31.71 & 28.60 & 23.92 & 21.78 & 17.87 \\
\hline & varying & 31.31 & 22.66 & 6.26 & na & 25.84 \\
\hline
\end{tabular}

Data Source:

GOVERNMENT OF INDIA, NATIONAL SAMPLE SURVEY ORGANISATION (1979): Survey results on consumer expenditure based on NSS $27^{\text {th }}$ round (Oct. 1972-Sept. 1973) data, Sarvekshana. The Jour. of NSSO, Vol.II, N'3, issue N 7 , January.

GOVERNMENT OF INDIA, NATIONAL SAMPLE SURVEY ORGANISATION (1986a): Survey results on consumer expenditure based on NSS $32^{\text {nd }}$ round (July 1977-June 1978) data, Sarvekshana, The Jour. of NSSO Vol.IX, No3, N²6, January.

GOVERNMENT OF INDIA, NATIONAL SAMPLE SURVEY ORGANISATIONS (1986c): Survey results on Consumer expenditure based on NSS $38^{\text {th }}$ round (January-December 1983) Sarvekshana, The Jour. of NSSO, Vol. IX, N4, Issue $\mathrm{N}^{\circ} 27$, April.

GOVERNMENT OF INDIA, NATIONAL SAMPLE SURVEY ORGANISATION (1990): Survey results on consumer expenditure based on NSS $43^{\text {rd }}$ round (July 1987 - June 1988) Sarvekshana, The Jour. of NSSO, Vol.XVII, N22 Issue No57, October-December, 1993.

GOVERNMENT OF INDIA, NATIONAL SAMPLE SURVEY ORGANISATION (1996a): Survey Results on Level and Pattern of Consumer Expenditure, NSS $50^{\text {th }}$ Round, July.

\section{Relative Poverty}

Attempts have been made in the past by researchers to study the sectoral, spatial and intertemporal changes in the pattern of consumer expenditure distribution as available from different rounds of National Sample Survey employing different inequality measures. However, it is being felt that the inequality is widening because of the feelings of relative 
deprivation of persons in a society arising out of the comparison of his situation with those of better off persons. The undoubted existence of wide spread poverty in the country is constantly forcing for its watch in terms of both absolute and relative dimension as well, for its remedial measures. In the context of poverty alleviation, the conceptual and measurement problems for poverty measurement in absolute terms had brought the concept of relative poverty closure to the concept of inequality. As the concept of relative poverty is closely related to the concept of economic inequality, an idea of relative poverty for its intertemporal changes may be obtained from the share of decile groups of population in total consumer expenditure and through inequality measures applied to NSS consumer expenditure data of different rounds which may be seen in tables 6 and 7 respectively.

Table 6: Percentage share in total consumer expenditure of decile groups of population by place of residence

\begin{tabular}{|c|c|c|c|c|c|c|}
\hline \multirow{2}{*}{$\begin{array}{l}\text { Deciles of } \\
\text { population }\end{array}$} & \multirow{2}{*}{$\begin{array}{c}\text { Place of } \\
\text { residence }\end{array}$} & \multicolumn{5}{|c|}{ Percentage share in total consumer expenditure } \\
\hline & & $1972-73$ & $1977-78$ & 1983 & $1987-88$ & 1993-94 \\
\hline & Rural & 3.8 & 3.5 & 3.8 & 4.0 & 4.1 \\
\hline $0-10$ & Urban & 3.5 & 3.2 & 3.4 & 3.4 & 3.4 \\
\hline & Rural & 5.3 & 4.9 & 5.2 & 5.3 & 5.4 \\
\hline $10-20$ & Urban & 4.7 & 4.5 & 4.6 & 4.6 & 4.6 \\
\hline & Rural & 6.3 & 5.9 & 6.2 & 6.2 & 6.4 \\
\hline $20-30$ & Urban & 5.7 & 5.4 & 5.5 & 5.4 & 5.4 \\
\hline & Rural & 7.0 & 6.5 & 6.9 & 6.9 & 7.1 \\
\hline $30-40$ & Urban & 6.0 & 6.3 & 6.7 & 6.1 & 6.4 \\
\hline & Rural & 8.0 & 7.5 & 8.0 & 7.8 & 8.0 \\
\hline $40-50$ & Urban & 7.7 & 7.1 & 7.1 & 7.1 & 7.3 \\
\hline & Rural & 8.5 & 8.3 & 9.0 & 8.8 & 8.9 \\
\hline $50-60$ & Urban & 8.1 & 8.4 & 8.2 & 8.3 & 8.4 \\
\hline & Rural & 9.6 & 9.6 & 9.9 & 9.8 & 10.0 \\
\hline $60-70$ & Urban & 10.1 & 9.4 & 10.3 & 9.6 & 9.8 \\
\hline & Rural & 11.8 & 11.4 & 11.7 & 11.6 & 11.6 \\
\hline $70-80$ & Urban & 11.4 & 12.5 & 11.4 & 11.6 & 11.8 \\
\hline & Rural & 14.3 & 14.1 & 14.4 & 14.2 & 14.0 \\
\hline $80-90$ & Urban & 15.2 & 14.2 & 15.0 & 15.1 & 15.2 \\
\hline & Rural & 23.4 & 28.4 & 24.7 & 25.3 & 24.3 \\
\hline $90-100$ & Urban & 27.6 & 29.0 & 27.9 & 28.9 & 27.7 \\
\hline
\end{tabular}

Data source:

1. GOVERNMENT OF INDIA, PLANNING COMMISSION (1993): Report of the Expert Group on Estimation of Poverty and number of poor.

2. GOVERNMENT OF INDIA, NATIONAL SAMPLE SURVEY ORGANISATION, (1996): Level and pattern of consumer expenditure, NSS $50^{\text {th }}$ round (July 1993 - June 1994), Report N²02. 
Table 7: Trends in inequality in size distribution of consumption expenditure by place of residence for different rounds of NSS: All India

\begin{tabular}{|c|c|c|c|c|c|c|}
\hline \multirow{2}{*}{$\begin{array}{l}\text { Inequality } \\
\text { measure }\end{array}$} & \multirow{2}{*}{$\begin{array}{c}\text { Place } \\
\text { of } \\
\text { residence }\end{array}$} & \multicolumn{5}{|c|}{ Period (round) } \\
\hline & & $\begin{array}{c}1972-73 \\
\left(27^{\text {th }}\right)\end{array}$ & $\begin{array}{c}1977-78 \\
\left(32^{\text {nd }}\right)\end{array}$ & $\begin{array}{r}1983 \\
\left(38^{\text {th }}\right) \\
\end{array}$ & $\begin{array}{c}1987-88 \\
\left(43^{\text {rd }}\right)\end{array}$ & $\begin{array}{c}1993-94 \\
\left(50^{\text {th }}\right)\end{array}$ \\
\hline (1) & $(2)$ & (3) & (4) & $(5)$ & (6) & $(7)$ \\
\hline \multirow[t]{2}{*}{ 1. Coefficient of variation } & Rural & 0.74 & 0.93 & 0.64 & 0.63 & 0.59 \\
\hline & Urban & 0.78 & 0.81 & 0.66 & 0.81 & 0.72 \\
\hline \multirow{3}{*}{$\begin{array}{l}\text { 2. Standard deviation of } \\
\text { logarithms }\end{array}$} & & & & & & \\
\hline & Rural & 0.53 & 0.57 & 0.52 & 0.27 & 0.41 \\
\hline & Urban & 0.46 & 0.61 & 0.57 & 0.27 & 0.54 \\
\hline \multirow{2}{*}{$\begin{array}{l}\text { 3. Relative mean deviation } \\
\text { (Kuznet's measure) }\end{array}$} & Rural & 0.42 & 0.48 & 0.42 & 0.22 & 0.40 \\
\hline & Urban & 0.49 & 0.50 & 0.47 & 0.25 & 0.49 \\
\hline \multirow[t]{2}{*}{ 4. Gini Coefficient } & Rural & 0.31 & 0.32 & 0.34 & 0.29 & 0.28 \\
\hline & Urban & 0.34 & 0.34 & 0.33 & 0.35 & 0.34 \\
\hline \multicolumn{7}{|l|}{ 5. Aitkinson's measure } \\
\hline \multirow[t]{2}{*}{ (i) $\mathrm{e}=0.5$} & Rural & 0.0772 & .1023 & .0730 & .0863 & .0660 \\
\hline & Urban & 0.0958 & .0962 & .0852 & .1040 & .0933 \\
\hline \multirow[t]{2}{*}{ (ii) $\mathrm{e}-2.0$} & Rural & 0.2448 & .2910 & .2385 & .2342 & .2109 \\
\hline & Urban & 0.2901 & .3080 & .2792 & .2993 & .2890 \\
\hline \multirow[t]{2}{*}{ (iii) $\mathrm{e}=3.0$} & Rural & 0.3295 & .4051 & .3222 & .3035 & .2799 \\
\hline & Urban & .3756 & .4446 & .3696 & .2995 & .3733 \\
\hline \multicolumn{7}{|l|}{ 6. Share of consumption } \\
\hline \multirow[t]{2}{*}{ (i) bottom $10 \%$ pop. } & Rural & 3.8 & 3.5 & 3.8 & 4.0 & 4.1 \\
\hline & Urban & 3.5 & 3.3 & 6.5 & 3.4 & 3.4 \\
\hline \multirow[t]{2}{*}{ (ii) bottom half pop. } & Rural & 30.4 & 9.6 & 30.2 & 30.2 & 31.0 \\
\hline & Urban & 27.6 & 27.5 & 27.9 & 26.8 & 27.1 \\
\hline \multirow[t]{2}{*}{ (iii) top $10 \%$ pop. } & Rural & 23.4 & 28.5 & 24.5 & 25.3 & 24.3 \\
\hline & Urban & 27.5 & 28.2 & 26.8 & 28.9 & 27.7 \\
\hline
\end{tabular}

Data source:

GOVERNMENT OF INDIA, NATIONAL SAMPLE SURVEY ORGANISATION: Tables with notes on Consumer expenditure, $27^{\text {th }}$ round Oct. 1972-Sept. 1973), Report N2284.

GOVERNMENT OF INDIA, NATIONAL SAMPLE SURVEY ORGANISATION: Report on the second quinquennial survey on Consumer expenditure, $32^{\text {nd }}$ round (July 1977 - June 1978), Report $N^{\circ} 311$.

GOVERNMENT OF INDIA, NATIONAL SAMPLE SURVEY ORGANISATION: Report on third quinquennial survey on Consumer expenditure, $38^{\text {th }}$ round (Jan - Dec. 1983).

GOVERNMENT OF INDIA, NATIONAL SAMPLE SURVEY ORGANISATION: Report on the Fourth quinquennial survey on Consumer expenditure, $43^{\text {rd }}$ round (July 1987 - June 1988), Report $N^{\circ} 373$.

GOVERNMENT OF INDIA, NATIONAL SAMPLE SURVEY ORGANISATION: (1996): Level and Pattern of Consumer Expenditure, $50^{\text {th }}$ round (July 1983 - June 1984), Report $N^{\circ} 402$. 
There has been a debate on the relationship between poverty, living standards and under nutrition mainly because the concept of poverty has its linkage with "expenditure" and the "purchasing power" of that expenditure. However, the phenomenon of poverty and phenomenon of under nutrition are not the same. Depending upon the consumer behaviour of different households, some households even with relatively low income are able to provide themselves with adequate nutrition while the some had income but do not do so because of ignorance and improvidence. The definition of calorie based poverty line rests on the argument that consumer behaviour varies from household to household and therefore an expenditure level at which actual data show that on an average a household with that level of consumption expenditure providing adequate nutrition to its members may be chosen as adequate calorie intake. Usually adequate calorie intake also insures adequate supply of other nutrients. It is being argued that the concept of poverty needs to be broadened and delinked with the concept of food poverty from poverty in general. This is possible by observable characteristics and may be checked through socio-economic parameters as many of the parameters are not dependent on the individual viz. social group, principal occupation of the household etc. Further the cash out flows incurred by the household on health, education and housing gets birth to some extent in the concept of poverty line but the concept of free and subsidised goods and services such as water, sanitation, health and education provided by the Government and/or charitable institutions do not get reflected in the concept of poverty line. The reason being that the elements of living environment such as health services, education, drinking water, access to transportation, communication and information, which contribute significantly to social and human development, cannot be quantified.

Expectation of a society changes with the passage of time and therefore inter temporal comparison or comparison between different societies will not be valid if poverty is thought of in terms of relative deprivation defined with reference to some average expectation of society.

Let us now look in to the problem. The first question is why should there be an attempt to determine a poverty line and to estimate the population below the poverty line? In a welfare state, it is always and should always be a matter of great concern if a large chunck of the population remains under nourished. The population of a country is not only a consuming mass but it is also a productive asset. Hence there should be a continuous watch with a view to maintain the quality of the population. We have seen that the population estimate below the poverty line is quite high in India. so the question naturally arises whether any further sophistication is immediately needed for relatively more precise and objective definition of poverty line compared to the on going concept which has several advantages:

1. It is a well defined indicator and can be determined on more or less objective basis.

2. Nutrition is the basic need which has to be met by the household itself, hence facilities are needed to identify the households or the population not being able to meet that requirement. 
3. The specific advantage with the method is that the estimate are based directly on the quantity of various food articles, hence the inter regional variations can be directly measured (in money terms however the poverty line may differ in different regions because of the existence of price differential).

4. It takes into account the money value required to purchase the food items for meeting the recommended energy level with the experience on other non food items.

5. Moreover, in a consumer expenditure survey, the expenditure on food and non food items are collected and hence it is possible to determine the total household expenditure and also the expenditure on non food items at the critical level of nutritional intakes defining the poverty line. Thus, there is a built in provision to get a dimensional idea about the consumption expenditure incurred on non food items.

6. Whereas there is scientific basis for deriving the minimum basic need for food, there is hardly any method to determine the norms for the non food items. Clothing is a basic need but what should be the minimum requirement of clothing is anybody's guess. It depends upon the quality of the cloth, climatic condition of the place of living, working status of the person, the society in which the person lives and so on. All these factors complicate the situation making it all the more difficult for evaluation of the minimum requirement of the basic need.

Thus, in the absence of any other suitable life index and looking towards the limitations of NSS data on consumer expenditure, the poverty line approach using available NSS data for determining the extent of poverty may be considered as the best one.

\section{Identification of Poor}

\section{Official Approach}

In the context of poverty alleviation programme in India, the official approach for identification of poor and the allocation of funds to the state Government under social sector development scheme, rests on Below Poverty Line (BPL) Surveys (actually census) in the rural sector and the official estimate of poverty. BPL census is being conducted by the state as per guidelines given by the centre which involves a cut-off point of an annual household income equivalent to expenditure per family for segregating the families (a) above poverty line and (b) below poverty line classified in to four categories viz., destitute; very very poor, very poor and poor.

The procedure adopted is as under:

i. The priority list of poor families is prepared by Block Development Officer (BDO) giving special emphasis to outlying hamlets, women headed households and nomadic families.

ii. The said list is then placed for approval in the meeting of the village assembly (Gram Sabha). This meeting is convened by BDO giving sufficient publicity through local means. 
iii. The village assembly is attended by local people, non officials, Blocks Officers and Bank Officers. Prominent voluntary action groups etc. are also associated with these meetings.

iv. The list of beneficiaries selected at this village assembly is displayed on the notice board of the village Panchayat and Block office. Sufficient time is given for filling objections. In case of any dispute regarding any name in the list it is decided by the Project Director in consultation with BDO.

v. The list of beneficiaries finally selected (master list) is got printed block wise by the Programme Implementation authorities and copies are made available to the field staff, block officials, bank and other concerned authorities.

This approach has posed serious questions in the identification of poor from the point of problems associated with the ascertainment of annual income of household which is known to be extremely difficult for many types of (rural) households. Even today, the NSS organisation has not evolved a satisfactory methodology for conducting household income survey in the country as may be seen in Joshi (1996a). Further the approach followed suffer from the point of widely varying household size and inherent bias of the respondents in giving information which would enable them to obtain the prescribed benefit. Much of the such classification of households are likely therefore, to arrive through a neglect of prescribed procedure, perception of the methodology used for estimation purposes, survey design and nature of data collected resulting in favour of non poor households for assistance under the programme. Attempts are therefore being made for including information on several identification variables for inclusion/exclusion criterion and also on consumption expenditure for launching a fresh BPL census in the rural sector.

Another approach for identification of poor households followed on pilot basis in the state of West Bengal as reported in Rudra etal (1994) included canvassing of two sets of schedules, one on "Household Expenditure" and the other on "Fulfilment of Basic Needs". The survey was conducted in the rural areas or 5 districts (19 villages) covering four regions during June 1990 - May 1991. Out of 4 regions covered in the surveys, the two regions were comprised of mainly non tribal cultivation based communities. The other two regions were comprised of partly hilly with some tribals and many tribals dependent on the forest. Good representation of households belonging to different social groups was ensured. The sample was drawn with a view to take in to account the various environmental, socio-economic and cultural factors. The Complete list of all households residing in each sample village was prepared and the non poor households were eliminated using several criteria viz., the possession of a pucca (well built) residential house, more than one set of plough, electricity in the house, etc. Finally, the sample households were chosen from the remaining households - the relatively poor households - separately for each village by circular systematic sampling in the form of two independent and interpenetrating sub samples. The total number of households, the number of relatively poor households and the number of households selected were 2598; 987 and 632 respectively. 
Information through questionnaire approach in the forms of Yes/No were obtained from the basic needs enquiry viz..,

1. Consumption of meat, fish and egg during last month.

2. $\mathrm{N}^{\circ}$ of bedrooms $(<1)$ per family.

3. Room height $(<1.68$ meters $)$.

4. Adequacy of dwelling for protection against room shows.

5. Woolen garments in the household.

6. $\mathrm{N}^{\circ}$ of woolen garments $(<1)$ per person.

7. Number of saris or similar garments $(<2)$ per adult female.

8. Matresses in the bedding.

9. Lack of blankets, quilts in the households.

10. $\mathrm{N}^{\circ}$ of dining plates $(<1)$ per adult member.

11. School education for child of age group 6-14.

12. Availability of two squares meals a day through out the last year and if not, whether the number of months when they did not get this was $>2$.

13. Availability of milk every day for children in the age group (0-4).

14. Member of household engaged in begging.

15. Availability of special food before and after delivery for female member who conceived during last three years.

16. Whether or not the household procured food items as gift or loan from some other household during last month.

17. Whether or not the household usually obtained food items by free collection from months or from land belonging to other.

The above 17 poverty indicators were closely related. The households were assigned by the deprivation score and simple criteria based on pragmatic consideration was followed for the $1^{\text {st }}, 2^{\text {nd }}$ and $3^{\text {rd }}$ level of poverty.

The first level of poverty was defined as ultra poor on the basis of non meeting of at least one of the following three criteria.

1. Availability of two squares meals a day for more than two months during the last 365 days.

2. Availability of saris or similar garments per adult female in the housing falling short of 2.

3. Member of household reporting begging.

The second level of poverty was arrived by classifying few indicators and deprivation score of identified indicators were obtained for households which did not have two square meals a day by number of months. The second level of poverty included the households with deprivation score 4 or more and the number of months without two square meals a day was 2 . The third level of poverty was defined by deprivation score of 1-3 and the number of months without two square meals a day was 0 or 1 . 


\section{Other Approaches}

Recently Bansil (1996) has made a study sponsored by Planning Commission, an official agency of the Government of India, on "Profile of the Visibly Poor" utilising the information on characteristics of households as available from the Household Consumption Expenditure Survey (HCES) conducted by National Sample Survey Organisation (NSSO) in its $43^{\text {rd }}$ round (July 1987 - June 1988) for the purpose of identification of poor in formulating appropriate policies in the context of poverty alleviation.

The study has been carried out at the regional level for the rural and urban areas in three states viz., Bihar, Maharashtra and Himachal Pradesh. These states were chosen on the ground of varying levels of development and poverty. The study is based on 24 characteristics viz., Caste, Religion, Activity, Sex, Family Size, House, type of dwelling, type of house, floor type, condition of house, source of energy, source of high living, milk animals, draught animals, land, land possessed categories, crops grown, income source, member working on public work, assistance during the last 5 years under IRDP, household purchases from rationshop, consumption of alcoholic beverages, consumption of fruits and journey undertaken in last 30 days. In all 17 items in the rural sector and 12 items in the urban sector were identified.

The available items of information was analysed for bottom and top 20 percent of households ranked by monthly per capita household total expenditure and the contrast has been measured in terms of ratio and the difference from the mean. Accordingly, two indices viz., Indicator Ratio (IR) and Distance Index (DI) were computed. Indicator Ratio (IR) was defined as the ratio for the indicator of the bottom two deciles and top two deciles expressed in percent. Distance Index was defined as the ratio of the distance of the value of two top and bottom deciles from the mean value expressed in percent. The higher value of these indices have been attributed for higher prevalence of that attribute among the poor as compared to the non poor and vice versa. For the state studied, the values of (i) IR greater than 130 and less than 70 (ii) DR greater than 150 and less than 75 were considered criterion for inclusion and exclusion of indicator respectively. 


\section{Bibliography}

AHLUWALIA. M.S. (1976): Inequality, poverty and Development. Journal of Development Economics. Vol.3. N³.

AHLUWALIA, M.S. (1978a): Rural Poverty in India: 1756-57 to 1973-74 in India: Occasional Papers. Staff Working Paper. Washington, D.C., World Bank, pp 1-92.

AHLUWALIA, M.S. (1978b): Rural poverty and Agricultural Performance in India. Journal of Development Studies, 14, 298-323.

AHLUWALIA, M.S., CARTER N.G. AND CHENERY, H.B. (1979): Growth and Poverty in developing countries. Journal of Development Economics vol. 6. pp 349-361.

AITKINSON, A.B. (1970): On the Measurement of Inequality. Journal of Economic Theory. Vol. 2. pp 244-263.

AITKINSON, A.B. (1975): The Economics of Inequality, Oxford University Press.

AITKINSON, A.B. (1991): Comparing poverty rates internationally: lesson from recent studies in developed countries. World Bank Economic Review, 5: 3-22.

AITKINSON, A.B. (1992): Measuring Poverty and Differences in Family, Economic Research Institute, New Delhi.

BANSIL, P.C. (1996): A Profile of the Visibly Poor, Techno Economic Research Institute, New Delhi.

BARDHAN, P.K. AND SRINIVASAN, T.N. (1971): Income Distribution. Pattern Trends and Policies, E.P.W. April 24. Vol. VI.

BARDHAN P.K. (1970): On The Minimum Level of Living and The Rural Poor Indian Economic Review. Vol. 5. No 1 .

BARDHAN, P.K. (1973): "On the Incidence of Rural Poverty in Rural India in the Sixties", Economic and Political WEEKLY, ANNUAL N 8, 245-255.

BARDHAN, P.K. (1974), "Pattern of Income Distribution in India, a Review", Sankhaya, Series-C. 36. 103-138.

BARDHAN, P.K. (1976): Poverty and trickle down in Rural India - A Quantitative Analysis in J.W. Mellor and M. Desai (eds) Agricultural Change and rural poverty variations on a theme by Dharam Narayan. Oxford University press. 
BHATTACHARYA, S.S., A.B. ROY CHOUDHURY AND P.D. JOSHI (1980): Regional Consumer price indices based on NSS Household Expenditure Data, Sarvekshana Vol. 3, No4: pp 107-12.

BHATTY, I.Z. (1974): Inequality and poverty in rural India in Poverty and Income Distribution in India (eds.) T.N. Srinivasan and P.K. Bardhan. Statistical Publishing Society. Calcutta.

CHATTORPADHYAY. M., BHATTACHARYA, N. AND RUDRA, A. (1988): Changes in level of Living in Rural West Bengal: Variations Across Socio-Economic Groups. Economic and Political Weekly.

DANDEKAR, V.M. AND N. RATH, 1971: Poverty in India, Indian School of Political Economy. Pune. First published in Economic and Political Weekly. Vol. 6 Nos. 1 \& 2 and 9 . January 1971. Bombay.

DANDEKAR, V.M. (1981): On Measurement of Poverty, EPW, Vol. XVI. N³0 July 25. pp 1241-1250.

DANDEKAR, V.M. (1982): On Measurement of Under-nutrition. EPW. Feb. 6.

DANDEKAR, V.M. (1996): The Indian Economy. 1947-1992. Population, Poverty and Employment. Sage publications, New Delhi.

GOVERNMENT OF INDIA. PLANNING COMMISSION (1962): Perspectives of Development. India 1960-61 to 1975-76: Implications of Planning for a minimum level of living. Also in Poverty and Income Distribution in India eds. T.N. Srinivasan and P.K. Bardhan, Statistical Publishing Society. Calcutta.

GOVERNMENT OF INDIA. PLANNING COMMISSION (1979): Report of the Task Force on Projections of Minimum Needs and Effective Consumption Demand.

GOVERNMENT OF INDIA. PLANNING COMMISSION (1981): A Technical Note on the Sixth Plan of India (1980-1985) Annexe-III. pp 81-84.

GOVERNMENT OF INDIA. PLANNING COMMISSION (1982): Report of the Expert Group on programme for alleviation of Poverty. Government of India. New Delhi.

GOVERNMENT OF INDIA. PLANNING COMMISSION (1984): The concept and estimation of Poverty Line. Perspective Planning Division. Government of India. New Delhi.

GOVERNMENT OF INDIA. PLANNING COMMISSION (1993): Report of the Expert Group on Estimation of Proportion and number of Poor. 
GOVERNMENT OF INDIA. PLANNING COMMISSION (1997): Press release on Estimate of Poverty. Perspective Planning Division. New Delhi, $11^{\text {th }}$ March.

GOVERNMENT OF INDIA. NATIONAL SAMPLE SURVEY ORGANISATION (1978): Calorie and Protein Values of Food items consumed per diem per consumer unit Twenty sixth Round (1971-72). NSS Report No 238. Vol I \& II. Department of Statistics. New Delhi.

GOVERNMENT OF INDIA. NATIONAL SAMPLE SURVEY ORGANISATION (1979): Survey results on consumer expenditure based on NSS $27^{\text {th }}$ round (Oct. 1972-Sept. 1973) data. Sarvekshana. The Jour. of NSSO Vol. I No $3, \mathrm{~N}^{\circ} 7$, January.

GOVERNMENT OF INDIA. NATIONAL SAMPLE SURVEY ORGANISATION (1983): Survey results on per capita per diem intake of calorie, protein and fat based on NSS $27^{\text {th }}$ round (Oct. 1972-Sept. 1973) data. Sarvekshana. The Jour. of NSSO Vol. 6. $\mathbf{N}^{\circ}$ 3 - 4. No 18 .

GOVERNMENT OF INDIA. NATIONAL SAMPLE SURVEY ORGANISATION (1986a): Survey results on consumer expenditure based on NSS $32^{\text {nd }}$ round (July 1977-June 1978) data. Sarvkshana. The Jour. of NSSO Vol. IX. No 3. No 26 January.

GOVERNMENT OF INDIA. NATIONAL SAMPLE SURVEY ORGANISATION (1986b): Per consumer unit per diem intake of nutrients - Thirty second Round (1977-78). NSS Report No 329. Department of Statistics. New Delhi.

GOVERNMENT OF INDIA. NATIONAL SAMPLE SURVEY ORGANISATION (1986c): Survey results on Consumer expenditure based on NSS $38^{\text {th }}$ round (January-December 1983) Sarvekshana. The Jour. of NSSO. Vol. IX. $\mathrm{N}^{\circ}$. 4 . Issue $\mathrm{N}^{\circ}$ 27, April.

GOVERNMENT OF INDIA. NATIONAL SAMPLE SURVEY ORGANISATION (1988a): Per capita and per consumer unit per diem intake of calorie, protein and fat and perception of people on adequacy of food - Thirty Eighth Round (1983). NSS Report N ${ }^{\circ}$ 348. Department of Statistics. New Delhi.

GOVERNMENT OF INDIA. NATIONAL SAMPLE SURVEY ORGANISATION (1988b): Level of Nutritional Intake of Population distributed over different expenditure classes - Thirty Eighth Round (1983). NSS Report No 353. Department of Statistics. New Delhi.

GOVERNMENT OF INDIA. NATIONAL SAMPLE SURVEY ORGANISATION (1989): Survey Results on per capita and per consumer unit per diem intake of calorie, protein and fat and perception of the people on adequacy of food based on NSS $38^{\text {th }}$ 
round (January-December 1983). Sarvekshana. The Jour. of NSSO. Vol.XIII. N 2. Issue $\mathrm{N}^{\circ} 41$ Oct.-Dec.

GOVERNMENT OF INDIA. NATIONAL SAMPLE SURVEY ORGANISATION (1990): Survey results on consumer expenditure based on NSS $43^{\text {rd }}$ round (July 1987-June 1988) Sarvekshana. The Jour. of NSSO.

GOVERNMENT OF INDIA. NATIONAL SAMPLE SURVEY ORGANISATION (1996a): Survey Results on Level and Pattern of consumer Expenditure. NSS 50 ${ }^{\text {th }}$ Round (July 1993-June 1994) Report N 402, May.

GOVERNMENT OF INDIA. NATIONAL SAMPLE SURVEY ORGANISATION (1996b): Survey Results on Nutrition Intake in India based on NSS $50^{\text {th }}$ Round (July 1993-June 1994) Report No 405. April.

JOSHI, P.D. (1979): On the Suitability of Displaced Log-normal Distribution In Graduating the Size Distribution of Total Consumer Expenditure. Sarvekshana. The Jour. of NSSO. Vol. 3. $\mathrm{N}^{\circ}$ 1. pp 4-8.

JOSHI, P.D. (1996a): Household Expenditure and Income Survey: Indian Experience. Paper presented at the firs meeting of the U.N. Expert Group on Household Income Statistics. Canberra. December.

JOSHI, P.D. (1996b): A bibliography of the literature on measurement of poverty (Unpublished).

JOSHI, P.D. (1997a): Statistical Dimensions of Poverty in India. Invited lecture in first P.V. Sukhatme Memorial Session in the XVII Annual Conference of the Indian Society for Probability and Statistics held in B.H.U. Varanasi during 10-13 February.

JOSHI, P.D. (1997b): Sensitivity Analysis on Measures of Poverty (Unpublished).

MINHAS, B.S. (1970): "Rural Poverty. Land Redistribution and Development Strategy. Indian Economic Review. Vol. 5, N 1. Also Sankhya Series C. Vol. 36 (1974), pp 252-263.

MINHAS, B.S. (1971a): Rural Poverty and Minimum Level of Living - A Reply. Indian Economic Review. April.

MINHAS, B.S. (1971b): More on Rural Poverty. A Glimmer of Progress. Indian Economic Review. $\mathrm{N}^{\circ} 6$.

MINHAS, B.S. (1971c): The poor, the weak and the Fourth Plan in A.J. Fonseca (Ed.), Challenge of Poverty in India. New Delhi. Vikas Publishing. 
MINHAS, B.S. (1974): Planning and the Rural Poor. S. Chand \& Co., Delhi 9.

MINHAS, B.S., KANSAL, S.M., KUMAR, J. AND JOSHI, P.D. (1986): On the Reliability of the Available Estimates of Private Consumption Expenditure in India. Journal of Income and Wealth. Vol. $9 \mathrm{~N}^{\circ} 2$. pp 71-93.

MINHAS, B.S., JAIN, L.R., KANSAL, S.M. AND SALUJA, M.R. (1987): On the Choice of appropriate Consumer Price Indices and Data Sets for Estimating the Incidence of Poverty in India. Indian Economic Review. Vol. XXII. N 7, pp 19-50.

MINHAS, B.S., JAIN, L.R., KANSAL, S.M. AND SALUJA, M.R. (1988): "Measurement of general cost of living for urban India, all-India and different states", Sarvekshana. The Jour. of NSSO XII. I. 1-23.

MINHAS, B.S. (1988): "Validation of Large Scale Sample Survey Data-Case of NSS Estimates of Household Consumption Expenditure". Sankhya. Series B. Vol. 50. Part 3. Supplement. pp 1-63.

MINHAS, B.S., JAIN, L.R., KANSAL, S.M. AND SALUJA, M.R. (1989a): Cost of living in rural India: 1970-71 to 1983: State-wise and All India. Technical Report $\mathrm{N}^{\circ}$ 8904, ISI, New Delhi.

MINHAS, B.S., KANSAL, S.M. (1989b): "Comparison of the NSS and the CSO Estimates of Private Consumption: Some Observations Based on 1983 Data". The Journal of Income and Wealth. Vol. II. No 1 . January, 1989, pp 7-24.

MINHAS, B.S., KANSAL, S.M. AND JAIN, L.R. (1989c): "Incidence of Urban Poverty in Different States (1970-71 to 1983)". Indian Statistical Institute. Technical Report $N^{\circ} 8902$. January.

MINHAS, B.S., JAIN, L.R. (1990): Incidence of Rural Poverty in Different States and All India 1970-71 to 1983". Agricultural Development Policy: Adjustments and Reorientation (Golden Jubilee Volume of Indian Society of Agricultural Economics), Oxford and IBH Publishing Co. New Delhi, pp. 342-81.

MINHAS, B.S., JAIN, L.R. AND TENDULKAR, S.D. (1991a): Declining Incidence of Poverty in the 1980s: Evidence from Artefacts. Economic and Political Weekly (613 July 1991). Table 3, p. 1675.

MINHAS, B.S., JAIN. L.R. AND TENDULKAR, S.D. (1991b): "Rural and Urban cost of living: 1983 to 1987-88. Statewise and All India". Journal of Indian School of Political Economy. Vol. 3. No 3. July-Sept 1991. 420-442.

OJHA, P.D. (1970): “A Configuration of Indian Poverty: Inequality and Levels of Living". Reserve Bank of India Bulletin, January. 
RUDRA, A. (1974): Minimum Level of Living - A Statistical Examination in Poverty and Income Distribution (ed). P.K. Bardhan and T.N. Srinivasan. Statistical Publishing Society. Calcutta.

RUDRA, A., CHAKRABORTY, S., MAZUMDAR, K. AND BHATTACHARYA, N. (1995): Criterion for identification of rural poor-Preliminary Results based on a survey in West Bengal in Foreign Capital-Welfare implications of growth (ed) $\mathrm{M}$. Chattopadhyay.

SEN, A.K. (1973): "Poverty, Inequality and Unemployment". Economic and Political Weekly. Special Number. Reprinted in Bardhan and Srinivasan: Poverty and Income Distribution in India. Statistical Publishing Society, 1974. p. 67.

SENGUPTA, S. AND JOSHI, P.D. (1978): Consumption of Cereals and Energy Content of Food Consumed. Sarvekshana - The Jour. of NSSO Vol. 2. No 1 July.

SENGUPTA, S. AND JOSHI, P.D. (1979): A Note on Determination of Poverty Line Based on NSS $27^{\text {th }}$ Round Data, Sarvekshana - The Jour. of NSSO, Vol. 3, $\mathrm{N}^{\circ} 1$, July.

SENGUPTA, S. AND JOSHI, P.D. (1981): Concept of Poverty line and estimate of Poverty at the regional level in India. Paper presented in the first National Conference on Social Science Research and problem of poverty organised by Indian Association of Social Science Institution. New Delhi. Also Social Science Research and Problem of Poverty (ed) Tarlok Singh. Concept Publishing Company. New Delhi. 1990.

SRINIVASAN. T.N. (1977): Poverty: Some measurement problems, Bull, Int. Stat. Institute 47 (4).

SUKHATME, P.V. (1961): The World's Hunger and Future Needs in Food Supply. Jour. Roy. Stat. Soc. Series A. Vol 124. pp 463-525.

SUKHATME, P.V. (1965): Feeding India's Growing Millions. Asia Publishing House. Bombay.

SUKHATME, P.V. (1977a): Incidence of Under-nutrition in India. Journal of Economics. Vol. XXXVIII. No 3. July-Sept. 1977.

SUKHATME, P.V. (1977b): Measurement of Poverty Based on Nutritional Needs. Bull. Int. Stat. Inst. 47(4) pp 553-56.

SUKHATME, P.V. (1978): Assessment of Adequacy of Diets at Different Income Level. EPW. Vol. XIII. pp 1373-1384. 
SUKHATME, P.V. (1980): Nutrition Policy - Need for Re-orientation. EPW. Vol. XV. N 26, pp 1101-1105 and Its Implication for Social Policy - Report on the Summer Institute. M.A.C.S. Pune.

SUKHATME, P.V. (1981a): On Measurement of poverty. EPW.Vol. XVI. N 32. Aug. 8. pp 1311-1324.

SUKHATME, P.V. (1981b): Measuring the Incidences of Under Nutrition - A comment. EPW. Vol. XVI. pp 1034-1036.

SUKHATME, P.V. (1989): Nutrition Adoption and Variability. European journal of Clinical Nutrition Vol. 43. pp 75-87 and three commentaries on the paper of Prof. P.V. Sukhatme by J.C. Waterlow. WPT James and Mrs. Healy in the same issue pp 203-10.

TENDULKAR, S. (1993): Social Welfare. Social Deprivation and Economic Growth. Some reflections on the Indian Experience; paper presented at the P.C. Mahalanobis birth Centenary Conference on "Planning and Economic Policy in India" held at I.S.I. Calcutta on June 29-31. 


\title{
POVERTY DEFINITIONS AND POVERTY IN TURKEY
}

by

\author{
Güzin Erdogan
}

State Institute of Statistics

Turkey 


\section{POVERTY DEFINITIONS AND POVERTY IN TURKEY}

\section{Introduction}

In Turkey, there is no official data for the poverty line and the level of poverty. The State Institute of Statistics (SIS) has started a project to produce statistics in this subject. However, we have not reached the conclusion yet. In this paper, the SIS expert thesis called "Poverty Line in Turkey" is the preliminary study. This paper includes the summary and the results of this thesis.

Turkey, as a developing country, has an attempt to be developed country. How much we have been successful in our effort can be criticized by various indicators. The living standards for human beings, as one of these indicators, give more remarkable results in order to have an idea of development. From this point of view, can we say indeed that we have raised the living standard of our people over certain level? Have our people enough economical power to lead their life easily? The answer of these questions, partially, depends on the studies to find out whether we have poor people in Turkey or not, and to put our position among other world countries. What is poverty? Who is poor? Does poverty have a certain standard? Simply, do we have a line to indicate for poverty level? This paper aimed to give answer to these questions and to calculate poverty line in Turkey. For this reason, many of the studies up to now have been concerned and the methods to determine poverty line and the numbers of poor people in Turkey have been examined (Erdogan, G., 1996).

\section{Definitions of Poverty}

Principally, poverty is defined as a fact that the people are unable to meet basic needs. Poverty can be defined in two ways. The first is the limited definition. Here, poverty is defined as of starving and of being homeless. The second is the broad definition. Poverty is defined as the position that food, clothing, housing and similar facilities satisfy the people to lead the life but under the general level of society (Ana Britannica, 1990). In this way, relative and absolute definitions of the poverty are established.

The relative poverty is defined as a lack of basic foods and services that are needed to lead a life physically. The absolute poverty assigns the position of people that are under the certain point of general level of wealth in case of income and expenditure.

\section{Poverty Line}

Poverty line is the cost of leading a life with the minimum standards. In determination of the level of living cost with the minimum standards, primarily, the minimum amount of calorie in a day needed by an individual to lead a life and the expenditure on food in order to have this amount of calorie are concerned. After that, by using the cost of other basic needs, such as housing, transportation, clothing and furniture, the poverty line is calculated. In this 
study, two kinds of poverty line have been calculated. The first concerns only the cost of minimum amount of calorie needed. That is, the cost of minimum food expenditures is calculated. The second approach takes into account not only cost of food, but also cost of basic needs such as housing, clothing, transportation and furniture.

\section{The Source of Data}

The source of data depends on the results of the Household Income and Consumption Expenditure Survey that was conducted in 1994 by SIS and carried out for one year with the households rotated in every month. The survey is categorised under various bases such as whole Turkey, urban and rural areas and seven geographical regions. In the survey, the settlements with the population 20,001 and over are called as urban places, the rest with the population 20,000 and less are rural areas. The geographical regions are Marmara Region, Aegean Region, Mediterranean Region, Central Anatolia Region, Black Sea Region, East Anatolia Region, Southeast Anatolia Region.

\section{Poverty Line by Cost of Minimum Food Expenditure}

In determination of poverty line by cost of minimum food expenditure, the cost of minimum amount of daily calorie which is sufficient for human being to lead a life is concerned. The needed amount of daily calorie changes by age and sex. In Table 1, the needed amount of daily calorie by sex is given for the average level of workers.

TABLE 1. The Amount of Daily Calorie by Age and Sex

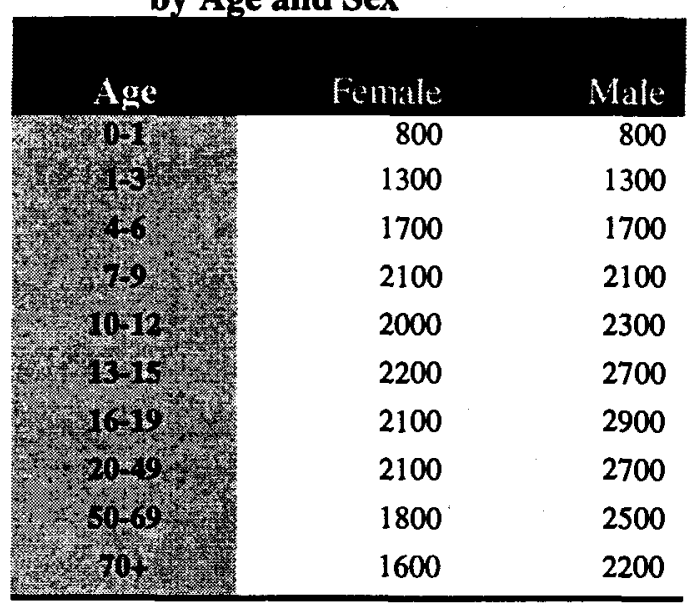

(Source: BAYSAL, Ayşe, (1993). General Nutrition, Hacettepe University, Ankara.)

Considering the amount of calorie given in Table 1, weekly amounts of food for properly nutrition of a household with four members, that it is sufficient for properly nutrition with economical cost, are given by food groups in Table 2 . 
TABLE 2. The Weekly Amounts of Food for a Household with four Members

\begin{tabular}{|c|c|c|}
\hline \multirow{4}{*}{$\begin{array}{l}\text { Group of frod } \\
\text { (1) Group }\end{array}$} & Food & Weekly anwounts $(\mathrm{kg})$ \\
\hline & Meat, poultry, fish, edible offal & 1.500 \\
\hline & Dried bean, lentil, chickpea & 1.250 \\
\hline & Egg & 20 units \\
\hline Group & Milk, yogurt & 7 \\
\hline & Cheese & 0.750 \\
\hline Group & Vegetables & 3 \\
\hline & Potatoes & 3 \\
\hline & Onion & 1 \\
\hline & Other vegetables & 1.500 \\
\hline & Fresh fruit & 4 \\
\hline top: & Bread & 5.600 \\
\hline & Boiled wheat & 0.500 \\
\hline & Rice & 0.500 \\
\hline & Macaroni & 0.500 \\
\hline & Flour & 0.500 \\
\hline & Edible oils & 0.500 \\
\hline & Margarine or butter & 0.500 \\
\hline & Olive & 0.500 \\
\hline & Sugar & 1 \\
\hline & Jam, honey & 0.500 \\
\hline jerom & Tomato paste & 0.500 \\
\hline & Salt & 0.500 \\
\hline 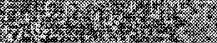 & Tea & 0.100 \\
\hline 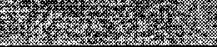 & Walnut, hazelnut & 0.100 \\
\hline
\end{tabular}

Source: BAYSAL, Ayşe, (1993). General Nutrition, Hacettepe

University, Ankara.)

Replacing the amounts given in Table 2 with monthly amounts, the monthly amounts of food needed for nutrition of a household with four members with minimum cost are calculated. Some of food groups compose of more than one item and item kinds. In order to choose these items and item kinds, and in determination of weights of these items, the data of 1994 Household Income and Consumption Expenditure Survey results is used as a source. All item kinds used in this study are given in Table 3 in food groups. 
Table 3: $\quad$ Item Kinds for Food Groups

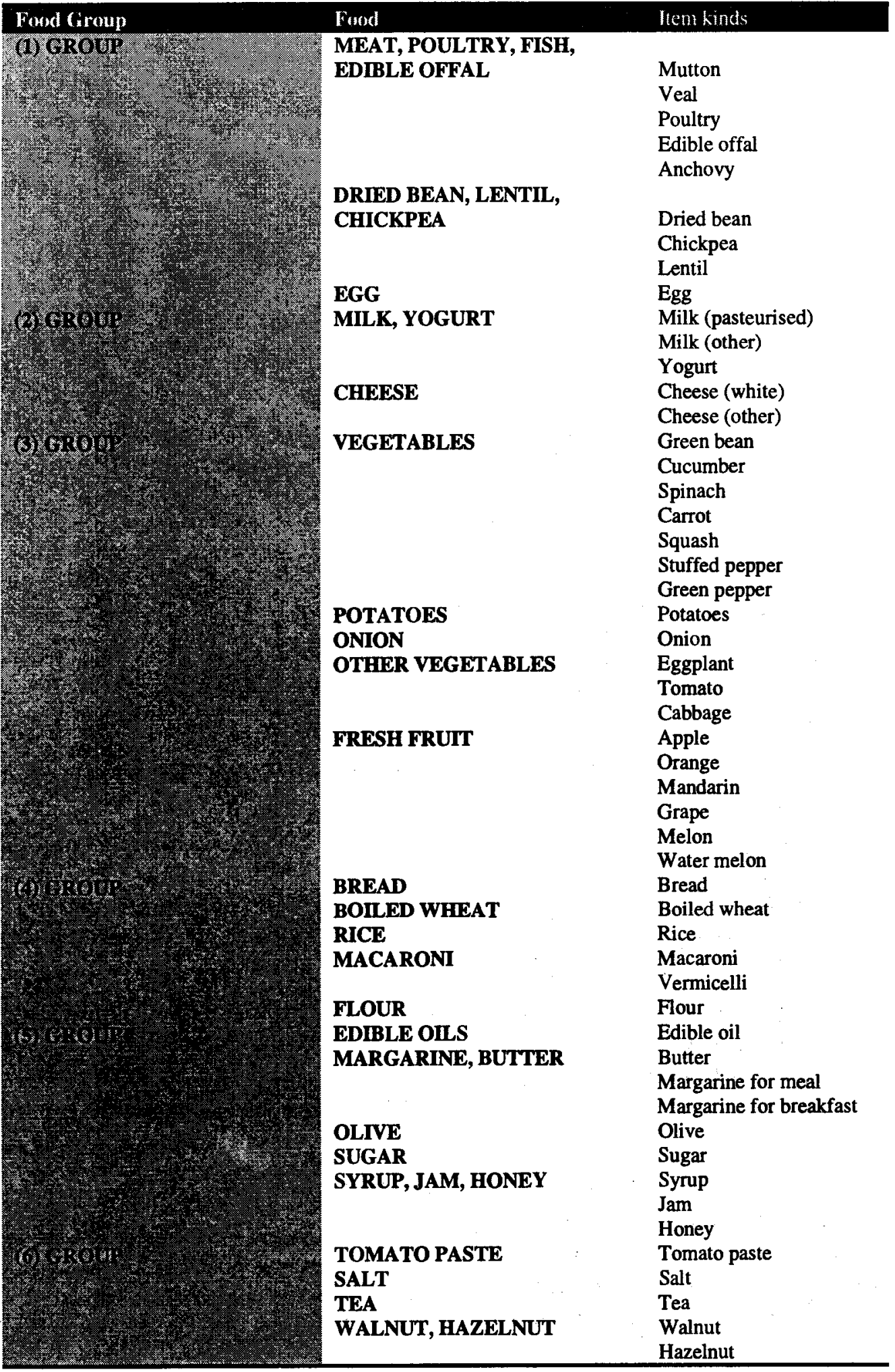


Consequently, the amounts of total 52 items by Turkey, rural, urban and 7 geographic regions have been determined. Average annual prices of item kinds in all settlements are multiplied by the amounts and average monthly food expenditure of a household with four members is calculated. On the basis of these results, poverty lines are calculated by the cost of monthly minimum food expenditures by household size. Monthly poverty lines by household size are determined and the households whose monthly expenditures are below the poverty line are called as poor households. Accordingly, poverty lines for an average size of household and an individual are calculated for each settlement. These values are given daily and monthly as US dollars.

Poverty lines per households and per person are respectively given in Table 4 and Table 5. The poverty lines based on the minimum food expenditure; the rates of poor households; and average numbers of household members are also included in table 4.

Table 4: Monthly and Daily Poverty Lines (US \$) for the Cost of Minimum Food Expenditure per Household (US \$) and the Rates of Poor Households

\begin{tabular}{|c|c|c|c|c|}
\hline & $\begin{array}{l}\text { Poverty } \\
\text { lines }\end{array}$ & & $\begin{array}{l}\text { Average } \\
\text { number of } \\
\text { household } \\
\text { member }\end{array}$ & $\begin{array}{l}\text { Rate } \\
\text { of poor } \\
\text { house- } \\
\text { hold }\end{array}$ \\
\hline Settlement & $\begin{array}{c}\text { Monthly } \\
\$\end{array}$ & $\begin{array}{c}\text { Daily } \\
\$\end{array}$ & & $(\%)$ \\
\hline TURKAY & 138 & 4.6 & 4.46 & 11 \\
\hline URAN & 136 & 4.5 & 4.25 & 7 \\
\hline 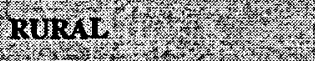 & 135 & 4.5 & 4.72 & 14 \\
\hline mingury? & 132 & 4.4 & 4.15 & 5 \\
\hline frompry & 104 & 3.5 & 3.82 & 3 \\
\hline 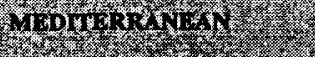 & 127 & 4.2 & 4.52 & 7 \\
\hline 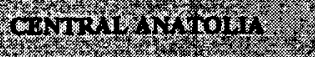 & 108 & 3.6 & 4.28 & 10 \\
\hline 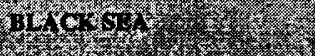 & 143 & 4.8 & 4.69 & 13 \\
\hline 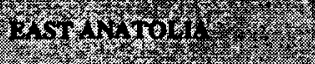 & 144 & 4.8 & 5.56 & 18 \\
\hline 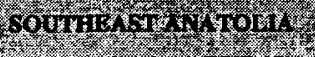 & 131 & 4.4 & 5.78 & 18 \\
\hline
\end{tabular}

It is seen in Table 4 that the households need minimum $138 \$$ a month and $4.6 \$$ a day in Turkey. The households living in urban places have to earn more than the households in rural. When this issues examined by regional base, it is clear that the households of East Anatolia Region whose size bigger have to earn more than the households of Aegean Region. Most of the poorest households live in East and Southeast Anatolia Region with $18 \%$. 
Table 5: Monthly and Daily Poverty Lines (US \$) for the Cost of Minimum Food Expenditure per Person (US \$) and the Rates of Poor Individuals

\begin{tabular}{|c|c|c|c|}
\hline & $\begin{array}{l}\text { Poverty } \\
\text { lines. }\end{array}$ & & $\begin{array}{l}\text { Rate } \\
\text { of poor } \\
\text { person }\end{array}$ \\
\hline Settlement & $\begin{array}{c}\text { Monthly } \\
\$\end{array}$ & $\begin{array}{c}\text { Daily } \\
\$\end{array}$ & (\%) \\
\hline TURKEY & 31 & 1.0 & 15 \\
\hline URBAy & 32 & 1.1 & 10 \\
\hline Rumat & 29 & 1.0 & 21 \\
\hline Mrromers & 32 & 1.1 & 7 \\
\hline regent. & 27 & 0.9 & 4 \\
\hline MabriterkaNaA & 28 & 0.9 & 11 \\
\hline 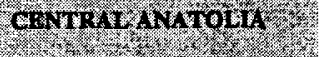 & 25 & 0.8 & 12 \\
\hline BLick sEd & 30 & 1.0 & 19 \\
\hline EAst A rianoin & 26 & 0.9 & 25 \\
\hline sourtimist anflom & 23 & 0.8 & 24 \\
\hline
\end{tabular}

When we look at Table 5 for poverty lines of individuals, a person in Turkey should earn 31 \$ month and 1 \$ a day in order to be over poverty line. In regional comparison, people in Marmara Region should earn more than the people in Southeast Anatolia Region. It does not mean that Southeast Anatolia Region is in the best position. The existence of bigger size of household in this region causes this result.

The households and individuals who are determined by the cost of minimum food consumption method can be defined as "extremely poor", because these households and individuals have no power even to meet their food consumption.

\section{Poverty Line on Cost of Basic Needs}

In basic needs approach, poverty lines are established using households minimum food consumption together with nonfood consumption. Housing is the biggest share in nonfood consumption. Transportation, clothing, furnishing have the other shares in nonfood consumption respectively. Poverty lines on the cost of basic needs which include the food and nonfood expenditures of households, are calculated for household size and settlements. Poverty lines per households and per person for the settlements and the average household size are respectively given in Table 6 and Table 7 . The values are given daily and monthly as US dollars. Therefore, $31 \%$ of households' and $38 \%$ of individuals' monthly earnings are 
below the poverty line in Turkey. The poorest households and persons live in Southeast Anatolia Region.

Table 6: Monthly and Daily Poverty Lines (US \$) for the Cost of Basic Needs per Household (US \$) and the Rates of Poor Households

\begin{tabular}{|c|c|c|c|c|}
\hline & $\begin{array}{l}\text { Poverty } \\
\text { lines }\end{array}$ & & $\begin{array}{l}\text { Average } \\
\text { member of } \\
\text { household } \\
\text { member }\end{array}$ & $\begin{array}{l}\text { Rate } \\
\text { of poor } \\
\text { house- } \\
\text { hold }\end{array}$ \\
\hline Settlements & $\begin{array}{c}\text { Monthly } \\
\$\end{array}$ & $\begin{array}{r}\text { Daily } \\
\$\end{array}$ & & $(\%)$ \\
\hline TURKEY & 198 & 6.6 & 4.46 & 31 \\
\hline URAAN & 188 & 6.3 & 4.25 & 28 \\
\hline Rurar:? & 211 & 7.0 & 4.72 & 32 \\
\hline Marmark & 220 & 7.3 & 4.15 & 29 \\
\hline Arcents & 208 & 6.9 & 3.82 & 24 \\
\hline 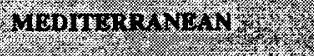 & 254 & 8.5 & 4.52 & 29 \\
\hline cratrat N N Toth & 170 & 5.7 & 4.28 & 30 \\
\hline Butckshats: & 194 & 6.5 & 4.69 & 34 \\
\hline 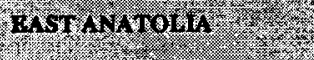 & 190 & 6.3 & 5.56 & 33 \\
\hline SOUTHEAST ANATOLI & 196 & 6.5 & 5.78 & 37 \\
\hline
\end{tabular}

When the Table 6 is examined, households need minimum $198 \$$ a month and $6.6 \$$ a day. In regional base, the households living in Mediterranean Region have the highest poverty line comparing with the other regions. Most of the poorest households live in Southeast Anatolia Region with $37 \%$. 
Table 7: Monthly and Daily Poverty Lines (US \$)

for the Cost of Basic Needs per Person

(US \$) and the Rates of Poor Person

\begin{tabular}{|c|c|c|c|}
\hline & $\begin{array}{l}\text { Poverty } \\
\text { lines }\end{array}$ & & $\begin{array}{l}\text { Rate } \\
\text { of poor } \\
\text { person }\end{array}$ \\
\hline Settlement & $\begin{array}{c}\text { Monthly } \\
\$\end{array}$ & $\begin{array}{c}\text { Daily } \\
\$\end{array}$ & $(\mathscr{H})$ \\
\hline TURKET: & 44 & 1.5 & 38 \\
\hline uparar & 44 & 1.5 & 34 \\
\hline notim & 45 & 1.5 & 39 \\
\hline What & 53 & 1.8 & 32 \\
\hline $\operatorname{lng} x$ & 54 & 1.8 & 27 \\
\hline 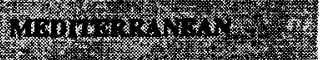 & 56 & 1.9 & 35 \\
\hline 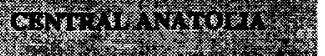 & 40 & 1.3 & 35 \\
\hline 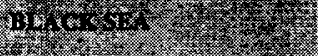 & 41 & 1.4 & 42 \\
\hline 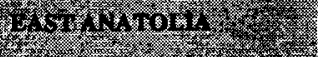 & 34 & 1.1 & 40 \\
\hline souran, st A Krou, & 34 & 1.1 & 44 \\
\hline
\end{tabular}

Looking at the Table 7, the person has to earn $44 \$$ a month or $1.5 \$$ a day in order to be over the poverty line. In regional basis, person living in Mediterranean Region should earn more money than the person living in East and Southeast Anatolia Region.

\section{The Comparison of 1987-1994 for Poverty}

In order to examine the dimension of poverty in respect of yearly changes, the 1994 and 1987 Household Income and Consumption Expenditure Survey Results were compared. This comparison is given in Table 8.

Table 8: The Rates of Poor Households in 1987 and 1994(\%)

\begin{tabular}{|c|c|c|c|}
\hline Methods & Settlements & 1987 & 1994 \\
\hline o mintingo: & Turkey & 13 & 11 \\
\hline & Urban & 4 & 7 \\
\hline & Rural & 20 & 14 \\
\hline costorowsig & Turkey & 31 & 31 \\
\hline$(1+2004)$ & Urban & 22 & 28 \\
\hline 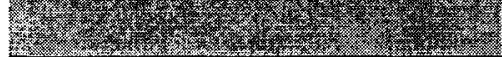 & Rural & 38 & 32 \\
\hline
\end{tabular}


When the comparing the results of 1987 and 1994 surveys, the rate of poor households increases in urban areas and decreases in rural areas in 1994 for both methods. When we examine the population growth for 7 year period, the population of urban areas increases with migration more than the population of rural areas.

\begin{tabular}{|c|c|c|c|}
\hline Ponulation & $\begin{array}{l}1987 \\
(1000)\end{array}$ & 1994 & Percentage \\
\hline Turkey & 52,561 & 60,576 & $\frac{15}{15}$ \\
\hline Urban & 25,764 & 32,700 & 27 \\
\hline Rural & 26,797 & 27,876 & 4 \\
\hline
\end{tabular}

At the same time, the migration from rural areas to urban areas was $18 \%$ within the period between 1985 and 1990.

\section{Conclusion}

In this paper, the level of poverty is defined according to the position of people who are under the general level of income in society. That is the poverty level does not only define the starvation and being homeless. Primarily, the minimum cost of food consumption which constitutes minimum amount of calorie needed by an individual to survive the life is calculated and the people under this value are classified as "extremely poor". For the second method, not only the cost of food, but also the cost of housing, clothing, transportation and furnishing is considered. If the household or person does not meet these costs, these people are called "poor".

In Turkey, poverty line for an individual is found out between $31 \$$ and $44 \$$ a month. If we think of Gross Domestic Product (GDP) per capita, which is 2,500 $\$$ a year or $208 \$$ a month, it is clear that GDP is not equally share in Turkey. To support this issue, it is enough to look at the expenditure shares of lowest and highest $20 \%$ of households in the 1994 Household Income and Consumption Expenditure Survey. If we sort the households in ascending order by their expenditure, it will be seen that while the lowest $20 \%$ of households has a share of $6 \%$, the highest has $47 \%$ of total expenditure. This big gap between household groups not only indicates inequality between groups but also this plays that the lowest income group satisfies with very few shares of expenditure. Surviving a life is not only based on the consumption for food, housing, clothing, transportation and furnishing, but also the consumption for health, education, culture and communication. According to the 1992 Human Development Report of United Nations (UN), Turkey is placed in the middle level developed people and 71 st in 160 countries (UNDP, 1992). In 1995 report, the place of Turkey raised to 66th order from 71 order which signals an improvement in the general level of wealth (UNDP,1995).

This improvement is supported by the results of 1987 and 1994 Household Income and Consumption Expenditure Survey results. The data of these two surveys show that the number of poor households decreased through in time. By equally distributing of GDP, households and individuals will have a new position over poverty line. It should not be forgotten that Turkey has this potential. 


\title{
MEASUREMENT OF POVERTY IN URUGUAY
}

\author{
by
}

Marcia Rama and María Dolores Fernández

Instituto Nacional de Estadísticas (INE)

Uruguay 


\section{Measurement of poverty in Uruguay}

In Latin America two methodological approaches, ones which differ from each other in the instruments used, are preferentially employed for the measurement of the phenomenon of poverty. A third methodology is derived as a combination of the first two.

The first procedure, called the "income method," is based on the determination of the minimum income which permits a household, in a particular time and place, to have resources sufficient to satisfy the basic needs of its members, quantified as a specific "basket" of goods and services. The use of this method is based on the calculation of the Poverty Line (PL), identifying the poor in income as those homes which are below the line.

The second methodology, called Unsatisfied Basic Needs (UBN), identifies a series of factors essential for adequate social development. These are related to the quality of the housing unit, degree of crowding (density of persons within the unit), provision of drinking water, availability of sewage service, school attendance, and subsistence capacity of the home. By means of this methodology homes are classified as having basic necessities unsatisfied when one or more of the factors is lacking.

Whereas the PL method is centered on current consumption by the home, the UBN approach emphasizes the offering of and access to public services. The third procedure is called the integrated or bi-dimensional measurement of poverty and is a combination of the two approaches. The utilization of this methodology produces a typology of four types of household:

1. Chronically poor, classified as poor by both of the first two methods.

2. Recently poor, households which are below the Poverty Line but do not have critical unmet needs by the UBN method.

3. Structurally poor households, defined as having basic needs unmet but falling above the poverty line.

4. Socially integrated households which do not experience the phenomenon of poverty (non-poor by both methods).

The present work, taking into account the three approaches for quantification of poverty, is based upon the first of these, that is the income method. On a national level during the last years of the past decade, a first methodological proposal for the measurement of poverty by said method was carried out, in spite of the fact that the current measures of poverty in Uruguay are conducted by CEPAL (Santiago, Chile) on the basis of the Household Survey of Expenditures and Income (HSEI) in 1982-83. 
The current analysis was developed within the framework of Project INE/CEPAL/BID "Improvement of Socioeconomic Information Systems in Uruguay," utilizing national urban data obtained by the Uruguayan National Institute of Statistics, from June 1994 through May 1995 (HSEI). The methodological design and the field work strategy of that survey were developed so as to provide information necessary for the construction of the Basic Food Basket (BFB) and the Poverty Line (PL).

The survey furnished recent data about patterns of consumption by households, permitting the realization of studies needed to revise and bring up to date the content and values of the $\mathrm{BFB}$ and PL.

Construction of the BFB takes into account the nutritional requirements of the population as well as its consumption patterns. Its monetary value is used as a threshold to define the population in conditions of indigency. It represents minimum alimentation based upon consumption patterns in the respective households and should not be employed as a an instrument to alimentary-nutrition education, since it does not constitute an ideal diet.

The nutritional needs of the average person, to which the "basket" refers, were determined on by: (1) the number of individuals and their distribution by age and sex; (2) weight and height of adults for the calculation of basal energy expenditure; and distribution by activity level and time used for occupational and discretionary purposes.

For the calculation of the basal metabolism energy expenditure, age, sex, weight and height were used as factors. The first two (age and sex) correspond to their sociodemographic distribution in the sample used in the Household Survey of Expenditures and Income 199495, analyzed by quintiles of income per person in Montevideo and the Interior. For weight and height, the equations from the report of FAO/OMS/UNU were used.

Individual protein requirements by sex and age were determined on the basis of the 1985 FAO/OMS/UNU 1985 recommendations and on those adopted in the UNU/Fundación CAVENDES meeting. These recommendations are calculated on the basis of protein with true digestibility of $80-85 \%$ and amino-acid quality of $90 \%$ in relation to milk and eggs. The quality of the protein in the Uruguayan diet is higher than that utilized in said report, thus assuring coverage of the necessities of the entire population.

In evaluating the $\mathrm{BFB}$, it was thought relevant to analyze, aside from energy and protein requirements, the balance of other ingredients, whose excess or deficit constitute a risk factor for the health and welfare of the population.

In the case of Uruguay, the other relevant nutrients are total fats (relation between saturated fatty acids, mono-unsaturated and poly-unsaturated), cholesterol, total alimentary fiber, vitamin $\mathrm{C}$, and iron. Taken into consideration were the nutritional goals for Uruguay established by the Ministry of Public Health ${ }^{\left[{ }_{1}\right]}$ and the Alimentation Guides for Latin America. 
Estimation of the protein requirement for the average person (Table 3, original report) again takes into account the distribution by age and sex in Montevideo and the Interior and the recommended individual daily intake.

The Poverty Line represents the cost of a "basket" of goods and services that guarantees, at the personal level, satisfaction of alimentation needs as well as other goods and services basic to life. This is calculated by means of the BFB, taking into account the proportion of the budget destined for alimentation in the households belonging to the stratum of reference. Thus it is equal to the amount of income below which a household does not have resources sufficient to satisfy basic needs, alimentary or otherwise, of its members. ${ }^{[1]}$

The reference stratum is the population group whose consumption pattern is employed to define the composition of the Basic Food Basket and to calculate the relationship between food expenditures and the total budget of the households (Engel Coefficient).

The reference stratum is that in which:

i) the expenditure for alimentation is sufficient to satisfy minimum needs; that is, the average caloric intake appears to be above the minimum estimated requirement for the population, and

ii) the structure of consumer expenditures for other goods and services does not show evidence of privation in the satisfaction of basic needs.

The households were ordered according to income per capita and grouped by deciles. In each of the resulting strata caloric intake and expense structure of the households was estimated. The reference stratum so defined corresponded to the group of households of the second decile, both in Montevideo and the Interior.

The second decile in Montevideo is the first which exceeds the estimated requirements of $2,150 \mathrm{Kcal}$ per person per day, presenting an apparent alimentary consumption of 2,354 Kcal per day. Similarly, the second decile in the Urban Interior shows consumption of 2,281 Kcal per day, exceeding the estimated requirement of $2,172 \mathrm{Kcal}$ per day for that geographic division.

With regard to the second condition the following aspects point to its fulfillment:

i) In the structure of non-food expenditures (housing, health, education, transportation, and clothing) of the second decile there is no evidence of consumption deprivation, given that the structure is similar to the contiguous larger deciles; in fact, the second deciles in Montevideo and the Interior do not present large divergencies from the structure of the adjacent deciles, three and four, and in some instances from that of the fifth, although in the majority of the cases the amount of expenditure proves to be clearly greater than that of the stratum selected as a reference. 
ii) neither did the variety of goods and services acquired by the households of the second decile show evidence that would lead one to assume there were important restrictions on the freedom of choice of goods in comparison with the adjacent deciles having greater economic capacity.

With regard to geographic distinctions, it was considered more adequate to maintain the areas as different populations and to define the stratum of reference and the BFB for each of them.

This decision was based on the significant differences which the two areas present with respect to:

i) income level,

ii) structure of needs based upon life styles (for example in the requirement of transportation expense) and

iii) facilities for meeting such needs

With regard to dietary patterns, such differences manifest themselves in:

i) the proportion of meals consumed in and outside the household, in each geographic category, and

ii) the price of foods, as affected by commercial markups, chains of intermediation, and quality and type of services associated with the supply of alimentary goods in each area.

The development of these topics is presented in the first two parts of the original version (in Spanish) of this document.

The third part deals with the construction of the Basic Food Basket and the Poverty Line.

The BFB is made up of a combination of goods the physical volume and composition of which satisfy the average requirements for energy (calories) and proteins of a reference population. It also reflects the consumption habits of the society and provides indications about the necessity of incorporating certain dietary adaptations to prevent illnesses associated with inadequate nutrition.

For the construction of the BFB, priority was given to the consumption habits of the population selected as stratum of reference. Thus the BFB does not represent an ideal diet, but instead includes the basic elements consumed by the reference group, adjusted for the caloric requirement and with minimum modifications which, if indeed they indicate the need to improve alimentation in certain parameters, nevertheless respect strongly the consumption patterns. 
The alimentary pattern of the households was defined after analyzing the types of food consumed, frequency of acquisition, expense, and quantity. For each food item the following were considered:

i) the frequency of acquisition (percentage of households which acquired it),

ii) the monthly expenditure per person for the item (percentage of food expenditures) and

iii) the physical quantity acquired per person.

After an exhaustive quality control of the implicit prices resulting in each case, it was decided to utilize the physical quantities declared in the Household Survey of Expenditures and Income. The survey collects information in terms of actual or gross weight, from which the net or edible portion of each food or group was estimated, using correction factors of local use estimated by the School of Nutrition of the University of the Republic.

On the basis of expenditures, the physical quantities of food consumed outside the household were also estimated. Average market prices were used for this, identified in the survey for each item (food or drink) in the corresponding period. Estimation of the nutritional composition of these foods was established after defining a physical composition for each item consumed outside the household.

The coefficients of nutritional composition of the foods $\left.{ }^{[}\right]$were used to determine the calories and nutrients corresponding to the physical quantities of each product.

Once the pattern of consumption of the households of the reference stratum was defined, the goods which make up the BFB were selected. The selection was based on two criteria: the proportion of household which consume each item and incidence of the same in the food expenditures.

The "basket" included, with very few exceptions, those goods which met one or more of the following conditions:

i) were acquired by more than $25 \%$ of the households,

ii) represented a least $1 \%$ of the food budget, or

iii) in the case where no item in a subrubric met the requirements set forth, the mostconsumed item within the subrubric was chosen.

Table salt, tea, and coffee were incorporated in spite of their not meeting any of the previous conditions.

According to the procedure indicated, 62 food items were selected for the Basic Baskets of Montevideo and Urban Interior. These represent $20 \%$ of the foods covered in the survey, but 
for the reference stratum constitute more than $80 \%$ of the expenditures for food and more than $85 \%$ of the dietary calories. The important reduction in the number of articles with respect to the original list respects, accordingly, the consumption habits of the respective population. The expenditure for foods which were not specified in the "basket" was accumulated within each subrubric, with the title "others." Table 4 (original document) shows the foods which make up the "basket," the proportion of households which consume them, and their part in food expenditures.

The elaboration of the BFB (Basic Food Basket) began with the consumption coresponding to the stratum of reference in each geographic area. The first step consisted in replacing the consumption of infrequent foods with frequently used foods, equivalent in caloric terms but lower in cost. Exempted from this treatment for nutritional reasons were "fish and shellfish," "vegetables, tubers, and fruits," and "other foods."

After specifying the foods for the "basket," the items were evaluated in terms of the most frequent risks in Uruguay. ${ }^{\left[{ }_{1}\right]}$ Upon evaluating nutritionally the consumption structure of the stratum of reference, it became evident that it was necessary to make adjustments in total calories, iron content, fats (cholesterol in Montevideo), and total fiber. The consumption of proteins was shown to be above necessary levels, and dietary variety was sufficient for adequate consumption of vitamins and minerals. Iron is the mineral the consumption of which was lowest in relation to the minimum recommendation, which corresponds to diets with high bio-availability of that mineral. Consumption of fruits and vegetables was below average, both in Montevideo and in the Interior.

Normative-type adjustments were made with regard to a small number of goods, seeking to respect the fundamental features of the food habits of the reference stratum.

The adjustments were as follows:

i) to increase the consumption of fiber, the quantity of fruits and vegetables was raised, assigning to the "basket" the average quantity of these items consumed in each geographic area (Montevideo and Interior).

ii) to make adequate the amount of iron, the fish category was increased, assigning to the "basket" the average quantity consumed by all households. It should be noted that the incorporation of more fruits and vegetables improves the conditions for absorption of iron, as a result of greater availability of Vitamin $\mathrm{C}$.

iii) With regard to fats, ordinary ground beef was replaced by the leaner "special" ground beef so that, without modifying habits, the households acquire a better-quality product with fewer lipidic components.

iv) given that protein consumption was above needed levels and in accordance with a suggestion coming from the Regional Workshop of Experts on Poverty Measurement, it was decided to reduce the volume of meat in the Montevideo 
"basket" to reach protein levels similar to those of the Interior. This reduction brought as a favorable consequence a drop in the Montevideo BFB'_ excessive fat content, especially saturated fats and cholesterol.

The Basic Basket included in this instance the calories of frequently used foods and those of non-replaced infrequently used items, plus those items incorporated for nutritional adjustment. Since the resulting total caloric level surpassed needs, a reduction in volumes was effected, proportional to the calories of the respective items, to bring them to cover the estimated caloric requirement for each geographic area.

From the nutritional point of view, the BFB presents the following noteworthy characteristics:

i) the caloric requirement is adjusted by geographic area,

ii) there is ample satisfaction of the estimated protein needs,

iii)Vitamin $\mathrm{C}$ content is above recommended amounts, a factor which favors the bioavailability of iron, and

iv) the calcium level meets recommended levels.

Nevertheless, by respecting strongly the habits of the population, the BFB has the following limitations:

i) it presents the maximum acceptable level for the proportion of calories coming from fats (recommended levels are from 3\% to 5\% lower than those of the "basket").

ii) it maintains a high proportion of saturated fatty acids and a low proportion of poly-unsaturated fatty acids.

iii)it has the minimum amount of iron recommended for diets with high bio-availability

iv) total fiber, although increased, is below the recommended amount.

On comparing the BFB of the Urban Interior with that of Montevideo, the following differences are noted:

i) in the reference stratum of the Urban Interior, a larger amount of baked goods $(5 \%)$, the result of greater consumption in the bread rubric (French bread, home-baked bread, and "galleta de campaña"), as well as the fact that "alfajor" cakes and croissants with fat appear in smaller quantities than in the BFB of Montevideo, 
ii) a larger amount of cereals (13\%), which is explained by a greater consumption of rice and dry noodles in the reference stratum of the Interior, with smaller amounts of fresh pasta (plain and filled) and the same quantity of wheat flour.

iii)a smaller amount of beef and its derivatives, although in the Interior the consumption of stewing meat and lamb/mutton is noted.

iv) in the Interior there is less consumption of fish and shellfish, dairy products, green vegetables, legumes, tubers, fruits, and soft drinks.

v) on the other hand, sugar consumption is $10 \%$ greater in the Interior.

To estimate cost of the BFB, it was decided to use the average implicit price of each item in the reference stratum, after eliminating out-of-range items by means of a quality control by household with a confidence interval calculated for the entire sample.

The cost of the "Basic Basket" per person per month for Montevideo, per 1,000 Kcal, was 5.63 pesos, which is $1 \%$ more than the reference stratum figure (5.56 pesos). The Urban Interior amount was 3.94 pesos, $2 \%$ higher in comparison with the reference stratum cost (3.86 pesos).

The total monthly, per-person cost of the Basic Food Basket, based on November 1994 prices, was 369.27 pesos for Montevideo and 260.75 pesos for the Urban Interior.

Accordingly, the cost of the BFB in Montevideo was $42 \%$ larger than that of the Urban Interior. This difference is due to a $9 \%$ difference in physical composition (notably, greater consumption of soft drinks, meats, breadstuffs and food of higher cost per calorie) and a $30 \%$ difference in the implicit prices of goods which are similar in both areas.

The Basic Food Basket assures alimentation adequate for nutritional requirements, but there are other basic needs of a non-dietary kind which should also be satisfied for individuals. Their quantification was carried out indirectly by means of the Orshansky Coefficient, which is defined as the quotient of dividing the total consumption expenditure, including housing, by the food expense, which is the inverse of the Engel Coefficient.

The Orshansky Coefficient is adequate when it is calculated in a stratum of households that does not present evidence of important privations in the expenditures. This requirement is met by definition in the reference stratum, inasmuch as the absence of evident privations was one of the conditions for its selection. Consequently, it is in the reference stratum that the Orshansky Coefficient should be calculated in order to estimate the cost of satisfying the basic non-dietary necessities. This cost, added to the Basic Food Basket, determines the Poverty Line. 
In the second decile of Montevideo, food costs represent $33.5 \%$ of the total consumption expenditures (housing included), making the Orshansky Coefficient 2.99. The food expenditure proportion is very near that observed in the third decile (32.5\%), which produces an Orshansky Coefficient of 3.08 . The $32.5 \%$ figure is almost nine percentage points more than that observed in the total of all households in Montevideo (24.8\%). In contrast, the first decile presents an Engel Coefficient of 0.41, making the Orshansky Coefficient 2.44 .

In the Interior, the reference stratum presents an Engel Coefficient of 0.377 , and thus the Orshansky Coefficient is 2.65. Again, this result is near that of the third decile (0.346), producing an Orshansky Coefficient of 2.69. The Interior reference stratum figure is near that of the third decile (Engel 0.346, Orshansky 2.89) and is eleven percentage points greater than that observed for all Interior households $(0.27)$.

For the considerations aforementioned, in the calculation of the Poverty Line use was made of the Orshansky coefficients corresponding to the total consumption expenditures, including housing value, in the reference strata.

With regard to the normative adjustment of food expenditures, which is done by estimating the BFB on the basis of the implicit diet in the reference stratum, one might also propose the need to correct the Orshansky coefficient. As was pointed out earlier, on estimating the BFB, a normative adjustment is made in the food expense; this adjustment changes the amount of food expense in the reference stratum and, on being multiplied by the respective Orshansky coefficient, also determines a corrected total expense level. For example, if the BFB requires a caloric consumption less than that observed in the reference stratum, by applying the indicated coefficient one adjusts downward in equal proportion the non-food expense.

Given the fact that the reference strata selected in this work present an implicit caloric intake only somewhat greater than the nutritional requirements with which the Basic Food Basket is calculated, it was understood that the correction alluded to should have little effect, and accordingly was not necessary. 
It should also be noted that no corrections were made to the Orshansky Coefficient based upon considerations about adult equivalents. The importance of these, as a consequence of existing differences in the size and composition of households, has led to the initiation of an analysis of the theme. ${ }^{\left[{ }_{1}\right]}$

The value of the proposed Basic Food Basket, equivalent to the Indigency Line, is 369.27 pesos monthly per person in Montevideo and 260.75 pesos in the Interior. Both values are calculated on the basis of November 1994 prices, whereas at prices of May 1996, the amounts rise to 549.41 pesos in Montevideo and 386.50 pesos in the Interior.

The Poverty Line per person is calculated by multiplying the Basic Food Basket cost by a constant -the Orshansky Coefficient- corresponding to the reference strata defined by geographic areas that were previously mentioned: 2.99 for Montevideo and 2.65 for the Interior. The value of the Poverty Line reaches 1,104 pesos for Montevideo, and 691 pesos for the Urban Interior, at November 1994 prices.

\begin{tabular}{|c|c|c|c|c|}
\hline \multirow[t]{2}{*}{ Values of BFB and PL } & \multicolumn{2}{|c|}{ At prices of November, 1994} & \multicolumn{2}{|c|}{ At prices of May, 1996} \\
\hline & Montevideo & Interior & Montevideo & Interior \\
\hline Proposed BFB & $\$ 369.27$ & $\$ 260.75$ & $\$ 549.41$ & $\$ 386.50$ \\
\hline $\begin{array}{l}\text { Orshansky } \\
\text { Coefficient }\end{array}$ & 2.99 & 2.65 & 3.15 & 2.79 \\
\hline Poverty Line & $\$ 1,104.12$ & $\$ 690.99$ & $\$ 1,729.37$ & $\$ 1,077.59$ \\
\hline
\end{tabular}

The cost of non-food necessities of the households and the quantification of the per capital value of the Poverty Line -at prices of November 1994 and May 1996- are described in greater detail in Part 3 of the original document, which includes in the appendix a methodology for updating said value according to variations in relative prices.

The final part of the original document includes the quantification of the proportion of households and persons with income below the BFB and PL during the period 1984-94, characterization of poverty according to certain socio-economic variables of the population in the areas studied (Montevideo and Urban Interior), and the access of those groups to social services in such fields as health, education, alimentation, and housing.

Finally it should be pointed out that this work constitutes a synthesis of material presented in the "Regional Workshop of Experts on Poverty Measurement" organized by INE-CEPAL and carried out in Montevideo March 12-13, 1996. Recommendations formulated at that time have been incorporated. 


\section{Bibliography}

Illa, G.,M." Temas de salud (II). Guía de Atención Primaria para educadores y docentes", UNICEF, 1991.

1 Feres, J.C.; León, A. "Magnitud de la situación de la pobreza". Revista de la CEPAL $N^{\circ} 41$.

For the calculation of the nutritional coefficients, the following sources were taken into acccount:

i. Tabla de Composición Química de los Alimentos elaborada por CENEXA (Mazzei, M.E.; Puchulu, M. R. Argentina, 1991). This work compiles informnation about the nutritional value of locally used foods through tables and national and foreign scientific publications as well as data provided by the food industry. Thus for each food this publication provides values obtained from more than one source. For the reasons mentioned in the text, also considered were data furnished by tables prepared in the United States. (Composition of Food Agriculture Handbook $N^{\circ}$ 8: Bernice K. Watt \& Annabel L. Merrill. U.S. Government Printing Office 1985.HBN8)

ii. Tabla de Composición Química de los Alimentos Chilenos. Schmidt Hebbel, H.; Pennacchiotti, I. Editorial Antártida S.A., 1979

iii. Information provided by national industry, particularly with regard to dairy products, meat derivatives, and some bakery products, such as crackers and cookies.

Bove, M.I.; Severi, M.C.; González, G."Obesidad: un problema social en el Uruguay". INDA, 1990.

"Situación de la Alimentación y Nutrición en el Uruguay: Referencia para el análisis de la política". Cooperación Técnica, OPP, BID. November 1992.

Día Mundial de la Alimentación; 16 October 1992; "Alimentación y Nutrición". FAO, October 1992.

Vigorito A. "Economías de Escala en el Gasto de los Hogares. Estimación de escalas de equivalencia" Montevideo, August 1996. 


\title{
POVERTY MEASUREMENT AND POVERTY STATISTICS IN AUSTRALIA
}

by

\author{
Maureen K. McDonald \\ Australian Bureau of Statistics \\ Australia
}




\title{
POVERTY MEASUREMENT AND POVERTY STATISTICS IN AUSTRALIA
}

\begin{abstract}
This paper provides an overview of the main poverty measures used in Australia. It briefly examines the needs of government for poverty measurement. In Australia, these needs relate to the targeted, non-contributory social security system which is designed primarily as a safety net for those with limited income from other sources.
\end{abstract}

In Australia, the Henderson Poverty Lines are the most commonly used measure of relative poverty. These lines were drawn up by a Commission of Inquiry into Poverty in the early 1970s. Since then there has been widespread debate on the appropriateness of these measures for Australian society. However, no acceptable alternatives have yet been found.

Against this background, the paper describes the role of the Australian Bureau of Statistics in the measurement of poverty. This role relates mainly to the provision of household income and expenditure data for poverty research. However, the ABS has also taken a lead in the expansion of direct income measures into the fields of resources other than cash income. It has done this at a practical level in its Fiscal Incidence Study. At a more theoretical level, the ABS has published a conceptual framework as a guide to the measurement of a broad range of household resources considered to affect economic well-being.

The ABS is also involved in giving expert advice to government and to private researchers on the use of income and expenditure data. It is currently involved in this way with research into the development of alternative poverty measures. These new approaches include a Budget Standards Project and developmental work on measuring living standards. 


\section{Contents}

1. Introduction

2. Policy needs and poverty measures

3. Poverty measurement in Australia

3.1 Henderson Poverty Lines

3.1.1 Criticisms of the Henderson Poverty Lines and equivalence scales

3.1.2 In defense of the Henderson Poverty Lines

3.2 Poverty line at $<50 \%$ of median equivalent income

3.3 Lowest equivalent income quintile

4. Research on alternative poverty measures for Australia

4.1 Budget standards approach

4.2 Living standards approach

5. ABS role in poverty measurement and poverty statistics

5.1 Household income and expenditure surveys

5.2 Incidence of government indirect benefits and taxes

5.3 Conceptual framework

5.4 ABS as technical adviser

6. Conclusion

Appendix 1 - Selected poverty statistics

Appendix 2 - Statistical units - definitions

Bibliography 


\section{Introduction}

The issue of poverty has been the subject of considerable research and debate in Australia for some decades. This continuing debate centres on the level and profile of poverty, its underlying causes and appropriate poverty alleviation programs.

Central to all of these issues is the more technical debate on how to define and measure poverty. While much use is made of the 'Henderson Poverty Lines' in Australia (see 3.1), debate continues on the relative advantages of indirect (income) measures and direct (living standards) measures. The merits or otherwise of different sets of equivalence scales are still discussed in academic papers. Debate also continues on whether the most appropriate counting unit for poverty measures is the individual, the income unit used for social security means tests, the family or the household. (See Appendix 2.)

Against this background of debate, the government does not officially recognise any particular measure of poverty. Nor does the Australian Bureau of Statistics publish official statistics on poverty. However the ABS publishes data on income distribution and 'low income' that uses the equivalence scales recommended for use with the Henderson Poverty Lines.

The Henderson Poverty Lines were produced as a result of two poverty studies in the 1960 s and 1970s. These studies were influential in raising public awareness of poverty. They also fueled an on-going debate on poverty measurement.

The first large study of poverty in Australia was carried out by the Institute of Applied Economic and Social Research (IAESR) at the University of Melbourne in 1966. Following wide-spread debate on the results of this study, the government set up a Commission of Inquiry into Poverty in 1972. (Both the Melbourne study and the subsequent Poverty Commission were headed by Professor Ronald Henderson of the IAESR.)

The Henderson Poverty Lines are the most commonly used poverty measure in Australia. They were first produced in the early 1970 s and have been updated each quarter since then. The poverty lines have, however, been the subject of considerable debate in the last two decades. Increasing dissatisfaction with the Henderson Poverty Lines has led to a growth in research on alternative measures in the 1990s. This research is divided across a number of alternative approaches to poverty measurement and these approaches are described later in this paper.

\section{Policy needs and poverty measures}

One of the primary purposes of the Australian social security system is the alleviation of poverty. Australia has a non-contributory social security system where pensions and allowances are paid to individuals and families deemed to be in financial need. Need is determined by use of income tests and assets tests are also applied for most payments. 
Pensions and allowances are available for those in need who are aged, sick, disabled or unemployed. Sole parents may also receive benefits and additional payments are made for children in low income families.

The development of measures of need and of poverty standards is particularly important in such a system where targeting of benefits to the most needy is the primary aim.

The successful setting of levels of payments in such a system also depends on the assessment of relative needs for different types of families. Policy makers in Australia therefore have a requirement for a set of equivalence scales that will reliably reflect the different income needs of families of different sizes and composition if such families are to attain a similar standard of living.

The suitability of the equivalence scales used for the Henderson Poverty Lines has been the subject of concern among both government policy makers and academics. This concern stems from the fact that the scales were not derived from knowledge of relative needs within Australia at the time (see 3.1.1 below). (At present, the Department of Social Security uses its own set of implicit equivalence scales for setting different rates of pensions and allowances.) Reliable data on the cost of children is a particularly important requirement for such policy makers.

Also with regard to children, the question of defining financial 'dependency' is a continuing issue. Levels of benefits paid to older adolescents and young adults who are still living with their parents will be affected by views on whether these children are (or should be deemed to be) independent of parental financial support. This issue is particularly important in the case of full-time students.

This raises the broader question of how income is shared within families and households and fuels the continuing debate on the most appropriate counting unit for poverty analysis.

At a broader level, government is also concerned that international comparisons of income inequality or poverty in different countries should reliably reflect actual differences in living standards. Concern with the quality of currently published comparisons was one of the motivations for the ABS to initiate the forming of the Canberra Group in 1996. This group has as one of its main aims the setting up of standards for measuring income inequality for international comparisons.

\section{Poverty measurement in Australia}

Poverty measurement in Australia has traditionally been based on the income/expenditure approach and the use of poverty lines. While there is some continuing debate in Australia over whether poverty should be measured in terms of opportunity (levels of income) or in terms of outcome (levels of consumption), the current poverty statistics are based on the income approach. 
The common use of the income approach partly reflects the dominant role played by the Henderson Poverty Lines in poverty measurement in Australia. The Commission of Inquiry chose the income approach on both practical and ideological grounds. Firstly they chose income because it was 'measurable'. On a more ideological note, the Commission stated that '...an adequate income is fundamental to a person's security, well-being and independence. .... An adequate income allows him freedom of choice and freedom to participate in activities of his choice. It contributes greatly to personal freedom and the extent of opportunities available.' (Commission of Inquiry into Poverty, 1975)

While the Henderson Poverty Lines remain the most commonly used measure, some Australian researchers prefer to use an alternative poverty line that relates equivalent income of particular families to the median equivalent income of all families in the population. This measure has often been used for international comparisons. In Australia, it is combined with varying sets of equivalence scales, particularly the Henderson equivalence scales or scales developed by the OECD.

Before discussing these two poverty lines in detail, it should be noted that the results derived from use of these measures are quite different. For example, based on results from the 1994-95 income survey, the proportion of income units deemed to be in poverty was 20 per cent using the Henderson Poverty Lines and 10 per cent using the measure of 'less than 50 per cent of median equivalent income'. (See Table 1, Appendix 1.) These differences in poverty statistics can be confusing for both government and the community.

The difference in the level of poverty using these two measures is further complicated by varying practices regarding the use of statistical units, reference periods for income and even the populations studied. Some poverty analyses are based on a restricted population that excludes families in business and some juveniles. Other analyses are based on the total population in private households. Use of alternative methods of updating the poverty lines can further complicate the picture. An overview by Whiteford of different results derived from poverty studies in Australia is attached in Table 2, Appendix 1.

\subsection{Henderson Poverty Lines}

The Henderson Poverty Lines are applied to the income of restricted family units called 'income units' and are based on weekly cash income receipts after the deduction of direct taxes. Alternative sets of poverty lines are available. One set uses 'detailed' equivalence scales that take into account a wide range of income unit characteristics such as family status, age, sex and work status of individuals. An alternative set uses simplified scales that allow only for consideration of parent/dependent child status and work status of individuals. The poverty lines can also be calculated for income before, or income after, housing costs.

The first poverty lines, set by Henderson and his colleagues in the Melbourne Study, were based on a minimum standard of living provided for by the basic wage in Australia. (The concept of a basic wage had been set by a landmark decision taken by the Arbitration Court 
in 1907 which set a basic wage that was to provide for 'the normal needs of the average employee regarded as a human being living in a civilized community'. (Henderson, Harcourt and Harper 1970.) The poverty line for the standard unit of two adults and two children was set at the Australian basic wage in 1966 plus the value of child endowment provided under the Social Security system.

Reporting on the setting of the lines for the Melbourne study, Professor Henderson and his colleagues justified the poverty line on the grounds that it was '... a definition of poverty so austere as, we believe, to make it unchallengeable. No one can seriously argue that those we define as being poor are not so.' (Commission of Inquiry into Poverty 1975.) Professor Henderson also commented that given its relationship to average earnings and social security child endowment, 'it is comparable to poverty lines that have been adopted in some surveys carried out overseas, particularly in the United Kingdom, the United States of America and Denmark.'

The up-dating of that poverty line has made it quite obviously a relative poverty measure. The poverty line for the standard unit adopted in the Melbourne study in 1966 had been approximately 57 per cent of seasonally adjusted average weekly earnings (AWE). When the Commission of Inquiry into poverty set the Henderson Poverty Lines in the early 1970s, this relationship with AWE was retained. For some years the lines were updated to retain this relationship to average weekly earnings. However, there was later concern about the fact that while the Henderson Poverty Lines were based on net (after tax) income, the AWE was a gross income measure. The method of adjusting the lines was therefore changed in the 1980s, when movements in the household disposable income per capita (HDIPC) were substituted. Over time, this has had the effect of increasing the value of the poverty lines at a greater rate than increases in AWE.

The choice of equivalence scales at the time the Henderson Poverty Lines were drawn up was complicated by the fact that there were no satisfactory Australian studies that provided a basis for determining relative needs of different families. The Poverty Commission therefore chose to use equivalence scales derived from a 1954 report on family budgets prepared by the Budget Standard Service of the Community Council of Greater New York.

\subsubsection{Criticisms of the Henderson Poverty Lines and equivalence scales}

Before examining the many criticisms of the Henderson Poverty Lines, it should be noted that despite extensive research and academic debate over the last two decades, critics agree that no acceptable alternatives have been developed for Australia.

With this in mind, it can be stated that the lines are the subject of concern on the following grounds: 
- The arbitrary basis for setting the poverty line for the standard unit

The setting of the Henderson Poverty Line for the standard unit at 57\% of average weekly earnings was seen to be fairly arbitrary and not necessarily based on a judgement of family needs in the early 1970s.

- The nature of equivalence scales used to adjust for different families

The equivalence scales did not necessarily reflect comparative needs of low income families in Australia in the 1970s given that they were based on a budget study carried out in another country many years before. The continued use of these scales in the late 1990s is strongly criticized.

- The method of updating the poverty line over time

The current method of updating the poverty lines, using the HDIPC is often criticized. The concept of household income in the national accounts is much broader than that used in the income distribution surveys on which most poverty studies are conducted. For example, the HDIPC includes items such as imputed interest on superannuation funds and imputed rent from owner-occupied dwellings - items that are excluded from income in the survey data.

It is not surprising, therefore that the growth of HDIPC and average weekly earnings have diverged over time. However, more importantly for the critics, increases in both the HDIPC and AWE have been greater than movements in the consumer price index. This means that the values of the Henderson Poverty Lines have increased much more than inflation over the last twenty years.

- Sensitivity of the poverty line to government social security payments

The Henderson Poverty Lines for some family types are very close to the maximum social security payments for these families. This means that very small increases in either the value of the social security payments or the poverty lines can result in large numbers of families being deemed to have fallen into (or moved out of) poverty, with little real change in their financial circumstances.

\subsubsection{In defense of the Henderson Poverty Lines}

As noted above, while there has been considerable criticism of the Henderson Poverty Lines and equivalence scales, no alternative measure has been produced that has gained wide acceptance by researchers in Australia.

In defense of the equivalence scales, it can be said that other studies have come up with similar results to those used for the Henderson Scales. The Henderson scales have also been 
defended on the grounds that they take into account a wider range of characteristics of families than do most other scales.

At a more general level, the sensitivity of the Henderson Poverty Lines to government benefit payments is likely to be shared by any other head count measure defined by a specific $\$$ value cut off point.

\subsection{Poverty line at $<50 \%$ of median equivalent income}

This measure has been used in some poverty studies in Australia in the 1990s. (Mitchell and Harding 1993.) The fact that it is an alternative measure of relative poverty has probably been influential in its use. Its use has also been partly influenced by a desire on the part of researchers to compare poverty in Australia with poverty trends in other countries.

However, this measure shares many of the advantages and disadvantages associated with the Henderson Poverty Lines. On the plus side, there is some advantage for presentation of data in having a simple cut-off point which clearly defines a poor population.

On the disadvantage side, the selection of the line at $50 \%$ of median income is, again, arbitrary. Its use still leaves the question of appropriate equivalence scales for Australia unanswered.

\subsection{Lowest equivalent income quintile}

The profile of families in the lowest equivalent income quintile is sometimes used as a proxy profile of poverty in Australia. The Australian Bureau of Statistics has traditionally preferred to use this measure and to describe families in this income range as having 'low income' rather than being in poverty.

However, this measure of families in the lowest quintile also shares many of the disadvantages of poverty lines. The choice of the quintile, rather than some other quantile, as cut-off point is again arbitrary. The use of this sharp cut-off point may result in a similar sensitivity to social security payments encountered when using poverty lines.

When the measure of 'lowest income quintile' is used as a proxy measure for poverty it suffers from an additional disadvantage in that the measure allows for no improvement, or deterioration, in the number of families deemed to be in poverty . By definition, the poor will always comprise 20 per cent of all families.

\section{Research on alternative poverty measures for Australia}

A number of new projects are under way in Australia to improve the basis of poverty measurement. The first of these is a budget standards study. The second is the move on a number of fronts to develop measures of living standards as direct measures of poverty. 


\subsection{Budget standards approach}

The Department of Social Security has funded a project designed to draw up low cost budgets for Australian households. This project is being carried out by the Social Policy Research Centre at the University of New South Wales. The study is designed to produce an alternative approach to income adequacy than that used in the Henderson Poverty Lines. In particular the aim is to develop income standards that have more relevance for Australian circumstances and values in the 1990s.

The work on the budget standards is being based largely on methods pioneered by the UK Family Budget Unit in the early 1990s. These methods are, however, being modified to Australian conditions. The budget standards work will take a relative approach to 'adequacy' or 'deprivation' rather than attempt to set subsistence budget standards.

Two standards are being derived, a low cost standard and a modest but adequate standard. The low cost budget is designed to allow for frugal living that will still allow for social and economic participation.

The modest but adequate standard provides for a higher level of living that would allow for full participation in Australian society and the basic options it offers. It is seen as falling somewhere around the median standard of living in Australia.

Results of the study are due to be published later this year. Professor Saunders, the Director of the project states that it remains to be seen whether these budget standards will provide the basis for replacing the Henderson Poverty Lines or whether they will produce another set of adequacy standards to complement them. (Saunders 1996a) It seems likely, however, that there will be considerable debate on the nature and quantities of items included in costing the standards.

\subsection{Living standards approach}

The poverty measures discussed above have been indirect measures concentrating in some fashion on the resources available to households. An alternative method of measuring poverty is the more direct approach that examines the outcome side of the picture, i.e. the living standards of the population. Measures of standards of living may include consideration of items such as health status, employment, housing and education. This approach was the subject of growing interest for government and researchers in Australia in the early 1990 s.

Between 1991 and 1994, the Australian Institute of Family Studies (AIFS) undertook a major study of the living standards of Australian families. The study took the view that living standards depended not only on cash income but also on the efficient delivery of necessary services to families. The Australian Living Standards Study (ALSS) adopted a 'spheres of life' approach that had been developed in Scandinavia. It examined fourteen spheres of life including health, housing, economic resources, transport; employment, 
education and social and political participation. The study also had an important goal of examining locational differences in living standards. A large body of literature has been produced from this study. (See de Vaus, D., 1996.)

Further study along these lines was carried out by two Australian academics whose report entitled 'Living Decently' has had a large impact on the poverty debate in Australia. (Travers and Richardson 1993.) Following publication of this report, the Department of Social Security funded a pilot survey on living standards of its clients in 1996. (Travers and Robertson 1996.) At present, the ABS is cooperating with the Department of Social Security in further building on this work on measurement of living standards in Australia. In the initial stages of this project, work will concentrate on the development of a conceptual framework for measuring living standards in the community.

The Living Standards Approach does, however, also have some disadvantages when used as a basis for poverty measurement. In particular, the resultant data is bulky and often difficult to integrate into a single summary measure of deprivation.

\section{ABS role in poverty measurement and poverty statistics}

As there is no officially sanctioned poverty measure for Australia, most poverty statistics reflect work carried out by academics and other research organizations.

The Australian Bureau of Statistics has not developed its own poverty measures and does not publish poverty statistics. This reflects, in part, the ABS's recognition of the inherently arbitrary nature of most poverty measures and the disparate results that can be obtained from the use of different measures. However, the ABS has played a very important part in most of the poverty research in Australia by providing a wide range of data on household income and expenditure and on other indicators of material resources. The ABS also provides analyses of income data (such as that contained in the Fiscal Incidence Study). It provides technical advice to other researchers and, most recently, it has developed a conceptual framework for household economic resources.

\subsection{Household income and expenditure surveys}

The ABS conducts a Household Expenditure Survey every five years and an annual Survey of Income and Housing Costs. Both of these surveys also provide data on the socio-economic characteristics of the population. Data from the surveys are made widely available in the form of publications and confidentialised unit record files for government and private researchers. Almost all poverty measurement in Australia is based on this survey data.

The quality of this data is very good. Response rates are high, partly because of legislation that requires the sampled population to co-operate in the surveys. The ABS also carries out imputation of missing data items to provide a complete picture of level and source of income for all private households. 
As with similar surveys conducted in other countries, there are some limitations in the data. In particular, the surveys do not collect information on the full range of economic resources available to households. For example, the surveys do not collect data on the receipt of capital transfers or on the households' wealth.

Some of the income data that is collected is subject to under-reporting. This is particularly the case with income from self-employment and with property income. The ABS is examining methods for overcoming these deficiencies via imputation to adjust for under-reporting.

For the 1998-99 Household Expenditure Survey, the ABS is also testing the inclusion of questions on capital receipts and disbursements and on financial stress for low income households.

\subsection{Incidence of government indirect benefits and taxes}

The ABS has also responded in other ways to the growing dissatisfaction in Australia with the measurement of poverty based on cash income only. Since the mid 1980s the ABS has been publishing results of a fiscal incidence study conducted using the results of its Household Expenditure Survey.

The study examines the effects of both selected government indirect benefits and indirect taxes on the distribution of household income. (ABS (1996a)). Indirect benefits included in the study include benefits provided by government expenditure on housing, health, education and welfare. This study provides an alternative measure of household income and shows the relative impact of government redistribution on households with low income or with other characteristics such as large families and the aged. While the primary aim of the study was not the measurement of poverty per se, the study has been used to provide an alternative profile of low income families.

The study does, however, suffer from the problem that not all government indirect benefits have been allocated. More theoretical and practical work remains to be carried out on possible allocation of these other benefits.

The study also raises the question of the validity of giving equal value to cash and in-kind benefits when the latter offer no element of choice of use for the recipients.

\subsection{Conceptual framework}

As noted above, the ABS provides the conceptual basis for most of the statistics used in measuring income and expenditure. It does this through the concepts, definitions and classifications which underpin the statistics of household income and expenditure.

More recently, the ABS has produced a conceptual framework for measuring household income, consumption, saving and wealth. (ABS 1995) This framework assists the poverty 
debate with its provision of a broad definition of economic well-being that goes beyond the concept of cash income.

Current poverty measures that are based solely on levels of cash income rely on an assumption that cash income is a good proxy measure for economic well-being. For some sections of the population this is not the case. For example, the exclusion of consideration of wealth from the measure of poverty will over-estimate the poverty levels for the elderly, many of whom have considerable assets in the form of home ownership. Exclusion of consideration of the value of household production and services may over-estimate the poverty of households where one spouse is engaged in full-time home duties. By including the value of imputed income from owner-occupied dwellings and the value of services produced within a household from unpaid work, the concept of economic resources is expanded. More importantly, poverty measures based on the broader concepts will show an alternative profile of households regarded as having low income.

In brief, the ABS's income framework maps out the relationship between the stocks and flows of all household economic resources and presents alternative measures of economic well-being for households. This broader concept of economic well-being can be measured from either the resources (receipts) side of household accounts or from the use of resources (disbursements) side.

On the resources side, the framework provides the following definition of economic well-being:

$$
\begin{aligned}
\text { Economic well-being }= & \text { disposable income } \\
& - \text { saving } \\
& + \text { transactional change in net worth } \\
& + \text { other change in stocks } \\
& + \text { notional wealth annuity. }
\end{aligned}
$$

The ABS recognizes that there are considerable practical problems for collecting or imputing much of the data necessary to operationalise this measure. However, the ABS also hopes that its current research program for improving the range of data for poverty measurement may provide some additional information to help fill out this broader picture.

\subsection{ABS as technical adviser}

In addition to its survey and conceptual work, the ABS also provides technical advice and assistance to government and private researchers on the use of ABS data to measure income distribution, income inequality and poverty. The ABS is also co-operating with those groups involved in developing alternative poverty measures.

For example, the ABS has recently carried out a study for the Department of Social Security on the sensitivity between Henderson Poverty Lines and the levels of government social security payments to families. (ABS 1996c) 
The ABS is also represented on steering committees for studies into income distribution and levels of adequacy. Most recently, the ABS provided a representative for an Interdepartmental Committee on Trends in Income Distribution in Australia (1995). An ABS representative is also on the steering committee for the Budget Standards Project mention in 4.1 above.

\section{Conclusion}

In summary, government policy makers, the $\mathrm{ABS}$ and private researchers have played a co-operative role in poverty research in Australia for some decades. All three groups have a current concern for widening the scope of the income concept for poverty measures and new work is being carried out on alternative 'living standards' measures.

The importance of this work will continue to be recognized as Australia faces the prospects of an aging population, structural change in the economy, and a non-contributory welfare system.

The continuing need for reliable international estimates of poverty will also remain. 
Appendix 1. Selected Poverty Statistics

Table 1: Poverty rates for income units ${ }^{(a)}$, Henderson Poverty Lines and < $50 \%$ of Median Equivalent Income, Australia, 1994-95

\begin{tabular}{lll}
\hline Income unit type & $\begin{array}{l}\text { Per cent of income } \\
\text { units below HPL }\end{array}$ & $\begin{array}{l}\text { Per cent of income } \\
\text { units below 50\% } \\
\text { MEI }\end{array}$ \\
Poverty Line &
\end{tabular}

One person income units

under 25 years

25-44 years

45-59/64 years ${ }^{(b)}$

aged

All one person income units

Couples, no dependents

aged

non-aged

All couples, no dependents

Couples with dependents

1 child

2 children

3 or more children

All couples with dependents

One parent income units

1 child

28.0

32.9

*36.2

3 or more children

All one parent income units
24.7

20.5

14.9

7.0

29.9

11.0

40.0

5.9

11.7

9.5

6.5

9.3

5.9

9.4

6.0

12.8

6.4

13.4

8.9

14.8

15.2

9.6
11.8

15.3

*28.1

15.7

All income units

19.6

10.0

(a) See Appendix 2 for definition of income units.

(b) Females $<60$ years of age, males $<65$ years of age, reflecting ages for eligibility for government Age Pensions. 
Table 2: Results of Studies of Poverty in Australia

\begin{tabular}{|c|c|c|c|c|}
\hline Study & Poverty Measure & Period & Data Source & Main Results \\
\hline $\begin{array}{l}\text { Saunders and } \\
\text { Matheson (1991) }\end{array}$ & $\begin{array}{l}\text { Henderson, } \\
\text { HDIPC }\end{array}$ & $\begin{array}{l}1981 / 82 \text { to } \\
1989 / 90\end{array}$ & $\begin{array}{l}\text { Income } \\
\text { Distribution } \\
\text { Survey (IDS) }\end{array}$ & $\begin{array}{l}\text { Poverty rate rose } \\
\text { from } 9.2 \text { to } 12.8 \%\end{array}$ \\
\hline $\begin{array}{l}\text { Bradbury and } \\
\text { Doyle } \\
(1992)\end{array}$ & $\begin{array}{l}\text { A. Henderson, } \\
\text { CPI } \\
\text { B. Henderson, } \\
\text { average survey } \\
\text { income }\end{array}$ & $\begin{array}{l}1983 / 84 \text { to } \\
1989 / 90\end{array}$ & $\begin{array}{l}\text { Microsimulatio } \\
\mathrm{n}, \\
\text { IDS }\end{array}$ & $\begin{array}{l}\text { A. Poverty rate fell } \\
\text { from } 11.3 \text { to } 9.4 \% \\
\text { B. Poverty rate rose } \\
\text { from } 11.3 \text { to } 11.4 \%\end{array}$ \\
\hline Saunders (1990) & $\begin{array}{l}\text { A. Henderson, } \\
\text { CPI } \\
\text { B. Henderson, } \\
\text { HDIPC }\end{array}$ & $\begin{array}{l}1982 / 83 \text { to } \\
1989 / 90\end{array}$ & $\begin{array}{l}\text { Microsimulatio } \\
\text { n, } \\
\text { IDS }\end{array}$ & $\begin{array}{l}\text { A. Poverty fell } \\
\text { from } 8.9 \text { to } 6.5 \% \\
\text { B. Poverty rose } \\
\text { from } 8.9 \text { to } 11.6 \%\end{array}$ \\
\hline Saunders (1994) & $\begin{array}{l}\text { Henderson, } \\
\text { HDIPC }\end{array}$ & $\begin{array}{l}1981 / 82 \text { to } \\
1989 / 90\end{array}$ & IDS & $\begin{array}{l}\text { Poverty rose from } \\
10.7 \text { to } 16.7 \%\end{array}$ \\
\hline $\begin{array}{l}\text { Harding and } \\
\text { Mitchell (1992) }\end{array}$ & $\begin{array}{l}50 \% \text { of median } \\
\text { income }\end{array}$ & $\begin{array}{l}1981 / 82 \text { to } \\
1989 / 90\end{array}$ & IDS & $\begin{array}{l}\text { Poverty fell from } \\
11.0 \text { to } 9.5 \%\end{array}$ \\
\hline $\begin{array}{l}\text { Mitchell and } \\
\text { Harding (1993) }\end{array}$ & $\begin{array}{l}60 \% \text { of median } \\
\text { income, poverty } \\
\text { gap }\end{array}$ & $\begin{array}{l}1981 / 82 \text { to } \\
1989 / 90\end{array}$ & IDS & $\begin{array}{l}\text { Poverty gaps stable } \\
\text { or falling slightly }\end{array}$ \\
\hline $\begin{array}{l}\text { Saunders and } \\
\text { Matheson (1993) }\end{array}$ & $\begin{array}{l}50 \% \text { of median } \\
\text { income }\end{array}$ & $\begin{array}{l}1981 / 82 \text { to } \\
1989 / 90 \\
\end{array}$ & IDS & $\begin{array}{l}\text { Poverty rose from } \\
9.3 \text { to } 9.4 \%\end{array}$ \\
\hline Harding (1995) & $\begin{array}{l}50 \% \text { of median } \\
\text { income, before } \\
\text { and } \\
\text { after the "social } \\
\text { wage" }\end{array}$ & 1994 & $\begin{array}{l}\text { Microsimulatio } \\
\mathrm{n}, \\
\text { IDS }\end{array}$ & $\begin{array}{l}\text { Poverty } \\
\text { substantially } \\
\text { reduced by "social } \\
\text { wage" (from } 12 \text { to } \\
4 \% \text { for couples } \\
\text { with children) }\end{array}$ \\
\hline $\begin{array}{l}\text { NATSEM } \\
(1996)\end{array}$ & $\begin{array}{l}\text { A. Henderson, } \\
\text { all } \\
\text { costs } \\
\text { B. Henderson, } \\
\text { after } \\
\text { housing costs }\end{array}$ & $\begin{array}{l}\text { November } \\
1995\end{array}$ & $\begin{array}{l}\text { Microsimulatio } \\
\text { n, } \\
\text { IDS }\end{array}$ & $\begin{array}{l}\text { A. Poverty at } \\
11.8 \% \\
\text { B. Poverty at } 9.2 \%\end{array}$ \\
\hline
\end{tabular}

Table reproduced from Whiteford, P., (1996) What do we know about poverty and income inequality in Australia? Mimeograph, Department of Social Security, Canberra. 


\section{Appendix 2. Statistical units - definitions}

Data from the ABS's household surveys of income and expenditure are produced for a number of different statistical units. Data on income is collected from individuals but is also aggregated during processing for, income units, families and households. Expenditure data is available only at the household level.

Definitions of statistical units

\section{Household}

A household is defined as a group of people who usually reside and eat together. Operationally it is defined as either:

(a) a one-person household, that is, a person who makes provision for his or her own food or other essentials for living without combining with any other person to form part of a multi-person household; or

(b) a multi-person household, that is, a group of two or more persons, living within the same dwelling, who make common provision for food or other essentials for living. The persons in the group may pool their incomes and have a common budget to a greater or lesser extent; they may be related or unrelated persons, or a combination of both.

\section{Family}

A family is broadly defined as two or more related people who usually live together.

More specifically, a family comprises two or more persons, one of whom is at least 15 years of age, who are related by blood, marriage (registered or de facto), adoption, step or fostering, and who are usually resident in the same household. A separate family is formed for each married couple, or for each set of parent/child relationships where only one parent is present.

\section{Income unit}

An income unit is defined as one person, or a group of related persons, within a household, whose command over income is assumed to be shared.

The relationships allowed for in the definition of income unit are restricted to those of marriage (registered or de facto) and of parent/dependent child.

A dependent child in this context is a resident offspring under the age of 15 years or aged 15-24 years who is a full-time student and has no spouse or child of their own present in the household. 


\section{Bibliography}

Australian Bureau of Statistics (1995), A Provisional Framework for Household Income, Consumption, Saving and Wealth, (6549.0), Canberra

ABS (1996a), The Effects of Government Benefits and Taxes on Household Income, (6537.0), Canberra

ABS (1996b), Income Distribution, Australia 1994-95 (6523.0), Canberra

ABS (1996c), Low income study, 1990 Survey of Income, Housing Costs and Amenities (unpublished report)

ABS (1997), A comparison of data on household income from the 1993-94 Household Expenditure Survey and the 1993-94 Australian National Accounts (unpublished paper).

Brownlee, H., (1990), Measuring Living Standards, AIFS Australian Living Standards Study, Paper 1, Melbourne

Commission of Inquiry into Poverty (1975), First Main Report, Poverty in Australia, AGPS, Canberra

de Vaus, D., (1996), The Australian Living Standards Study in Australian Institute of Family Studies, Family Matters No. 43, Autumn 1996, Melbourne

Henderson, R. F., Harcourt, A. and Harper, R. J. A., (1970), People in Poverty, A Melbourne Survey, Cheshire, Melbourne

Mitchell, D. and Harding, A. (1993), Changes in poverty among families during the 1990s: poverty gap versus poverty head-count approaches, NATSEM Discussion Paper No. 2, Canberra

Murray, C., (1996) Modest but Adequate and Low Cost Food Budget for Australian Households, Budget Standards Unit Working Paper Series No 2. October 1996, University of New South Wales, Sydney

Oxley, C., Prosser, B. and King, A., Poverty lines: measurement issues in Carter, J (ed) (1991), Measuring Child Poverty, Child Policy Review 6, Brotherhood of St Laurence, Melbourne

Oyen, E., Miller, S. M. and Samad, S. A. (eds), (1996), Poverty: A Global Review. Handbook on International Poverty Research, Scandinavian University Press, Oslo

Saunders, P., (1994) Welfare and Inequality - National and International Perspectives of the Australian Welfare State, Cambridge University Press Saunders, P., (1996) Poverty and Deprivation in Australia, in ABS, Year Book Australia, 1996 (1301.0), Canberra

Saunders, P., (1996a) Development of Indicative Budget Standards for Australia: Project Outline and Research Methods, Budget Standards Unit Working Paper No 1. September 1996, University of New South Wales, Sydney Social Security, Department of, (1995), Developing a Framework for Benchmarks of Adequacy for Social Security Payments, Policy Discussion Paper No. 6, AGPS, Canberra

Travers, P. and Richardson, S., (1993), Living Decently: Material Well-being in Australia, Oxford University Press 
Travers, P. and Robertson, F., (1996) Relative Deprivation Among DSS Clients:

Results of a Pilot Survey, National Institute of Labour Studies Monograph Series No. 2, NILS, SA

Whiteford, P., (1985) A family's needs: equivalence scales, poverty and social security, Department of Social Security Research Paper No 27, Canberra

Whiteford, P., (1996), What do we know about poverty and income inequality in Australia? mimeograph, Department of Social Security, Canberra. 



\section{POVERTY MEASUREMENT IN AUSTRALIA: The effect of government non-cash benefits and location}

by

\section{David Wilson}

Australian Institute of Health and Welfare Australia 


\section{Poverty measurement in Australia: The effect of government non-cash benefits and location}

\section{Introduction}

In Australia there has been a continuing interest in measuring the multi-dimensional aspects of poverty. The Commission of Inquiry into Poverty in the early 1970s examined a wide range of issues including links between poverty and illness, service delivery, location and disadvantage. (Commission of Inquiry into Poverty 1975)

The Australian Institute of Health and Welfare has undertaken analyses of the relationship of poverty and disadvantage to health and also to housing and community services as part of its core work reporting health and welfare assistance information in Australia. The Institute has examined poverty and housing costs in its series of biennial reports on Australia's welfare services and analysed relationships between health and income in the counterpart report on Australia's health. (AIHW 1996, AIHW 1995).

\section{Current measurement issues}

The paper presented by the Australian Bureau of Statistics (ABS) at this seminar discusses details of the Australian social security system and identifies the issues relating to poverty measurement. This paper further examines some of the issues raised in relation to broader measures of assistance.

Several aspects of the current Australian environment indicate the need for a multidimensional approach to poverty measurement that recognizes the effects of non-cash assistance and location. These include:

- the use by governments of both cash and non-cash assistance to address poverty;

- recent real growth in the size of government outlays in the area of health and welfare services including targeted assistance;

- an increase in the complexity of transactions between governments and individuals over time, often involving a mix of both cash and non-cash assistance;

- a growing trend to de-institutionalize services with more health and welfare services appearing in private dwellings and data collections are coming across increasing service rich/cash poor households; and

- recognition that the effectiveness of assistance to disadvantaged households often varies with location due to factors such as price and accessibility.

\section{Increased complexity of transactions}

In Australia, growth in the complexity of government transactions with households involving cash and non-cash assistance have made cash only poverty measures less useful. 
For example in health, the introduction of a co-payment for previously free pharmaceuticals has meant:

- for pensioners pharmaceuticals, under the Pharmaceutical Benefit Scheme(PBS) move from being free to $\$ 2.60$ each;

- aged pensioners receives $\$ 5.20$ extra cash per fortnight to cover this increased cost;

- there is an increase in cash income, these pensioners are apparently better off, but their

basket of goods costs more and on average is believed to be revenue neutral for households and government;

- a cash only analysis concludes an increase in income and possible shift in poverty levels.

The importance of fully measuring these effects is likely to increase in Australia where governments are currently reviewing and proposing reforms in several areas of assistance. These changes involve shifts in the mix of cash and non-cash assistance which traditional poverty measures have trouble compensating for.

\section{Structural change}

Australian governments, both national and State, are currently examining options to improve the effectiveness and efficiency of the assistance they provide. In the area of housing assistance, which has historically developed as two separate streams of assistance, one for private renters involving cash assistance and the other for public renters involving a non-cash rebate, structural change to improve the comparability and transparency of assistance may produce distortions to cash measures of poverty.

One current proposal for housing assistance could see the national government responsibility shift from capital funding for public housing to an income support role, providing cash rent assistance as it currently does for disadvantaged private renters. The implications for measurement are:

- in terms of government outlays there would likely be a revenue neutral transfer of around $\$ 1$ billion from capital housing transfers to social security cash transfers;

- in terms of cash poverty measures approximately 300,000 public renters would appear better off by the amount of cash rent assistance they would receive(in place of their current non-cash rebate);

- their command over goods and services is likely to remain neutral if the cash subsidy is equal to their current non-cash rebate;

- in international comparisons it would improve Australia's standing in terms of cash poverty and income distribution analysis and see an increase in total outlays for the government purpose classification identifying social security and welfare outlays.

There is a need to ensure that changes in government roles and financing relationships do not create statistical artefacts in poverty measures. 


\section{Measuring inequities}

Related to this has been an increased awareness of inequities in assistance having major implications for poverty analysis. Over time, different rates of growth and degrees of substitutability of government programs between similar cash and non-cash assistance or between areas have highlighted the need for a multi-dimensional approach to poverty. Examples of these concerns are:

- Inequities between similar cash and non-cash benefits: - the 1993 Industry Commission Public Housing Inquiry noted that the value of Department of Social Security cash rent assistance per recipient household was $\$ 1200$ p.a. while the non-cash rebate for public housing tenants was $\$ 3020$ p.a..(Industry Commission 1993)

- Inequities in similar non-cash benefits over geographic or social class groups: - The Audit Office of NSW noted that for children's services the Department of Community Services' Preschool subsidy per eligible child in 1992-93 was $\$ 437$ in the most-disadvantaged $10 \%$ of local government areas while for the least-disadvantaged $10 \%$ of local government areas the subsidy was \$563. (Audit Office of NSW 1994)

\section{Data availability}

The measurement of the effect of non-cash assistance and location aspects of poverty in Australia has been supported by three major Australian Bureau of Statistics (ABS) initiatives:

- the compilation and release of data on the effects of government benefits and taxes on household income (ABS 1996) - the first release of this data in 1987 meant Australia has an official set of income estimates covering the five income concepts covering all types of transactions between the state and the individual, namely cash and non-cash benefits and direct and indirect taxes, similar to the United Kingdom Central Statistical Office work regularly published there since the 1960s;

- the development of a set of socio-economic indexes from the 1986 ABS Population Census and their inclusion in subsequent data; and

- the increased availability of confidentialised unit record files from the suite of ABS household surveys and a one percent sample of the Population Census.

This has greatly helped organisations such as the Australian Institute of Health and Welfare (AIHW) to analyse and attempt to quantify complex issues surrounding poverty measurement.

This paper examines how this information has been used outside the ABS by government agencies and researchers to further develop broader poverty methodologies. 


\section{Measuring multi-dimensional aspects of poverty}

In Australia, a range of agencies are undertaking the development of methodologies to improve information on poverty and income distribution issues. A major portion of this work has been carried out, or funded by, the two major Commonwealth social policy agencies, namely, the Department of Health and Family Services(DHFS) and the Department of Social Security(DSS).

In addition to undertaking in-house analysis both Departments fund external agencies including:

- $\quad$ the Australian Institute of Health and Welfare (AIHW);

- the National Centre for Social and Economic Modelling(NATSEM);

- the Australian Institute of Family Studies(AIFS); and

- the Social Policy Research Centre(SPRC) at the University of New South Wales.

This major focus of this paper is on the measurement work of the AIHW and related work previously undertaken at the Department of Health and Family Services.

\section{The measurement of non-cash services in poverty}

In Australia, governments (Commonwealth, State and local) use both cash and non-cash forms of assistance to address issues around poverty and living standards. While some assistance is directly aimed at reducing poverty other forms often have an indirect effect.

The Social Outlays Project undertaken at the Department of Health and Family Services, then titled Department of Health, Housing, Local Government and Community Services (DHHLGCS) in the early 1990s analysed the ABS Household Expenditure Survey data and produced three reports on these issues. The main results of the reports are summarised as follows.

Report 1, titled "The distribution of the health, housing and community service outlays of government amongst households, 1988-89" (DHHLGCS 1993a) found that:

- In 1988-89 the average weekly government outlay per household on health, housing and community services was $\$ 61.29$ This represents a total of $\$ 22.04$ per person a week of which $\$ 16.91$ or 77 percent was for health care.

- The per capita value of assistance to low income households is, on average, twice that for all households.

- The poorest 30 percent of households consumed over 40 percent of these government outlays. Over 60 percent of housing benefits and 56 percent of community service outlays were consumed by the poorest 30 percent of households.

- In 1988-89 a larger share of these outlays were directed to the lower income households than in 1984 
The second report, "The distribution of government and household outlays on health care, 1988-89"(DHHLGCS 1993b) showed:

- Australian governments provide over 80 percent of health care expenses for low income households compared with an average of 68 percent for all households and 56 percent for the highest income households.

- Targeted health programs such as the Pharmaceutical Benefits Scheme (PBS) provide valuable subsidies for low income households and the aged:

- $\quad$ the value of government provision of pharmaceuticals for aged pensioner households was on average $\$ 14.15$ per week.

- the high use of prescription medicines by low income households, particularly the aged, is not reflected in high household expenditure on prescriptions by these households; and

- $\quad$ the PBS has an important income effect with an estimated value for aged pension households of approximately 8 percent of their gross income.

- The omission of the redistributive characteristics of the Australian health care system underrates the contribution of government services in redirecting scarce resources to assisting those most in need.

The third report titled, "The distribution and impact of government rental housing, 1988-89" (DHHLGCS 1993c) reported:

- Government rental dwellings are mostly occupied by households from low income groups with 58 percent of all government renters in the lowest three income deciles (the poorest 30 percent of all households).

- Housing costs for government renters were 70 percent of the average housing costs for all households in 1988-89. In 1984 they were 83 percent of the average housing costs.

- Government renters spent only 15 percent of their total expenditure on goods and services on housing, compared with 20 percent for private renters.

- Low income government renters have greater purchasing power, reflected in a higher cash income remaining after housing costs, than do private renters on a similar income.

- Single parent households are the government renter group that, on average, receive the highest level of government rental subsidy.

\section{Issues for poverty measurement:}

The three reports concluded that:

- Government non-cash outlays on health, housing and community services have an income replacement effect, by reducing the cash budget commitment of households, they contributes significantly to their level of well-being. 
- This income effect causes changes to household demand functions effectively changing their budgetary constraints and allowing a command over goods and services that is higher than apparent from household cash income alone.

- The effect of this becomes apparent when comparing the budget or income effect of government renters, which has an average value of $\$ 28.40$ per week, with government pensioners and beneficiaries in private rental markets who in 1988-89 received extra cash assistance to a maximum of $\$ 15$ per week.

- The case is more complex for community services where a range of benefits from total care in nursing homes to subsidised child care are provided, but to a very narrowly defined group of recipients. Child care fee relief in 1993 had a recipient value of $\$ 4625$ p.a. and this assistance is not included in cash income analysis.

- While no detailed Australian analysis has been undertaken, due to the lack of an official poverty line, the significance of non-cash transfers is highlighted by the U.S. Congressional Budget Office which estimates that the inclusion of in-kind benefits in income statistics would cause the number of people in poverty in the U.S. to decline to approximately 9 million compared with the official poverty statistics showing nearly 25 million people in poverty. (US Department of Commerce 1984)

- The inclusion of social wage benefits in poverty analysis can change the relative and absolute income levels of certain households and thus alter the outcomes of income redistribution and poverty analysis. Conversely the exclusion of non-cash benefits can lead to the relative disadvantage of different groups being misrepresented.

The Institute is currently updating this work and the following section provides a summary of the work currently under way (forthcoming discussion paper).

\section{The effect of housing, health and community services outlays on households in 1993-94}

In 1993-94 the size of government non-cash social outlays across all levels of government in Australia was:

- Health: $\$ 23,537$ million

- Housing: $\$ 3,820$ million

- Community services: $\$ 6,319$ mill

- Education services: $\$ 19,748$ mill

For health, housing and community services outlays this represents a subtotal of $\$ 33,676$ million. This compares with cash income support outlays of the Department of Social Security(DSS) and Department of Veteran's Affairs(DVA) of cash transfers of $\$ 40,133$ million in the same period.

Main results from the 1993-94 analysis show:

- In 1993-94, government outlays on health, housing and community services for households averaged $\$ 84.76$ per household per week. 
- The average per capita government outlay for people in the $20 \%$ of households with the lowest incomes was just under twice that for all people.

- Out of pocket health expenses for disadvantaged households were low. Governments provided $79 \%$ of total health care expenses for low income households compared with an average of $69 \%$ for all households.

- Housing costs for government renters were $76 \%$ of the average housing costs for all households .

- Households which had disability support pensions as their principal source of income received over three times the average benefit from community services.

- The value of government provision of pharmaceuticals for aged pensioner households was on average $\$ 9.65$ per week.

- Approximately $14 \%$ of households in the lowest quintile were government renters. Their average benefit was equal to $\$ 59.80$ per household.

- The average value to all government renters was estimated to be $\$ 54.23$ per week.

- Household renting public housing in New South Wales received the highest benefits of all States which were equal to $\$ 66.99$ per week. The lowest benefits were received by households in the Northern Territory who received benefits of $\$ 40.24$ per week.

- Community services contributed $\$ 19.38$ per household per week, with over two thirds of the total outlays being directed to the lowest two income quintile groups. The largest average value of $\$ 35.48$ was in the second lowest income quintile and the smallest average weekly benefit of $\$ 4.68$ occurred in the highest quintile.

- Households which had government pensions and allowances as their principal source of income received more than double the average benefit from community services. Households which had age pensions and disability support pensions as their principal source of income received particularly high benefits of \$54.03 and \$63.64 per week respectively.

\section{Changes to income distribution}

- Non-cash benefits enhanced rather than offset the redistributive effect of government cash transfers.

- The gap between the incomes of the richest and poorest was less when health and welfare outlays are included.

- The average income of the poorest $20 \%$ of the population rose by $30 \%$ from $\$ 152$ to $\$ 217$ a week while the average income of the top $20 \%$ rose by only $3 \%$ when non-cash health and housing benefits were added to income.

Ignoring how this mix affects poverty measurement can create significant problems. Changes over time in the mix of cash and non-cash benefits going to particular groups will impact on the reliability of either absolute or relative measures of poverty.

\section{Measurement issues:}

There are a number of issues that are currently being examined:

- The use of expenditure /income ratios and relationships 
- Household level analysis and income unit data

- Measuring amenity aspects such as security of tenure in public housing

- improved concepts and methods

- data availability

\section{Problem areas}

Particular issues that need further examination are:

- the quality of allocations for community service areas - child care, aged and disability;

- concerns regarding quality of the 1993-94 HES data - it reports 470,000 public renter households while housing authorities report only 380,000 households;

- allocating benefits to persons in non-private dwellings

\section{The effect of location and distance on disadvantage}

An important concern relating to poverty has been measuring the impact of geography in terms of prices and access to services and opportunities. This has been a most problematic are due to:

- poor availability of detailed data on prices, income and expenditure for small areas; and

- a lack of established analytical concepts and methods for interpreting the large numbers of variables and observations for summary or surrogate measures that may be available from data from population censuses.

Currently, the best source of data providing comparable and consistent coverage for small areas is the ABS Population Census. This section of the paper examines approaches that provide a measurement of location into the analysis of poverty. Two approaches are discussed:

- the use of socio-economic indexes from the Population Census to examine the effect of location on disadvantage; and

- incorporating variations in costs into the analysis of housing and poverty.

\section{The ABS socio-economic indexes}

For the 1986 Population Census the ABS produced four sets of socio-economic indexes to provide a summary or overview of areas. Each index summarised a different set of underlying variables from the 1986 Population Census. Three of the ABS indexes have been used to study issues around locational disadvantage:

- Index of relative socio-economic disadvantage;

- Economic resources index; and

- Index of education and occupation 
The indexes are derived using principal component analysis of 1986 Census data. Each index has been designed to have an average across all Collectors Districts (CDs) in Australia of 1000 and a standard deviation of 100 index points. A similar set of indexes was produced for the 1991 Population Census.

The indexes reflect the status of an area, rather than the status of individuals. It is possible for a person possessing high-status attributes to be resident in a CD which may have a low score on some or all of the indexes. It is not appropriate to make inferences regarding a particular individual on the basis of the index scores. For example, the Relative Socioeconomic Disadvantage Index summarises 21 variables related to economic resources of households, education, occupation, family structure and ethnicity. An area has a low value on the index if it contained a large proportion of households with low status attributes.

In the 1986 Census there was an average of 350 dwellings in each urban $C D$, with this declining in rural areas as population densities decreased. This standard figure reduced to 250 for the 1991 Census, which reduced the ease of any inter-Censal comparisons between CDs based on their sizes. A detailed definition of CDs and their structure is to be found in the ABS 1986 and 1991 Census Dictionaries Catalogue, ABS Catalogue Number 2901.0. More detail on the derivation and application of these indexes is contained in the ABS publication, Socioeconomic Indexes for Areas, ABS Catalogue No. 1356.0.

\section{The index of relative socio-economic disadvantage}

This index provides a broad indication of the overall socioeconomic profile of an area. The main limitation of this index is that while it recognises some aspects of income and expenditure the data are not detailed and several questions regarding their quality have been raised. The index also excludes factors such as inherited wealth, savings, indebtedness, and differences in property values and living costs between regions.

The variables used to compile the index of relative socio-economic disadvantage focus on attributes such as the percentage of:

- families with incomes of less than $\$ 12,000 \mathrm{pa}$,

- households with no cars,

- houses with one or no bedrooms,

- households renting, both privately and in public housing,

- private dwellings housing two or more families,

- households in improvised accommodation,

- the population without formal qualifications,

- the population who left school before the age of 15 ,

- employed people in a range of occupational categories,

- unemployed people,

- sole headed families, 
- people over 15 years old who are separated or divorced, and

- people with a range of ethnic backgrounds and those lacking fluent English.

Economic resources index

The index of economic resources reflects the economic profile of families, using a range of variables which include the percentage of:

- households purchasing the dwelling,

- households with three or more motor vehicles,

- households with four or more bedrooms,

- the average number of bedrooms per person,

- households renting privately,

- single parent families with incomes greater than $\$ 40,000$,

- two parent families with incomes greater than $\$ 40,000$,

- mortgages greater than $\$ 600$ per month,

- rent more than $\$ 150$ per week, and

- group households.

Education and occupation variables were excluded because they were highly correlated with the income variables. Generally a high score indicates households with high incomes and mortgages in large houses, while a low score means that the CD has a high proportion of people on low incomes in small dwellings.

\section{Index of education and occupation}

The variables used to derive the index of education and occupation include the percentage of the population:

- with degrees or higher education, trade, other qualifications or none;

- who never attended school or who left at 15 years of age;

- aged 15 years and older who are at school, at TAFE, at CAE or university;

- employed as managers or administrators, professionals, para-professionals, trade-people, clerks, sales or personnel workers, labourers, both men and women,

- unemployed, men and women.

This index was designed to classify the educational and occupational structure of each CD. It does not distinguish between current activities and completed educational qualifications and contains no income component.

\section{The Local Area Research Studies on Locational Disadvantage}

One of the first applications of these Census indexes to the issue of poverty was in the Local Area Research Studies (LARS), conducted as part of the Commonwealth 
Government's 1990/91 Social Justice Strategy. (Department of Health, Housing and Community Services 1991) These studies examined the relationship between the planning and provision of services and infrastructure and locational disadvantage. The approach was similar to the area studies conducted as part of the Henderson Inquiry (Commission of Inquiry into Poverty 1975a,b).

Their principal aim was to examine how socioeconomic disadvantages are exacerbated by where people live because of differing levels of access to affordable housing, employment, training and education opportunities, and physical and social infrastructure. The studies sought to assess the way in which inequity or inefficiencies in the provision of infrastructure and services may worsen the situation of disadvantaged groups.

Locational disadvantage was defined as:

"disadvantage, primarily as a result of geographic location, in gaining physical access to employment and training, community, health and education services and facilities such as public transport and physical infrastructure."

In relation to poverty measurement the interest is in the attempt to combine data on populations, services and infrastructure. A major component of the studies was the examination of the range of nationally comparable and locally specific data for the 10 LGAs in which the studies were undertaken. Six studies were undertaken in urban fringe areas and four in non-metropolitan areas.

In each of the areas a series of colour maps were produced showing values for each $C D$ in the LGA for each of the three ABS indices. The following page presents a copy of the map for the area of Elizabeth in South Australia. Maps of population density were also produced.

Population density is defined as the number of people per square kilometre. Because CD boundaries encompass similar numbers of dwellings they can provide more detailed picture of population density within the LGA. Areas of greatest socioeconomic disadvantage in the study areas did not always correspond with areas of densest population, although there tended to be more disadvantage in the more densely settled areas.

The use of a single variable, or index, which reflects several aspects of the disadvantage in the study areas was seen a useful aid to assist in the social and economic analysis being undertaken. Many aspects of the socioeconomic profile of a community cannot be measured directly but there may be several variables which are recognised as contributing to a particular dimension.

The studies found that in both urban fringe and non-metropolitan areas, disadvantaged groups were further disadvantaged due to their location. Factors underlying this 'double disadvantage" were: 
- inadequacies in the regional or urban planning and development process;

- poor public transport;

- limited regional employment opportunities;

- failure to match service provision to population growth; and

- general service delivery problems. 


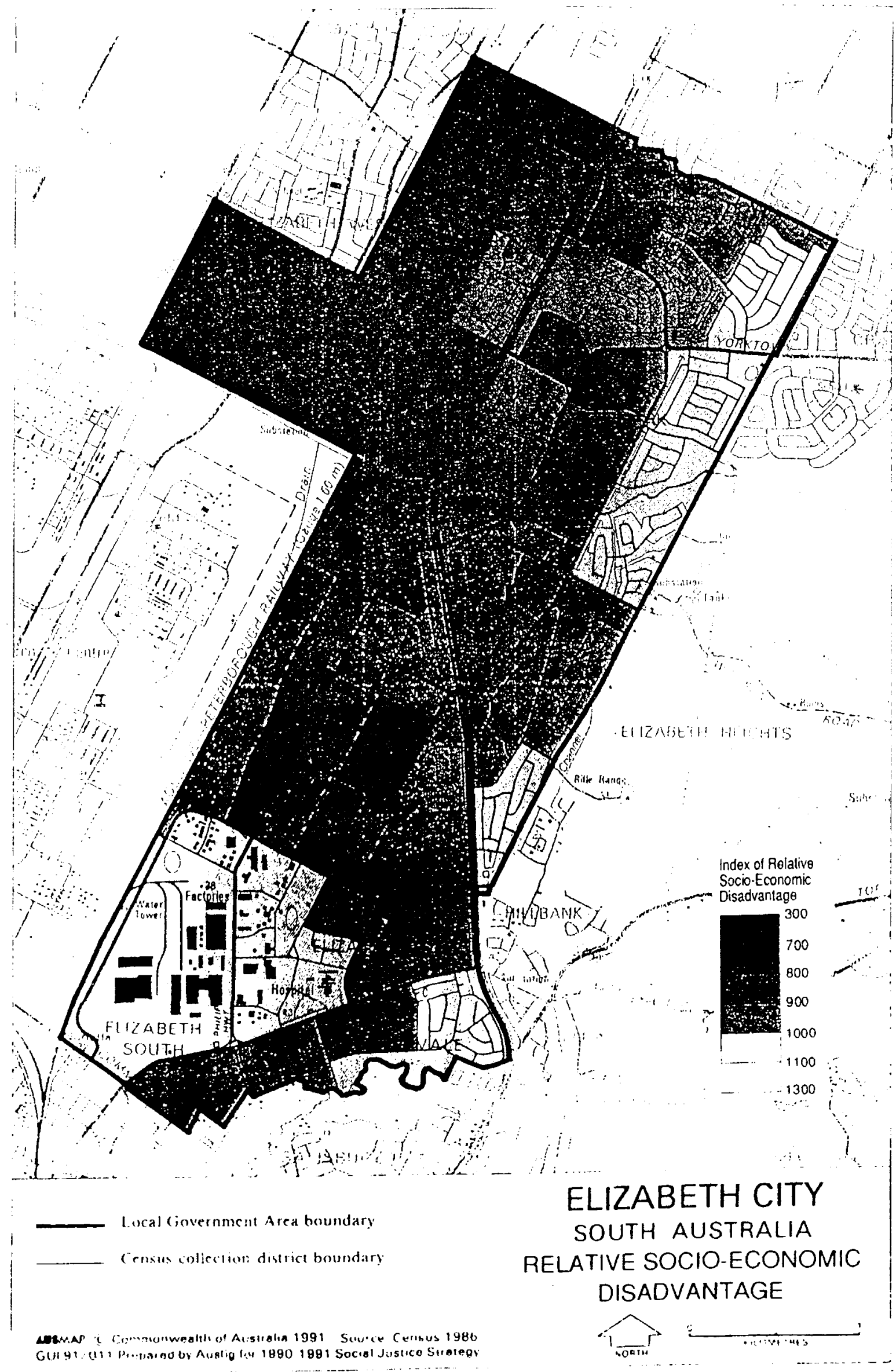


While such studies have policy implications they also raise several poverty measurement issues:

- how can detailed data about an area be related to the well-being of individual households?

- can measures such as the ABS indices be incorporated into mainstream cash poverty analyses?

While work is progressing in Australia in examining how to make better use of such data in measuring poverty it has opened up a range of measurement issues on how to relate cash household poverty measures to broader notions of disadvantage.

Incorporating variations in costs into the analysis of housing and poverty: the 1995 AIHW model of housing needs

The issues surrounding the effects of non cash benefits and locational variations on poverty measurement are illustrated in an analysis of housing need undertaken by the institute and published in its bi-ennial report, "Australia's Welfare Services and Assistance 1995".

The analysis incorporated concerns that the relationship between poverty and housing costs was more complicated than a purely financial one. The study quantified several important components of the relationship namely, affordability, location and adequacy of dwelling.

The model used 1991 Population Census data to analyse housing needs and poverty allowing for the effects of:

- different family sizes and types;

- regional differences in living expenses;

- the cost of non-housing items;

- non-financial aspects of housing and poverty.

The AIHW undertook this analysis on the 1991 Census data using the Henderson afterhousing poverty line and the Canadian National Occupancy Standard to identify those requiring housing assistance. The restrictions of using the limited range of Census data items on housing and income and two measures, the Henderson poverty line and the Canadian National Occupancy Standard, both of which are only one of several possible methods, means that the analysis can be considered only indicative.

Following the analysis the high number of households with incomes below the statutory levels of assistance in Australia raised the question of whether Census data is a reliable source for income analysis of the detail required. This issue is difficult to solve as eligibility periods, the duration of spells in and out of cash poverty and lack of data on assets of the type used to determine eligibility are not recorded for the Census. 
A problem with the 1991 Census was the collection of only range data rather than actual dollar values for income and housing costs. This was addressed by the development of techniques to model the range distribution to derive point estimates.

The major assumptions incorporated into the model were:

- Affordable housing costs vary with household size and composition

- a low-income benchmark be incorporated dependent on household size and composition and household location; and

- households with no capacity to pay housing costs due to income being below a predetermined amount should be separately identified.

The analysis produced from the 1995 AIHW model of housing needs is still widely used by some agencies to provide indications of those requiring assistance. While the assumptions used in this model have been criticised its underlying approach provides the breadth of variables relevant to examining housing assistance issues. The model is still the only Australian model that examines affordability, appropriateness and adequacy allowing for variations in household size and regional variations in rents.

The Institute is currently examining the components of the model in light of these criticisms to develop a series of modules that would be able to examine the issues of affordable, appropriate and adequate housing, under different sets of assumptions. The Institute is also examining ways of incorporating other aspects which are difficult to quantify such as amenity, physical quality, location and security of tenure. Similarly the issue of including data on homelessness into such analysis is yet to be addressed.

\section{Summary}

While Australia has no official poverty measure there is continuing data development and analysis being undertaken by statistical agencies, government policy makers and researchers to provide improved measurement and debate on how Australia should examine poverty. This interest extends both locally and internationally as further development of poverty measure relies heavily on the experience of all others who have grappled with these statistics. 


\section{Bibliography}

Audit Office of NSW, (1994) Performance Audit Report; Children's services - Preschool and Long Day Care

Australian Bureau of Statistics, (1996) The Effects of Government Benefits and Taxes on Household Income, (6537.0) Canberra

Australian Institute of Health and Welfare, (1996) Australia's Health 1996, AGPS , Canberra

Australian Institute of Health and Welfare, (1995) Australia's Welfare Services and Assistance 1995, AGPS , Canberra

Commission of Inquiry into Poverty (1975) First Main Report, Poverty in Australia, AGPS , Canberra

Commission of Inquiry into Poverty (1975a) A study of Heidelberg, Victoria, Research Study number 16, AGPS , Canberra

Commission of Inquiry into Poverty, (1975a) A study of Hindmarsh, South Australia, Research Study number 17, AGPS , Canberra

Department of Health, Housing and Community Services (1991) Social Justice Local Area Research studies on Locational Disadvantage: Project Report, Policy Development Division

Department of Health, Housing, Local Government and Community Services, (1993a) The Distribution of Health, Housing and Community Service Outlays of Government amongst Households, 1988-89 (Progress Report Number 1 of the Social Outlays Project), AGPS, Canberra

Department of Health, Housing, Local Government and Community Services, (1993b) The Distribution of Government and Households Outlays on Health Care, 1988-89 (Progress Report Number 2 of the Social Outlays Project), AGPS, Canberra

Department of Health, Housing, Local Government and Community Services, (1993c) The Distribution and Impact of Government rental Housing, 1988-89 (Progress Report Number 3 of the Social Outlays Project), AGPS, Canberra

Industry Commission (1993) Public Housing Volume 1: Report, Industry Commission, AGPS, Canberra

US Department of Commerce (1984) Estimates of Poverty including the Value of Noncash Benefits: 1983, Bureau of the Census, Technical Paper number 52, 



\title{
ANALYSES OF HOUSEHOLD INCOME STATISTICS IN THE UNITED KINGDOM
}

\author{
by \\ Dennis Roberts \\ Office for National Statistics \\ United Kigndom
}




\section{Analyses of household income statistics in the United Kingdom}

\section{Introduction}

1 The paper describes the main analyses of household income data undertaken by the Government Statistical Service in the United Kingdom. The analyses are The Effects of Taxes and Benefits on Household Income produced by the Office for National Statistics and Households Below'Average Income (HBAI) produced by the Department of Social Security.

2 The Effects of Taxes and Benefits on Household Income estimates the distributional impact of taxation and government expenditure on household income. The series, which has been produced annually since the early 1960s, takes original or market income as its starting point and then estimates how government intervention in the form of tax raising and spending redistributes income between households. For this reason, the analysis is also known as the redistribution of income (ROI).

3 Households Below Average Income provides estimates of patterns of personal disposable income and of changes over time. It attempts to measure people's potential living standards derived from goods and services financed from disposable income. The series, which uses 1979 as a base year, is now produced annually. The latest report, the seventh in the series, covers the years 1979 to $1993 / 94$. As the title would suggest, HBAI concentrates on the lower part of the income distribution, but provides comparisons with the upper part where appropriate.

4 The main data source for both these analyses has been the Family Expenditure Survey. This is a continuous household survey carried out each year with an achieved sample of about 7,000 households (about 1 in every 3,000 households). The response rate is around 70 per cent although it has fallen slightly in recent years. The survey covers private households only, people living in hotels, lodging houses, and in institutions such as old peoples' homes are excluded. Each person aged 16 and over keeps a full record of purchases made during 14 consecutive days and answers questions about hire purchase and other payments. The respondents also give detailed information, where appropriate, about income (including cash benefits received from the state) and payments of income tax. Information on age, occupation, education received, family composition and housing tenure is also obtained.

5 HBAI is in the process of moving its base to the Family Resources Survey, a new survey of household income sponsored by the Department of Social Security (DSS). This survey provides detailed information about the characteristics and finances of households. The questionnaire covers primarily income, but also other areas of interest to the DSS such as informal care of the elderly and disabled, occupational pensions, childcare and savings. The survey is much larger than the FES with an achieved sample of 25,000 households. The ROI cannot make use of the survey as it does not collect data on expenditure. 


\section{Redistribution of Income}

6 ROI examines the impact of government taxation and expenditure on the distribution of income by allocating the revenue to those households which paid the taxes and the expenditure to those households which benefited from it, wherever this is possible. Some outlays and revenue cannot be allocated to households, for example there is no clear conceptual basis for determining the benefit to each household of defense expenditure. In practice, between 55 an 60 per cent of both revenue and expenditure are allocated to households. ROI illustrates the redistributive effects of taxes and benefits through a sequence of income concepts, namely:

\begin{tabular}{|c|c|}
\hline original income & $\begin{array}{l}\text { income from employment, investment, } \\
\text { occupational pensions, etc. }\end{array}$ \\
\hline gross income & original income plus government cash benefits \\
\hline disposable income & gross income less direct taxation \\
\hline post-tax income & disposable income less indirect taxes \\
\hline final income & $\begin{array}{l}\text { post-tax income plus imputed income from government } \\
\text { non-cash benefits such as education, health, etc. }\end{array}$ \\
\hline
\end{tabular}

7 Original income is the annualized market income of all members of the household, where annualized wages, for example, are calculated as the annual rate based on the respondent's normal wage abated from time lost through unemployment, sickness, etc. Income in kind from company cars and subsidized loans are included as part of original income. Income from cash benefits is based on information from the respondents as are direct taxes, that is income tax, local taxes and National Insurance contributions. Indirect taxes (value added tax, excise duties, custom duties, etc.) are assigned to households on the basis of their expenditure on goods and services. The assumption is adopted that indirect taxes levied on and paid by businesses are fully passed on to households in the prices they pay for goods and services. The national benefits of government expenditure on state education, health, housing and travel subsidies are allocated to households. The Allocation of health expenditure is on an "at risk" or insurance principle whereas the allocation for the other expenditure is based on usage.

8 The basic unit of analysis is the household, as spending on many items, particularly on food, housing, fuel and light, is joint spending by members of the household. Households are ranked according to disposable income after allowing for differences in household composition. The equivalence scale used to adjust for household composition is known as the McClements scale. It was developed in the mid-seventies based on expenditure data from the FES. At present the analysis is only for survey households. However, work is currently underway to test the feasibility of re-weighting the data to reflect the population of the UK.

9 The results show the different sources of income and the taxation paid by households by quantile groups and by household type. The analysis aims to present the most meaningful 
results for the year, figures cannot be easily compared over time as the tax-benefit system and the FES change. However, shares of income and Gini coefficients are sufficiently robust to shed light on broad trends in income distribution and are shown from 1977 onwards. The latest article, for 1995-96, was published in the March 1997 edition of Economic Trends.

\section{Households below average income (HBAI)}

10 HBAI reports on the income distribution in the current period and on the particular types of people to be found at various points in the income distribution as well as describing how the distribution has changed over time and how different socio-economic groups have fared. In addition, the latest report makes use of information from the British Household Panel Survey to analyze the income mobility of individuals, particularly those at the lower end of the distribution, over time. The report is based upon individuals, not households.

11 Income in HBAI refers to disposable household income: that is income after the deduction of income tax, National Insurance contributions and local government taxes. Each person's income is aggregated across the household and adjusted to reflect the composition of the household by using the McClements equivalence scale. The data used is for current income: that is the income reported at the time of the survey interview.

12 HBAI uses two measures of income, one before housing costs have been deducted (BHC), the other after (AHC). The two income measures are seen as complementary indicators of changes and differences in living standards over time. The need for two measures arises from the variation in housing costs: in part this reflects variations in the quality of housing, but there are also significant costs variations which do not reflect quality variations.

13 Research has shown that current income as reported in a household survey may not necessarily be the best indicator of living standards for some households. This is particularly true of households with members who are self-employed. In view of this, a comparison between income and expenditure distributions is shown and some results are presented both excluding and including households with self employed members.

14 Comparison of real income levels over time are made using price index deflators: the Retail Prices Index (RPI) net of local taxation for the Before Housing Cost (BHC) incomes and the RPI net of all housing costs for After Housing Cost (AHC) income.

15 The survey results are grossed up so that population totals reflect the whole household population of the UK. Different grossing factors are applied to different types of benefit unit in order to correct for the over -and under- representation of these groups.

16 An adjustment is made to the FES and the FRS data to compensate for the haphazard variation in the numbers of very rich households in each year's survey, which results from the limited sample size and the relatively poor response rate of such households. This adjustment is made using information from anonymised tax records supplied by the Inland Revenue. 
17 The latest report, Households Below Average Income 1979 - 1993/94, was published by the Stationery Office in November 1996. The analysis in this edition covers the calendar years: 1979; 1992 and 1993 combined; and the financial years 1993/4 and 1994/5 combined. 



\section{INCOME DISTRIBUTION AND POVERTY IN EU12 - 1993}

by

EUROSTAT

Luxembourg 


\section{Income Distribution and Poverty in EU12 - 1993}

This "Statistics in Focus" outlines the findings of the European Community
Household Panel in the area of income distribution and poverty in the
European Union of 12 countries (EU 12) in 1993.
Just over a quarter of the income in the EU12 in 1993 was shared among the
top $10 \%$ of households, while income for the bottom $10 \%$ amounted to $2 \%$ of
the total. According to Eurostat working definitions and concepts, 57 million
individuals lived in poor households in the EU12 in 1993. Among them,
children (less than 16 years old) accounted for 13 million, i.e. one out of every
5 children in the Union.
Denmark had the lowest proportion of poor households and Portugal the
highest in the reference year.
The risk of poverty is greater in some household types than in others. This is
particularly so for those households which comprise a single parent and
where all children are aged under 16. Households where the reference person
is unemployed are also more likely to be poor than others.

The objective of this report is to give an initial general outline of income distribution and poverty in the European Union as revealed by the European Community Household Panel (ECHP).

Given the critical role of conventions and concepts in interpreting income distribution, the findings and conclusions of extensive research commissioned by Eurostat since the 1980s have been chosen as a starting point'. In particular the definitions already agreed by the European Council of Ministers (19/12/1984), have been used.

Consequently, the figures that are presented here may differ from national estimates for two main reasons, i) data sources and ii) conventions and concepts (see Technical Box p. 180181).

\section{Income distribution in EU12}

Income distribution data are usually expressed in terms of the percentage of total income received by given tranches of the population; in table 1, we consider the population of households arranged in groups of $10 \%$ or "deciles". The income concept used throughout

\footnotetext{
${ }^{1}$ Eurostat (1990), "Poverty in Figures - Europe in the early 1980s", Theme 3, Series C

Eurostat (1994), "Poverty Statistics in the late 1980s - Research based on Micro-data", Theme 3, Series C (OPOCE, Luxembourg)
} 
this paper is total net monetary income for calendar year 1993 ; roughly, it includes all sources of monetary incomes received by the household (wages, dividends, ...) net of income taxes, and monetary social transfers such as pensions and private transfers received. As is usual, the varying size and composition of households has been taken into account using an equivalence scale. (For these conventions and concepts refer to Technical Box p. 13-14). Having regard to these conventions, it transpires that in none of the then 12 Member states were income shares proportio-nately distributed across all households in 1993:

- the $20 \%$ poorest households received between $6 \%$ (Greece, Spain, Italy and Portugal) and 9\% (Belgium, Denmark and Ireland) of total household net monetary income ; whereas

- the $20 \%$ richest households, received between 33\% (Denmark) and 46\% (Portugal) (Table $1)$.

For EU 12 as a whole, figures were respectively $6 \%$ and $41 \%$.

The Gini coefficients are useful summary tools for imparting a quick impression of the spread of incomes. They vary from 0 (no inequality) to 1 (total inequality). As measured by the Gini coefficient, Portugal appeared to have the highest degree of inequality in the EU as a whole: 0,42 versus 0,35 for the EU average. Greece $(0,38)$, United Kingdom and Italy (both 0,37) came next. Denmark was well under the EU average with 0,25 (table 1).

Table 1:

Household ${ }^{1}$ net income distribution in EU 12, 1993

\begin{tabular}{|c|c|c|c|c|c|c|c|c|c|c|c|c|c|}
\hline & EU12 & $\overline{\mathbf{B}}$ & DK & $\bar{D}$ & $\overline{E L}$ & $\bar{E}$ & $F$ & IRL & $T$ & $L$ & NL & $\bar{P}$ & UK \\
\hline \multicolumn{14}{|c|}{ Decile shares (\%) of total household net monetary income } \\
\hline Bottom 1 & 2 & 3 & 5 & 3 & 2 & 2 & 3 & 3 & 2 & 3 & 3 & 2 & 3 \\
\hline 2 & 4 & 6 & 7 & 6 & 4 & 4 & 5 & 6 & 4 & 5 & 5 & 4 & 5 \\
\hline 3 & 6 & 7 & 8 & 6 & 5 & 6 & 6 & 6 & 6 & 6 & 6 & 5 & 6 \\
\hline 4 & 7 & 8 & 8 & 7 & 7 & 7 & 7 & 6 & 7 & 7 & 7 & 6 & 7 \\
\hline 5 & 8 & 9 & 8 & 8 & 7 & 7 & 8 & 7 & 8 & 7 & 7 & 7 & 7 \\
\hline 6 & 9 & 9 & 9 & 9 & 9 & 8 & 9 & 8 & 9 & 9 & 9 & 8 & 9 \\
\hline 7 & 10 & 10 & 10 & 10 & 10 & 10 & 10 & 10 & 11 & 10 & 10 & 10 & 10 \\
\hline 8 & 12 & 12 & 11 & 12 & 13 & 12 & 12 & 12 & 12 & 12 & 13 & 12 & 12 \\
\hline 9 & 15 & 14 & 13 & 15 & 15 & 15 & 15 & 16 & 16 & 14 & 15 & 16 & 15 \\
\hline Top 10 & 26 & 22 & 20 & 23 & 27 & 27 & 25 & 27 & 26 & 27 & 25 & 30 & 28 \\
\hline $\begin{array}{l}\text { Gini } \\
\text { coetficients }\end{array}$ & 0.35 & 0.31 & 0.25 & 0.3 & 0.38 & 0.35 & 0.33 & 0.34 & 0.37 & 0.32 & 0.34 & 0.42 & 0.37 \\
\hline
\end{tabular}

1 Equivalised net monetary income has been used for ranking the households - for "equivalisation" see Technical box, p. 180-181.

Source: Eurostat - ECHP, First wave, 1994. 


\section{Poverty line: a matter of definition}

Ensuring continuity with previous Eurostat works is one of the reasons for using the poverty line at " $50 \%$ of the national average". Also in its first Cohesion Report (8/11/1996), the European Commission uses "50\% of the national average".

National practices in this domain are varied, for example,

- Luxembourg and the United Kingdom: $50 \%$ of the mean

- France: $50 \%$ of the median

- Italy: the mean per-capita expenditure for a two-person household

- Netherlands: the minimum income according to the General Assistance Act

Eurostat has tested the " $50 \%$ of the national median"method. The level of the poverty linewas reduced (425 PPPs versus 489 PPPs), resulting in i) lower poverty rates and ii) a slightly different ranking of the countries.

\section{Working definition of poverty and poverty lines}

The broad definition of poverty used in this report is taken from the EU Third Poverty Programme, European Council Declaration of 19 December 1984 :

"The poor shall be taken to mean persons, families and groups of persons where resources (material, cultural and social) are so limited as to exclude them from the minimum acceptable way of life in the Member States in which they live."

This is a relative notion which cannot be implemented in its entirety. It has to be translated into a 'working definition', however arbitrary, in terms of consumption, expenditure or income. Based on the above-mentioned Eurostat research the following pragmatic choice of the poverty line is made :

"The poverty line is 50\% of the arithmetic mean of equivalised net expenditure/income."

A poverty line is a benchmark income which is used to determine which household is poor or not. A household with an income lower than the poverty line is defined as "poor". The poverty lines used here are country-specific since they are defined as half $(50 \%)$ of the average equivalised annual net monetary income of the households in a country (see 
Technical Box p. 180-181). The 50\% threshold provides a certain continuity with estimates of poverty made by the Commission in the past ${ }^{2}$.

Although low income does not in itself reflect cultural and social aspects, it should generally be a reasonable surrogate for poverty.

According to these conventions, in 1993 average equivalised net monthly income was 489 Purchasing Power Parities (PPPs) in EU12 as a whole. With the exception of Luxembourg which is well above this figure (990 PPPs), the poverty line ranged from 311 (Portugal) to 562 PPPs (Germany) in 1993 (table 2).

\section{Table 2:}

Poverty lines in 1993

$50 \%$ of average equivalised net monthly income ${ }^{1}$

\begin{tabular}{l|rr}
\hline \multicolumn{1}{c|}{ Country } & $\begin{array}{c}\text { National } \\
\text { currencies }\end{array}$ & $\begin{array}{c}\text { Purchasing } \\
\text { Power } \\
\text { Parities } \\
\text { (PPPs) }^{2}\end{array}$ \\
\hline Belgium & 22330 & 540 \\
Denmark & 5328 & 527 \\
Germany & 1248 & 562 \\
Greece & 67940 & 325 \\
Spain & 48090 & 377 \\
France & 3716 & 516 \\
Ireland & 294 & 403 \\
Italy & 667600 & 411 \\
Luxembourg & 38750 & 990 \\
Netherlands & 1175 & 516 \\
Portugal & 42580 & 311 \\
United & 378 & 541 \\
Kingdom & & \\
EU 12 & & 489 \\
\hline
\end{tabular}

${ }^{1}$ See Technical box p. 180-181.

${ }^{2}$ Purchasing Power Parities (PPPs) convert national currencies into units of currency with identical purchasing power in all countries enabling international comparisons to be made (see technical box p. 180-181).

\footnotetext{
${ }^{2}$ Earlier Eurostat research used the expenditure yardstick for measuring poverty because it was generally more reliable than the income data derived from the national household budget surveys, which was the only available source that could be used in the research on "Inequality and Poverty in Europe 1980-1985", Eurostat "Rapid Reports"1990/7. That restriction now vanishes with the ECHP.
} 


\section{The extent of poverty}

Having regard to the above mentioned conventions, there were about 57 million individuals in the EU12 living in nearly 23 million poor households in 1993 (table 3). Of course, not all persons in a poor household might be poor because the resources at its disposal might be very unequally distributed. For the same reason, some individuals who are resident in households above the poverty line may actually be living in poverty. There is no way, at present, of measuring such issues relating to intra-household distribution of resources.

Table 3:

The extent of poverty in 1993 (in thousands)

\begin{tabular}{|l|r|r|r|}
\hline \multicolumn{1}{|c|}{ Country } & $\begin{array}{c}\text { Households below } \\
\text { poverty line }\end{array}$ & $\begin{array}{c}\text { Individuals living } \\
\text { in households } \\
\text { below poverty line }\end{array}$ & $\begin{array}{c}\text { Children living in } \\
\text { households below } \\
\text { poverty line }\end{array}$ \\
\hline Belgium & 508 & 1289 & 302 \\
Denmark & 216 & 318 & 42 \\
Germany & 4515 & 9099 & 1888 \\
Greece & 872 & 2258 & 380 \\
Spain & 8872 & 7631 & 1730 \\
France & 3523 & 7591 & 1487 \\
Ireland & 238 & 759 & 322 \\
Italy & 3429 & 10895 & 2245 \\
Luxembourg & 22 & 60 & 18 \\
Netherlands & 842 & 1919 & 443 \\
Portugal & 915 & 2537 & 577 \\
United Kindgom & 5474 & 12805 & 3859 \\
EU 12 & 22825 & 57162 & 13292 \\
\hline
\end{tabular}

${ }^{1}$ Children: less than 16 years.

Source: Eurostat - ECHP, First wave, 1994.

The proportion of households below the poverty line reached $17 \%$ in the EU 12 as a whole. Portugal was well above the EU average with $29 \%$, then came Greece (24\%) and the United Kingdom (23\%). At the other extreme, Denmark had the lowest poverty rate (9\% of Danish households). In the remaining countries, the rates ranged from $13 \%$ in both Germany and Belgium to $21 \%$ in Ireland. The poverty rate for Luxembourg is comparatively high (14\%) because its average income, and hence its (relative) poverty line, is high (Figure 1). 
Figure 1:

Proportion of poor households - 1993

$\%$

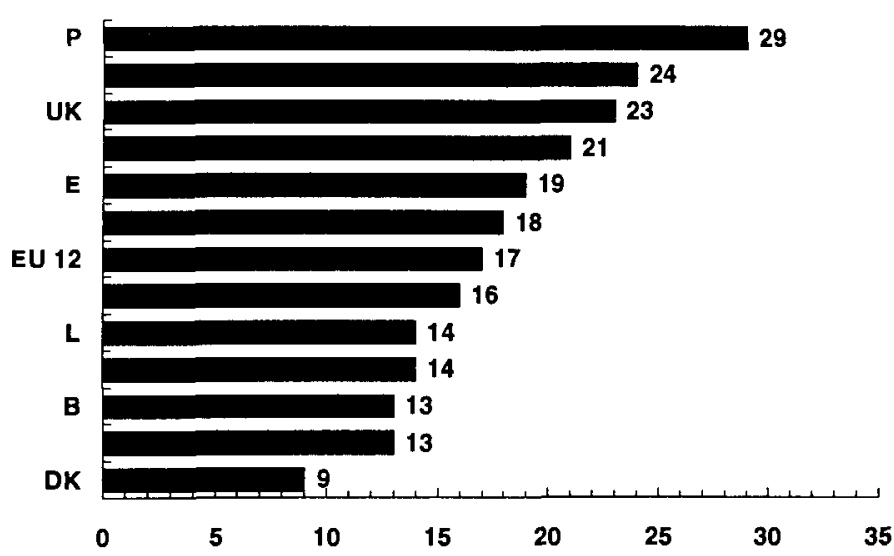

Source: Eurostat - ECHP, First wave, 1994.

If we consider individuals living in households below the poverty line, the ranking was comparable and the percentages varied from 6\% in Denmark to 26\% in Portugal (Figure 2).

Figure 2:

Proportion of individuals living in poor households - 1993

$\%$

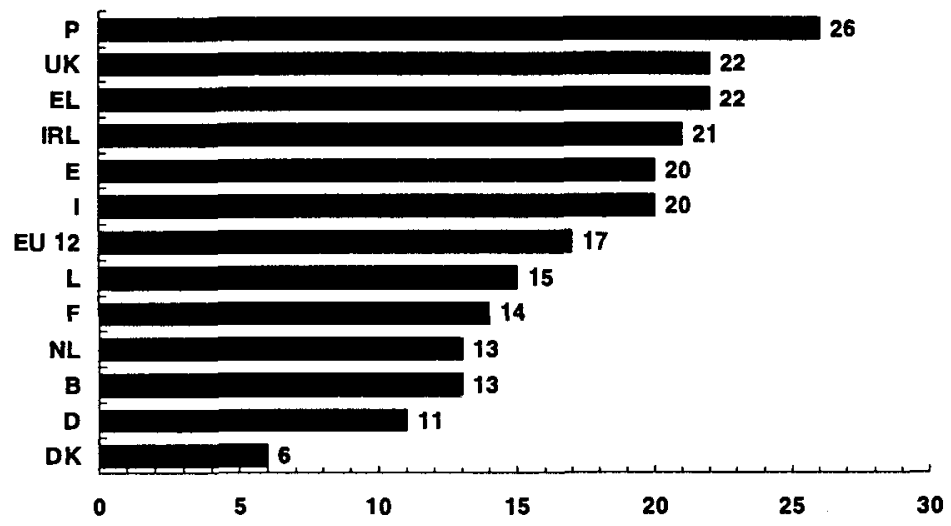

Source: Eurostat - ECHP, First wave, 1994.

The number of children living in poor households was over 13 millions in the then 12 Member states, i.e. $20 \%$ of all the Union's children. These proportions were higher for United Kingdom (32\%), Ireland (28\%), Portugal (27\%), Spain (25\%), Italy (24\%) and Luxembourg (23\%). The lowest percentage was in Denmark (5\%) (Figure 3). 
Figure 3:

Proportion of children living in poor households - 1993

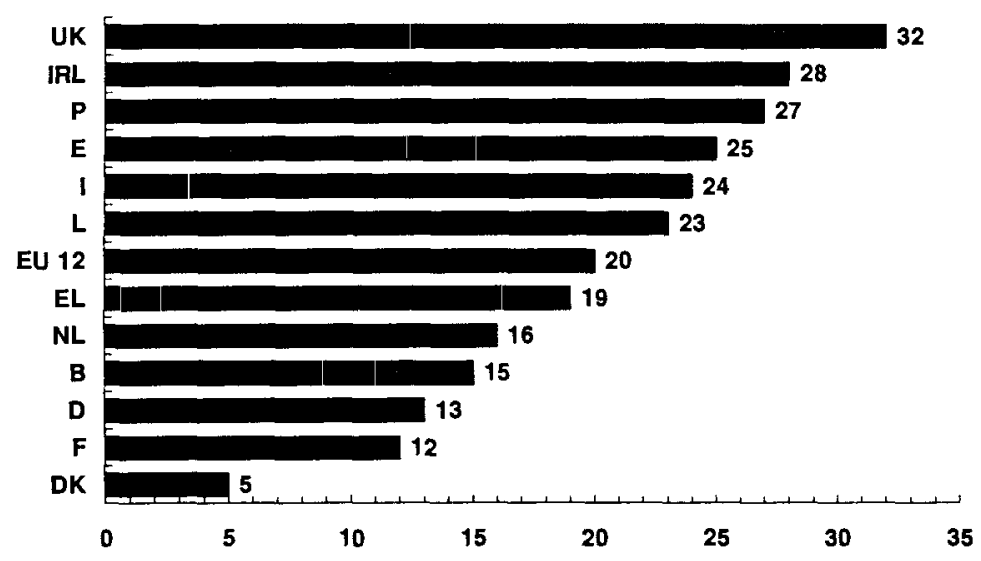

Source: Eurostat - ECHP, First wave, 1994.

\section{Characteristics of poor households}

Who are the poor? Answering this question requires an analysis of the composition of poor households by social groups.

In 1993, representing $19 \%$ of the total, the most common profile of poor households was that of a person living alone and aged over 65 years. Couples without children also formed a significant portion at $18 \%$, while couples with at least one child aged 16 or over comprised $13 \%$ of this category (table 4 ).

It should be noted that these figures encompass two phenomena : on the one hand the relative share of each group in total population and on the other hand the risk to each group of falling into the poverty trap.

Some types of households are more likely to be "poor" than others. As measured by the poverty rate, it is evident that at the EU 12 level, the poverty risk was much higher for "single parents with all children under 16" than for "couples with one child under 16", $36 \%$ versus $11 \%$ in 1993 (table 4). 
Table 4:

The poor in 1993 by household type ${ }^{1}$, EU 12

\begin{tabular}{l|c|c}
\hline \multicolumn{1}{c|}{ Household type } & $\begin{array}{c}\text { Distribution of } \\
\text { poor households } \\
\%\end{array}$ & Poverty rate \\
& 19 & $\%$ \\
\hline One person aged 65 or over & 10 & 27 \\
One person aged $30-64$ & 7 & 15 \\
One person aged under 30 & & 31 \\
Single parent with all children $<16$ & 5 & 36 \\
Single parent with at least 1 child $\geq 16$ & 4 & 17 \\
& & 13 \\
Couple without children & 18 & 11 \\
Couple with one child $<16$ & 5 & 14 \\
Couple with two childrren $<16$ & 8 & 23 \\
Couple with three children or more $<16$ & 5 & 15 \\
Couple with at least one child $\geq 16$ & 13 & 17 \\
Other Households & & \\
Total & 6 & - \\
\hline
\end{tabular}

${ }^{1}$ As demonstrated in the aforementioned research the precise composition of the poor can be affected by the equivalence scales used.

Source: Eurostat - ECHP, First wave, 1994.

Some of the more noticeable features of risk at national level are given below, though it should be remembered that national estimates are subject to larger sampling errors.

Single parent with all children under 16: In 1993, respectively $65 \%$ and $53 \%$ of those households were poor in Ireland and the United Kingdom; this household type accounted for between $3 \%$ and $4 \%$ of all households in these countries. The EU12 average was 36\%, and the Danish percentage was $8 \%$.

Young one-person households (person aged under 30) : It was in the Netherlands and in France ( $42 \%$ each) that the poverty risk was highest, and in Ireland and Spain that it was lowest (13\% each), though such young "households" might, because of their poverty, be concealed in large households containing parents. At the EU level, the percentage was $31 \%$.

One-person elderly households (65 or over) : $55 \%$ of such households were below the poverty line in Portugal, the highest in the EU. Then came Greece (46\%), Ireland and the United Kingdom (42\% each). The EU12 average was $27 \%$. The lowest figures were to be found in Belgium and The Netherlands (16\% both). 
Large families (couples with 3 children or more): It was in Portugal (43\%) and the United Kingdom (40\%) that these households ran the highest risk of poverty. The EU average was $23 \%$. In France and Denmark, $10 \%$ of such households were poor.

Table 5 shows that households whose reference person was classified as unemployed accounted for $13 \%$ of all poor households in 1993 . However, $46 \%$ of all households whose in Northern Europe than in the South.

The first column of table 6 shows the percentage of poor households which experience specified shortages. The second column presents the percentages of all EU households experiencing this shortage. For example, $58 \%$ of poor households, as opposed to $31 \%$ of all households, said, in 1993, that they could not afford a week's annual holiday away from home. However, mortgage costs are a burden for $13 \%$ of households whether categorised as poor or not.

Table 5:

The poor households by labour market status in 1993, EU 12

\begin{tabular}{l|c|c}
\hline \multicolumn{1}{c|}{$\begin{array}{c}\text { Labour market status of } \\
\text { household reference person }\end{array}$} & $\begin{array}{c}\text { Distribution of poor } \\
\text { households } \\
\%\end{array}$ & Poverty rate \\
\hline $\begin{array}{l}\text { The working poor: } \\
\begin{array}{l}\text { Employer + self employed } \\
\text { + family worker + employee }\end{array}\end{array}$ & 35 & 10 \\
$\begin{array}{l}\text { Unemployed } \\
\text { Retired }\end{array}$ & 13 & 46 \\
$\begin{array}{l}\text { Other economically inactive: } \\
\text { in education, training or } \\
\text { apprenticeship/doing } \\
\text { housework, } \\
\text { looking after children/etc. }\end{array}$ & 33 & 22 \\
Total & 19 & 43 \\
\hline
\end{tabular}

${ }^{1}$ See Technical Box p. 180-181. 
Table 6:

Non monetary poverty indicators in 1993, EU 12

\begin{tabular}{l|c|c}
\hline Indicators & $\begin{array}{c}\text { Percentage of EU 12 } \\
\text { poor households }\end{array}$ & $\begin{array}{c}\text { Percentage of all } \\
\text { EU 12 households }\end{array}$ \\
\hline Damp walls, floors, foundation & 21 & 14 \\
Receives housing benefit & 18 & 9 \\
Mortgage costs are a burden & 13 & 13 \\
Not able to make ends meet & 37 & 18 \\
Cannot keep the home adequately warm & 28 & 15 \\
Cannot afford a week's annual holiday away & & 31 \\
from home & 58 & 15 \\
Cannot afford new clothes & 30 & 7 \\
Cannot afford eating meat, fish, etc. every second & 17 & \\
day & & 17 \\
Cannot afford to have friends or family for a & & \\
drink or meal, at least once a month & 33 & \\
\hline
\end{tabular}

Source: Eurostat - ECHP, First wave, 1994. 


\section{TECHNICAL BOX}

The European Community Household Panel (ECHP) is a multidimensional household survey that covers various topics: income, health, education, housing, migration, demographic and employment characteristics, etc. The first wave was conducted in 1994, in the then EU Member states, i.e. excluding Austria, Finland and Sweden. The sample totalled some 60,500 households selected randomly.

Based on a harmonised questionnaire, the ECHP yields a centralised comparable micro data base in Eurostat that can be used flexibly to shed light on policy issues. As the ECHP is a panel, i.e. an attempt is made to interview the same individuals every year, it will in due course provide information on social dynamics. For a detailed description of the ECHP methodology ref. "The European Community Household Panel (ECHP): Volume 1 - Survey methodology and implementation", Theme 3, Series E, Eurostat, OPOCE, Luxembourg, 1996.

\section{Decile group}

The main method of analyzing income distribution is to rank units (households, individuals, ...) by a given income measure and then to divide the ranked units into groups of equal size. Groups comprising $10 \%$ of units are known as "decile groups". Thus the "bottom decile group" is the $10 \%$ of units with the lowest incomes.

\section{Total net monetary income}

This concept covers all market incomes (wages, self-employment income, investment income, rent received) plus social transfers received, including all types of pensions plus private transfers received, minus income taxes and social insurance contributions. Some of the components were missing for a number of households and these had to be imputed. Those $2 \%$ of households for which imputation was not possible and no income information was available, were excluded from the analysis. Imputed rent (i.e. the rent owner-occupiers would have to pay if they did not own the dwelling they live in) as well as personal income taxes are not included.

\section{Equivalence scales}

The aim of equivalence scales is to adjust incomes for the varying size and composition of households. Clearly a 2-person household with 10,000 ECUs cannot generally be said to have the same standard of living as a 5-person household with the same amount of income. Dividing the income by the number of persons in the household would assume that a child costs as much as an adult to live and/or that 2 adults living together cost twice as much as one adult living alone. The equivalence scale used in this report is the modified OECD 
scale, i.e. 1.0 for the first adult, 0.5 for every other adult in the household and 0.3 for every child younger than 14 . These modifications emerged from the research commissioned by Eurostat, "Poverty statistics in the late 1980s - Research based on micro data", particularly from sensitivity analyses of a variety of scales and their impact on rates and composition of poverty.

Equivalised net monetary income is derived by dividing the total net monetary income of the household by the number of 'adult equivalents'. Thus, a household with 2,100 ECUs per month and comprising 2 adults and 2 children will have an income of 1,000 ECUs per adult equivalised or, put another way, an equivalised income of 1,000 ECUs.

\section{Poverty line and poor households}

Average equivalised net monetary income is obtained by dividing the total net monetary income by the number of 'adult equivalents' in the population. $50 \%$ of that average, the arithmetic mean, is taken as a working definition of the poverty line. All households below this line are regarded as "poor".

\section{Purchasing Power Parity (PPP)}

Money incomes in national currencies across countries cannot be compared. Conversion could be done by the use of foreign exchange rates but exchange rates are affected by many factors and so they do not reflect relative purchasing power between countries. Studies are done in countries to see what a particular basket of goods and services, i.e. the same basket as far as possible, would cost. These studies give rise to PPPs, which convert every national monetary unit into a common reference currency of which every unit can buy the same amount of goods and services across the countries in a specific year.

The reference person in the household is usually the head of the household but not in all cases. The reference person was decided on the following order of criteria: the head if economically active; otherwise the head's spouse or partner, if economically active; otherwise the oldest economically active person. In a household without any economically active person, the head was automatically selected as the reference person.

\section{Labour market status}

The status chosen for the reference person is that which corresponded to the modal number of months in 1993. Thus, for example, if the person concerned was unemployed for 5 months in 1993, in training for 4 months and employed for 3 months, he or she would be classified as unemployed. 


\section{Eurostat}

Directorate E: "Social and Regional Statistics and geographical Information system"

For further Information:

Eric Marlier, Walter Wolf,

Tel: (352) 4301-35254

Fax: (352) 4301-34415

This report was prepared in the context of a study on Poverty carried out by Mr. Deo Ramprakash for Eurostat 


\title{
POVERTY MEASUREMENT IN INDONESIA
}

\author{
by \\ Agus Sutanto \\ Central Bureau of Statistics (CBS) \\ Indonesia
}




\title{
Poverty Measurement in Indonesia
}

\section{ChAPTER I}

\author{
Introduction
}

\subsection{Background and Objectives}

Since the first five-years national development plan (1969) Indonesian economy has experienced rapid growth. The average rate of economic growth in the 1970's has reached around 7,5 per annum. During the world economic recession in the eighties decade, the Indonesian economy recorded a growth rate of more than 5\% per annum. In early $1990 \mathrm{~s}$, the economy has again, reached a high growth rate of above $7 \%$ per annum.

Such high economic performance is accompanied by improvements in welfare of the people, including the low income group, as shown in the reduction of the number of people living below poverty line. Since the past thirty years the percentage of Indonesian population living below poverty line has declined significantly, from nearly $70 \%$ in 1969 to $11.34 \%$ in 1996 . To enhance the poverty alleviation programs, the government of Indonesia has placed new emphasis on such programs. Recently, the government has launched a new strategy of attacking poverty by specifically targeting the low income group. Policies and other measures are also directed toward enhancing the poverty alleviation program.

Such emphasis on poverty alleviation programs has increased demand for poverty and the related information. So far, the official data which are available are the type of macro data, such as poverty incidence data, poor village data, and general characteristics of poor people and poor village, which are compiled by Central Bureau of Statistics (CBS). A better planning and monitoring would require more sets of information, both with a macro perspective and micro one, and other indicators which are more sensitive to poverty phenomena, to able to show a number of important aspects of poverty.

The government of Indonesia has shown its strong commitment and placed high priority in reducing the number of poor people and narrowing the gap between the high income group and the low income group as outlined in the broad guidelines of state policy. Statistics on the magnitude and severity of poverty can provide direct evidence of the success of the economic growth in raising living standard of the poor. The statistics on poor village may help locate the poor, as the majority of people living in a poor village is likely to be poor.

The objective of this paper is to present a short summary of what the CBS has done in poverty measurement. The methodology for measuring the magnitude and severity of poverty is also explained. In addition, it describes the methodology for poor village identification. Current development in poverty measurement is also highlighted. 


\subsection{Poverty Concept}

Indonesia has compiled poverty statistics since 1984. Up to now, the poverty incidence data is available for the following years: 1976, 1978, 1980, 1981, 1984, 1987, 1990, 1993, and 1996. The poverty concept used in such measures has not been changed from time to time. It refers to the fulfilment of basic needs items, including both foods and non-food. However, in terms of methodology of measuring the minimum requirement, there has been some improvement.

Indonesia adopts a basic needs approach. Poor people is defined as those failing to meet the minimum standard of food necessities and minimum non food necessities. The minimum of food necessities is defined as equivalent to 2100 calorie per capita per day, based on the recommendation of the 1978 Food and Nutrition Seminar. For non-food, the minimum requirement is defined as the average consumption of the reference group, which is a group of people living just above the poverty line.

One problem with the concept used in the present indicator is quite clear. It refers to inability of the indicator to show the gap between the average income of the poor and the poverty line. Moreover, the present standard is practically still below a proper life standard. With the present standard, a person living above the poverty line cannot necessarily afford to enjoy social and other activities properly. To overcome such problems, CBS is now attempting to develop a new standard, which is expected to be able to represent a proper life standard, to complement the existing standard.

Alternative concepts have also been introduced by a number of researchers. Sayogyo (1974) also applied a basic need approach, but defined a poor person as a person having income equivalent to of less than $30 \mathrm{~kg}$ rice per capita per month, for urban, and less than 20 $\mathrm{kg}$ rice per capita per month, for rural. Sam F. Poli (1978), modifying Sayogyo's measure, arrived at an equivalent of $40 \mathrm{~kg}$ rice for urban, and $27 \mathrm{~kg}$ rice for rural. In spite of its simplicity, the rice equivalent poverty line, for one thing, suffers from the following problem. Overtime, consumption patterns changes, and so does the relative price. Such phenomena cannot be taken into account by the price of rice only.

Parera (1977) also based his poverty line on a number of essential food and non food

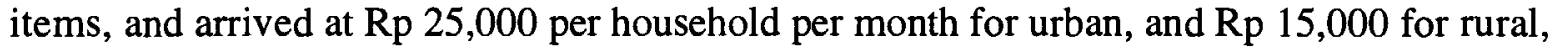
in 1976. World Bank criteria set the urban poverty line as much as $\$ 75$ for urban, and $\$ 50$ for rural. The World Bank concepts, however, disregard any changes in prices and in consumption patter, hence implies a lowering real standard.

With regard to poor village indicator, as a means of targeting, the accuracy of poor village data can always be debatable since the poor lives not only in poor villages, and not everybody in a poor village is poor. Efforts are also pursued toward developing a method for better targeting, by identifying poor people. 


\section{ChAPTER II}

\section{Data and Methodology}

\subsection{Source of Data}

The national household socio-economic survey (SUSENAS) serves as the major data used in measurement of poverty line. SUSENAS was carried out in 27 provinces in Indonesia using sample of around 65000 households spread over urban and rural areas. The basic data is used to calculate the amount of rupiah which meets exactly the 2100 calorie per capita per day. The value of the minimum basic non-food items such as housing, fuels, clothing, education, health and transportation is also estimated based on SUSENAS data. Furthermore, the incidence of poverty is computed based on SUSENAS data.

Data from special survey on prepared food (food consumption outside household) is also used besides the SUSENAS data. Survey on prepared food was carried out in the period January 1990-March 1991, in 27 provinces in Indonesia, covering both urban and rural areas, with a sample size of 2120 households per quarters. One of the objectives of this survey is to assess the ration between expenditure on prepared food consumed outside to the total expenditure as reported in the SUSENAS.

SUSENAS collects data on consumption of foods and beverages as well as non-food items in detailed. However, SUSENAS consumption data is suspected to suffer from underestimation due to memory laps error. Consequently, the average per capita expenses for food needed correction. Such correction was done by using the result of the prepared food survey. Population projection is also used in projecting the number of poor to the year end, as SUSENAS is carried out in February.

The 1993 as well as the 1996 methodology involves special survey on non-food essential commodity basket. The first survey was carried out in 1993 and the second one in 1996. The main objective of these surveys is to identify the essential non-food commodity consumed by population living just above the poverty line. The commodity bundle is then used to estimate the minimum non-food requirement to be used in the poverty line. The 1993 survey involved only 800 households, spread over 10 provinces. The later one was carried out throughout the country in 27 provinces, with around 4500 sample of households.

\subsection{Establishing Poverty Line}

The methodology used in measuring the 1990 poverty line is similar to that of the previous years. Poverty line is defined as the amount of rupiahs per capita per month spent to statisfy the minimum needs for food and non food. As mentioned before, the 2100 gram calorie criteria is based on the recommendation of the workshop of food and nutrition 1978. Non food expenditures comprise expenditures for housing, fuels, clothing, education, health 
and transportation, which have to be satisfied. The rupiah value of the 2100 calorie is estimated from SUSENAS. It is obtained by multiplying the implicit price of calorie (paid by the reference group) by 2100 . This rupiah value is then set as the food sufficiency line.

SUSENAS provides a table of the number of people by expenditure groups, which have been arranged in ascending order. Then the average per capita expenditure for food in each class is computed by dividing the amount spent for food by the number of population in each class. It is suspected that the average expenditure for food recorded by SUSENAS might not fully cover food consumed outside household, due memory lapse error. The result of the prepared food survey of 1990-1991 is used to adjust for such underestimation. SUSENAS gives a lower share of prepared food expenditure in the total food expenditure compared to the result of the prepared food survey. The difference between these two shares is the used as the bases for marking up the SUSENAS figure.

The price of the calories in each expenditure class is obtained by dividing the total amount of expenditure in each class by the amount of calories consumed. The figure shows that the higher the expenditure group is, the more expensive is the calories consumed. The next step is to divide the total expenditure by the price of the calories in respective class. The result shows the amount of calorie intake if one spends all of his money entirely to satisfy his needs for food. These figures hence, shows the degree of sufficiency in calorie intake. Through interpolation then the amount of average per capita expenditure per month which meets the 2100 calories requirement can be determined. This value represents the food sufficiency line.

To arrive at the poverty line, the value of expenditures for basic non-food items has to be added to this food sufficiency line. The minimum needs for non-food consists of housing, clothing, healthcare, education and transportation (Appendix 1). In 1990, the food sufficiency line is estimated at $\mathrm{Rp} 17,520$ for urban and $\mathrm{Rp} 12,617$ for rural. The non-food sufficiency line is $R p$ 3,094 for urban, and $R p 678$ for rural. The 1990 poverty line is, therefore, $\operatorname{Rp} 20,614$ for urban, and $\operatorname{Rp} 13,295$ for rural.

In the 1993 method, the rupiah value of the 2100 calorie obtained by first identifying the essential food commodity bundle which is equivalent to 2100 calorie. This is done by using SUSENAS data on food consumption. Selection of such commodities was carried out based on the percentage of household consuming the commodity, by also considering the budget share. A commodity which is consumed by only less than $15 \%$ of the households is dropped from the bundle, as it does not represent a commonly consumed commodity. Next, a number of commodities is then selected on the basis of its budget share: the higher budget share has a greater chance of being selected. As much as 52 food items was then selected. This bundle which is believed to best represent the consumption pattern of the reference group, is adjusted so that the calorie content is exactly 2100 calorie. The rupiah value of these commodities is then set as the food sufficiency line. Appendix 2 shows the 1993 food commodity bundle for Indonesia. 
The method makes no allowance to distinguish urban commodity bundle from rural as long as they are in the same province. Commodity bundle, however, differs from one province to another to reflect differences in consumption pattern among provinces.

With regard to the non-food line, the special survey on non-food essential commodity is used to assess the ratio of a selected non-food item to its respective group of commodities. For example, if child footwear is selected, the ratio of expenditure for child footwear to footwear is computed, to be applied to the SUSENAS data, as SUSENAS collects information not as detailed as what is collected through this special survey. This survey inquires information on non-food consumption in a more detailed manner than the SUSENAS because its main objective is to assess such ratios. Commodity is also selected based on the percentage of household consuming the commodity and the budget share. The 1993 method identifies as much as 46 non-food items as the basic necessities of the reference group. The value of these 46 commodities is then estimated using SUSENAS data, and the value represents the non-food line. The 1993 food commodity bundle is presented in Appendix 3.

Since the basic non-food commodity bundle survey is carried out with limited sample, of only 800 household spread over 10 provinces, it provides only the national estimate of the non-food line. For provincial level, it is assumed that the ratio of non-food consumption to total consumption of the reference group is the same for all provinces and is equal to the national level ratio.

In principle the 1996 method is the same with the 1993 method. The food sufficiency line is estimated by identifying the basic food bundle which is equivalent to 2100 . The 1993 commodity bundle is replaced with the 1996 bundle to allow for any shift in consumption pattern as well as the change in prices. The difference between the 1996 poverty line and the 1993 poverty line, therefore, represents both price changes and shift in consumption pattern. The 1996 commodity bundle also consists of 52 commodities. For some provinces, however, the number of commodities is slightly lower. Similar to the 1993 method, the bundle is the same for urban and rural, but they differ to some degree, from province to province, reflecting the corresponding consumption pattern. Appendix 4 represents the 1993 food commodity bundle.

The non-food sufficiency line is also determined based on basic non-food commodity bundle survey, which was carried out in 1995. The non-food commodities are selected based on the percentage of household consuming such items (applying a 15\% threshold) and on the budget share. Selected commodities are then grouped into 26 types of commodities, which covers clothing, housing, health services, education services, transportation, fuels, and other personal expenses. Since the 1995 basic non-food commodity bundle survey is based on larger sample, of around 4500 households spread over the 27 provinces, it provides estimate of basic non-food bundle for each province. The bundle differs from one province to another, and also, from urban to rural. Appendix 5 and 6 show the non-food commodity bundle for urban and for rural, respectively. 


\subsection{Measuring Poverty Incidence and Characteristics of the Poor}

In arriving at the number of people below the poverty line, an interpolation technique is applied. Having known the poverty line, and having a table of the number of people by expenditure class, interpolation gives the number of people living below the poverty line, and hence, the percentage of the poor. Given this percentage, an estimate of the number of people living below poverty line at the year end can be obtained based on the population projection. Table 1 presents the number of people living below poverty line since 1976 up to 1996 . Chapter 3 discusses the estimates of the poverty incidence.

Having identified the poor, characteristics of the poor can be assessed. SUSENAS data collects information on a number of social, economic, and demographic characteristics such as education level of head of household, main source of income, number of hou sehold members, sex of household head, working hours, and floor area. Characteristics of the poor are discussed on Chapter 4.

\subsection{Measuring Poverty Gap}

Head Count Index is the most commonly used poverty measure. It gives the proportion of the population living below the poverty line. This measure, however, does not indicate how poor the poor are. It is unchanged if a poor person becomes poorer. A transfer from a poor person to somebody else does not affect this measure.

One index which can reflect changes in the degree of poverty has been introduced by Foster, Greer and Thorbeck, known as FGT measure. One type of FGT measure, which is the Poverty Gap Index (FGT-P1) provides a good indication of changes in the degree of poverty. This is the average, over all households, of the gap between poor's income (expenditure) and the poverty line, expressed in percentage. This measure, therefore, shows the depth of the poverty. But this measure is not sensitive to the distribution of the poor, either.

The FGT-P2, which is another type of FGT measure, is a Distributionally Sensitive Index. It provides a distributionally sensitive measure. The FGT measure can serve as either a head count index, poverty gap index, or the distributionally sensitive index, based on the choice of a parameter $\alpha$. The larger is $\alpha$, the more sensitive index to the severity of poverty. To measure the severity of poverty, Indonesia adopts the Foster-Greer-Thorbecke (FGT) measure.

The FGT formula is as follows:

$$
P_{\alpha}=\frac{1}{n} \sum_{i=1}^{q}\left[\frac{z-y_{i}}{z}\right]^{\alpha} \Rightarrow \alpha=0,1,2
$$


$\mathrm{z}=$ poverty line

$\mathrm{y}_{\mathrm{i}}=$ average monthly per capita expenditure of persons below poverty line.

$$
\text { (i }=1,2, \ldots q), y_{i}<z
$$

$q=$ number of persons below poverty line

$\mathrm{n}=$ number of population

This formula applies 3 kinds of $\alpha$, giving 3 measures of $P_{\alpha}$, for $\alpha=0,1$ and 2. As already mentioned, the higher is the value of $\alpha$, the more this measure is becoming sensitive to measure the "depth" of the poverty.

For $\alpha=0$, this is simply the head count index, measuring the proportion of the population with a standard of living below the poverty line $\mathrm{P}_{0}=\frac{q}{n}$. For example if $11.4 \%$ of the population are classified as poor, then $\mathrm{P}_{0}=0.1134$.

$q=$ number of population below the poverty line

$\mathrm{n}=$ total number of the population

As this index measures only the percentage of people living below poverty line, one of its drawbacks is obvious. This measure, for example, does not indicate how poor the poor are. It is unchanged if a poor individual becomes poorer.

For $\mathrm{P}_{1}$ :

$$
P_{1}=\frac{1}{n} \sum_{i=1}^{g}\left[\frac{z-y_{i}}{z}\right]
$$

This index measures the gap between the average income of the poor and the poverty line. A value of $P_{1}=0.1$, for example, means that the overall average income of the poor is $10 \%$ below the poverty line.

For $\alpha=2$, this measure is sensitive to the distribution of income among the poor. It satisfies the main axioms for a desirable poverty measure, which requires that when a transfer is made from a person who is poor to someone who is also poor, the measure indicates a decrease in aggregate poverty.

The FGT-P2 measure can be explained as follows. With $\alpha$ entering a power of that ratio, then the higher the value of $\alpha$, the more this measure is sensitive to income gap, as the difference between income and poverty line is then taken to the power of $\alpha$. Let $y_{j}$ denote the per capita consumption of the $\mathrm{j}^{\text {th }}$ person. Let the population are ranked in ascending order of consumption (taking consumption per capita as the indicator). 
As mentioned before, the poverty line is $\mathrm{z}$ and let the poverty gap for individual $\mathrm{j}$ is $\mathrm{g}_{\mathrm{j}}=\mathrm{z}$ $y_{j}$. Total population is denoted as $n$, and $q$ is the number of poor people. The FGT-P2 may then be written as:

$P_{2}=\frac{1}{n} \sum_{j=1}^{q}\left[\frac{z-y_{j}}{z}\right]^{2}$

\subsection{Measuring Income Distribution}

Indonesia adopts the income distribution proposed by the World Bank and also applies Gini Coefficient measures. In measuring equity in income distribution, the World Bank classified the population into 3 groups: the lowest $40 \%$, the middle $40 \%$, and the highest $20 \%$.

The inequity is then measured based on the income of the lowest $40 \%$ group, expressed as percentage of the total income of the whole population. Inequality is said to be "high" if the percentage share is less than 12 percent. It is considered as "modest" if it is in the range of 12-17 percent, and "low" if it is above 17 percent.

Gini Ratio is another measure of income inequality, with values ranging between 0 and 1.0. The overall degree of inequality is low if the index is approaching zero. On the other hand, inequality is of high degree if the ratio is near one.

The problem with the income distribution measurement usually has to do with the income data. The reliability of data from various series on income is usually low. Indonesia uses expenditure data as a proxy of income.

\section{Chapter III}

\section{Poverty Incidence and Poverty Gap}

\subsection{Poverty Line}

Poverty line, as mentioned before, is the value of expenditure to cover the minimum for food commodity, equivalent to 2100 calorie per capita per day, plus the minimum needs for non-food, such as for housing, fuels, clothing, education, health and transportation. The value of the poverty line changes from one period to the other due to differences in prices and consumption pattern.

The 1976 poverty line is estimated at Rp. 4522 per month for urban, while for rural area the level of poverty line is lower, i.e. Rp. 2849 (Table 3.1). Hence a household of 5 
members in urban area needs at the minimum Rp. 22610 and in rural area Rp. 14245. Poverty line increased to Rp. 9777 in urban area and to Rp. 5877 in rural area in 1981. By 1990 , a person in urban area had to spend at least $\mathrm{Rp} 20614$, while in rural area, the poverty line was Rp. 13295. This means that within 5 years during the period 1976-1981 poverty line increased by $16.7 \%$ per annum in urban area, and by $15.6 \%$ in rural area.

Poverty line both in urban area increased at a decelerating rate during 1981-1990, increasing by $8.6 \%$ in urban, and by $9.5 \%$ in rural. During the $1990-1993$ period urban poverty line increased by $10.6 \%$, while rural poverty line increased by $11.1 \%$. During 1993 1996 period, urban poverty line increased by more or less the same speed as it was during 1990-1993. In rural area, however, the poverty line increased faster, i.e., by $14.5 \%$.

Thus, on average, the rate of increase of the poverty line is faster than inflation rate, both in urban and rural area. The higher poverty line reflects price increases as well as improvement in consumption pattern. Meanwhile, poverty line in rural area increases faster than that of urban area, reflecting a better standard of living in rural area, which is approaching that of urban.

Table 3.1 gives detail figures on poverty lines for the 1976-1990 period. The higher level of urban poverty line relative to the rural one is to be ascribed to the difference in consumption pattern of the people in respective area. The needs of rural people is typically fewer than that of urban people, and mostly consists of food.

For urban area, in 1996, Southeast Sulawesi has the lowest poverty line, while Jakarta and East Kalimantan constitute the highest. These two provinces also had the highest poverty line in 1993. The lowest in 1993 urban area was Central Sulawesi and Lampung. For rural, Central Sulawesi and South Sulawesi have the lowest poverty line in 1996, while East Kalimantan and Central Kalimantan are the highest. In 1993, the lowest poverty line for rural area was found in Lampung, while the highest was also found in East Kalimantan.

\subsection{Poverty Incidence}

Compared to 1976, both the number and percentage of the poor have decreased, reflecting the success of development in improving the standard of living of the lowest layer of the population. In 1976 the number of people below the poverty line was still 54.2 milliion or $40.08 \%$ of the total population. This number gradually declined to 30.0 milliion or $17.42 \%$ in 1987, while in 1990 the number of poor was around 27.2 million or approximately $15.08 \%$ of the population of Indonesia.

The decline in both the number and percentage was faster in rural area than in urban area. The number of poor has declined from 44.2 million in rural area in 1976, or $40.37 \%$, to 20.3 million or $16.44 \%$ in 1987. In 1990 there remained 17.8 million persons or about $14.33 \%$ (Table 3.1). During 1976-1990 the percentage of poor in urban area also declined continuously from $38.79 \%$ in 1976 to $20.14 \%$ in 1987 , and $16.75 \%$ in 1990 . In absolute 
number it went down slightly from 10.0 million in 1976 to 9.4 million in 1990 . Hence, urban poor declined slower than rural poor during the 1976-1990 period. Urban poor declined by less than $0.5 \%$ per annum, while rural poor declined by $5.4 \%$ per annum during 1976-1990.

Government has shown its high priority in the development programs related to agricultural sector, which notably dominates rural area. The fact that Indonesia achieved a self sufficiency in rice, in 1984 proved the relentless efforts which the government of Indonesia has put on the development of rural area. The better success in rural compared to urban area has also something to do with other programs related to development of small scale industry, and village co-operative establishments.

During 1993-1996 the number of poor declined faster than during the period 1990-1993, both in urban and in rural area. The number of poor in urban declined by $6.1 \%$ per annum during 1993-1996, hence faster than during 1990-1993, which declined by $2.5 \%$. For rural area, the rate of decline is $3.8 \%$ during 1993-1996, and 1.1\% during 1990-1993.

Thus, in contrary to the period of 1976-1990, the period after 1990 shows that urban poor decline faster than rural poor, although in terms of absolute number, the reduction in rural area is much higher than that in urban area. This is actually quite logical. In rural area, with the number of poor being much smaller after 1990, then it is more difficult in rural area to reduce the number of poor at the same rate as it was in the period before 1990 . With regard to urban area, since 1990, price stabilisation has been pursued much more intensively to dampen the effect of loose money policy launched in 1990. To some degree, such efforts affect the price changes in urban area, which is slightly lower in urban than in rural area, leading to a lower increase in the poverty line in urban than in rural.

Table 3.2-3.4 present the estimated number of the poor in each province for the year 1993 and 1996. The table shows that every province exhibit a decline in both the number of poor and the percentage of the poor. In terms of number of poor, West Java shows the largest reduction, with the number of poor declining by 650 thousands, followed by Central Java (dropped by 461 thousands) and East Java (fell by 377 thousands). Other provinces which experience significant drop are West Sumatera, South Sumatera, Central Kalimantan.

In terms of percentage of the poor, East Kalimantan experiences the largest drop, of around 9.6 per cent points. Other provinces which show a decline in the percentage of the poor by more than 4 per cent points are: West Sumatera, Jambi, South Sumatera, Bali, East Timor, South Kalimantan, East Kalimantan, and Maluku. Provinces in Sulawesi Island only experience slight reduction, probably because poverty level in these provinces are already quite low (around 8-10\% in 1996).

Indonesia places high priority to the development of the eastern part of Indonesia, which includes Kalimantan Island, Sulawesi Island, Nusa Tenggara Islands, Maluku, and Irian Jaya. As will be mentioned later in chapter V, in 1996, all villages in Maluku, Irian Jaya, 
East Timor, and East Nusa Tenggara, is liable for Rp. 20 million fund for developing small scale business for the poor. The success of such effort should reflect in the reduction in the number of poor in eastern part of Indonesia. The above figures, which show that provinces in Kalimantan and some other provinces in eastern part of Indonesia experience a significant reduction in the number of poor, thus, to some degree constitutes an evidence of the success of poverty alleviation program. Also, the fact that poverty level declined faster after 1993 than before, may indicate the success of the IDT program.

\subsection{The Severity of Poverty}

Improvement in welfare of the low level of income is shown in the persistent reduction of the number and percentage of people living below poverty line. The narrowing gap between average expenditure of people below poverty line and the poverty line provides stronger evidence that the level of income of the people below the poverty line has improved.

During the period 1987-1990 reduction of the number and percentage of the poor in urban area was not yet accompanied by a relative improvement in level of income of the poor, as shown by the widening gap between the average income of poor and the poverty line. The FGT-P1 measure which was 3.15 in 1987, increased to 3.23 in 1990 (Table 3.5). It means that the increase of the average income of people living below poverty line was lack behind the increase of the minimum standard of living. In rural area, however, the decline in poverty incidence was accompanied by the narrowing gap between the average income of the poor and the poverty line, with the poverty gap decreased from 2.83 in 1987 to 2.06 in 1990. Nationally, during 1987-1990 the poverty gap decreased from 2.92 to 2.42 .

The picture after 1990 shows persistent improvements in the poverty gap, both in urban and in rural area. Poverty gap declined to 2.23 and 1.59 in 1993 and 1996, respectively for urban area, while for rural area, the poverty gap fell to 1.99 in 1993 and 1.80 in 1996.

In terms of the distributionally sensitive index, the severity of poverty has declined persistently during 1987-1996. Nationally, the distributionally sensitive index declined from 0.95 in 1987 to 0.41 in 1996 for urban area, and from 0.76 to 0.43 for rural area.

\subsection{Income Distribution}

Table 3.6 shows that, measured in terms of income, the Gini ratio of Indonesia is much higher than if it is measured in terms of expenditure. In 1978 Gini ratio reached 0.4738 , and slightly decreased to 0.4448 in 1982 . The data, hence, indicates a quite high over all income inequality in Indonesia. Despite limitation in income data, it is quite convincing, since the problem with income data is most likely underestimates of the high income group.

Due to difficulty in collecting income data, CBS applies expenditure data as a proxy of income. The figures show significantly lower Gini Ratios if measured in terms of expenditure than in terms of income. The over all Gini Ratio was 0.32 in 1987. The data 
shows some interesting points. There has been a tendency for increasing income inequality since 1987. Gini Ratio has increased to 0.36 in 1996, compared to 0.32 in 1987 and 1990. Meanwhile, the urban-rural pattern has changed since the application of expenditure data. With income data, urban income inequality tends to be better than that of rural. With expenditure data, however, rural income inequality tends to be much better than urban. But such phenomena only confirms the severe problem of income distribution measurement if expenditure data is used, instead of income data. Rural people typically spend only on simple things, with less variety compared to urban population. Thus total expenditure tends to be more homogeneous in rural than in urban.

With regard to the World Bank criteria, the pictures show improving condition of the lowest 40\% until 1987, but worsening condition, although very slightly since 1990.

\section{Chapter IV}

\section{Characteristics of the Poor}

\subsection{Household Size}

Both urban and rural poor household show a larger size than non-poor household. In 1990 in urban area, every poor household has on the average 5.6 members, while in rural area the average number is 6.1 persons (Table 4.1). The overall urban and rural average number of household members is 5.9 persons, while non-poor households have less members, only 4.5 persons in urban cities and 4.1 persons in rural.

In 1996, household size has declined, with both poor and non-poor household having smaller household size. Urban poor household shows an average of 5.3 persons, while rural poor household has on average 5.4 persons. For non-poor household, the figures are 4.3 for urban, and 4.2 for rural.

\subsection{Sex of Head of Household}

In terms of the sex of the head of household, there is not much difference between poor and non poor household. Also, urban and rural household does not differ significantly. In 1996 around 88 to $89 \%$ of both poor household and non poor household in rural area is male-headed household and only around 11 to $12 \%$ is female headed household (Table 4.2). In urban area, the figure is around 87 to $88 \%$.

\subsection{Level of Education of Head of Household}

In general the level of education of most of the Indonesian population is still low. According to the 1990 Population Census, $73 \%$ of the total population aged 10 years and 
over had completed at the maximum primary school. Table 4.3 shows that majority of poor household head has level of education no higher than primary school, and the percentage of those who has finished junior high school is very minor.

In 1996 , more than $85 \%$ of urban poor household is headed by a person having education level at the maximum primary school. At level of education higher than senior high school, the percentage is low, around $6 \%$. In rural area, the picture is much worse, with only $1.5 \%$ having senior high school background or higher, and nearly $95 \%$ have level of education no higher than primary school. The figure for 1993 is worse compared to 1996.

\subsection{Source of Main Income}

As expected, the main source of income of Indonesian households is agricultural sector. Table 4.4 shows the dominance of the agricultural sector as a main source of income of poor households, both in urban and rural areas. Trade sector serves as the second most important source of income, followed by industrial sector.

In rural area, in 1996, around $80 \%$ of poor household relied on agricultural sector as the main source of income. Trade and manufacturing industry constitute less than $5 \%$ each. For urban, main source of income is more evenly distributed among industry, although agricultural sector still dominates, with around $25 \%$ or urban poor household relying on this sector as the main source of income. The percentage of those having trade and manufacturing industry as the main source of income is 19 and $11 \%$, respectively.

\subsection{Working Hour}

Table 4.5 shows that being poor has nothing to do with the hours of work. Poor people also work as long as the non-poor, the difference is not significant. In 1996, around $40 \%$ of urban poor head of household works more than 45 hours a week, while the percentage for non poor household is $43 \%$. The percentage of those working less than 15 hours per week is $20 \%$ for urban poor and $19 \%$ for urban non poor.

In rural, the figure shows that both poor and non-poor work shorter than those in urban area. Only $24 \%$ of poor household head working more than 45 hours per week. There is also a tendency that in rural area, the poor work shorter than the non-poor, but the evidence is not very convincing.

The picture for 1993 seems better than that of 1996, with both poor and non-poor household working longer in 1993 than in 1996. Between poor and non-poor, the difference is also more convincing. But this is due to the data, which refers to total working hours, including additional jobs, for 1993, while it refers only to working hours in the main job, for 1996. 


\section{CHAPTER V}

\section{Other Poverty Data than Issues}

\subsection{Poor Village Identification}

To enhance the poverty alleviation program in helping the millions still below the poverty line, the government of Indonesia initiated a new strategy bsed on specific targeting in 1993. The government, through the IDT (Inpress Desa Tertinggal) program, which is Presidential Instruction on Poor Village Development, provides financial assistance to the poor living in the poor villages. This program then started in 1994.

Efforts have been made to identify poor village, as it is believed that majority of people in a poor village are poor. Thus, poor village identification is carried out to locate the poor people. In early 1993, based on the Village Potency Data of 1990, then Central Bureau of Statistics developed a methodology for poor village identification. Due to time constraint, the method was quite simple, and hence suffers from a number of problems. This method has been modified in 1994.

In the 1993 method, as much as 27 indicators were used, for urban village, and 28 indicators were used for rural village. Those indicators were selected based on their simple correlation with the per capita expenditure in a village. Those indicators comprise of indicators on village infrastructure, demographic characteristics of the people, and housing condition. Each indicator was scored relying more on judgement. Total score of a village is then compared to the average score in the respective province. Thus, each province applies different standard. Provided that the total score of a village is far below the standard, which is represented by the mean minus 1 standard deviation, then the village is tentatively classified as poor.

To arrive at a better conclusion, second and third criteria were applied. According to the second criteria, a village is classified as poor if its total score is less than the value of the quartile of the respective province. The third criteria is based on the perception of the head of subdistricts. To be more reliable, this perception has been confronted with independent observation of CBS field staffs. Provided that at least two of these three criteria classify a village as poor, than the village is finally classified as poor.

Such method results in 20633 poor village out of 65554 villages in Indonesia in 1993, hence around $33 \%$ of Indonesian villages were classified as poor village. This data was then used as a basis for allocating financial assistance, as much as $\mathrm{Rp} 20$ million rupiahs, or around $\$ 9000$ per poor village for three consecutive years. This fund is meant for developing small business for the poor, and not meant for infrastructure. Small groups of poor people were then established in every poor village. The government provide financial assistance, a person to help develop small business for the poor, and established the related 
organizational structure and mechanism, under the IDT program. In addition, to enhance the development of poor village, a new program called Development of Poor Village Infrastructure Program was initiated.

The 1993 methodology suffers from the following problems. Some variables are not sensitive and difficult to measure. Indicator about "the presence of primary school", for example, is not sensitive, as every village, including poor village has at least one primary school. "Crude death rate", "crude birth rate", and "enrollment ratio" at a village level are difficult to measure. More over, scoring was based more on judgement, and did not rely on statistical test. In addition, the use of "the presence of public facilities", instead of "access to public facilities" as indicators are believed to be less accurate, since what important is actually the access, not the presence.

Improvement of the methodology was done in 1994, based on the 1993 village potency data. Under this method, variables are scored and selected based statistical test. For this purpose, the per capita expenditure is used as the reference data. Thus indicators, for example, population density, and percentage of household having a TV set, are broken down into a number of classes based on their correlation with the reference data. If the statistical test suggest that the mean of per capita expenditure of two classes are significantly different, then there is a reason to separate those two classes. Indicators are assigned scores, also based on the value of the reference data. Other improvement refers to the use of access to public facilities, instead of the presence of public facilities. Variables were selected based on multiple correlation test.

The 1994 method involves 17 indicators for urban, and 18 indicators for rural. Theoretically, around 41000 villages are classified as poor under this method. Around 2000 villages which were classified poor by the 1993 method, turned out to be non poor according to the 1994 method. The 1994 is believed to be superior in terms of methodology, and is believed to be able to identify poor village more accurately than the previous method.

However, since the government has committed to provide poor village financial assistance for three consecutive years, then all villages which have been classified poor by the 1993 method, were still considered in the program, and were given financial assistance, irrespective of whether or not they are classified as poor by the new method. Due to budget limitations, only the lowest layer of the villages found to be poor by the 1994 method would be added into the program. As much as 3916 new poor villages then entered into the program in 1994. Some villages which entered into the program earlier, however, were not given the second financial assistance, i.e., if they have only less than 50 household in the village. The government applied a criteria as follows: a village with only less than 50 household is liable only for one year financial assistance, a village with the number of household between 50 and 100 is liable for two consecutive years financial assistance, while a village with 100 household or more is liable for three consecutive years financial assistance. 
Applying such criteria, as much as 22094 poor villages were found in 1994. As much as 20498 poor villages are those which have been identified in 1993 (135 out of 20633 villages were found merged with others), 3916 new poor villages (based on the 1994 method), while as much as 2320 poor villages were no longer liable for financial assistance for having only less than 50 household in a village. These 22094 poor village started receiving financial assistance in 1995.

Latest development shows higher priorities given by the government to the eastern part of the country. Since 1996, every village in the following provinces were considered into the program, irrespective of whether according to the 1994 method they are either poor or non poor: East Nusa Tenggara, East Timor, Maluku, and Irian Jaya. In addition, all villages in very remote areas were also considered into the program. For this purpose, the Governor of each province were asked to provide information about remote villages which have not been touched by the IDT program, to be considered into the program. After taking out the villages which were no longer liable for additional financial assistance (due to the number of household), in 1996 it was found as much as 22054 villages which were liable for financial assistance.

\subsection{Establishing a Comfortable Living Standard}

As already mentioned, the present poverty indicator suffers from its inability to show the severity of poverty. This problem, however, can be overcome by applying the FGT measures. The present indicator, however, also suffer from another limitation. With the present standard, which is a minimum food consumption equivalent to 2100 calorie and minimum non food standard - set based on the consumption pattern of the nearly poor people- is clearly below a proper live standard. In other words, a person having income above the poverty line currently defined, is not necessarily able to perform his social activities with ease. Those having living standard just above the poverty line typically live in a very tight budget, and not very likely to be able to perform his activities comfortably.

Entering the seventh national development plan, it is time to attract more policy concerns on this matter. CBS attempts to develop a new standard, higher than present standard to complement the present standard of poverty to be used as a means of targeting for the future. Such standard would be able to indicate the number of people, which though are no longer poor, but still living below a comfortable living standard.

CBS plans to do a survey on middle income groups in major big cities, to study their consumption pattern. It is assumed that being able to consume and enjoy goods and services as much as good as what these population consume, would make a person life comfortable. An in-depth study inquiring the life style of the middle income group will also be conducted to complement the survey. These efforts are expected to be able to provide a list of goods and services of proper standard to be used in constructing the comfortable living standard. 


\subsection{Poor People Identification}

The stronger commitment of the government to alleviate poverty problem has increased demand for detailed information. The Ministry of Planning has initiated a village data base for the basis of planning and monitoring. An even stronger demand appear in the form of information about who is poor and non poor.

The Ministry of Population and Family Planning has initiated an effort to identify nonprosperous family. The concept used is however, very different from the poverty concept adopted by the country. The concept used in this non prosperous family program identification refers to Maslow's theory, which stratifies people needs into 5 levels, based on social welfare approach. The main purpose of non prosperous family identification is to identify the problem facing each family, so that treatment can be given correctly. A study done by CBS (1995) shown that these two concepts are significantly different. A large portion of those considered non-prosperous family turned out to be non poor under the poverty concept, and a significant portion of those classified as non-prosperous family are still poor according to the present poverty concept.

In the absence of information about who is poor in a village, the non prosperous family data is often used despite differences in the concepts. Answering to such a strong demand, CBS attempts to conduct a study to develop a method for identifying poor people. It is believed that a number of simple questions would be able to identify whether or not a person is poor. Such questions may take the following form:

1. Frequency of having meet in their dishes.

2. The way they purchase rice, sugar, cooking oil: whether daily?

3. Condition of the house: non permanent, floor area per person.

4. The income: whether falls under the lowest class.

5. Etc.

In addition to such simple questions, respondent will also be asked detailed information as asked in the SUSENAS, to be able to classify them into poor or non poor as currently defined. Statistical tests are expected to be able to reveal whether criteria used for poor people identification consistent with the formal concept of poverty.

\subsection{IDT Program Monitoring}

IDT program has been launched since 1994. The Ministry of Planning has initiated a number of studies and efforts to monitor the progress of the small business run by the poor. Most studies are basically in-depth studies meant for finding out problems for better solution. A macro type of criteria which shows the success of the program in general is not yet available. Such criteria is very important to measure the success in general. 
Since 1995 CBS has done a study to develop a criteria for monitoring the success of the implementation of the IDT program. This study has been continued in 1996, and in 1997. With great enthusiasm, at least two provinces (DKI Jakarta, and East Java) have initiated to apply the criteria of success to evaluate the implementation of IDT program in their own province.

In principle, CBS established a criteria of success in economic sense. This criteria is based on information such as:

1. Whether the small business is still running.

2. Whether the family already enjoyed the profit.

3. Whether problems seem to be able to be overcome.

4. Whether the family has bought household appliances, simple furniture, perform simple housing repair using the profit of the small business.

5. Whether asset is higher than its initial value.

A poor family is then to be classified into one of these four level of impacts:

1. Fail.

2. Not yet showing an impact.

3. Showing a limited impact.

4. Showing a significant impact.

In order to test the validity and sensitivity of the criteria, a number of hypotheses were tested, such as:

1. A poor family with a poorer background tends to be less successful.

2. A proper assistance from the village leader, group leader, and other related assistance would enhance the success.

3. A better village infrastructure and climate would enhance the success.

4. A proper selection of the small business (matching with the family skill) would enhance the success.

5. Etc.

The studies (1995 and 1996) shows that such hypotheses tend to be supported by the data. This findings leads to a tentative conclusion that the criteria so established is on the right track and can be further tested using a wider range of sample. The 1995 study was carried out in 4 provinces, using around 2200 sample of poor household small business. The 1996 study involves 4200 poor household small business, spread over in 6 provinces. The 1997 study is planned to be conducted in 10 provinces with around 8000 poor household small business. 


\section{Chapter VI}

\section{Recommendations}

The needs for helping the millions of poor improve their standard of living is very urgent. It is therefore important to establish a certain simple standard as a means of policy targeting. The success of the poverty alleviation program should be judged, partly, on the basis of the number of people living below such standard. Meanwhile, efforts have to be done to improve the present measurement, and enriched information regarding the poverty alleviation endeavors.

International comparison of standards among countries is important, and very ideal, but it should not be done at the expense of national interest of alleviating poverty as soon as possible. After all, characteristics and the needs differ from country to country.

It is important to supplement such simple poverty standard with other measures of poverty to reveal other problems which the simple standard may not be able to identify. Such information is very important to draw more government attention.

In addition to absolute poverty measures, relative measures are very urgent, as it may be able to show whether income gap is widening. In the case of problems of collecting income data, an in-depth study may help. Such study for example, may be able to show the income gap between the lower layer of employee and the high rank manager. Basically, any information which may draw more government attention is recommended. 


\section{Table 3.1 Poverty Line, and Poverty Incidence, 1976-1996}

\begin{tabular}{|c|c|c|c|c|c|c|c|c|}
\hline \multirow{3}{*}{$\begin{array}{l}\text { Year } \\
(1)\end{array}$} & \multicolumn{2}{|c|}{ poverty ino } & \multicolumn{3}{|c|}{ Percentage Below roventy the } & \multicolumn{3}{|c|}{ polory yoldence (wilion) } \\
\hline & Urban & Rural & Urban & Pural & torant Rtrat & orban & Rorat & Orban+hural \\
\hline & $(2)$ & $(3)$ & (4) & $(5)$ & $(6)$ & 17 & $(8)$ & 19 \\
\hline 1976 & 4522 & 2849 & 38.79 & 40.37 & 40.08 & 10.0 & 44.2 & 54.2 \\
\hline 1978 & 4969 & 2981 & 30.84 & 33.38 & 33.31 & 8.3 & 38.9 & 47.2 \\
\hline 1980 & 6831 & 4449 & 29.04 & 28.42 & 28.56 & 9.5 & 32.8 & 42.3 \\
\hline 1981 & 9777 & 5877 & 28.06 & 26.49 & 26.85 & 9.3 & 31.3 & 40.6 \\
\hline 1984 & 13731 & 7746 & 23.14 & 21.18 & 21.64 & 9.3 & 25.7 & 35.0 \\
\hline 1987 & 17381 & 10294 & 20.14 & 16.14 & 17.42 & 9.7 & 20.3 & 30.0 \\
\hline 1990 & 20614 & 13295 & 16.75 & 14.33 & 15.08 & 9.4 & 17.8 & 27.2 \\
\hline 1993 & 27905 & 18244 & 13.45 & 13.79 & 13.67 & 8.7 & 17.2 & 25.9 \\
\hline 1996 & 38426 & 27413 & 9.71 & 12.30 & 11.34 & 7.2 & 15.3 & 22.5 \\
\hline
\end{tabular}


Table 3.2 Poverty Incidence by Province, 1993-1996.

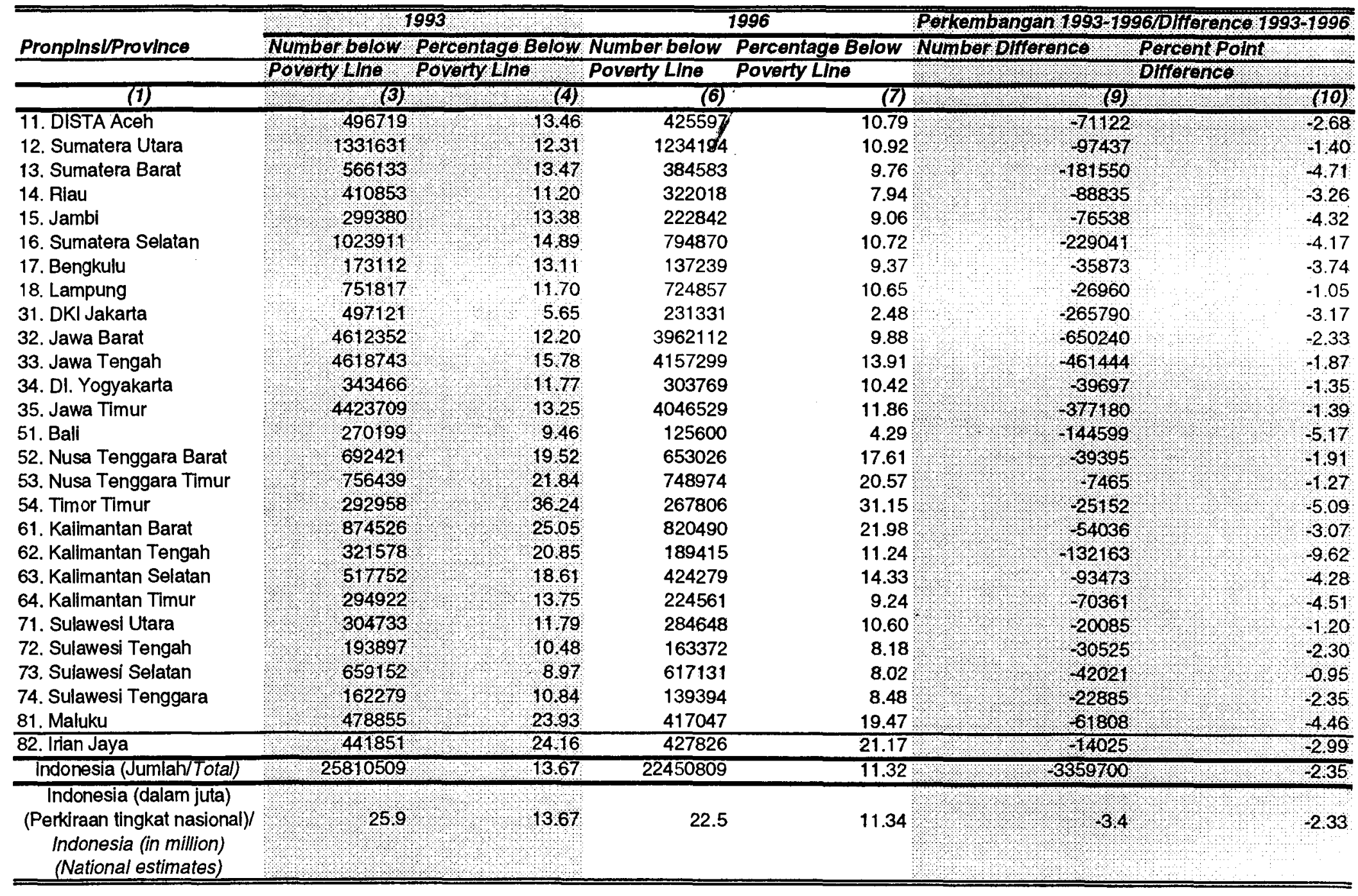


Table 3.3 Poverty Incidence by Province, 1993-1996

\begin{tabular}{|c|c|c|c|c|c|c|c|c|c|}
\hline \multirow{4}{*}{ Prompinsi/Province } & \multicolumn{3}{|c|}{$1993, \quad$ } & \multicolumn{3}{|c|}{1996} & \multicolumn{3}{|c|}{ Difference $1993-1996$} \\
\hline & \multirow{2}{*}{\multicolumn{3}{|c|}{ 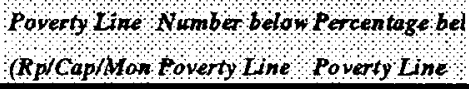 }} & \multirow{2}{*}{\multicolumn{3}{|c|}{$\begin{array}{l}\text { Number below Percentage be. } \\
\text { Poverty Line Poverty Line }\end{array}$}} & \multirow{2}{*}{\multicolumn{3}{|c|}{ 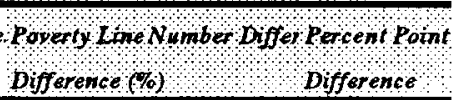 }} \\
\hline & & & & & & & & & \\
\hline & $(2)$ & $(3)$ & (4) & (5) & $(6)$ & (7) & $(8)$ & (9) & $(10)$ \\
\hline 11. DISTA Aceh & 29020 & 6919 & 1013 & 38701 & 67625 & 7.86 & 3336 & 2294 & 227 \\
\hline 12. Sumatera Utara & 26822 & 494479 & 1172 & 40356 & 457037 & 9.51 & $\$ 0,46$ & 3742 & 221 \\
\hline 13. Sumatera Barat & 27535 & 84073 & 8.6 & 42445 & 64434 & 5.58 & 5426 & 19639 & $3,0 s$ \\
\hline 14. Riau & 31846 & 81589 & 6.6 & 41807 & 72280 & 5.10 & 3128 & 9309 & 155 \\
\hline 15. Jambi & 28507 & 57030 & 1022 & 37229 & 56543 & 8.04 & 30,60 & 487 & 218 \\
\hline 16. Sumatera Selatan & 33484 & 39785 & 1932 & 43934 & 267594 & 11.81 & 31,21 & 130263 & 2751 \\
\hline 17. Bengrulu & 2906 & 32067 & 10,26 & 35798 & 25307 & 6.40 & 20,14 & 6760 & 3,86 \\
\hline 18. Lampung & 22374 & 101382 & 1162 & 34105 & 105241 & 9.32 & 32,43 & 2,41 & 2,30 \\
\hline 31. DKI Jakarta & 39530 & 497121 & 5.65 & 50280 & 231331 & 2.48 & 2719 & 265790 & 317 \\
\hline 32. Jawa Barat & 30559 & 2327139 & 15,5 & 41688 & 1879653 & 10.50 & 36,42 & 447486 & 8,05 \\
\hline 33. Jawa Tengah & 24204 & 1525901 & 1736 & 35712 & 1283073 & 12.97 & 4753 & 242828 & -439 \\
\hline 34. DI. Yogyakarta & 28367 & 222303 & 1435 & 35841 & 207881 & 11.66 & 26,35 & 14422 & 269 \\
\hline 35. Jawa Timur & 26680 & 1704433 & 16,85 & 36452 & 1520902 & 13.43 & 36.63 & 183531 & 3,42 \\
\hline 51. Bali & 30066 & 106092 & 188 & 38801 & 60960 & 5.75 & 2905 & 4132 & 6,13 \\
\hline 52. Nusa Tenggara Bara & 25503 & 141751 & 2198 & 33918 & 136269 & 19.11 & 33.00 & 5482 & 2287 \\
\hline 53. Nusa Tenggara Timu & 28862 & 73278 & 1637 & 31796 & 72708 & 13.73 & 3325 & 570 & 2,64 \\
\hline 54. Timor Timur & 29780 & 14814 & $20+8$ & 43657 & 11598 & 13.60 & 46,60 & 3216 & 7,18 \\
\hline 61. Kalimantan Barat & 33864 & 130801 & 1784 & 47589 & 94605 & 11.49 & 40,53 & 36196 & 66,35 \\
\hline 62. Kalimantan Tengah & 35261 & 51823 & 1636 & 47507 & 26416 & 6.62 & 3473 & 25407 & -9.74 \\
\hline 63. Kalimantan Selatan & 34107 & 113929 & 1411 & 43987 & 100734 & 10.99 & 28,97 & 1319 & 312 \\
\hline 64. Kalimantan Timur & 40012 & 116681 & 1003 & 49761 & 64233 & 5.22 & 2437 & 82488 & 5,1 \\
\hline 71. Sulawesi Utara & 25600 & 52288 & 8,10 & 35064 & 44665 & 6.12 & 3697 & 1623 & 108 \\
\hline 72. Sulawesi Tengah & 22166 & 27842 & 363 & 31234 & 21194 & 4.58 & 40,91 & 6648 & 3,05 \\
\hline 73. Sulawesi Selatan & 25024 & 257162 & 13.04 & 36281 & 241230 & 10.75 & 4498 & 15932 & 229 \\
\hline 74. Sulawesi Tenggara & 24210 & 26555 & 875 & 28689 & 26510 & 6.80 & 18.50 & 45 & -195 \\
\hline 81. Maluku & 91872 & 36123 & 806 & 37472 & 34342 & 6.17 & 175 & 1781 & 189 \\
\hline 82. Irian Jaya & 33060 & 56675 & 1231 & 45486 & 48824 & 9.27 & 3759 & $\$ 851$ & 304 \\
\hline Indonesia (Jumlah/Total) & & 8807107 & 1345 & & 7223189 & 9.81 & & 1583918 & 3,64 \\
\hline $\begin{array}{l}\text { Indonesia (in million) } \\
\text { (Narional estimases) }\end{array}$ & 27905 & 87 & 19445 & 38246 & 7.2 & 9.71 & & 1 & 374 \\
\hline
\end{tabular}


Table 3.4 Poverty Incidence by Province, 1993.1996

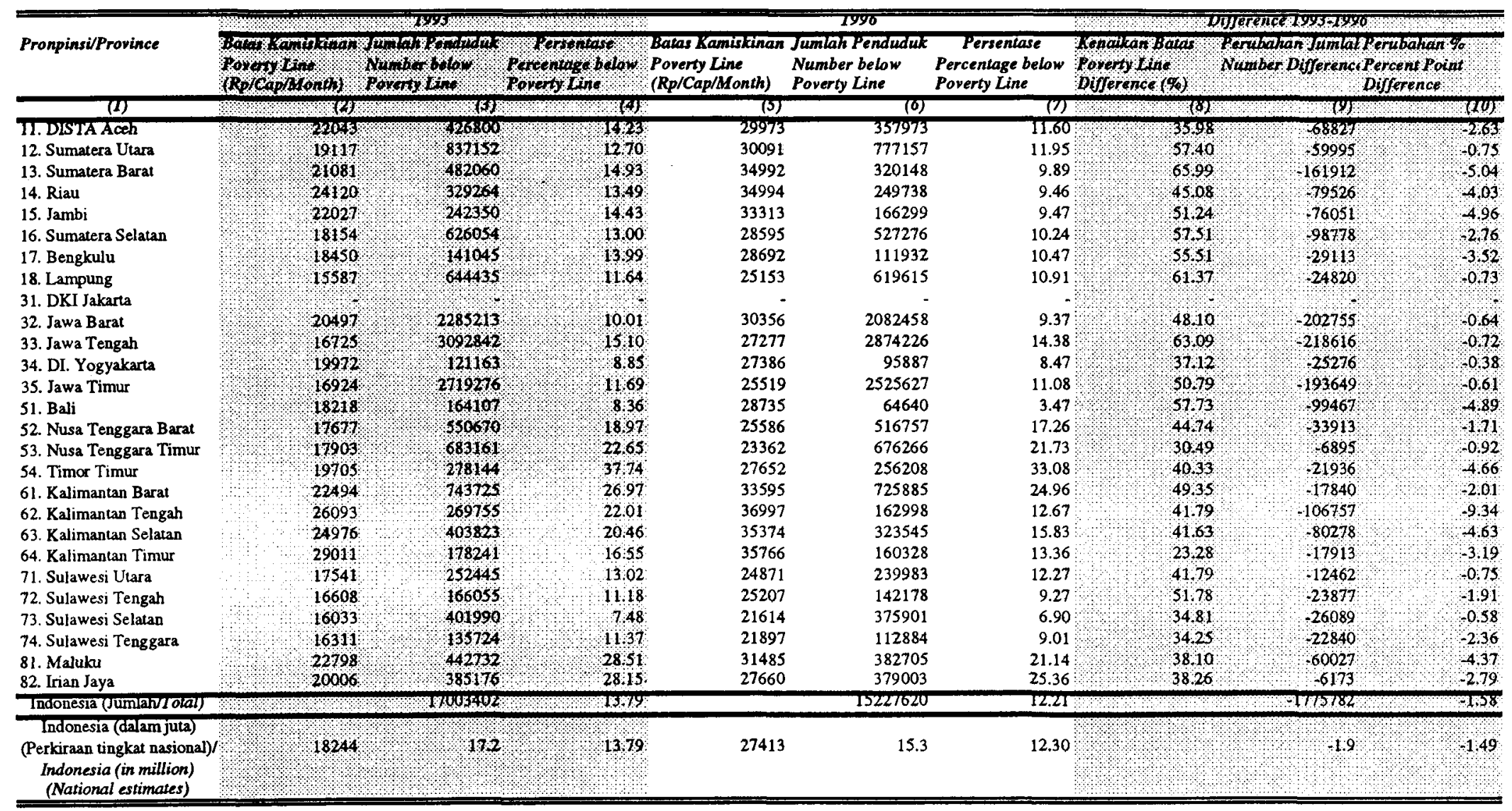


Table 3.5 Severity of Poverty by FGT Measures 1987 - 1996

\begin{tabular}{|c|c|c|c|c|}
\hline FGT Poverty Measures & 1987 & 1990 & 1993 & 1996 \\
\hline (1) & (2) & (3) & (4) & (5) \\
\hline \multicolumn{5}{|l|}{1 Head Count Index $(P o)$} \\
\hline $\begin{array}{l}\text { - Urban } \\
\text { - Rural }\end{array}$ & $\begin{array}{l}20.14 \\
16.44\end{array}$ & $\begin{array}{l}16.75 \\
14.33\end{array}$ & $\begin{array}{l}13.03 \\
12.64\end{array}$ & $\begin{array}{c}9.66 \\
12.00\end{array}$ \\
\hline - Urban + Rural & 17.42 & 15.08 & - & - \\
\hline \multicolumn{5}{|l|}{2 Poverty Gap Index (P1) } \\
\hline $\begin{array}{l}\text { - Urban } \\
\text { - Rural }\end{array}$ & $\begin{array}{l}3.15 \\
2.83 \\
2.92\end{array}$ & $\begin{array}{l}3.23 \\
2.06 \\
2.49\end{array}$ & $\begin{array}{l}2.23 \\
1.99\end{array}$ & $\begin{array}{l}1.59 \\
1.80\end{array}$ \\
\hline \multicolumn{5}{|c|}{$\begin{array}{l}2 \text { Distributionally Sensitive Index } \\
(P 2)\end{array}$} \\
\hline $\begin{array}{l}\text { - Urban } \\
\text { - Rural } \\
\text { - Urban + Rural }\end{array}$ & $\begin{array}{l}0.95 \\
0.76 \\
0.81\end{array}$ & $\begin{array}{l}0.94 \\
0.53 \\
0.66\end{array}$ & $\begin{array}{c}0.61 \\
0.50 \\
-\end{array}$ & $\begin{array}{c}0.41 \\
0.43 \\
-\end{array}$ \\
\hline
\end{tabular}

Source: Processed from SUSENAS data 
Table 3.6 Gini Ratio and World Bank Criteria, 1978-1996

\begin{tabular}{|l|r|r|r|r|r|r|}
\hline $\begin{array}{l}\text { Gini Ratio/ } \\
\text { World Bank } \\
\text { Criteria }\end{array}$ & 1978 & 1982 & 1987 & 1990 & 1993 & 1996 \\
\hline Gini Ratio & & & & & & \\
Urban & 0.4075 & 0.3799 & 0.3187 & 0.3376 & 0.33 & 0.3624 \\
Rural & 0.4764 & 0.4353 & 0.2638 & 0.2519 & 0.26 & 0.2736 \\
Urban + Rural & 0.4738 & 0.4448 & 0.3216 & 0.3213 & 0.34 & 0.3557 \\
& & & & & & \\
& & & & & & \\
World Bank & & & & & & \\
Criteria & 18.13 & 19.55 & 20.87 & 21.31 & 20.33 & 20.25 \\
Lowest 40\% & 36.53 & 38.28 & 37.48 & 36.75 & 36.91 & 35.05 \\
Middle 40\% & 45.34 & 42.27 & 41.65 & 41.94 & 42.76 & 44.70 \\
Highest 20\% & & & & & & \\
\hline
\end{tabular}


Table 4.1 Average number of household members, 1990-1996

\begin{tabular}{|l|r|r|r|r|r|r|}
\hline Area & \multicolumn{2}{|c|}{ Poor } & \multicolumn{2}{|c|}{ Non-Por } & \multicolumn{2}{|c|}{ All Households } \\
\cline { 2 - 7 } & 1990 & 1996 & 1990 & 1996 & 1990 & 1996 \\
\hline & & & & & & \\
Urban & 5.6 & 5.3 & 4.5 & 4.3 & 4.7 & 4.6 \\
Rural & 6.1 & 5.4 & 4.1 & 4.1 & 4.4 & 4.2 \\
Urban + & 5.9 & 5.3 & 4.3 & 4.2 & 4.5 & 4.3 \\
Rural & & & & & & \\
\hline
\end{tabular}

Source: SUSENAS 1990 and 1996.

Table 4.2 Percentage Number of Households by Sex of the Heads of Household 1993-1996

\begin{tabular}{|l|r|r|r|r|r|r|}
\hline $\begin{array}{l}\text { Sex of the head of } \\
\text { households }\end{array}$ & \multicolumn{2}{|c|}{ Urban } & \multicolumn{2}{c|}{ Rural } & \multicolumn{2}{c|}{ Urban + Rural } \\
\cline { 2 - 6 } & 1993 & 1996 & 1993 & 1996 & 1993 & 1996 \\
\hline & & & & & & \\
Poor household & 86.6 & 87.7 & 88.2 & 89.4 & 87.7 & 88.9 \\
Male & 13.4 & 12.3 & 11.8 & 10.6 & 12.3 & 11.1 \\
Female & 100.00 & 100.00 & 100.00 & 100.00 & 100.00 & 100.00 \\
Sub-total & & & & & & \\
& & & & & & \\
Non-poor & & & & & & \\
household & 87.2 & 87.1 & 87.4 & 87.9 & 87.3 & 87.6 \\
Male & 12.9 & 12.9 & 12.6 & 12.1 & 12.7 & 12.4 \\
Female & 100.00 & 100.00 & 100.00 & 100.00 & 100.00 & 100.00 \\
\hline Sub-total & & & &
\end{tabular}

Source: SUSENAS 1993 and 1996 
Table 4.3 Percentage of Poor Households by Level of Education of Household Head, 1993-1996

\begin{tabular}{|l|r|r|r|r|r|r|}
\hline \multirow{2}{*}{ Level of education } & \multicolumn{2}{|c|}{ Urban } & \multicolumn{2}{c|}{ Rural } & \multicolumn{2}{c|}{ Urban + Rural } \\
\cline { 2 - 7 } & \multicolumn{1}{|c|}{1993} & \multicolumn{1}{c|}{1996} & \multicolumn{1}{c|}{1993} & 1996 & 1993 & 1996 \\
\hline Not completed primary & 57.0 & 51.6 & 72.0 & 66.0 & 67.1 & 61.5 \\
school & 31.4 & 34.2 & 24.3 & 28.5 & 26.6 & 30.3 \\
Primary school & 7.0 & 8.1 & 2.8 & 4.0 & 4.2 & 5.3 \\
Junior high & 4.6 & 6.2 & 0.8 & 1.5 & 2.1 & 3.0 \\
school & & & & & & \\
Senior high school or & 100 & 100 & 100 & 100 & 100 & 100 \\
higher & & & & &
\end{tabular}

Source: SUSENAS 1993 and 1996

Table 4.4 Percentage of Households by Main Source of Income 1993-1996

\begin{tabular}{|c|c|c|c|c|c|c|}
\hline \multirow{2}{*}{ Source of income } & \multicolumn{2}{|c|}{ Urban } & \multicolumn{2}{|c|}{ Rural } & \multicolumn{2}{|c|}{ Urban + Rural } \\
\hline & 1993 & 1996 & 1993 & 1996 & 1993 & 1996 \\
\hline Agricultu & 25.6 & 26.1 & 79.5 & 79.2 & 62.0 & 62 \\
\hline Industry & 12.1 & 11.2 & 5.2 & 4.6 & 7.4 & 6. \\
\hline Trade & 21.6 & 19.3 & 5.0 & 4.7 & 10.4 & 9. \\
\hline Services \& & 40.7 & 43.4 & 10.3 & 11.5 & 19.6 & 21 \\
\hline Total & 100 & 100 & 100 & 100 & 100 & 100 \\
\hline
\end{tabular}


TABLE 4.5 Percentage Number of Households by Working Hour 1993 - 1996

\begin{tabular}{|l|r|r|r|r|r|r|}
\hline \multirow{2}{*}{ Working Hour } & \multicolumn{2}{|c|}{ Urban } & \multicolumn{2}{c|}{ Rural } & \multicolumn{2}{c|}{ Urban + Rural } \\
\cline { 2 - 6 } & \multicolumn{1}{|c|}{1993} & \multicolumn{1}{|c|}{1996} & \multicolumn{1}{c|}{1993} & 1996 & 1993 & 1996 \\
\hline & & & & & & \\
Poor Household & & & & & & \\
$<15$ hour & 7.8 & 20.4 & 9.2 & 14.4 & 8.7 & 16.3 \\
$15-29$ & 15.0 & 12.4 & 22.8 & 21.4 & 20.3 & 18.6 \\
$30-45$ & 27.4 & 28.0 & 33.8 & 40.3 & 31.7 & 36.5 \\
$>45$ & 49.8 & 39.3 & 34.3 & 23.9 & 39.3 & 28.7 \\
Total & 100 & 100 & 100 & 100 & 100 & 100 \\
\hline Non Poor Households & & & & & & \\
$<15$ hour & 5.0 & 19.3 & 8.8 & 15.9 & 7.6 & 17.1 \\
$15-29$ & 7.8 & 7.9 & 20.2 & 18.3 & 16.1 & 14.5 \\
$30-45$ & 28.9 & 29.8 & 33.8 & 35.9 & 32.2 & 33.7 \\
$>45$ & 58.3 & 43.1 & 37.4 & 30.0 & 44.1 & 34.7 \\
Total & 100 & 100 & 100 & 100 & 100 & 100 \\
\hline
\end{tabular}


Appendix 1. The 1990 Non-Food Commodity Bundle

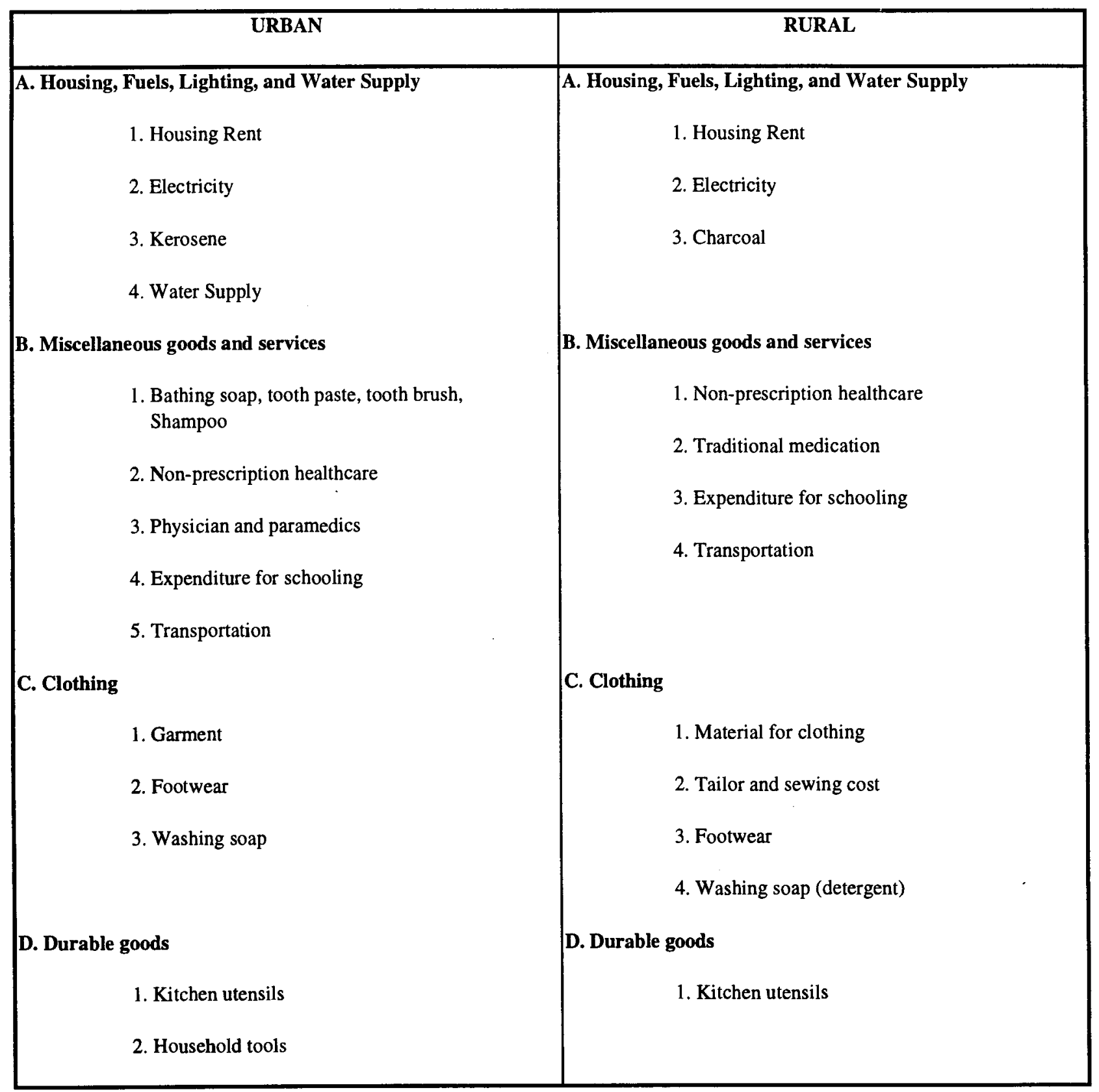


Appendix 2. The 1993 Food Commodity Bundle

\begin{tabular}{|c|c|c|c|}
\hline No. & Commodity & $\begin{array}{l}\text { Expenditure per c } \\
\text { Urban }\end{array}$ & $\begin{array}{l}\text { er month } \\
\text { Rural }\end{array}$ \\
\hline 1 & Local Rice & 4530.7 & 3618.64 \\
\hline 2 & Classified Rice & 2751.44 & 3036 \\
\hline 3 & Imported Rice & 113.01 & 112.34 \\
\hline 4 & Glutinous Rice & 24.66 & 46.06 \\
\hline 5 & Corn & 12.04 & 168.98 \\
\hline 6 & Wheat flour & 99.87 & 49.9 \\
\hline 7 & Cassava & 121.45 & 185.87 \\
\hline 8 & Sweat potato & 73.59 & 91.37 \\
\hline 9 & Dried cassava & 1.41 & 35.39 \\
\hline 10 & Sago flour & 9.01 & 24.14 \\
\hline 11 & Tuna fish & 283.16 & 125.58 \\
\hline 12 & Cakalang fish & 92.14 & 53.28 \\
\hline 13 & Indian Mackerel & 396.66 & 137.31 \\
\hline 14 & Milk fish & 373.45 & 118.72 \\
\hline 15 & Anchovies & 201.8 & 197.27 \\
\hline 16 & Beef & 1031.39 & 198.15 \\
\hline 17 & Pork & 97.59 & 91.17 \\
\hline 18 & Domestic chicken & 351.75 & 319.15 \\
\hline 19 & Bones with a bit meat & 106.68 & 16.11 \\
\hline 20 & Chicken eggs & 1167.11 & 476.41 \\
\hline 21 & Duck eggs & 96 & 130.11 \\
\hline 22 & Canned milk & 426.27 & 114.99 \\
\hline 23 & Dried canned milk & 685.33 & 72.95 \\
\hline 24 & Spinach & 237.95 & 133.62 \\
\hline 25 & Swamp cabbage & 192.87 & 116.85 \\
\hline 26 & String beans & 220.31 & 200.49 \\
\hline 27 & Cassava leaves & 75.56 & 127.76 \\
\hline 28 & Cayenne pepper & 223.81 & 255.1 \\
\hline 29 & Peanuts & 137.46 & 101.06 \\
\hline 30 & Tofu & 664.26 & 308.09 \\
\hline 31 & Fermented soybean cake & 705.77 & 400.59 \\
\hline 32 & Fermented peanuts cake & 13.67 & 12.52 \\
\hline 33 & Oranges & 348.41 & 60.15 \\
\hline 34 & Pineapple & 30.76 & 30.82 \\
\hline 35 & Ambon banana & 248.27 & 112 \\
\hline 36 & Papaya & 178.96 & 53.51 \\
\hline 37 & Coconut oil & 579.78 & 503.1 \\
\hline 38 & Coconut & 319.11 & 324.12 \\
\hline 39 & Margarine & 63.26 & 4.01 \\
\hline 40 & Cane sugar & 1346.07 & 985.36 \\
\hline 41 & Tea & 230.03 & 138.37 \\
\hline 42 & Coffee (powder) & 415.51 & 241.85 \\
\hline 43 & Salt & 95.14 & 89.43 \\
\hline 44 & Candlenuts & 103.54 & 55.42 \\
\hline 45 & Fish paste & 103.31 & 96.11 \\
\hline 46 & Brown sugar & 154.42 & 138.72 \\
\hline 47 & Chips & 246.21 & 110.41 \\
\hline 48 & Noodle & 288.59 & 102.72 \\
\hline 49 & Bread & 250.6 & 31.4 \\
\hline 50 & Dried bread & 274.03 & 105.92 \\
\hline 51 & Filtered cigarette & 2471.73 & 1100.35 \\
\hline \multirow[t]{2}{*}{52} & Tobacco & 36.99 & 216.41 \\
\hline & TOTAL & 23302.89 & 15576.15 \\
\hline
\end{tabular}


Appendix 3. The 1993 Non-Food Commodity Bundle

\begin{tabular}{|c|c|c|c|}
\hline \multirow[t]{2}{*}{ No. } & \multirow{2}{*}{ Commodity } & \multicolumn{2}{|c|}{ Expenditure per capita per month } \\
\hline & & Urban & Rural \\
\hline \multirow{4}{*}{$\mathbf{I}$} & A. Housing, Fuels, lighting, and water supply & 1748 & 835 \\
\hline & Housing & 161 & 44 \\
\hline & Housing rent & 96 & 0 \\
\hline & Housing maintenance & 65 & 44 \\
\hline 2 & Fuels & 1039 & 606 \\
\hline 3 & Lighting & 395 & 105 \\
\hline 4 & Water supply & 113 & 51 \\
\hline \multirow[t]{4}{*}{5} & Other housing expenses & 40 & 30 \\
\hline & Matches & 40 & 30 \\
\hline & B. Goods and services & 1927 & 493 \\
\hline & Bathing supplies & 225 & 140 \\
\hline 6 & Bating soap & 118 & 74 \\
\hline \multirow[t]{2}{*}{7} & Tooth paste & 107 & 65 \\
\hline & Beauty care & 63 & 43 \\
\hline 8 & Hairtonic & 26 & 20 \\
\hline \multirow[t]{2}{*}{9} & Powder & 37 & 23 \\
\hline & Hair care & 53 & 32 \\
\hline \multirow[t]{2}{*}{10} & Hair cut & 53 & 32 \\
\hline & Health care & 149 & 73 \\
\hline 11 & Public Health Center & 25 & 14 \\
\hline 12 & Physician \& paramedics & 67 & 28 \\
\hline \multirow[t]{2}{*}{13} & Non prescription health care & 57 & 31 \\
\hline & Expenditure for schooling & 151 & 81 \\
\hline 14 & School fee and tuition & 91 & 42 \\
\hline 15 & Books & 37 & 21 \\
\hline \multirow[t]{2}{*}{16} & Stationers & 22 & 17 \\
\hline & Transportation & 348 & 104 \\
\hline 17 & Bus, Train. other 4 wheel vehicle & 300 & 82 \\
\hline \multirow[t]{2}{*}{18} & Tricycle, cart, 2 wheel vehicle & 48 & 23 \\
\hline & Recreation & 7 & 3 \\
\hline 19 & Movies & 7 & 3 \\
\hline & Other goods and services & 32 & 19 \\
\hline 20 & Tooth brush & 24 & 14 \\
\hline $2 \mathrm{I}$ & Photo & 8 & 5 \\
\hline & C. Clothing, Footwear, hat, uniforms & 1412 & 969 \\
\hline 22 & Adult male garment & 283 & 222 \\
\hline 23 & Adult female garment & 297 & 223 \\
\hline 24 & Child garment & 305 & 219 \\
\hline 25 & Adult male footwear & 91 & 53 \\
\hline 26 & Adult female footwear & 62 & 33 \\
\hline 27 & Chile footwear & 89 & 57 \\
\hline 28 & Soap and detergent & 252 & 144 \\
\hline 29 & Other clothing, footwear, and hat & 33 & 18 \\
\hline & Tooth brush & 15 & 12 \\
\hline & Others (handkershift, etc.) & 18 & 6 \\
\hline & D. Durable goods & 113 & 111 \\
\hline & Household furniture & 6 & 2 \\
\hline 30 & Radio cassette & 5 & 2 \\
\hline 31 & Cassette & 1 & 0 \\
\hline & Household & 25 & 21 \\
\hline 32 & Mattress & 7 & 8 \\
\hline 33 & Pillows & 2 & 1 \\
\hline 34 & Bedsheets and pillowcases & 13 & 9 \\
\hline 35 & Mattress & 3 & 3 \\
\hline & Household tools & 22 & 22 \\
\hline 36 & Broom & 17 & 15 \\
\hline 37 & Knife, scissors, etc. & 5 & 7 \\
\hline & Kitchen utensils & 51 & 59 \\
\hline 38 & Stove & 13 & 7 \\
\hline 39 & Plate & 21 & 27 \\
\hline 40 & Spoon, fork, glass, etc. & 12 & 17 \\
\hline 41 & Other utensils & 5 & 8 \\
\hline & Light goods & 9 & 7 \\
\hline 42 & Bag, including school bag & 9 & 7 \\
\hline & E. Tax and insurance & 86 & 77 \\
\hline 43 & Land and building tax & 51 & 55 \\
\hline 44 & Other fee & 35 & 22 \\
\hline & F. Party and ceremonies & 216 & 181 \\
\hline 45 & Religion ceremonies & 128 & 87 \\
\hline 46 & Traditional ceremonies & 88 & 94 \\
\hline & TOTAL & 4602 & 2668 \\
\hline
\end{tabular}


Appendix 4. The 1996 Food Commodity Bundle

\begin{tabular}{|c|c|c|c|c|c|c|}
\hline \multirow[t]{2}{*}{ COMMODITY } & \multicolumn{2}{|c|}{$\begin{array}{l}\text { Volume per capita } \\
\text { per month }\end{array}$} & \multicolumn{2}{|c|}{$\begin{array}{l}\text { Value per capita } \\
\text { per month }\end{array}$} & \multicolumn{2}{|c|}{ Calorie } \\
\hline & Urban & Rural & Urban & Rural & Urban & Rural \\
\hline 1. Domestic rice & 5.180 & 5.247 & 4972 & 4758 & 616.43 & 624.36 \\
\hline 2. Classified rice & 3.272 & 3.836 & 3137 & 3457 & 400.85 & 469.90 \\
\hline 3. Imported rice & 0.155 & 0.159 & 145 & 149 & 18.70 & 19.19 \\
\hline 4. Glutinous rice & 0.009 & 0.023 & 11 & 24 & 1.14 & 2.71 \\
\hline 5. Corn & 0.020 & 0.328 & 10 & 138 & 2.13 & 34.94 \\
\hline 6. Wheat flour & 0.042 & 0.033 & 40 & 33 & 4.66 & 3.65 \\
\hline 7. Cassava & 0.396 & 0.853 & 108 & 188 & 17.26 & 37.23 \\
\hline 8. Sweet potato & 0.156 & 0.225 & 57 & 72 & 6.52 & 9.38 \\
\hline 9. Dried cassava & 0.005 & 0.090 & 2 & 38 & 0.54 & 10.17 \\
\hline 10. Sago flour & 0.013 & 0.082 & 7 & 44 & 1.49 & 9.29 \\
\hline 11. Tuna fish & 0.128 & 0.111 & 305 & 211 & 3.86 & 3.34 \\
\hline 12. Indian Mackerel & 0.124 & 0.084 & 297 & 152 & 3.40 & 2.30 \\
\hline 13. Milk fish & 0.056 & 0.026 & 175 & 69 & 1.94 & 0.89 \\
\hline 14. Anchovies & 0.350 & 0.480 & 164 & 181 & 2.69 & 3.69 \\
\hline 15. Beef & 0.024 & 0.007 & 234 & 56 & 1.64 & 0.47 \\
\hline 16. Pork & 0.005 & 0.018 & 27 & 86 & 0.67 & 2.51 \\
\hline 17. Domestic chicken & 0.031 & 0.048 & 141 & 205 & 3.15 & 4.86 \\
\hline 18. Bones with a bit meat & 0.007 & 0.001 & 33 & 5 & 0.30 & 0.05 \\
\hline 19. Chicken eggs & 0.339 & 0.165 & 820 & 394 & 15.49 & 7.55 \\
\hline 20. Dug eggs & 0.243 & 0.282 & 57 & 64 & 1.01 & 1.18 \\
\hline 21. Canned milk & 0.129 & 0.038 & 239 & 73 & 5.75 & 1.70 \\
\hline 22. Dried canned milk & 0.010 & 0.002 & 93 & 16 & 1.66 & 0.36 \\
\hline 23. Spinach & 0.292 & 0.297 & 193 & 157 & 1.11 & 1.13 \\
\hline 24. Swamp cabbage & 0.335 & 0.313 & 182 & 139 & 1.88 & 1.76 \\
\hline 25. String bean & 0.251 & 0.308 & 188 & 196 & 2.31 & 2.83 \\
\hline 26. Tomato & 0.875 & 0.541 & 120 & 68 & 0.55 & 0.34 \\
\hline 27. Cassava leaves & 0.168 & 0.447 & 76 & 162 & 3.56 & 9.46 \\
\hline 28. Onion & 1.374 & 1.226 & 393 & 338 & 1.61 & 1.43 \\
\hline 29. Chilies & 0.700 & 0.510 & 430 & 285 & 0.62 & 0.45 \\
\hline 30. Cayenne pepper & 0.630 & 0.869 & 195 & 246 & 1.84 & 2.54 \\
\hline 31. Peeled peanuts & 0.033 & 0.026 & 73 & 53 & 5.03 & 3.96 \\
\hline 32. Tofu & 0.502 & 0.323 & 538 & 337 & 13.38 & 8.62 \\
\hline 33. Fermented soybean cake & 0.540 & 0.396 & 611 & 435 & 25.73 & 18.89 \\
\hline 34. Rambutan & 0.175 & 0.073 & 212 & 76 & 1.61 & 0.68 \\
\hline 35. Zalacca & 0.101 & 0.048 & 107 & 42 & 4.54 & 2.14 \\
\hline 36. Ambon banana & 0.157 & 0.178 & 139 & 105 & 3.37 & 3.82 \\
\hline 37. Papaya & 0.208 & 0.151 & 101 & 58 & 2.39 & 1.73 \\
\hline 38. Coconut oil & 0.375 & 0.329 & 621 & 538 & 86.9 & 76.21 \\
\hline 39. Coconut & 0.691 & 1.055 & 306 & 358 & 30.76 & 46.95 \\
\hline 40. Cane sugar & 6.393 & 5.860 & 970 & 916 & 77.57 & 71.11 \\
\hline 41. Brown sugar & 0.673 & 0.775 & 102 & 110 & 8.45 & 9.74 \\
\hline 42. Tea & 0.494 & 0.420 & 195 & 151 & 2.17 & 1.85 \\
\hline 43. Coffee (powder) & 0.508 & 0.450 & 326 & 259 & 5.96 & 5.28 \\
\hline 44. Salt & 1.342 & 1.511 & 84 & 92 & & \\
\hline 45. Candlenuts & 0.224 & 0.146 & 90 & 58 & 4.76 & 3.10 \\
\hline 46. Fish paste & 0.304 & 0.341 & 94 & 97 & 2.53 & 2.84 \\
\hline 47. Crips & 0.577 & 0.404 & 153 & 93 & 8.71 & 6.10 \\
\hline 48. Instant Noodles & 1.408 & 0.604 & 438 & 184 & 16.71 & 7.16 \\
\hline 49. Sweeten bread & 1.215 & 0.841 & 181 & 116 & 6.54 & 4.53 \\
\hline 50. Dried bread & 0.238 & 0.136 & 114 & 59 & 3.38 & 1.93 \\
\hline 51. Cookies & 3.229 & 2.492 & 295 & 181 & 14.8 & 11.42 \\
\hline 52. Filtered cigarrette & 2.193 & 1.170 & 1894 & 885 & & \\
\hline TOTAL & & & 20495 & 17207 & 1450 & 1557.72 \\
\hline Equivalent to 2100 calorie & & & 29681 & 23197 & & \\
\hline Total commodities & & & 52 & 52 & & \\
\hline
\end{tabular}


Appendix 5. The 1996 Non-Food Commodity Bundle

Indonesia - Urban

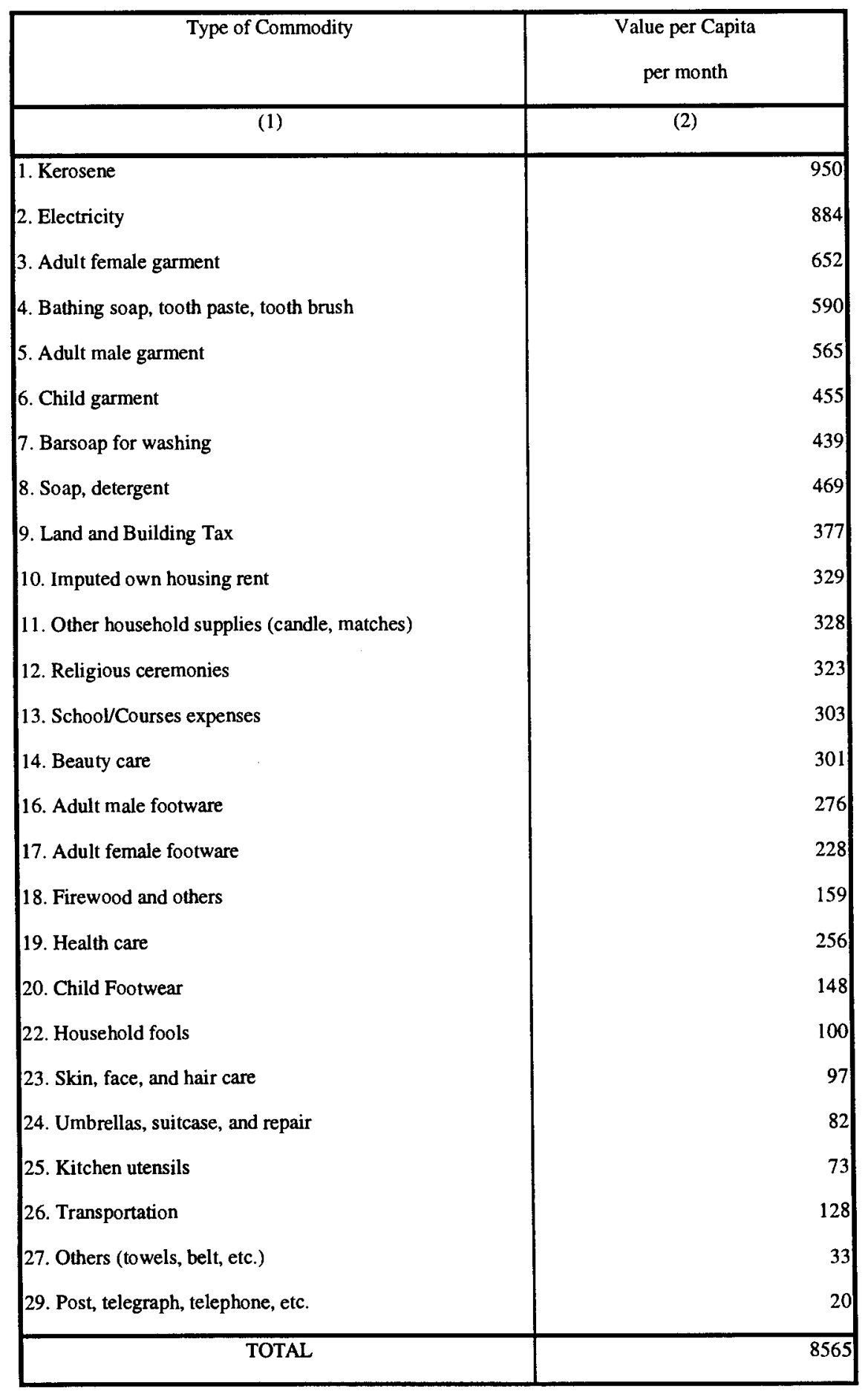


Appendix 6. The 1996 Non-Food Commodity Bundle

Indonesia - Rural

\begin{tabular}{|c|c|}
\hline Type of Commodity & $\begin{array}{l}\text { Value per Capita } \\
\text { per month }\end{array}$ \\
\hline (1) & $(2)$ \\
\hline 1. Firewood and others & 705 \\
\hline 2. Kerosene & 422 \\
\hline $\begin{array}{l}\text { 3. Bathing soap, tooth paste, tooth } \\
\text { brush } \\
\text { 4. Child garment }\end{array}$ & $\begin{array}{l}358 \\
336\end{array}$ \\
\hline 5. Adult male garment & 246 \\
\hline 6. Soap, detergent & 228 \\
\hline 7. Adult female garment & 227 \\
\hline $\begin{array}{l}\text { 8. Other household supplies (candle, } \\
\text { matches) } \\
\text { 9. Electricity }\end{array}$ & $\begin{array}{l}195 \\
178\end{array}$ \\
\hline 10. Religious ceremonies & 163 \\
\hline 11. School/Courses expenses & 175 \\
\hline 12. Health care & 146 \\
\hline 13. Beauty care & 108 \\
\hline 14. Adult male footware & 118 \\
\hline 15. Barsoap for washing & 114 \\
\hline 16. Kitchen utensils & 37 \\
\hline 17. Land and Building Tax & 103 \\
\hline 18. Child footwear & 101 \\
\hline 19. Adult female footwear & 67 \\
\hline 20. Skin, face, and hair care & 49 \\
\hline 21. Household fools & 29 \\
\hline 22. Others (towel, belt, etc.) & 16 \\
\hline 23. Transportation & 35 \\
\hline 24. Post, telegraph, telephone, etc. & 5 \\
\hline 25. Housing & 55 \\
\hline TOTAL & $\overline{4216}$ \\
\hline
\end{tabular}


Appendix 7. Foodline, Non-Food line, and Poverty line, 1996

\begin{tabular}{|c|c|c|c|c|c|c|}
\hline \multirow[t]{2}{*}{ Province } & \multicolumn{3}{|c|}{ Rural } & \multicolumn{3}{|c|}{ Urban } \\
\hline & Food & Non Food & $\begin{array}{c}\text { Poverty } \\
\text { line }\end{array}$ & Food & Non Food & $\begin{array}{l}\text { Poverty } \\
\text { line }\end{array}$ \\
\hline (1) & (2) & (3) & (4) & (5) & (6) & (7) \\
\hline DISTA ACEH & 25494 & 4479 & 29973 & 32795 & 5906 & 38701 \\
\hline SUMATERA UTARA & 24989 & 5102 & 30091 & 33110 & 7246 & 40356 \\
\hline SUMATERA BARAT & 29646 & 5346 & 34992 & 35517 & 6928 & 42445 \\
\hline RIAU & 29524 & 5470 & 34994 & 35080 & 6727 & 41807 \\
\hline JAMBI & 28436 & 4877 & 33313 & 31632 & 5597 & 37229 \\
\hline SUMATERA SELATAN & 24544 & 4051 & 28595 & 36703 & 7231 & 43934 \\
\hline BENGKULU & 24304 & 4388 & 28692 & 30012 & 5786 & 35798 \\
\hline LAMPUNG & 21086 & 4067 & 25153 & 28353 & 5752 & 34105 \\
\hline DKIJAKARTA & & & - & 38324 & 11956 & 50280 \\
\hline JAWA BARAT & 25460 & 4896 & 30356 & 32696 & 8992 & 41688 \\
\hline JAWA TENGAH & 22812 & 4465 & 27277 & 28528 & 7184 & 35712 \\
\hline D.I JOGJAKARTA & 22711 & 4675 & 27386 & 29326 & 6515 & 35841 \\
\hline JAWA TIMUR & 21513 & 4006 & 25519 & 28899 & 7553 & 36452 \\
\hline BALI & 22634 & 6101 & 28735 & 30279 & 8522 & 38801 \\
\hline N.T.B. & 21545 & 4041 & 25586 & 28296 & 5622 & 33918 \\
\hline N.T.T. & 19400 & 3962 & 23362 & 26341 & 5455 & 31796 \\
\hline TIMOR TIMUR & 23331 & 4321 & 27652 & 36688 & 6969 & 43657 \\
\hline KALIMANTAN BARAT & 27885 & 5710 & 33595 & 39456 & 8133 & 47589 \\
\hline KALIMANTAN TENGAH & 31658 & 5339 & 36997 & 40199 & 7308 & 47507 \\
\hline KALIMANTAN SELATAN & 29773 & 5601 & 35374 & 36920 & 7067 & 43987 \\
\hline KALIMANTAN TIMUR & 29547 & 6219 & 35766 & 41097 & 8664 & 49761 \\
\hline SULAWESI UTARA & 20769 & 4102 & 24871 & 28046 & 7018 & 35064 \\
\hline SULAWESI TENGAH & 20916 & 4291 & 25207 & 24965 & 6269 & 31234 \\
\hline SULAWESI SELATAN & 18522 & 3092 & 21614 & 29217 & 7064 & 36281 \\
\hline SULAWESI TENGGARA & 18888 & 3009 & 21897 & 24157 & 4532 & 28689 \\
\hline MALUKU & 26533 & 4952 & 31485 & 31526 & 5946 & 37472 \\
\hline IRIAN JAYA & 23355 & 4305 & 27660 & 36794 & 8692 & 45486 \\
\hline
\end{tabular}


Appendix 8. Composition of Poverty Line

\begin{tabular}{|c|c|c|c|c|c|}
\hline \multirow[t]{2}{*}{ Province } & \multicolumn{2}{|c|}{ Food Line } & \multicolumn{2}{|c|}{ Non Food Line } & \multirow[t]{2}{*}{ Total } \\
\hline & Rural & Urban & Rural & Urban & \\
\hline (1) & (2) & (3) & (5) & (6) & (7) \\
\hline DISTA ACEH & 85.06 & 84.74 & 14.94 & 15.26 & 100 \\
\hline SUMATERA UTARA & 83.04 & 82.04 & 16.96 & 17.96 & 100 \\
\hline SUMATERA BARAT & 84.72 & 83.68 & 15.28 & 16.32 & 100 \\
\hline RIAU & 84.37 & 83.91 & 15.63 & 16.09 & 100 \\
\hline JAMBI & 85.36 & 84.97 & 14.64 & 15.03 & 100 \\
\hline SUMATERA SELATAN & 85.83 & 83.54 & 14.17 & 16.46 & 100 \\
\hline BENGKULU & 84.71 & 83.84 & 15.29 & 16.16 & 100 \\
\hline LAMPUNG & 83.83 & 83.13 & 16.17 & 16.87 & 100 \\
\hline DKIJAKARTA & & 76.22 & & 23.78 & 100 \\
\hline JAWA BARAT & 83.87 & 78.43 & 16.13 & 21.57 & 100 \\
\hline JAWA TENGAH & 83.63 & 79.88 & 16.37 & 20.12 & 100 \\
\hline D.I JOGJAKARTA & 82.93 & 81.82 & 17.07 & 18.18 & 100 \\
\hline JAWA TIMUR & 84.30 & 79.28 & 15.70 & 20.72 & 100 \\
\hline BALI & 78.77 & 78.04 & 21.23 & 21.96 & 100 \\
\hline N.T.B & 84.21 & 83.42 & 15.79 & 16.58 & 100 \\
\hline N.T.T & 83.04 & 82.84 & 16.96 & 17.16 & 100 \\
\hline TIMOR TIMUR & 84.37 & 84.04 & 15.63 & 15.96 & 100 \\
\hline KALIMANTAN BARAT & 83.00 & 82.91 & 17.00 & 17.09 & 100 \\
\hline KALIMANTAN TENGAH & 85.57 & 84.62 & 14.43 & 15.38 & 100 \\
\hline KALIMANTAN SELATAN & 84.17 & 83.93 & 15.83 & 16.07 & 100 \\
\hline KALIMANTAN TIMUR & 82.61 & 82.59 & 17.39 & 17.41 & 100 \\
\hline SULAWESI UTARA & 83.51 & 79.99 & 16.49 & 20.01 & 100 \\
\hline SULAWESI TENGAH & 82.98 & 79.93 & 17.02 & 20.07 & 100 \\
\hline SULAWESI SELATAN & 85.69 & 80.53 & 14.31 & 19.47 & 100 \\
\hline SULAWESI TENGGARA & 86.26 & 84.20 & 13.74 & 15.80 & 100 \\
\hline MALUKU & 84.27 & 84.13 & 15.73 & 15.87 & 100 \\
\hline IRIAN JAYA & 84.44 & 80.89 & 15.56 & 19.11 & 100 \\
\hline
\end{tabular}


Appendix 9. Rate of Change of Food Line, Non-Food Line, and Poverty Line, 1993-1996

Urban

\begin{tabular}{|c|c|c|c|c|c|c|c|c|c|}
\hline \multirow{3}{*}{$\frac{\text { Province }}{\text { (1) }}$} & \multicolumn{3}{|c|}{1993} & \multicolumn{3}{|c|}{1996} & \multicolumn{3}{|c|}{ Rate of Growth per year } \\
\hline & Food & Non Food & Poverty Line & Food & Non Food & Poverty Line & Food & Non Food & overty Line \\
\hline & (2) & (3) & (4) & (5) & (6) & (7) & (8) & (9) & (10) \\
\hline DISTA ACEH & 24,234 & 4,786 & 29,020 & 32,795 & 5,906 & 38,701 & 10.61 & 7.26 & 10.07 \\
\hline SUMATERA UTARA & 22,399 & 4,423 & 26,822 & 33,110 & 7,246 & 40,356 & 13.91 & 17.88 & 14.59 \\
\hline SUMATERA BARAT & 22,977 & 4,538 & 27,515 & 35,517 & 6,928 & 42,445 & 15.62 & 15.15 & 15.55 \\
\hline RIAU & 26,594 & 5,252 & 31,846 & 35,080 & 6,727 & 41,807 & 9.67 & 8.60 & 9.50 \\
\hline JAMBI & 23,806 & 4,701 & 28,507 & 31,632 & 5,597 & 37,229 & 9.94 & 5.98 & 9.31 \\
\hline SUMATERA SELATAN & 27,962 & 5,522 & 33,484 & 36,703 & 7,231 & 43,934 & 9.49 & 9.40 & 9.48 \\
\hline BENGKULU & 24,882 & 4,914 & 29,796 & 30,012 & 5,786 & 35,798 & 6.45 & 5.60 & 6.31 \\
\hline LAMPUNG & 18,684 & 3,690 & 22,374 & 28,353 & 5,752 & 34,105 & 14.91 & 15.95 & 15.09 \\
\hline DKIJAKARTA & 33,011 & 6,519 & 39,530 & 38,324 & 11,956 & 50,280 & 5.1 & 22.40 & 8.35 \\
\hline JAWA BARAT & 25,519 & 5,040 & 30,559 & 32,696 & 8,992 & 41,688 & 8.61 & 21.29 & 10.91 \\
\hline JAWA TENGAH & 20,212 & 3,992 & 24,204 & 28,528 & 7,184 & 35,712 & 12.17 & 21.64 & 13.84 \\
\hline DI. YOGYAKARTA & 23,689 & 4,678 & 28,367 & 29,326 & 6,515 & 35,841 & 7.38 & 11.67 & 8.11 \\
\hline JAWA TIMUR & 22,280 & 4,400 & 26,680 & 28,899 & 7,553 & 36,452 & 9.06 & 19.73 & 10.96 \\
\hline BALI & 25,108 & 4,958 & 30,066 & 30,279 & 8,522 & 38,801 & 6.44 & 19.78 & 8.87 \\
\hline NTB & 21,297 & 4,206 & 25,503 & 28,296 & 5,622 & 33,918 & 9.93 & 10.16 & 9.97 \\
\hline NTT & 19,927 & 3,935 & 23,862 & 26,341 & 5,455 & 31,796 & 9.75 & 11.50 & 10.04 \\
\hline TIMOR TIMUR & 24,869 & 4,911 & 29,780 & 36,688 & 6,969 & 43,657 & 13.84 & 12.37 & 13.60 \\
\hline KALIMANTAN BARAT & 28,279 & 5,585 & 33,864 & 39,456 & 8,133 & 47,589 & 11.74 & 13.35 & 12.01 \\
\hline KALIMANTAN TENGAH & 29,446 & 5,815 & 35,261 & 40,199 & 7,308 & 47,507 & 10.93 & 7.91 & 10.45 \\
\hline KALIMANTAN SELATAN & 28,482 & 5,625 & 34,107 & 36,920 & 7,067 & 43,987 & 9.03 & 7.90 & 8.85 \\
\hline KALIMANTAN TIMUR & 33,413 & 6,599 & 40,012 & 41,097 & 8,664 & 49,761 & 7.14 & 9.50 & 7.54 \\
\hline SULAWESI UTARA & 21,378 & 4,222 & 25,600 & 28,046 & 7,018 & 35,064 & 9.47 & 18.46 & 11.06 \\
\hline SULAWESI TENGAH & 18,510 & 3,656 & 22,166 & 24,965 & 6,269 & 31,234 & 10.49 & 19.70 & 12.11 \\
\hline SULAWESI SELATAN & 20,897 & 4,127 & 25,024 & 29,217 & 7,064 & 36,281 & 11.82 & 19.62 & 13.18 \\
\hline SULAWESI TENGGARA & 20,217 & 3,993 & 24,210 & 24,157 & 4,532 & 28,689 & 6.11 & 4.31 & 5.82 \\
\hline MALUKU & 26,616 & 5,256 & 31,872 & 31,526 & 5,946 & 37,472 & 5.81 & 4.20 & 5.54 \\
\hline IRIAN JAYA & 27,608 & 5,452 & 33,060 & 36,794 & 8,692 & 45,486 & 10.05 & 16.82 & 11.22 \\
\hline INDONESIA & 23,303 & 4,602 & 27,905 & 29,681 & 8,565 & 38,246 & 8.4 & 23.01 & 11.08 \\
\hline
\end{tabular}


Appendix 10. Rate of Change of Food Line, Non-Food Line, and Poverty Line, 1993-1996

Rural

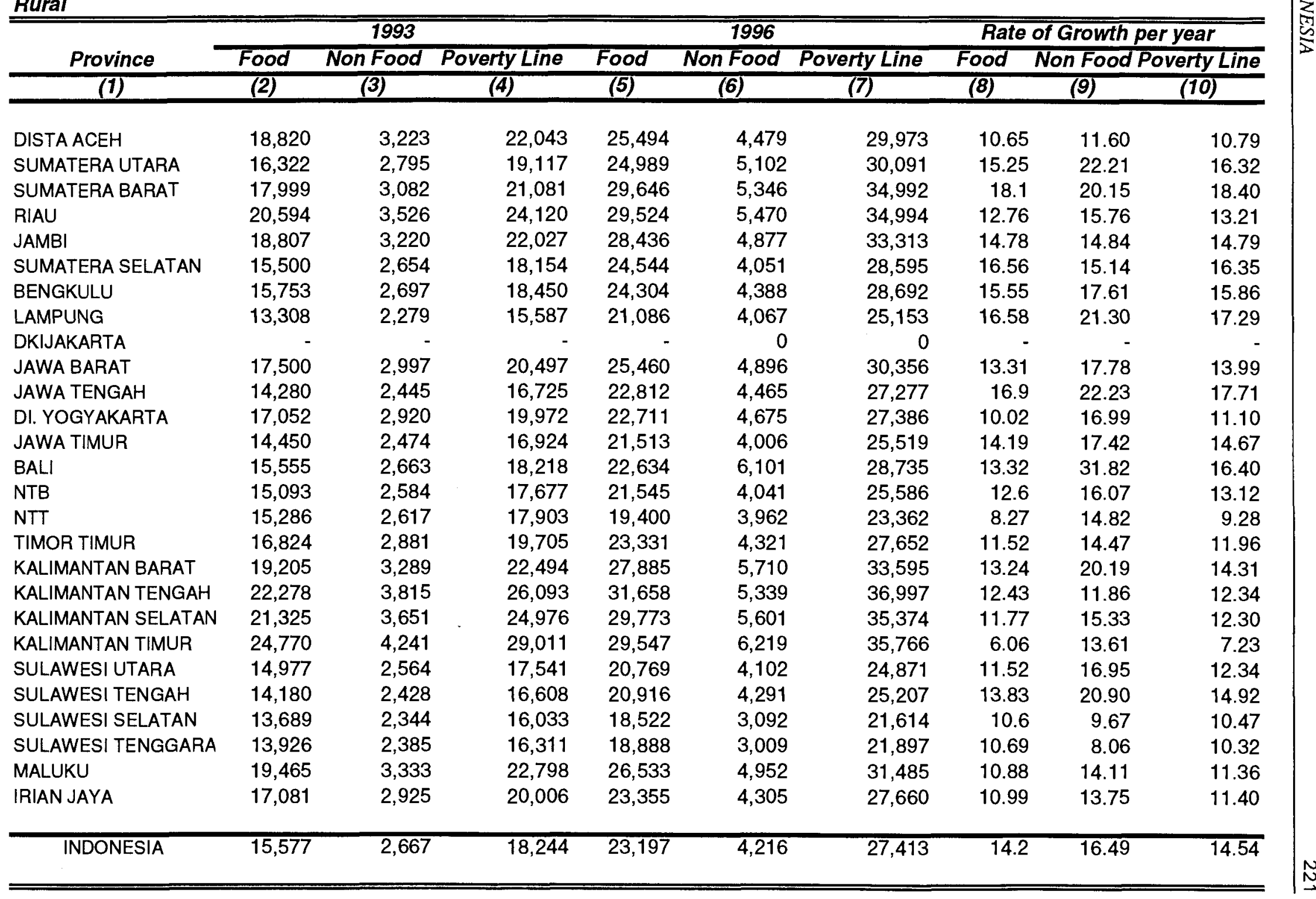


Appendix II. Worksheet for Interpolation

Indonesia - Urban

\begin{tabular}{lllll}
\hline \hline Monthly Per Capita & Number & $\begin{array}{l}\text { Cumulative } \\
\text { Number } \\
\text { Expenditure Class }\end{array}$ & Poverty Line Percentage & Number \\
& of People & & of the poor of the poor \\
& & & (Million)
\end{tabular}

\begin{tabular}{|c|c|c|c|c|c|}
\hline$<15.000$ & 19524 & 19524 & & & \\
\hline $15.000-19.999$ & 89111 & 108635 & & & \\
\hline $20.000-24.999$ & 548543 & 657178 & & & \\
\hline $25.000-29.999$ & 145977 & 2110155 & & & \\
\hline $30.000-34.999$ & 2546874 & 4657029 & & & \\
\hline $35.000-39.999$ & 3362199 & 8019228 & 38246 & 9.71 & 7.2 \\
\hline $40.000-44.999$ & 4010445 & 12029673 & & & \\
\hline $45.000-49.999$ & 4209837 & 16239510 & & & \\
\hline $50.000-54.999$ & 4046309 & 20285819 & & & \\
\hline $55.000-59.999$ & 3870544 & 24156363 & & & \\
\hline$>=60.000$ & 46282336 & 70438699 & & & \\
\hline
\end{tabular}

Appendix 12. Worksheet for Interpolation

Indonesia - Rural

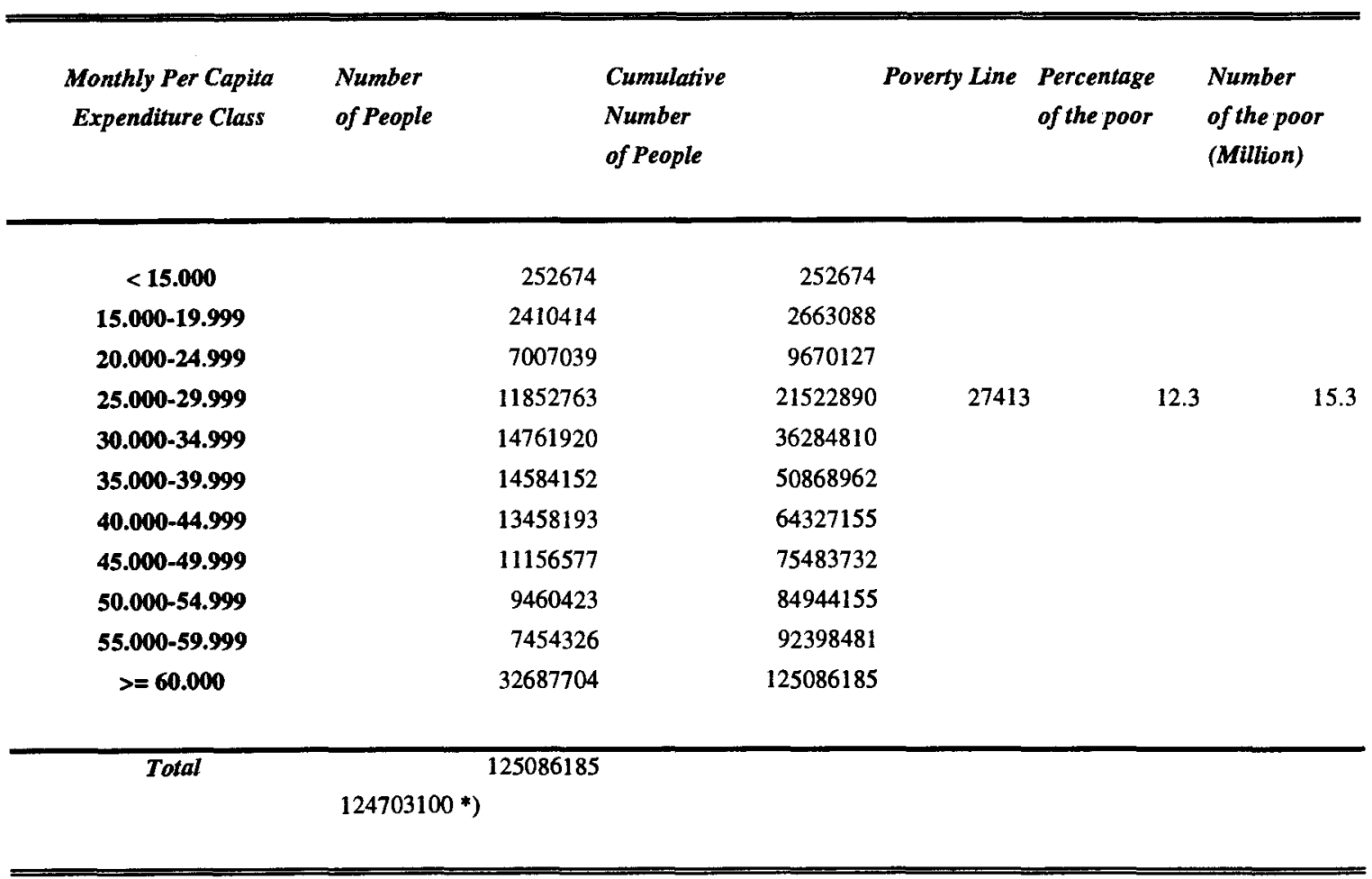


MEASURING INCOME DYNAMICS:

The Experience of Canada's Survey of Labour and Income Dynamics

by

Maryanne Webber

Statistics Canada

Canada 


\section{MEASURING INCOME DYNAMICS: The Experience of Canada's Survey of Labour and Income Dynamics}

\section{INTRODUCTION}

In 1993, Statistics Canada launched a longitudinal household survey called the Survey of Labour and Income Dynamics (SLID). This survey is designed to track the labour market activities, family changes and income levels of Canadians over a period of time.

This was not Statistics Canada's first foray into the field of panel household surveys. Indeed, SLID had a predecessor, the Labour Market Activity Survey (LMAS), which was active from 1986 to 1991. LMAS was sponsored by Human Resources Development Canada, the federal government department responsible for labour market policy and for the administration of many labour market and social programs. LMAS data are still being "mined" by researchers. But there was a major content shortcoming: the lack of family income data.

Increasingly, analysts are concerned with the interrelationships between the labour market and the family's economic well-being. To some extent, we have witnessed a relaxing of the traditional barriers that existed between labour market research and research focused on family welfare issues. SLID's purpose is to provide a more holistic view, shedding light on the links between family, work and income. To do this, the survey needed to be longitudinal, and to track both family changes and income changes over time.

Statistics Canada has a long-established time series of low income data based on the annual Survey of Consumer Finances (SCF). These data are intensely used, and form the basis of several regular or ad hoc publications by groups concerned with poverty and income inequality. The existing cross-sectional data have been very useful for monitoring trends in income distribution, for understanding the variations by type of family and for analyzing the role of government transfers in maintaining income levels. However, the development of effective programs and measures requires a better understanding of the persistence of income inadequacy and of the events that trigger flows into and out of low income. At what stage should government programs intervene? What types of measures are the most fruitful?

The funding for SLID was obtained because several policy departments of the federal government recognized that this is an important data gap in the national statistical system, worthy of a stable long-term survey program.

This paper traces the history of SLID, from its development to today. It discusses some of the current challenges and lessons learned along the way. 


\section{SLID OVERVIEW}

Because of its mandate to look at labour market behaviour, family circumstances and income, SLID carries a broad selection of variables. The labour market variables encompass information on the characteristics of jobs held during the year; for example, start and end dates, industry, occupation, hours worked, wage rate, union status, pension coverage, how the job was obtained and the reason for job loss. The dates of work absences are captured, along with the reasons for absence. During spells where no job was held, there are questions on job search and the desire for employment. This detailed information is summarized into higher-level variables that encapsulate the person's labour market patterns, including weekly labour force status (a value of employed, unemployed or not in the labour force for each week of the year), annual labour force status (a summary variable showing all the labour force states experienced during the year), the number of jobs held in the year, the total weeks of employment and unemployment, and so on. In addition, there is a range of family-level labour market variables summarizing the extent and nature of labour market involvement for the family as a whole.

The personal characteristics captured by the survey include basic demographics, educational activity, educational attainment, marital history, ethnocultural variables, such as immigration status and ethnic origin, and geographical mobility.

For income, the survey identifies about 20 specific sources of income, along with amounts. Also, total income before taxes, income taxes paid and after-tax income are recorded. Again, the amounts are available for both the individual and for the family as a whole. The income questions account for a small proportion of the total survey content, but the other variables are valuable in interpreting the data on income stability and adequacy.

\section{Main survey design and data collection features}

SLID is designed to be a continuous survey, but with a sample that changes over time. Each panel of about 15,000 households is selected for six years. An interview is conducted each year, in January, to collect and update information on labour market activities (over the previous year), educational activities and family changes. Then, in May, the household is contacted again to collect income information for the previous year -- unless the people in that household have agreed that we can access their tax records, assuming of course that they have completed a tax return. About $60 \%-70 \%$ of respondents have tax returns and agree to allow access. Otherwise, income information is collected via an interview. This is done in May rather than January to coincide with the time that most people have completed their tax returns and therefore have the relevant information close at hand. This is particularly important for people who are self-employed. Labour information is collected for persons aged 16 to 69 and income is collected for persons 16 and over. Family information covers persons of all ages. 
The individuals living in the dwellings selected at the beginning of a panel are called longitudinal respondents. These persons are followed for six years, whether they move or not, and regardless of age. In addition, the survey interviews cohabitants: people who share a dwelling with a longitudinal respondent at some time during the six years, although they were not initially selected for the sample. Cohabitants remain part of the sample as long as they continue to reside with a longitudinal respondent. This ensures that the family information collected on longitudinal respondents is up to date.

Unlike most Statistics Canada surveys, SLID is a voluntary survey. Although a six-year commitment on the part of respondents is significant, every effort has been made to maintain response burden at a tolerable level by keeping the interviews short. They take about one half-hour to complete per household.

\section{The data processing challenge}

Although difficult, the task of finalizing the questionnaire and collecting the first wave of data was not as demanding as the subsequent data processing stage. The survey's first reference year was 1993 . It took roughly 24 months to process the first wave of data. The results for 1993 were released in June 1996.

The processing of the first wave was time-consuming because we wanted to build a database that would accommodate future "waves" of data. A longitudinal database must deal with the issue of how to represent time. Spells, events and transitions are the meat of a longitudinal survey. In general, the experience gained from building databases for cross-sectional surveys offers few clues on how to capture changes experienced over time.

\section{Improving timeliness}

While the results for 1993 were being processed, data collection continued each year. The 1994 results will be published in June 1996, which means that it will take 12 months to process the second wave, compared with 24 months for the first wave. When SLID is fully stable, data will be released within 15 months of the end of the reference year. However, because there is some "catching up" to do, we do not expect to reach this timeliness target until the 1999 reference year.

\section{Dissemination focuses on microdata}

So far, the main objective in data dissemination has been to make a public use microdata file available, and to ensure that our documentation is solid enough to allow researchers to do their work. But this is just the tip of the iceberg. We have heard from many data users that the survey content is of great interest but they cannot (for reasons of time or technical training) work directly with the microdata. To ensure that there is a broad user base for the survey, it is therefore important to produce studies or tables that reflect transitions and flows -- that is, longitudinal rather than cross-sectional tables. The design of such tables is 
definitely a challenge, but it is one that we will be taking on in the coming year.

The protection of confidentiality is an important issue in the dissemination of public use microdata. With the first wave, the approach adopted was a combination of suppression of certain variables, rounding of income amounts, and collapsing of variables (such as age) into categories. However, as the amount of information on each person grows over time, the protection of confidentiality becomes increasingly difficult. There is an initiative underway at Statistics Canada to make microdata available through a "remote access" system. Essentially, researchers outside Statistics Canada would write and test their programs using a test file that we provide. The program would be submitted to Statistics Canada via Internet, executed against the full database, checked to ensure that the results are not problematic from a confidentiality perspective, and transmitted back to the researcher. Although simple in principle, the approach would require well-developed guidelines, fast turnaround and high caliber test files to work efficiently.

\section{POVERTY DYNAMICS IN SLID: WHAT ARE WE LOOKING FOR IN THE DATA?}

With the release of 1994 data in June, it will be possible to begin analyzing income dynamics using SLID. Two years is too short a period to look at the persistence of poverty but we can at least look at flows into and out of low income.

Currently, the most prominent measure in Canada is the Low Income Cut-off (LICO). As noted in the Appendix, LICOs vary by family size and size of community. There are 35 cutoffs in all. They are adjusted each year for changes in the cost of living.

LICOs refer to family income. The family in this case is defined as all persons living in the same dwelling and related by blood, marriage, common-law union or adoption. Family income is derived by summing the individual incomes of all persons belonging to the same family. Because a person's family composition can change over time, the approach we have adopted is to "freeze" family composition on December 31 of each year. Family income is thus the sum of the individual incomes of all people living together on December 31 of the year in question.

Since family composition can change over time, it would be difficult if not impossible to use the family as a unit of analysis in studies of income dynamics. The individual is a much more manageable unit of analysis, but we are interested in a family characteristic, namely family income. Family income is therefore treated as a characteristic of all the individuals belonging to a given family. (This is not an unusual approach in cross-sectional low income studies in Canada. For example, estimates of child poverty are based on this notion of individuals classified by their family income.)

When the data for 1994 are available, we plan to look at flows into and out of low income using the following simple transition table: 


\begin{tabular}{|l|l|l|}
\hline \multirow{2}{*}{1993} & \multicolumn{2}{|c|}{1994} \\
\cline { 2 - 3 } & Below LICO & Not below LICO \\
\hline Below LICO & & \\
\hline Not below LICO & & \\
\hline
\end{tabular}

The population to be included will be longitudinal respondents of all ages, classified by their family income level in the two years. This will give us an initial reading on the magnitude of these flows in relation to the population below the LICO in both years -- in itself new information.

Then, a number of possible reasons for change will be considered. One possible source is government transfer payments that may have been initiated or terminated. Another is change in market income, for example, someone in the family having started a new job or lost a job. A third important cause could be an event in the family itself -- for example, a family breakup, a youth returning to the home of his parents, and so on.

\section{DATA QUALITY ISSUES AND MEASURES TO ENHANCE QUALITY}

Longitudinal household surveys share some of the quality problems of cross-sectional surveys, and they have additional concerns. In terms of quality, income is generally not a popular survey topic among respondents. The survey staff were concerned from the outset that, over time, refusals would increase to the point where the data would not be of acceptable quality. This concern was the main reason for offering respondents the option of providing their income information via tax records rather than an interview.

As with other income household surveys, there are concerns about unreported income sources, under-reporting of amounts, and under-representation of high-income households. To some extent, this can be evaluated by comparisons to external data sources. For example, there are aggregate estimates available for payments made through various government transfer programs and for total wages and salaries.

Every year, the SLID estimates will be evaluated against these external sources. The evaluation for 1993 resulted in some fine-tuning of the processing (for example, more rigorous editing of outlier values), and pinpointed areas for further study. Although the survey's goal is not to produce aggregate income estimates, these comparisons provide useful information on quality. 
The quality concerns are not all on the income side of the survey. Recall is a potential problem in the collection of information on labour market activities, particularly among respondents who have complex activity patterns. Past retrospective surveys, looking at labour market activities over a full year, have shown that there is a tendency to forget short spells of unemployment occurring at the beginning of the year and also to "telescope" both employment and unemployment spells, that is, recall them as having occurred closer to the survey date than they really did. The effects of said errors include, for example, underestimation of unemployment and distortion of seasonal patterns.

Our main strategy for ensuring quality of the labour market information is to structure the interview in a way that assists the recall task and to feed back selected information from the previous interview. Regarding the interview structure, rather than proceed in chronological fashion, the first step is to identify the dates of jobs held. After the employment spells have been fixed, the interviewer then proceeds to "fill in the holes", identifying job search activities that occurred between employment spells. The rationale for this approach is that jobs are easier to recall and situate in time than job search activities.

Respondents are also fed back information on jobs in progress at the end of the previous year, which helps to reduce "seam problems". (Because of recall problems, surveys like SLID find a large number of employment and unemployment spells starting and ending at the "seam" between two reference periods.) Feeding back information has been shown to reduce this phenomenon.

Longitudinal surveys are particularly concerned about sample attrition -- a gradual erosion of the sample due to increased refusals and failure to trace respondents who have moved since the last interview. After three waves, SLID has retained about $81 \%$ of the respondents aged 16 and over who were contacted in Wave 1:

\begin{tabular}{|l|l|l|}
\hline Panel 1: & \multicolumn{1}{|c|}{ N } & \multicolumn{1}{|c|}{$\%$} \\
\hline Total longitudinal respondents 16+ & 30,900 & 100 \\
\hline Responded in all 3 waves & 25,000 & 81 \\
\hline Did not respond in any wave & 2,100 & 7 \\
\hline Dropped out after first wave & 1,900 & 6 \\
\hline Dropped out after second wave & 1,900 & 6 \\
\hline
\end{tabular}

Non-response is caused by many factors. Outright refusals and failure to trace account for roughly half of all non-response. Results differ a little between January and May. In 1994, $25 \%$ of all non-response in January was due to refusals and $21 \%$ were unable to trace cases. 
In May, $28 \%$ were refusals and $16 \%$ were unable to trace. To put the results on failed tracing attempts into perspective, there were 2,700 respondents who moved in 1994, of whom 2,200 or $83 \%$ were successfully traced to their new address. The remaining nonresponse -- that due to causes other than refusal and failure to trace -- is attributed to a wide variety of factors. However, it is likely that a good portion of this is in fact undetected refusals and changes of address. Over time, it is probable that the proportion of noninterviews due to reasons other than refusals and failure to trace will decline.

As noted earlier, SLID interviews people now living with longitudinal respondents who were not present at the beginning of the panel. This is mainly done to ensure that the family information on longitudinal respondents is complete, but it serves a second purpose as well: it improves the capacity of the survey to produce cross-sectional estimates by refreshing the sample. The following table shows a cross-sectional view of response. Because the sample was actually selected in January 1993 (at the beginning of the first reference year), there were already cohabitants identified in January 1994, when the labour and income results for the 1993 reference year were collected. The table shows an eligible population of 32,100 (that is, longitudinal respondents and cohabitants aged 16 and over) in Panel 1 for 1993 and 34,000 one year later. Part of the increase is due to 15 year-olds turning 16 , the rest is due to cohabitants:

\begin{tabular}{|l|l|l|}
\hline Panel 1 & 1993 & 1994 \\
\hline $\begin{array}{l}\text { Eligible population (longitudinal } \\
\text { respondents + cohabitants, 16+) }\end{array}$ & 32,100 & 34,000 \\
\hline Responding & 29,400 & 30,000 \\
\hline Non-response & 2,700 & 4,000 \\
\hline$\%$ responding & $92 \%$ & $88 \%$ \\
\hline
\end{tabular}

The results show a substantial amount of change occurring within the family, and this is often associated with geographical mobility. It is a phenomenon that makes the conduct of longitudinal surveys more difficult but, at the same time, increases their usefulness.

\section{SUMMARY}

The development of the Survey of Labour and Income Dynamics began in 1992. Five years later, we are on the point of releasing the second wave of data. The main design and data collection challenges have been dealt with. The data processing and timeliness concerns are the current focus of our attention. The development of products that are accessible to a wide base of data users and the question of access to detailed microdata are among the challenges ahead. 
As for any new survey, there is enthusiasm about SLID among data users. But longitudinal surveys typically take some time to bear fruit, partly because they are complex, but mainly because it requires an accumulation of data in order to create a longitudinal picture. It is important to sustain interest and support for the survey during its early years -- a period of great vulnerability for longitudinal surveys.

With the release of SLID's second wave, it will not yet be possible to study persistence of low income. However, we can examine the magnitude of flows into and out of low income and to look at associated labour market and family events.

The first SLID results on low income dynamics will be published in an environment where there is already extensive use made of cross-sectional income data. The approach will be to expand on the information already in the public domain by adding a new dimension. In time, this information will increase our understanding of the issues affecting the duration of low income spells and the factors that are the most important in triggering flows into and out of poverty. Thus, the data on income dynamics will be complementary to the trend information already available on income levels and income distribution.

\section{APPENDIX}

\section{Statistics Canada's Low Income Cut-offs (LICOs)}

The Low Income Cut-offs published by Statistics Canada have been described as a hybrid approach, containing elements of both absolute and relative low income measurement. LICOs are calculated using data from the Family Expenditure Survey. This survey, which has typically been done on a national scale every four years or so, is a comprehensive survey of all expenditures made by the household over a calendar year. The survey also collects income data.

The procedure involves determining the overall proportion of income that is spent on food, shelter and clothing, then adding 20 percentage points to that figure. This is an arbitrary amount, but it has been used since the first low income cut-offs were calculated in 1959. The resulting proportion has shifted down from about $70 \%$ in 1959 to $56 \%$ based on expenditure patterns in 1992.

The Family Expenditure Survey data is then used to estimate income levels by family size and size of community where average expenditure on food, shelter and clothing is $56 \%$ of income. There are seven family size categories and five size of community variables, so a table of low income cut-offs has 35 values. With every new Family Expenditure Survey, the LICOs are updated to reflect the current proportion of income spent on food, shelter and clothing. In the intervening years, the Consumer Price Index is used to update the values. 

TOPIC 2

The Unmet Basic Needs (UBN) Methods 



\title{
MONITORING LIVING CONDITIONS AND POVERTY IN SOUTH AFRICA
}

\author{
by
}

\author{
Ros Hirschowitz and Mark Orkin \\ Central Statistical Service \\ South Africa
}




\section{Monitoring Living Conditions and Poverty in South Africa}

\section{Introduction}

Politically, South Africa has finally emerged triumphant from the oppression of apartheid. April $27^{\text {th }}, 1994$, signified the most dramatic change in our country. A democratic government was elected by all the people, for the first time.

The political battle has been won, but the war against poverty and under-development is still in its initial stages. An essential element in winning this new war is information. The full extent of poverty and under-development in South Africa has yet to be determined. The Central Statistical Service (CSS) has a crucial role to play in this regard. As the official data-gathering organisation is South Africa, the country will depend on it to provide reliable, relevant information on the basis of which changes in the extent of poverty can be monitored over time.

In common with many other developing countries, poverty in South Africa today is clearly differentiated along racial' ${ }^{1}$, gender and urban - non-urban ${ }^{2}$ divides. In addition to these common features, however, poverty in the country has certain unique features which can best be understood if viewed against the background of the country's history of apartheid and oppression.

\section{Historical background}

Although oppression of Africans started long before 1948, this section of the paper focuses on the apartheid era, after the National Party came to power. There are at least three key aspects of apartheid that influenced the way in which poverty developed in the country. Laws were introduced to determine what people could learn, what work they could do, and where they could live.

To determine what Africans in an apartheid-based society could learn, a system of inferior education was introduced through the Bantu Education Act of 1953. This Act was specifically designed for Africans to "equip them only for a subsidiary role in life" (Wilson and Thompson, 1971). In spite of ongoing resistance to this form of education, the current attempts to redress past policies, its effects are still obvious in South Africa today. The 1995 October household survey of the CSS shows that $20 \%$ of African females, and $14 \%$ of African males have received no education, compared with fewer than $1 \%$ of whites of both

\footnotetext{
${ }^{1}$ The apartheid-based race classification of South Africans as African, coloured, Indian and white is being retained by the CSS to enable it to monitor change in life circumstances of those who were previously disadvantaged.

${ }^{2}$ An urban area is one where previously there was a fully established local authority. A non-urban area had a different structure, for example, a tribal authority or a regional authority.
} 
sexes. On the other hand, only $6 \%$ of African females and males, have received a tertiary education, compared with $24 \%$ of white females, and $30 \%$ of white males.

Coupled with a legally enforced system of inferior education for Africans was the control of access to the labour market. The type of work Africans could do was determined by a legally enforceable system of job reservation. Acts of parliament such as the Bantu Labour Act of 1953, the Wage Act of 1955, and, in particular, the Industrial Conciliation Act of 1956, were introduced to prevent Africans from having a voice in the workplace and from doing skilled work. Africans "were forced into the lowest paying, least satisfying jobs" (Friedman, 1987). Even though these laws have been repealed, their impact can still be felt. The 1995 October household survey of the CSS shows that 50\% of African females, and $34 \%$ of African males are found in elementary occupations, compared with $1 \%$ of white females and $2 \%$ of white males. On the other hand, only $4 \%$ of African males and $2 \%$ of females are in managerial posts, compared with $19 \%$ of white males, and $8 \%$ of white females.

There were also a whole series of laws which controlled where people could live and where they could seek work. Some of these laws, for example the Land Acts of 1913 and 1936, giving Africans access to $13 \%$ of the land, were introduced before 1948. But subsequently, a whole range of Acts were passed, which created the "bantustans", forced Africans to move into these overcrowded wastelands and prevented them from seeking employment in the rest of the country.

Even though South Africa is now a unified country, and people can choose where they wish to live and work, the impact of these laws can still be felt. The 1995 October household survey shows that, among Africans, it is mainly older people (73\% of females and $67 \%$ of males aged 65 years or more) and children (74\% of males and $73 \%$ of females aged between 0 and 14 years) who live in non-urban areas. Access to land is extremely limited in the former "bantustans", therefore small-scale agriculture is often not an option as an income-generating activity, and many households tend to rely on state pensions and remittances from workers in urban areas for survival (Platsky and Walker, 1985).

\section{Monitoring poverty in South Africa before 1994}

The monitoring of living conditions and poverty by means of household surveys, based on samples which over the entire country, is relatively new in South Africa. In the past, the old CSS tended to give the collection of poverty-related information a low priority. The development of country-specific indicators to monitor poverty in the country over time was neglected, even though a Human Development Index (HDI) for South Africa as a whole was calculated, based on the 1991 population census, certain parts of the country, namely the former "TBVC states"3 were excluded.

\footnotetext{
3 The areas constituting Ciskei, Bophutatswana, Venda and Ciskei were given the status of independent states by the apartheid government, while the remaining six "bantustans" were called independent territories.
} 
There were separate statistical offices in the former "TBVC states" to collect data on these fragmented bits of land, but the information collected by these offices was never adequately integrated into South African statistics.

\section{The 1996 population census}

But now all this is changing. A new management structure and new ways of organising work have been introduced into the CSS. For the first time since 1970, a population census was conducted in South Africa in October 1996, in which the CSS enumerated and obtained information on all the people in the country, including the former "TBVC states". Whenever requested, face-to-face interviews were conducted. This census is a milestone for the CSS. After data processing has been completed, we shall know where everyone in the country lives and works. We shall be able to give planners at all levels of government and in the private sector information on poverty, living conditions and community requirements, for each part of the country. We shall also be able to improve our sampling methodology for future household surveys, since we shall have a more reliable sampling frame.

\section{Previous household surveys}

Prior to 1993, small-scale monthly current population surveys were the main methods used by the CSS to update demographic data. But in 1993, a new, annual survey, based on a sample of 30.000 households - the October household survey (OHS) was introduced. This first survey of its kind excluded the former "TBVC states".

In October 1994, however, the OHS included the former "TBVC states". It was conducted among 30.000 households, covering the entire country. A second household survey of this magnitude, coupled with an income and expenditure survey (IES), was conducted in 1995. In November 1996, a third OHS was conducted, but only among 16000 households, immediately after the enumeration phase of the population census. The data processing for that survey is still underway.

A programme of household surveys should make it possible, not only to describe the situation in a country at a given point in time, but also to measure change in people's life circumstances as and when new government policies are implemented.

Other recent studies, such as the one conducted by the World Bank together with the University of Cape Town's Southern Africa Labour and Development Research Unit (SALDRU) in late 1993 among 9000 households, have also attempted to determine the extent of poverty in the country. Unlike the OHS programme, this study aimed at making international comparisons. Nevertheless, there are many overlapping findings between the two groups of surveys. 


\section{The two surveys on which this paper is based}

In this paper, the results of both the 1995 OHS, and the 1995 IES, which followed shortly after the OHS, and where the same households were re-visited, are reported.

\section{The 1995 October household survey}

The 1995 October Household Survey (OHS) was conducted among 30000 households throughout the country. The questionnaire, in the same vein as the previous ones, contains questions about the household as a whole, as well as on all individual members.

In the household section, questions are asked about type of dwelling (or dwellings) in which the household lives, access to facilities such as electricity, tap-water, toilets and regular refuse removal, access to health and social welfare services, and the safety and wellbeing of the household.

In the section completed for each individual in the household, questions are asked on age, gender, education, marital status, migration, use of health services, economic activity, unemployment, employment and self-employment.

\section{The 1995 income and expenditure survey}

The same households were visited for both the OHS and the IES. The field workers first administered the OHS questionnaire, and they returned at a later date to administer the questionnaire for the IES.

The main purpose of the 1995 IES was to collect new base-line information on expenditure patterns of South Africans. This survey is used primarily for calculating weights for household purchases of goods and services for the Consumer Price Index (CPI). It is repeated on a five yearly basis.

What was unique about the 1995 IES was the collection of income and expenditure data from the whole country, including urban and non-urban areas, and the former "TBVC states". In 1990, when the previous IES was undertaken, information on expenditure was collected only from the 12 largest urban areas in the country, ignoring buying patters in small towns and rural areas. What is also unique is the linking of two data sets, to obtain demographic, social, income and expenditure information from households.

\section{Survey methodology for both the 1995 OHS and the IES}

Since these two surveys were linked, the same sampling, fieldwork and data capture methods were used for both studies. 
Drawing a sample

Information was obtained from 30000 households, representing all households in the country. Altogether, 3000 enumerator areas (Eas) were drawn for the sample, and ten households were visited in each EA. This was an improvement compared with 1994, when only 1000 EAs were selected, and information was obtained from 30 households per EA. The 1995 sample was stratified by province, urban and non-urban areas and race.

The 1991 population census was used as a frame for drawing the sample. However, this census was not fully comprehensive and it has certain shortcomings. For example, (a) the former "TBVC states" were excluded, and the population size in these areas relies on estimates, (b) a "sweep census" was done in certain parts of the country where no enumerator areas had been demarcated, (C) in other parts of the country, notably informal settlements, aerial photography, backed by small-scale surveys, was used to estimate population size, and (d) no allowance was made for new informal settlements, which were springing up all over South Africa, to be incorporated into the sampling frame.

In 1995, some attempts were made to overcome sampling problems occurring as a result of the above problems. For example, magisterial districts where a "sweep census" had taken place were sub-divided into smaller units, and new informal settlements were incorporated into the boundaries of existing enumerator areas.

\section{The fieldwork}

In the 30000 households which were sampled throughout South Africa, information was collected through fact-to-face interviews. During these interviews, field workers administered a questionnaire to a responsible person in each household.

Problems were experienced in returning to the same household for the OHS and the IES, particularly in informal settlements and in rural areas, where addresses were not available, and where demarcation of the EA or listing of households had not been undertaken for the 1991 census. These problems were solved, as far as possible, during the data-capture process by matching responses to common questions in the two surveys.

\section{Data capture}

Data capture of both the 1995 OHS and the IES took place at the head office of the CSS. This process involved linking the information contained in the 1995 OHS with that contained in the IES. The linking of the two data sets was regarded as an important exercise, because details concerning household income and expenditure patters (IES) could be added to details about education, employment and overall life circumstances (OHS), thus giving a more comprehensive socio-economic description of life in South Africa. 
Weighting the sample

Data concerning households were weighted by the estimated number of households in the country in the various provinces, according to the proportions found in urban and non-urban areas, and by the race of the head of the household. First, we weighted the data on individuals, and the weight assigned to the head of household was used as the weight for the household.

Data on individuals within households were weighted by age, race and gender, according to CSS estimates of the size of the population living in urban and non-urban areas in the nine provinces. All further discussions in this report are based on weighted figures.

\section{Comparison with 1994 OHS data}

Since different methodologies were used for drawing samples in 1994 and 1995, and since diverse problems were encountered as a result of these varying sampling techniques, the 1994 and 1995 OHS data sets are presently not directly comparable in all respects. At this stage, they are essentially separate snapshots of different parts of the country during two consecutive years. The CSS is busy calculating design effects and confidence intervals for selected items in both the 1994 and 1995 data sets. Once this exercise is completed, direct comparisons will be possible.

There are certain similarities between these two surveys when looking at overall broad patterns. For example, access to water and toilet facilities remains problematic in non-urban areas in both surveys. Unemployment remains high, and the proportion of Africans in elementary occupations such as cleaning and garbage removal remains similar.

\section{Selected poverty-related results of the 1995 OHS and IES}

The effects of the segregation of South Africans along racial lines during the apartheid era continue to be felt. Living conditions of South Africans differ vastly between different race groups.

\section{The population of South Africa}

Altogether, there are approximately 41.5 million people living in South Africa, in about nine million households. Seventy six percent of the people in this country are African, while $13 \%$ are white, $9 \%$ are coloured and $2 \%$ are Indian (see Figure 1 ).

Although, overall, half the South African population lives in non-urban areas, urban versus non-urban residence varies by race. Almost two in every three (63\%) Africans live in non-urban areas, compared with only one in every six $(16 \%)$ coloureds, one in every ten whites (9\%) and one in every $20(5 \%)$ Indians. Gauteng and the Western Cape are largely urban provinces, while the other provinces are predominantly non-urban (see Figure 2). 
In the Western and Northern Cape, the majority of the population are coloured, while in all the other provinces, the vast majority of people are African (see Figure 3).

\section{Demographic description}

\section{Age distribution}

Regarding the age distribution of the South African population, among whites, this distribution resembles that of "developed" countries. Relatively few children are being born and the proportion of older people is increasing (see Figure 4). Among Africans, on the other hand, the age distribution of the population resembles that of "developing" countries. There are proportionately more children and fewer older people, compared with whites (see Figure 5).

Among Africans males, proportionately more children and older people live in non-urban areas, but proportionately fewer of those of working age live in urban areas (see Figure 6). A similar pattern can be found among African females. A large proportion of both older women and female children are found in non-urban areas. However, more than half of all African females of working age continue to remain in the non-urban areas, compared with just over $40 \%$ of males (see Figure 7).

This is a reflection of the extent of the apartheid-based migrant worker system in the country which is still continuing, and the break-up of families as a result of this system.

\section{Work opportunities}

Work opportunities in South Africa are rather limited, and unemployment is high. Two definitions of unemployment have been used in South Africa - the strict and the expanded definition. Both definitions include people who are aged 15 years or older, and who are not employed, but who are available for work. But they differ from each other in the following way. A requirement of the first or strict definition is that a given individual has taken specific steps to seek employment in the four week period prior to a given point in time. According to the strict definition, the unemployment rate is $17 \%$ of the economically active population.

The second or expanded definition focuses on the desire to work, irrespective of whether or not the person has take active steps to find work. According to the expanded definition, the unemployment rate is $29 \%$ of the economically active population. Altogether, in 1995 , there were 14.4 million economically active people in the country. Of these people, 10.2 million were employed or self employed (1.7 million of these in the "informal sector"), and 4.2 million were unemployed. 
It has been widely recognised that the restricted definition is too limited in the present South African context, where many unemployed people have ceased to actively seek work. Transport and other costs entailed in job seeking, often with negative results, have actively discouraged people from going out and looking for work. In other words, there are people who would readily accept work, but who have given up seeking it.

The extent of unemployment varies by race and gender. Among the economically active African population, three in every ten $(29 \%)$ males, and just under one in every two (47\%) females who are available for work, are unemployed, yielding an aggregate of $37 \%$ for Africans. There are proportionately fewer coloured, Indian and white unemployed people, compared to Africans (see Figure 8; for more details of unemployment among Africans by gender and province, see Table 1$)$.

This unemployment rate does not differ significantly from the survey on poverty in South Africa conducted by the World Bank in association with the South African Labour and Development Research Unit (SALDRU) of the University of Cape Town. This study included the "discouraged" unemployed in its calculation of the rate of unemployment. In common with the CSS expanded definition, these people had not sought employment in the four week prior to the interview.

\section{Occupations of the employed}

White employed males tend to be found in wide spectrum of jobs, including artisan's and skilled blue collar (29\%), managerial (19\%), semi-professional and technical (17\%), and professional $(9 \%)$ occupations, while white employed females tend to be found in clerical $(47 \%)$ and semi-professional $(21 \%)$ occupations (see Figure 9 ).

Among employed Africans, however, a different employment pattern is evident - $34 \%$ of employed African males and 50\% of employed African females are in elementary or unskilled occupations (see Figure 10). In part, this is a reflection of the poor access to education among Africans, but it is also evidence of the legacy of job reservation during the apartheid era.

\section{Description of living conditions in households}

When examining the type of housing in which households live, we find that, while almost all coloured $(91 \%)$, Indian and white (99\% for both groups) households are found in formal housing units such as houses, flats or semi-detached houses, among Africans, a relatively large proportion of households are found in traditional dwellings $(21 \%)$, shacks (10\%), hostels or single rooms $(8 \%)$. The types of dwellings in which Africans live vary in urban and non-urban areas. More than one in every three non-urban African dwellings (38\%) is a traditional dwelling, while one in every sic African urban dwellings (16\%) is a shack (see Figure 11). 
Number of people per household

On average, there are more people living in an African (4.8) or coloured (4.7) household, than in an Indian (4.3) or a white (3.2) one. But African dwellings tend to contain fewer rooms than white dwellings. For example one in four (40\%) African dwellings contain only one to three rooms, compared with only one in every $12(8 \%)$ of white dwellings (see Figure 12).

Overcrowding

African and coloured households tend to live in overcrowded dwellings, compared to white households. For example, among formal (brick) houses occupied by Africans containing three rooms or fewer, one in every five (19\%) have seven or more people living in them. However, only one in every hundred (1\%) houses with one to three rooms occupied by whites has seven or more people. In addition, one in every 10 shacks (9\%) occupied by Africans contains seven or more people, while no whites in our sample live in shacks.

\section{Access to facilities and services}

Compared with other households, relatively few African households have access to domestic infra-structure or services. While almost all Indian and white households and at least three quarters of coloured households have taps inside their dwellings, flush toilets, electricity and regular refuse removal by a local authority, approximately one in three African households have access to these services (see Figure 13).

Among African households, sources from which water is obtained vary in urban and nonurban areas. For example, 56\% of African households in urban areas obtain water from taps inside the dwellings, compared with $12 \%$ of households in non-urban areas (see Figure 14).

As far as toilet facilities are concerned, the vast majority of coloured (83\%), almost all Indian (97\%) and all (100\%) white households have flushing toilets, compared with one in three (34\%) African households. However, $72 \%$ of African households in urban areas have a flushing toilet, compared with only $7 \%$ of non-urban households. One in five (20\%) nonurban and one in a hundred (1\%) urban African households do not have any toilet facilities at all (see Figure 15).

\section{Household incomes and expenditure}

We measured the extent of poverty in the country on the basis of answers given to income and expenditure questions in the IES. By means of quintiles, we could compare the life circumstances of the lowest $20 \%$ of households with the other groups, including the highest. 


\section{Identifying income and expenditure quintiles}

Two different sets of quintiles were obtained - those based on income and those based on expenditure.

To calculate income quintiles, the information obtained on all sources of annual income for each household was used. This total income was divided, as closely as possible, into five groups or income categories, as indicated in Table 2. To calculate expenditure quintiles, the same procedure was used.

We dealt with undeclared income and expenditure during the process of identifying quintiles in the following way: if a household did not indicate a total income, but it did indicate total expenditure, the amount of total expenditure was used as a proxy for household income, but if a household did not indicate its total expenditure, but it did indicate its total income, total income was used as a proxy for household expenditure.

We took into account the debate regarding whether income or expenditure should be used to describe the economic situation among households by examining the relationship between these two variables. We found an extremely high correlation $(r=0.98 ; \mathrm{p}<0.001)$ between the two measures. Therefore we chose to describe households in terms of their income distributions.

\section{Distribution of incomes in South Africa}

Income in South Africa is unevenly distributed by race, with the largest race group in the country being the poorest. Africans constitute $76 \%$ of the total population. Figure 16 indicates that $23 \%$ of African households are in the lowest income category, compared with $11 \%$ of coloured, and only $1 \%$ of Indian and white households. On the other hand, $65 \%$ of white households are found in the highest income category, compared with $45 \%$ of Indian, $17 \%$ of coloured and $10 \%$ of African households.

Income in South Africa is also unevenly distributed by gender. Female-headed households have significantly lower incomes than male-headed ones. Figure 17 shows that, irrespective of race, $26 \%$ of female-headed households are in the lowest income category, as against $13 \%$ of male-headed households. On the other hand, $27 \%$ of male-headed households are in the highest income quintile, compared with $11 \%$ of female-headed households.

When examining income distributions by gender in urban and non-urban areas, urban male-headed households tend to have the highest incomes, followed by urban female-headed ones. The households with the lowest incomes tend to be female-headed households in nonurban areas (see Figure 18).

When examining expenditures patterns, we used expenditure quintiles. We find that households in the lowest expenditure quintile account for only 3\% of total annual expenditure in the country as a whole, while those in the highest quintile account for $61 \%$ of 
total annual expenditure (See Figure 19). Those households in the lowest quintile tend to spend $50 \%$ of their total annual expenditure on food, while those in the highest quintile tend to spend $18 \%$ of their total expenditure on food. Households in the lowest quintile tend to spend $36 \%$ of the total annual food expenditure on grains and cereals, while those in the highest quintile spent $17 \%$ the total annual food expenditure on these items (see Figure 20).

\section{Possible indices to measure change in South Africa over time}

We now go back to the 1994 OHS, where the CSS made some preliminary attempts to develop South African specific indices of poverty and living conditions, based on principal components factor analysis. Once we have examined the design effects, and the confidence intervals for both the 1994 and the 1995 OHS, we should be able to run additional factor analyses on the 1995 data, and compare the two data sets.

We included all questions from the 1994 OHS on income, employment, living conditions and safety and security in this factor analysis.

\section{Index of standards of living conditions}

We found that scores obtained on all questions which we asked related to living conditions (for example, type of housing, access to electricity, tap-water, toilet facilities etc.) grouped together, and loaded highest on one factor. Therefore we felt that we could combine the scores obtained on housing and living conditions to form an index of living conditions standard of South African households, which could be monitored over time.

We divided these combined scores into quartiles. The first quartile is indicative of very low the second of low, the third of medium and the fourth of high standards regarding living conditions. Using these scores, we found that $43 \%$ of African households were found in the very low and $35 \%$ in the low category of living conditions, while no white households were found in the very low category, and $3 \%$ of white households were found in the low category. On the other hand, $64 \%$ of white households were found in the high category, compared with $7 \%$ of African households. Therefore the standard of housing and living conditions among whites is much higher than among Africans (see Figure 21).

If we use the same questions and method of scoring, and the same cut-off points for each of these categories in future household surveys, we shall be able to monitor changes in living conditions among South Africans in different race groups over time.

\section{Index of poverty}

The same factor analysis showed that scores obtained on questions related to education level of the head of household, employment of the head and the combined income of members of the household tended to group together into a common factor which we defined as a measure of poverty for each race group. Combined scores were consequently divided into four categories of poverty for each race group (see Figure 22). These scores, and their cut-off points, may, in future be used to measure changes in poverty status over time. 
Index of felling safe

An addition to the above two factors, a third factor related to poverty - feeling safe - was also obtained. This factor included items related to the high crime rate in South Africa, and it measured how safe individuals felt in their neighbourhoods and in their homes.

\section{Core questions for future monitoring}

The questions asked in the 1994 and 1995 OHSs could, in future, form the core of questions on the basis of which to measure living condition standards, poverty, and feelings of being safe. However, at this stage, we need to establish the validity of the factors as monitoring indices. In addition, we are not sure at present whether and to what extent the way in which we have formulated our questions will change in relation to the findings of the population census. Household surveys to monitor poverty are still in their infancy in South Africa.

\section{Ongoing household surveys}

The field work of the 1996 OHS followed soon after the population census, in November. The data are presently being processed. We should then have three surveys which to compare.

While surveys are expensive, poverty monitoring through surveys is relatively new field for the CSS. At present, we lack adequate household information on poverty for planning purposes. Therefore we plan to continue our programme of annual household surveys, to enable us to monitor change in poverty status and living conditions over time.

\section{Summary}

Monitoring poverty in South Africa is a relatively new field. Indeed, the first household survey covering the entire country, including the former "TBVC" states, was conducted among 30000 households in October 1994. This survey clearly indicated that there were large discrepancies in living conditions and in circumstances of poverty between the various race groups in urban and non-urban areas. We have attempted to develop indices of poverty and living conditions on the basis of this survey. But these remain tentative, and need further verification.

A further survey among 30000 households was conducted in October 1995. In this paper, we gave the main findings of the 1995 OHS and the accompanying IES.

There are a number of areas of South African life that have been brought into sharp focus in the 1995 OHS. These include racial and gender disparities in all spheres of life, as well as large differences in life circumstances along the urban - non-urban divide. In addition, the extent of unemployment in the country, and the type of employment opportunities that are available have also been highlighted. 
The 1995 OHS has shown that vast inequalities exist in the country. As these inequalities are addressed, not only racial differences, but also discrepancies in urban and non-urban life circumstances in South Africa will require careful monitoring in future. Of the 31.7 million Africans, 19.8 million live in non-urban areas. Proportionately more young African children, women and older people than men are found in non-urban areas. Education level of inhabitants tends to be lower in non-urban areas, and income-generating or employment opportunities are fewer.

African households in non-urban areas are unlikely to have access to electricity, tapwater, flush toilets or telephones. They are also likely to be poorer than other households. African female-headed households in non-urban areas are the poorest households in the country. Poor households account for an extremely small proportion of total annual household expenditure. A large proportion of expenditure in these households goes on food - mainly grains and cereals.

Another household survey was conducted in November, 1996 (the population census took place in October). We should therefore soon have comparable data over three years. Once we have calculated design effects for all three surveys, we shall be able to start to observe how life circumstances in South Africa are changing over time. 


\section{References}

Friedman, S. Building tomorrow today. African workers in trade unions, 1970-1984. Johannesburg: Ravan Press.

Hirschowitz, R. and Orkin, F.M. (1996). Living in South Africa. Selected findings of the October household survey. Pretoria: CSS.

Platsky, L. and Walker, C. The surplus people. Forced removals in South Africa. Johannesburg: Ravan Press.

Wilson, M. and Thompson, L. (1971). The Oxford history of South Africa. II. South Africa 1870-1966. London: Oxford University Press.

World Bank/SALDRU. 1995. Key indicators of poverty in South Africa. Pretoria: Ministry of the Office of the President: Reconstruction and Development Programme. 
Table 1: Unemployment rates among Africans in South Africa in October 1994

\begin{tabular}{|c|c|c|c|}
\hline \multicolumn{4}{|c|}{ Unemployment among Africans by gender, province and urban - non-urban areas } \\
\hline Province & $\begin{array}{c}\text { Total } \\
\% \\
\end{array}$ & $\begin{array}{c}\text { Male } \\
\%\end{array}$ & $\begin{array}{c}\text { Female } \\
\%\end{array}$ \\
\hline \multicolumn{4}{|l|}{ South Africa: } \\
\hline Total & 36.9 & 28.9 & 46.9 \\
\hline Urban & 33.3 & 27.5 & 41.3 \\
\hline Non-urban & 40.9 & 30.6 & 52.4 \\
\hline \multicolumn{4}{|l|}{ Western Cape: } \\
\hline Total & 31.0 & 23.1 & 45.0 \\
\hline Urban & 35.4 & 27.5 & 46.8 \\
\hline Non-urban & 1.4 & - & 9.2 \\
\hline \multicolumn{4}{|l|}{ Eastern Cape: } \\
\hline Total & 47.4 & 42.1 & 52.5 \\
\hline Urban & 40.5 & 37.6 & 43.5 \\
\hline Non-urban & 52.1 & 45.3 & 58.1 \\
\hline \multicolumn{4}{|l|}{ Northern Cape: } \\
\hline Total & 34.1 & 27.8 & 45.5 \\
\hline Urban & 47.4 & 42.9 & 53.8 \\
\hline Non-urban & 9.7 & 6.9 & 18.8 \\
\hline \multicolumn{4}{|l|}{ Free State: } \\
\hline Total & 29.4 & 21.2 & 39.5 \\
\hline Urban & 39.5 & 33.5 & 46.1 \\
\hline Non-urban & 18.0 & 8.8 & 30.9 \\
\hline \multicolumn{4}{|l|}{ KwaZulu Natal: } \\
\hline Total & 40.2 & 32.9 & 48.1 \\
\hline Urban & 33.4 & 28.9 & 39.0 \\
\hline Non-urban & 44.6 & 35.8 & 53.4 \\
\hline \multicolumn{4}{|l|}{ North West: } \\
\hline Total & 35.8 & 27.9 & 47.5 \\
\hline Urban & 29.1 & 23.5 & 38.6 \\
\hline Non-urban & 40.9 & 31.6 & 53.6 \\
\hline \multicolumn{4}{|l|}{ Gauteng: } \\
\hline Total & 28.7 & 22.9 & 37.8 \\
\hline Urban & 29.7 & 24.1 & 38.5 \\
\hline Non-urban & 10.7 & 4.6 & 23.6 \\
\hline \multicolumn{4}{|l|}{ Mpumalanga: } \\
\hline Total & 37.4 & 27.3 & 52.1 \\
\hline Urban & 39.9 & 31.8 & 51.1 \\
\hline Non-urban & 36.5 & 25.6 & 52.5 \\
\hline \multicolumn{4}{|l|}{ Northern Province: } \\
\hline Total & 44.4 & 32.7 & 54.8 \\
\hline Urban & 31.8 & 22.9 & 43.7 \\
\hline Non-urban & 46.4 & 34.8 & 56.3 \\
\hline
\end{tabular}


Table 2: Income and expenditure quintiles

\begin{tabular}{|l|c|c|c|c|c|}
\hline & $\begin{array}{c}\text { Quintile 1 } \\
\text { Range }\end{array}$ & $\begin{array}{c}\text { Quintile 2 } \\
\text { Range }\end{array}$ & $\begin{array}{c}\text { Quintile 3 } \\
\text { Range }\end{array}$ & $\begin{array}{c}\text { Quintile 4 } \\
\text { Range }\end{array}$ & $\begin{array}{c}\text { Quintile 5 } \\
\text { Range }\end{array}$ \\
\hline Income & R 400-6868 & R6869-12660 & R12691-23940 & R23941-52800 & R53801 + \\
\hline Expenditure & R 332-6340 & R6341-11589 & R11590-21908 & R2190949497 & R49498 + \\
\hline
\end{tabular}





\section{POVERTY IN THE HUMAN DEVELOPMENT PERSPECTIVE: CONCEPT AND MEASUREMENT}

by

UNDP 


\section{Poverty in the Human Development Perspective: Concept and Measurement}

It is in the deprivation of the lives that people can lead that poverty manifests itself. Poverty can involve not only the lack of the necessities of material well-being, but the denial of opportunities for- living a tolerable life. Life can be prematurely shortened. It can be made difficult, painful or hazardous. It can be deprived of knowledge and communication. And it can be robbed of dignity, confidence and self-respect-as well as the respect of others. All are aspects of poverty that limit and blight the lives of many millions in the world today.

\section{Defining poverty in the human development perspective}

Since its launch in 1990 the Human Development Report has defined human development as the process of enlarging people's choices. The most critical ones are to lead a long and healthy life, to be educated and to enjoy a decent standard of living. Additional choices include political freedom, other guaranteed human rights and various ingredients of self-respect-including what Adam Smith called the ability to mix with others without being "ashamed to appear in public". These are among the essential choices, the absence of which can block many other opportunities. Human development is thus a process of widening people's choices as well as raising the level of well-being achieved.

If human development is about enlarging choices, poverty means that opportunities and choices most basic to human development are denied - to lead a long, healthy, creative life and to enjoy a decent standard of living, freedom, dignity, self-respect and the respect of others.

The contrast between human development and human poverty reflects two different ways of evaluating development. One way, the "conglomerative perspective", focuses on the advances made by all groups in each community, from the rich to the poor. This contrasts with and alternative viewpoint, the "deprivational perspective", in which development is judged by the way the poor and the deprived fare in each community. Lack of progress in reducing the disadvantages of the deprived cannot be "washed away" by large advances-no matter how large-made by the better-off people.

Interest in the process of development concerns both perspectives. At a very basic level, the lives and successes of everyone should count, and it would be a mistake to make our understanding of the process of development completely insensitive to the gains and losses of those who happen to fare better than others. It would go against the right of each citizen to be counted, and also clash with the comprehensive concerns of universalist ethics. Yet a part-a big part-of the general interest in the progress of a nation concentrates specifically on the state of the disadvantaged.

Successive Human Development Reports have been concerned with both ways of looking at progress. This Report explores in particular the deprivations in human development, including a measure of human development from a deprivational perspective. 


\section{Poverty has many dimensions}

Concerns with identifying people affected by poverty and the desire to measure it have at times obscured the fact that poverty is too complex to be reduced to a single dimension of human life. It has become common for countries to establish an income-based or consumption-based poverty line. Although income focuses on an important dimension of poverty, it gives only a partial picture of the many ways human lives can be blighted. Someone can enjoy good health and live quite long but be illiterate and thus cut off from learning, from communication and from interactions with others. Another person may be literate and quite well educated but prone to premature death because of epidemiological characteristics or physical disposition. Yet a third may be excluded from participating in the important decision-making processes affecting her life. The deprivation of none of them can be fully captured by the level of their income.

Also, people perceive deprivation in different ways-and each person and community defines the deprivation and disadvantages that affect their lives.

Poverty of lives and opportunities-or human poverty-is multidimensional in character and diverse rather than uniform in content.

\section{How does human poverty relate to other approaches?}

Over the years the concept of poverty has been defined in different ways (box 1.1).

\section{Three perspectives on poverty $\quad$ (box 1.1)}

- Income perspective. A person is poor if, and only if, her income level is below the defined poverty line. Many countries have adopted income poverty lines to monitor progress in reducing poverty incidence. Often the cut-off poverty line is defined in terms of having enough income for a specified amount of food.

- Basic needs perspective. Poverty is deprivation of material requirements for minimally acceptable fulfilment of human needs, including food. This concept of deprivation goes well beyond the lack of private income: it, includes the need for basic health and education and essential services that have to be provided by the community to prevent people from falling into poverty. It also recognizes the need for employment and participation.

- Capability perspective. Poverty represents the absence of some basic capabilities to function-a person lacking the opportunity to achieve some minimally acceptable levels of these functionings. The functionings relevant to this analysis can vary from such physical ones as being well nourished, being adequately clothed and sheltered and avoiding preventable morbidity, to more complex social achievements such as partaking in the life of the community. The capability approach reconciles the notions of absolute and relative poverty, since relative deprivation in incomes and commodities can lead to an absolute deprivation in minimum capabilities. 
Poverty in the human development approach draws on each of these perspectives, but draws particularly on the capability perspective. In the capability concept the poverty of a life lies not merely in the impoverished state in which the person actually lives, but also in the lack of real opportunity - due to social constraints as well as personal circumstances-to lead valuable and valued lives.

In the capability concept the focus is on the functionings that a person can or cannot achieve, given the opportunities she has. Functionings refer to the various valuable things a person can do or be, such as living long, being healthy, being well nourished, mixing well with others in the community and so on.

The capability approach concentrates on functioning information, supplemented by considering, where possible, the options a person had but did not choose to use. For example, a rich and healthy person who becomes ill nourished through fasting can be distinguished from a person who is forced into malnutrition through a lack of means or as a result of suffering from a parasitic disease. In practice such discrimination is difficult when dealing with aggregate statistics (as opposed to detailed micro studies of individuals), and the practical uses of the capability concept in poverty analysis have been mainly with simple functioning data. The Human Development Report too presents information that is essentially about living conditions and functionings.

In choosing particular aspects of living for special investigation in a poverty study, there is need for public discussion. There is an inescapable element of judgement in any such selection. In constructing any index of poverty (such as the human poverty index presented in this Report), the selections and the weights have to be explicitly stated and clarified so that public scrutiny can occur. It is very important that the standards to be used are not determined on a top-down basis, but are open to-if possible, emerge fromparticipatory, democratic process. One of the purposes of the Human Development Report has been precisely to facilitate such a process, and this applies to poverty analysis as well.

The "sustainable livelihood approach" to the study, of poverty has particularly emphasized the need for local participation. In this approach each community can define criteria of well-being and the key elements of deprivation as they appear in the local context. This process brings out the concerns and worries of vulnerable people that are persistently neglected in national statistics and in many studies of poverty (box 1.2).

In the 1970s the concept of social exclusion came into the literature to analyse the condition of those who are not necessarily income-poor-though many are that too-but who are kept out of the mainstream of society even if not income-poor. The inadequacy of traditional definitions of poverty, based on incomes and consumption, was widely acknowledged to explain these new concerns. 
BOX 1.2

\section{Criteria of ill-being}

The following criteria, drawn from various participatory studies, were used by, local people in Asia and Sub-Saharan Africa for defining poverty and ill-being:

-Being disabled (for example, blind, crippled, mentally impaired, chronically sick).

-Lacking land, livestock, farm equipment, a grinding mill.

-Being unable to decently bury their dead.

-Being unable to send to send their children to school.

-Having more mouths to feed, fewer hands to help.

-Lacking able-bodied family members who can feed their families in a crisis.

-Having bad housing.

-Suffering the effects of destructive behaviours (for example, alcoholism).

-Being "poor in people", lacking social support.

-Having to put children in employment.

-Being single parents.

-Having to accept demeaning or low-status work.

- Having food security for only a few months each year.

- Being dependent on common property resources.

Source.- Chambers 1997

\section{Measurement of poverty and the human poverty index}

Can the concept of human poverty be targeted and monitored? Can an overall measure of poverty be developed that can inform as well as be used for policy? Can an internationally comparable measure be defined?

This Report introduces a human poverty index (HPI) in an attempt to bring together in a composite index the different features of deprivation in the quality of life to arrive at an aggregate judgement on the extent of poverty in a community. Human Development Report 1996 attempted this through a particular version of the "capability poverty measure". The HPI pursues the same approach, focusing on a broader and more representative set of variables, in a consistent relationship to the human development index (HDI).

Like many, other concepts, Human poverty is larger than any particular measure, including the HPI. As a concept, human poverty includes many aspects that cannot be measured-or are not being measured. It is difficult to reflect them in a composite measure of human poverty. Critical dimensions of human poverty excluded from the HPI for these reasons are lack of political freedom, inability to participate in decision-making, lack of personal security, inability to participate in the life of a community and threats to sustainability and intergenerational equity. 


\section{Poverty depends on the context}

The nature of the main deprivations varies with the social and economic conditions of the community in question. The choice of indicators in the HPI cannot but be sensitive to the social context of a country. For example, an index that concentrates on illiteracy and premature mortality may be able to discriminate between Pakistan and Sri Lanka more easily than it can between, say, France and Germany.

Issues of poverty in the developing countries involve hunger, illiteracy, epidemics and the lack of health services or safe water-which may not be so central in the more developed countries, where hunger is rare, literacy is close to universal, most epidemics are well controlled, health services are typically widespread and safe water is easy to tap. Not surprisingly, studies of poverty in the more affluent countries concentrate on such variables as social exclusion. These can be forceful deprivations and very hard to eliminate in all countries. But they take on relatively greater prominence in the affluent ones. There is no real possibility of constructing an index of human poverty that would be equally relevant in the different types of countries.

Given the pervasiveness of poverty in poor countries, the HPI developed is aimed at that context and the variables chosen reflect that (box 1.3). the nature of poverty in rich countries deserves a specialized study—and a more specialized index-focusing on those deprivations particularly relevant for those countries.

\section{The three indicators of the human poverty index}

The HPI presented in this Report concentrates on the deprivation in three essential elements of human life already reflected in the HDI-longevity, knowledge and decent a living standard.

The first deprivation relates to survival - the vulnerability to death at a relatively early age-and is represented in the HPI by the percentage of people expected to die before age 40 .

The second dimension relates to knowledge-being excluded from the world of reading and communication - and is measured by the percentage of adults who are illiterate.

The third aspect relates to a decent standard of living, in particular, overall economic provisioning. This is represented by a composite of three variables-the percentage of people with access to health services and to safe water, and the percentage of malnourished children under five.

A few observations must be made about this last variable and about why income does not figure in the HPI. The logic underlying the construction of the economic provisioning variable is that the GNP included in the HDI is actually an amalgam of private and public facilities, since public services are paid out of aggregate national income. 
Private income could not be an adequate indicator of an individual's economic facilities, which also include crucial public services (such as health care arrangements and a safe water supply). But why is private income not chosen to supplement the information on public facilities?

BOX 1.3

\section{The HPI-useful for policy-makers?}

The human poverty index can be used in at least three ways.

1. As a tool for advocacy. If poverty is to be eradicated, public opinion and support needs to be mobilized to the cause. The HPI can help summarize the extent of poverty along several dimensions, the distance to go, the progress made. Income poverty also needs to be measured-but income alone is too narrow measure.

2. As a planning tool for identifying areas of concentrated poverty within a country. The HDI has been used in many, countries to rank districts or counties as a guide to identifying those most severely disadvantaged in terms of human development. Several countries, such as the Philippines, have used such analyses as a planning tool. The HPI can be used in a similar way, to identify those most seriously affected by human poverty. Though ranking by any one index alone would be possible-say, by illiteracy rate, lack of access to health services or the percentage in income poverty - the HPI makes possible a ranking in relation to a combination of basic deprivations, not one alone.

3. As a research tool. The HDI has been used especially when a researcher wants a composite measure of development. For such uses, other indicators have sometimes been added to the HDI. The HPI could be similarly used and enriched-especially if other measures of poverty and human deprivation were added, such as unemployment.

Although greeted with controversy when first launched in 1990, the HDI has found an increasing following as a simple measure of human development. The HDI provides an alternative to GNP, for assessing a country's standing in basic human development or its progress in human development over time. It does not displace economic measures but can serve as a simple composite complement to other measures like GNP.

The HPI can similarly serve as a useful complement to income measures of poverty. It will serve as a strong reminder that eradicating poverty will always require more than increasing the incomes of the poorest.

Further work is merited to explore how the HPI and the HDI could be enriched and made more robust in situations where a wide range of data on different aspects of poverty and human development are available.

What the HPI does not show. The HPI provides a measure of the incidence of human poverty in a country (or among some other group), say $25 \%$. This means that judged by the HPI, an "average" of some $25 \%$ of the country's population is affected by the various forms of human poverty or deficiency included in the measure. But unlike with a headcount measure, it is not possible to associate the incidence of human poverty with a specific group of people or number of people. 
One of the problems in assessing the prevalence of income poverty is that the use of the same poverty line in different countries can be very misleading because of the variation in "necessary" commodities. Depending on the prevailing patterns of consumptionclothing, accommodation and such tools of communication and interaction as radios and telephones-many provisions are taken to be essential for social participation in one community without being treated as such in another. As a result, the minimum income needed to escape social estrangement can be quite different between communities.

Given the social pressure, these felt "needs" may compete-for relatively poor people in rich countries - even with the provision of resources for food, nutrition and health care. This can explain the prevalence of some hunger and malnutrition, especially among children, even in the United States, where incomes are high but inequalities generate a heavy burden of "necessity" in the direction of socially obligated consumption, often to the detriment of health and nutritional spending. So, the assessment of poverty on the basis of a low minimum cut-off income used for poor countries fails to show any poverty in generally affluent societies, even when the relatively poor in those societies may lack social participation and may even suffer from hunger and malnutrition.

An alternative is to use different poverty lines in different countries. But it is not easy to decide what the appropriate variations would be and how the respective poverty lines could be estimated. The official national lines cannot serve this purpose, since they reflect other influences, especially political ones, and cannot be used for international comparisons. The general need for a variable cut-off line of poverty is easier to appreciate than it is to find adequate values for variable poverty fines in different communities.

A more practical possibility is to be less ambitious and focus on material deprivation in hunger and malnutrition, not on income. A very high proportion of personal income goes to food and nourishment, especially for poor people in poor countries.

For this we can use information on food intake, which relates to personal incomes. Alternatively, there are estimates of malnutrition, but these are influenced by a number of variables, such as metabolic rate, climatic conditions, activity patterns and epidemiology. Since our concern is with the lives that people can lead, there is a case for going straight to the prevalence of malnutrition, and this is what is done in the HPI, concentrating specifically on the malnutrition of children, which is relatively easier to measure and for which usable data are more uniformly available.

For public provisions, access to health services and to safe water were chosen. Combining these two access variables with the prevalence of malnutrition gives a fairly broad picture of economic provisioning-private and public - to supplement the information on survival and literacy.

These are the basic informational ingredients of the HPI. It must be emphasized that there is some inescapable arbitrariness in any such choice. The choice was made on the basis 
of balancing considerations of relevance on the one hand, and the availability and quality of data on the other. There are inevitable compromises made, and it would be idle to pretend that even the variables that have been included have high-quality data for every country. There has been an attempt, in these selections, to strike a balance between the demands of relevance and the need for tolerably usable data, and these choices would certainly remain open to criticism and public scrutiny.

\section{Weighting and aggregation}

The process of aggregation can be sensitive to the overlaps in the three dimensions of the HPI. For example, consider a case in which in each of the three categories of deprivation, $30 \%$ of people fad to meet the minimum requirement. This can be so because the same $30 \%$ fail in all three fields. But it can also be that a different $30 \%$ fail in each category. Or we may have some combination of the two extremes. In the first extreme case only $30 \%$ are affected by poverty, but they are deprived on all three fronts. In contrast, in the second extreme case as many as $90 \%$ of the population are deprived altogether, but each group has inadequacy in merely one field. Even though information on overlaps (or covariance) is not easy to obtain (since data regarding the different variables come from different sources), these distinctions can be important in describing poverty. They can also be crucial for causal analysis, since deprivation of one kind often feeds others.

However, when it comes to constructing an index, it is not easy to decide whether $30 \%$ of people with inadequacies of all three types represents larger social poverty than $90 \%$ of people having one deficiency each. It is a matter of the importance to be given to depth vis-à-vis breadth. For the purpose of the HPI, the two cases have been treated as equivalent, so that in some sense depth and breadth have been equally considered.

There is a further issue to be addressed in deriving an aggregate index, namely that of substitutability between the three components of the HPI. This is done through an explicit procedure of using an additional weight $(\alpha)$. When $(\alpha$ is taken to be 1 , perfect substitutability is presumed, and the aggregate is obtained by simply averaging the three deprivations. The opposite case of no substitutability corresponds to $\alpha$ being taken to be infinity. In that case the largest of the percentage shortfalls rules the roost. For example, if $30 \%$ fail in field one, $50 \%$ in field two and $45 \%$ in field three, then the overall extent of poverty, in this case, is simply $50 \%$.

Perfect substitutability is too extreme an assumption, and goes against the sensible requirement that as the deprivation in some field becomes relatively more acute, the weight placed on removing deprivation in that field should increase. Nor is the other extreme, zero substitutability, very easy to support, since it implies that any increase in deprivation in any category other than the one with the highest rate of deprivation must leave the aggregate poverty measure completely unchanged. Both extremes are avoided by choosing an intermediate value of $\alpha$. 


\section{The human development index and the human poverty index}

While human development focuses on progress in a community as a whole, human poverty, focuses on the situation and progress the most deprived people in the community.

The distinction between the two is analogous to the distinction between GNP and the income-based poverty index. In the income-based perspective, poverty incidence is needed to monitor progress in eliminating poverty. In the same way, the HPI is needed to judge the extent of human poverty in a country and to monitor its progress.

The growth rate of GNP per person gives an account of progress seen in the conglomerative perspective-everyone's income counts in the GNP total. In contrast, the reduction of an income-based poverty index - such as the decline in the proportion of people below the poverty-line income-uses the deprivational perspective, concentrating only on the incomes of the poor. In this income-based perspective, it would make little sense to argue that since GNP is already based on income information, any income-based poverty measure must be a substitute for GNP. Nor would it be sensible to suggest that the availability of GNP as an indicator makes it redundant to seek a measure of income poverty. GNP and the income poverty measures use the income information in different perspectives-with GNP taking a conglomerative view and the income poverty measures focusing specifically on people poor in income.

\begin{tabular}{lcl}
\hline Perspective & Income & Human life \\
\hline Conglomerative & GNP per capita & HDI \\
& & \\
Deprivational & Headcount index & HPI \\
\hline
\end{tabular}

The relationship between the HDI and the HPI has to be seen in a similar way. Both have to use the rich categories of information associated with human developmentcharacteristics of human lives and quality of living that go far beyond what income information can provide. But while the HDI uses these characteristics in the conglomerative perspective, the HPI must use them in the deprivational perspective. The availability of GNP measures does not obviate the need for an income-based poverty indicator, nor does the HDI measure eliminate the need for an HPI.

\section{Values and rankings of the human poverty index}

Estimates of the HPI have been prepared for 78 developing countries having adequate data (table 1.1). The HPI value indicates the proportion of the population affected by the three key deprivations in their lives-showing how widespread human poverty is.

At the top of the rankings are Trinidad and Tobago, Cuba, Chile, Singapore, Costa Rica-these countries have reduced human poverty to an HPI value of less than $10 \%$. In other words, these countries have reduced human poverty to the point at which it affects less than $10 \%$ of the population. 
At the bottom are the seven countries whose HPI exceeds 50\%-Niger, Sierra Leone, Burkina Faso, Ethiopia, Mali, Cambodia and Mozambique. And in almost half the 78 countries covered, the HPI exceeds $34 \%$, implying that about a third of their people suffer human poverty.

How does the HPI compare with income-based measures of poverty?

- Some countries have done better in reducing income poverty than human poverty. In Côte d'Ivoire and Egypt less than $20 \%$ of the people are income-poor, but $35 \%$ or more are affected by human poverty. These countries could pay more attention to reducing basic deprivations in choices and opportunities, especially by extending access to basic education and health services.

- Other countries have done better in reducing human poverty than income povertyChina, Costa Rica, Kenya, Peru, the Philippines, Zimbabwe. These countries have invested heavily in reducing deprivations in basic human capabilities.

Progress in reducing poverty in income and progress in reducing poverty in human choices and opportunities do not always move together. Regression analysis indicates a weak relationship between the headcount index of income poverty and HPI (figure 1.1). So, in monitoring progress, the focus should not be on income poverty alone, but on indicators of human poverty as well.

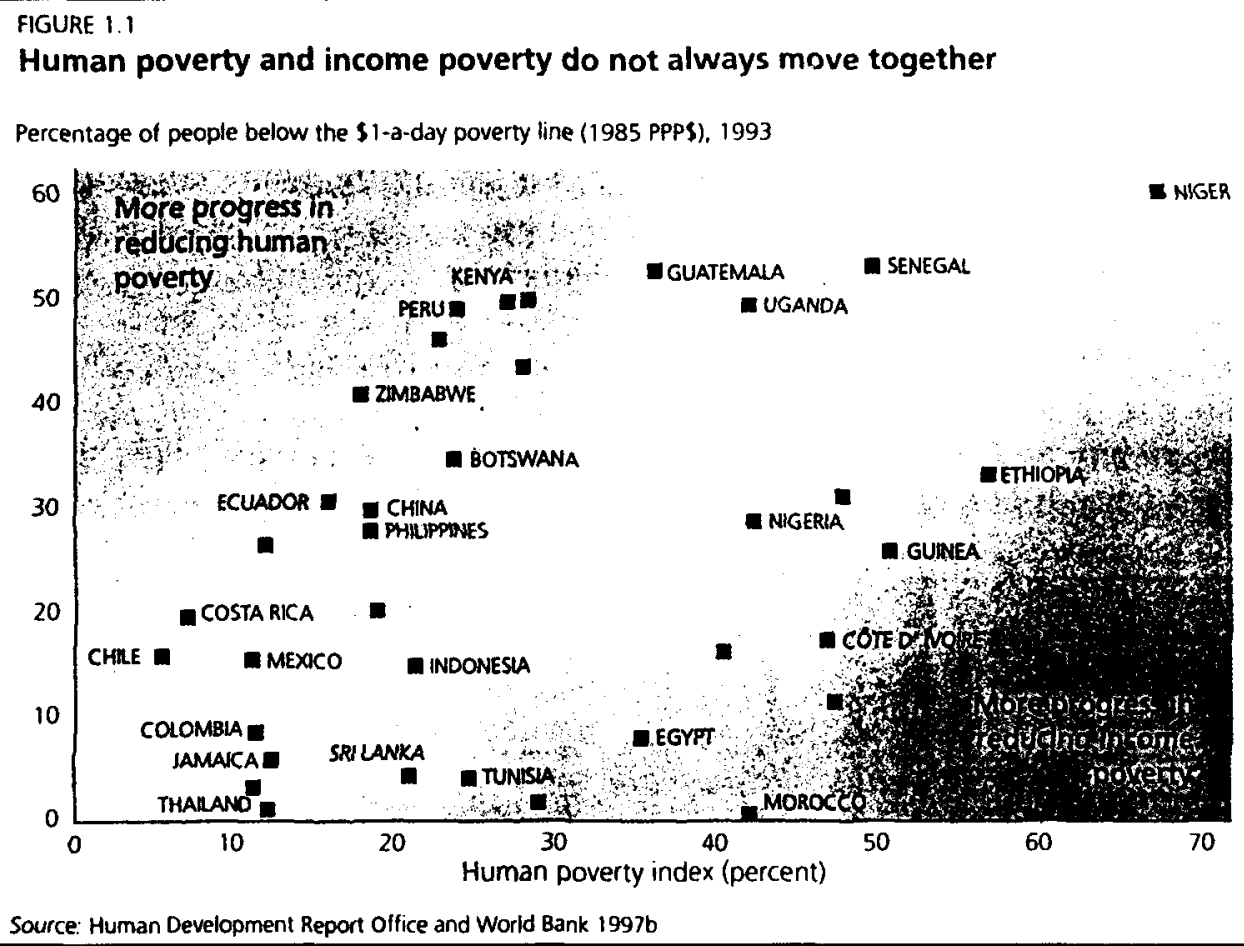


Comparing the HPI with the HDI reveals stark contrasts in some countries. These differences can alert policy-makers to the need to make human development better distributed, more pro-poor (figure 1.2). The HDI measures the overall progress of a country in human development. It can mask unequal distribution of that progress and the widespread human poverty that remains. Countries such as Namibia, Morocco, Pakistan, Egypt, Guatemala and Cambodia rank higher in the HDI than in the HPI-signalling the need for greater attention to human development for the most deprived. 


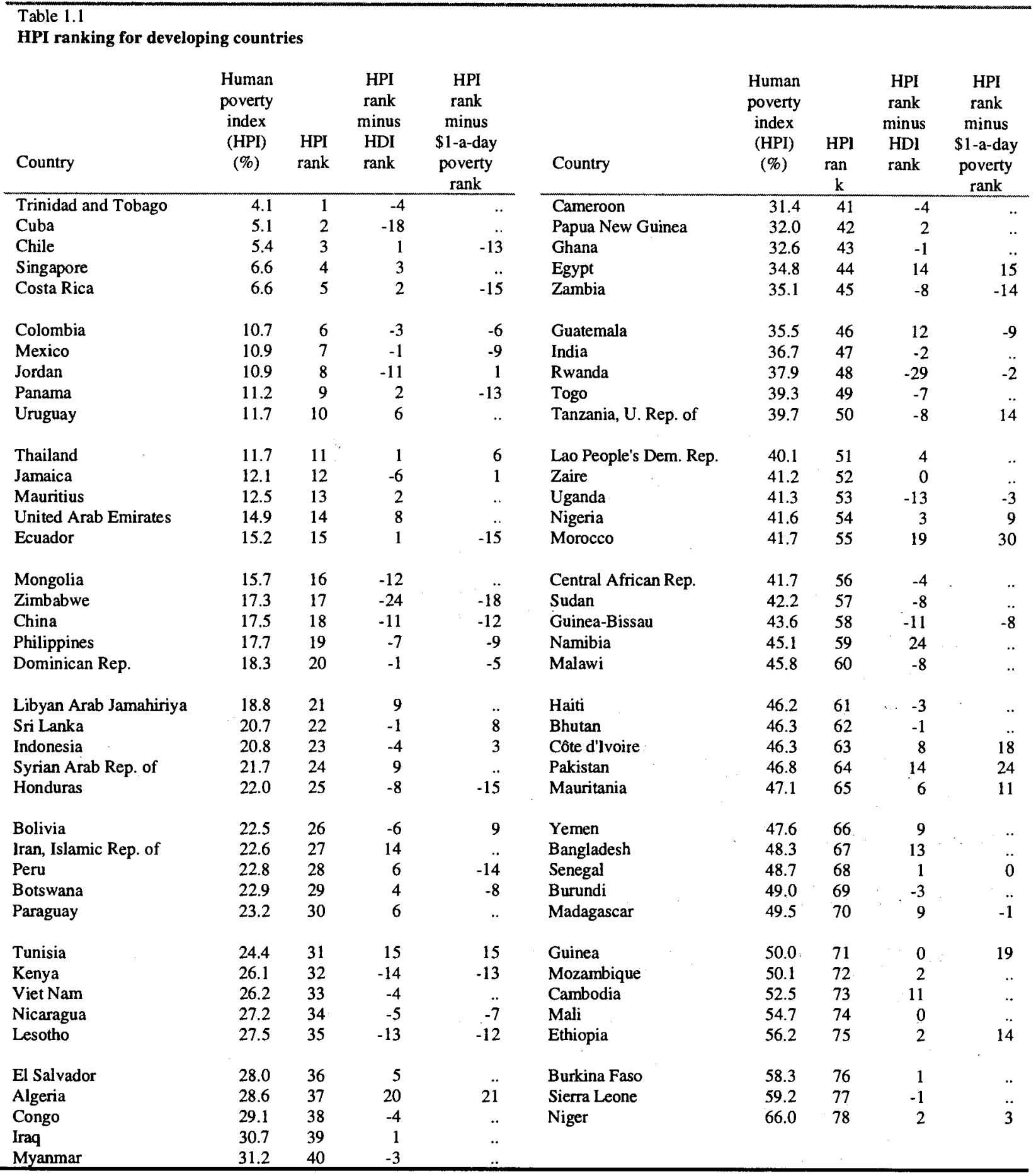

Note: HDI and $\$ 1$-a-day poverty ranks have been recalculated for the universe of 78 countries. A negative number indicates that country performs better on the HPI than on the other measure, a positive the opposite.

Source: Human Development Report Office and World Bank 1996. 


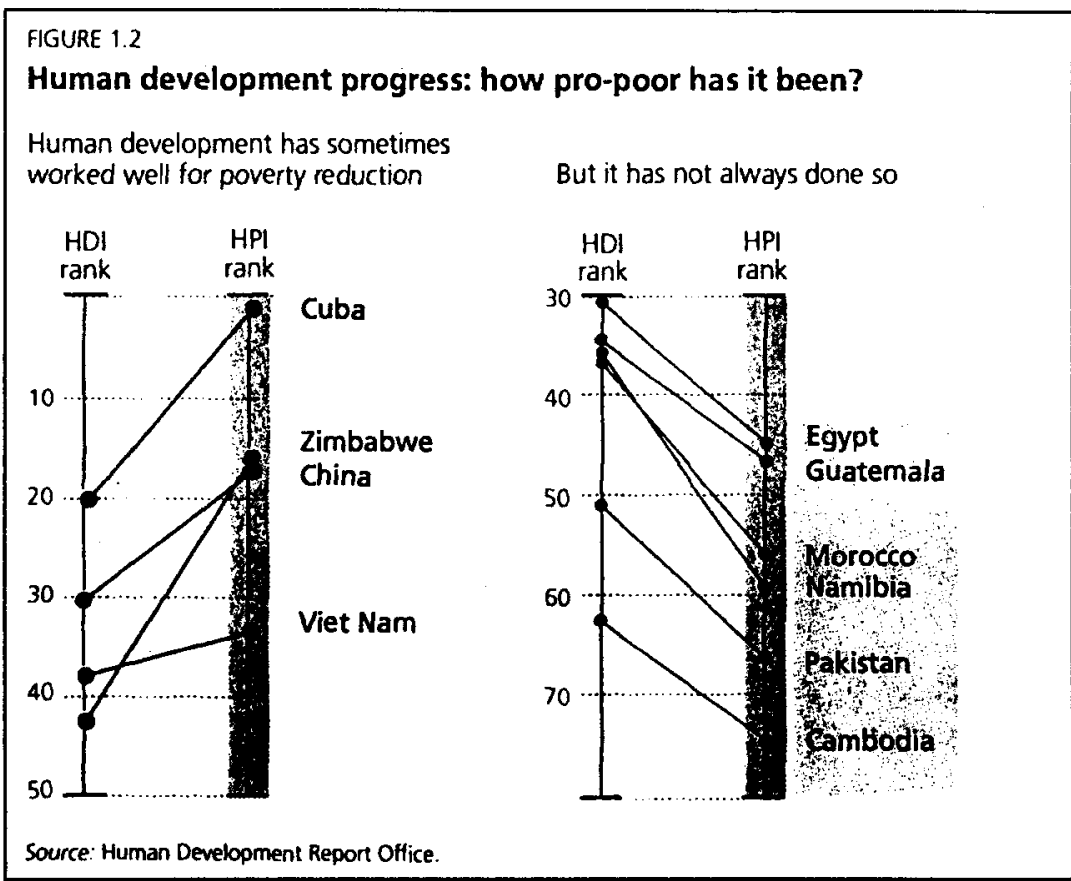

Other countries rank much higher in the HPI than in the HDI-such as Zimbabwe, Cuba, China, Zambia and Viet Nam. In these countries overall progress in human development was pro-poor, effectively helping the most deprived lift themselves out of human poverty.

The countries at the bottom of the HPI rankings also rank near the bottom in the HDI. In these countries the overall progress in human development has been too low to raise the majority of their people from poverty.

\section{Regional and global human poverty}

HPI estimates for regions show that:

- Human poverty affects a quarter of the developing world's population, while income poverty affects a third.

- Human poverty is most widespread in Sub-Saharan Africa and in South Asia, affecting about $40 \%$ of the people.

- Progress in reducing human poverty and income poverty do not always go together. The contrasts are most stark in the Arab States, where income poverty was reduced to $4 \%$ by 1993 but human poverty was still 32\%, and in Latin America and the Caribbean, where human poverty has been reduced to $15 \%$ but income poverty is still $24 \%$ (figure 1.3 ). 


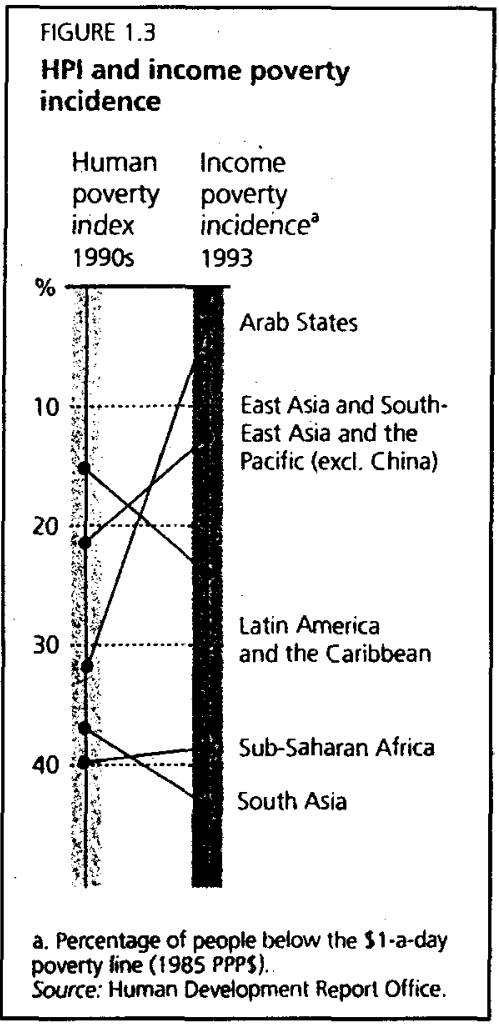

\section{Trends in human poverty}

The trends in human poverty in developing countries with available data show that although all were able to reduce the incidence of human poverty during the past two decades, the extent and pattern of reduction differed (table 1.2). 
Table 1.2

Trends in HPI for selecting developing countries 1970-90

HPI Value Change in

$(\%)$ HPI value

(\%)

\begin{tabular}{lccc}
\cline { 2 - 4 } Country & 1970 & 1990 & $1970-90$ \\
\hline Thailand & 34 & 12 & 66 \\
Mexico & 30 & 11 & 63 \\
Chile & 13 & 5 & 59 \\
Costa Rica & 15 & 7 & 56 \\
Trinidad and Tobago & 9 & 4 & 54 \\
Sri Lanka & 35 & 21 & 41 \\
Panama & 17 & 11 & 36 \\
Mauritius & 19 & 13 & 35 \\
Peru & 28 & 23 & 19 \\
\hline
\end{tabular}

Source: Human Development Report Office

While Mexico and Thailand were able to reduce the incidence of human poverty by two-thirds, Peru, starting from a similar base, reduced it by less than a fifth. A similar comparison can be made for Costa Rica and Panama.

\section{The disaggregated human poverty index}

Estimating separate HPIs for groups or regions reveals disparities and contrasts within countries, and pinpoints concentrations of poverty (figure 1.4). 


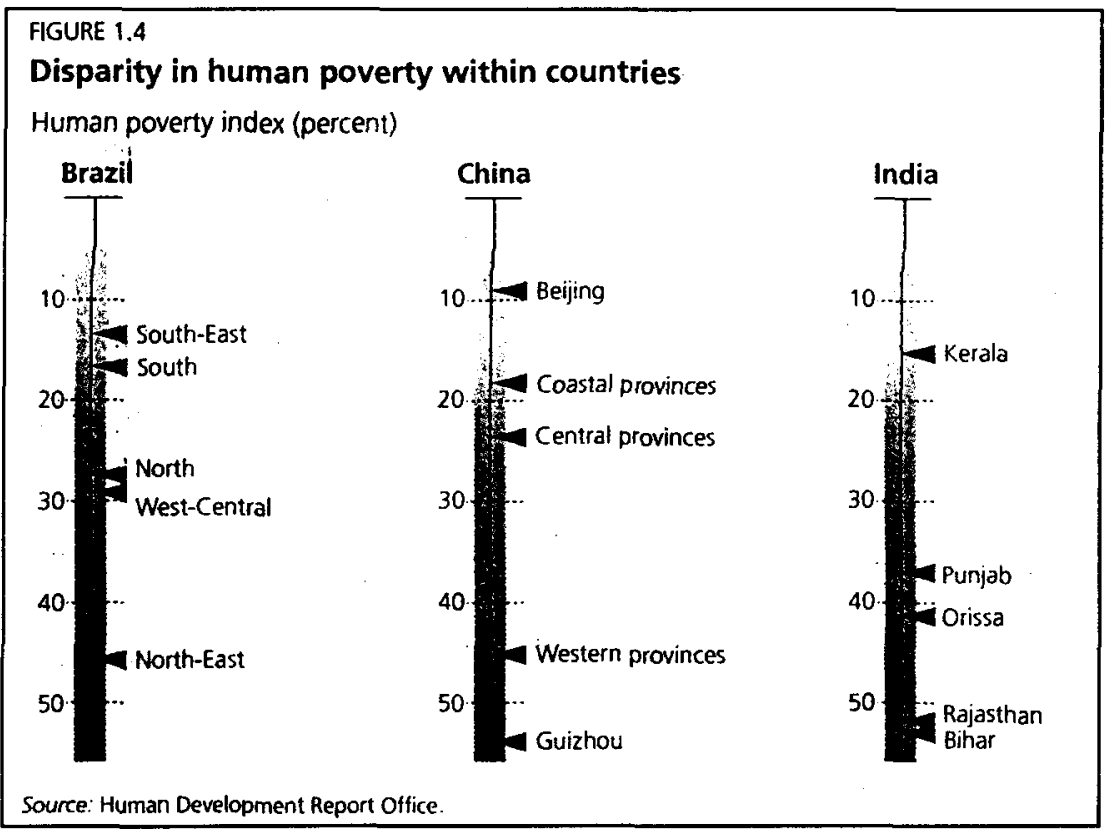

Brazil-sharp contrasts exist between the North-East region, with an HPI of $46 \%$, and the South and South-East, with HPIs of only $17 \%$ and $14 \%$. These disparities have grown over the past two decades, as the incidence of human poverty declined by two-thirds in the South, but only a third in the North-East.

China-Disaggregated HPIs for Chinese provinces show stark contrasts. Human poverty is far more pervasive in the remote interior provinces of the western region (with an HPI of $44 \%$ ) than in the coastal region (with an HPI of $18 \%$ ).

India-Kerala is well ahead, having reduced human poverty to $15 \%$, a clear reflection of the state's policy commitment to equity and human development. In Rajasthan and Bihar human poverty is pervasive - at more than $50 \%$. 



\section{ON STATISTICAL MAPPING OF POVERTY: SOCIAL REALITY, CONCEPTS AND MEASUREMENT}

by

Sonia Rocha

Instituto de Pesquisas Econômicas Aplicadas (IPEA)

Brazil 


\section{On Statistical Mapping of Poverty: Social Reality, Concepts and Measurement}

\section{Relating Concepts and Measurement to Social Reality}

Poverty is a complex phenomenon. It might be broadly defined as a situation in which needs are not sufficiently satisfied, although to make the concept operational one should necessarily specify which needs are these and at what level they are considered to be appropriately met. In each case, the relevant definition depends basically on the standards of living and on the way different human necessities are generally met in a given society. Being poor means not having access to the minimum required to function adequately in that society.

This general definition requires qualification regarding the concepts of absolute and relative poverty. Absolute poverty is theoretically associated to the vital minimum. The concept of relative poverty incorporates the concern with inequality or relative deprivation, where the bare minimum is socially guaranteed. Differences among countries in respect to levels of socioeconomic development and cultural traditions require concepts of poverty that take their specificity into account. Nevertheless, the persistence of widespread and chronic deprivation of basic needs nowadays makes absolute poverty the obvious priority in terms of definition, measurement and political action from the international point of view. That is why absolute poverty is the underlying concept when international agencies place the theme at the center of their agenda. The 1990 World Bank report estimates that one billion people lived in poverty in that year, which implies the idea of absolute poverty without directly coping with the problem of determining which minimum is not being met.

Defining the relevant and operational poverty concepts and choosing the adequate measurement procedures is the result of a sensible and informed analysis of social reality. On one hand, it is a matter of identifying the essential causes of poverty in a given society. Is it widespread and affects the majority of the population or is it locally concentrated? Which are its roots? Is it a traditional syndrome or does it result from economic and technological changes? What are its main features - under-nutrition, low schooling, lack of access to public services or unemployment and marginality? Who are the poor in terms of some essential characteristics?

This overall information on the poverty syndrome is the key element for conceiving a framework in which poverty analysis and anti-poverty policies are to evolve. Specifically it means adopting concepts and measurement instruments that seems the most appropriate to a specific context in terms of social reality and data gathering possibilities. Although the main objective in dealing with poverty consists in the design and operation of social policies, concepts and measures being solely instrumental, the choices made at this very first step play an essential role. Obtaining positive policy results later on will largely depend on how sensibly poverty has been defined at the outset, both in terms of the social reality and of measurement possibilities. 
Considering the ample variety of poverty situations worldwide that have led to an equally large number of essays in terms of definition, measurement and policies, it would be certainly useful to identify "typical" poverty situations to which correspond successful experiences in terms of conceptual and measurement choices. This implies the idea that the quest for a single internationally agreed recommendation on poverty concepts and measurement methods is not a feasible or productive path. Conversely, to identify and systematize experiences in a wide array of situations seems more promising in the interest of improving the way of dealing with poverty. for instance:

A simple schematic typology of poverty situations could be taken as departing point,

a) Poverty where resources are insufficient to guarantee the basic minimum for the majority of the population - That is the case of countries where poverty is widespread and resources are scarce overall. In this context, the definition of an operational concept of poverty using very simple data responds to a minimum requirement: the availability of a basic tool for establishing policy priorities and monitoring results from social programs.

b) Poverty associated to an inadequate pattern of growth - In this case the absolute poverty syndrome is often associated to a component of inequality. These countries present income levels higher than those in a), which generally correspond to a less severe restriction in terms of data. Defining poverty concepts according to specific social features - for instance, poverty being predominantly urban or rural - and to the availability of data can highlight an array of interesting analytic possibilities.

c) Poverty in developed countries - poverty in industrial urban societies is generally linked to income inequality and social exclusion. Since statistical data is seldom an important restriction, the design of the analytical framework is essentially determined by social policies objectives.

Associating a typology, as the one suggested above, to different conceptual approaches and levels of complexity of measurement methodologies could be conceived as a way to organize diversity and to indicate promising paths. One of the Expert Group's possible tasks would be to recommend a set of conceptual and measurement procedures in accordance with different national situations. Taking into account that poverty incidence and development of the statistical system are in general inversely related, a central concern shall be to identify procedures that have been successfully adopted in countries under diverse stages of development. In this sense, it would be especially useful to highlight the most critical issue: the possibilities of defining and measuring poverty, as well as of designing anti-poverty policies in countries in the first category, where statistical information is scant no household survey is available, for example. Under these circumstances, which is the best way to make the poverty concept operational? Despite the fact that the development of the statistical system is desirable, it is certainly important to tune information needs and the advancement of the statistical system to social realities and general priorities. On the other 
extreme case, which concerns developed countries, it is relevant to verify how improvements in the statistical system and the adoption of sophisticate techniques - like the use of panels from household surveys - have led to a better understanding of the dynamics of poverty. Such subsidies may be useful both for reorienting social policies in developed countries, and for highlighting more general issues on poverty concepts and measurement in other countries.

In the following two sections we shall deal with the relationship between poverty concept and measurement. The aim is not only to demonstrate that there is an ample scope of possibilities concerning the choice of conceptual and empirical approaches to poverty, but that it is possible to conceive a scale of growing complexity in both regards. Choosing the most appropriate combination according to socioeconomic development and availability of statistics in each country is essential for dealing successfully with poverty concerns and social policy design.

\section{From Basic Needs to Insufficiency of Income - Scaling up Concepts According to Social Reality}

In order to make the poverty concept operational for social policy purposes, two basic approaches, not mutually exclusive, can be identified: the basic needs and the poverty line.

\section{a) The basic needs approach}

The most basic needs are those related to physical survival. Undernutrition, which is often associated to poor health and high mortality rates, especially among infants, is still chronic in many countries. Famine, as result of bad weather, war and/or inadequate administration of scarce resources eventually creates large contingents of people who risk death without emergency aid. Thus, this malnutrition approach to poverty is, unfortunately, still operational for identifying the poor, even when considered in its most direct form, that is, the physical characteristics of the population. Anthropometric evidences of low weight in adults, or low height for age among children, as well as high mortality rates are all indicators of extreme poverty. It may refer to a micro approach, aiming at identifying individuals with adverse characteristics; alternately, the macro approach consists in delimiting a population in which these individuals are strongly represented. In both cases, this approach is anchored on physical indicators and relates unequivocally to the concept of absolute poverty. Considering insufficiency of income or resources for acquiring food has different implications and thus not fit here.

Adopting the more general basic needs approach to poverty means going beyond food needs to incorporate a wider range of human necessities, such as education, sanitation, shelter. Differently from the malnutrition approach, defining the poor based on minimum achievements in such aspects offer various possibilities. Firstly, it allows for using different judgments concerning the way to rank the poor, depending on the number of aspects for 
which the minimum achievements are not met, and/or on the score derived from the weights attributed to each unmet need. Secondly, it allows for considering more or less strictly these basic needs, according to the present situation in each specific society. Reading and writing skills are, for instance, very basic requirements, but in societies where literacy is widespread this basic need criterion will not discriminate the poor. A higher educational requirement might be considered - primary schooling is a possible way of scaling up the requirement -, thus demonstrating there is an implicit relative component when this approach to poverty is adopted. The relative component is also obvious when establishing sanitation and shelter basic needs. In the case of sanitation, the rural/urban context is to be explicitly taken into account, since it is more essential to have adequate sewerage in urban areas because of their higher demographic density. On the other hand, basic needs in terms of shelter have to be necessarily viewed in terms of cultural and climatic realities.

\section{b) The poverty line approach}

While the basic needs approach is specially useful in respect to access to public nonmarketable goods and services, the poverty line has became the most usual tool to define poverty in terms of command over resources to satisfy needs normally placed in the sphere of private consumption. It consists in attributing a monetary value to a set of basic goods and services, and identifying as poor those whose income is lower than the defined minimum. Using an income parameter in order to distinguish those to whom the basic minimum is not guaranteed requires a strong assumption: different people have the same needs and derive the same welfare from a given income. In practice, the poverty line remains just an income parameter, telling nothing about the real conditions of access to goods or services.

There is a fundamental methodological distinction when adopting the poverty line approach. Firstly, poverty lines may be defined in relation to the absolute poverty concept, thus associated to the value of a basic bundle of goods and services. Originally applied by Rowntree to early twentieth century York, England, it disseminated in the industrialized countries and became the most usual approach to defining and measuring absolute poverty the world over. Nevertheless, establishing the composition of the basic basket of goods and services and valuing it in accordance to some absolute poverty concept is not an easy task. There are plenty of choices to be made along the way, most of them necessarily arbitrary, and it is unavoidable to embody relative poverty considerations even when aiming at defining an absolute poverty income parameter (Ravallion, 1992).

The most conceptually strict component of the absolute of poverty line is the estimate value of the food expenditure necessary to attain the recommended food energy intake (This parameter is usually referred as "indigence line" or "extreme poverty line"). For developing countries, this can be the most appropriate parameter for defining the poor. It is noteworthy that even when defining the poor as those who would be unable to buy the basic food basket, using an income parameter means that we are measuring poverty, not hunger or undernutrition, as it was the case in the basic needs approach. 
Defining the poor on the basis of a higher income parameter, that is, one that encompasses both the costs of the food basket and an allowance for non-food goods is necessarily more cultural bound. When defining the non-food needs composition and value there is no consensual minimum to be used as reference, which differs from the situation of using the nutritional requirements for the food basket. In this sense, even when intentionally referring to the absolute poverty concept, poverty lines are more prone to incorporate relative poverty considerations than the indigence line.

As a matter of fact deviating from the most basic basket when establishing the composition of the bundle and services goods may be a conscious policy alternative. Thus, poverty defined according to this less strict income parameter incorporates relative poverty components, which may be conceptually adequate given the socioeconomic conditions and policy objectives.

Alternatively, the poverty line approach is directly associated to the relative poverty concept: this is the relevant approach when the basic necessities of life are covered, and inequality among households becomes the main concern. In this case, the income parameter is generally defined in relation to the median or the mean value of the income distribution, thus avoiding the tricky questions of defining a basket of goods and services and of valuing it. This approach responds to the concern with the rights of citizens to operate in a modern monetary urban society. The income parameter, although not guaranteeing the same utility or level of welfare for different households, has the advantage of not imposing consumption preferences on individual decision-makers.

While associating the poverty line to the relative poverty concept is simple, both conceptually and empirically, the use of the poverty line in respect to absolute poverty remains tricky. Almost a hundred years after the first empirical studies by Rowntree (1901), there is still no clear-cut solution to absolute poverty definition. Furthermore, the use of absolute poverty concept demands a sophisticated database, including household income and consumer prices surveys, still unavailable in many underdeveloped countries. Even when data is available, basing the poverty definition on the income variable may not be an adequate choice in countries which are essentially rural and where most of the basic necessities of life are not obtained through monetary exchanges. Conceptual choices must be made so as to grasp the relevant aspects and to pose the right questions in respect to poverty in each country. This concern about notional specificity and the search for the most adequate conceptual solution adds extra problems to comparative studies. Given the differences among countries, comparative studies will be limited to a few selected indicators so as to rank countries according to their level of poverty. The scale will be probably useless to differentiate among the richest countries, but it may be helpful to enhance the understanding of national poverty, to provide the means for designing anti-poverty policies and for monitoring results obtained in terms of poverty incidence.

Making poverty definitions operational in each socioeconomic and cultural context requires conceiving them to be compatible with measurement possibilities and social policy objectives. 


\section{Measuring Poverty - Social Realities and Data Restrictions}

Most of the research effort on poverty is concentrated on measuring its extent, generally focusing on the number of the poor, based on income of the individual or the household. It has been extensively discussed and well documented in the literature that a) there are no objective standards of measurement; b) that the different measures have shortcomings, both theoretical and empirical; c) and that the choice of one measure instead of another may lead to quite different results. Nevertheless, once a measurement is obtained, its background shortcomings and restrictions are often minimized, and results are often compared to others based on different concepts and premises. The necessary link between concept and measurement is often lost, which has perverse effects on the use of the available measures in designing social policies and/or evaluating their outcomes.

A recent review on poverty research (Oyen, 1996) shows that most efforts on poverty mapping has followed paths that have been set for developed countries, thus being strongly dependent on the model of statistical data collection long established in these countries. Adopting income-based measures of poverty and deriving a poverty profile for the subpopulation defined by a certain cut-off point requires, beyond the outstanding importance of the income variable in the relevant socioeconomic setting, a relatively developed statistical system. The resources and effort needed to follow this path may be out of reach for many developing countries.

A more modest approach may be perfectly adequate to figure out poverty incidence and its characteristics. The basic needs approach, which represented a clear inflection in the way of looking at development and poverty in the sixties, is a possible alternative (Adelman, 1974). It was originally suggested in order to shun the GDP or the per capita income as key variables in determining the level of development, which were widely use as basis for ranking the countries or for defining regional development priorities within countries. Avoiding income would permit to circumvent its measurement problems, which are particularly acute in comparative studies. Furthermore, there was mounting resistance to associate income to well being, and to envision economic growth as a development objective, since it did not necessarily trickle down to the poor. Accordingly, social progress could be better assessed by considering the effectiveness by which basic needs of the population were actually met "as measured by the flow of goods and services enjoyed in a unit of time" (Drewnowski and Scott, 1966).

Empirically, the procedure consists in defining the best indicator for each basic need, which should take known characteristics of poverty in a given society and the availability of data on the living conditions of the population into account. Some authors argue that the most essential need is related to guaranteeing life itself and, in this sense, "life expectancy at birth would be a good single measure of basic needs" (Hicks and Streeten, 1979). The evaluation of how basic needs are being met may be as detailed as data permits, but it is probably easy to reach a consensus that the most basic needs are food, sanitation, and 
schooling. Nevertheless, the way satisfaction is defined for each of these needs is best served on a case by case basis'.

Two aspects are of foremost importance when adopting the basic needs approach. The first concerns the fact that satisfaction of needs are to be evaluated on the basis of effective results (for instance, reduction of the number of persons affected by a certain disease) instead of the means deployed to attain that goal, like the number of vaccines administered or the value of expenditure for disease control. This sensible restriction makes many usual social indicators inappropriate when adopting the basic needs approach. ${ }^{2}$ Secondly, avoiding the income variable both as an indicator per se and as cut-off criterion, which is certainly an advantage when household survey data is not available, represents a shortcoming in terms of information. It results in ignoring that income compensates for certain adverse conditions, especially those that derive from inadequate provision of public services. If the basic need is defined, for instance, as access to water from the public network, ignoring income means placing on the same ground a family who lives in a densely populated slum in the outskirts of the city and another whose dwelling is located in a newly developed well-to-do condominium. This last one has an obvious advantage: it can use its income to pay for the services of water trunks.

The more culture bound are the selected indicators, the more difficult it is to establish international comparisons. Nevertheless it is conceivable to agree to some basic indicators which are deemed relevant in different contexts. The United Nations Development Program, for example, has developed a very simple index - the Human Development Index (HDI) - in order to rank different countries on their performance in terms of three basic aspects, two of them being schooling and life expectancy, which fit perfectly as basic needs indicators. A larger set of indicators conceived as to take poverty characteristics and data restrictions in each country into account provides an useful tool, both for poverty analysis and social policy design on a national basis, and for international comparisons.

While a basic needs set of indicators may do without income information from a household survey, such information is an essential data requirement when using the poverty line approach. Comparing observable household income to the poverty line is central to deriving the two basic sets of results. The first set consists in the so-called income-based measures of poverty, which include the headcount, income gap ratio, measures of inequality, and eventually synthetic indexes encompassing these three different dimensions of insufficiency of income. ${ }^{3}$ In respect to the second set of results, the income parameter is the

1. To have guaranteed access to safe water is clearly a basic need. The appropriate definition of what might be an acceptable access vary across different societies, for example, water from internal plumbing, a community well or any of a variety of intermediate possibilities.

2. This is the case of social indicators that refer to inputs, like the number of doctors to the population or the value of expenditures in social programs.

${ }^{3}$ Haguenaars (1986) presents an excellent overview of income-based poverty indicators, particularly in respect to axiomatic requirements and measurement errors. 
cut-off point for delimiting the poor sub-population, which may then be characterized in relation to living conditions also investigated in the household survey. In this sense, combining income and living condition variables is one of the advantages of using the poverty line approach.

Thus, the minimum necessary requirement for using the poverty line approach is a household survey on income and other population characteristics. From the Population Census, which takes places every five or ten years and is considered a essential component of the statistical system in all countries, it is possible to derive a general benchmark in terms of poverty incidence and profile. However, the quality of the results obtained depends on the significance, relevance, and acuity of measurement of the income variable, which may vary widely in different settings. Availability of household sample surveys in shorter time intervals provides for a closer monitoring of the least structural aspects of poverty, like the relationship between the impact of the level of productive activity on income and poverty.

Data needs associated to the poverty line approach may be scaled up to include panels of informants designed for long-term monitoring. Their aim is to have long-term evidence on the characteristics of poverty dynamics, that is, which factors affect poverty incidence - positive or negatively - in a particular setting. Panels are specially useful for identifying long-term impacts of public policies aimed at the poor, so that careful consideration of their results may represent an important contribution to the understanding of poverty and designing anti-poverty programs, even under diverse socioeconomic-economic conditions.

Besides the data requirements from household surveys, using the poverty line approach to absolute poverty depends on information for establishing the income parameter itself. As in the case of the household survey, data requirements can also be scaled according to available resources and policy priorities. In the least demanding case, the poverty line can be conceived as the value associated to a basic food basket. This value can be obtained through a linear programming procedure using available information on the most popular food items, their nutritional content and consumers prices. Establishing an absolute poverty line without a consumption survey means to make arbitrary choices concerning what the appropriate Engel coefficient is in a particular case. Nevertheless, even where very scant statistical information is available, it is possible to derive two poverty line parameters, the one associated to the food basket being theoretically the most sound, since it is based on universally accepted nutritional requirements.

A more careful definition of the minimum value of the basic consumption bundle depends on some sort of consumption survey, preferentially one which allows for considering consumption patterns associated to different income levels. Results in terms of consumption per decile of the income distribution, for instance, provide the means for making various choices concerning the poverty line. Strictly adopting consumer's preferences in face of the income restriction means selecting as the basic consumption bundle the one that allows for satisfying nutritional requirements at the lowest cost. Many other possibilities for establishing the food basket and the allowance for the non-food needs 
have been conceived under different situations. Nevertheless, availability of household budget survey data is essential for exploring these possibilities.

The household budget survey is a complex and expensive sample survey, which has an important place in advanced statistical systems: among its various uses, it provides key information for establishing a detailed national production account, inputs for macroeconomics models and weights for the consumers price index. Nevertheless, its execution, even at quinquennial intervals, commands low priority in countries where the core of a basic statistical system is not in place yet ${ }^{4}$. The use of budget survey results for establishing poverty lines represents a very marginal benefit considering the total costs of this survey. Consequently, it is unlikely they will be carried on just for this purpose.

Since a household budget survey generally means that a consumers price system is available, updating the values for the poverty lines defined for a base year becomes a simple task yielding more reliable values than when prices are based on independent estimates.

A final observation on the use of the poverty lines approach is due. It is hardly conceivable that a single income parameter may adequately reflect the cost of satisfying the basic necessities of an individual in families with different characteristics (size and composition) living in diverse spatial settings (regional and urban/rural). Differences in family size and composition may suggest taking economies of scale and scales of equivalence into consideration when applying the poverty line approach. Although theoretical possibilities are well mapped, choices are necessarily arbitrary, thus leading to inevitable controversies concerning the results obtained. The use of the simple per capita household income as variable is probably the safest and the least demanding approach in terms of statistical data and processing.

With respect to the spatial component, allowance for differences in the cost of living of the poor in different areas of the same country should be made when establishing poverty lines. If data on consumption and prices at the sub-national level are available, they should be used to go as far as possible in defining local specific poverty lines. Whenever a national poverty line is crudely defined from a minimum cost food basket, at least a urban/rural breakdown is recommended on the basis of the current knowledge on the lower monetary needs for living in rural areas.

${ }^{4}$ Defining what the core of a national statistical system should be is obviously a very controversial issue. Probably there would be little dissent when population and economic census, vital registers, financial and foreign trade statistics are proposed. 


\section{MEASUREMENT OF POPULATION'S LIVING STANDARDS} BY APPLYING DIFFERENT METHODOLOGIES:

\section{THE MEXICAN EXPERIENCE}

by

\section{Miguel Cervera}

Instituto Nacional de Estadística, Geografía e Informática (INEGI)

$$
\text { México }
$$


Contents.

I. Introduction.

II. Unsatisfied Basic Needs Method (UBN).

III. Poverty Lines Method (PL).

IV. Alternatives for Welfare Measurement. 


\section{Measurement of Population's Living Standards by Applying Different Methodologies: The Mexican Experience}

\section{INTRODUCTION}

The assessment of the population living standards is a theme that has been of great importance along the history for nations and for multilateral organisms fostering economic development. Also, because of the crisis periods faced during last two decades, governments of different nations are increasingly concerned since macroeconomic unbalances have deteriorated the population's living standards, mainly in developing countries.

In Ibero-America the debt crisis and the subsequents macroeconomic adjustment programs, implied that large sectors of the society were affected in their living standards, worsening their already precarious situation, as had been documented by different investigations in the sense that major effects of adjustment processes have relied on sectors that showed great lacks and currently face margination conditions and social backwardness. ${ }^{1}$

Currently poverty erradication represents one of the principal concerns of the region's governments, and it constitutes one of the priorities in the working agenda of the meetings convened by different multilateral organisms for analyzing this phenomenon. Presently, social development and welfare improvement are a fundamental condition to preserve social peace and encourage countries' economic development and their total integration into the trade blocks under way in differents world regions.

In Mexico, several are the actions that have been undertaken by the society and the government to improve the living conditions of important population segments throughout the national territory.

The data base elaborated by the INSTITUTO NACIONAL DE ESTADÍSTICA, GEOGRAFÍA E INFORMÁTICA (INEGI) of Mexico, has allowed researchers and private organizations and universities to make different studies to learn and to evaluate the evolution of poverty in Mexico in the period between $1984-1992 .^{2}$

\section{UNSATISFIED BASIC NEEDS METHOD (UBN)}

Differents efforts have been taken up by public and private national researchers, as well as by international organisms, to develop objective methodologies to quantify the

\footnotetext{
'For further datails look for PREALC “La Deuda Social en América Latina”, Santiago de Chile, 1989.

${ }^{2}$ See INEGI-CEPAL "Metodology document Magnitud y Evolución de la Pobreza en Mexico 19841992”,Mexico 1983.
} 
segment of the population without access to the minimum satisfactors that guarantee an adequate life level and therefore several lacks of short-term and structural order.

Some of the proposed methodologies have been oriented to evaluate the structural needs observed in households due to the lack of access to several basic services as well as lacks of the households members in terms of educative aspects, access to health services and in the household's potential economic capacity to satisfy the familys consumption needs.

In accordance to the above, the idea came about developing a measurement method to assess the access to and the satisfaction for a minimum set of servicies considered essential to the country's population in order to reach an adequate living standard. This method is known as UNSATISFIED BASIC NEEDS (UBN). ${ }^{3}$

For correct use of the UBN method the set of basic satisfactors (SBS) and its components must be defined. These are linked to the availability of basic infraestructure and services; that is, a set of needs wich requires complete satisfaction considered indispensable for life, is specified.

As the second step, the appropiate variables must be selected to produce indicators expressing degrees of satisfaction for the set of defined needs.

The consumption pattern is valued at purchase prices payed by households; this value is commonly known as the indigence or extreme poverty line.

Then family incomes are compared with the cost of the set of basic satisfactors (SBS) and, in accordance to their financial capacity, households are classified as follows:

- Extreme poverty households: When the household income is less than the cost of the family's SBS. In other words, family incomes are not sufficient to satisfy its feeding needs.

- Poor households: When family income is higher than the SBS cost, but two times less than this value. value.

- Non poor households : When family income is two times higher than the SBS

Policies designed to overcome poor's conditions are associated to household economic capacity and must be directed to encourage the creation of permanent jobs and to improve earnings levels of the employed population.

This methodology is widely accepted and it is used by a large number of countries and especialized international agencies interested in learning about the evolution of world

\footnotetext{
${ }^{3}$ First works about Ibero-America subject were encouraged by CEPAL using as data base housing and population Census.
} 
poverty. In the same way, in Mexico this methodology generates the official figures about the extent and evolution of poverty and its application is under the responsibility of the INSTITUTO NACIONAL DE ESTADÍSTICA, GEOGRAFÍA E INFORMÁTICA.

In spite of its dissemination and use this proposal is not exempt from criticism since a intense discussion is under way to determine whether consumption or income should be used as the variable to evaluate the degree of satisfaction of the family needs.

On the other hand, there are also discussions on the need to embody in the measurement the criteria of adult-equivalent units to introduce the notion of economies of scale built-in in the households. Even though from a conceptual point of view this is a correct approach, there is no consensus about what scales must be used given that all available scales present differents problems of conceptual and operative nature, and it has not been possible to measure the biases introduced in the poverty quantification because of this situation.

In the Mexican case, the basic needs used in some studies to quantify the poverty under this approach are:

- Precarious housing: When the house construction materials present some of the following characteristics: cardboard wall, scrap materials, reed, bamboo, palm, wattle and daub.

- Unavailability of basic housing services: This situation is present when the house has not electric energy or piped water or street connected drainage, or when the house has not a bathroom for exclusive use by the household members.

- Crowding: When the average number people per bedroom is higher than three.

- Scholarship unattendance: When there are household residents, between 7 and 14 years of age, with no elementary school completed.

- Household economic capacity: When the relationship within the household between the members of the family and the economically active people is higher than 4 , and the head of the household is illiterate or has no instruction completed or incomplete elementary school. ${ }^{4}$

Once the indicators are selected, a minimum level for each one is defined to identify and quantify the amount of population below the established welfare minimum. Finally, households are classified in different welfare levels according to the number of basic needs that were unsatisfied as follows:

\footnotetext{
${ }^{4}$ Refers to basic education in Mexico comprising 6 years.
} 
- Extreme poverty households: Considered in this situation are those households showing three or more unsatisfied basic needs.

- Poor households: Those showing unsatisfaction in one or two defined basic needs.

- Non poor households : Those satisfying all of their basic needs.

The application of the method described assumes data availability on those selected variables for the target households. In Mexico the application of this methodology makes use of the data produced by the population and housing census to identify the geographic zones or population groups with higher lacks. Poverty maps have been produced for a country regionalization based on different welfare levels. These maps have been made at federative entities level (states), municipalities, and by groups of blocks. In the same way, applications have been made with data obtained from different income and expenditure surveys conducted in Mexico since 1983 (1983, 1989, 1992, 1994 and 1996) which have allowed to evaluate lacks of the Mexican population from different conceptual approaches.

Because of the variables included in the analysis, it has been said that this method measures the structural type of poverty. This is so because the indicators used in the evaluation are associated to the holding of the household's permanent assets. Likewise, the method characteristics relate to a relative poverty notion in terms described by Sen. ${ }^{5}$ For these reasons policy objectives defined to overcome the population structural types of lacks must be oriented to promote and foster investment in basic infraestructure in the different forms of welfare that have been evaluated.

Despite of its easy application, this method presents several inconvenients of practical use because it doesn't have a well supported conceptual and methodological framework linking the poverty notion with the households essential needs. In the same way, there are not objective procedures to decide over the index numbers to be evaluated, nor in the definition of values in each one of them. On the other hand, it is important to point that it is assumed that indicators are equally relevant in the household utility function, and once that a family is considered poor, it never leaves this condition despite the fact that for the rest of the satisfactors the minimum level has been achieved. Finally, it is mentioned that the population volume in poverty situation grows in an undefined way as long as the number of satisfactors to be evaluated increases; this means that poverty measurement is not independent from the selected indicators.

\section{POVERTY LINES METHOD (PL)}

Some measuring alternatives proposed by several authors who considered the biological aspects of poverty must be maintained in the discussion ${ }^{6}$. So, Rowtree in his famous document on the poverty in York defined families in "primary poverty" as those

\footnotetext{
${ }^{5}$ Sen, A. "Conceptos de Pobreza" en América Latina: El Reto de la Pobreza Características, Evolución y Perspectivas. PNUD, Santa Fe de Bogota, 1991.

${ }^{6}$ Important works made by Rowntree in 1901, may be consulted and cited by Sen op. cit.
} 
"whose total incomes are inssuficient to cover the related basic needs with the maintenance of the single physical efficiency".

This type of approach has received different criticisms (Towsend (1971 and 1974) and Reint (1971)), authors of technical capacity as Amartya K. Sen, have stated that hunger is the most notorius poverty aspect. It is possible to state that although malnutrition only looks at one aspect of poverty it is a central dimension of social development evaluating margination and careless situations in underdeveloped countries.

In regard to the above, the POVERTY LINES METHOD (PL) or income method represents an adequate alternative to assess the effect of the short term economic situation in the population's living standards.

Due to its characteristics, it is said that this method measures poverty of the short term type since households consumption needs are associated with their financial capacity, which keeps a close relation with changes in the economic cycle. Also, because of its measuring characteristics it is said it evaluates the poverty phenomenon from a point of view of absolute deprivation following the notion by Sen.

The application of this method requires the following phases of work. First, the population energetic needs must be defined, taking into account the differences by age and gender, as well as by the geographic zone where families are located. In the same way, physical activities of the hosusehold members must be considered, both in productive activities and for recreation. Finally, to determine protein and energy requirements, it is neccesary to include a surplus allowing women in fertil age to face higher energetic needs derived from pregnancy and maternal lactancy.

Later on, food consumed by households must be transformed into nourishment and then to identify a population group that satisfying the established minimum in terms of calories and proteins will be the refference group.

From the consumption pattern observed in the refference group (Basic Food Basket (BFB)), a consumption pattern is proposed following the observed demand structure and preserving the population nutritional balance.

To determine the population's nutritional needs, the described methodology takes into account the population structure by age and gender, as well as its geographic location, hence it does not require correction by economies of scale. However, the determination of needs other than feeding, contents a high degree of subjectivity that has not yet been overcome. 


\section{ALTERNATIVES FOR WELFARE MEASUREMENT}

The combination of the two methods above described makes it possible to have a complete vision of the population structural and short-term poverty. This is done by an Integrated Methodology for poverty measurement (PIM). In Mexico evaluations have also been realized to put together different dimensions of poverty data which is used to design programs and to define policies oriented to aminorate extreme poverty and to overcome the lacks of marginated groups.

On the other hand, data availability in Mexico has allowed to attempt other alternatives to evaluate welfare levels. Using data produced by the population and housing census, INEGI (1994) ${ }^{7}$ produced a study to classify every municipality as well as groups of blocks within the country's localities into different strata in accordance to observed values in several social, demographic and economic indicators.

Applying multiparametrical statistical methods, an algorythm was used to form homogeneus groups by optimizing an objective function that maximizes the variability between groups and minimizes it within them ${ }^{8}$.

It is necessary to point out that this methodology does not permit quantifying poor population, but it provides the possibility of grouping municipalities (or groups of blocks) with similar lacks.

7See INEGI, "Niveles de Bienestar en Mexico". Mexico, 1994.

${ }^{8}$ Details about the used method can be consulted in Jarque C. "A solution to the Problem of Optimum

Stratification in Multivariate Sampling". Journal of the Royal Statistical Society. Serie C. Vol, 30. No. 2, 1981. 


\section{TOPIC 3}

Relative Poverty Measurements 



\section{POVERTY MEASUREMENT IN FRANCE}

by

\section{Madior Fall}

Institut National de la Statistique et des Etudes Economiques (INSEE) France 


\section{Poverty measurement in France}

\section{DIFFERENT APPROACHES TO POVERTY}

Different approaches are possible specially in France where there is no «Official » definition for poverty (there is an «usual » definition : half median of income per consumption unit). To schematise it can be considered that approaches are different according to answers given by each researcher to the three following basic questions :

- Will our arguments be based on objective data or will subjective angles be considered ?

- Will only the income be considered or will the consumption and more generally the various angles of living conditions come into it ?

- Are we looking for an absolute or a relative measurement of poverty ?

\section{Definition can be :}

- Objective R type approaches (based on financial Ressources) being subdivided whether they are absolute or relative

- Objective LC type approaches (Living conditions) being also subdivided whether they are absolute or relative

- SWB type approaches (Subjective well being) based on answers to subjective questions such as « from what level of income can we declare a household is well being » or « what would be the minimum income required to make ends meet »?

The total we can get (as for households or individuals) significantly vary from an approach to an other, and moreover the typical poor profile is very different. For instance, the living conditions approach emphasises a significant proportion of poor elderly people who subjectively feel to be well off.

Not one of these approaches is really better than the others. Main characteristics, advantages and disadvantages of each proposed option can be pointed out.

\section{- SUBJECTIVE APPROACHES:}

They are very noticeable because they allow to differently consider two different households with the same income, nearly identical consumption, depending on the level of well being they feel to get from it.

Is this an advantage or a disadvantage ? The answer to this question depends on the ethical choices of what can be taken for allowed or not allowed with an approach of social inequalities. Discussion of the same nature will be encountered with approaches based upon consumption (expensive tastes, a.s.o...) 
Do we have to consider as being not poor someone who is objectively without any financial means but is satisfied with his lot, and to the opposite do we consider as poor someone insatiable having higher incomes?

These different approaches are used often in international studies. It is to be pointed out that results depend very much on the way the question is asked and which expressions are used.

Consumption and standard of living approaches are based on the observation of the various factors defining a household environment (accommodation, equipment), its different consumption items (food, activities, transportation ...) as well as facts that can have influence on the transition from consumption to standard of living (state of health...). Inquiries can easily measure relevant facts (or at least their money components) and reflect not only the closest present but also the past in a certain extent. They also deeply depend on the household choices as regards to its decision to either consume or save, and also between the different consumption items.

Again these different characteristics can be received either as advantages or as disadvantages depending on whether we need to measure an immediate and short-term poverty, or a recurrent poverty according to whether individual tastes as they are be considered as a relevant data.

Referring to the only income the following polar characteristics are to be pointed out: individual tastes are nearly not considered, but the incomes can strongly vary from one year to another and thus is not very relevant to establish a continuous standard of living. In addition it cannot be easily measured both through the fiscal sources and through inquiries near households : capital incomes are not well known just as incomes of self-employed. The transition from the income to the standard of living assumes that a unit of consumption system can be defined for a several person household, so that the «household size » effect be corrected. The usually used system called 'Oxford Scale' ( 1 for the first adult then 0,7 for the next and 0,5 for children) does not seem to be as relevant as it was at the time of its implementation. Or course results depend very much on this deflator. In France as in European community we adopt now the OECD scale ( 1 for the first adult then 0.5 for the next and 0.3 for children), which follows from the comparison between families with children and single persons about the transformation of fashion consumption. This equivalent scale is adopted also by EUROSTAT in their recent studies.

The real standard of living can finally be higher than expected when only considering the monetary income : the great significance of the family production and of the transfers in kind between households (assistance) have to be pointed out.The exclusion and lack of integration angle being a very important component of poverty is probably better taken into consideration with approaches different from the ones based on the only income. 


\section{- ABSOLUTE OR RELATIVE?}

The «absolute» approaches take as given a minimal basket of goods to be consumed to survive. The concepts of minimum living wage (defined as the minimal level of consumption for surviving) are based on eating needs, as defined by nutritionists as per sex and age, they also can explicitly include needs considered as basic (accommodation, clothing). This concept used by researchers is different from the official minima income concepts, as minimum vieillesse (minima for elderly people), and RMI (minimum income for integration). To a larger extend the minimum social income concepts include goods considered as « normal » and « obvious » by the most part of a society.

The « relative » approaches are the ones adopted by researchers in France (and also INSEE and EUROSTAT) and assume that as soon as incomes are unequal there are cases of relative poverty. The distribution foot defines poor even if the lowest income in the society is high enough allows to obtain the minimal consumption basket.

The « absolute » approaches suffer from the normative nature of the basket definition that is more and more embarrassing since the account of the only food consumption is wandered (and even on that point agents differ). They are considered as not very adequate to a developed society.

The «relative» approaches suffer from the arbitrary nature of the threshold kept (1/2 average, $1 / 2$ median, $40 \%$ of the average, $40 \%$ of the median ...) and can explain that if we consider the income definition problems, together with measurement and calculation of consumption units problems we could get and estimation of the total number of poor varying from 4 millions to over 9 millions people in France. The widely accepted definitions lead to consider as far as income is concerned a proportion of a little bit more than $10 \%$ of the households which corresponds to a total number of persons between 4.5 and 5.5 millions of poor.

\section{RELATIONSHIP BETWEEN POVERTY MEASUREMENT AND DEFINITION OF INCOME}

With the definition of the equivalence scale (here it is the Oxford scale) the calculation of the number of poor households or individuals depends in a large extend on the type of income considered.

As integration in the poor household category depends on a relative factor (the half-median) there is no mechanical relation between neither the average level of income even nor the poverty point and the total number of individual or households counted as being poor. In addition, it will be noticed that slight variations in terms of households can prove to be higher in terms of individual : thus the transition between available money income (after tax) and extended income does not alter very much the total number of poor households $(+2.9 \%)$ but does notably affect the total number of poor individual $(+17.5 \%)$. 
The various thresholds can vary by $14 \%$ according to whether we consider property incomes or not. It can be interesting to locate these different thresholds compared with the social minima covered by the law. It can be noticed that the thresholds defined in terms of halfmedian income per consumption unit are covered by the legal minima. The SMIC when it is considered as being the income of one individual is over the poverty threshold. But if we consider a two children family, the SMIC made up with family benefits remains very much under the poverty threshold. The same two children family receiving two SMIC will get out of poverty. The RMI is lower that the poverty threshold but to the opposite the MINIMUM VIEILLESSE' levels quite well these money thresholds. Consequently the Minimum Vieillesse directly affects the relative poverty of the elderly.

It is to be noticed that this measurement has been calculated from inquiries made near « ordinary » households and by definition do not take into consideration the extremely poor emerging population with no fixed address. This population is estimated at about 2 or 3 hundred thousands people.

\section{SOME IMPORTANT RULES OF POVERTY MEASUREMENT IN FRANCE}

The 6 recommendations about the measure of Poverty .

1. Make better measure of some kind of income like wealth's income, Transfers between family members, social transfers, alimonies ....

2. Include wealth in the income's definition (fictive loans for owners, both interest (imputed and received)

3. Chose equivalence scale adapted to actual consumption

for example : - Modify unit consumption $\mathrm{m}=1+0.35 *(\mathrm{n}-1)$

- different Scales based on the nth power like $m=\operatorname{sqrt}(n)$

or $\mathrm{m}=$ (nadult $+0.7 *$ nchild) to the power of 0.6

where nadult : number of adult in household

nchild : number of children in household

- OECD scale describe before.

4. Chose the permanent income despite the instantaneous income (use of Panel data should allow it).

5. Study of non cash components of the standard of living like family production, subsistence farming, potential income, income including individual public expenditure, social benefits in kind.

\footnotetext{
1 The social minima implicitly use equivalence scales : for instance concerning the minimum vieillesse if we consider a couple, the second recipient receive $80 \%$ of the benefits allowed to the first. When considering the RMI the second personn of the household receives $50 \%$ of the amount received by the first one and the third one receives only $30 \%$ of this amount.
} 
6. Replace the poverty rate by poverty indexes (which verify monotony axiom and transfer axiom) like :

- poverty intensity

- measure inequality between poor people (i.e. Sen index, Foster index ...).

The interpretation of these indexes is not easy for non statisticians (and sometimes for them).

\section{SOME RESULTS ON THE MONETARY POVERTY IN FRANCE:}

In $1994,10 \%$ of the households are counted as being poor as they have a standard of living at their disposal lower than the half median of the total population. This poor households percentage is overall the same than the one observed in 1984 ; however poverty of the youngest households is increasing. This instant measurement has to be completed with the dynamic poverty study. A household panel follow-up during two consecutive years shows a very important mobility either with inputs or outputs. On the other hand this panel does not allow yet to isolate pockets of poverty lasting on several years or the recurrence of poverty for a household.

The income definition chosen to calculate a poverty threshold has a great consequences on both the number and more specially the structure of the poor populations. Thus if we consider the money assistance between households, the poverty ratio decreases poverty specially amongst the youngest households. Considering property of the main home the resulting monetary benefits always favour the elderly (the most part of them own their home) over youngest households, the working class, large or single parent families.

Poverty development favours retired people over the labour force households.

\section{POVERTY DURABILITY AND DEVELOPMENT:}

Cross-section surveys entitle both a diagnosis of instant poverty (as of the survey date) and an analysis of these diagnosis developing with the time. It would be necessary to consider the same households or the same individuals chosen within a panel during several years in order to be able to appreciate the real poor population development. Then the risk of remaining or becoming poor could be evaluated and the poor population changes could be measured between different dates.

Only two surveys, in France, have been worked in this direction. The first one uses surveys made near the households from 1987 to 1994 regarding overall economic situation. The second one has been worked from two different waves for the European community household panel (1993 and 1994). Panel data of the same type have already generated surveys of the same nature in various foreign countries (USA, Belgium, Luxembourg ...) as well as in «Lorraine » where a regional panel data had been collected between 1985 and 
1990. However the main problem using a few numbers of panel waves is the occurrence of interference linked by errors which appears on income measures. This is not a problem easy to resolve because it makes transition in poverty very hazy.

An other estimate of the poverty mobility characteristics during two running years can be calculated with the two first waves of the European household panel. An individual poverty rate will be generated as of each date from this representative panel : a person will be declared as poor when the household income is lower than the half median standard of living. From the data it will be noticed that the individual poverty rate has a value close to both the one of the rate got with the households and the results obtained from the overall economic situation surveys.

\section{WITH AN ECONOMIC RECESSION PERIOD THE POVERTY EXIT IS RARE}

The total poverty mobility measured with the rotation rate in overall economic situation surveys does not really change between 1987 and 1994. But inequalities between poor and not poor households increased by the end of the 80 s in probability terms.

\section{INCOME ADJUSTED TO FICTITIOUS RENTS: CONSEQUENCES ON THE POVERTY MEASUREMENT}

Considering a same unit per consumption income the situation of households can be very different depending on whether they are owners of their accommodation or not. Thus an estimate is carried out for the incomes adjusted to the fictitious rents.

Transition to the adjusted income increases the number of poor for the youngest, the working class and large and single parent families.

\section{V . OTHERS APPROACHES DEVELOPED AT INSEE}

1. In continuation of Atkinson-Bourguignon's analysis about the link between demography and poverty conception, Chambaz and Maurin (INSEE) have studied the poverty development using general sequential comparisons procedures on household's distribution income from 1977 to 1994.

2. The next studies at INSEE will be concentrated on individual poverty and not on household poverty. This direction is imposed by the recent increasing of the number of homeless persons. 


\section{VI . Some selected poverty statistics}

Table 1 . Poverty rates according to reference person's activity (\%)

\begin{tabular}{|l|c|c|c|}
\hline & 1984 & 1989 & 1994 \\
\hline \multicolumn{3}{|c|}{ Poverty rate based on corrected wealth's income per unit consumption } \\
Total household & 10.4 & 9.6 & 9.9 \\
labour force & 9.9 & 9.9 & 11.4 \\
retired & 11.5 & 9.0 & 6.9 \\
\hline \multicolumn{3}{|c|}{ Poverty rate based on declared income per unit consumption by household in family } \\
\multicolumn{4}{|c|}{ expenditure surveys } \\
Total household & 9.9 & 8.8 & 9.2 \\
labour force & 8.7 & 8.8 & 10.1 \\
retired & 12.5 & 8.7 & 7.3 \\
\hline
\end{tabular}

Table 2. Thresholds of poverty and minimum legal income

\begin{tabular}{|c|c|c|c|c|}
\hline & Thresholds $^{1}$ & SMIC & $\begin{array}{l}\text { Minimum } \\
\text { vieillesse }\end{array}$ & $\mathrm{RMI}^{2}$ \\
\hline \multicolumn{5}{|c|}{ Amount ( francs 1994) } \\
\hline 1984 & 36101 & 54857 & 37401 & - \\
\hline 1989 & 37452 & 55958 & 38487 & 27682 \\
\hline 1994 & 39801 & 58577 & 38323 & 27576 \\
\hline \multicolumn{5}{|c|}{ Ratio of annual average rate (\%) } \\
\hline $1989 / 84$ & 0.8 & 0.4 & 0.6 & - \\
\hline $1994 / 89$ & 1.2 & 0.9 & -0.1 & -0.1 \\
\hline \multicolumn{5}{|c|}{ Global ratio (\%) } \\
\hline $1994 / 84$ & 10.2 & 6.8 & 2.5 & \\
\hline
\end{tabular}

1. Poverty line at $<50 \%$ of median equivalent income (income before taxes with correction of under evaluation of wealth's income )

2. For one person 
Table 3. Low household's standard of living's according to socio economic group

\begin{tabular}{|c|c|c|c|c|c|c|c|}
\hline \multirow[t]{2}{*}{$\begin{array}{l}\text { Socio economic group of the } \\
\text { reference person }\end{array}$} & \multirow{2}{*}{$\begin{array}{c}\begin{array}{c}\text { Number of } \\
\text { households }\end{array} \\
1994\end{array}$} & \multicolumn{3}{|c|}{ Household poverty rate (en \%) } & \multicolumn{3}{|c|}{$\begin{array}{l}\text { Breakdown of poor households } \\
(\%)\end{array}$} \\
\hline & & 1984 & 1989 & 1994 & 1984 & 1989 & 1994 \\
\hline$\overline{A L L}$ & 23155880 & 10.4 & 9.6 & 9.9 & 100 & 100 & 100 \\
\hline Farmers & 414615 & 35.9 & 31.2 & 25.6 & 9 & 8 & 5 \\
\hline Craftsman & 584999 & 15.1 & 16.7 & 12.0 & 4 & 5 & 3 \\
\hline Traders & 398059 & 17.3 & 11.6 & 16.1 & 2 & 2 & 3 \\
\hline $\begin{array}{l}\text { Employers, managers, private } \\
\text { professional }\end{array}$ & 2579329 & 0.8 & 0.7 & 1.6 & 1 & 1 & 2 \\
\hline Employees & 2753217 & 6.0 & 5.7 & 10.4 & 7 & 7 & 12 \\
\hline Skilled workers & 3343829 & 10.2 & 9.0 & 11.4 & 17 & 16 & 17 \\
\hline non skilled and farm workers & 1143754 & 18.6 & 22.4 & 27.7 & 12 & 13 & 14 \\
\hline Retired farmers & 760956 & 26.8 & 19.0 & 20.3 & 9 & 7 & 7 \\
\hline Retired non farmer self employed & 783753 & 16.1 & 16.5 & 9.1 & 5 & 5 & 3 \\
\hline Retired managers & 2185663 & 1.2 & 1.5 & 0.2 & 1 & 1 & 0 \\
\hline Others Retired wage-eaming & 3515459 & 10.8 & 7.5 & 6.2 & 16 & 12 & 10 \\
\hline $\begin{array}{l}\text { Others non-working population } \\
\text { from which : }\end{array}$ & 1578176 & 25.8 & 29.0 & 31.8 & 15 & 21 & 22 \\
\hline Students & 362710 & 57.5 & 48.9 & 60.0 & 5 & 8 & 10 \\
\hline $\begin{array}{l}\text { Non-working population less than } \\
60 \text { years old }\end{array}$ & 502036 & 26.1 & 30.8 & 31.8 & 6 & 7 & 7 \\
\hline $\begin{array}{l}\text { Non-working population more than } \\
60 \text { years old }\end{array}$ & 659629 & 14.6 & 16.2 & 14.5 & 4 & 5 & 4 \\
\hline
\end{tabular}

Table 4 : Without student's households : Impact on poverty rate

\begin{tabular}{|l|c|c|c|}
\hline \multirow{2}{*}{ socio economic group } & \multicolumn{3}{|c|}{ Poor household rate (\%) } \\
\cline { 2 - 4 } & 1984 & 1989 & 1994 \\
\hline ALL (without student's household) & 10.0 & 8.9 & 9.1 \\
\hline Other non-working population & 20.5 & 23.3 & 23.4 \\
\hline
\end{tabular}

Poverty line at $<50 \%$ of median equivalent corrected income per Oxford consumption unit Source : Enquétes Budget de famille, INSEE. 


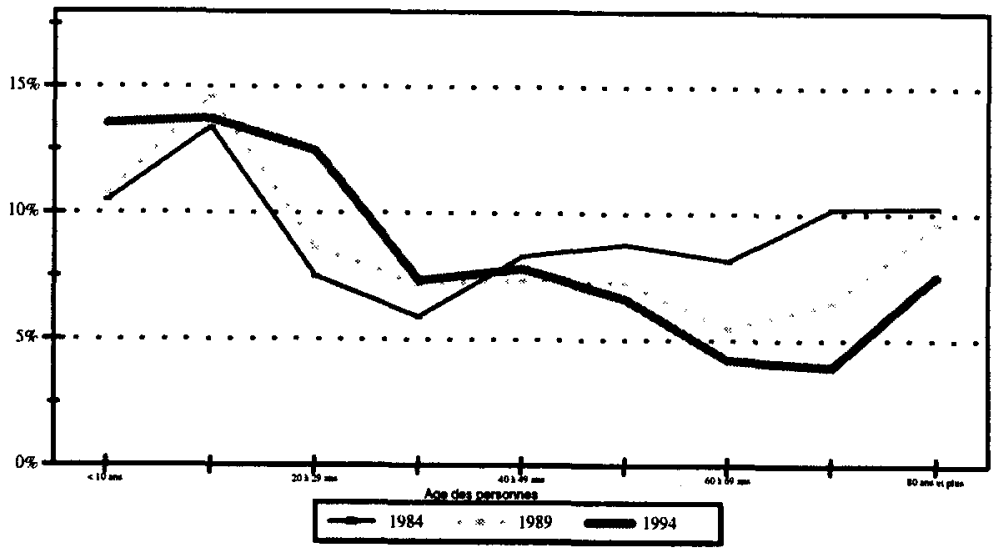

Poverty threshold: $\mathbf{5 0 \%}$ of median equivalent corrected income per Oxford consumption unit Source : Enquête Budget de farmille, revenus corrigés, INSEE.

Table 5 : Monetary poverty rate of the households according to their composition (\%)

\begin{tabular}{|l|c|c|c|c|c|c|}
\hline \multirow{2}{*}{ Type of household } & \multicolumn{3}{c|}{ Poor household rate } & \multicolumn{3}{c|}{$\begin{array}{c}\text { Poor household rate } \\
\text { (Without student's households) }\end{array}$} \\
\cline { 2 - 7 } & 1984 & 1989 & 1994 & 1984 & 1989 & 1994 \\
\hline ALL & 10.4 & 9.6 & 9.9 & 10 & 8.9 & 9.1 \\
Single person & & & & & & \\
60 years old or less & 8.3 & 9.0 & 11.9 & 5.8 & 5.3 & 7.8 \\
Over 60 years old & 11.0 & 9.2 & 7.6 & 11.0 & 9.2 & 7.6 \\
Couple without children & & & & & & \\
60 years old or less & 4.5 & 4.3 & 5.7 & 4.1 & 4.2 & 5.3 \\
Over 60 years old & 11.6 & 8.2 & 5.4 & 11.6 & 8.2 & 5.4 \\
Couple with children & & & & & & \\
1 child & 6.4 & 5.9 & 7.1 & 6.4 & 5.9 & 7.1 \\
2 children & 8.4 & 8.6 & 9.5 & 8.4 & 8.6 & 9.5 \\
3 children and over & 22.6 & 21.0 & 19.7 & 22.6 & 21.0 & 19.7 \\
Single parent family & 13.8 & 20.4 & 20.5 & 13.8 & 20.4 & 20.5 \\
Others & 15.0 & 11.4 & 14.3 & 15.0 & 11.4 & 14.3 \\
\hline
\end{tabular}

Poverty threshold: $\mathbf{5 0 \%}$ of median equivalent corrected income per Oxford consumption unit Source : Enquêtes Budget de familles, INSEE 
Table 6 : Transition of the household from poverty to non poverty between 1987 and 1994 (\%)

\begin{tabular}{|c|l|l|l|}
\hline Period & \multicolumn{1}{|c|}{$\begin{array}{c}\text { Poverty exit rate } \\
\text { (\%) }\end{array}$} & $\begin{array}{c}\text { Poverty entrance } \\
\text { rate }\end{array}$ & Rate of Turnover \\
\hline From 1987 to 1988 & 55.8 & 6.0 & 11.8 \\
From 1988 to 1989 & 50.2 & 6.8 & 11.4 \\
From 1989 to 1990 & 49.1 & 7.5 & 12.2 \\
From 1990 to 1991 & 45.8 & 7.0 & 11.2 \\
From 1991 to 1992 & 45.8 & 6.1 & 11.1 \\
From 1992 to 1993 & 39.8 & 6.1 & 10.6 \\
From 1993 to 1994 & 44.8 & 5.9 & 11.1 \\
\hline
\end{tabular}

Source : Enquêtes de Conjoncture auprès des ménages, 1987 à 1994, INSEE

Table 7: Transition of the individuals from poverty to non poverty between 1994 and 1995 according to age (\%)

\begin{tabular}{|l|c|c|c|c|}
\hline & & $\begin{array}{c}\text { Transitions } \\
\text { between } 1994 \text { and } \\
1995\end{array}$ & & \\
\cline { 3 - 5 } individual age & $\begin{array}{c}\text { Poverty rate for } \\
1994\end{array}$ & Poverty exit rate & $\begin{array}{c}\text { Poverty entrance } \\
\text { rate }\end{array}$ & Rate of turnover \\
\hline ALL & 15 & 36 & 6 & 10 \\
\hline Below 20 years old & 22 & 31 & 7 & 13 \\
\hline From 20 to 29 & 17 & 43 & 6 & 13 \\
From 30 to 39 & 13 & 41 & 5 & 10 \\
\hline From 40 to 49 & 11 & 30 & 5 & 8 \\
From 50 to 64 & 11 & 40 & 5 & 9 \\
From 65 to 74 & 7 & 34 & 4 & 6 \\
F5 and Over & 11 & 50 & 9 & 13 \\
\hline
\end{tabular}

Source : Panel européen des ménages, INSEE Vagues 1994 et 1995 
Table 8: Transition of the individuals from poverty to non poverty between 1994 and 1995 according to household composition development (\%)

\begin{tabular}{|c|c|c|c|c|c|}
\hline \multirow{2}{*}{$\begin{array}{c}\text { Development in composing the } \\
\text { household from which the individual } \\
\text { comes }\end{array}$} & \multirow{2}{*}{$\begin{array}{c}\text { Percentage of } \\
\text { concerned } \\
\text { persons }\end{array}$} & \multirow{2}{*}{\begin{tabular}{|c|}
$\begin{array}{c}\text { Poverty rate } \\
\text { for } 1994\end{array}$ \\
\end{tabular}} & \multicolumn{3}{|c|}{ Transitions between 1994 and 1995} \\
\hline & & & $\begin{array}{c}\text { Poverty exit } \\
\text { rate }\end{array}$ & $\begin{array}{c}\text { Poverty } \\
\text { entrance rate }\end{array}$ & $\begin{array}{l}\text { Rate of } \\
\text { turnover }\end{array}$ \\
\hline $\begin{array}{l}\text { No change within the household } \\
\text { between } 1994 \text { and } 1995 \\
\text { Single person below } 60\end{array}$ & 4.1 & 13 & 35 & 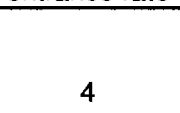 & 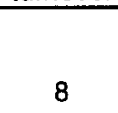 \\
\hline Single person over 60 & 4.5 & 9 & 57 & 6 & 10 \\
\hline Single parent family & 5.6 & 26 & 32 & 7 & 14 \\
\hline Couple without children & 18.3 & 7 & 29 & 4 & 6 \\
\hline Couple with 1 child & 15.0 & 9 & 49 & 4 & 8 \\
\hline Couple with 2 children & 21.3 & 10 & 51 & 4 & 9 \\
\hline Couple with 2 children or over & 16.3 & 30 & 25 & 12 & 16 \\
\hline Other households & 1.2 & 22 & 38 & 14 & 19 \\
\hline $\begin{array}{l}\text { Change within the household } \\
\text { between } 1994 \text { and } 1995 \\
\text { Moving in couple }\end{array}$ & 1.1 & 23 & 45 & 12 & 19 \\
\hline Couple with an additional child & 3.3 & 14 & 19 & 7 & 9 \\
\hline Couple with one child less & 4.4 & 22 & 45 & 3 & 12 \\
\hline Couple $\rightarrow>$ single person & 1.2 & 8 & (82) & 9 & 16 \\
\hline Couple $->$ single parent family & 0.8 & 25 & 25 & 20 & 21 \\
\hline Single parent family with one child less & 0.6 & 23 & (54) & 3 & 14 \\
\hline Other changes & 2.3 & 31 & 40 & 12 & 20 \\
\hline All & 100 & 15 & 36 & 6 & 10 \\
\hline
\end{tabular}

Source : Panel européen des ménages, INSEE Vagues 1994 et 1995 


\section{References}

Hourriez J. M., Olier L. 1997, «Estimation d'une échelle d'équivalence », à paraître INSEE.

Bourguignon F., Fields G.1997, «Discontinuous losses from poverty, generalized $P \alpha$ measures, and optimal transfers to poor » in Journal of public economics pp. 155-175.

Chambaz C., Maurin E. 1996, «La persistance dans la pauvreté et son évolution : une évaluation sur données françaises » Economie et Prévision $\mathrm{N}^{\circ} 122$ France

Collection Synthèses N5, 1996 «Revenus et patrimoine des ménages », Statistique Publique, INSEE

Chambaz C., Maurin E. 1996, «Atkinson and Bourguignon's dominance Criteria : Extended ans Applied to the Measurement of Poverty in France», Working paper $\mathrm{N}^{\circ} 9619$, INSEE, Direction des statistiques démographiques et sociales.

Accardo J., Fall M., 1996, «La mesure des revenus dans les enquêtes ménages et fiabilité des indicateurs d'inégalités dérivés », Working paper $\mathrm{N}^{\circ} 9602$, INSEE, Direction des statistiques démographiques et sociales.

Lollivier S.,Verger D., 1996, «Une approche de la pauvreté par les conditions de vie », Pièce jointe ${ }^{\circ} 5$, Séminaire de recherche INSEE.

Chambaz C., Maurin E. 1996, « Niveau de vie et pauvreté en France entre 1977 et 1994 : Une application des comparaisons séquentielles de distributions ", Pièce jointe $n^{\circ} 4$, Séminaire de recherche INSEE.

Fleurbaey M. 1995, «Equal opportunity or equal social outcome? », Economics and Philosophy 11:25-55

Collection Synthèses $\mathrm{N}^{\circ} 1,1995$ «Revenus et patrimoine des ménages », Statistique Publique, INSEE

Chambaz C., Choquet O. , Grimler G., Hourriez J. M., Herpin N. , Legris B., Méron M., Verger D., 1995, «Aspects de la pauvreté », Document de travail N9404, INSEE, Directions des statistiques démographiques et sociales.

Atkinson A. B., 1983, «The measurement of Economic mobility », in Social Justice and Public Policy, pp. 61-75. 


\title{
STATISTICAL SOURCES FOR THE STUDY OF POVERTY AND INEQUALITY
}

by

\author{
Paloma Seoane \\ Instituto Nacional de Estadística (INE)
}

España 


\section{Statistical sources for the study of poverty and inequality}

\section{SUMMARY}

This paper presents an overview of the statistical sources associated with each of the various statistical approaches applied in the study of poverty and social exclusion, on the basis of the conceptualization recently formulated by a majority of experts. It follows the guidelines broadly agreed within the European Union' and refers to practice in Spain.

The problem of poverty will therefore be examined from four different, though largely complementary, standpoints: objective poverty as measured by monetary indicators, subjective poverty, poverty as measured by physical indicators critical deficiencies) and chronic poverty.

\section{STATISTICAL SOURCES FOR THE STUDY OF POVERTY}

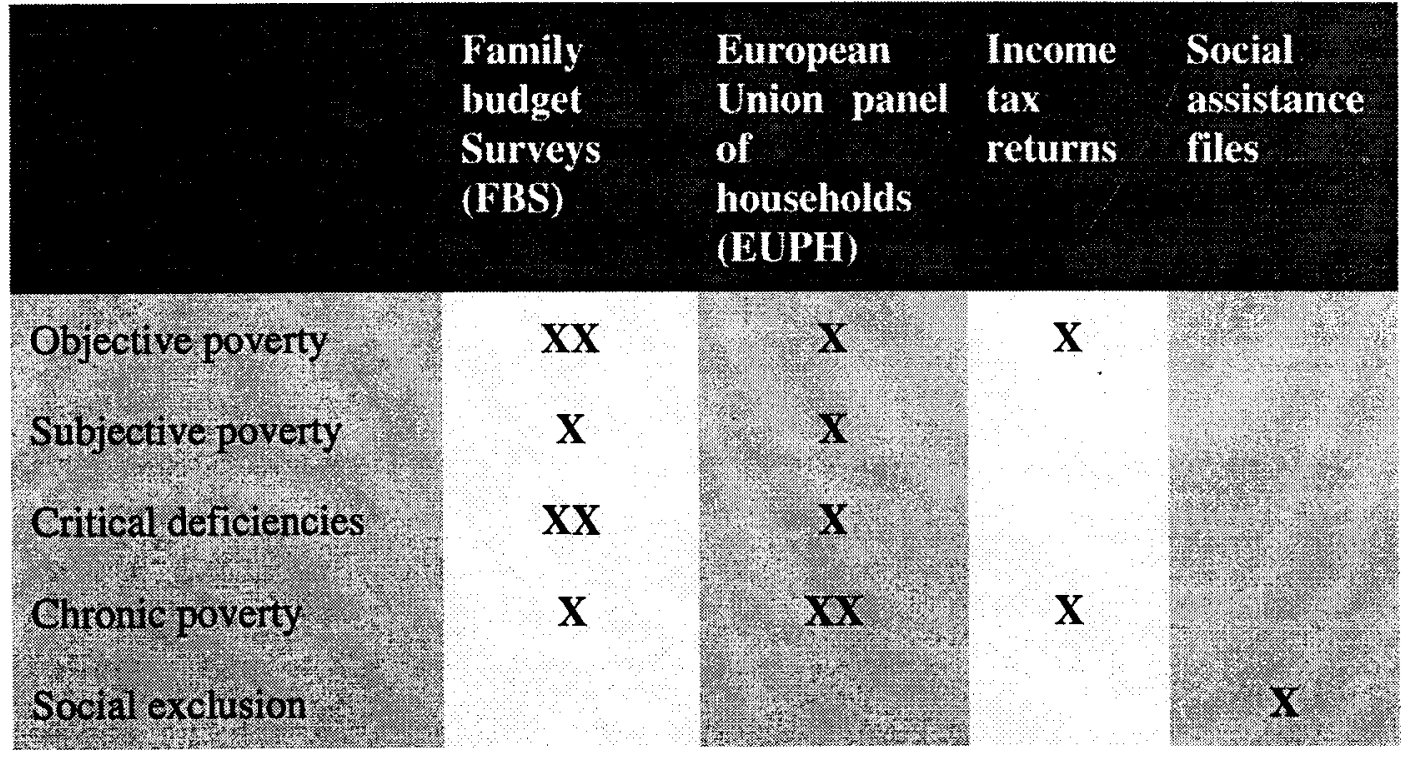

'According to the definition adopted by the European Union (EU) in the COUNCIL decision of 19 December 1984, the poor are "persons, families and groups where resources (material, cultural and social) are so limited as to exclude them from the minimum acceptable way of life in the member States in which they live". 


\section{Objective poverty}

The publications and studies so far produced by the National Statistical Institute of Spain (INE) summarize objective measures of poverty based on directly observable variables --chiefly income and expenditure-- in terms of relative poverty lines, which makes them equivalent to inequality indicators. There is no consensus or clear demand by users for absolute poverty lines, which are of limited interest in countries such as Spain. A number of studies, however, including a recent study by INE, do define an extreme poverty line of $25 \%$ average per capita expenditure in Spain; those spending less are identified as living in absolute poverty.

The statistical basis for studies on poverty-line-based objective measures of poverty is the family budget survey.

The reason for this is simple: the family budget survey is a carefully conducted statistical operation, and the sample size is large (approximately 25,000 households and a sampling fraction of 1/400). The survey yields a vast amount of information (on geographic, demographic and socio-economic variables for each household surveyed and for each member of that household; monetary standard-of-living indicators; the dwelling the household occupies and the ownership and use of particular goods, services and household equipment; and the household's subjective perceptions of its situation both in the present and the past).

This wealth of information makes up for the limitations of such surveys.

The unit of analysis is the household, on the assumption that its members have a similar standard of living regardless of the financial contribution they make to the common budget.

The choice of a monetary indicator of well-being is complex. In theory, the most acceptable standard-of-living indicator should be total household income over the year. A household's economic resources do not depend, however, only on its income at a given moment, and an indicator composed of income plus wealth.

Nevertheless, income can vary from year to year according to the economic situation, and a decline in income at a particular time does not necessarily entail a drop in the standard of living. Inequality, poverty and standard of living in general are phenomena that tend to be more stable than annual income. Generally speaking, then, the concept of permanent income lends itself better to the aims of such a study. The lack of information on long-term household income, however, makes it necessary to look at alternative options. Many authors use expenditure as a monetary indicator, on the assumption that it is more accurate than temporary income as an indicator of permanent income. This choice is not without problems, however, for household expenditures depend on what stage it has reached in the life cycle and are also affected by the environmentin which the household lies. The choice of expenditures or income is thus not an easy one, and there is no universal agreement on which is more appropriate. The solution has been to use both and compare the results. 
The question arises, however which expenditures and what income? Monetary expenditure and income only. Or would it be well to include a non-monetary component, i.e., the value imputed to own-use output and payment in kind?

Since our aim is to obtain a standard-of-living indicator, and since there are certain households for which it is indeed very important to take account of non-monetary expenditure (or income), it would be helpful to include non-monetary components in the study.

In addition, in order to be able to treat families of differing size in a standard way, the monetary indicator based on total household expenditure and income may be replaced by one based on per capita expenditure and income. ${ }^{2}$

Although, as mentioned above, the majority of studies are based on family budget surveys, this is not the only source that can be used in the study of poverty and inequality.

In 1994, INE set up a Community-wide statistical operation, in conjunction with the other members of the European Union, involving a European Union household panel.

The panel goes beyond conventional cross-sectional surveys in that it does not merely describe the population's situation at one particular point in time but also provides longitudinal information on the same households and persons at a number of points in time. The households selected for the first round of surveys are retained in the sample for the following rounds; new members can be incorporated and members that leave the household -or the household as a whole-- can be followed up as long as they continue to reside in a private or collective household within the European Union.

\section{Subjective poverty}

The objective of a study on poverty should not be merely to identify less privileged households in terms of income or expenditure.

Research in this area should include, inter alia, information on how the households themselves perceive their situation and should also focus on those that feel excluded from a minimum acceptable level and classify themselves as poor.

Subjective poverty lines are based on the perception that the households themselves have of their needs.

Such parents lines use income as a monetary indicator of standard of living and have an advantage over objective standards in that they do not require the use of equivalency scales (the household itself takes size into account in providing information on income).

${ }^{2}$ A discussion on the choice of a suitable scale of equivalence can be found in INE/Autonomous University of Madrid, Desigualdad y pobreza en España, a study based on family budget surveys 1973-1974, 1980-1981 and 1990-1991. 
The subjective poverty lines used by the European Union are the Kapteyn line (SPL), the Leyden (LPL) and the Deleek line.

With the inclusion, at the recommendation of EUROSTAT, of a subjective poverty module in the most recent household budget surveys, it has been possible not only to calculate subjective lines as described above, but also to study households that consider themselves poor (let us not forget that in the final analysis, poverty in the sense of social exclusion or marginalization involves a high degree of subjective evaluation).

\section{Critical deficiencies}

Analyses based on objective relative poverty lines enable us to identify the number of persons who are poor (in the sense that they are poorer than the rest). However, it is hard to say how poor these poor may be; i.e., are they merely worse off than the rest or are they unable to meet the most basic needs in that country people (even those in the lowest strata), consider vital.

It is difficult, however, to decide which needs should be considered basic. Moreover, if a household does not have a particular item, one must determine the reason: a matter of choice or lack of means.

Since the family budget surveys collect a wide ranged information on household furnishings and fittings and on the features and amenities of the dwelling... physical indicators now emerging from these surveys offer an alternative perspective on poverty.

It is a matter of determining how poor is poor, that is, of coming closer to a definition of absolute poverty.

For this purpose, the most recent study carried out by the Institute provides findings on ownership, dwelling characteristics and the chief source of income of households considered to be poor at lines corresponding to $25 \%, 40 \%$ and $50 \%$ of per capita expenditure and income, compared with data for the non-poor (defined as those whose per-capita income-expenditure level exceeds $50 \%$ of the average per capita income-expenditure level of the population). The situation of poor households as defined by Leyden and of those who perceive themselves as poor was also analysed.

Lastly, family budget and household panel surveys are the existing statistical sources for developing physical indicators of poverty. Household panel surveys have an advantage over family budget survey in that the information they record on capital assets owned by the household shows:

- whether the household has a given asset; or,

- if the household does not have such an asset, whether this is because:

- it cannot afford it, although it would like to have it, or

- it chooses not to, or for other reasons. 


\section{Chronic poverty}

Family budget surveys have one major limitation as far as poverty studies are concerned. Although their methodology does make it possible to determine the percentage of poor households and study their characteristics and thus to observe the actual development of poverty in different sub-segments of the population, it is inadequate (since the surveys are not on-going panel-type surveys, which follow up on individuals at different periods in time) when it comes to the analysis of one particularly worrying trend: i.e., the tendency for households identified at a given moment as poor to sink into a state of longterm or chronic poverty.

If poverty were a temporary phenomenon and the poor households of today could stop being poor tomorrow, there would be little cause for concern, since, even if at a given time households suffered certain hardships, such households would not be part of a permanent class.

However, we know that this is not the case and that there are certain sub-groups suffering from persistent poverty. It is imperative that these sub-groups should be described in a study specifically designed.

In order to identify those households suffering from persistent poverty, it would be necessary to monitor the same households (or individuals) over a period of time or, alternatively, to request selected households at a given point to give an account of their history or give their own assessment of their present situation compared with previous periods.

The household panel survey, as suggested earlier, is the ideal source of information for a study of chronic poverty (individuals are followed up throughout their life), since it can be noted at a given point in time what part of the population considers itself poor to what extent this situation can be considered chronic (that is, it has been below the poverty line in previous years), to what extent social protection measures can offer a way out of poverty... in short, how people become poor, have they escape from poverty and what the root causes are.

Nevertheless, an attempt has been made, using the information recorded in the 1990/1991 household budget survey, which relates the household's current situation with its previous circumstances, to estimate the extent of chronic poverty.

1. How would you describe the current economic situation of your household compared with the average economic situation of your parents' household?

( The possible response may be much worse, worse, the same, better, much better or do not know/no reply),

This question has been incorporated into the analysis in order to add information on the perception that families have of their inter-generational background or history. 
2. What do you think is to be the main reason for the change in your standard of living compared with what it was 10 (or 5 or 1 ) years ago?

- The size and/or needs of the household have changed.

- The employment situation of one of the household members has changed;

- Although the employment situation is the same, the household's purchasing power has changed.

The response to this question will reflect the causes, as identified by the households themselves, of the change in their circumstances. 



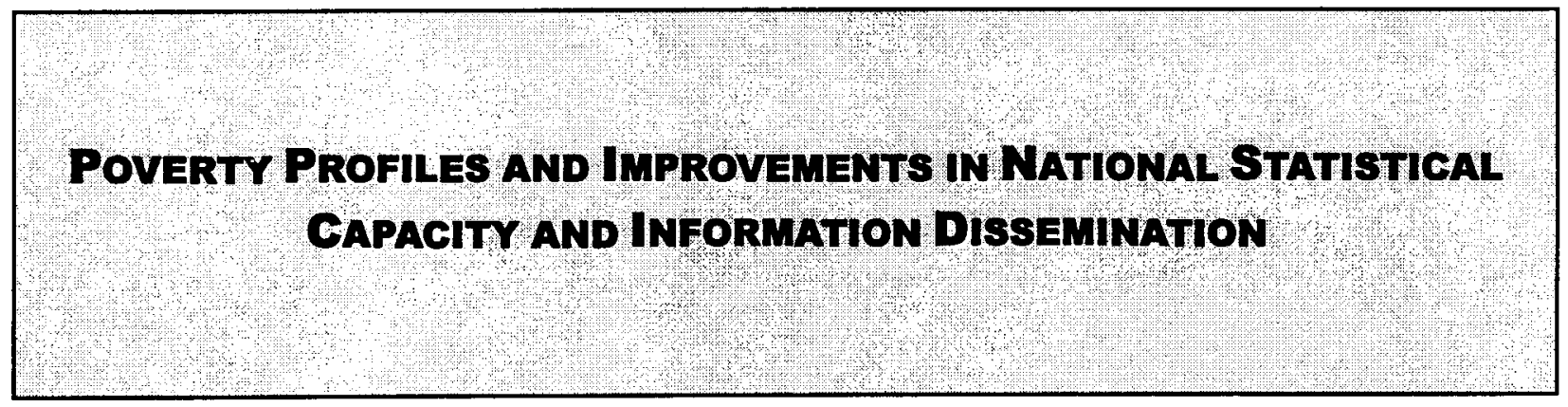



DRAFT

NOT TO BE QUOTED WITHOUT PERMISSION OF THE AUTHOR

\title{
DIMENSIONS OF POVERTY AND DIRECTIONS OF MEASUREMENT TALKING POINTS FOR DISCUSSION
}

by

\author{
Michael Ward \\ Statistical Advisory Services \\ Development Data Group \\ International Economics Department \\ The World Bank
}




\section{Dimensions of Poverty and Directions of Measurement Talking Points for Discussion}

\section{Introduction}

The persistence of poverty for more than a billion people in the world continues to be the foremost development challenge. Poverty exists and always has existed. This is not only a truism in relative terms but a fact in an absolute sense. For a long time, therefore, a key question that has faced policy makers is how to alleviate poverty? In particular, in developing countries, how can those with power and responsibility help those who are born poor to escape their poverty? In this quest, they encounter a major gap in the current armory of statistical measures to evaluate and monitor poverty. This is the ability to track what happens to those families who are poor and remain poor, why this happens and which families escape poverty and by what means. Panel information to throw light on this important problem is missing and so analyst have had to resort to other techniques to measure the different aspects of poverty.

The following paper explores the wider dimensions and social contexts of poverty and provides an annotated summary of some of the main themes of discussion focusing on how to measure these different dimensions of poverty. This note adds little to the ongoing debate on the process of poverty alleviation, but by presenting various matrices of observed conditions of poor households, it draws attention to the inherent complexity and interconnected skeins of influence surrounding the problem of implementing appropriate policies of poverty reduction. It puts forward some measures that help to identify the chronically poor - who are not always those solely suffering from special disabilities. It suggests why, despite economic growth, such groups continue to exist.

\section{The Institutional Legacy}

The note draws attention to the institutional context which, although frequently constraining progress in this area, receives less emphasis than it should in benefit-incidence assessments and current discussions of policy. The problem is manifested in many countries by what appears to be a widening income gap and inequality. Because the gains in economic growth accrue disproportionately to property owners, progress is accompanied by certain social distortions that include, to take just two examples, increasing environmental degradation and declining personal security. In the developed industrial countries the number of poor people has declined and, historically, households have tended to move in and out of poverty during their lifetime. In low income developing countries, by contrast, it is mostly the same people who remain poor from one period to the next. Why does this continue to occur and what are the implications for a broader based strategy? The evidence provided by income distribution maps, even when disaggregated by administrative province or by urban and rural communities, essentially fails to capture this critically important characteristic. Such statistics, like unemployment data, show only the share or total number 
who are poor. But comparisons of income distributions over time and across social groups are important in reflecting the institutional and structural rigidities that exist in society.

An important objective of this paper, therefore, apart from its intention to assess the significance of the different dimensions of poverty, is to underline the presence of chronic poverty among the same group of people that frequently persists from the cradle to the grave. In these circumstances, economic growth - of the magnitude achieved in the past two decades in many poor countries - hardly touches those in the lowest income deciles.

\section{ECONOMIC GROWTH AND INCOME DISTRIBUTIONS (at normal current prices)}

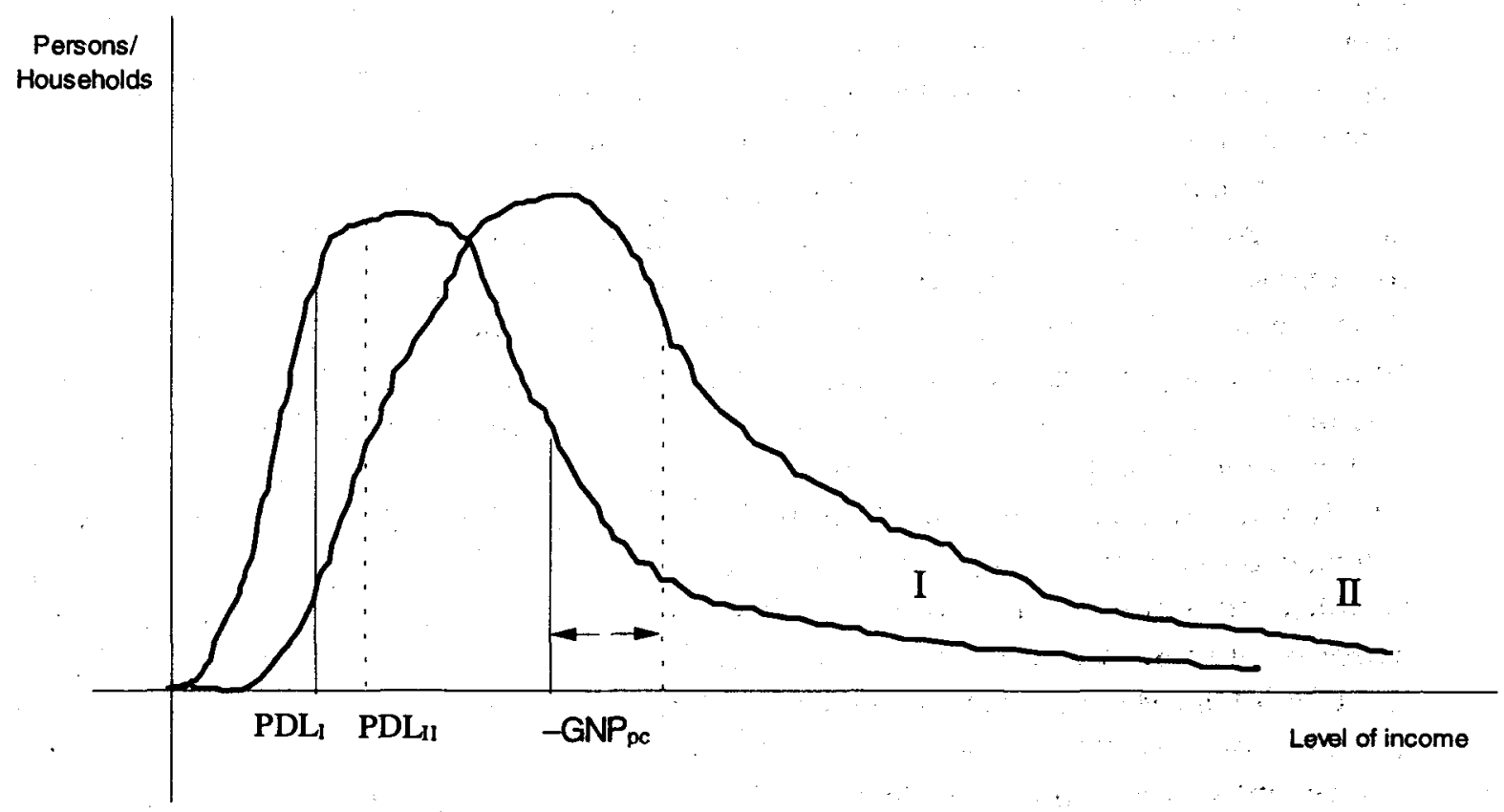

\section{Lessons of History}

The history of poverty alleviation, particularly through the period of early industrialization, is not so much a story of economic success as a chronicle of the individual efforts and personal zeal of social reformers, political activists, journalists, classical writers and broadsheet propagandists. Their attempts to remove social evils and injustice by describing living conditions and breaking down the barriers of prejudice helped empower poor people. Disraeli's "Two Nations" - the rich and the poor - in his novel "Sybil" (published in 1845) is just one publication that reflected, for example, the divided nature of society in Britain. It came following a period of social instability during which the country had been wracked by persistent labor unrest among both agricultural workers and industrial 
labors; episodes reflected in events like the Tolpuddle martyrs, Peterloo massacre and Chartist riots. Traditional rural society, as characterized by small peasant farmholdings, found itself in a particularly unsettled state because it was locked into lines of crop production where the long term trend in prices through an extended period of depression was downwards, and the domestic terms of trade had not yet turned in their favor. Whole communities, particularly through the winter months, were regularly pauperized, being forced (by those who employed them) to fall on the mercy of communal poor relief provided by the Parish. In essence, the social framework that provided so little opportunity for poor people to gain a permanent escape from poverty also created the institutions that perpetrated pauperism and perpetuated their poverty.

Why are the specific circumstances and events of more than 150 years ago in Britain of relevance to current discussion? As Thomas Carlyle noted (Chartism, 1839), conditions of instability are created in a society when people are cooped up in mean houses and narrow streets, without savings, adequate poor relief or even gardens of their own to grow food, who can be thrown out of work or put on reduced wages at a moment's notice. This is because a significant class not only loses its sense of community and belonging but also realizes it has no ownership or control of its own destiny. The indiscriminate massing of people in urban areas who do not participate in decisions affecting their state of life and who are drawn together solely by their link (albeit not permanent) to an employer through the cash nexus, does not create conditions conducive to social development. In crushing popular expression (which, by any standards, was well justified by the appalling and unpredictable living conditions in which most households survived) and by resorting to public force, the few in authority clearly exposed the weaknesses and unsustainable nature of the economic solution. The root of the Chartist movement, and similar labor movements elsewhere up to the present day, lay in the common desire to raise working people to that level in society and which they could lay claim to a just reward from their efforts and utility. It led men of poverty to take vengeance on men of property for apparent wrongs. For as long as the latter remained detached from lower class radicalism and were not seen to be sympathetic to the just demands of those who worked long hours for little reward, economic progress could not be a positive force for good even if labor productivity was rising.

England was not alone. Reformists throughout the Continent recognized that economic strategy by itself, and expanding industrialization, were clearly not sufficient to bring about social change and removal of poverty. Other barriers had to be overcome. They saw progress being achieved through political reform, a restructuring of the balance of power, greater freedom of expression, the expansion of education and the opening up of opportunities - including the right to organize to protect employment and advance social and political causes. These were the primary means to advance personal status. Neither was Marx, as a publicist for radical political reform, alone. Following other illustrious predecessors like Mill and Ricardo and fired up by the earnest journalistic reports of the appalling working conditions in NW Industrial Britain that were regularly filed by his friend and associate, Engels, he could still refer in the latter half of the $19^{\text {th }}$ Century to the inevitable "iron law of wages". This "law" would ensure that an exploited workforce would 
remain forever on the lowest subsistence wages and thus continue to suffer an impoverished state of life.

There was, at the time, therefore, widespread expressions of concern against a perceived unrestrained tyranny of rulers who had the unfair weight of the law on their side and who could frequently rely on the "establishment" and the military to help preserve the economic status quo. Eventually, progress came as economic gains paid off; Marx and other fellow travelers were proved wrong, but mainly because economic progress had been accompanied by political and institutional reform and the proliferation of schools of learning had enabled many to grasp new opportunities to break out of the stranglehold of their position. Even in the countries of the former Soviet Union much of the eventual improvement in real labor conditions can be attributed to their strong industrial democracies.

Similar situations do not exist perhaps to quite the same extent today in poor countries, but aspects of such social relations in production and "non-engagement in economic activity" are widely prevalent and have analogous relevance to the modern economic conditions many still face. It is not the lack of economic opportunities in poor countries that dissuades foreign investment but the uncertainty and potential instability that frightens off those who could make a difference to living standards.

In looking at the specific issues and at what analysts and policy makers perceive as poverty (and its causes), the following section summarily examines the single, dual and multiple dimensions of being poor and why the phenomenon of poverty remains so intractable. The pattern clearly suggests this reflects not only economic, but social and institutional constraints on opportunities and access, and the persistence of ignorance. In effect, poverty is the outcome of "inadequate social functioning" (Jackson, 1970).

\section{Strategy, Policy and Poverty Assessment}

The World Bank's 1990 World Development Report on Poverty set out to put the record straight in laying out the basic strategy for poverty reduction. The two key elements proposed were, first, to promote broadly-based economic growth to generate increased income earnings for the poor; and, second, to establish conditions to ensure that the poor were afforded improved access to education, health care and other social services. The report argued it was also particularly important that safety nets were established for the most vulnerable. In evaluating the effectiveness of policies to alleviate poverty two issues need to be addressed; how has poverty itself changed? And how has policy changed to affect the conditions of the poor? (This is a somewhat wider question than simply trying to monitor the effectiveness of a specific poverty alleviation policy).

On the first issue, the typical Bank poverty assessment analyzes three things:

1. Who are the poor? What are the economic, demographic, and social characteristics of the poor? 
2. Why are they poor? (To underline the need to review the major macroeconomic and regulatory issues that impede poverty reduction).

3. What can be done to reduce poverty? Identifying the specific policy and public expenditure changes that can help to reduce poverty more effectively.

On the second issue, the Bank recognizes the essential need to go beyond humanitarian holding measures and related short term palliatives and to stress the importance of developing an integrated multi-dimensional strategy. As part of its own poverty reduction approach and recognition of the need for greater equity and involvement, the Bank has significantly increased its lending to the social sectors, especially health and education, and encouraged countries to improve the efficiency and effectiveness of their overall macroeconomic policies so that the benefits of growth can be spread throughout the population.

\section{Bank Poverty Measures}

Before discussing what needs to be measured in a more expanded notion of poverty and, implicitly, its causes, it is useful to record what is currently being done in this field by the World Bank.

The Bank works directly on issues of poverty measurement, both through its general policy focus on poverty alleviation and associated monitoring and assessment activities as well as more directly in compiling internationally comparable poverty lines. In addition to these specific measures (which are illustrated in Annexes 6 and 7 taken from the Bank's new World Development Indicators 1997) the Bank produces, in partnership with its country members and other international agencies like the UNSD, ILO, WHO, etc., a wide range of indicators of social progress to complement the core information it produces on income levels and the distribution of income and consumption.

Thus, in the broad area of poverty and living standards measurement, the Bank compiles and broadly disseminates, through a wide variety of instruments, the following information:

- Levels of poverty among the population associated with National poverty datum lines separately distinguishing between urban and rural areas.

- Internationally comparable measures of poverty based on a predefined "standard" poverty level across all countries (1 US dollar per head per day in "equivalent" purchasing power parity terms).

- Social indicators based on administrative registers and survey results.

- Living Standards Measurement Surveys (LSMS) that provide data on production, income and expenditure patterns at the household level as well information on the general conditions of living and access to public services and amenities.

- Other community related and household based surveys for selected countries such as 
the "Core Welfare Indicators Questionnaires" (CWIQ) that illustrate household and individual status, provide policy performance measures and generate indicators to help monitor changes in welfare.

- For specific years and sectors, like health and education, assessments of the benefits and cost/tax burden by population groups of providing such services. (In particular, in the receipt of "free" or "below cost" services, and the analysis of "who pays" $v$. "who receives" consumption goods and services used by households).

- Special research studies that examine such questions as "do the poor pay more" and "do they pay more for their food?", "what are the types of sources of goods and services poor people consume?" and "who stay poor and why?".

Much of this information can now be found in the Bank's "World Development Indicators" and "Atlas" publications and accompanying CD-ROM that provides extensive time series data and access to the Internet.

\section{Measuring the Characteristics of Poverty}

Apart from the separate question of assessing "vulnerability", there are, fundamentally, two primary "superficial" (that is outwardly visible) dimensions of poverty. These relate to flows of income - or more strictly, "incomings" - to poor households, and the inter-related stock or status of poor people and their families. The two features, naturally, are often closely correlated but overlaying this distinction, is the inevitable legacy of poverty inherited from progenitors who were themselves poor. The inability of chronically poor people to gain access to the range of assets and services that might alleviate their poor condition, represents one of the major problems to be solved.

Logistically, none of these measures provide any direct link the nature of the poverty policy itself - as distinct from general economic progress and macro strategy - but each aspect delivers a particular message and helps send a specific signal to those concerned with improving the situation of poor people.

\subsection{Flow Measures}

a. Single Dimension

(i) Poverty Datum Lines (PDL)

To determine the number of people who are poor, and - to a more limited extent - to identify who are poor.

- Relative, pre-defined share, say $40 \%$, of a given average income, e.g. mean, median or mode and percentile levels.

- Absolute; national, urban, rural. Based on minimal nutritional requirements, basic needs, etc. can be adjusted for actual expenditures 
made and prices paid by poor households.

- Comparable; 1\$ per person per day in 1985 international prices (purchasing power parity comparisons).

\section{Problems of Determining Valid PDLs}

- Better to use income or consumption?

- How to incorporate the value of non-market (own produced) consumption of goods and services .

- Should the measures relate to household, family or individual standards? (Variations in household size and composition over time and between areas, within and between countries, can distort the significance of changes and observed differences in poverty).

- What to do when the survey reference base is truncated, or not comparable and not consistent over time? (See Annex).

- What value should be applied to non-priced goods and services?

- What prices do poor people pay? Are they higher or lower than average: For which products?

- How are different measures of poverty affected by the underlying income distribution?

- What is the inherent scale of preferences of poor families? How does this change? Difficulties of identifying "target" groups.

(ii) Poverty Gap Measures

The mean shortfall below the poverty line (defined as the level of income that represents zero shortfall) expressed as a percentage of poverty line. This reflects depth of poverty and its incidence. Both PDLs and poverty gap measures are strongly affected by the concentration of income in particular parts of distribution "bunching".

(iii)Simple Indicators

- Infant mortality

- Life expectancy

- Literary levels

- Services delivered (received)

b. Two-Dimensional

(i) Poverty (Income or Consumption) and Nutrition (Calorie Intake) 
Calorie intake

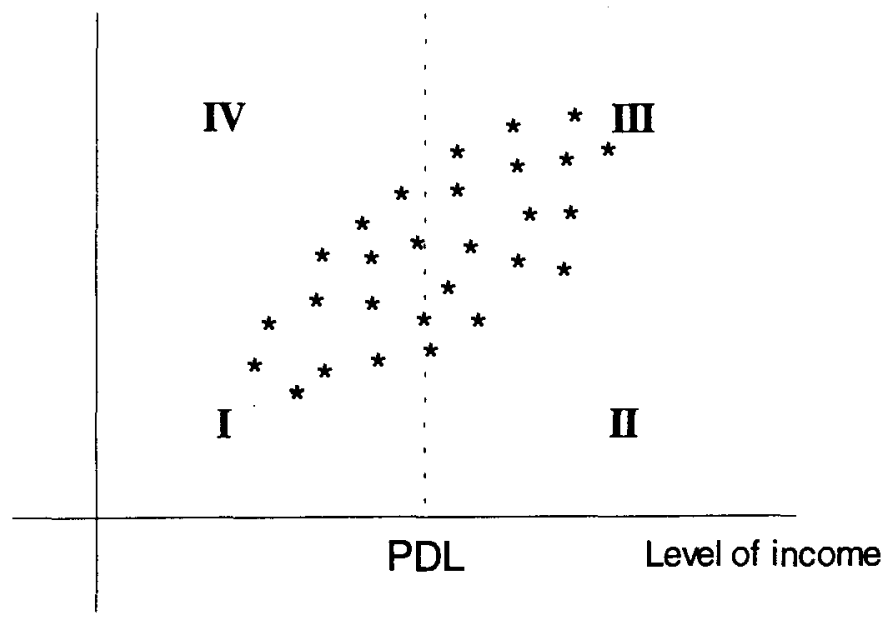

- People (households) in quadrant I are clearly "Poor".

- Those in quadrant III are, equally, "Non-Poor".

- But what about those in areas II and IV?

- Those in II have enough income but do not eat enough to subsist satisfactorily (perhaps because they don't have good access to food or sufficient education to choose a proper diet).

- Those in IV do not have sufficient income (apparently) but eat more than enough to survive (own farming? good resource use and nutritional practice?).

(ii) Nutritional Intake (Calories) and Protein Requirements

Protein needs

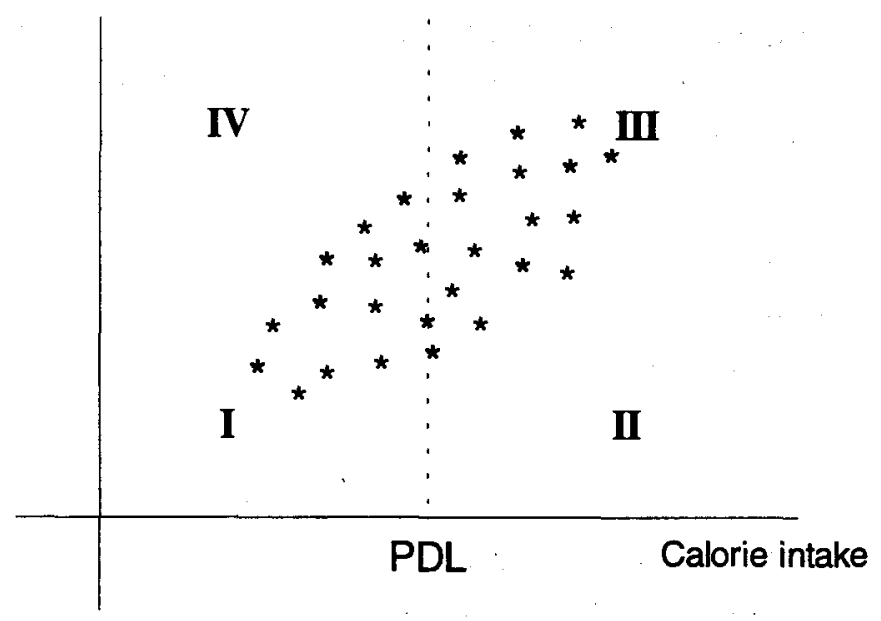


- Again, quadrant I households must be a focus of policy.

- Quadrant III have enough basic nutrition and protein to lead healthy lives.

- Quadrant II and IV demand policy attention.

(iii)Nutrition and Education

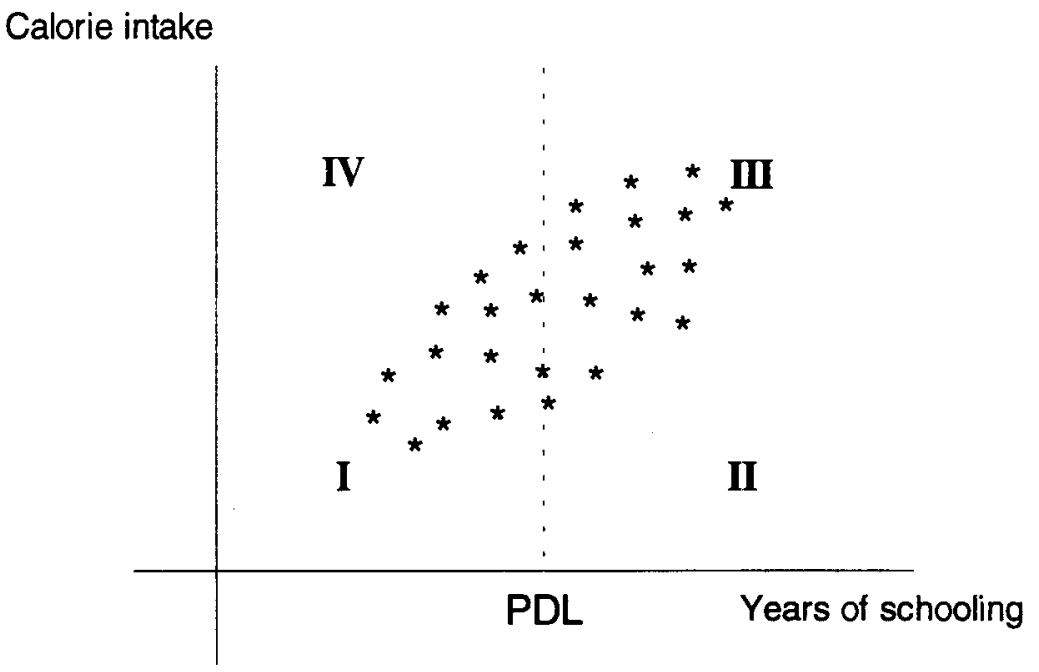

c. Multi-dimensional

These cannot be shown so easily in graphical form, but can be analyzed by defining, first, basic reference states, e.g. urban, rural; industrial, agricultural; employed, unemployed; educated or uneducated - or more complex inter-related categories of them, e.g. urban industrial unemployed, and plotting the key characteristics concerning income and nutritional flows, etc. each group faces.

\subsection{STOCK MEASURES}

\section{a. Single Dimension}

(i) Economic

- Ownership of land, property, productive assets.

- Sills and job experience.

- Economic "engagement" status (i.e., occupation, employment).

- Possession of financial and other liquid assets, e.g. jewelry, (as a protection against "vulnerability"). 
(ii) Social

- Housing quality and location.

- Services, private and collective, available.

- Access - physical, economic (cost), legal and institutional - to supporting services and facilities.

- Human Capital.

- Education (level).

- Health (status).

(iii)Intangibles

- Independence.

- Security.

- Political freedom.

- Equality.

\section{b. Multi-Dimensional}

The association of assets - physical capital (communal and personally available) and human capital - with basic rights and access to conditions that can improve peoples standards of living (see Table 3,4 and 5).

\section{Tracking Official Policies; Beneficiary Assessment and Benefit-Incidence Analysis}

Techniques are being developed to try and track more effectively the impact of government policies on the population in general and specific target groups in particular. Through household income and expenditure surveys, specific user-service studies and extensions to existing administrative procedures, administrations are now better able to assess their effectiveness, to focus more effectively on groups at risk and determine appropriate priorities. Furthermore, through the more exact linking (at the minimum, at the classificatory and definitional level) of household surveys data with administrative files, some authorities have been able to provide a more transparent picture of the way their services and facilities are used by different people and household groups. In the area of providing public health and educational services of different types this has important implications for understanding how real opportunities are made more open to the poor and how such services are effectively delivered to them. The diagrams below provide two interesting illustrations of how such more detailed functional analysis of expenditures can be linked to households of different income levels and tell an interesting story that has policy relevance. 


\section{CHART 1: INCIDENCE OF CASH BENEFITS IN HUNGARY, 1989}

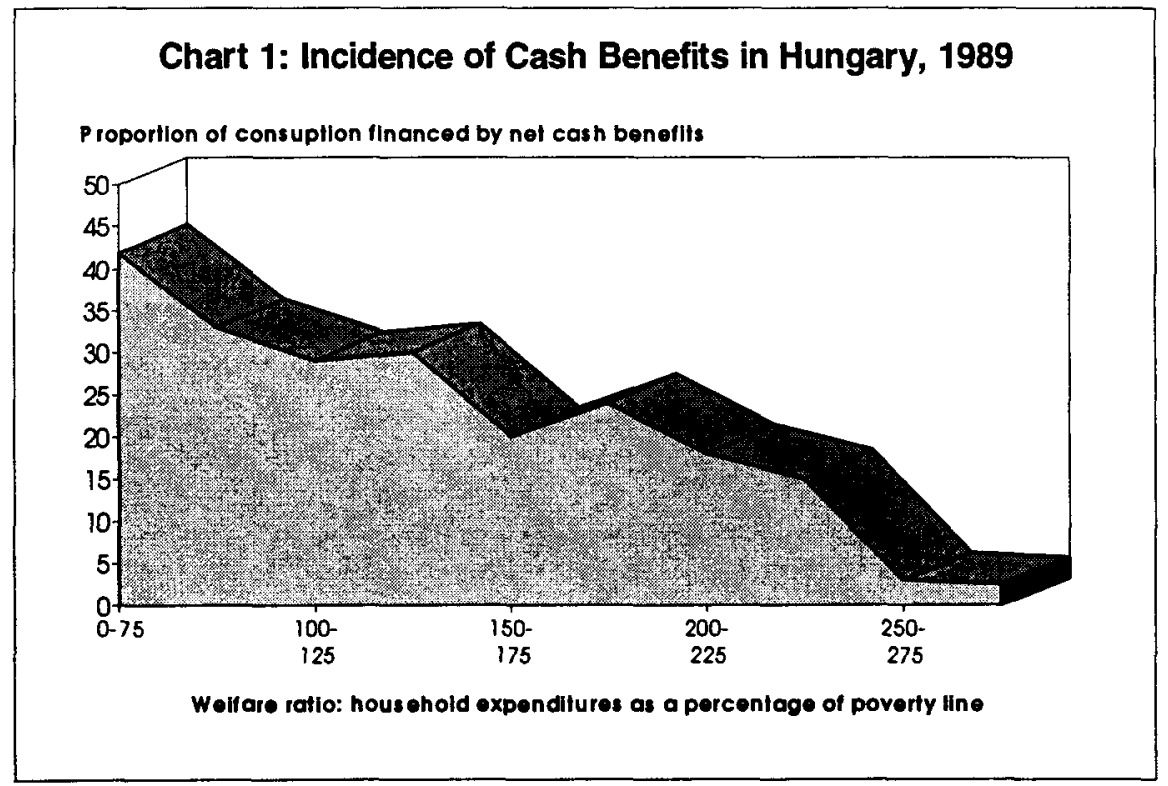

INCIDENCE OF EDUCATION EXPENDTURE (ANDIAX)

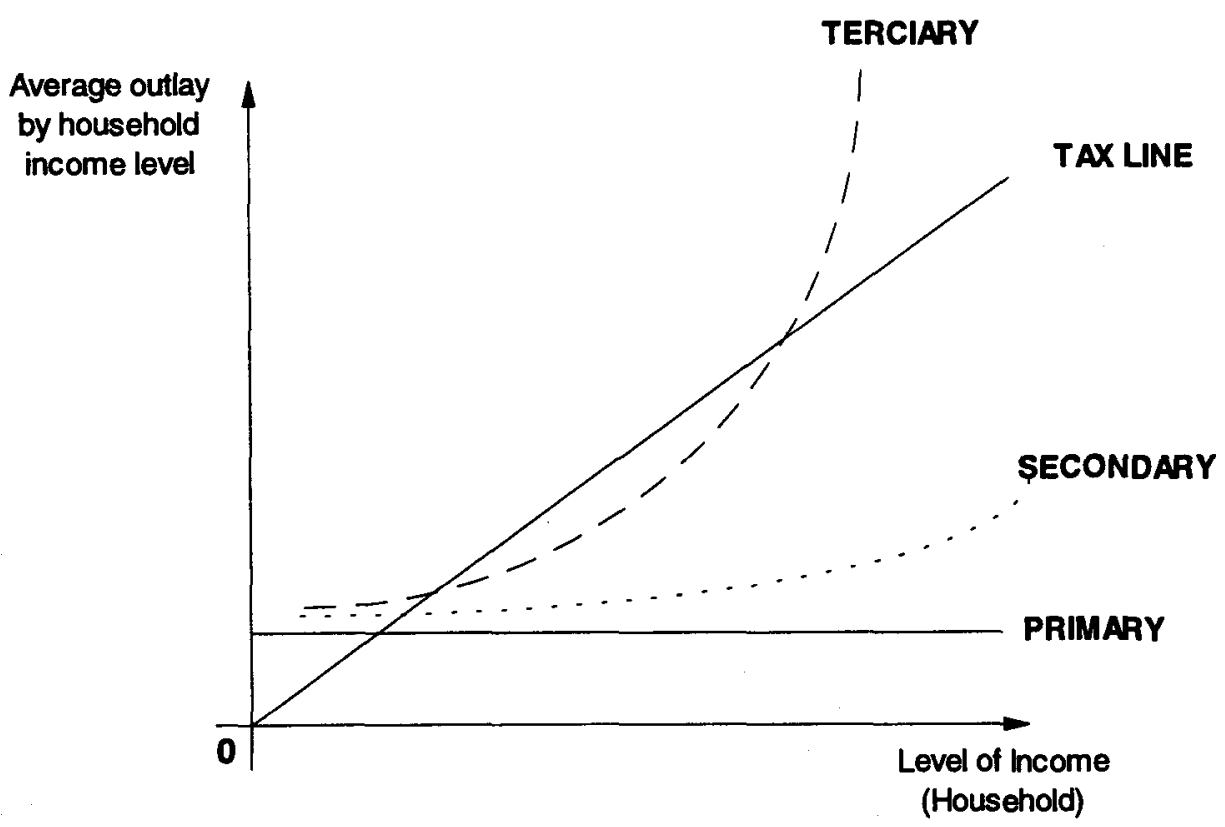


In the area of personal expenditures and, particularly, food consumption outlays, studies are being carried out in a number of African countries under Bank auspices to determine whether the poor pay more for their food and whether what they receive for their money is of the same quality as that generally available in the market. It is argued that because the poor tend to buy in small quantities, are not regularly able to shop at the cheapest outlets and have often to buy when cash is available rather than when market conditions are favorable, there are many more living below "national" poverty datums lines than in officially reported. A broad measure of such disparities, and of the differences between urban and rural areas, has been obtained from the detailed outlet specific price and expenditure surveys carried out under the ICP purchasing power parities exercise.

Determining the relationships between economic and social status and the delivery of public services and specific policies is an area of investigation that would clearly benefit from further expansion, if governments are serious abut improving the effectiveness of their poverty reduction programs.

\section{Figure 1. A typology of poverty concepts}

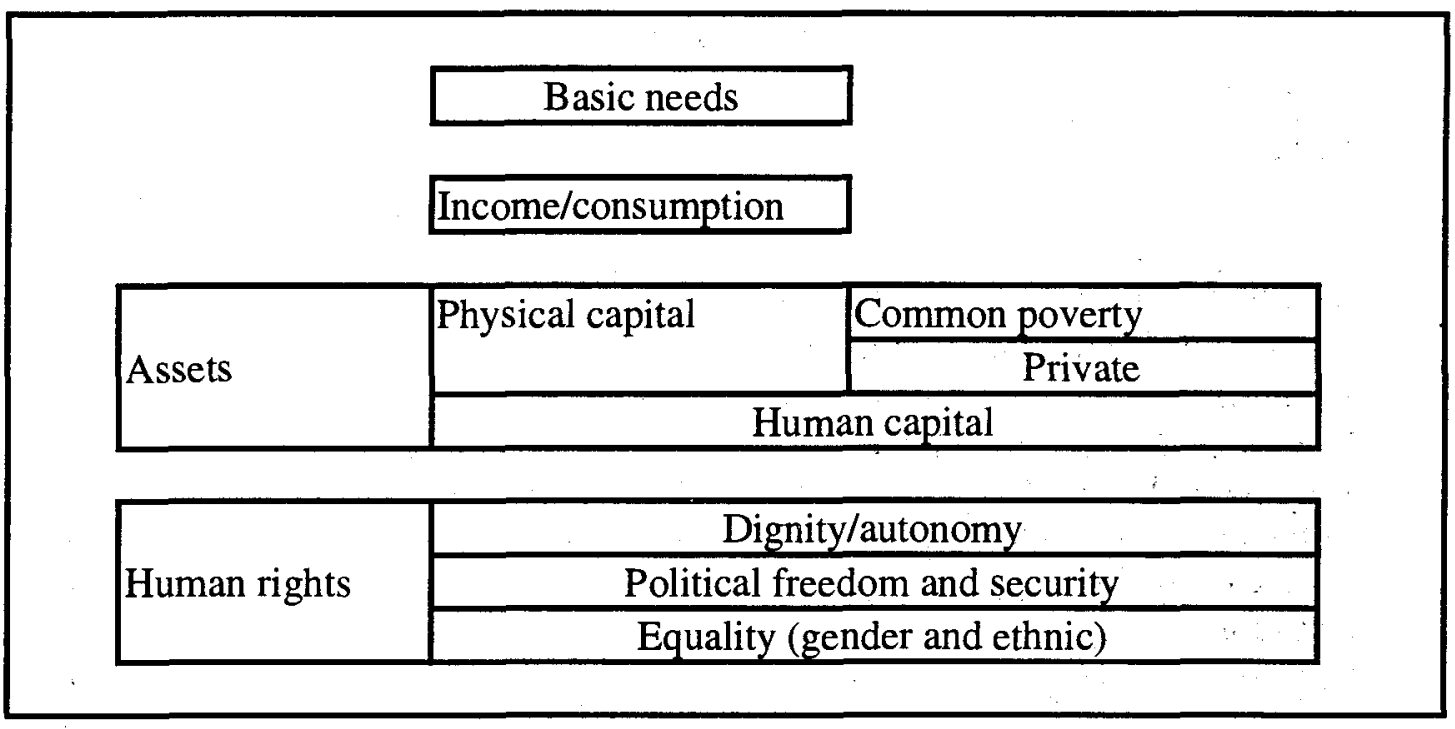


Figure 2. Typology of poverty lines

\begin{tabular}{|l|l|l|}
\hline \multirow{3}{*}{ Absolute } & Calorie requirement & $\begin{array}{l}\text { Calories only } \\
\text { Calorie cost divided by food share } \\
\text { Calories plus basket of goods } \\
\text { (costed or estimated) }\end{array}$ \\
\cline { 2 - 3 } & $\begin{array}{l}\text { Basket of goods } \\
\text { (including food) }\end{array}$ & \\
\hline
\end{tabular}

\begin{tabular}{|l|l|l|}
\hline \multirow{2}{*}{ Relative } & Relative to income base & $\begin{array}{l}\text { Multiple of wage } \\
\text { Share of mean income or expenditure }\end{array}$ \\
\cline { 2 - 3 } & $\begin{array}{l}\text { Scientific percentage of } \\
\text { income distribution }\end{array}$ & \\
\hline
\end{tabular}

\section{Table 3. Indicators of changing well-being for households with declining income}

\begin{tabular}{lrr}
\hline Variable & \multicolumn{2}{c}{$\begin{array}{c}\text { Percent of } \\
\text { households }\end{array}$} \\
& $1963-66$ & $1982-84$ \\
\hline Residing on patron's land & 31 & 0 \\
Taking loan from other besides patron & 13 & 47 \\
Withdrawing children from school during crop season & 17 & 6 \\
Having ready cash at home of Rs 200 or more during slack season & 0 & 26 \\
Relying on day-to-day petty purchases of key provisions & 100 & 51 \\
Occasionally consuming green vegetables in non-crop season & 0 & 100 \\
Consuming rice on non-festive occasions & 0 & 14 \\
Women and children regularly wear shoes & 0 & 36 \\
House with separate quarters for human and animals & 6 & 52 \\
Possessing radio & 0 & 7 \\
\hline
\end{tabular}

Source: N.S. Jodha "Poverty Debate in India: A Minority View" Economic and Political Weekly, 1988. 


\section{Table 4. Numbers of main groups of the poor}

\begin{tabular}{lrr}
\hline Group & $\begin{array}{c}\text { Number } \\
\text { (millions) }\end{array}$ & $\begin{array}{c}\text { Size } \\
\text { (per cent) }\end{array}$ \\
\hline Ethiopia (share of poor) & & \\
Chronic poor & 16.50 & 61.7 \\
Draught affected & 7.40 & 27.3 \\
Refugees & 0.49 & 1.3 \\
Displaced returnees and ex-soldiers & 2.10 & 7.3 \\
??? civil servants & 0.33 & 1.2 \\
??? & & \\
Total poor (millions) & 26.9 & 100.0 \\
& & \\
Uganda (share of population) & & \\
Orphaned, displaced and abandoned children & 0.78 & 4.6 \\
The handicapped & 1.25 & 7.3 \\
Members of female-headed households & 3.78 & 22.0 \\
Older people and their dependents & - & - \\
Landless peasants & - & - \\
The ??? & 3.15 & 18.3 \\
Population (millions) & 17.2 & 52.1 \\
\hline
\end{tabular}

Source: Ethiopia and Uganda PAs.

Table 5. List of techniques used in participatory analysis

\begin{tabular}{|c|c|}
\hline Technique & Description \\
\hline $\begin{array}{l}\text { Analysis of secondary } \\
\text { sources }\end{array}$ & $\begin{array}{l}\text { Discussion of aerial photos or satellites images on issues such as } \\
\text { land conditions and tenure. }\end{array}$ \\
\hline Mapping and modeling & $\begin{array}{l}\text { Constructing maps of community or community facilities (or three } \\
\text { dimensional models) on the ground or on/using paper. }\end{array}$ \\
\hline Transacts & $\begin{array}{l}\text { Walking through an area, perhaps associated with a mapping } \\
\text { exercise. }\end{array}$ \\
\hline $\begin{array}{l}\text { Time lines and trend } \\
\text { analysis }\end{array}$ & $\begin{array}{l}\text { Chronologies of major events or graphs of seasonal patterns or } \\
\text { perceived time trends (rainfall, prices, etc.) }\end{array}$ \\
\hline $\begin{array}{l}\text { Oral histories and ethno } \\
\text { biographies }\end{array}$ & $\begin{array}{l}\text { Usually personal (common use in PAs, see Box } 6.1 \text { for a typical } \\
\text { example), but can extend to crops, animals, etc. }\end{array}$ \\
\hline Seasonal calendars & Seasonal calendar for items such as rainfall, diet and sickness. \\
\hline Daily time use analysis & $\begin{array}{l}\text { Indicating time spent and work effort/drudgery, perhaps with } \\
\text { seasonal variations. }\end{array}$ \\
\hline Livelihood analysis & Income, expenditure, credit and debt etc. often by month or season. \\
\hline $\begin{array}{l}\text { Participatory linkage } \\
\text { diagramming }\end{array}$ & Diagram of chains of causality. \\
\hline
\end{tabular}


Venn (or chapati)

diagrams

Well-being or wealth ranking

Analysis of difference Matrix scoring and ranking

Estimates and quantification

Key probes

Stories and case studies
Showing the relative importance of different individuals and/or institutions in the community.

Ranking individuals or households be well-being or wealth, often used to determine indicators (see Box 2 for example from Ghana PA).

Differences by gender, wealth group etc.

Scoring (often using seeds) for different crops, soils etc.

Quantification is done using local materials such as seeds and stones, can be combined with wealth ranking.

Questions to lead into key issues.

To uncover coping strategies etc.

Source: Robert Chambers "The origins and practice of participatory rural appraisal", World Development vol. 22, pp. 959-961, 1994.

\section{What survey instruments are available?}

\section{How to measure, what to measure and what data to gather?}

Many techniques, from large to small, quick and continuing, general and selective can be used to gather information on well-being. These include:

1. Census (population, agriculture).

2. Full Household (income and expenditure) Surveys, including LSMS.

3. LSMS (Living Standards Measurement Surveys).

4. Limited Consumption (e.g. Food) Surveys.

5. Farm surveys (FAO Crop Yield Studies).

6. Farmer's surveys (Casley).

7. Credit surveys (especially rural credit).

8. Appraisal (expert judgment) methods (including Rapid Rural Appraisals).

9. CWIQ (core welfare indictors questionnaire).

10. Health/Nutrition surveys (physical weighing and measuring).

11. Participatory analysis and focus group approaches.

12. Administrative files and registrations (e.g. as for education, transport use, etc.).

13. Performance indicators and other derived social signals.

Some of these methods are demanding of time and real resources (particularly staffing) if done properly, while others are selective and purpose specific and more limited in their perspectives (see the attached diagram "The CWIQ in Context"). 


\section{ANNEX 1}

\section{Poverty lines - difficult to compare}

International comparisons of poverty data entail both conceptual and practical problems. Different countries have different definitions of poverty, and consistent comparisons between countries can be difficult. Local poverty lines tend to have higher purchasing power in rich countries, where more generous standard are used than in poor countries.

Is it reasonable to treat two people with the same standard of living differently - in terms of their command over commodities - because one happens to live in a better-off country? It can be argued that to make consistent international comparisons, we should try to hold the real value of the poverty line constant, just as is typical when making comparisons over time.

The poverty measures given under the international poverty line attempts to do this. Here the poverty line is set for all countries at $\$ 1$ a person per day, in 1985 international prices, and adjusted to local currency using exchange rates aimed at assuming purchasing power parity for consumption. The figure of $\$ 1$ a day was chosen for the World Bank's World Development Report 1990: Poverty because it is typical of the poverty lines in lowincome countries. Of course, by the same token, it is lower - often much lower - than the poverty lines found in middle or high income countries.

Currency conversions can be problematic, however. Using standard purchasing power parity (PPP) exchange rates, such as those from the Penn World Table, is clearly preferable to using official exchange rates, because many commodities are not traded internationally. But PPP rates were designed not for making international poverty comparisons, but for comparing aggregates from national accounts. It would be better to design special purpose PPP rates for the poor. But with no such rates now available, the standard PPP rates for consumption appear to be the best option.

Just as there are problems in comparing a poverty measure for one country with that for another, there can also be problems in comparing poverty measures within countries. For example, the cost of living is typically higher in urban than in rural areas. (Food staples, for example, tend to be more expensive in urban areas). So the urban poverty line should be higher than the rural poverty line. But it is not always clear that the difference between urban and rural poverty lines properly reflects the difference in the cost of living.

For some countries the urban poverty line in common use has a higher real value meaning that it allows poor people to buy more commodities for consumption - than does the rural poverty line. Sometimes the difference has been so large as to imply that the incidence of poverty is greater in urban than in rural areas, even though the reverse is found 
when adjustments are made for differences in the cost of living. As with international comparisons, when the real value of the poverty line varies, it is not clear how meaningful such urban-rural comparisons are.

The problems of making poverty comparisons do not end there. Further issues arise in measuring household living standards. The choice between income and consumption as a welfare indicator is one issue. Incomes are generally more difficult to measure accurately, and it can also be argued that consumption accords better with the idea of the standard of living than does income, which can vary over time even if the standard of living does not. But consumption data are not always available, and when they are not there is little choice but to use income.

There are still other problems. In some countries an allowance is made for differences in household size and composition when determining who is poor, while in others no allowance is made. Household survey questionnaires can also differ widely, for example, in the number of distinct categories of consumer goods they identify and in the order in which questions are asked. Survey quality varies, and even similar surveys may not be strictly comparable.

Comparisons across countries at different levels of development also pose a potential problem, because of differences in the relative importance of consumption of nonmarket goods. The local market value of all consumption in kind including consumption from own production, particularly important in underdeveloped rural economies) should be included in the measure of total consumption expenditure. Similarly, the imputed profit from production of nonmarket goods should be included in income. This is not always done, though such omissions were a far bigger problem in surveys before the 1980s. Survey data now routinely include valuations for consumption or income from own production. Nonetheless, the methods of valuation vary - for example, some surveys use the price at the nearest market, while other use the average farmgate selling price. 


\section{ANNEX 2}

\section{About the data}

It is impossible to create a data set on poverty and distribution that is strictly comparable across countries. But the poverty measures given under the international poverty line are designed to reduce the comparability problems in several ways. Nationally representative surveys have been used, surveys conducted either by national statistical offices or by private agencies under government or international agency supervision.

The poverty measures are based on the most recent purchasing power parity (PPP) estimates, from the latest version of the Penn World Table (PWT 5.6). These estimates include revisions to PPP exchange rates in the previous version of the table (PWT 5.0) to incorporate better data. The revisions resulted in significant changes, the most striking relating to China. Using the updated PPP exchange rates for consumption from PWT 5.6 produces an estimate of the percentage of China's population living on less than $\$ 1$ a day (in international prices) in 1992 nearly triple that estimated using the PPP rates from PWT 5.0, with the same distribution data. For India, however, the revised PPP rates result in a lower estimate for this indicator. Such changes in the estimated incidence of poverty occur because a large change in the PPP for a country can produce dramatically different poverty lines in local currency.

Whenever possible, consumption has been used as the welfare indicator for deciding who is poor. A person is said to be poor if he or she lives in a household whose total consumption per person is less than the poverty line. The measure of consumption is generally comprehensive, including that from own production as well as all food and nonfood goods purchased. When only household incomes are available, the average level of income has been adjusted to accord with either a survey-based estimate of mean consumption (when available) or an estimate based on consumption data from national accounts. This procedure adjusts only the mean, however; nothing can be done to correct for the difference in Lorenz (income distribution) curves between consumption and income.

Empirical Lorenz curves were weighted by household size, so they are based on percentiles of population, not households. In all cases the measures of poverty have been calculated from primary data sources (tabulations or household data) rather than existing estimates. Estimation from tabulations requires an interpolation method: the method chosen was Lorenz curves with flexible functional forms, which have proved reliable in past work.

\section{Definitions}

- Survey year is the year in which the underlying data were collected.

- Rural poverty rate is the percentage of the rural population deemed poor. 
- Urban poverty rate is the percentage of the urban population deemed poor.

- National poverty rate is the percentage of the population living below the poverty line deemed appropriate for the country by its authorities. National estimates are based on population-weighted subgroup estimates from household surveys.

- Population below $\$ 1$ a day is the percentage of the population living on less than $\$ 1$ a day at 1985 international prices, adjusted for purchasing power parity.

- Poverty gap is the mean shortfall below the poverty line (counting the nonpoor as having zero shortfall) expressed as a percentage of the poverty line. This measure reflects the depth of poverty as well as its incidence.

\section{Data sources}

Poverty measures are prepared by the Poverty and Human Resources Division of the World Bank's Policy Research Department. National poverty lines are based on the World Bank's country poverty assessments. International poverty lines are based on primary household survey data obtained from government statistical agencies and World Bank country departments.

The World Bank has prepared an annual review of poverty trends since 1993. The most recent is Poverty Reduction and the World Bank (1996f).

\begin{tabular}{|c|c|c|c|c|c|c|c|}
\hline & \multicolumn{4}{|c|}{ National poverty line } & \multicolumn{3}{|c|}{ International poverty line } \\
\hline & \multicolumn{4}{|c|}{$\begin{array}{c}\text { Population } \\
\text { below the } \\
\text { poverty } \\
\text { line }\end{array}$} & \multicolumn{3}{|c|}{$\begin{array}{l}\text { Population } \\
\text { below }\end{array}$} \\
\hline & $\begin{array}{c}\text { Survey } \\
\text { year }\end{array}$ & $\begin{array}{c}\text { Rural } \\
\%\end{array}$ & $\begin{array}{c}\text { Urban } \\
\%\end{array}$ & $\begin{array}{c}\text { National } \\
\% \\
\end{array}$ & $\begin{array}{c}\text { Survey } \\
\text { year }\end{array}$ & $\begin{array}{c}\$ 1 \text { a day } \\
\%\end{array}$ & $\begin{array}{c}\text { Poverty gap } \\
\% \\
\end{array}$ \\
\hline Albania & 1996 & -- & $\cdots$ & 19.6 & - & - & -- \\
\hline Algeria & -- & -- & -- & -- & 1988 & 1.6 & 0.4 \\
\hline Angola & -- & -- & -- & -- & -- & -- & -- \\
\hline Argentina & 1991 & -- & -- & 25. & -- & -- & -- \\
\hline Armenia & -- & -- & -- & -- & -- & -- & -- \\
\hline Australia & -- & - & -- & -- & -- & -- & -- \\
\hline Austria & -- & -- & -- & -- & -- & -- & -- \\
\hline Azerbaijan & -- & -- & -- & -- & -- & -- & -- \\
\hline Bangladesh & $1991-92$ & 47.6 & 46.7 & 47.5 & -- & -- & -- \\
\hline Belarus & -- & -- & - & -- & -- & -- & - \\
\hline Belgium & -- & -- & - & -- & -- & - & -- \\
\hline Benin & 1995 & -- & -- & 33.0 & -- & -- & -- \\
\hline Bolivia & -- & -- & -- & -- & 1990-91 & 7.1 & 1.1 \\
\hline $\begin{array}{l}\text { Bosnia and } \\
\text { Herzegovina }\end{array}$ & -- & -- & - & -- & -- & -- & -- \\
\hline Botswana & -- & -- & -- & -- & $1985-86$ & 34.7 & 13.3 \\
\hline Brazil & 1990 & 32.6 & 13.1 & 17.4 & 1989 & 28.7 & 11.6 \\
\hline Bulgaria & -- & -- & -- & -- & 1992 & 2.6 & 0.8 \\
\hline Burkina Faso & -- & -- & -- & - & - & -- & -- \\
\hline Burundi & 1990 & -- & -- & 36.2 & - & -- & -- \\
\hline Cambodia & -- & -- & -- & -- & -- & -- & -- \\
\hline
\end{tabular}




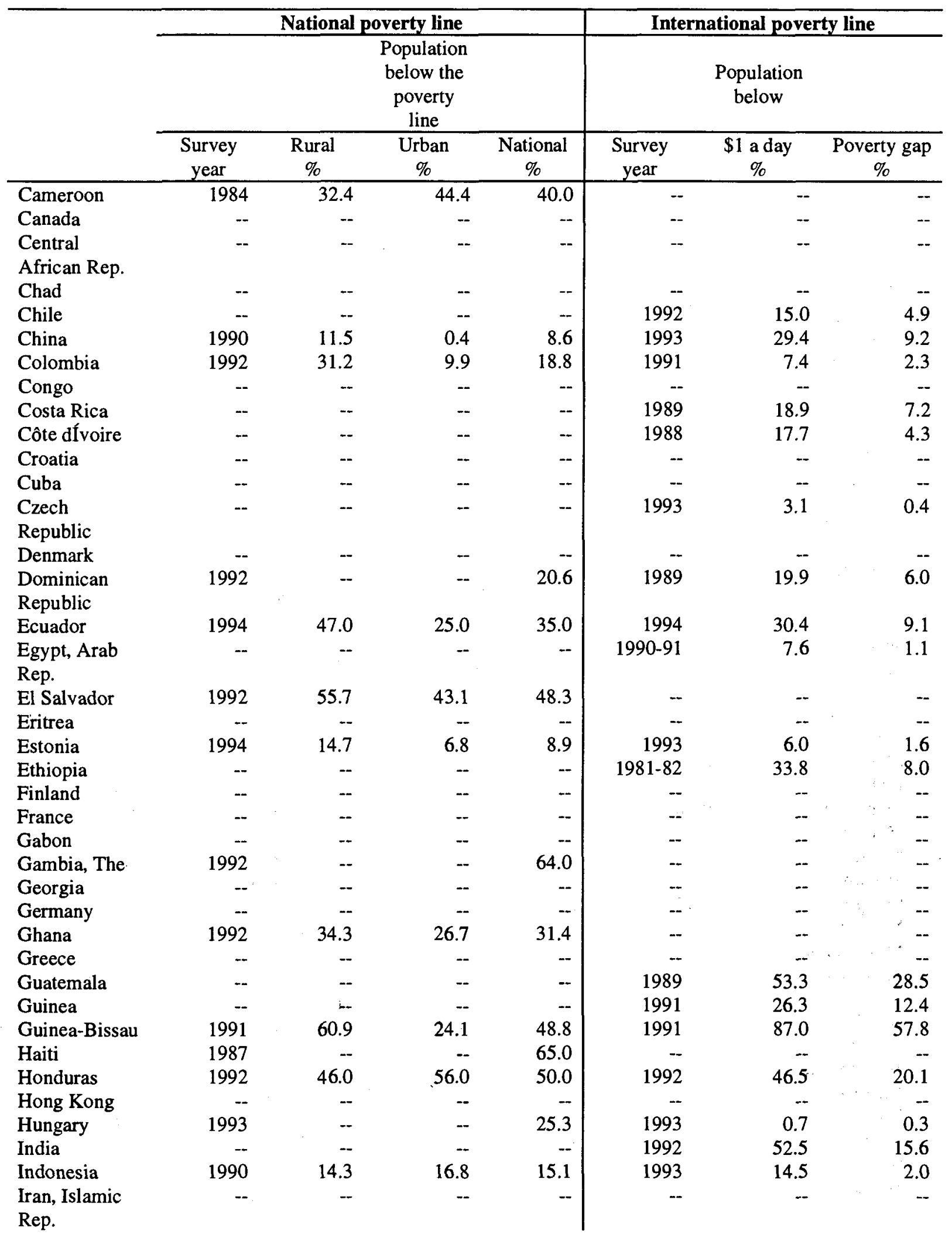




\begin{tabular}{|c|c|c|c|c|c|c|c|}
\hline & \multicolumn{4}{|c|}{ National poverty line } & \multicolumn{3}{|c|}{ International poverty line } \\
\hline & \multicolumn{4}{|c|}{$\begin{array}{c}\text { Population } \\
\text { below the } \\
\text { poverty } \\
\text { line }\end{array}$} & \multicolumn{3}{|c|}{$\begin{array}{l}\text { Population } \\
\text { below }\end{array}$} \\
\hline & $\begin{array}{c}\text { Survey } \\
\text { year }\end{array}$ & $\begin{array}{c}\text { Rural } \\
\%\end{array}$ & $\begin{array}{c}\text { Urban } \\
\%\end{array}$ & $\begin{array}{c}\text { National } \\
\%\end{array}$ & $\begin{array}{c}\text { Survey } \\
\text { year }\end{array}$ & $\begin{array}{c}\$ 1 \text { a day } \\
\%\end{array}$ & $\begin{array}{c}\text { Poverty gap } \\
\%\end{array}$ \\
\hline Iraq & -- & -- & -- & - & -- & -- & - \\
\hline Ireland & -- & -- & -- & -- & -- & -- & -- \\
\hline Israel & -- & -- & - & - & -- & -- & - \\
\hline Italy & -- & -- & - & - & -- & -- & -- \\
\hline Jamaica & 1992 & -- & -- & 34.2 & 1993 & 4.7 & 0.9 \\
\hline Japan & - & -- & - & -- & -- & -- & -- \\
\hline Jordan & 1991 & -- & -- & 15.0 & 1992 & 2.5 & 0.5 \\
\hline Kazakstan & -- & -- & - & -- & -- & -- & -. \\
\hline Kenya & 1992 & 46.4 & 29.3 & 42.0 & 1992 & 50.2 & 22.2 \\
\hline $\begin{array}{l}\text { Korea, Dem. } \\
\text { Rep. }\end{array}$ & -- & -- & - & -- & -- & - & - \\
\hline Korea, Rep. & - & -- & -. & -- & -- & -- & - \\
\hline Kuwait & - & -- & -- & -- & -- & - & - \\
\hline $\begin{array}{l}\text { Kyrgyz } \\
\text { Republic }\end{array}$ & 1993 & 52.2 & 32.0 & 45.4 & 1993 & 18.9 & 5.0 \\
\hline Lao PDR & 1993 & 53.0 & 24.0 & 46.1 & -- & -- & - \\
\hline Latvia & -- & -- & -- & -- & -- & -- & - \\
\hline Lebanon & -- & -- & -- & - & -- & -- & -- \\
\hline Lesotho & 1993 & 53.9 & 27.8 & 49.2 & $1986-87$ & 50.4 & 24.8 \\
\hline Libya & -- & -- & -- & - & -- & -- & -- \\
\hline Lithuania & -- & -- & - & -- & 1993 & 2.1 & 0.5 \\
\hline $\begin{array}{l}\text { Macedonia, } \\
\text { FYR }\end{array}$ & 1990 & 28.0 & 24.0 & -- & -- & -- & -- \\
\hline Madagascar & -- & $-\infty$ & -- & -- & 1993 & 72.3 & 33.2 \\
\hline Malawi & -- & -- & -- & - & -- & -- & -- \\
\hline Malaysia & 1989 & & & 15.5 & 1989 & 5.6 & 0.9 \\
\hline Mali & - & - & -- & -- & -- & -- & -- \\
\hline Mauritania & 1990 & -- & -- & 57.0 & 1988 & 31.4 & 15.2 \\
\hline Mauritius & 1992 & -- & - & 10.6 & - & -- & -- \\
\hline Mexico & 1988 & - & - & 10.1 & 1992 & 14.9 & 3.8 \\
\hline Moldova & - & $\cdots$ & - & -- & 1992 & 6.8 & 1.2 \\
\hline Mongolia & 1995 & 33.1 & 38.5 & 36.3 & - & -- & -- \\
\hline Morocco & $1990-91$ & 18.0 & 7.6 & 13.1 & $1990-91$ & 1.1 & 0.1 \\
\hline Mozambique & -- & - & -- & -- & -- & -- & $\cdots$ \\
\hline Myanmar & -- & - & -- & -- & -- & -- & -. \\
\hline Namibia & -- & - & -- & -- & -- & -- & $\ldots$ \\
\hline Nepal & $1995-96$ & 44.0 & 23.0 & 42.0 & 1995-96 & 53.1 & 16.9 \\
\hline Netherlands & -- & - & -- & -- & -- & -- & $\ldots$ \\
\hline New Zealand & -- & -- & -- & -- & -- & -- & $\ldots$ \\
\hline Nicaragua & 1993 & 76.1 & 31.9 & 50.3 & 1993 & 43.8 & 18.0 \\
\hline Niger & - & - & -- & -- & 1992 & 61.5 & 22.2 \\
\hline Nigeria & $1992-93$ & 36.4 & 30.4 & 34.1 & 1992-93 & 28.9 & 11.7 \\
\hline Norway & -- & -- & - & -- & -- & - & - \\
\hline Oman & - & -- & - & -- & -- & - & $\ldots$ \\
\hline
\end{tabular}




\begin{tabular}{|c|c|c|c|c|c|c|c|}
\hline & \multicolumn{4}{|c|}{ National poverty line } & \multicolumn{3}{|c|}{ International poverty line } \\
\hline & \multicolumn{4}{|c|}{$\begin{array}{c}\text { Population } \\
\text { below the } \\
\text { poverty } \\
\text { line }\end{array}$} & \multicolumn{3}{|c|}{$\begin{array}{c}\text { Population } \\
\text { below }\end{array}$} \\
\hline & $\begin{array}{c}\text { Survey } \\
\text { year }\end{array}$ & $\begin{array}{c}\text { Rural } \\
\%\end{array}$ & $\begin{array}{c}\text { Urban } \\
\%\end{array}$ & $\begin{array}{c}\text { National } \\
\% \\
\end{array}$ & $\begin{array}{c}\text { Survey } \\
\text { year }\end{array}$ & $\begin{array}{c}\$ 1 \text { a day } \\
\%\end{array}$ & $\begin{array}{c}\text { Poverty gap } \\
\%\end{array}$ \\
\hline Pakistan & 1991 & 36.9 & 28.0 & 34.0 & 1991 & 11.6 & 2.6 \\
\hline Panama & -- & -- & -- & - & 1989 & 25.6 & 12.6 \\
\hline $\begin{array}{l}\text { Papua New } \\
\text { Guinea }\end{array}$ & -- & -- & -- & -- & -- & -- & -- \\
\hline Paraguay & 1991 & 28.5 & 19.7 & 21.8 & - & -. & -- \\
\hline Peru & 1991 & 68.0 & 50.3 & 54.0 & 1994 & 49.4 & 20.5 \\
\hline Philippines & 1991 & 71.0 & 39.0 & 54.0 & 1988 & 27.5 & 6.9 \\
\hline Poland & 1993 & -- & - & 23.8 & 1993 & 6.8 & 4.4 \\
\hline Portugal & -- & -- & -- & -- & -- & -- & -- \\
\hline Puerto Rico & -- & -- & -- & -- & - & -- & -- \\
\hline Romania & 1994 & 28.0 & 15.6 & 21.5 & 1992 & 17.7 & 4.2 \\
\hline Russian & 1994 & - & -- & 30.9 & 1993 & 1.1 & 0.1 \\
\hline Federation & & & & & & & \\
\hline Rwanda & 1993 & -- & -- & 51.2 & 1983-85 & 45.7 & 11.3 \\
\hline Saudi Arabia & -- & -- & -- & -- & -- & -- & -- \\
\hline Senegal & -- & -- & -- & -- & $1991-92$ & 54.0 & 25.5 \\
\hline Sierra Leone & -- & -- & -- & -- & -- & -- & -- \\
\hline Singapore & - & -- & -- & -- & -- & -- & -- \\
\hline Slovak & -- & -- & -- & -- & 1992 & 12.8 & 2.2 \\
\hline Republic & & & & & & & \\
\hline Slovenia & -- & -- & -- & -- & -- & -- & -- \\
\hline South Africa & - & -- & -- & -- & 1993 & 23.7 & 6.6 \\
\hline Spain & -- & -- & -- & -- & - & -- & -- \\
\hline Sri Lanka & 1991 & 24.4 & 18.3 & 22.4 & 1990 & 4.0 & 1.0 \\
\hline Sudan & -- & -- & -- & -- & -- & -- & -- \\
\hline Sweden & -- & -- & -- & -- & - & -- & - \\
\hline Switzerland & -- & - & -- & -- & - & -- & - \\
\hline Syrian Arab & - & -- & -- & - & - & -- & -- \\
\hline Republic & & & & & & & \\
\hline Tajikistan & -- & -- & -- & -- & -- & -- & -- \\
\hline Tanzania & 1991 & -- & -- & 51.1 & 1993 & 16.4 & 3.7 \\
\hline Thailand & 1992 & 15.5 & 10.2 & 13.1 & 1992 & 0.1 & 0.0 \\
\hline Togo & $1987-89$ & -- & -- & 32.3 & -- & - & - \\
\hline $\begin{array}{l}\text { Trinidad and } \\
\text { Tobago }\end{array}$ & 1992 &.- & -. & 21.0 & - & -- & -- \\
\hline Tunisia & 1990 & -- & -- & 14.1 & 1990 & 3.9 & 0.9 \\
\hline Turkey & -- & -- & -- & -- & -- & -- & -- \\
\hline Turkmenistan & -- & -- & -- & -- & 1993 & 4.9 & 0.5 \\
\hline Uganda & $1992-93$ & -- & -- & 55.0 & $1989-90$ & 50.0 & 14.7 \\
\hline Ukraine & 1995 & -- & -- & 31.7 & -- & -- & -- \\
\hline $\begin{array}{l}\text { United Arab } \\
\text { Emirates }\end{array}$ & -- & -- & -- & -- & -- & -- & -- \\
\hline $\begin{array}{l}\text { United } \\
\text { Kingdom }\end{array}$ & -- & -- & -- & - & - & -- & -. \\
\hline
\end{tabular}




\begin{tabular}{|c|c|c|c|c|c|c|c|}
\hline & \multicolumn{4}{|c|}{ National poverty line } & \multicolumn{3}{|c|}{ International poverty line } \\
\hline & \multicolumn{4}{|c|}{$\begin{array}{l}\text { Population } \\
\text { below the } \\
\text { poverty line }\end{array}$} & \multicolumn{3}{|c|}{$\begin{array}{l}\text { Population } \\
\text { below }\end{array}$} \\
\hline & $\begin{array}{c}\text { Survey } \\
\text { year }\end{array}$ & $\begin{array}{c}\text { Rural } \\
\%\end{array}$ & $\begin{array}{c}\text { Urban } \\
\%\end{array}$ & $\begin{array}{c}\text { National } \\
\% \\
\end{array}$ & $\begin{array}{c}\text { Survey } \\
\text { year }\end{array}$ & $\begin{array}{c}\$ 1 \text { a day } \\
\%\end{array}$ & $\begin{array}{c}\text { Poverty gap } \\
\% \\
\end{array}$ \\
\hline United States & -- & -- & -- & - & -- & $\cdots$ & -- \\
\hline Uruguay & -- & -- & -- & -- & - & -- & -- \\
\hline Uzbekistan & -- & -- & -- & -- & -- & -- & -- \\
\hline Venezuela & 1989 & -- & -- & 31.3 & 1991 & 11.8 & 3.1 \\
\hline Vietnam & 1993 & 57.2 & 25.9 & 50.9 & -- & -- & -- \\
\hline $\begin{array}{l}\text { West Bank } \\
\text { and Gaza }\end{array}$ & -- & -- & -- & -- & -- & -- & -- \\
\hline Yemen, Rep. & 1992 & 19.2 & 18.6 & 19.1 & -- & -- & - \\
\hline $\begin{array}{l}\text { Yugoslavia, } \\
\text { Fed. Rep. }\end{array}$ & -- & -- & -- & -- & - & - & -- \\
\hline Zaire & -- & -- & -- & -- & -- & -- & - \\
\hline Zambia & 1993 & -- & -- & 86.0 & 1993 & 84.6 & 53.8 \\
\hline Zimbabwe & $1990-91$ & -- & -- & 25.5 & $1990-91$ & 41.0 & 14.3 \\
\hline
\end{tabular}




\title{
THE PROFILE OF POVERTY: GENDER INDICATORS
}

\author{
by
}

ECLAC - UNSD 


\section{THE PROFILE OF POVERTY: GENDER INDICATORS}

\section{A. Analytic framework}

Measurements of poverty are a fundamental response to the need for designing and monitoring policies oriented to overcome the conditions of poverty. Naturally, in the first stage, it is necessary to define with the greatest possible precision, the phenomenon of poverty and its scope, for which the definition of an indicator of poverty that synthesizes its magnitude and permits the stratification of the population plays a strategic role in the mobilization of politicized will.

For this reason, it should not be surprising that in the majority of countries initial emphasis has been placed on the establishment and on the calculation of indicators that measure the magnitude of poverty. They have served to illustrate that the scale of the problem and its evolution over time have merited the transformation of its solution in a priority topic. So, it has been necessary to define other analytic and quantitative instruments with the objective of designing and follow-up policies.

The principal objective of this work is to describe how various analytical dimensions of poverty serve to orient policies that contribute to overcoming it and, above all, to provide guidelines for coordinating specific policies and programmes for different social areas.

This involves the definition of poverty profiles using a set of indicators that describe the situation and the characteristics of the persons and families that belong to poor groups. In Latin America, the population of those in poverty displays a high degree of heterogeneity. There exist, for example, notable differences between the rural and urban poor; between those who are poor owing to short-term economic circumstances and those whose situation responds more closely to structural long-term factors; between those who belong to households in which the employed members depend on salary or on income of their own generation, and those who are employed in sectors using little or high capital investment. In this manner, by using categories related to geographic location, education, employment, gender characteristics, or the demographic structure of households, strata can be identified in poverty, sharing common characteristics between some groups, and different from those of other groups.

The establishment of poverty profiles can play a fundamental role on the design of policies that, on the one hand, facilitate the identification of target groups and, on the other hand, benefits the coordination of anti-poverty policies with employment, educational, and gender policies, or with those oriented to improve the specific situation of certain vulnerable groups.

In this work, various advances developed in Latin America are presented in relation to poverty profiles, related, in particular, to those aspects in which gender plays an important role.

\section{B. Conceptual and methodological aspects}

In those works on the estimation of poverty, a variety of conceptual elements are incorporated, such as, in this case, the dimensions of gender, that afterward have been put into operation using available sources of information. 
Among these elements, there will be highlighted in this note the incorporation of women in economic activity, the relation between their domestic responsibilities and their occupational participation, the segmentation of the employment market, the salary differences between men and women doing similar work, the access of women to different educational levels, the contribution of their earnings to the formation of household incomes, and the importance of being household head, whether they live as a couple or form part of big families.

All of these aspects have particular importance for developing countries. Involved here are phenomena that in developed countries have had a long evolution and, in many cases, the indicators that describe them have achieved a considerable degree of stability. Thus, for example, the participation of women in economic activity reach values less different from that of men. On the contrary, in developing countries and particularly in Latin America, the participation of women has achieved levels and a dynamism that now constitute an important characteristic of social transformation. In this sense, the attempts to create indicators that reflect these phenomenon constitutes, without doubt, tasks of great relevancy. All the aspects that reveal these characteristics will not be described here, only those indicators that make it possible to establish clear links to the phenomenon of poverty will be focus.

In effect, for many of these dimensions, their relation has been examined with the situation of household welfare. In this regard, progress has been made in incorporating -in this case- the dimension of gender in the design of anti-poverty policies. In what follows, there will be described briefly some of these categories, the indicators used for their quantitative measured, the establishment of their linkage with the condition of poverty; and comments will be provided on the statistical sources used. Additionally, in point $\mathrm{C}$ are presented some examples based on The Social Panorama of Latin America, a report prepared annually by ECLAC, in which the methodology described is used for conducting a follow-up on recent tendencies in the fields of gender, poverty and female labour participation in the region.

\section{B.1 Indicators}

Following, 4 blocks of indicators will be described, with which it is aimed to reveal the mentioned dimensions.

A relation has been established between men and women as head of indigent, poor non-indigent and non-poor households and the following five indicators:

1. Labour force participation.

Proportion of households' head economically active for each sex.

2. Average years of schooling.

Simple average for each sex, of the number of years of schooling of the households' head.

3. Open unemployment rate.

Proportion unemployed of the economically active households' head for each sếx.

4. $\quad$ Average hours worked per week.

Simple average for each sex, of the weekly hours worked by employed households' head. 
5. Average hourly earnings.

Index in which 100 equals the average hourly earnings of all heads of household of both sexes.

(See table $\mathrm{N}^{\circ}$ 1)

The relation between the position in the household (head of household, spouse, daughter, son, and other relative) of men and women and the labour force participation depending on their belonging to indigent, poor non-indigent and non-poor households. (See tables $\mathrm{N}^{\circ} 2 \mathrm{a}$ and $\mathrm{N}^{\circ} 2 \mathrm{~b}$ )

The comparison between poor and total households in relation to the following indicators:

\section{Percentage of households with a couple.}

Proportion of households with head and spouse with respect to total households of the category.

2. Percentage of households where head and spouse are both economically active.

Proportion of households with head and spouse economically active with respect to total (See table $\mathrm{N}^{\circ} 3$ ) households with head and spouse present in each category.

The impact of women earnings in household income and the extent of urban poverty in relation to indigent, poor non-indigent and non-poor households using the following indicators:

\section{Percentage of spouse income in total household income.}

Proportion of total household income corresponding to labor income of the spouse, in each category.

2. Percentage of indigence, non-indigence and poverty that contrast the present situation with the following hypothesis:

i) Omitting women's earnings.

Proportion of indigent, non-indigent poor and total poor households if earnings of women actually working were not considered.

ii) Omitting spouses' earnings.

Proportion of indigent, non-indigent poor and total poor households if earnings of spouses actually working were not considered.

iii) If all economically inactive spouses were employed.

Proportion of indigent, non-indigent poor and total poor households if all economically inactive spouses were employed earning an income equal to the average earned by economically active spouses in each category of poverty.

(See tables $\mathrm{N}^{\circ} 3$ and $\mathrm{N}^{\circ} 4$ )

The significance of female-headed household in the condition of indigent, non-indigent poor and non-poor using the following indicators: 
1. Percentage of female-headed households at each poverty level.

Proportion of households headed by females in each category of poverty.

2. Distribution of female-headed households by poverty level.

Distribution of the hundred percent of female-headed households along the different poverty levels and the non-poor.

3. Incidence of poverty, by type of household.

Percentage of poor at each type of household distinguishing female-headed households in each type.

\section{Distribution of households by type and poverty level.}

Distribution by type of household and female-headed, of the hundred percent of households at each poverty level.

( See tables $\mathrm{N}^{\circ} 5, \mathrm{~N}^{\circ} 6$ and $\mathrm{N}^{\circ} 7$ )

\section{B.2 Sources of information}

\section{Household surveys}

The principal source of information for the calculation of social indicators such as those mentioned above is the multipurpose household survey. Most countries regularly conduct this type of survey in which are investigated a broad set of individual and family characteristics (demographic, household, education, occupation, income, etc.) In turn, in recent years efforts are being made to expand the geographic and topical coverage of these surveys and to improve the quality of their information, which opens up new possibilities for the use of the data that they provide.

\section{Population censuses}

These censuses are also an important source of information for analysis such as in the case of budget analysis. Although their frequency is less than that of household surveys (only every ten years), and though they investigate a narrower range of themes, they do promote the development of studies of greater geographic disaggregation. They also supply a sample framework for the design and implementation of surveys.

\section{National accounts}

Information from administrative files and estimations of national accounting are increasingly being used to complement, and even to evaluate, the information available from population censuses and from household surveys. Such is the case, for example, with the family account of the System of National Accounts, which constitutes a very important source of information for the reliability analysis of the measurements of income that are obtained from the sample replacements. 


\section{Examples of gender and poverty issues ${ }^{1 /}$}

\section{Women's labour force participation and contribution to family income}

In households in which both spouses are gainfully employed, the woman brings in approximately $30 \%$ of household income. This significant and increasing contribution is critical in raising many households above the poverty line and in alleviating want in some of the poorest households. The percentage is, of course, much higher for households headed by a woman.

Thanks to their increasing participation in the labour force, women's contribution to household income has reached significant levels and continues to grow in nearly all the countries of the region. The tendency is particularly striking in the case of women who are spouses, $2 /$ notwithstanding the greater difficulties they face in managing both their domestic responsibilities and income-generating activities, performed inside or outside the home. Because of their earnings, poverty indexes in urban areas are much lower than they would otherwise be if these women were not gainfully employed.

In most of the countries, the proportion of households in which both spouses were gainfully A employed increased between the end of the 1970s and the start of the 1990s (see table 3). It is significant that this increase is observable among all households, even among poor households, where the educational levels of women are lower and their opportunities of finding gainful employment are fewer. The percentage of households in which both spouses are economically active ranges from $27 \%$ to $43 \%$ of total two-parent households in urban areas. The proportion is lower in poor households (from $10 \%$ to $36 \%$ ), which may be attributable to the fact that women in poor households typically have greater domestic responsibilities, particularly in the area of child care, and fewer facilities on which they can draw to assist them in domestic tasks. Other contributing factors are their more limited opportunities for finding gainful employment and the lower wages they can earn.

Although women who are part of a couple are relatively less likely to be gainfully employed than women who are single or heads of household, their economic contribution as a group is very important. Within the past decade, women's contribution to family income has tended upwards, and the figures for the last few years show that the trend is continuing. In the countries of the region, approximately $30 \%$ of household income in urban households in which both spouses are employed now comes from the woman's earnings. It is highly significant that on average in one out of three urban households with a male head of household in which both spouses are employed, the woman's contribution is similar to the man's and represents from $40 \%$ to $60 \%$ of combined household income.

To reiterate, the spouse's contribution to family income has made poverty indexes much lower than they would have been without those earnings. If the income contributed to the household by spouses were eliminated, urban poverty levels would rise by $2 \%$ to $7 \%$, representing a $10 \%$ to $20 \%$ increase in the incidence of poverty. If has also been found that if the income contributed by all the economically active women living in the household (spouses or otherwise) were eliminated, poverty indexes would rise in most of the countries by $10 \%$ to $19 \%$. Thus, one can conclude that in Latin America the economic contribution of women to family income enables a large percentage of households to maintain themselves above the poverty line (see table 4).

\footnotetext{
1/ Excerpts from the Social Panorama of Latin America, published by ECLAC.

2 / For purposes of this chapter the term "spouse"referes not only to married women, but also to women living in a consensual union of any kind
} 
In order to assess the impact of women's increasing labour force participation on income levels, the family income of poor households was recalculated on the hypothesis that spouses now economically inactive would obtain gainful employment bringing them an income similar to that currently earned by economically active spouses in poor income strata. The calculation showed that the increase in family income would result in a reduction in the incidence of urban poverty of $2 \%$ to $8 \%$, depending on the country. In the case of Mexico, for example, the percentage of poor households would drop from $29.4 \%$ to $22.9 \%$, raising some four million persons above the poverty line. ${ }^{3}$

${ }^{3}$ It should be borne in mind that these estimates give only a rough idea of the potential impact of an increase in the number of spouses gainfully employed, since it is probable that the average income of women would change as a result of their entry into the labour force in large numbers. 
Figure 1

PERCENTAGE OF URBAN HOUSEHOLDS WITH BOTH SPOUSES ECONOMICALLY ACTIVE

TOTAL HOUSEHOLDS

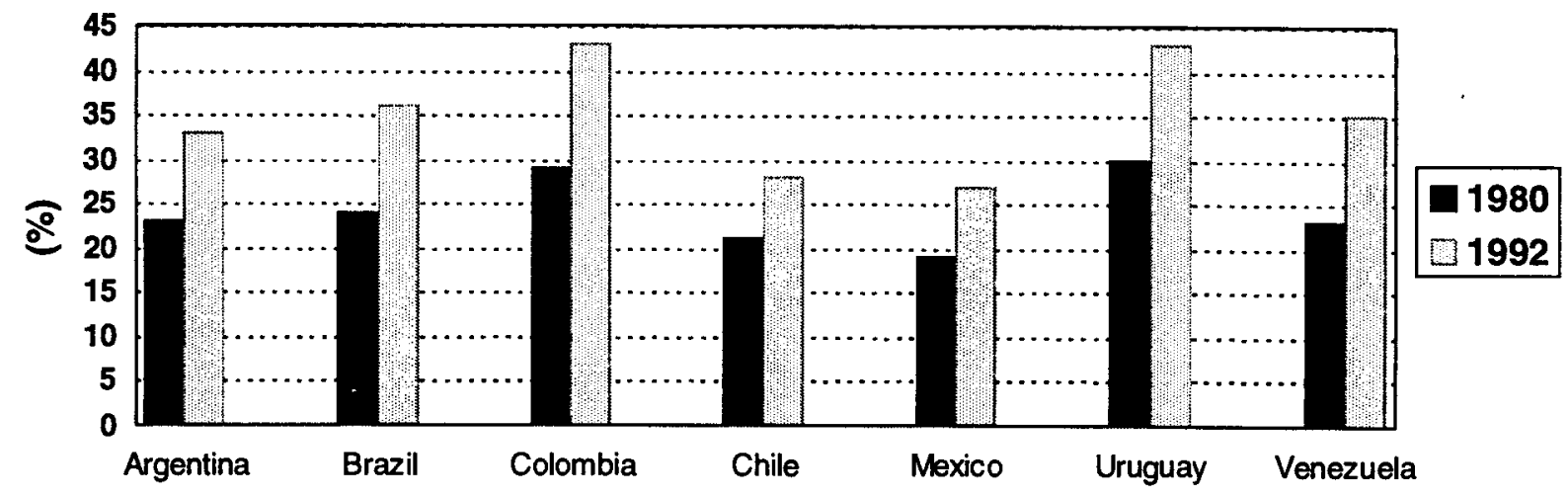

POOR HOUSEHOLDS

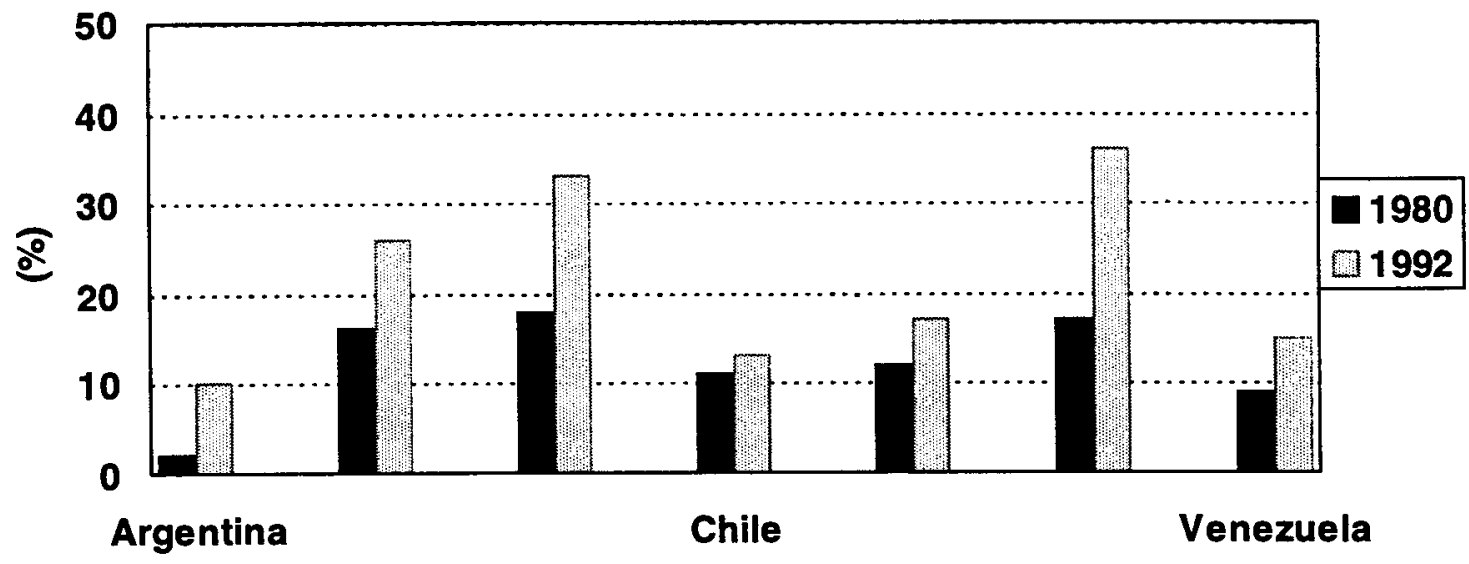

Source: ECLAC, on the basis of special tabulations of data from household surveys. 
Figure 2

CONTRIBUTION OF SPOUSE TO FAMILY INCOME, 1992

(Urban areas)

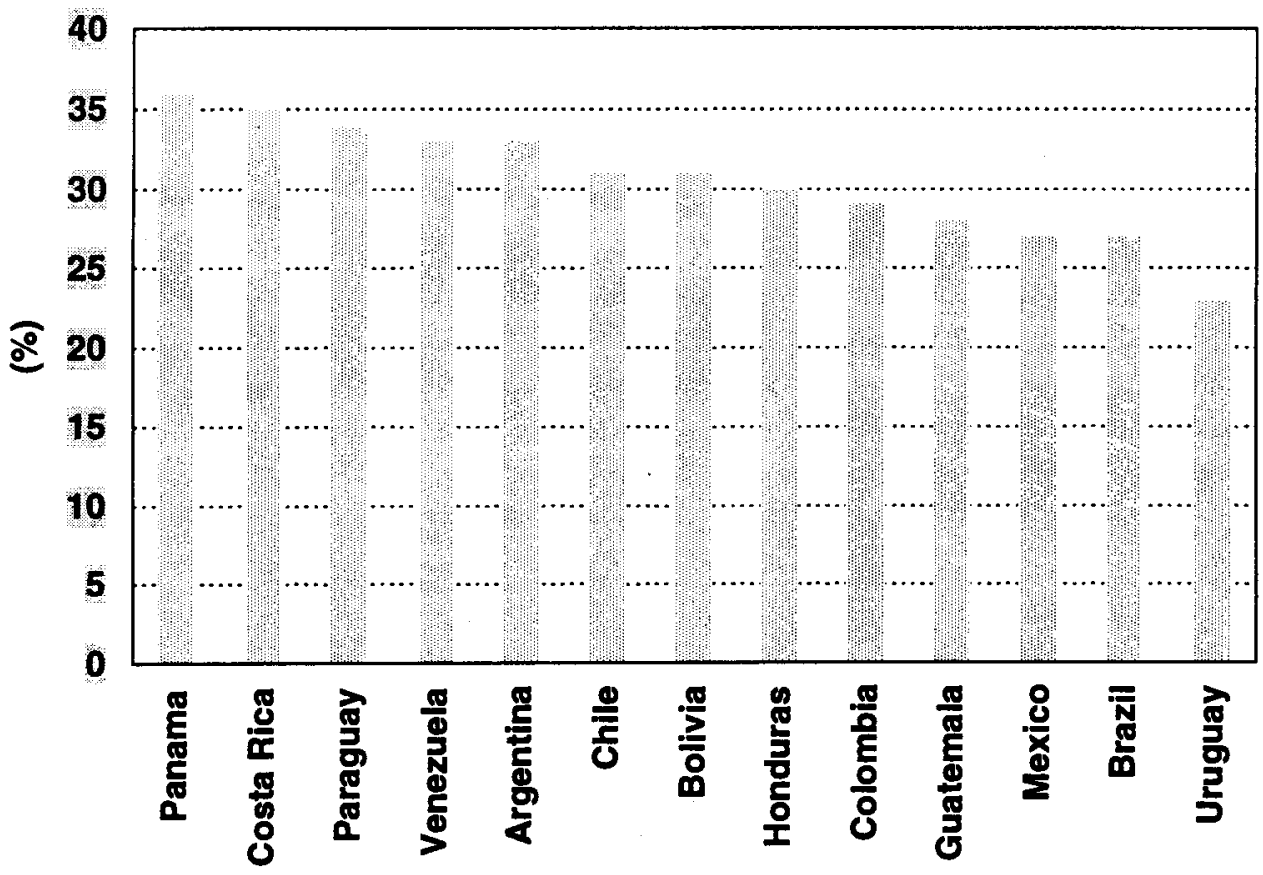

Figure 3

EXTENT OF POVERTY WITH AND WITHOUT CONTRIBUTION OF SPOUSE, 1992 (Urban areas)

w No contribution E Present level w With contribution

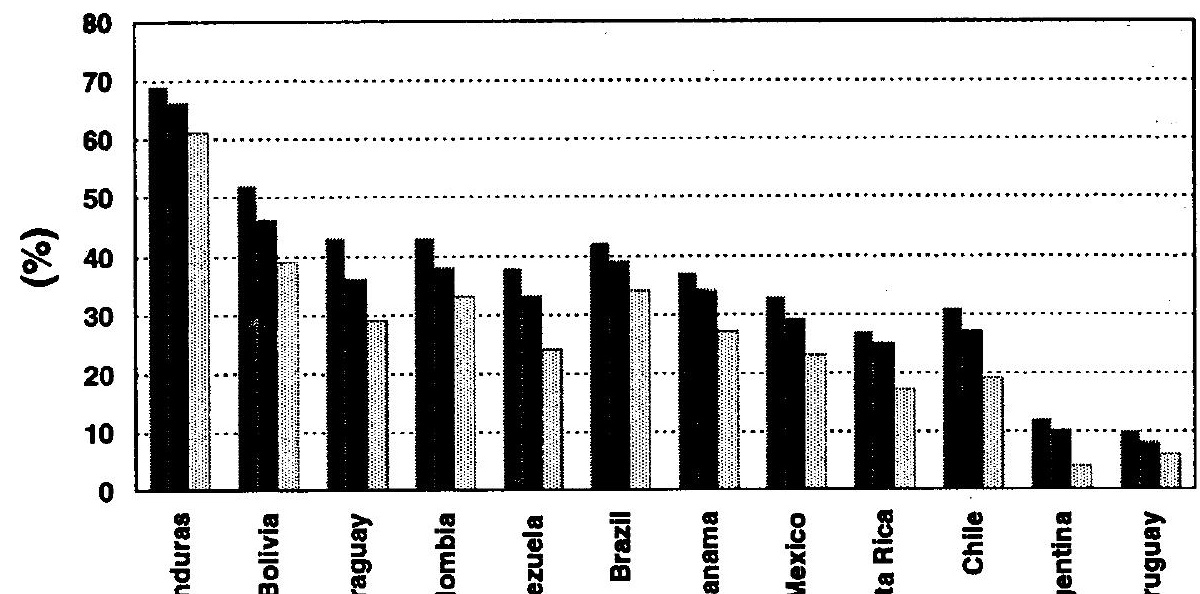




\section{Female-headed households and poverty}

The number of households headed by women continues to grow, a phenomenon that is occurring in a context of other significant demographic changes, including a decline in fertility rates and a reduction in average household size. Female-headed households are particularly common among the poorer economic strata, and this situation places multiple responsibilities and pressures upon women heads of household to the detriment of the members of the household.

Among the far-reaching changes influencing the well-being of the population and the situation of women are two trends associated with demographic changes that are modifying the structure of households in the region. The first is a steady reduction in household size, particularly in urban areas, as a result of several factors: a reduction in the number of children, reflecting lower fertility rates; a decline in the proportion of multi-generational households; and a corresponding increase in single-parent families and single-person households. In terms of family structure, nuclear family households consisting of a couple with or without children now predominate. In most of the countries of the region, this category of household now accounts for $70 \%$ or more of the total. (see figure 4 and 5)

The second notable trend is the increased proportion of female-headed households, although censuses and household surveys tend to obscure the true extent of the phenomenon by not recognizing female headship when the male member of the couple lives in the household. ${ }^{4}$ In most of the countries of the region, at least one out of every five urban households is headed by a woman. Part of the phenomenon of female headship is an increase in the number of single-parent households, which are predominantly headed by very young or by elderly women, and of single-person households, resulting in part from the aging of the population and the greater longevity of women, who tend to form new unions less frequently than men. With some exceptions, women heads of household are generally divorced, widowed or single. ${ }^{5}$

The tendency towards an increase in female-headed households was very marked in Latin America in the past decade, and it is highly probable that the trend will be maintained throughout the 1990s. Between 1980 and 1992, of total urban households the percentage headed by women increased in 10 out of 12 countries. The countries that recorded the largest increases, ranging from $2 \%$ to $5 \%$, were Argentina, Costa Rica, Paraguay and Uruguay (see figure 6 and 7, and table 5).

The marked increase in poverty in the region during the 1980s was reflected in a larger number of indigent households headed by women, which have now become one of the chief recipient groups for social programmes.

A breakdown by sex supports the conclusion that in 7 of 11 countries poverty is more common among households headed by women than those headed by men. The exceptions are two countries with low poverty levels (Argentina and Uruguay) and two countries with intermediate poverty levels (Chile and Mexico) (see table 5). The differential is even greater among extremely poor or indigent

4 In all countries of the region, less than $5 \%$ of the women who identify themselves as the head of the household have a spouse living with them, whereas the figure is over $90 \%$ for men in this situation.

5 Another factor that may have contributed to the increase in the percentage of female-headed households and that merits closer examination is the greater instability of unions. 
households, an income level at which family units headed by women are more common. Extreme poverty, particularly in urban areas, is most apt to be a problem among households where there is no male partner and where the female head must earn income to support the household in addition to handling domestic tasks. In 8 out of 13 countries, indigent households headed by women represent from $15 \%$ to $25 \%$ of female-headed households. In Honduras the percentage rises to $46 \%$, while in Argentina and Uruguay the percentage is close to $1 \%$. To give an idea of the extent of the problem, the number of people living in such households in urban areas in Brazil is some two and a half million, and another six hundred thousand are in the same situation in the major cities of Colombia.

Beyond the fact that there has been a marked increase in the number of female-headed households, an analysis of the data compiled by household surveys shows that such households are more vulnerable. Households headed by women continue to have lower per capita household income than those headed by men, so that the extent to which their income falls below the poverty line is even greater.

Female-headed households constitute a top-priority target group for social policies aimed at reducing extreme poverty in the region, but because of their special characteristics they require policies that consider more than the merely quantitative aspects of the problem. A good example is the question of how tasks are organized and shared within the household, including the issue of the excessive work load of women who must handle paid employment and household duties at the same time, and of the physical and mental toll this effort takes. Policy proposals must also take into account that households in this category are quite heterogeneous; the head of household may be an elderly widow, an adolescent mother or simply a woman of reproductive age with children. 
Figure 4

TREND IN FERTILITY RATES, 1970-1975 AND 1990-1995

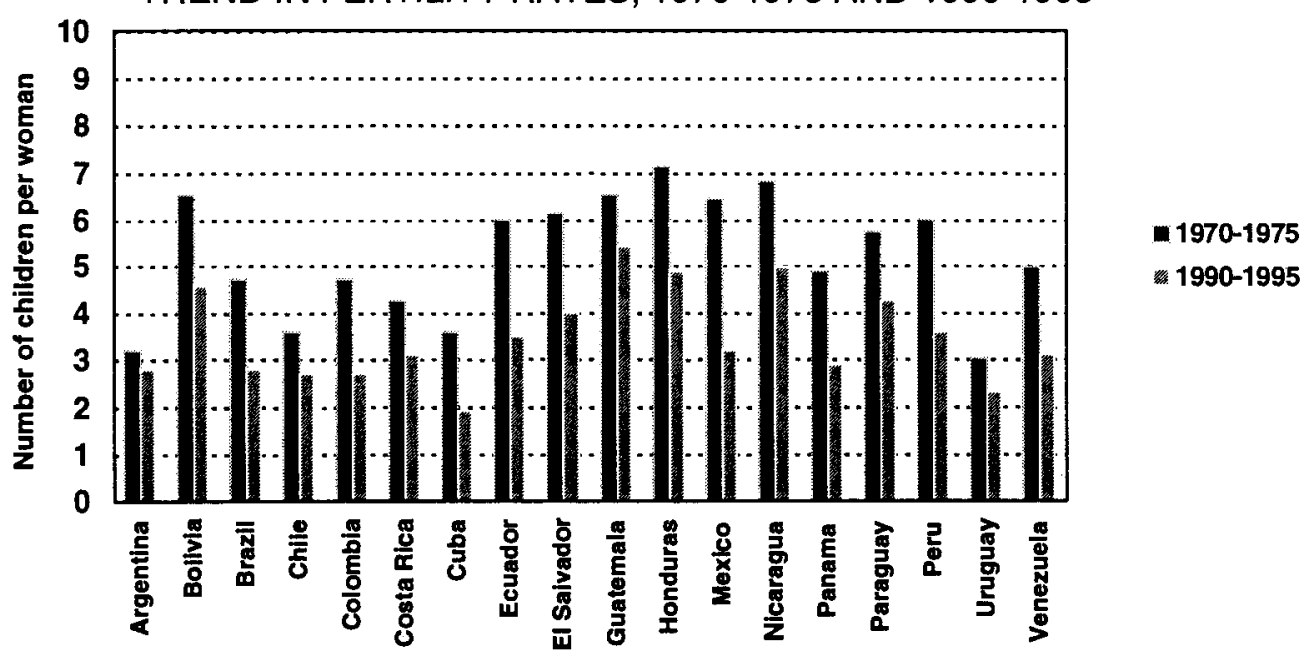

Figure 5

TREND IN AVERAGE SIZE OF HOUSEHOLD, 1970 AND 1990

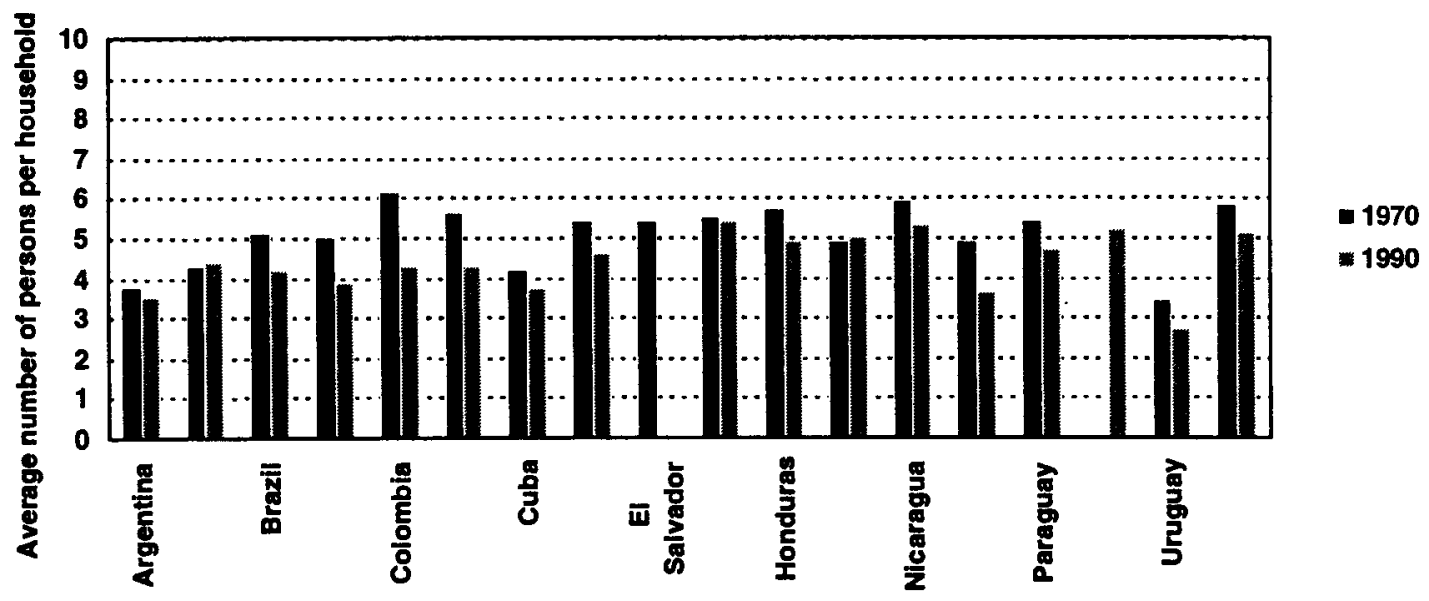

Source: ECLAC, on the basis of official figures supplied by the countries. 
Figure 6

FEMALE-HEADED HOUSEHOLDS, 1980 AND 1992

(Urban areas)

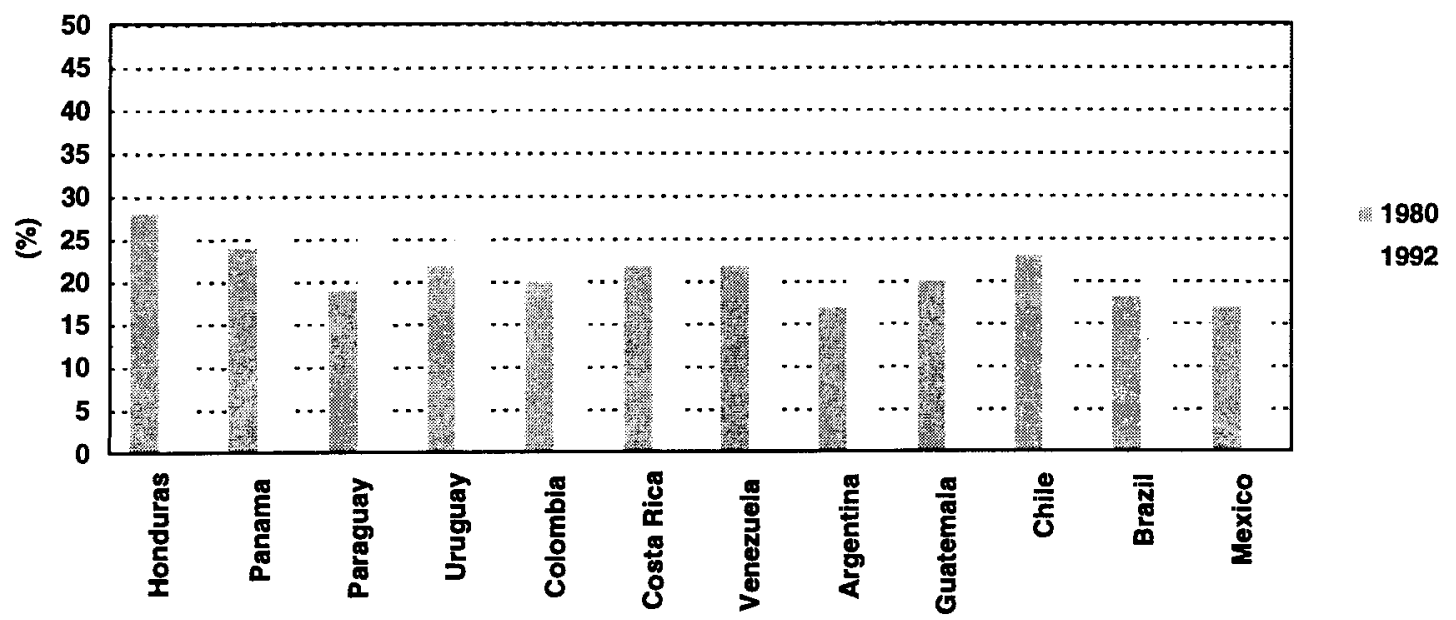

Figure 7

FEMALE-HEADED HOUSEHOLDS IN EXTREME POVERTY, 1992

(Urban areas)

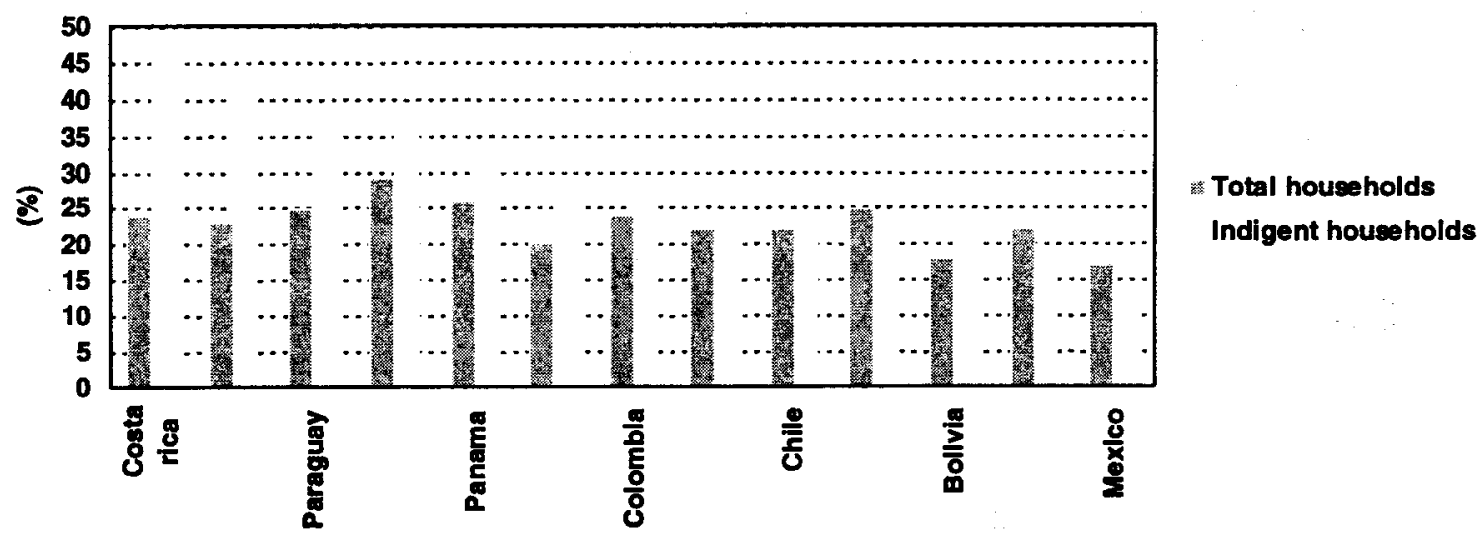

Source: ECLAC, on the basis of special tabulations of data from household surveys. 


\section{Gender and poverty}

Female heads of household experience higher rates of unemployment, lower numbers of hours worked, lower salaries and greater difficulties in entering the labour market than do male heads of household. The low income and high degree of vulnerability of poor households headed by women suggest that they should continue to be a priority target of social policy.

One of the chief factors contributing to household poverty is that female heads of household generally face greater difficulties than male heads of household. This explains why a larger proportion of households headed by women than by men fall into the lower income strata.

An examination of the data from urban areas reveals marked differences between the sexes in the following variables that determine the resources of the household: i) the level of education of the head of household; ii) the degree of labour force participation; iii) the number of hours worked and the income earned (see table 1).

The factor that most heavily influences income differences is the level of education; on average, female heads of household have two fewer years of schooling than male. In the case of the women who are economically active, this gap translates into earnings $20 \%$ to $40 \%$ lower than they could obtain if they had the same level of education as male heads of household, apart from the fact that women in general earn less than men even with the same level of education. This increases the chances that households headed by women will fall below the poverty line. ${ }^{6}$

The above factors, together with the problems women without a spouse encounter in combining domestic responsibilities with paid employment, explain the lower level of economic activity of women in that situation in comparison with male heads of household. While the labour force participation rate of men who are heads of household ranges from $80 \%$ to $90 \%$ in urban areas, the comparable figures for women are $40 \%$ to $60 \%$. On the other hand, the percentage of female heads of household who are economically active is much higher than that of women who are spouses, daughters or other female relations of male heads of household.

In contrast to the figure for males, the labour force participation rate of female heads of household is much lower among indigent and non-indigent poor households than among non-poor households, and this confirms the importance of women's earnings. 'In this regard, policies designed to help female heads of household with children to enter the labour force and in general to engage in income-producing activities inside or outside the home can be of great value in reducing poverty indexes. Such policies may include increasing preschool enrollment, extending the length of the school day and increasing the availability of day-care centres (see box below).

6 See ECLAC, Social Panorama of Latin America, 1994 edition, chapter VI.

7 7'The only exceptions are in Argentina and Uruguay, where the figures reveal the opposite picture; the explanation may lie in measurement problems attributable to the small size of the sample. In 1992, only 1.4\% of urban households in both countries were classified as indigent. 


\section{INCREASING PRESCHOOL ENROLMENT}

Preschool enrollment grew significantly over the past two decades. In 1970, the number of children of both sexes attending preschool was under two million, representing less than $5 \%$ of the population aged three to five years. In 1990, there were around ten million children enrolled, close to $20 \%$ of children in that age group. One of the factors contributing to this growth was the concern for preparing young children for primary school in order to reduce scholastic failure in the primary grades.

Although preschool enrollment has increased in all cases, current levels of enrollment and the pace at which they have grown vary widely from one country to the next. Despite overall growth, percentage enrollment is still very low; it does not exceed $30 \%$ of children of the relevant age group in any of the countries and is below $10 \%$ in a number of cases.

With respect to the above figures, it should be noted that the information available is uneven; in some cases the figures refer only to children five years of age who are not yet old enough to enter the first grade of primary school, while in others they refer to children aged two to six. In the first instance, percentage enrollment is reported at a little under $60 \%$ in urban areas, while in the second the figures hover around $10 \%$, indicating that the growth in preschool enrollment has been chiefly at the level preparatory to primary school. Clearly, the higher percentage of enrollment has been motivated by concern for preparing children for school, rather than for enabling women to enter the labour force.

Data on urban areas reveal that in most countries the rate of open unemployment is higher for women than for men and hence affects female relatively more than male heads of household (see table 1). The differential is even more marked among the economically active population below the poverty line, reflecting the greater difficulties women who have recently entered the labour market encounter in obtaining employment and their greater likelihood of being laid off during a period of general unemployment. This situation contributes significantly to the higher incidence of poverty among households headed by women.

The shorter working hours of women who are heads of household is one of the more obvious consequences of the problems members of this group have in entering the labour force when they have no social and family support systems to help them care for the younger children. In all the countries studied, female heads of household work an average of five to ten fewer hours per week than male heads of household. In this regard, it is significant that the differential is even more marked among the poor and that the gap is widest among the indigent, where women face the greatest difficulties in juggling the roles of mother and worker.

Moreover, the problems already described are further aggravated by the fact that women earn lower pay per hour worked. Income differentials among heads of household are similar to those observable for the economically active population as a whole, although they are lower among the poor and even lower among the indigent. The differential in urban areas is between $20 \%$ and $30 \%$ in most of the countries. 


\section{TABLES}


Table 1

LATIN AMERICA (13 COUNTRIES): CHARACTERISTICS OF HEADS OF HOUSEHOLD IN URBAN AREAS

\begin{tabular}{|c|c|c|c|c|c|c|c|c|c|}
\hline \multirow[t]{2}{*}{ Country } & \multirow[t]{2}{*}{ Year } & \multicolumn{2}{|c|}{ Total households } & \multirow[t]{2}{*}{ Indigent } & households & \multicolumn{2}{|c|}{$\begin{array}{c}\text { Non-indigent poor } \\
\text { households }\end{array}$} & \multicolumn{2}{|c|}{$\begin{array}{l}\text { Non-poor } \\
\text { households }\end{array}$} \\
\hline & & Men & Women & & Women & Men & Women & Men & Women \\
\hline ARGENTINA & 1992 & & & & & & & & \\
\hline Labour force participation & & 83 & 45 & 76 & 72 & 66 & 35 & 85 & 46 \\
\hline Average years of schooling & & $\ldots$ & $\ldots$ & $\ldots$ & $\ldots$ & $\ldots$ & $\ldots$ & $\ldots$ & $\ldots$ \\
\hline Open unemployment rate & & 4.6 & 4.8 & 36.6 & 0.0 & 20.6 & 38.9 & 2.8 & 3.1 \\
\hline Average hours worked per week & & 50 & 40 & 37 & 19 & 49 & 35 & 50 & 40 \\
\hline Average hourly earnings $\mathrm{a}$ & & 101 & 91 & 27 & 40 & 38 & 46 & 106 & 50 \\
\hline BOLIVIA & 1992 & & & & & & & & \\
\hline Labour force participation & & 92 & 67 & 85 & 61 & 92 & 68 & 93 & 68 \\
\hline Average years of schooling & & 10.1 & 7.2 & 7.6 & 5.1 & 8.8 & 6.8 & 11.6 & 8.3 \\
\hline Open unemployment rate & & 3.9 & 2.5 & 15.9 & 4.6 & 3.1 & 3.2 & 1.0 & 1.4 \\
\hline Average hours worked per week & & 45 & 40 & 46 & 38 & 46 & 39 & 45 & 40 \\
\hline Average hourly earnings a & & 106 & 65 & 34 & 23 & 50 & 42 & 149 & 91 \\
\hline BRAZIL & 1990 & & & & & & & & \\
\hline Labour force participation & & 88 & 51 & 83 & 42 & 89 & 47 & 89 & 56 \\
\hline Average years of schooling & & 5.8 & 4.6 & 2.8 & 2.4 & 3.8 & 2.9 & 7.2 & 6.4 \\
\hline Open unemployment rate & & 2.7 & 2.4 & 12.6 & 7.8 & 2.0 & 2.0 & 0.8 & 0.9 \\
\hline Average hours worked per week & & 46 & 39 & 47 & 39 & 47 & 39 & 46 & 39 \\
\hline Average hourly eamings a/ & & 105 & 67 & 20 & 15 & 35 & 23 & 144 & 100 \\
\hline COLOMBIA & 1992 & & & & & & & & \\
\hline Labour force participation & & 91 & 61 & 94 & 59 & 92 & 62 & 90 & 61 \\
\hline Average years of schooling & & 8.2 & 6.9 & 5.7 & 5.0 & 6.1 & 5.1 & 9.5 & 8.2 \\
\hline Open unemployment rate & & 2.6 & 5.3 & 7.6 & 13.5 & 3.3 & 4.6 & 1.1 & 3.4 \\
\hline Average hours worked per week & & 51 & 46 & 52 & 45 & 52 & 47 & 51 & 46 \\
\hline Average hourly earnings a & & 104 & 81 & 24 & 24 & 47 & 39 & 144 & 110 \\
\hline COSTA RICA & 1992 & & & & & & & & \\
\hline Labour force participation & & 85 & 50 & 55 & 28 & 85 & 51 & 87 & 54 \\
\hline Average years of schooling & & 8.4 & 7.4 & 5.2 & 5.0 & 6.7 & 5.7 & 9.0 & 8.3 \\
\hline Open unemployment rate & & 1.3 & 4.6 & 19.9 & 17.1 & 2.2 & 10.0 & 0.2 & 1.8 \\
\hline Average hours worked per week & & 49 & 40 & 44 & 26 & 50 & 36 & 49 & 42 \\
\hline Average hourly earnings o/ & & 103 & 83 & 40 & 49 & 49 & 48 & 117 & 94 \\
\hline CHILE & 1992 & & & & & & & & \\
\hline Labour force participation & & 86 & 46 & 88 & 41 & 89 & 47 & 86 & 46 \\
\hline Average years of schooling & & 9.5 & 7.7 & 8.1 & 6.4 & 8.0 & 6.3 & 10.1 & 8.2 \\
\hline Open unemployment rate & & 2.4 & 4.2 & 14.7 & 19.8 & 3.1 & 4.9 & 0.9 & 2.7 \\
\hline Average hours worked per week & & 51 & 46 & 50 & 42 & 51 & 45 & 51 & 46 \\
\hline Average hourly earnings a/ & & 105 & 65 & 27 & 22 & 39 & 29 & 129 & 78 \\
\hline
\end{tabular}


Table 1 (concluded)

\begin{tabular}{|c|c|c|c|c|c|c|c|c|c|}
\hline GUATEMALA & 1989 & & & & & & & & \\
\hline Labour force participation & & 95 & 55 & 95 & 37 & 97 & 60 & 94 & 62 \\
\hline Average years of schooling & & 5.6 & 4.2 & 2.9 & 2.7 & 4.0 & 2.2 & 7.6 & 5.9 \\
\hline Open unemployment rate & & 1.3 & 2.1 & 4.0 & 6.4 & 0.8 & 1.5 & 0.5 & 1.2 \\
\hline Average hours worked per week & & 49 & 44 & 49 & 41 & 51 & 42 & 48 & 46 \\
\hline Average hourly earnings a & & 102 & 84 & 27 & 27 & 50 & 44 & 161 & 118 \\
\hline HONDURAS & 1992 & & & & & & & & \\
\hline Labour force participation & & 94 & 58 & 93 & 55 & 93 & 59 & 95 & 65 \\
\hline Average years of schooling & & 7.1 & 5.0 & 4.3 & 3.6 & 6.3 & 5.1 & 10.2 & 7.4 \\
\hline Open unemployment rate & & 3.6 & 1.6 & 7.1 & 2.2 & 2.1 & 1.6 & 1.5 & 0.6 \\
\hline Average hours worked per week & & 52 & 45 & 51 & 45 & 53 & 46 & 52 & 45 \\
\hline Average hourly eamings a & & 108 & 69 & 42 & 33 & 69 & 62 & 189 & 131 \\
\hline MEXICO & 1992 & & & & & & & & \\
\hline Labour force participation & & 91 & 54 & 92 & 66 & 91 & 58 & 90 & 53 \\
\hline Average years of schooling & & $\ldots$ & $\ldots$ & $\ldots$ & $\ldots$ & $\ldots$ & $\ldots$ & $\ldots$ & $\ldots$ \\
\hline Open unemployment rate & & 1.4 & 0.7 & 0.3 & 1.9 & 1.1 & 0.0 & 1.7 & 0.8 \\
\hline Average hours worked per week & & 49 & 40 & 50 & 33 & 50 & 42 & 49 & 40 \\
\hline Average hourly earnings $\mathrm{a}$ / & & 103 & 79 & 23 & 20 & 36 & 31 & 134 & 96 \\
\hline PANAMA & 1991 & & & & & & & & \\
\hline Labour force participation & & 84 & 54 & 86 & 44 & 88 & 54 & 82 & 58 \\
\hline Average years of schooling & & 8.8 & 8.4 & 5.8 & 6.0 & 6.9 & 6.9 & 9.8 & 9.6 \\
\hline Open unemployment rate & & 6.3 & 13.5 & 23.2 & 42.4 & 6.4 & 23.5 & 3.0 & 3.9 \\
\hline Average hours worked per week & & 43 & 39 & 37 & 29 & 43 & 40 & 44 & 40 \\
\hline Average hourly earnings a & & 103 & 88 & 29 & 27 & 50 & 39 & 124 & 108 \\
\hline PARAGUAY & 1992 & & & & & & & & \\
\hline Labour force participation & & 90 & 52 & 89 & 43 & 89 & 46 & 91 & 58 \\
\hline Average years of schooling & & 9.0 & 6.6 & 5.9 & 4.1 & 6.9 & 5.0 & 10.2 & 8.0 \\
\hline Open unemployment rate & & 3.7 & 3.9 & 17.5 & 4.9 & 4.3 & 8.4 & 1.3 & 2.4 \\
\hline Average hours worked per week & & 51 & 47 & 56 & 40 & 51 & 49 & 50 & 49 \\
\hline Average hourly earnings a & & 103 & 85 & 34 & 23 & 50 & 32 & 129 & 114 \\
\hline URUGUAY & 1992 & & & & & & & & \\
\hline Labour force participation & & 78 & 40 & 91 & 73 & 86 & 50 & 77 & 39 \\
\hline Average years of schooling & & 7.3 & 6.4 & 5.3 & 5.7 & 5.7 & 4.7 & 7.5 & 6.5 \\
\hline Open unemployment rate & & 2.0 & 5.1 & 16.5 & 16.5 & 5.2 & 8.0 & 1.4 & 4.6 \\
\hline Average hours worked per week & & 48 & 34 & 43 & 28 & 48 & 29 & 48 & 34 \\
\hline Average hourly earnings a & & 103 & 78 & 31 & 18 & 39 & 26 & 110 & 82 \\
\hline VENEZUELA & 1992 & & & & & & & & \\
\hline Labour force participation & & 92 & 51 & 78 & 29 & 87 & 44 & 95 & 63 \\
\hline Average years of schooling & & 8.1 & 6.4 & 5.9 & 5.2 & 6.4 & 5.2 & 8.8 & 7.2 \\
\hline Open unemployment tate & & 4.3 & 3.4 & 34.1 & 22.1 & 5.9 & 2.6 & 1.3 & 0.7 \\
\hline Average hours worked per week & & 41 & 37 & 44 & 35 & 42 & 38 & 41 & 37 \\
\hline Average hourly earnings a/ & & 108 & 81 & 42 & 35 & 66 & 55 & 121 & 94 \\
\hline
\end{tabular}

Source: ECLAC, on the basis of special tabulations of data from household surveys.

a/ Index in which 100 equals the average hourly earnings of all heads of households of both sexes. 
Table 2.A

LATIN AMERICA (12 COUNTRIES): LABOUR FORCE PARTICIPATION IN URBAN AREAS

\begin{tabular}{|c|c|c|c|c|c|c|c|c|c|c|}
\hline \multirow[t]{2}{*}{ Country } & \multirow[t]{2}{*}{ Poverty level } & \multicolumn{4}{|c|}{ MEN } & \multicolumn{5}{|c|}{ WOMEN } \\
\hline & & Total & $\begin{array}{c}\text { Head of } \\
\text { household }\end{array}$ & Son & $\begin{array}{l}\text { Other } \\
\text { relative }\end{array}$ & Total & $\begin{array}{l}\text { Head of } \\
\text { household }\end{array}$ & Spouse* & Daughter & $\begin{array}{l}\text { Other } \\
\text { relative }\end{array}$ \\
\hline \multirow[t]{4}{*}{ ARGENTINA } & TOTAL & 77 & 81 & 69 & 67 & 39 & 43 & 35 & 48 & 32 \\
\hline & INDIGENT & 65 & 71 & 55 & 52 & 25 & 72 & 18 & 31 & 0 \\
\hline & NON-INDIGENT POOR & 65 & 66 & 64 & 52 & 18 & 31 & 10 & 28 & 30 \\
\hline & NON-POOR & 78 & 82 & 69 & 69 & 41 & 44 & 38 & 50 & 33 \\
\hline \multirow[t]{4}{*}{ BOLIVIA } & TOTAL & 75 & 88 & 48 & 62 & 46 & 66 & 46 & 36 & 50 \\
\hline & INDIGENT & 66 & 80 & 34 & 42 & 33 & 61 & 30 & 25 & 25 \\
\hline & NON-INDIGENT POOR & 74 & 89 & 40 & 61 & 42 & 67 & 43 & 31 & 36 \\
\hline & NON-POOR & 78 & 91 & 55 & 66 & 53 & 67 & 53 & 42 & 58 \\
\hline \multirow[t]{3}{*}{ BRAZIL } & TOTAL & 82 & 86 & 77 & 77 & 45 & 50 & 38 & 58 & 46 \\
\hline & INDIGENT & 74 & 79 & 65 & 64 & 33 & 42 & 25 & 43 & 30 \\
\hline & NON-INDIGENT POOR & 83 & 85 & 80 & 76 & 41 & 45 & 33 & 56 & 37 \\
\hline \multirow[t]{4}{*}{ COLOMBIA } & TOTAL & 80 & 90 & 64 & 79 & 50 & 59 & 44 & 50 & 56 \\
\hline & INDIGENT & 80 & 93 & 55 & 71 & 38 & 57 & 30 & 38 & 38 \\
\hline & NON-INDIGENT POOR & 80 & 91 & 60 & 82 & 43 & 60 & 36 & 45 & 45 \\
\hline & NON-POOR & 81 & 89 & 67 & 79 & 55 & 59 & 51 & 54 & 62 \\
\hline \multirow[t]{4}{*}{ COSTA RICA } & TOTAL & 74 & 83 & 60 & 69 & 37 & 48 & 29 & 46 & 37 \\
\hline & INDIGENT & 47 & 54 & 39 & 36 & 23 & 27 & 13 & 33 & 18 \\
\hline & NON-INDIGENT POOR & 73 & 84 & 54 & 58 & 25 & 49 & 11 & 31 & 34 \\
\hline & NON-POOR & 76 & 84 & 63 & 74 & 42 & 53 & 34 & 50 & 40 \\
\hline \multirow[t]{4}{*}{ CHILE } & TOTAL & 75 & 85 & 59 & 69 & 37 & 44 & 30 & 44 & 43 \\
\hline & INDIGENT & 71 & 86 & 43 & 55 & 22 & 40 & 14 & 26 & 24 \\
\hline & NON-INDIGENT POOR & 75 & 88 & 52 & 66 & 25 & 44 & 14 & 35 & 24 \\
\hline & NON-POOR & 76 & 84 & 62 & 71 & 42 & 45 & 36 & 49 & 48 \\
\hline \multirow[t]{4}{*}{ HONDURAS } & TOTAL & 80 & 92 & 66 & 66 & 44 & 56 & 40 & 42 & 44 \\
\hline & INDIGENT & 78 & 90 & 65 & 57 & 33 & 52 & 25 & 34 & 25 \\
\hline & NON-INDIGENT POOR & 81 & 91 & 72 & 66 & 44 & 57 & 37 & 49 & 39 \\
\hline & NON-POOR & 82 & 94 & 61 & 74 & 58 & 62 & 59 & 48 & 61 \\
\hline \multirow[t]{4}{*}{ MEXICO } & TOTAL & 79 & 89 & 62 & 69 & 36 & 53 & 29 & 46 & 24 \\
\hline & INDIGENT & 82 & 92 & 69 & 67 & 20 & 62 & $12^{\circ}$ & 22 & 18 \\
\hline & NON-INDIGENT POOR & 80 & 88 & 66 & 74 & 31 & 58 & 21 & 44 & 27 \\
\hline & NON-POOR & 78 & 89 & 60 & 67 & 39 & 51 & 34 & 49 & 23 \\
\hline \multirow[t]{8}{*}{ PANAMA } & TOTAL & 74 & 81 & 65 & 68 & 43 & 51 & 38 & 46 & 46 \\
\hline & INDIGENT & 74 & 85 & 66 & 50 & 28 & 40 & 20 & 33 & 16 \\
\hline & NON-INDIGENT POOR & 76 & 87 & 67 & 63 & 36 & 49 & 24 & 41 & 38 \\
\hline & NON-POOR & 74 & 79 & 64 & 72 & 49 & 55 & 45 & 51 & 51 \\
\hline & TOTAL & 83 & 87 & 76 & 81 & 51 & 51 & 44 & 54 & 59 \\
\hline & INDIGENT & 80 & 82 & 80 & 65 & 35 & 43 & 30 & 46 & 11 \\
\hline & NON-INDIGENT POOR & 85 & 89 & 78 & 80 & 38 & 43 & 31 & 47 & 41 \\
\hline & NON-POOR & 83 & 88 & 75 & 83 & 57 & 56 & 52 & 57 & 67 \\
\hline \multirow[t]{4}{*}{ URUGUAY } & TOTAL & 74 & 75 & 73 & 67 & 46 & 39 & 47 & 57 & 33 \\
\hline & INDIGENT & 79 & 88 & 74 & 56 & 47 & 73. & 44 & 41 & 27 \\
\hline & NON-INDIGENT POOR & 78 & 83 & 69 & 76 & 42 & 47 & 38 & 50 & 29 \\
\hline & NON-POOR & 73 & 74 & 74 & 67 & 46 & 38 & 47 & 58 & 34 \\
\hline \multirow[t]{4}{*}{ VENEZUELA } & TOTAL & 80 & 90 & 65 & 75 & 39 & 51 & 37 & 39 & 36 \\
\hline & INDIGENT & 64 & 76 & 51 & 52 & 20 & 29 & 13 & 23 & 16 \\
\hline & NON-INDIGENT POOR & 74 & 85 & 59 & 66 & 27 & 43 & 19 & 29 & 26 \\
\hline & NON-POOR & 83 & 94 & 69 & 79 & 47 & 63 & 45 & 45 & 43 \\
\hline
\end{tabular}

Source: ECLAC, on the basis of special tabulations of data from household surveys.

* Translator's note: The term "spouse" denotes a married woman as a woman living in a consensual union. 
Table 2.B

LATIN AMERICA (7 COUNTRIES): LABOUR FORCE PARTICIPATION IN RURAL AREAS

\begin{tabular}{|c|c|c|c|c|c|c|c|c|c|c|}
\hline \multirow[t]{2}{*}{ Country } & \multirow[t]{2}{*}{ Poverty level } & \multicolumn{4}{|c|}{ MEN } & \multicolumn{5}{|c|}{ WOMEN } \\
\hline & & Total & $\begin{array}{c}\text { Head of } \\
\text { household }\end{array}$ & Son & $\begin{array}{l}\text { Other } \\
\text { relative }\end{array}$ & Total & $\begin{array}{l}\text { Head of } \\
\text { household }\end{array}$ & Spouse* & Daughter & $\begin{array}{c}\text { Other } \\
\text { relative }\end{array}$ \\
\hline \multirow[t]{4}{*}{ BRAZIL } & TOTAL & 91 & 92 & 90 & 79 & 41 & 44 & 37 & 52 & 32 \\
\hline & INDIGENTES & 89 & 91 & 88 & 66 & 38 & 52 & 33 & 45 & 26 \\
\hline & POBRES NO INDIG. & 89 & 89 & 90 & 79 & 37 & 32 & 36 & 51 & 26 \\
\hline & NON-POOR & 93 & 94 & 92 & 84 & 46 & 48 & 41 & 59 & 38 \\
\hline \multirow[t]{4}{*}{ COSTA RICA } & TOTAL & 85 & 88 & 82 & 71 & 28 & 40 & 18 & 43 & 28 \\
\hline & INDIGENTES & 59 & 61 & 56 & 42 & 15 & 23 & 9 & 19 & 11 \\
\hline & POBRES NO INDIG. & 79 & 87 & 68 & 58 & 17 & 45 & 7 & 26 & 19 \\
\hline & NO POBRES & 88 & 92 & 85 & 76 & 32 & 46 & 21 & 49 & 32 \\
\hline \multirow[t]{4}{*}{ CHILE } & TOTAL & 79 & 83 & 73 & 73 & 19 & 22 & 14 & 29 & 21 \\
\hline & INDIGENTES & 69 & 81 & 50 & 53 & 9 & 14 & 5 & 14 & 11 \\
\hline & POBRES NOINDIG. & 77 & 86 & 61 & 66 & 10 & 20 & 7 & 15 & 12 \\
\hline & NO POBRES & 80 & 83 & 78 & 76 & 24 & 24 & 18 & 36 & 25 \\
\hline \multirow[t]{4}{*}{ HONDURAS } & TOTAL & 89 & 94 & 84 & 74 & 28 & 45 & 23 & 32 & 22 \\
\hline & INDIGENTES & 90 & 96 & 85 & 70 & 24 & 51 & 17 & 29 & 12 \\
\hline & POBRES NO INDIG. & 85 & 91 & 83 & 69 & 28 & 31 & 24 & 37 & 25 \\
\hline & NO POBRES & 89 & 94 & 81 & 85 & 43 & 46 & 42 & 41 & 49 \\
\hline \multirow[t]{4}{*}{ MEXICO } & TOTAL & 86 & 90 & 82 & 62 & 26 & 60 & 21 & 33 & 16 \\
\hline & INDIGENTES & 88 & 92 & 85 & 58 & 19 & 63 & 18 & 17 & 14 \\
\hline & POBRES NO INDIG. & 88 & 92 & 85 & 59 & 23 & 58 & 19 & 31 & 9 \\
\hline & NO POBRES & 84 & 89 & 79 & 66 & 31 & 60 & 24 & 40 & 20 \\
\hline \multirow[t]{4}{*}{ PANAMA } & TOTAL & 84 & 87 & 81 & 74 & 24 & 33 & 17 & 33 & 23 \\
\hline & INDIGENTES & 83 & 84 & 85 & 63 & 14 & 22 & 8 & 20 & 16 \\
\hline & POBRES NO INDIG. & 86 & 91 & 84 & 73 & 19 & 30 & 9 & 33 & 15 \\
\hline & NO POBRES & 83 & 86 & 79 & 77 & 30 & 39 & 24 & 39 & 29 \\
\hline \multirow[t]{4}{*}{ VENEZUELA } & TOTAL & 87 & 93 & 79 & 85 & 23 & 39 & 19 & 24 & 20 \\
\hline & INDIGENTES & 80 & 88 & 68 & 67 & 12 & 26 & 4 & 12 & 10 \\
\hline & POBRES NO INDIG. & 85 & 93 & 73 & 84 & 15 & 35 & 10 & 17 & 13 \\
\hline & NO POBRES & 89 & 94 & 82 & 88 & 30 & 47 & 26 & 31 & 25 \\
\hline
\end{tabular}

Source: ECLAC, on the basis of special tabulations of data from household surveys.

* Translator's note: The term "spouse" denotes a married woman as a woman living in a consensual union. 
Table 3

LATIN AMERICA (13 COUNTRIES): CONTRIBUTION OF SPOUSE* TO FAMILY INCOME IN URBAN AREAS

\begin{tabular}{|c|c|c|c|c|c|c|c|c|}
\hline \multirow{3}{*}{ Country: } & \multirow{3}{*}{ Year } & \multicolumn{4}{|c|}{ Percentage of households with: } & \multirow{2}{*}{\multicolumn{3}{|c|}{$\begin{array}{l}\text { Spouse income as percentage } \\
\text { of household income cl }\end{array}$}} \\
\hline & & \multicolumn{2}{|c|}{ Head \& spouse a } & \multicolumn{2}{|c|}{$\begin{array}{l}\text { Head \& spouse both } \\
\text { economically active b/ }\end{array}$} & & & \\
\hline & & Total & Poor & Total & Poor & Total & Indigent & Non-Indigent Poor \\
\hline \multirow[t]{3}{*}{ ARGENTINA } & 1980 & 75 & 75 & 23 & 2 & 32 & 24 & 19 \\
\hline & 1986 & 73 & 79 & 28 & 7 & 35 & 0 & 31 \\
\hline & 1992 & 71 & 82 & 33 & 10 & 33 & 41 & 38 \\
\hline BOLIVIA & 1992 & 74 & 77 & 43 & 34 & 31 & 36 & 34 \\
\hline \multirow[t]{3}{*}{ BRAZIL } & 1979 & 76 & 73 & 24 & 16 & 27 & 26 & 27 \\
\hline & 1987 & 72 & 68 & 34 & 24 & 29 & 24 & 28 \\
\hline & 1990 & 74 & 71 & 36 & 26 & 27 & 29 & 28 \\
\hline \multirow[t]{3}{*}{ COLOMBLA } & 1980 & 73 & 74 & 29 & 18 & 20 & 21 & 21 \\
\hline & 1986 & 71 & 73 & 34 & 22 & 30 & 38 & 34 \\
\hline & 1992 & 71 & 73 & 43 & 33 & 29 & 35 & 32 \\
\hline \multirow[t]{3}{*}{ COSTA RICA } & 1981 & $\ldots$ & $\ldots$ & $\ldots$ & $\ldots$ & ... & $\ldots$ & $\ldots$ \\
\hline & 1988 & 76 & 71 & 29 & 13 & 33 & 30 & 24 \\
\hline & 1992 & 71 & 65 & 27 & 11 & 35 & 24 & 35 \\
\hline \multirow[t]{3}{*}{ CHILE } & 1980 & $\ldots$ & $\ldots$ & $\ldots$ & $\ldots$ & $\ldots$ & $\ldots$ & $\ldots$ \\
\hline & 1987 & 72 & 74 & 21 & 11 & 32 & 30 & 30 \\
\hline & 1992 & 72 & 76 & 28 & 13 & 31 & 33 & 33 \\
\hline \multirow[t]{3}{*}{ GUATEMALA } & 1980 & $\cdots$ & $\ldots$ & $\ldots$ & $\ldots$ & $\ldots$ & $\ldots$ & $\ldots$ \\
\hline & 1987 & 73 & 75 & 29 & 21 & 33 & 32 & 33 \\
\hline & 1989 & 72 & 75 & 33 & 21 & 28 & 29 & 29 \\
\hline \multirow[t]{3}{*}{ HONDURAS } & 1980 & $\ldots$ & $\ldots$ & $\ldots$ & $\ldots$ & $\ldots$ & $\ldots$ & $\ldots$ \\
\hline & 1988 & 66 & 65 & 39 & 29 & 27 & 34 & 29 \\
\hline & 1992 & 65 & 64 & 38 & 28 & 30 & 24 & 32 \\
\hline \multirow[t]{3}{*}{ MEXICO } & 1984 & 76 & 84 & 19 & 12 & 31 & 0 & 5 \\
\hline & 1989 & 78 & 84 & 23 & 13 & 29 & 24 & 27 \\
\hline & 1992 & 77 & 85 & 27 & 17 & 27 & 23 & 25 \\
\hline \multirow[t]{3}{*}{ PANAMA } & 1979 & 64 & 59 & 40 & 22 & 35 & 48 & 37 \\
\hline & 1986 & 67 & 66 & 33 & 14 & 36 & 41 & 34 \\
\hline & 1991 & 65 & 64 & 35 & 21 & 36 & 45 & 34 \\
\hline \multirow[t]{2}{*}{ PARAGUAY } & 1986 & 74 & 77 & 45 & 32 & 33 & .31 & 35 \\
\hline & 1992 & 70 & 68 & 41 & 28 & 34 & 28 & 34 \\
\hline \multirow[t]{3}{*}{ URUGUAY } & 1981 & 70 & 73 & 30 & 17 & 28 & 22 & 24 \\
\hline & 1986 & 70 & 74 & 38 & 27 & 28 & 29 & 24 \\
\hline & 1992 & 67 & 79 & 43 & 36 & 23 & 18 & 17 \\
\hline \multirow[t]{3}{*}{ VENEZUEEL A } & 1981 & 69 & 60 & 23 & 9 & 37 & 27 & 37 \\
\hline & 1986 & 71 & 64 & 30 & 13 & 32 & 27 & 32 \\
\hline & 1992 & 69 & 63 & 35 & 15 & 33 & 30 & 33 \\
\hline
\end{tabular}

Source: ECLAC, on the basis of special tabulations of data from household surveys.

*Translators note: The term "spouse" denotes a married woman as a woman living in a consensual union.

a/ Calculated with respect to total households.

b/ Calculated with respect to total households with head and spouse present.

c/ Refers to spouse's income from gainful employment. 
Table 4

LATIN AMERICA (11 COUNTRIES): ESTIMATES OF THE EXTENT OF URBAN POVERTY

\begin{tabular}{|c|c|c|c|c|c|}
\hline & & 2 & XTENT OF POY & TY & \\
\hline Country & 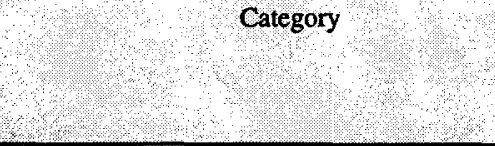 & Hypothesis 1 a & Hypothesis 2 b/ & $\begin{array}{l}\text { Total poor and } \\
\text { indigent } \\
\text { households }\end{array}$ & Hypothesis $3 \mathrm{cl}$ \\
\hline ARGEMTINA & INDIGENT HOUSEHOLDS & 7 & 3 & 1 & 1 \\
\hline & NON-INDIGENT POOR HOUSEHOLDS & 13 & 10 & 8 & 4 \\
\hline & TOTAL POOR HOUSEHOLDS & 20 & 12 & 10 & 4 \\
\hline BOLIVIA & INDIGENT HOUSEHOLDS & 31 & 23 & 18 & 13 \\
\hline & NON-INDIGENT POOR HOUSEHOLDS & 27 & 29 & 28 & 26 \\
\hline & TOTAL POOR HOUSEHOLDS & 58 & 52 & 46 & 39 \\
\hline BRAZIL & INDIGENT HOUSEHOLDS & 25 & 19 & 17 & 13 \\
\hline & NON-INDIGEINT POOR HOUSEHOLDS & 22 & 23 & 22 & 20 \\
\hline & TOTAL POOR HOUSEHOLDS & 47 & 42 & 39 & 34 \\
\hline COLOMBIA & INDIGENTHOUSEHOLDS & 26 & 18 & 15 & 12 \\
\hline & NON-INDIGENT POOR HOUSEHOLDS & 25 & 25 & 23 & 21 \\
\hline & TOTAL POOR HOUSEHOLDS & 52 & 43 & 38 & 33 \\
\hline COSTARICA & INDIGENT HOUSEHOLOS & 17 & 9 & 8 & 6 \\
\hline & NON-NDIGENT POOR HOUSEHOLDS & 21 & 19 & 17 & 12 \\
\hline & TOTAL POOR HOUSEHOLDS & 38 & 27 & 25 & 17 \\
\hline CHII: & INDIGENT HOUSEHOLDS & 13 & 8 & 7 & 4 \\
\hline & NON-INDIGENT POOR HOUSEHOLDS & 25 & 22 & 20 & 15 \\
\hline & TOTAL POOR HOUSEHOLDS & 38 & 31 & 27 & 19 \\
\hline HONDURAS & NDIGENT HOUSEHOLDS & 53 & 42 & 38 & 34 \\
\hline & NON-NDIGENT POOR HOUSEHOLDS & 22 & 27 & 27 & 27 \\
\hline & TOTAL POOR HOUSEHOLDS & 75 & 69 & 66 & 61 \\
\hline MEXICO & INDIGENT HOUSEHOLDS & 13 & 8 & 7 & 5 \\
\hline & NON-INDIGENT POOR HOUSEHOLDS & 26 & 25 & 23 & 18 \\
\hline & TOTAL POOR HOUSEHOLDS & 39 & 33 & 29 & 23 \\
\hline PANAMA & INDIGENT HOUSEHOLDS & 24 & 16 & 14 & 12 \\
\hline & NON-INDIGEINT POOR HOUSEHOLDS & 21 & 21 & 20 & 15 \\
\hline & TOTAL POOR HOUSEHOLDS & 46 & 37 & 34 & 27 \\
\hline PARAGUAY & INDIGENT HOUSEROLDS & 26 & 16 & 13 & 10 \\
\hline & NON-INDIGENT POOR HOUSEHOLDS & 28 & 27 & 22 & 19 \\
\hline & TOTAL POOR HOUSEHOLDS & 54 & 43 & 36 & 29 \\
\hline URUGUAY & INDIGENT HOUSEHOUDS & 3 & 2 & 1 & 1 \\
\hline & NON-NDIGENT POOR HOUSEHOLDS & 9 & 8 & 6 & 5 \\
\hline VENEZUELA. & INDIGENT HOUSEHOLDS & 24 & 13 & 11 & 8 \\
\hline & NON-INDIGEINT POOR HOUSEHOLDS & 25 & 25 & 22 & 17 \\
\hline & TOTAL POOR HOUSEHOLDS & 48 & 38 & 33 & 24 \\
\hline
\end{tabular}

Source: ECLAC, on the basis of special tabulations of data from household surveys.

a/ Hypothesis 1: Extent of poverty if women were not employed; calculated by omitting women's earning.

b/ Hypothesis 2: Extent of poverty if spouses* were not employed; calculated by omitting spouse's earnings.

c/ Hypothesis 2: Extent of poverty if all spouses were employed; calculated by hypothesizing that economically inactive spouses were earning an income equal to the average earned by economically active spouses in poor and indigent income levels, respectively.

* Translator's not: The term "spouse" denotes a married woman as a woman living in a consensual union. 
Table 5

LATIN AMERICA (13 COUNTRIES): FEMALE-HEADED HOUSEHOLDS IN URBAN AREAS

\begin{tabular}{|c|c|c|c|c|c|c|c|c|c|}
\hline \multirow[t]{2}{*}{ PAIS } & \multirow[t]{2}{*}{ AÑO } & \multicolumn{4}{|c|}{$\begin{array}{l}\text { Percentage of female-headed households } \\
\text { at each poverty level }\end{array}$} & \multicolumn{4}{|c|}{$\begin{array}{c}\text { Distribution of female headed households } \\
\text { by poverty level }\end{array}$} \\
\hline & & Total & Indigent & Non-indigent poor & Non-poor & Total & Indigent & Non-indigent poor & Non-poor \\
\hline \multirow[t]{4}{*}{ ARGENTINA } & 1980 & 18 & 36 & 17 & 18 & 100.0 & 2.8 & 3.4 & $\begin{array}{l}93.7 \\
\end{array}$ \\
\hline & 1986 & 20 & 27 & 16 & 20 & 100.0 & 3.6 & 5.1 & 91.3 \\
\hline & 1992 & 22 & 15 & 18 & 23 & 100.0 & 1.0 & 6.6 & 92.4 \\
\hline & 1994 & 24 & 22 & 20 & 24 & 100.0 & 1.0 & 7.5 & 91.1 \\
\hline \multirow[t]{2}{*}{ BOLIVIA } & 1992 & 18 & 21 & 16 & 17 & 100.0 & 21.1 & 28.4 & 50.6 \\
\hline & 1994 & 18 & 20 & 17 & 18 & 100.0 & 15.5 & 25.8 & 58.7 \\
\hline \multirow[t]{4}{*}{ BRAZAL } & 1979 & 19 & 33 & 20 & 16 & 100.0 & 17.4 & 20.7 & 62.0 \\
\hline & 1987 & 21 & 33 & 25 & 18 & 100.0 & 20.8 & 23.2 & 56.0 \\
\hline & 1990 & 20 & 27 & 22 & 18 & 100.0 & 22.4 & 24.3 & 53.3 \\
\hline & 1993 & 22 & 23 & 21 & 22 & 100.0 & 17.1 & 21.5 & 61.4 \\
\hline \multirow[t]{4}{*}{ COLOMBIA } & 1980 & 20 & 23 & 21 & 19 & 100.0 & 13.9 & 22.4 & 63.8 \\
\hline & 1986 & 23 & 26 & 22 & 22 & 100.0 & 16.0 & 19.8 & 64.3 \\
\hline & 1992 & 24 & 26 & 24 & 23 & 100.0 & 18.3 & 23.1 & 60.6 \\
\hline & 1994 & 24 & 24 & 24 & 24 & 100.0 & 16.1 & 24.0 & 59.9 \\
\hline \multirow[t]{4}{*}{ COSTA RICA } & 1981 & 22 & 53 & 38 & 18 & 100.0 & 12.9 & 18.5 & 68.6 \\
\hline & 1988 & 19 & 38 & 21 & 18 & 100.0 & 11.5 & 16.1 & 72.4 \\
\hline & 1992 & 24 & 46 & 25 & 22 & 100.0 & 14.6 & 17.8 & 87.6 \\
\hline & 1904 & 24 & 42 & 27 & 22 & 100.0 & 9.8 & 14.0 & 76.2 \\
\hline \multirow[t]{4}{*}{ CHALE } & 1987 & 23 & 27 & 23 & 22 & 100.0 & 16.1 & 24.1 & 59.8 \\
\hline & 1992 & 22 & 24 & 21 & 22 & 100.0 & 7.8 & 19.7 & 72.6 \\
\hline & 1894 & 22 & 27 & 21 & 22 & 100.0 & 7.1 & 16.0 & 76.8 \\
\hline & 1996 & 23 & 29 & 22 & 23 & 100.0 & 5.3 & 13.8 & 81.1 \\
\hline \multirow[t]{2}{*}{ GUATEMALA } & 1987 & 20 & 23 & 19 & 20 & 100.0 & 30.9 & 24.8 & 44.3 \\
\hline & 1989 & 22 & 23 & 21 & 22 & 100.0 & 24.2 & 24.3 & 51.5 \\
\hline \multirow[t]{3}{*}{ HONDURAS } & 1980 & 28 & 39 & 26 & 23 & 100.0 & 38.5 & 23.6 & 37.9 \\
\hline & 1992 & 29 & 35 & 30 & 21 & 100.0 & 46.4 & 28.8 & 25.0 \\
\hline & 1894 & 25 & 28 & 25 & 21 & 100.0 & 45.8 & 29.2 & 25.0 \\
\hline \multirow[t]{4}{*}{ MEXICO } & 1984 & 17 & 18 & 13 & 19 & 100.0 & 6.3 & 15.7 & 78.0 \\
\hline & 1989 & 16 & 14 & 14 & 17 & 100.0 & 8.2 & 21.9 & 69.9 \\
\hline & 1992 & 17 & 14 & 12 & 19 & 100.0 & 5.6 & 15.8 & 78.7 \\
\hline & .1824 & 17 & 11 & 16 & 18 & 100.0 & 4.0 & 21.3 & 74.7 \\
\hline \multirow[t]{4}{*}{ PANAMA } & 1979 & 25 & 50 & 25 & 20 & 100.0 & 27.7 & 17.1 & 55.2 \\
\hline & 1986 & 24 & 31 & 27 & 22 & 100.0 & 16.4 & 19.1 & 64.4 \\
\hline & 1891 & 26 & 34 & 29 & 24 & 100.0 & 18.0 & 22.0 & 60.0 \\
\hline & 1824 & 25 & 35 & 25 & 24 & 100.0 & 12.1 & 16.2 & 71.7 \\
\hline \multirow[t]{2}{*}{ PARAGuaY } & 1986 & 19 & 26 & 14 & 20 & 100.0 & 22.3 & 21.7 & 56.0 \\
\hline & 1992 & 25 & 36 & 24 & 23 & 100.0 & 19.3 & 21.3 & 59.4 \\
\hline \multirow[t]{4}{*}{ URUGUAY } & 1981 & 22 & 25 & 22 & 22 & 100.0 & 2.5 & 7.4 & 90.1 \\
\hline & 1986 & 23 & 28 & 19 & 23 & 100.0 & 3.1 & 8.8 & 88.1 \\
\hline & 1892 & 25 & 21 & 18 & 26 & 100.0 & 1.1 & 4.8 & 94.2 \\
\hline & 1994 & 27 & 21 & 23 & 27 & 100.0 & 0.8 & 4.0 & 95.1 \\
\hline \multirow[t]{4}{*}{ VENEZUELA } & 1981 & 22 & 50 & 31 & 19 & 100.0 & 10.5 & 18.7 & 70.7 \\
\hline & 1986 & 22 & 44 & 27 & 18 & 100.0 & 16.4 & 21.1 & 62.5 \\
\hline & 1992 & 23 & 42 & 27 & 10 & 100.0 & 18.9 & 25.0 & 56.1 \\
\hline & 1994 & 25 & 34 & 28 & 21 & 100.0 & 18.7 & 30.8 & 50.5 \\
\hline
\end{tabular}

Source: ECLAC, on the basis of special tabulations of data from household surveys. 
Table 6

LATIN AMERICA (13 COUNTRIES): INCIDENCE OF POVERTY a/ IN URBAN AREAS, BY TYPE OF HOUSEHOLD

\begin{tabular}{|c|c|c|c|c|c|c|c|c|c|c|c|}
\hline \multirow{3}{*}{ Country } & \multirow{3}{*}{ Year } & \multirow{3}{*}{ Total } & \multicolumn{7}{|c|}{ Type of household } & & \\
\hline & & & \multirow{2}{*}{$\begin{array}{l}\text { One } \\
\text { person }\end{array}$} & \multicolumn{4}{|c|}{ Nuclear } & \multicolumn{2}{|c|}{ Extended } & \multicolumn{2}{|c|}{ Composite } \\
\hline & & & & Childless & Complete & $\begin{array}{l}\text { Male } \\
\text { headed }\end{array}$ & $\begin{array}{l}\text { Female } \\
\text { headed }\end{array}$ & Complete & $\begin{array}{l}\text { Female } \\
\text { headed }\end{array}$ & Complete & $\begin{array}{l}\text { Female } \\
\text { headed }\end{array}$ \\
\hline \multirow[t]{2}{*}{ ARGENTINA } & 1980 & 4.9 & 4.4 & 3.5 & 6.4 & 5.5 & 8.8 & 3.4 & 6.0 & $\ldots$ & 6.7 \\
\hline & 1992 & 9.8 & 0.5 & 12.5 & 10.9 & 4.6 & 12.0 & 11.1 & 14.2 & $\ldots$ & 6.7 \\
\hline \multirow[t]{2}{*}{ BOLIVIA } & 1980 & $\ldots$ & $\cdots$ & $\ldots$ & $\cdots$ & $\cdots$ & $\ldots$ & $\ldots$ & $\cdots$ & ... & ... \\
\hline & 1992 & 45.7 & 26.4 & 27.7 & 51.2 & 32.2 & 52.9 & 38.4 & 48.0 & 16.3 & 45.0 \\
\hline \multirow[t]{2}{*}{ BRAZIL } & 1979 & 28.9 & 9.0 & 13.0 & 31.3 & 23.4 & 47.5 & 27.6 & 35.6 & 17.2 & 19.0 \\
\hline & 1990 & 38.5 & 33.6 & 24.4 & 39.2 & 36.0 & 49.2 & 41.1 & 50.6 & 24.3 & 30.8 \\
\hline \multirow[t]{2}{*}{ COLOMBIA } & 1980 & 35.5 & 11.6 & 16.0 & 36.9 & 29.5 & 39.7 & 33.6 & 41.6 & 26.5 & 27.8 \\
\hline & 1992 & 38.2 & 13.0 & 17.3 & 41.6 & 28.9 & 42.1 & 40.4 & 44.4 & 28.1 & 25.3 \\
\hline \multirow[t]{2}{*}{ COSTA RICA } & 1988 & 20.5 & 14.1 & 10.6 & 19.3 & 18.8 & 30.3 & 21.4 & 30.5 & 26.5 & 17.2 \\
\hline & 1992 & 24.9 & 25.3 & 18.4 & 23.6 & 16.8 & 31.4 & 22.0 & 37.0 & 20.4 & 15.1 \\
\hline \multirow[t]{2}{*}{ CHILE } & 1987 & 36.6 & 13.0 & 11.4 & 41.0 & 27.3 & 41.2 & 40.5 & 44.6 & 27.8 & 27.5 \\
\hline & 1992 & 27.4 & 9.6 & 8.9 & 32.3 & 16.2 & 29.7 & 29.1 & 33.1 & 35.5 & 21.9 \\
\hline \multirow[t]{2}{*}{ GUATEMALA } & 1986 & 54.4 & 29.3 & 32.6 & 58.9 & 51.9 & 59.2 & 58.6 & 53.9 & 52.9 & 54.9 \\
\hline & 1992 & $\ldots$ & ... & $\ldots$ & $\ldots$ & $\ldots$ & $\ldots$ & ... & $\ldots$ & $\ldots$ & $\ldots$ \\
\hline \multirow[t]{2}{*}{ HONDURAS } & 1988 & 52.9 & 15.2 & 32.3 & 55.1 & 45.0 & 65.0 & 52.6 & 68.9 & 39.8 & 47.3 \\
\hline & 1992 & 65.6 & 20.4 & 50.9 & 66.9 & 35.7 & 79.7 & 63.6 & 78.9 & 57.6 & 67.3 \\
\hline \multirow[t]{2}{*}{ MEXICO } & 1988 & ... & $\cdots$ & $\ldots$ & $\ldots$ & $\ldots$ & ... & $\ldots$ & $\ldots$ & $\ldots$ & ... \\
\hline & 1992 & 29.4 & 2.8 & 10.6 & 33.6 & 18.5 & 21.0 & 38.0 & 29.0 & 13.5 & 43.3 \\
\hline \multirow[t]{2}{*}{ PANAMA } & 1980 & $\ldots$ & $\ldots$ & $\ldots$ & $\ldots$ & $\ldots$ & $\ldots$ & $\ldots$ & $\ldots$ & $\ldots$ & $\ldots$ \\
\hline & 1991 & 33.6 & 21.8 & 14.8 & 35.8 & 31.3 & 44.2 & 34.7 & 42.4 & 25.9 & 31.8 \\
\hline \multirow[t]{2}{*}{ PARAGUAY } & 1986 & 45.7 & 20.9 & 20.8 & 46.4 & 36.0 & 52.4 & 60.6 & 46.7 & 39.0 & 43.4 \\
\hline & 1992 & 35.6 & 26.4 & 11.9 & 41.6 & 28.1 & 41.6 & 32.5 & 45.7 & 29.6 & 35.1 \\
\hline \multirow[t]{2}{*}{ URUGUAY } & 1981 & 9.2 & 3.3 & 2.8 & 12.8 & 9.4 & 14.8 & 10.6 & 11.4 & 9.9 & 12.5 \\
\hline & 1992 & 7.7 & 0.9 & 1.4 & 11.7 & 3.5 & 9.0 & 11.3 & 9.1 & 16.9 & 8.9 \\
\hline \multirow[t]{2}{*}{ VENEZUEIA } & 1981 & 17.8 & 0.1 & 9.9 & 17.0 & 14.7 & 34.5 & 11.0 & 34.6 & 14.7 & 30.8 \\
\hline & 1992 & 31.8 & 28.6 & 19.9 & 29.9 & 28.1 & 42.6 & 22.9 & 34.9 & 29.3 & 43.5 \\
\hline
\end{tabular}

Source: ECLAC, on the basis of special tabulations of data from household surveys.

a/ Percentage of poor and indigent households out of the total number of households. 
Table 7

LATIN AMERICA (12 COUNTRIES): DISTRIBUTION OF HOUSEHOLDS BY TYPE AND POVERTY LEVEL, IN URBAN AREAS (1992) (Percentages)

\begin{tabular}{|c|c|c|c|c|c|c|c|c|c|c|}
\hline \multirow[t]{2}{*}{ Country } & \multirow{2}{*}{$\begin{array}{l}\text { Poverty } \\
\text { level }\end{array}$} & \multirow[t]{2}{*}{ Total } & \multirow{2}{*}{$\begin{array}{c}\text { One } \\
\text { person }\end{array}$} & \multicolumn{3}{|c|}{ Nuclear. } & \multicolumn{2}{|c|}{ Extended } & \multicolumn{2}{|c|}{ Composite } \\
\hline & & & & Childless & Complete & $\begin{array}{l}\text { Female } \\
\text { headed }\end{array}$ & Complete & $\begin{array}{l}\text { Female } \\
\text { headed }\end{array}$ & Complete & $\begin{array}{l}\text { Female } \\
\text { headed }\end{array}$ \\
\hline \multirow[t]{3}{*}{ ARGENTINA } & Indigent & 100.0 & $\because-$ & 2.2 & 64.0 & 6.4 & 16.9 & 6.4 & $\because$ & $\because$ \\
\hline & Non-indigent poor & 100.0 & 0.8 & 22.5 & 48.9 & 8.8 & 10.0 & 6.4 & $\because$ & 0.4 \\
\hline & Non-poor & 100.0 & 14.4 & 14.9 & 45.6 & 6.7 & 9.6 & 4.2 & 0.5 & 0.5 \\
\hline \multirow[t]{3}{*}{ BOLIVIA } & Indigent & 100.0 & 4.3 & 3.5 & 62.9 & 11.1 & 11.1 & 6.1 & 0.5 & 0.1 \\
\hline & Non-indigent poor & 100.0 & 3.5 & 3.6 & 66.0 & 8.8 & 10.9 & 5.8 & 0.4 & 0.6 \\
\hline & Non-poor & 100.0 & 9.0 & 7.8 & 53.0 & 7.2 & 15.2 & 5.4 & 1.8 & 0.4 \\
\hline \multirow[t]{3}{*}{ BRAZIL } & Indigent & 100.0 & 1.0 & 4.2 & 71.6 & 5.4 & 12.6 & 4.0 & 1.0 & 0.2 \\
\hline & Non-indigent poor & 100.0 & 7.6 & 8.8 & 58.4 & 5.1 & 15.0 & 3.8 & 1.2 & 0.1 \\
\hline & Non-poor: & 100.0 & 8.8 & 12.8 & 53.9 & 4.8 & 14.0 & 3.0 & 2.4 & 0.3 \\
\hline \multirow[t]{3}{*}{ COLOMBIA } & Indigent & 100.0 & 2.8 & 2.6 & 56.2 & 11.4 & 14.7 & 10.3 & 1.4 & 0.8 \\
\hline & Non-indlgent poor & 100.0 & 0.9 & 2.1 & 54.6 & 9.8 & 19.3 & 10.9 & 1.9 & 0.6 \\
\hline & Non-poor & 100.0 & 6.7 & 6.7 & 48.0 & 8.8 & 17.4 & 8.3 & 2.7 & 1.2 \\
\hline \multirow[t]{3}{*}{ COSTA RICA } & Indigent & 100.0 & 13.6 & 6.4 & 33.5 & 19.1 & 10.1 & 16.5 & 0.7 & 0.2 \\
\hline & Non-indigent poor & 100.0 & 2.0 & 4.6 & 56.0 & 9.8 & 14.2 & 11.5 & 1.2 & 0.8 \\
\hline & Non-poor & 100.0 & 5.5 & 7.5 & 52.8 & 9.2 & 15.2 & 7.4 & 1.4 & 1.1 \\
\hline \multirow[t]{3}{*}{ CHILE } & Indigent & 100.0 & 4.0 & 3.3 & 56.6 & 9.2 & 16.0 & 9.1 & 1.1 & 0.8 \\
\hline & Non-indlgent poor & 100.0 & 2.2 & 2.6 & 57.7 & 7.9 & 17.6 & 9.9 & 1.4 & 0.7 \\
\hline & Non-poor & 100.0 & 9.5 & 10.9 & 46.1 & 7.3 & 16.5 & 7.4 & 1.5 & 0.9 \\
\hline \multirow[t]{3}{*}{ HONDURAS } & Indigent & 100.0 & 2.0 & 1.6 & 42.7 & 14.6 & 18.5 & 15.3 & 3.3 & 2.2 \\
\hline & Non-indigent poor & 100.0 & 0.7 & 4.0 & 43.5 & 10.9 & 20.1 & 15.8 & 3.6 & 1.4 \\
\hline & Non-poor & 100.0 & 10.8 & 4.7 & 42.6 & 6.3 & 21.2 & 7.9 & 4.8 & 1.7 \\
\hline \multirow[t]{3}{*}{ MEXICO } & Indigent & 100.0 & 0.1 & 0.9 & 64.6 & 6.9 & 21.2 & 5.8 & 0.4 & 0.2 \\
\hline & Non-indigent poor & 100.0 & 0.6 & 3.0 & 63.9 & 5.0 & 21.5 & 5.5 & 0.2 & 0.3 \\
\hline & Non-poor & 100.0 & 7.3 & 8.9 & 54.0 & 8.5 & 15.6 & 5.7 & 0.5 & 0.2 \\
\hline \multirow[t]{3}{*}{ PANAMA } & Indigent & 100.0 & 10.8 & 3.5 & 61.0 & 19.6 & 1.0 & 0.8 & 0.1 & 0.7 \\
\hline & Non-indigent poor & 100.0 & 5.6 & 5.1 & 65.2 & 17.1 & 1.1 & 0.4 & 1.6 & 0.7 \\
\hline & Non-poor & 100.0 & 13.6 & 12.5 & 55.5 & 11.1 & 1.5 & 1.0 & 1.3 & 0.5 \\
\hline \multirow[t]{3}{*}{ PARAGUAY } & Indigent & 100.0 & 5.7 & 0.7 & 44.6 & 12.2 & 13.4 & 15.0 & 4.2 & 4.2 \\
\hline & Non-indigent poor & 100.0 & 4.7 & 3.6 & 46.9 & 5.7 & 17.1 & 11.5 & 9.0 & 1.7 \\
\hline & Non-poor & 100.0 & 7.9 & 10.2 & 36.7 & 6.4 & 18.1 & 8.5 & 9.5 & 2.7 \\
\hline \multirow[t]{3}{*}{ URUGUAY } & Indigent & 100.0 & 1.8 & 1.7 & 66.0 & 11.3 & 8.5 & 8.3 & 2.5 & 0.0 \\
\hline & Non-Indigent poor & 100.0 & 1.9 & 3.5 & 60.1 & 7.5 & 16.6 & 7.9 & 1.6 & 1.1 \\
\hline & Non-poor & 100.0 & 16.5 & 18.8 & 39.6 & 6.9 & 10.0 & 6.6 & 0.7 & 0.8 \\
\hline \multirow[t]{3}{*}{ VENEZUELA a } & Indigent & 100.0 & 0.5 & 2.7 & 36.0 & 18.0 & 19.5 & 23.4 & n.d. & n.d \\
\hline & Non-indigent poor & 100.0 & 6.3 & 3.0 & 44.4 & 7.6 & 24.4 & 14.5 & n.d. & n.d \\
\hline & Non-poor & 100.0 & 5.1 & 5.4 & 45.8 & 6.9 & 26.0 & 10.7 & n.d. & n.d \\
\hline
\end{tabular}

Source: ECLAC, on the basis of special tabulations of data from household surveys.

a Figures for extended households also include composite households. 



\title{
GOALS FOR CHILDREN, EXCLUSION AND VULNERABILITY: \\ Expanding the usefulness of household surveys
}

\author{
by
}

\begin{abstract}
Alberto Minujin
Regional Office for Latin America and the Caribbean UNICEF
\end{abstract}




\section{Goals for children, exclusion and vulnerability: Expanding the usefulness of household surveys}

\section{Introduction}

Social statistics are evolving rapidly in Latin America and the Caribbean (LAC). Institutional and macroeconomic reforms have significantly changed the social structure of the region. Old problems have worsened and new problems have arisen. The goals defined at the World Summit for Children focused world wide attention on the situation of children and women and called for follow up actions that require intensive monitoring. In this context, the demand for social statistics needed for the design, execution and monitoring of policies has increased significantly. In this paper, we examine the development of analytical tools and statistical indicators in two areas -monitoring child goals and measuring and monitoring of poverty and vulnerable groups- where demand has been important. In the final section, an attempt to measure excluded and vulnerable groups is presented as a way of capturing new social conditions in LAC.

\section{Monitoring goals for children}

\subsection{Goals for children and poverty}

A significant and influential step taken in the direction of full respect for human rights what could eventually be considered a landmark in history- is the United Nations Convention on the Rights of the Child (CRC). It has been ratified by most of the countries in the world - 179 by the end of 1995- and has had considerable impact on legal and institutional systems.

The CRC was adopted by the United Nation's General Assembly on November 20, 1989, as a result of more than 10 years of deliberation among different nations. Less than a year later and transcending all political, cultural and social boundaries, the World Summit for Children (WSC) brought together leaders from more than 150 countries and defined what would become the major guidelines of private and public policies for children and adolescents around the world. The WSC was held in 1990 and established a set of goals centered on women's and children's issues, recognizing the strong correlation between poverty and the survival and development indicators for these two population groups'. The formulation of the WSC goals and the posterior commitment expressed by world leaders to reach them by the year 2000 constitutes an important milestone in the struggle against the threats to child welfare.

\footnotetext{
${ }^{1}$ We can speak of interaction but, for example, we can observe a significant increase of immunization coverage without a decrease in poverty. Increases in poverty don't necessarily imply a deterioration of some survival indicators like infant mortality rate.
} 
In the framework of UNICEF's firm conviction that all children are equal, the rights and specific goals agreed upon include all youngsters, regardless of their socioeconomic background. Infants struggling with indigence, children working in the streets, college students and babies born to affluent families are all entitled to the same rights. However, the achievement of goals regarding basic needs - for example, the reduction in the infant and maternal mortality rates, the increase in the number of children immunized and the expansion of access to water, sanitation and basic education, among others- implies a reduction of the disparities between the poor and the non-poor, and a greater concentration of public and private policies and programmes on the most disadvantaged and vulnerable groups.

The struggle against poverty and the efforts undertaken to achieve the goals for children in the areas of survival and development are holistically related (UNICEF, 1990; UNICEF, 1996).

\subsection{From Needs to Rights}

This century has witnessed a significant expansion in the consideration of human rights, which have evolved from civil to political rights, and from there to social rights. This process implies a shift from the traditional needs approach to a rights approach, having important consequences for public policies, monitoring and evaluation.

In Latin America and the Caribbean, subsequent WSC follow-up meetings attended by leaders and government officials from the Hemisphere addressed the need to update some of these goals and add certain specifications as well as the necessity of defining new ones according to the special circumstances of the Region. Table 1 in the Appendix illustrates the number of new goals that were defined in each meeting ${ }^{2}$. While the WSC goals are centered on mother-and-child health and nutrition without disregarding other relevant areas, the new ones encompass additional issues pertaining to child development, women and child rights and participation. Table 2 contains a few of the new goals.

\footnotetext{
${ }^{2}$ These new goals are contained, among others, in the Narino Accord, the main outcome of the Second Ministerial Meeting on Children and Social Policy held in Santafé de Bogotá, and in the Santiago Accord, the result of the Third Ministerial Meeting on Children and Social Policy in the Americas, held in Santiago de Chile. (UNICEF, Regional Office for Latin America and the Caribbean, 1995; UNICEF, Regional Office for Latin America and the Caribbean, and others 1996)
} 
Table 2

Selected new goals defined at Ministerial Meetings in the Region

Ensure that all couples have access to relevant information on parenting and the developmental needs of children and adolescents.

Universalize access to information and to adequate means of prevention and control of HIV/AIDS infections and their consequences.

Eliminate gender bias and include gender equity notions in all learning material.

Incorporate human rights, life skills, environmental issues and health and nutrition (including reproductive health) in all learning material

Eliminate all types of discrimination on the grounds of race, culture, social status, religion, nationality or gender.

Promote de-institutionalization of children and establish preventive and rehabilitative systems for children in conflict with the law or in especially difficult circumstances.

Eliminate labor and highly dangerous activities for children.

Contribute to the attention of victims of domestic \& sexual abuse.

Provide integrated care to adolescent mothers.

Develop programmes to increase men's equitable participation in family life and in the rearing and care of children.

Source: UNICEF and others (1995) The Priority is Children: an Overview of Meetings held Internationally and in the Americas UNICEF, Regional Office for Latin America and the Caribbean

\subsection{Monitoring goals: Multiple Indicator Cluster Surveys (MICS) and Household Surveys(HS)}

The definition of goals and the explicit commitment of governments to achieve them, pose the complicated issue of monitoring and evaluating progress, which must be assessed. As stated by the former Norwegian Ombudsman for Children, "laws, national and international, are, after all, words on paper. They may codify attitudes, but the real results depend upon how they are implemented, what is done to follow up and to reach the ideals." (Himes, 1995) Even though UNICEF has constantly worked to support governments in the task to monitor and evaluate the goals established at the WSC, severe problems related to the 
quality, availability and periodicity of information may arise. This is specially true in developing countries, where the available sources of information are rarely reliable or recurrent and often lack substantial disaggregation by income level, gender or socio economic group. Furthermore, the need for trustworthy information that is comparable in time magnifies the extent of the problem.

During the early 1990s, several initiatives were introduced with considerable success. One of these initiatives is the Multiple Indicator Cluster Surveys (MICS), produced with the collaboration of UNICEF, World Health Organization (WHO), United Nations Population Fund (UNFPA), Child Development Center (CDC) and the United Nations Statistical Office, with the purpose of reporting progress on the achievement of the WSC goals. These household cluster surveys are population-based data gathering systems and they can provide a snapshot of the target population at a determined point in time and a characterization of the most vulnerable, and when properly conducted they can yield data that will meet the strict requirements for reporting progress on the goals. MICS are intended to complement, but not replace, established monitoring systems and can be used in countries that lack information systems with the purpose of filling information gaps, as well as to improve programme delivery in data- rich countries. Specifically, multiple indicator surveys can: (a) fortify local level programme monitoring, (b) satisfy national level goal monitoring needs (c) perform at low cost (d) produce rapid findings (e) strengthen existing national capacities for monitoring and (f) ensure internationally comparable results. (UNICEF, 1994, 1995)

As can be seen in Graph 1 in the Appendix, MICS have been implemented in several regions and have managed to provide crucial information in a timely fashion, thus facilitating the monitoring process and yielding parallel data between countries.

\subsection{LAC- Household Surveys}

In Latin America and the Caribbean, indicators were developed to confront the complex socio economic trends that characterized the last two decades. However, special attention was paid to monetary indicators at the expense of sociodemographic information. Furthermore, adjustment policies and restrictive measures affected the public sector and reduced the design and development of information systems. Nowadays, social information in the Region ranges from the complex and reliable to the primitive and questionable, and thus is characterized by a great heterogeneity in terms of its complexity, availability and quality. This issue will be further discussed in the last section of this paper.

There are two main, complementary approaches in the region to the use of household surveys for monitoring goals for children. The first approach is based on the incorporation of additional modules on specific topics and this has become a common practice in the region. Several countries, such as Argentina, have undertaken this experiment, including several questions on infant mortality, breastfeeding and other issues in the survey questionnaire, while others such as the English Caribbean islands and Brazil have incorporated MICs modules. 
The second approach consists of processing the regular information gathered by surveys and defining new categories or variables that enable the construction of indicators for the monitoring of some of the goals. One of the biggest advantages of this practice is the possibility of having access to periodic information at relatively low cost and using it to assess the situation of children, adolescents and women.

ECLAC and UNICEF have been unifying efforts in this field, and ECLAC's household data base provides the opportunity to obtain new indicators from the regular information incorporated in the household surveys. There are 12 countries included in this data base and the information is comparable between countries and through time. A great portion of the results of this exercise on data maneuvering is included in ECLAC's Social Panorama of Latin America (ECLAC 1993,1994,1995, 1996) and in a UNICEF and ECLAC publication, Equity in Accomplishing Goals for Children. (UNICEF -ECLAC 1996) These indicators provide a broader outlook on social problems, incorporate information on children, adolescents and women into the analysis of poverty and, at the same time, represent a valuable tool for the monitoring of child goals. Table 3 provides a description of the indicators developed and evidences their contribution to the analysis of poverty and to the process of monitoring the goals for children.

The applicability of these indicators was illustrated in a recent assessment of equity in Brazilian education. One of the goals pertaining to education required the use of the indicator "Proportion of repeaters" (see Table 3) to assess the progress made in reducing repetition rates.

TABLE 3

\begin{tabular}{|l|l|}
\hline EDUCATION & \\
\hline $\begin{array}{l}\text { 1. Educational Climate } \\
\text { (S Years of schooling of all persons aged } \\
15 \text { or more who live in the household)/(S } \\
\text { Persons of that age who live in the } \\
\text { household) }\end{array}$ & $\begin{array}{l}\text { A significant relationship has been } \\
\text { established between the educational } \\
\text { climate and children who are behind in } \\
\text { their studies and the number of years of } \\
\text { schooling completed. } \\
\text { This indicator is not useful in the direct } \\
\text { measurement of a goal but it is useful for } \\
\text { comprehending the global problem } \\
\text { (insufficient or lack of schooling) and } \\
\text { tackling some of its causes. }\end{array}$ \\
\hline $\begin{array}{l}\text { 2. Primary school completion } \\
\text { \% of children age 15 who have completed } \\
\text { at least } 6 \text { years of schooling }\end{array}$ & $\begin{array}{l}\text { Helps to measure progress on the goal } \\
\text { "An increase to more than 50\% by 1995 } \\
\text { in the proportion of boys and girls who } \\
\text { complete their primary education" }\end{array}$ \\
\hline & \begin{tabular}{l} 
\\
\hline
\end{tabular}
\end{tabular}




\begin{tabular}{|l|l|}
\hline $\begin{array}{l}\text { 3. Proportion of children behind in their } \\
\text { studies } \\
\text { (S Children 7-14 years old who are one or } \\
\text { more grades behind in their studies) / } \\
\text { (Total number of children 7-14 years old) }\end{array}$ & $\begin{array}{l}\text { Helps to measure progress on goals } \\
\text { related to repetition and drop out rates. }\end{array}$ \\
\hline $\begin{array}{l}\text { 4. Proportion of repeaters } \\
\% \text { of children 9-10 years old who attend } \\
\text { school and have not passed at least two } \\
\text { grades by that age. }\end{array}$ & $\begin{array}{l}\text { It measures progress on the goal "A 10 per } \\
\text { cent reduction in repetition in the first } \\
\text { two primary grades..." }\end{array}$ \\
\hline
\end{tabular}

\section{LABOUR}

5. Difference in years of schooling between working and non working youngsters 13-17 by poverty categories: indigents, non indigent poor and non poor.

S(Years of schooling of non working youngsters ; 13-17) - S(Years of schooling of working youngsters $;$

$\mathrm{i}=$ indigents, non indigent poor or non poor

6. Monthly earnings (in terms of the percapita poverty line) disaggregated by years of schooling.

7. Labour force participation of women by position in household.

$S$ (Females $i$ in the labour force) / (Total Females)

$\mathrm{i}=$ Female spouses, daughters or female heads of household

8. Labour force participation of spouses by years of schooling and number of children $<5$ years old.

\section{Hours worked by children 13-17}

(S Hours worked by children and adolescents 13-17 by gender in rural and urban areas) / (S Number of children and
It helps to analyze the relationship between poverty, child labour and education.

It evidences the correlation between low schooling and low future income.

This is an important aid in the analysis of gender equity. It shows the relationship between family hierarchies and labor force participation.

This indicator provides relevant information regarding the relationship between education, number of children per household and larger income (through the spouse's participation in the labour force).

This indicator provides an overview of the infant and adolescent labour panorama and informs on progress made on the goal to abolish activities that might interfere 


\begin{tabular}{|c|c|}
\hline $\begin{array}{l}\text { adolescents 13-17 who work in rural and } \\
\text { urban zones) }\end{array}$ & with children's schooling. \\
\hline $\begin{array}{l}\text { 10. Percentage of young people } 13-17 \\
\text { who neither work nor study } \\
\text { The indicator used is limited to young men } \\
\text { to avoid the statistical bias due to the fact } \\
\text { that females who do domestic work in their } \\
\text { households are not included in the } \\
\text { economically active population, which } \\
\text { would lead to an overestimation of the } \\
\text { phenomenon. }\end{array}$ & $\begin{array}{l}\text { This is an important indicator because in } \\
\text { the lower socioeconomic strata this group } \\
\text { is one of the "hard cores" of poverty and } \\
\text { includes those who will be involved to a } \\
\text { large extent in the vicious circle of the } \\
\text { reproduction of poverty in the short and } \\
\text { medium term. }\end{array}$ \\
\hline $\begin{array}{l}\text { 11. Monthly labour income capacity } \\
\text { equivalent of those who receive an } \\
\text { income and work more than } 20 \text { hours a } \\
\text { week } \\
\text { (Hourly Income* 176) / Per capita monthly } \\
\text { poverty line } \\
\text { This indicator standardizes the labour } \\
\text { remuneration per unit of time and } \\
\text { purchasing power by expressing the } \\
\text { income earned in a } 44 \text { hour working week } \\
\text { as a multiple of the value of the per capita } \\
\text { poverty line. Even though it cannot be } \\
\text { used to assess the well being derived from } \\
\text { each level of remuneration, it represents an } \\
\text { approximation to the socio economic value } \\
\text { implicit in the remuneration for each type } \\
\text { of employment. }\end{array}$ & $\begin{array}{l}\text { It is useful in demonstrating that } \\
\text { individuals with little education have very } \\
\text { small earning capacities, and that the gap } \\
\text { between this group and individuals with } \\
10 \text { or more years of schooling is } \\
\text { widening. In the area of policies, } \\
\text { programmes of technical capacitation and } \\
\text { other initiatives aimed at young people } \\
\text { without formal education are essential so } \\
\text { that they can increase their human capital. }\end{array}$ \\
\hline 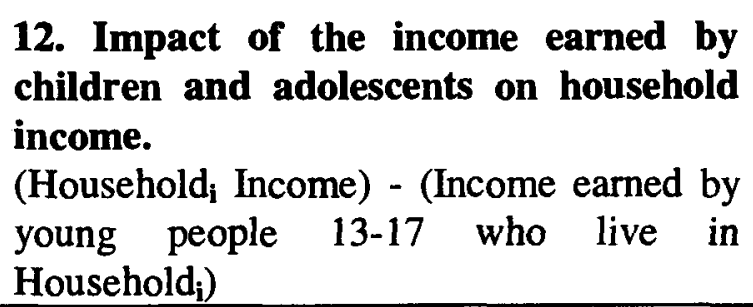 & $\begin{array}{l}\text { This indicator illustrates that child and } \\
\text { adolescent labour cannot be assessed } \\
\text { independently from poverty and } \\
\text { indigence. }\end{array}$ \\
\hline
\end{tabular}

Source: UNICEF, ECLAC 1996 Equity in Accomplishing Goals for Children UNICEF Regional Office for Latin America and the Caribbean ECLAC, 1993, 1994, 1995, 1996 Social Panorama of Latin America 
From Graph 2 and Table 4, it can be concluded that there is an improvement in the global situation, but inequity continues to be high and in the rural areas it is intensifying.

The distances between children in the different socioeconomic strata are extremely pronounced, particularly considering this is a calculated rate (i.e., falling behind in the first two primary grades). In urban zones of Brazil, 54 per cent of the children in the poorest quartile had fallen behind in school. This segment was less than 9 per cent in the wealthiest quartile (see Table 4).

The foregoing underscores the fact that inequity in school performance begins at very early age. At 9 or 10 years, one sees major differences in delayed schooling among children from homes in the different income brackets, whether due to late admission, repetition in the first or second grades, or both. This supports arguments in favor of establishing programmes and monitoring goals for these age groups, with an emphasis on the poorest strata.

\section{Poverty and Vulnerable groups}

\subsection{Capturing the new economic and social trends in the Region: a challenge for sources of information}

During the last years, most Latin American countries have witnessed a swift paced transformation of their economies that has triggered a profound reorganization of their social structures. Variations in the labor market, in social security coverage and in socioeconomic relationships in general, have made it necessary to complement the conventional classification of poor and non-poor with a more ample definition that manages to perceive the numerous emerging social groups. Economic and State reforms, privatization of basic services, impoverishment of the middle sectors, and the emergence of the "new poor", make up part of the present complex panorama in the region. The labor market has experienced a process of diversification that has resulted in greater disparity among and within its different branches and categories. Previously homogeneous categories have been divided into multiple smaller groups that differ greatly among themselves. Moreover, changes in the structure of social security coverage have further contributed to shifting old hierarchies and rearranging the portion of population that could be considered in need of social assistance. Therefore, not only the poor are the object of social policy, but among the poor and nonpoor, other classifications are needed to identify groups that are fundamental for the socioeconomic analysis and relevant in the realm of public policy.

The new social panorama in the region is characterized by a dynamic process where different groups converge. One approach at present being explored derives the definition of these groups from the concept of exclusion (Castel, 1995; Rosanvallon, 1995: Bustelo and Minujin, 1996). Exclusion is not a dichotomic concept that divides the population in two groups; there are a series of intermediate situations that blur the frontier between the included and excluded. The concept of exclusion constitutes an ample notion that applies to diverse spheres. 
In particular, one might highlight political, economic and social exclusion. Political exclusion is directly related to what can be called formal citizenship. Economic and social exclusion are related to participation in collective life and while the first one refers to employment and social protection, the latter is concerned with individual and collective interrelations in the context of what has been labeled social capital (Putnam, 1993).

When looking at the social panorama of LAC in the framework of social exclusion, three groups of people can be distinguished (See Graph 3).

The first group is made up mainly of middle and upper class individuals who are socially included, that is, they have a relatively high income and, at the same time they are supported by a stock of economic and social capital. The individuals in this group are also covered by social security and have a quality jobs. Another group is defined as vulnerable, and is formed of poor sectors that are striving for new mechanisms of inclusion and by middle sectors which have become impoverished and have lost inclusion channels. They have low quality of social coverage or no coverage at all and low quality or informal jobs. This situation of vulnerability has acquired considerable importance in recent years and now affects large portions of the population, posing a meaningful problem for the present and future of the region. Those included in this group try not to fall into an inferior situation and find that ascending to a better category is extremely difficult. The third group is composed of the excluded: individuals with extremely low incomes who are greatly at risk, suffering from educational and cultural barriers and with no social coverage who hold informal jobs or are unemployed. The excluded group is composed mainly of the structurally poor ${ }^{3}$, - those who have a lack of access to certain commodities and services- and also encompasses a portion of the pauperized or new poor ${ }^{4}$, and of those who suffer a series of disadvantages that very seriously limit not only their present living conditions but also their capabilities to participate in society (Sen 1992). The vulnerable group contains poor individuals who are searching for new channels of inclusion and recently impoverished population groups who have suffered an important social transition, while the included comprise all those whose needs are almost or totally satisfied and who possess a rather stable stock of social and economic capital.

These three categories, in particular the one formed by the vulnerable, undergo constant changes, expanding and contracting in accordance with the tendencies of the economy and the socioeconomic relationships. Even though the "exclusion zone" encompasses some structural poor and other pauperized or conjecturally poor, it does not necessarily coincide with the poor defined as those below the poverty line. Although the latter is a well-proven approach to measuring poverty, the increasing social heterogeneity, the presence of the "new

${ }^{3}$ The structural poor refers to those who have historically suffered from deprivation.

4 The "new poor" are mainly those impoverished during the 80 s crisis, middle class sectors and historically structural poor whose condition has deteriorated. For further analysis see (Beccaria and Minujin, 1991; Minujin and Vinocur, 1989) 
poor", and the decrease of the representativity of unions, among others, require the development of complementary measurements to analyze and tackle poverty.

To better illustrate the difference between identifying an individual as poor and examining his problems through this new approach, let us consider the case of an individual whose income exceeds the poverty line. He is employed in the industrial sector and is fully covered by social security. After a major restructuring of the industrial firm, he finds himself selling encyclopedias from door to door. Although his income has fallen, he still manages to earn above the poverty line, but he and his family no longer have social security and they are spending their economic capital and are suffering the deterioration of the social net. Under the traditional approach, this individual was not poor in the past and is not poor now, but from this perspective, he has suffered a transition and has gone from being included to being vulnerable. On the other hand, not all the people under the poverty line, that is to say, the poor people, can be considered excluded-In Colombia, $38 \%$ of salaried workers in the formal sector are below the poverty line, but in terms of social integration, it is clear that this category differs from those comprised by the "informals". The main difference between this approach and the traditional definition of poverty is that it goes beyond measurement and calculations and is fundamentally of a conceptual nature.

\subsection{Measuring exclusion and vulnerability through household surveys}

The measurement of exclusion and vulnerability through household surveys is a complicated task, given the limited ability that they have to perceive ongoing social transformations. Household surveys provide a relatively accurate snapshot of the situation at a given moment (stock indicators) but have difficulty in capturing relevant aspects of a dynamic process (flow or process indicators). In an effort to overcome this obstacle, we undertook an experiment using Venezuela's 1994 household survey with the objective of complementing the analysis of poverty through the incorporation of the previously explained groups: excluded, vulnerable and included.

Prior to the complete description of the experiment and with the objective of providing a solid conceptual background, let us look briefly at a summary of the methodologies usually used in LAC to measure poverty.

Two different approaches have been systematically used to assess poverty in the Region. The first one is referred to as the Basic Needs approach (BN) and takes into account the material facts that evidence a lack of access to commodities and services defined as necessary, such as housing, overcrowding, access to drinking water, sewage and electricity among others. This method requires the prior definition of a minimum standard for each need, and those households that do not meet one or more of the needs are catalogued as poor (Minujin, 1991).

The second approach is called the Poverty Line (PL) and presupposes a commodities basket which allows all basic needs to be satisfied. It takes into account the cultural 
consumption patterns of a given society at a certain time in history. Once the basic commodities basket has been assessed, its value becomes the poverty line. According to this criterion, households with incomes below the poverty line would be considered "poor".

Even though the assessment of poverty through both methods should depict similar situations, recent experiences in Latin American countries have revealed that its size and magnitude vary greatly according to the methodology used. It has been observed that the basic needs criterion perceives the structural poor, a group of individuals who have historically suffered from deprivation and whose physical living conditions (housing, sewage and drinking water, among others) are inadequate. These individuals have not had the possibility, throughout time, of gaining access to services considered essential, and structural changes must take place in their quality of life in order to reverse the situation. On the other side, the poverty line approach detects the pauperized or new poor. These are households who meet the basic structural needs but whose income is not enough to cover their basic consumption basket. As mentioned previously, this group has become especially important in the past fifteen years in LAC, since the crisis and consequent socio economic structure has greatly affected the population's income level (Minujin, 1991).

The simultaneous implementation of both methods is frequently undertaken with the objective of capturing both types of poverty and permits households to be catalogued in the following global manner:

Table 5

\begin{tabular}{|l|l|l|}
\hline & Income below PL & Income above PL \\
\hline With unmet BN* & Structural poor & Structural poor \\
\hline Without unmet BN & New Poor & Non poor \\
\hline
\end{tabular}

Source: Minujin, 1991

*A household with unmet basic needs is defined on the basis of the following factors: (i) poor-quality housing (defined by the type of dwelling and materials used for walls, roofs and floors); (ii)overcrowding (defined as more than three people per room, excluding bathrooms and kitchen) ; (iii)lack of access to drinking water and to a suitable sewage disposal system;(iv) presence in the household of children of school age who do not attend school; and (v) insufficient subsistence capacity (due to the low level of education of the head of household as the primary provider in a household with a high dependency ratio) (CEPAL, 1996). 


\subsection{Example using Venezuela's 1994 household survey}

\section{Methodology:}

The source for our experiment was Venezuela's 1994 household survey, which contained the socio economic information relevant for the statistical analysis that we undertook The survey had national coverage and contained questions pertaining to the household, the head of household and each of its members. We combined this data, including information related to the material aspects of the home, the education and labor characteristics of the head of household and of each of its members.

\section{Excluded group:}

As can be seen in Table 6, both methods to measure poverty were used simultaneously to compose the different population groups. The excluded group, as previously explained, is made up of individuals who historically have suffered from deprivation and who require structural changes to better their living conditions and quality of life in general. Aside from the households which possess certain characteristics that are captured through the NB and PL approaches, other families that suffer from further disadvantages are also included in the excluded group. More specifically, in addition to households with extremely inadequate living conditions and very low income, households that are headed by an individual without a permanent contract and with one or more of the following characteristics are also catalogued as excluded: (i)income below the poverty line and headed by women with young children (ii)income below the poverty line and headed by unemployed individuals; (c) less than an average of two years of education for every person older than 25 . As can be seen, this group is not only composed of households with low income or unmet basic needs, but also of those who suffer serious labor or education disadvantages and have accumulated a series of vulnerabilities throughout the years. In Venezuela, according to the results we obtained, $20.7 \%$ of the population is excluded.

\section{Vulnerable group:}

The vulnerable group is partly made up of households whose living conditions are somewhat deficient and whose per capita income is in some cases below the poverty line, but yet their global situation is better than those catalogued as excluded. In addition to these households, the vulnerable group also comprises those with certain characteristics that affect them in a negative manner. These refer to specific aspects related to the labor market and the educational background of the household, more specifically households with one or more of the following characteristics: (i) a per capita income inferior to $1.5 \mathrm{PL}$ and headed by an unemployed person; (ii) an underemployed head of household; (iii) a per capita income inferior to $1.25 \mathrm{PL}$ and headed by an individual who has completed high school education; (iv) a per capita income inferior to $1.5 \mathrm{PL}$ and headed by individuals who have pursued third level education; ( $v$ ) a head of household who is not employed under a fixed-term contract; 
(vi) a head of household with a contract with less than a three-month duration; (vii) a head of household who works only a few months a year when his or her services are required. According to this definition, $25.6 \%$ of Venezula's population is vulnerable.

Table 6

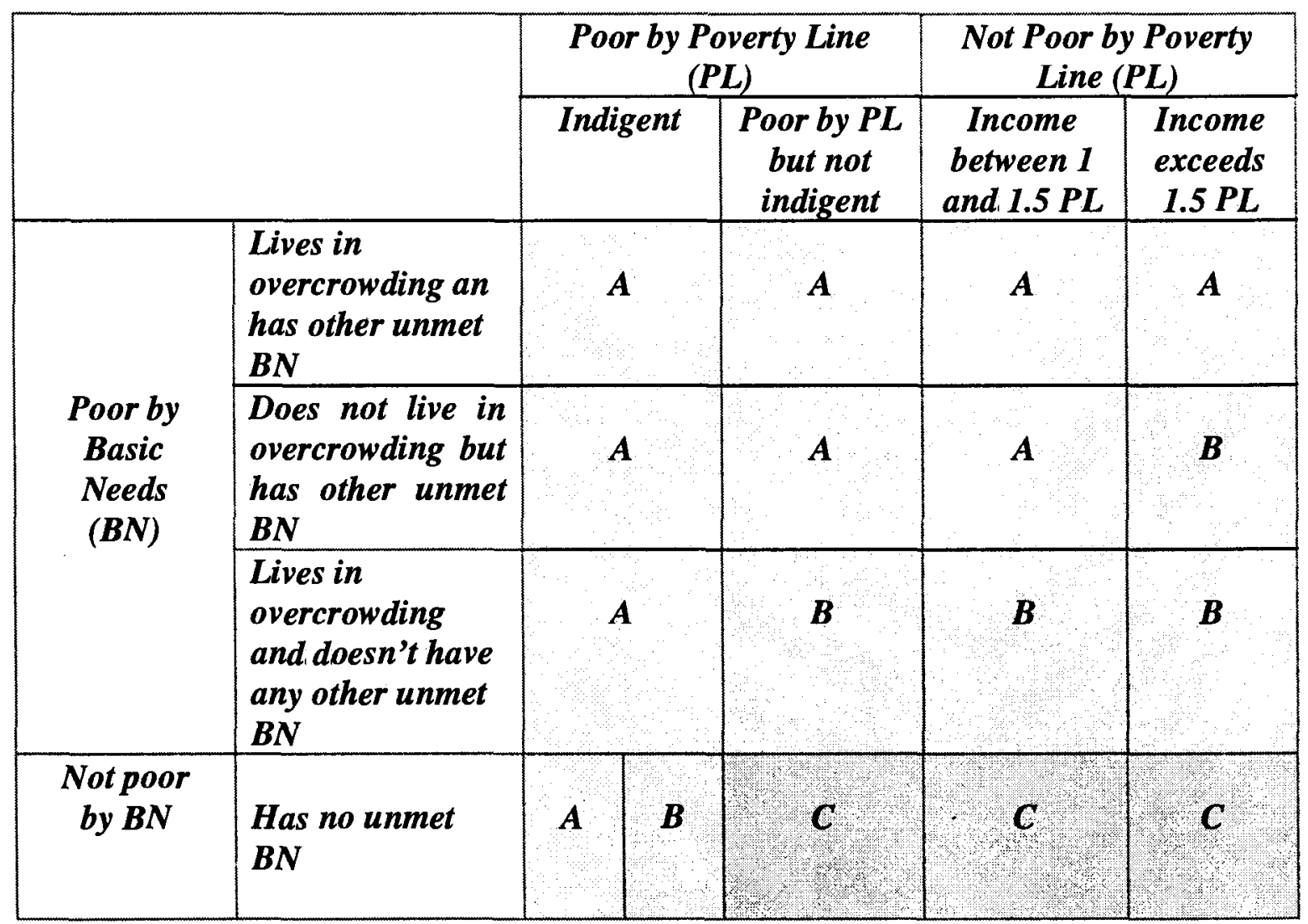






${ }^{1}$ The definition of BN used in this paper takes into account the physical condition of the home (construction materials and general conditions), access to water, sewage and electricity and overcrowding (defined as four or more people sleeping in a single room).

${ }^{2}$ The excluded group is composed of the households which in addition to satisfying the conditions described in the right part of the table, are not headed by an individual who works under a fixed term contract. In other words, if a household has one or more of the characteristics that would otherwise classify it as excluded but its head has a fixed term labor contract, the HH would not be included in this group.

${ }^{3}$ In addition to the households who satisfy the conditions described in the right part of the table, the Vulnerable group also includes those that would otherwise classify as excluded but that are headed by an individual who has a fixed term labor contract.

\section{Final Remarks}

Household surveys are a powerful and flexible source of information for the analysis of poverty. The periodic data allows the definition of variables and categories that prove to be valuable in the analysis of poverty and the social situation in general.

Some of the goals for children contained in the WSC can be monitored through household surveys, not only in a global manner but disaggregated by social groups and gender, thus facilitating the analysis of equity. 
The understanding of new economic and social structures and processes makes it necessary to capture situations like exclusion and vulnerability beyond the traditional analysis of poverty. Even though this is only partially possible with the information gathered by household surveys at present, the experience with Venezuela's data shows that in spite of the restrictions, important advances can be made in this direction. 


\section{BIBLIOGRAPHY}

Beccaria, Luis A. and Minujin, Alberto "Alternative Methods for Measuring the Evolution of Poverty" Proceedings of the 45th Session Invited papers, Bulletin of the ISI, Vol LI, Book 1, Amsterdam 1985

Boltvinik, Julio "Conceptos y mediciones de la pobreza predominantes en América Latina: Evaluación crítica" in America Latina: El reto de la pobreza, características, evolución y perspectivas PNUD Santafé de Bogotá, 1992

Bustelo, Eduardo and Minujin, Alberto, 1996 "La política social esquiva", in Espacios, Revista Centroamericana de Cultura Política, No. 8 July-Dec. 1996

Castel, Robert, 1995 Les métamorphoses de la question sociale.Une chronique du salariat, Fayard ed., Paris

Desai, Meghand "Methodological Problems in the Measurement of Poverty in Latin America" Document prepared for the Proyecto Regional para la Superación de la Pobreza, 1990

ECLAC (Economic Commission for Latin America and the Caribbean), 1993, 1994,1995,1996 Social Panorama of Latin America, LC/G 1768, September 1993 /1844, November 1994 / 1886, December 1995/ January 1997.

Himes, James R, 1995 Implementing the Convention on the Rights of the Child UNICEF, Martinus Nijhoff Publishers

Minujin, A. y Vinocur, P. "Quienes son los pobres?" en Las dimensiones sociales de la crisis. Economía de América Latina, N. 18/19, México, 1989

Minujin, Alberto, 1991 "New and Old Poverty in Argentina: the Consequences of the Crisis"in Bulletin of the International Statistical Insititute, Volume 1, Cairo.

Minujin, Alberto and Sanjurjo, Martha, 1993 "National Labor Force of Hosuehold Surveys as a Feasible Means of Monitoring Goals and Targets for Children in the $90 \mathrm{~s}$ : the Argentine Experience" in Bulletin of the International Statistical Insititute, Tome LV, Book 2, Firenze.

Minujin, Alberto, 1995 "Squeezed: the Middle Class in Latin America" in Environment and Urbanization, Vol. 7, No. 2.

Putnam, Robert, 1993 Making Democracy Work, Princeton University Press. 
Raczynski, D. 1994 "Políticas sociales y programas de combate a la pobreza en Chile: balance y desafíos", Colección Estudios CIEPLAN, No. 39, June

Rosanvallon, Pierre, 1995 La Nouvelle Question Sociale, Editiond du Seuil, Paris

Sáinz, Pedro, 1996 "Latin American Experience on the Production of Household Income Statistics and Integration with Administrative Data" presented at the Expert group on household income statistics in Canberra ECLAC, Santiago, Chile

Sen, Amartya, 1992 Inequality Reexamined, New York: Rusell Sage Foundation; Cambridge Mass: Harvard University Press

UNICEF, 1990 First Call for Children, UNICEF N.Y

UNICEF, 1994 "Encuestas de conglomerados de indicadores múltiples para las metas de mitad de década", CF/EXD/1994-011

UNICEF, 1995 Monitoreo del progreso hacia las metas de la Cumbre Mundial de la Niñez, un manual práctico para encuestas de Indicadores Múltiples

UNICEF, IDB, WB, FAO,UNFPA, ILO, PAHO/WO, UNDP,UNESCO,USAID, 1995 The Priority is Children: An Overview of Meetings Held Internationally and in the Americas.

UNICEF- ECLAC 1996, Equity in Accomplishing the Goals for Children UNICEFRegional Office for Latin America and the Caribbean

UNICEF, 1996 Third Ministerial Meeting on Children and Social Policy, UNICEFRegional Office for Latin America and the Caribbean 
Table 1

Number of goals for children, adolescents and women defined in each meeting

\begin{tabular}{|c|c|c|c|}
\hline $\begin{array}{l}\text { Nocith } 2 \\
\text { Nutition }\end{array}$ & $\begin{array}{l}\text { Wac } \\
\text { Mpe } \\
23\end{array}$ & $\begin{array}{c}\text { Noiniño } \\
\text { odsedifod a } \\
+1\end{array}$ & $\begin{array}{l}\text { Somiliago } \\
+20 \text { gocto } \\
+2\end{array}$ \\
\hline Educution & 4 & +2 & +5 \\
\hline Bights & 1 & +3 & +5 \\
\hline Women's & & & +7 \\
\hline $\begin{array}{l}\text { Follow } \\
\text { op and }\end{array}$ & & +1 & +5 \\
\hline
\end{tabular}

Source: UNICEF ( 1996) The Priority is Children

UNICEF, Regional Office for Latin America and the Caribbean

\section{Graph 1}

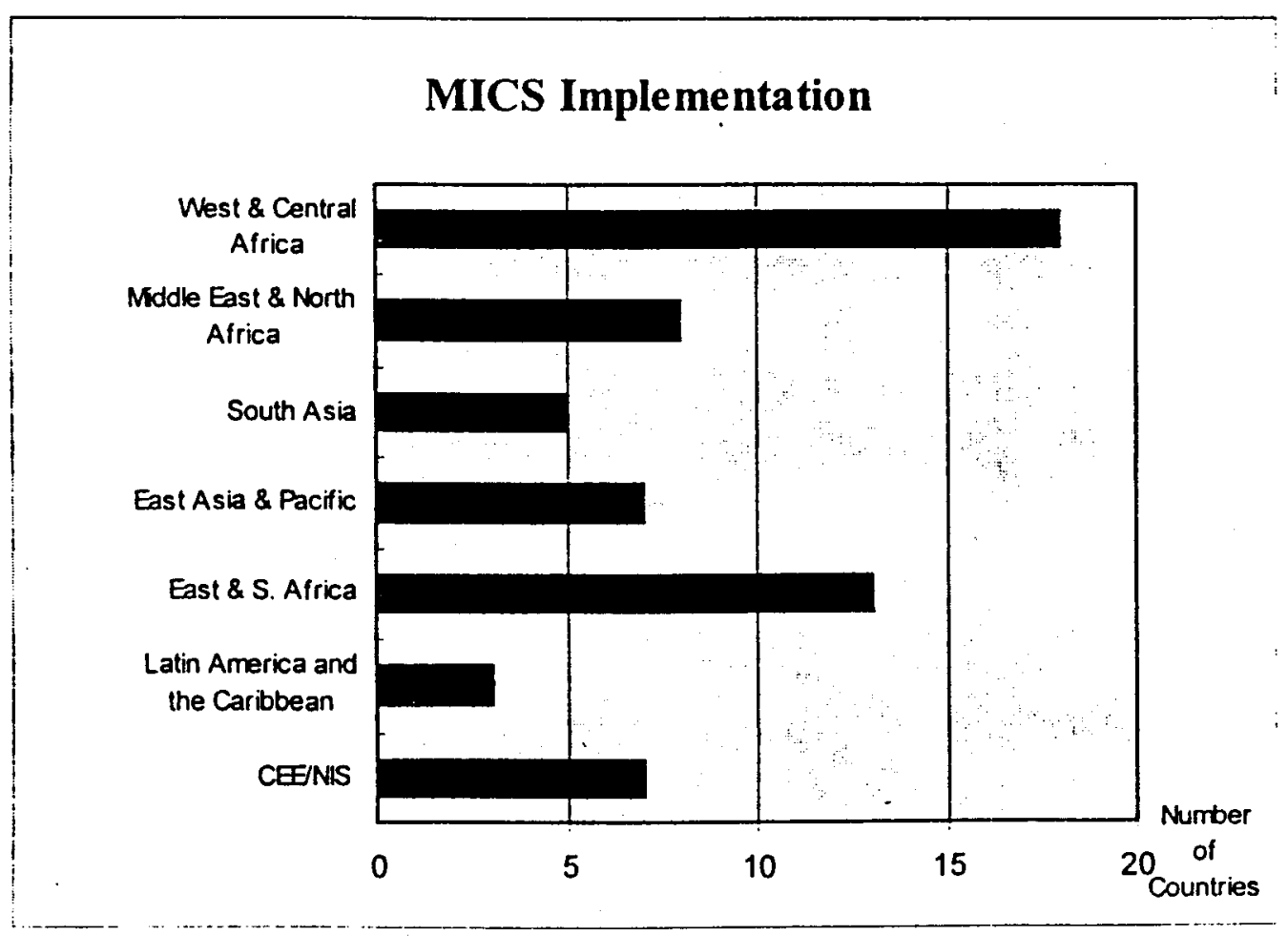

Source: UNICEF, Regional Office for Latin America and the Caribbean 


\section{GRAPH 2 \\ Brazil (Rural Zones)}

Percentage of boys and girls age 9 or 10 (depending on whether the age of primary school admission in the country is 6 or 7 years) who attend school and had not completed at least two grades by that age.

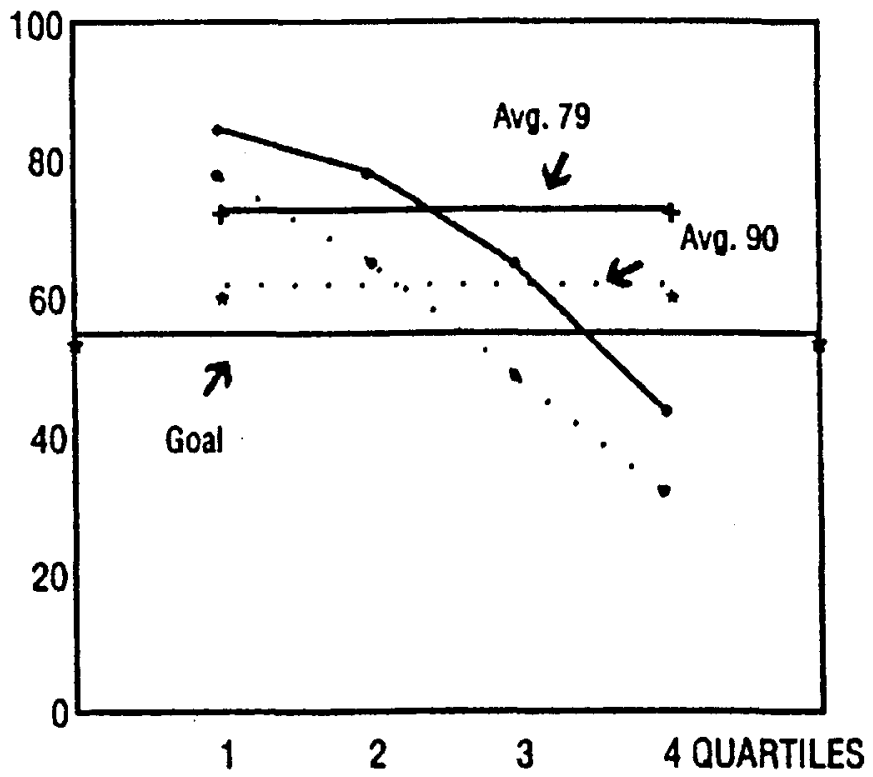

Brazil (Urban Zones)

Percentage of boys and girls age 9 or 10 (depending on whether the age of primary school admission in the country is 6 or 7 years) who attend school and had not completed at least two grades by that age.

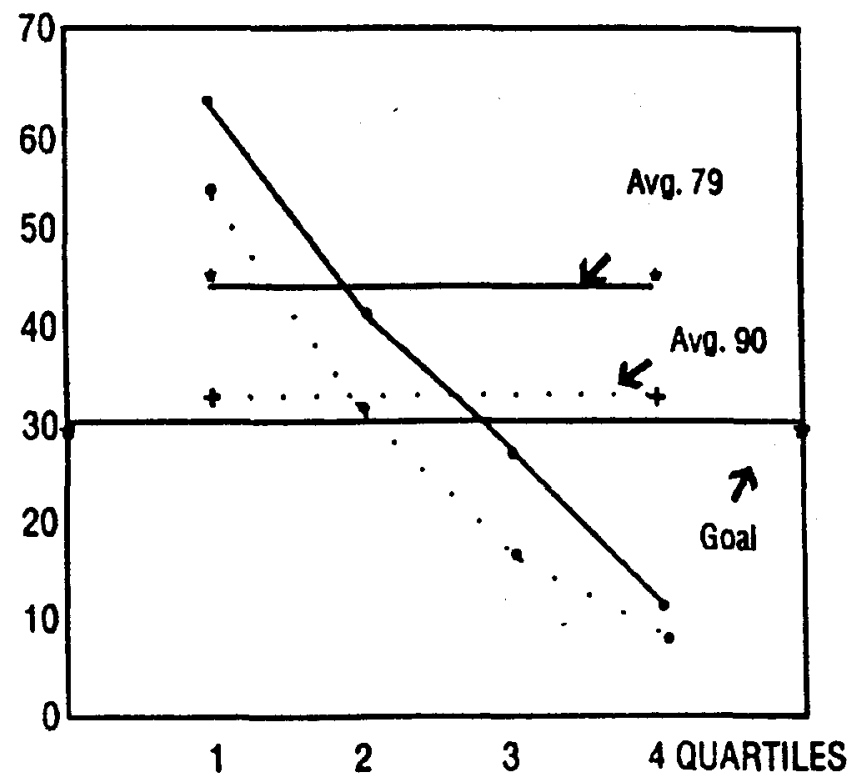

Source: UNICEF. ECLAC Equity in Accomplishing Goals for Children UNICEF Regional Office for Latin America and the 


\section{Graph 3}

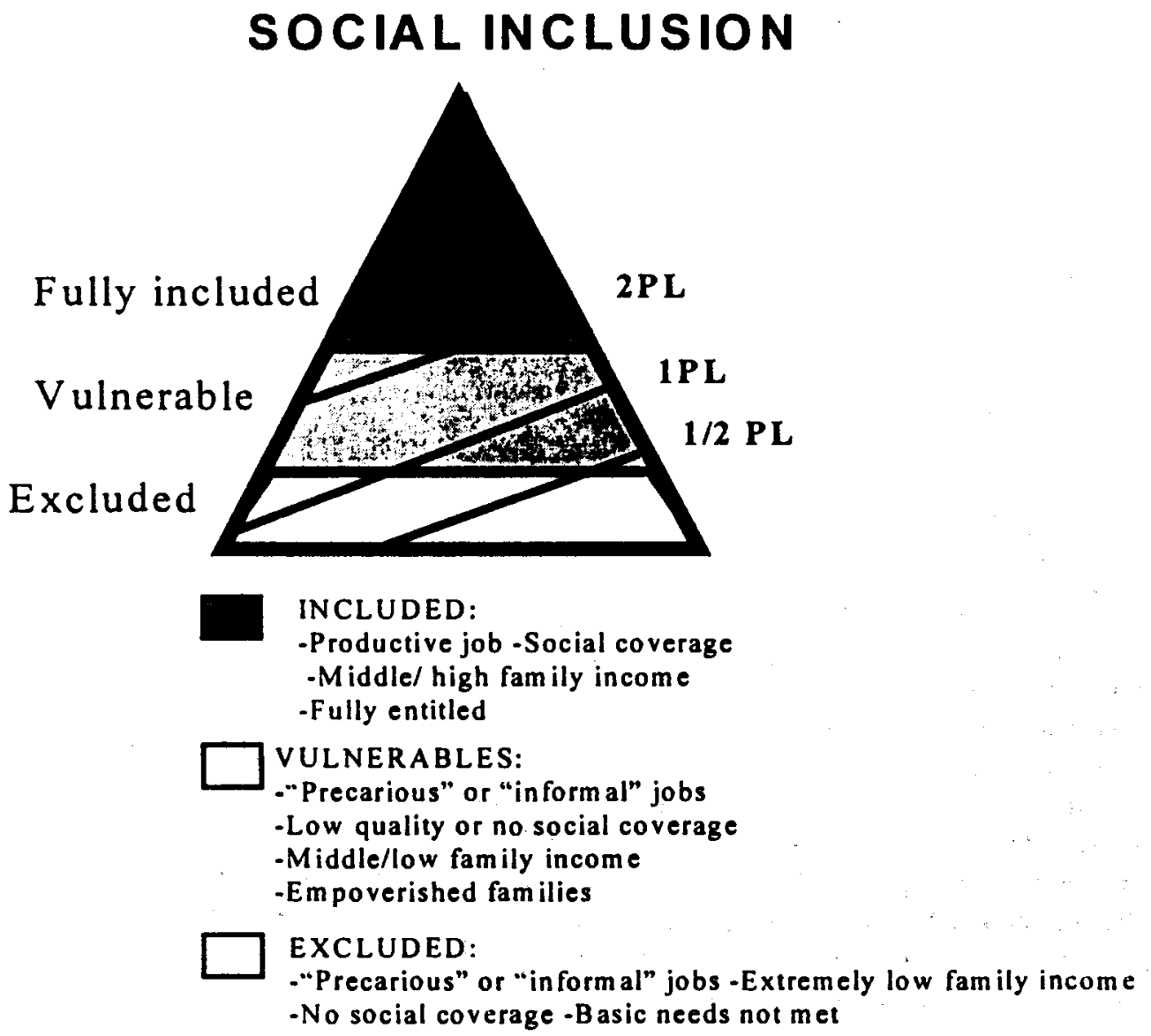




\section{Table 4}

Percentage of boys and girls age 9 or 10

(depending on whether the age of primary school admission in the country is 6 or 7 years) who attend school and had not passed at least two grades by that age.

(Urban Zones)

\begin{tabular}{|c|c|c|c|c|c|c|c|}
\hline & \multicolumn{2}{|c|}{ Total } & \multicolumn{4}{|c|}{ Income Quartiles } & \multirow{2}{*}{$\begin{array}{c}\text { Coefficient of } \\
\text { Inequity }\end{array}$} \\
\hline \multirow{2}{*}{$\begin{array}{l}\text { BRAZIL } \\
\text { Urban }\end{array}$} & & & $\begin{array}{c}1 \\
\text { (Q1) }\end{array}$ & $\begin{array}{c}2 \\
\left(Q_{2}\right)\end{array}$ & $\begin{array}{c}3 \\
\text { (Q3) }\end{array}$ & $\begin{array}{c}4 \\
(Q 4)\end{array}$ & \\
\hline & 1979 & 43.8 & 62.6 & 41.2 & 26.9 & 11.5 & 0.38 \\
\hline & 1990 & 32.9 & 53.8 & 31.2 & 17.1 & 8.2 & 0.32 \\
\hline \multirow[t]{3}{*}{ Rural } & & & 0 & 775 & 613 & A7 & ก 36 \\
\hline & 1979 & 11.0 & 83.8 & 11.0 & 04.3 & 42.4 & 0.36 \\
\hline & 1990 & 60.6 & 77.4 & 65.1 & 47.6 & 30.8 & 0.38 \\
\hline
\end{tabular}

Source: UNICEF, ECLAC Equity in Accomplishing Goals for Children UNICEF Regional Office for Latin America and the Caribbean

- An Inequity index based on the percentage of achievement in each quartile was defined to facilitate an analysis of equity in the accomplishment of the goals. The Inequity Index: (3(Q4-Q1)+2(Q4-Q2)+(Q4-Q3)) $/ 600$ In this formula, Q1, Q2, Q3 and Q4 correspond to the value of the indicator in each quartile. Q1 is the value of the first quartile (the poorest) and Q4 corresponds to the population living in households belonging to the fourth quartile (the wealthiest) The Coefficient of Inequity: 3(Q4-Q1)+2(Q4-Q2)+(Q4-Q3) 
Nutritional Status Indicators and Instruments for Measuring and Monitoring Poverty and Equity

\author{
by \\ Beverley Carlson \\ Social Development Division \\ Economic Commision for Latin America and the Caribbean
}




\section{Nutritional Status Indicators}

Nutritional status indicators measure the percentage of children in a population who are malnourished, and as such are proxy indicators of poverty. Food is only one element in malnutrition: for a child to grow well, he or she also needs a healthy environment, basic health services, well-informed parents, and good-quality child care. The nutritional level of a nation's children is therefore more than an indicator of child well-being. It is also one of the most important overall measures of poverty and national development efforts and one of the few "true"impact indicators of human development being a direct measure of the status of children. Nutritional status indicators are also very sensitive to short term changes in food intake and health conditions i.e. the early effects of poverty, as well as reflecting the long term effects of inter-generational poverty. Children are one of the most vulnerable population groups and they are among the first to show the effects of poverty.

Unlike mortality indicators, such as infant mortality and under-five mortality which are perhaps the best known human impact indicators, nutritional status indicators describe the situation of children still alive, thereby serving not only as a statistical measure of the magnitude and distribution of malnutrition and poverty, but also permitting the opportunity to intervene in individual cases, communities and schools with preventive and compensatory programmes.

Nutritional status is measured through the anthropometric assessment of protein energy malnutrition by indices constructed from the height, weight and age of children.

Three nutritional status indicators bounding the early childhood period are especially powerful markers of early childhood development and the impact of poverty at different stages of their growth and development.

- Low birth weight: the percentage of children born with a birth weight below 2500 grams. This indicator measures the nutritional status of children at birth, as a predictor of the child's likelihood to grow and develop, and as an indirect measure of the health and nutritional status of the mother of the child and, in aggregate terms, of pregnant women and mothers as a vulnerable group.

- Underweight children under five: the percentage of children moderately or severely malnourished, defined as having a weight-for-age which is more than two standard deviations below the median weight-for-age (using the international standard recognized by WHO). This indicator has become the recognized indicator for measuring and monitoring child malnutrition, globally, regionally and within nations. (In Latin America and the Caribbean and in some industrialized countries, obesity is often more significant than underweight, especially among children living in poverty. The same survey and census procedures are used and the prevalence of obesity can be calculated at the analysis stage, together with underweight malnutrition.)

- Stunting of primary school entrants: the percentage of children, moderately or severely stunted, defined by having a height-for-age which is more than two standard deviations 
below the median height-for-age (using the international standard recognized by WHO). This indicator, taken at the end of the early period of growth and development (pre-primary school) is a cumulative indicator of the overall nutritional and health status of the child at the beginning of its school-going years. The prevalence of stunting in primary school entrants is used to target school assistance programmes, notably school feeding, and to identify poverty pockets and map their distribution.

\section{Measuring Nutritional Status in National Household Surveys}

Estimating national and global malnutrition requires nationally representative household surveys. These are stand-alone national nutrition or health surveys e.g. the Health and Nutrition Examination Survey in the USA (HANES); the Demographic and Health Surveys (DHS) being carried out in many developing countries or, particularly important from the poverty assessment standpoint, nutritional status survey modules that are linked to ongoing national household survey programmes, usually nationally representative surveys of household income, consumption and expenditure. These surveys are eminently "do-able" although not enough countries are measuring nutrition frequently enough. The methodology has been tested and proved feasible, even in very poor countries, as part of national household survey programmes managed by local authorities and with local resources, even in the poorest countries. This is important because these are the countries that ususally have the severest nutritional and poverty problems.

The United Nations, with the cooperation of WHO and member governments, developed technical guidelines on Assessing Nutrition in Young Children and How to Weigh and Measure Children for carrying out national survey modules of nutritional status as part of national household survey programmes. More recently UNICEF, together with BBC Television OpenUniversity Production Centre, produced a video training programme entitled "Figuring the Problem: Surveying Nutritional Status". This package uses the Bangladesh experience as the working example.

\section{Nutrition Survey Modules}

The best source of nutritional status or surveillance data, especially within the context of poverty assessment, is as part of continuous national household sample survey programmes carried out by national statistical offices within the framework of national official statistics. Why is this so?

The arguments in the past against sample surveys were that they were ad hoc and therefore expensive, that they could provide an estimate for only one point in time during the year, that data would be collected only once every three to five years, and that surveys undertaken or supported by outside groups such as the DHS were suitable for getting data for the use of mutlilateral or bilateral development agencies but were not surveys in which the countries themselves felt they had a vested interest. It was also argued that "lay" interviewers 
employed by national household survey programmes were not suitable measurers of young children because of the reluctance of mothers to entrust their children to them and because of their lack of familiarity with the techiques of measurement. A further criticism was the slow speed at which data from these surveys were processed and analyzed.

Virtually all of these drawbacks have been reduced over the last decade due to a variety of circumstances. Ad hoc surveys can be expensive but adding anthropometry to an existing programme through piggy-backing means a marginal additional cost usually involving only the cost of the equipment, training, and possibly some initial technical assistance. The growth of national household survey capabilities in developing countries has increased with the increasing understanding of the importance of household surveys for measuring poverty and other key development issues. In addition, major internationally supported household survey programmes including the DHS and the Living Standards Measurement Survey are measuring nutritional status.

It has been recognized that lay personnel can weigh and measure children perfectly well if trained properly. This was made easier with the availability of How to Weigh and Measure Children and through joint cooperation of the National Statistical Offices (NSO's) and the Ministries of Health in the planning, organization and enumerator training programmes of the survey. The very important benefit of piggy-backing anthropometry onto household surveys programmes is that generally NSO's have better established sampling capabilities and use sampling clusters which are usually more representative of the country than is the case in other potential sources of data.

For example, the operational problems of applying sampling principles in clinics is not at all easy. For many years, the internationally accepted estimate for malnutrition among India's children was $63 \%$. New estimates put the figure at $53 \%$. Unfortunately, while malnutrition might be thought to have dropped $10 \%$ this is not in fact the case. The older figure was based on estimates made by the National Institute of Nutrition in Hyderabad and was based on sample surveys in only eight states, limited to rural areas and mostly in South India. The new estimate of $53 \%$ comes from the recent National Family Health Survey which collected detailed information from 25 states and was designed to be representative of $99 \%$ of India's young child population.

Many countries have now developed continuous or permanent household survey programs where data for one survey or another are being collected continuously from a fairly large sample of households. Anthropometric measurements are already being collected periodically in a number of these programmes. If it were judged that continuous data were needed and this was accorded a national priority in the overall plan of work then measuring the prevalence of malnutrition and the effects of poverty, as well as its links with causal factors in the household, could be made a regular feature of national household surveys, providing quarterly estimates of the prevalence and distribution of malnutrition.

This is what Bangladesh did by adding a nutritional module to its Household Expenditure Survey (HES), in which the Bangladesh Bureau of Statistics collects information on 
household income, expenditure, consumption and other economic, demographic and social variables. A Child Nutritional Status Survey was initiated in 1985-86. This survey followed the same sample covered by the HES. Again in 1989-90 the Child Nutrition Survey was done covering almost fifty half of the HES sample. Since nutritional status data were collected from the same households as the HES, descriptions of nutritional status by HES classifications were possible. Income and expenditure variables were analyzed in relation to nutritional status in the survey report. Trends were analyzed and the surveys were timed in such a way as to coincide with the medium term development plan, as a means of evaluation.

An especially important quality of piggy-backing a small nutritional status module onto a continuous survey is the potential to analyze these data with a wide panorama of policy relevant information, including the determinates and correlates of poverty, ranging from household food consumption, expenditure, income, labour force participation, to the use of health services, health status and mortality as in the Bangladesh Botswana, Kenya, Morocco, Nigeria, Peru, and Zimbabwe, household survey programmes.

\section{School Height Censuses: Where are the Neediest Children?}

In everyday life people use body weight to monitor their state of health. In newborns and young children weight gain is one of the principal indicators of healthy development and lack of it signals a problem needing correction. The height of growing children is often measured regularly by families and in communities, but the meaning and interpretation of growth has traditionally been the responsibility of the medical profession with poor growth being associated with poor health but not necessarily with poverty or social issues.

The height of first grade schoolchildren summarizes their health and nutrition histories from birth and reflects the environment in which they grew up. The first grade height census, sometimes complemented by other information also provided by the school, is a unique and inexpensive national instrument for locating geographically the areas of greatest poverty in the country where the neediest children and their families live. This is done through determining the prevalence or percentage of children entering primary school who are "stunted"or have low height for their age. The census can be carried out annually and produce results within a few months, as Chile does. The small size of the units (schools) in the school system and their large number and good coverage (primary schools are found in virtually all communities) makes it possible to identify vulnerable areas in districts, municipalities, or neighborhoods, both in urban and rural areas. The cost of such a census is no more than 10 cents per first grade schoolchild in the most expensive cases, and considerably lower when it becomes a routine task in the education system.

Consequently, the height census of children entering the first grade can be recommended as an excellent and inexpensive tool for detecting different levels of social risk, for making a more equitable allocation of the resources of social programmes, giving more to those who need more, and for evaluating the impact of these measures over time. 


\section{How are Countries Using School Height Censuses?}

1. Detection of social differences and use in programs. The height census provides results for every school in the country. Thus the school becomes a watchpost from which to observe the needs of children within the school, as well as the social conditions which surround it in the community and in the household.

2. Identification of priority areas. The different levels of risk within a country or a region can be drawn on a map by combining the data for schools in the same municipal area, district, province, region and state, up to the national level.

3. Equitable allocation of resources. Once the differences have been identified, resources can be allocated in such a way as to ensure that those with the greatest need receive more, as for example in allocating resources from school feeding programs.

4. Impact evaluation. The registration and systematic collection of information on the height of children entering the first grade makes it possible to construct time series and evaluate trends. The development plans in an area or sector should be reflected in the evolution of these indicators. Anthropometric data from school censuses and school samples, and combined with household surveys of school-going children, are powerful tools for social programme evaluation as, for example, in ECLAC's current evaluation of the National School Feeding Programme of Uruguay.

\section{Country Experience in School Height Censuses}

The first experience with height censuses of children entering the first grade was in Central America where this work was developed by the Institute for Nutrition for Central America and Panama and with financial and technical support from the US National Academy of Sciences. It was through this work that the scientific basis for the school census was first established. Costa Rica was the first country to use the instrument in 1979 and all Central American countries in the region have taken one or more censuses which have been used for the allocation of social funds. A number of other Latin American countries have taken a school height census, including Argentina, Chile, Ecuador, Peru, and Uruguay, as well as other countries e.g. the Philippines and Kenya. 


\section{Bibliography}

Bangladesh Bureau of Statistics (1991), Report of the Child Nutritional Status Survey, 19891990, Bangladesh Bureau of Statistics, Dhaka, April.

Carlson, B. A. (1987), "Core Indicators for the Interagency Food and Nutrition Surveillance Programme (FNS)", UNICEF, New York, October.

(1989), "An Index of Child Development - Nutritional Status", Internal Memorandum to Mr. James P Grant, Executive Director, 16 January 1989.

(1990), Nutritional Surveillance in the 1990s, World Summit Issue, UNICEF Intercom, UNICEF, New York, July.

Carlson, B.A., Wardlaw, T. M., (1990), A Global Regional and Country Assessment of Child Malnutrition, Staff Working Paper Number 7, UNICEF, New York, January (forthcoming).

ECLAC (Economic Commission for Latin America and the Caribbean) (1997), "Dónde Están los más Necesitados", Seria Política Social, Santiago, Chile.

Gopalan C. (1987) Heights of Populations: An Index of their Nutrition and Socio-economic Development, NFI Bulletin $\underline{8}$ (3), New Delhi.

Grosh, M.E., Munoz, J. (1996), A Manual for Planning and Implementing the Living Standards Measurement Study Survey, LSMS Working Paper Number 126, The World Bank, Washington, D.C.

IRD/Macro Systems, Inc. (1991), Proceedings of the Demographic and Health Surveys World Conference, Washington, D.C., 3 vols. Columbia, Maryland.

República de Peru (1994), I Censo Nacional de Talla en Escolares, 1993, Ministerio de Educación, PROPACEB, Lima.

UNDP (United Nations Development Programme) (1996), Human Development Report 1996, New York, Oxford Univerity Press.

UNICEF (United Nations Children's Fund) (1992), Figuring the Problem: Surveying Nutritional Status, Video programme distributed to UNICEF offices and governments worldwide. Available through: William Hetzer, Chief, Radio/Television/Film Section, UNICEF, New York. (1996), The Progress of Nations, UNICEF, New York. 
(1996), State of the World's Children, 1996, Oxford, Oxford University Press.

United Nations (1986) Sampling Frames and Sampling Designs for Integrated Household Survey Programmes, U.N. Statistical Office, NHSCP, New York.

(1988), How to Weigh and Measure Children: Assessing the nutritional status of young children through household surveys, National Household Survey Capability Programme, (DP/UN/INT-81-041/6E), New York.

(1990), Assessing the Nutrition Status of Young Children, National Household Survey Capability Programme, (DP/UN/LNT-88-X01/8E), New York.

Valverde, V. et al. (1986), Use and Constraints of Schoolchildren's Height Data for Planning Purposes, Food and Nutrition Bulletin, U.N. University $\underline{8}$ (3).

Waterlow, J.C. (1972) Classification and Definition of Protein-calorie Malnutrition, British Medical Journal, $\underline{3}$ 566-569, 1972

Waterlow, J. C. (1992), Protein Energy Malnutrition, Edward Arnold, London.

WHO (World Health Organization) (1996), The World Health Report, 1996, Fighting Disease, Fostering Development, Geneva.

World Bank (1993), Investing in Health. World Development Report, 1993, Washington, D.C.

(1996), From Centralized Planning to the Market Economy, World Development Report, Washington, D.C.

(1996), The World Bank Atlas, 1996, The World Bank, Washington D.C. 


\section{A BRIEF OVERVIEW OF UNFPA EXPERIENCE IN LATIN AMERICA AND THE CARIBBEAN IN POVERTY STATISTICS AND MEASUREMENT}

by

José Miguel Guzmán

UNFPA Office for Latin America and the Caribbean 


\section{A Brief Overview of UNFPA Experience in Latin America and the Caribbean in Poverty Statistics and Measurement}

\section{Poverty issues in UNFPA Agenda}

The Cairo Conference points out that " widespread poverty remains the major challenge to development efforts. Poverty is often accompanied by unemployment, malnutrition, illiteracy, low status of women, exposure to environmental risks and limited access to social and health services, including reproductive health services...Poverty is also closely related to inappropriate spatial distribution of population, to unsustainable use and inequitable distribution of such natural resources as land and water, and to serious environmental degradation" (Chapter III, paragraph 3.13, United Nations, 1994) ${ }^{1 .}$

Taking this into account, it has been stated that achieving poverty eradication is one of the main objectives that Governments should develop through appropriate population and development policies and programmes as a way to raise the quality of life for all people. It also considers that special attention should to be given to women, because they are generally the "poor of the poor" and because they also are "keys actors in the development process". For that reason, it is established that "...eliminating social, cultural, political and economic discrimination against women is a prerequisite of eradicating poverty...". (Paragraph 3.16, Chapter 3, United Nations, 1994).

UNFPA considers poverty issues as crucial in all its actions in the population field because it is considered that programmes that attack poverty, help poor people to have a greater control of different aspects of their lives, including sexual and reproductive health. Poverty considerations ${ }^{2}$ are included when dealing with reproductive health (unmet need for information, and services), women empowerment (elimination of discrimination against women), population and development issues, including environment (investments in the human resource development of the poor). UNFPA support in this field has also been given by direct technical assistance through the staff of the Country Support Team for Latin America and the Caribbean (UNFPA-CST-LAC).

Poverty measurement and analysis are considered by UNFPA of utmost importance: a) to identify social groups in order to focus policies and actions in the main areas covered by UNFPA; b) to monitor poverty trends as a main indicator in the Post-Cairo Agenda; c) to disentangle the complex effect of population dynamics as a crucial factor in the intergenerational transfer of poverty; and d) to provide poverty indicators that can be used in advocacy activities as a way to create awareness among politicians and decision-makers, on the need to implement social policies directed to disadvantaged groups of population.

\footnotetext{
1 United Nations (1994). Report of the International Conference on Population and Development. Cairo, 5 13 September 1994. A/CONF/171/13, Cairo, Egypt.

${ }^{2}$ See: Draft Guidance Note on Populatyion and Poverty Alleviation. UNFPA, New York, 1997 (draft).
} 


\section{EXPERIENCES OF UNFPA IN LATIN AMERICA AND THE CARIBBEAN}

In the following paragraphs some recent UNFPA supported projects in the region related with poverty issues are mentioned. This is not an exhaustive review of the UNFPA projects in the region; only some recent examples are considered.

Contribution to the identification of disadvantaged social groups in order to focus population and other social policies

UNFPA has supported several projects in the region related to the definition of disadvantaged people, using census and survey data. The objective in these cases has been to assist countries in the establishment of a factual database to help them in the process of focusing social policies. In most cases, support has been given to the preparation of poverty maps and indicators not only at the national levels but also at the local levels using census data (i.e. Peru, Paraguay, Bolivia, Honduras) ${ }^{3}$. In those cases, the methodology used to measure poverty has been that of Unmet Basic Needs (UBN). In Peru, UNFPA has collaborated with the National Statistical Office (INE) in the process of definition of these indicators for the 1992 Population and Housing Census. In the case of Honduras, the use of census has been complemented with new information coming from household surveys using the Poverty Income Line methodology ${ }^{4}$.

UNFPA has also given support to other activities such as workshops, training courses and seminars. These are related to the development of statistical data systems including poverty and other social indicators. This is the case of the Workshop on Techniques for Analysis of Census Data for Population and Development Planning, conducted in Cayman Islands and the Workshop conducted in St. Kitts and Nevis "Improving the Data Supply Modality of the Caribbean" . These two activities were conducted in 1996 with ECLAC participation. In both cases, the focus has been put on the need of updated and good quality basic indicators, including poverty statistics.

\section{Support to specific research on poverty issues}

In Peru , UNFPA has given financial and technical support to a specific study related to poverty problems ${ }^{6}$ using census data and UBN methodology. Poverty indicators have been

${ }^{3}$ See: INEI (1994). Mapa de Necesidades Básicas Insatisfechas de los Hogares a Nivel Distrital .Tomo I. INEI, UNFPA, Lima, Agosto de 1994.

${ }^{4}$ Secrataría de Planificación, Coordinación y Presupuesto (1990). Documentos sobre Población, Pobreza y Empleo. Proyecto SECPLAN/OIT/FNUAP-HON/87/P02. Políticas de Población y Empleo. Tegucigalpa, Honduras.

${ }^{5}$ ECLAC, CDCC, UNIC (1996). FOCUS .UN in the Caribbean. The Newsleter of the United Nations System in the Caribbean, Port Spain, 1996.

6 INEI (1995). Dimensiones y Características de la pobreza en el Peru, 1993. INEI, UNFPA. Lima, Perú, Julio 1995 (prepared by Julián Antezana). 
calculated and related to other population variables such as household size, nuptiality, infant mortality, etc. This has helped to show the very important disparities in each of these variables, between poor and non-poor families, stressing the need of specific policies to reduce these demographic differentials.

In Jamaica, the UNFPA CST has participated (May-June 1995) in an International Agency Mission, organized by the UNDP, to assist the Government of Jamaica in the formulation of a Poverty Eradication Strategy. A document has been elaborated underlying the relationship between poverty and population dynamics in Jamaica ${ }^{7}$. Emphasis has been given to the strategic area of UNFPA support to contribute to reduce the gap of poor and non-poor regarding areas such as reproductive health and family planning, family life education and adolescents. A new version of this document for all the Caribbean Countries has been prepared as background document of the Caribbean Ministerial Meeting on Eradication of Poverty $^{8}$.

In El Salvador, the UNFPA CST has collaborated with FUSADES in the elaboration of a project which one of its main objectives is a diagnosis of the relationship between demographic dynamic, poverty conditions and environment .

\section{Women empowerment and poverty}

UNFPA has supported regional and national projects related this subject. At the national level, an important support has been given to the strengthening of the national capacities in formulation and management of gender, population and poverty projects. This has been the case of a project in Panama to support the Ministry of Planning and Economic Policy (PAN/93/P02). One of the components of this project has been the preparation of a document on the relationships of gender, population and poverty. At the regional level, UNFPA has given support to ECLAC for a research on gender, poverty and women participation, which has been include in the ECLAC Social Panorama, $1995^{\circ}$. This research showed the very important role played by women participation in the possibilities of poverty alleviation in Latin America countries.

Indigenous population and other marginalized groups.

An important area of action and research has been directed to some specific social groups considered as targets for intervention: poor rural areas, urban slums and squatter settlements

7 González, G. (1995) . Poverty and Population Dynamics in Jamaica. Inputs for a Poverty Eradication Strategy. UNFPA CST, Santiago, Chile (Draft).

${ }^{8}$ González, G. (1996) . Population Dynamics and Poverty in the Caribbean: Issues and Policy Implications. UNFPA CST, Santiago, Chile (Draft).

9 ECLAC (1995). Social Panorama of Latin America, 1995. Santiago, Chile. 
and, particularly, indigenous groups (i.e. research in popular sectors in Paraguay ${ }^{10}$; research and services projects on indigenous population in countries such as Bolivia, Panama, Guatemala and Ecuador). In most cases, the support has been given to reproductive health projects, but it has also included other components such as gender issues and population and development aspects.

\section{SOME SUGGESTIONS REGARDING POVERTY MEASUREMENT AND ANALYSIS}

With ECLAC's technical orientation, the Latin America region has profited with the existence of an important agreement regarding definition of poverty indicators. In fact, as mentioned above, UNFPA support in the region has been more oriented to the use of poverty indicators than to its development.

Taking into account the UNFPA CST experience in the region, we would like to propose the following issues for discussion:

1) How to incorporate the socio-cultural aspects of poverty

With the exclusion of rural-urban division, poverty indicators are usually obtained by using the same definitions for the whole of the country, which has the hypothesis that societies are homogeneous from a socio-cultural point of view. However, this is not the case. The variable used to calculate poverty indicators may have a different meaning for different socio-cultural settings.

2) How to deal with the competing needs of having a global set of indicators for comparison purposes and the need to take into account the socio-cultural diversity of different settings

This is related with the first question and becomes more important if we consider that policies designed to eradicate poverty must consider the social and cultural characteristics of different groups of population.

3) How to ameliorate poverty indicators using limited information. In this same way, what to do in order to increase quality of information

In most cases, poverty indicators are derived from census data. The advantage of using this kind of data is that it is possible to know the incidence of poverty for all the administrative division. But it has two drawbacks: 1) census are taken every 10 years (sometimes more than that) and, 2) questions only allow to measure UBN indicators. On the other hand, household surveys, are more oriented to the measurement of poverty, but they do not allow to measure poverty for small administrative units (and in most cases

\footnotetext{
10 See Román, M.L. (1996). Tengo que Luchar: Mujeres jefas de hogar en ocupaciones urbanas. Facultad de Ciencias Económicas, Universidad Nacional de Asunción y Fondo de Poblacion de las Naciones Unidas. Asunción, Paraguay.
} 
they do not include questions on demographic and health issues). Thus, two issues seem of great importance in this regard: the actual possibilities to obtain poverty indicators for small areas and the quality of data to be used.

4) What else is needed regarding poverty statistics.

The need of specific research regarding poverty issues seems crucial in this moment. Poverty analysis should help to clarify some relationships such as the way generational transfer of poverty occurs, the linkages between poverty and gender discrimination, the way to incorporate deprivation components (not only economic, housing or educational deficits) in new indicators of poverty

Another issue is how poverty is experienced in different social groups. The worst effects of poverty are probably greater in cases where the level of social organization and social coherence and solidarity are less extended and where the social or ethnic discrimination still prevails.

These items do not cover the whole field of poverty statistics improvements, but at least they show some areas in which new efforts must be made in the near future. 


\section{POVERTY STATISTICS: Implications for linkages} between health policy and to reduce poverty

by

PAHO 


\section{Poverty Statistics: Implications for linkages between health policy and to reduce poverty}

The Pan American Health Organization and the World Health Organization have increasingly placed emphasis on equity in health. PAHO has specifically identified in its 1996-1998 program, plans for empirically establishing the links between health and poverty reduction. Its biennial publication, The Health Conditions in the Americas cover the most complete range of epidemiological information on the region as well as interpretations of health reforms geared towards equity. The 1998 edition will draw upon the information contained in the Living Standards and poverty assessment surveys in an attempt to relate epidemiological and poverty trends. The main objective is to understand more clearly what management and financial options within the health reform agendas in the region can contribute toward the reduction of poverty'.

In addition to income expenditure, health indicators form the core of direct human measures of poverty e.g. nutritional status. The World Bank has identified a wider range of health indicators ${ }^{2}$. It includes weight for height (wasting), weight for age (underweight) and height for age (stunting) which is being recommended by UNECLAC as an anthropomorphic measure of nutritional status to be included in household and poverty assessment surveys.

It is becoming increasingly clear that health is a precondition of development, and that better health enhances economic well being, specially among the lowest income groups. A pioneering study by Behrman (1990) illustrates in his model of health in the household how poverty may affect inputs into human resource development and how the health output may affect productivity. The evidence presented in a recent study (WHO, 1996), aptly summarizes the situation as follows:

- Better health reduces production losses caused by workers' ill health

- Better health reverses the proportion of children who can enroll in school and the educatability of those children, thereby increasing human capital

- Better health frees resources previously spent on treating illness for other uses

- Better health increases national wealth by making available natural resources (such as cultivable land) that had previously been rendered inaccessible because of disease

\footnotetext{
${ }^{1}$ A current PAHO project Managing the process of health reform to reduce the Impact of Poverty in the Caribbean is being done in collaboration with the UNDP, CDB, CARICOM, IDB, CLAD, CARICAD and UNECLAC.

${ }^{2}$ Sonya Carvalho and Howard White Indicators for Monitoring Poverty Reduction. World Bank Discussion Papers \# 254, 1995.
} 
- Better health financing methods can affect a country's economic performance.

While poverty need not be equated with low health status, in reality it often is. Despite evidence that poverty has declined within the Region 1990-94 (UNECLAC 1996) there is a relatively large number of household with less income to maintain nutritional standards, less disposable income to pay out of pocket expenses for health care and less from which to make contributions to health insurance schemes. The poor are more reliant on public health facilities and have been the most affected by the on-going economic crisis. In some countries like Colombia and Jamaica, mainly due to the deterioration in quality, the poor spend a significant proportion of their income on private services. They also are least educated and live in periurban locations and are most susceptible to communicable diseases, the surge in STDs including HIV/AIDS, increasing violence and homicides among males, 14-35 years. Table 1 illustrates the trends between consumption and welfare measure showing the consistency between income inequality and poverty.

\section{POVERTY ASSESSMENT SURVEYS IN THE CARIBBEAN}

Table 2 shows estimates of poverty for Caribbean countries based on availability of information.

Under the sponsorship of the World Bank, LSMS have been done in the Caribbean Guyana (1993-94); Jamaica (1988-1995); Trinidad and Tobago (1994-95). Jamaica since 1990 has developed its own methodology called the Survey of Living Conditions. IDB has produced a Poverty and Income Distribution in Barbados 1996-1997, based on the results of the Poverty and Living Conditions Module (PLCM) of the Continuous Labor Force Sample Survey (CLFSS) done by the Statistical Services of Barbados.

Special attention is being drawn to the poverty assessments for Belize and the smaller countries of the OECS done by the Caribbean Development Bank. The process is provided in Figure 1 and the instrument includes:

(a) Macro-economic/socio/political influences

- resource flows

(b) Objective measures

- composition of the poverty line

- $\quad$ expenditure data

- community level situational analysis

(c) Subjective measures

- Focus group discussions 


\section{RESOURCE FLOWS TO HOUSEHOLDS}

Given the composition identified in Figure 2, these help to determine actual income possibilities for reducing or enhancing household status or for investing present resources into future capabilities e.g. education.

\section{THE POVERTY LINE}

It is developed on the basis of food and non-food requirements. The food requirements have been established on the basis of CFNI estimates for a family of four (man, woman and two children under 12 years with adult equivalents of 0.3 ). The average of this household of 4 provides a per capita expenditure on food which when multiplied by size of household determines the indigence line. The non-food assumptions added to the indigence line for various household sizes determine the poverty line by size of households.

\section{EXPENDITURE DATA}

Certain assumptions were made in developing the expenditure data for each household. One of the most debatable relates to housing. Rental accommodation represented a very small share of the accommodation used by households in the survey and there were problems in computing rent for owner occupied buildings. In the circumstances, housing costs used were mortgage payments, and 10 percent of any allocations to house repairs. Insurance premiums were included in expenditure, as well as house and land taxes. The household presumably exercises choice over the area and the kind of house in which to live. Income tax was excluded since the household has no control over the resources taken by the Government. Twenty percent $(20 \%)$ of the purchase price of household durables were admitted into current expenditure, the assumption being that refrigerators and the like have a useful life of about five years.

\section{COMMUNITY-LEVEL SITUATIONAL ANALYSIS}

The identification of the poorest communities is done by a combination of objective (quantitative) and subjective (qualitative) methods. The former made use of the latest Population and Housing Census data, based on housing characteristics, educational qualifications, household income, and environmental conditions, while the latter use of the evaluations of judges consisting of National Assessment Teams (NAT) members who were actively involved in the delivery of social services e.g. in health, education, community development, agriculture, and who were able to reinforce or confirm the objective selections from the census data as they exist across the Regions of the islands or Districts. 
The poverty indicators emerging are:

(a) Housing characteristics

Availability of amenities in the home

- Water supply - piped water in dwellings.

- $\quad$ Toilet facilities - in respect of sewer and septic tank

- $\quad$ Electricity

(b) Educational qualifications of persons ages 15 to 24 years

Status - low, moderate, low

(c) Household Income - from all sources

Status - low, moderate, low

(d) Environmental Conditions - Sanitation

Districts were ranked 1 to 12 from the lowest to the highest according to the selected indicators.

(e) Health

- $\quad$ Perception of access

- Main illness

- $\quad$ Financing

\section{FOCUS GROUP DISCUSSIONS}

The focus group discussions are carried out based on a topic list generated from the community household questionnaire administered to heads of households. They involve a cross-section of stakeholders: nurses, teachers, community workers, representatives of NGO's, the law enforcement services. They help to interpret inconsistencies in the quantitative data and provide a critical role in the formulation of policy e.g. targeting for safety-net programs.

\section{PAHO/WHO NEXT STEPS}

PAHO/WHO is desirous to participate in the refinement of instruments on poverty statistics to be able to make better decisions about the impact of health on poverty reduction. 


\section{THE PROCESS}

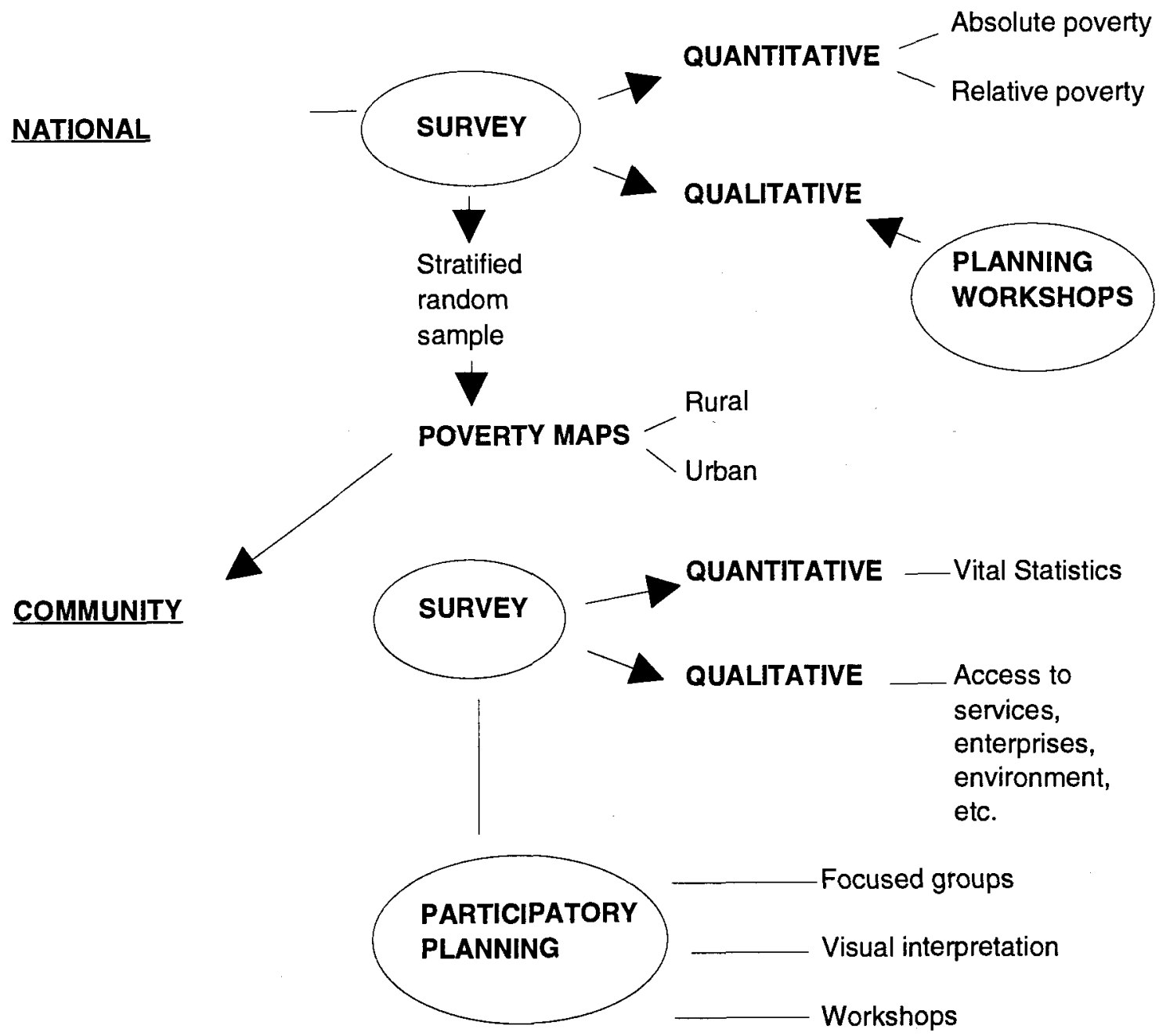


Figure 2

Framework of Resource Flows to Households

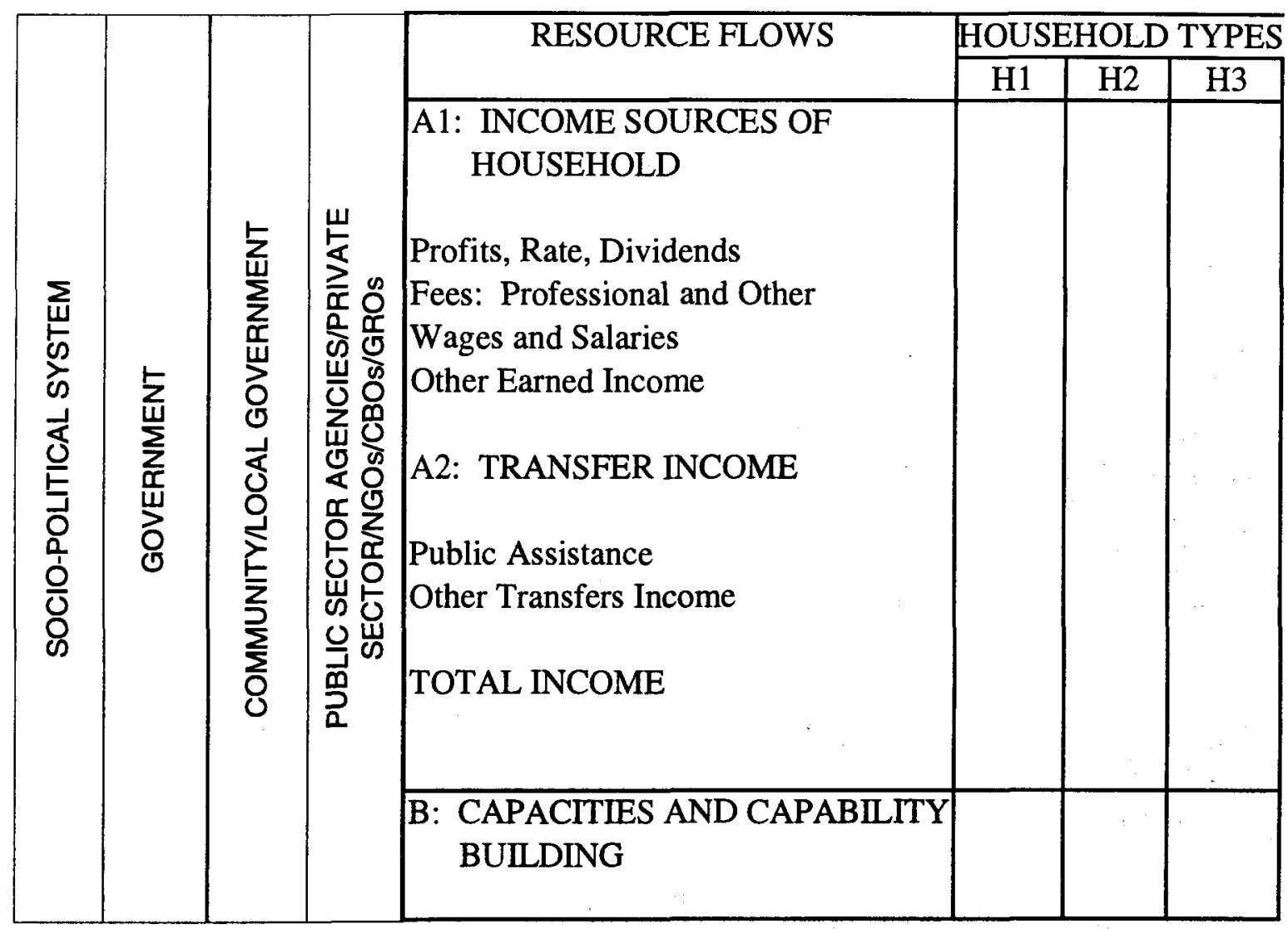

Source: Henry and Mondesire (1995). 
Table 1: The Distribution of Consumption/Welfare in Selected Caribbean Countries

\begin{tabular}{|c|c|c|c|c|c|c|}
\hline Country & \multicolumn{6}{|c|}{ Welfare Measure } \\
\hline & \multicolumn{6}{|c|}{ Quintile Group } \\
\hline & Gini & Poorest & Q2 & Q3 & Q4 & Q5 \\
\hline & $\begin{array}{c}\text { Coefficien } \\
t\end{array}$ & Q1 & & & & \\
\hline Belize & 0.510 & n.a. & n.a. & n.a. & n.a. & n.a. \\
\hline Dominican Republic & 0.490 & 4.2 & 7.9 & 12.5 & 19.7 & 55.6 \\
\hline Guyana & 0.423 & 4.1 & 8.2 & 13.3 & 19.3 & 55.1 \\
\hline Jamaica & 0.430 & 6.5 & 10.8 & 15.2 & 22.3 & 45.2 \\
\hline St. Lucia & 0.468 & 7.11 & 11.99 & 16.63 & 22.64 & 41.63 \\
\hline Trinidad and Tobago & 0.420 & 4.7 & 8.6 & 12.8 & 21.2 & 52.7 \\
\hline \multicolumn{7}{|c|}{ (Quintile Groups derived using Income) } \\
\hline Antigua and Barbuda & 0.525 & n.a. & n.a. & n.a. & n.a. & n.a. \\
\hline The Bahamas & 0.515 & 3.4 & 8.8 & 37.2 & & 50.6 \\
\hline Barbados & 0.460 & 5.8 & 12.8 & 37.4 & & 44.0 \\
\hline Dominica & 0.488 & n.a. & n.a. & n.a. & n.a. & n.a. \\
\hline Grenada & 0.504 & n.a. & n.a. & n.a. & n.a. & n.a. \\
\hline Haiti & n.a. & n.a. & n.a. & n.a. & n.a. & n.a. \\
\hline St. Kitts/Nevis & 0.445 & n.a. & n.a. & n.a. & n.a. & n.a. \\
\hline $\begin{array}{l}\text { St. Vincent and } \\
\text { Grenadines }\end{array}$ & 0.448 & n.a. & n.a. & n.a. & n.a. & n.a. \\
\hline Suriname & 0.573 & n.a. & n.a. & n.a. & n.a. & n.a. \\
\hline
\end{tabular}

n.a.: Not Available; RPI - Regional Price Index

Notes: The Gini Coefficient is an index which represents inequality in the distributionof income and consumption. Most quintile groups were constructed using per capita household expenditure adjusted for household composition (equivalence scales) and regional price differentials. Where income is used in the determination of quintiles, it is indicated. Quintile 1 represents the poorest 20 percent of the population while Quintile 5 represents the wealthiest 20 percent.

Source: Bahamas, Barbados, Dominica, Grenada, Haiti, St. Kitts/Nevis quintile groups and Gini Coefficient estimates based on IDB estimates reported in Greene, E. "Reducing Poverty in the Caribbean by Interventions in Health and Education". Belize, SLC 1995, Dominican Republic IES, 1990, Guyana HIES/LSMS 1993, Jamaica SLC 1992, St. Lucia, SLC, 1995, Trinidad and Tobago, SLC 1992. 
Table 2: Poverty Estimates of Selected Caribbean Countries

\begin{tabular}{|c|c|c|c|c|c|c|c|c|c|}
\hline Country & \multicolumn{9}{|c|}{ Poverty Indicator } \\
\hline $\begin{array}{l}\text { (Poverty Measure } \\
\text { derived using } 2400 \\
\text { Kcal Food Basket) }\end{array}$ & $\begin{array}{l}\text { Extreme } \\
\text { Poverty }\end{array}$ & $\begin{array}{c}\text { Head } \\
\text { Count } \\
\text { Index } \\
(P 0)\end{array}$ & $\begin{array}{c}\text { Poverty } \\
\text { Gap } \\
\text { Index } \\
\text { (P1) }\end{array}$ & $\begin{array}{c}\text { Poverty } \\
\text { Severity } \\
\text { P2) }\end{array}$ & $\begin{array}{c}\text { Annual Per } \\
\text { Capita } \\
\text { Poverty } \\
\text { Line }\end{array}$ & $\begin{array}{c}\text { Daily Per } \\
\text { Capita } \\
\text { Equivalent } \\
\text { US\$ } \\
\text { Poverty } \\
\text { Line }\end{array}$ & $\begin{array}{c}\text { Integrated } \\
\text { Poverty } \\
\text { Index } \\
\text { (Severe } \\
\text { Poverty > } \\
0.40 \text { ) }\end{array}$ & \begin{tabular}{|c|} 
Basic \\
Needs \\
Index \\
(Very \\
Needy BNI \\
$<0.50$ ) \\
\end{tabular} & $\begin{array}{l}\text { Human } \\
\text { Development } \\
\text { Indicator }\end{array}$ \\
\hline Belize & 7.0 & 34.6 & 12.5 & 6.4 & $1313(\mathrm{~B} \$)$ & $\$ 1.80$ & 0.501 & 0.677 & 0.666 \\
\hline Dominican Republic & 11.8 & 20.6 & n.a. & n.a. & $4550(\mathrm{RD} \$)$ & $\$ 1.24$ & 0.38 & 0.699 & 0.638 \\
\hline Guyana & 29.0 & 43.2 & 16.2 & 8.2 & $47,500(\mathrm{G} \$)$ & $\$ 1.04$ & 0.591 & 0.773 & 0.580 \\
\hline Jamaica & n.a. & 34.2 & 10.6 & 4.4 & $4151(\mathrm{~J} \$)$ & $\$ 1.76$ & 0.688 & 0.831 & 0.749 \\
\hline St. Lucia & 5.3 & 25.1 & 6.5 & 3.5 & $2136(\mathrm{EC} \$)$ & $\$ 2.17$ & 0.355 & 0.773 & 0.709 \\
\hline Trinidad \& Tobago & 11.0 & 21.2 & 7.3 & 3.7 & $2,420(\mathrm{TT} \$)$ & $\$ 1.56$ & 0.239 & 0.885 & 0.855 \\
\hline \multicolumn{10}{|c|}{ Poverty estimates derived using alternative methods } \\
\hline Antigua and Barbuda & n.a. & 12.0 & n.a. & n.a. & n.a. & n.a. & 0.223 & 0.892 & 0.796 \\
\hline Bahamas & n.a. & 5.0 & n.a. & n.a. & n.a. & n.a. & n.a. & n.a. & 0.854 \\
\hline Barbados & n.a. & 8.0 & n.a. & n.a. & n.a. & n.a. & 0.057 & 0.926 & 0.894 \\
\hline Dominica & n.a. & 33.0 & n.a. & n.a. & n.a. & n.a. & 0.501 & 0.782 & 0.749 \\
\hline Grenada & n.a. & 20.0 & n.a. & n.a. & n.a. & n.a. & 0.192 & 0.862 & 0.707 \\
\hline Haiti & n.a. & 65.0 & n.a. & n.a. & n.a. & n.a. & 0.755 & 0.439 & 0.354 \\
\hline St. Kitts/Nevis & n.a. & 15.0 & n.a. & n.a. & n.a. & n.a. & 0.282 & 0.8 & 0.73 \\
\hline St. Vincent \& the Grenadines & n.a. & 17.0 & n.a. & n.a. & n.a. & n.a. & 0.396 & 0.776 & 0.732 \\
\hline Suriname & n.a. & 47.0 & n.a. & n.a. & n.a. & n.a. & 0.356 & 0.677 & 0.818 \\
\hline
\end{tabular}

\section{n.a.: Not Available.}

Sources: Head count Index, Antigua and Barbuda, Barbados, Dominica, Grenada, St. Kitts/Nevis, St. Vincent and the Grenadines poverty estimates from IDB as reported in Green, E. "Reducing Poverty in the Caribbean by Interventions in Health and Education", PAHO, Table 1.1. Belize (1995) Poverty Assessment, Kairi Consultants; Dominican Republic, 1994, "Estabillización Apertura y Pobreza en República Dominicna, 1986-1992", Fundación Economía y Desarrollo, Inc.; Guyana 1993 HIES/LSMS as reported in World Bank, 1994 "Guyana: Strategies for Reducing Poverty", Report No. 12861 GUA; Haiti (1987) Poverty estimate reported in ECLAC, 1993, "Poverty Issues and Poverty Alleviation in the Caribbean", Working Paper. Jamaica, Survey of Living Conditions (1992) estimates derived from: "Jamaica: A Strategy for Growth and Poverty Reduction, Country Economic Memorandum; St. Lucia (1995) calculations from Survey of Living Conditions as reported in CDB St. Lucia Poverty Assessment; Suriname (1986), reported in IDB, 1994, "Suriname: Macro Economic and Social Sector Update"; Trinidad and Tobago 1992, Survey of Living Conditions as reported in World Bank, 1995, "Trinidad and Tobago: Poverty and Unemployment in An Oil Based Economy", Report No. 14382 TR.

Integrated poverty Indices and Basic Needs Indices from IFAD, "The State of World Rural Poverty: A Profile of Latin America and the Caribbean". HDI from UNDP. 



\title{
POVERTY STATISTICS AND MEASUREMENT IN AFRICA
}

\author{
by \\ Siddig A. Salih \\ Economic Commission for Africa
}




\section{Poverty Statistics and Measurement in Africa}

The purpose of this paper is two-folds. First, to outline the experience of the United Nations Economic Commission for Africa (ECA) on poverty statistics and measurements. Second, to present the elements of ECA's medium-term work programme on poverty statistics and measurement. Issues on poverty statistics and measurements represent major component of ECA's theme on poverty and social policy.

The theme on poverty assessment and analysis have been accorded, for the first time since the establishment of ECA in 1958, highest priority in the renewal strategy of the Commission, currently underway, to serve Africa better. Indeed, all elements of ECA's work programme are designed to achieve the ultimate goal of reducing poverty in Africa. The reason is obvious. There is a new paradigm shift suggesting that poverty reduction is an overarching goal of development. That consensus should inform and inspire development in Africa, where, by many estimates, more than half of the African population live in abject poverty; and more seriously the number is increasing (World Bank 1996:9). Twenty two of the 25 countries in UNDP's category of "low human development"- which have low literacy, low income and low life expectancy - are in Africa; so too are 33 out of 47 on the UN's list of Least Developed Countries.

Since this paper is oriented within the new strategic vision of ECA towards its overarching goal of reducing poverty in Africa, section 2 overviews the strategic framework defining the Commission's programmes and structure. Section 3 identifies modalities for enhancing the impact of the new work programme. Section 4 addresses the major substantive issues relating to poverty measurement, while section 5 highlights the data requirements and the accompanying plan to make ECA a focal point for poverty statistics in Africa.

ECA's Mandate and its Strategic Focus Approach:

Similar to all UN Regional Commissions of the world, ECA reports to ECOSOC through the Conference of African Ministers responsible for Economic and Social Development and Planning. ECA concluded last year's Conference of African Ministers responsible for Economic and Social Development that gave ECA a definite mandate to renew itself along the lines of the new strategic direction presented in May 1996 to serve Africa better (ECA 1996). The impetus for reform at ECA comes from several driving forces. One of the main significant source is the fact that African countries are going through multiple transitions, from state-dominated to free-market oriented economies, from autocracy to democracy, and, in some cases from conflict to rehabilitation to reconstruction. As member States change, ECA must change to respond to their needs. 
Several institutions (such as African Development Bank (ADB), African research networks and the Bretton Woods Institutions) have focused on short to medium-term economic problems facing African countries. There is an urgent need to build on and complement the on-going policy analysis work on the performance of the African economy by bringing in the least-researched and overlooked issues of long-term and structural nature of these economies to the attention of African policy makers, their development partners and analysts concerned with African development.

By focusing on the long-term nature of economic growth, the sustainability issues, and social policy (where there is wide agreement and emerging consensus); ECA will pave the way to fulfill the mandate that its highest legislative organ has given it. To operationalize the long-term strategic narrowing of ECA's agenda and priorities, ECA will concentrate over its medium-term work plan on only five substantative areas plus a cross-cutting issue of gender. These thematic areas are economic and social policy analysis; food security and sustainable development; development management; harnessing information for development; and promoting regional cooperation.

The mandate of the renewal and implementation of the work programme will be guided by four key principles: excellence, greater impact, cost-effectiveness and enhanced partnership. Indeed, the strategic focus will enable ECA to forge effective partnership/networking with significant players in Africa's development; i.e., successful African policy institutions, leading multilateral organizations and important bilateral donors of official development assistance.

Modalities:

In its poverty monitoring and analysis sub-programme, ECA is increasingly looking to build effective partnerships with a range of African NGOs (such as African Economic Research Consortium (AERC) through its recently launched project on poverty, income inequality and labor market issues); African Poverty Research Network (APRN) linking up policy makers, planners, researchers, NGOs, etc; and other organizations working on similar kinds of poverty issues in Africa (such as ADB, ILO, SPA Working Group on Poverty and Social Policy, UNDP, UNICEF, the World Bank and other external partners).

Building on its coordinating abilities among agencies and stemming from its co-chairship of the UN System-wide Special Initiative on Africa, ECA is establishing regional fora for concerned parties to facilitate a better understanding of poverty reduction schemes and programmes implemented by African countries together with exchange of experiences and best practices among policy makers, practitioners, civil society and NGOs. Such fora have been utilized in training and capacity-building arrangement (such as the upcoming joint ECA/EDI training workshop on poverty measurement in Africa, scheduled to be held in Addis Ababa on late June 1997) and further extended to other social sectors (such as the June Forum on cost-sharing in the social sector of Sub-Saharan Africa (SSA), in collaboration with the World Bank and UNICEF). The objective of the latter is to reach a 
consensus on the principles of cost-sharing arrangements and develop guidelines from the practical implementation of such arrangements based on the experiences and lessons learned in SSA.

The growing knowledge, experiences and the progress to date in poverty work programme in Africa will enable us to undertake further work on topics that were not addressed sufficiently within the past and on-going collaborative efforts. These include assessing the quality of poverty reducing growth strategies, particularly equitable growth; adoption and adaptation of successful anti-poverty policies and programmes with genderethnicity dimensions; innovative techniques (such as the newly developed core welfare indicators questionnaire (CWIQ) by the World Bank ) to integrate quantitative and qualitative data relating to poverty reduction strategies to investment in social sectors; and internalizing the thread that runs across these topics and themes, namely, establishing and maintaining a regional database/archive to monitor poverty over time.

\section{$\underline{\text { Measurement Issues }}$}

In its poverty assessment work, ECA's role is to exploit synergies with other UN specialized programmes operating in the region and with other research, training and civic organizations involved in similar areas of analysis. ECA is keenly aware of the need to work in collaboration with other partners; recognizing the comparative advantages of these agencies, their mandates and mindful of the need for a continuing dialogue; with the view of avoiding duplication.

Operationally, ECA has already forged partnerships in the area of poverty reduction with ADB, AERC, UNDP, UNICEF, the World Bank and other poverty networks in the continent. ECA takes cognizance of the work programme and activities undertaken by these institutions. This paper adopts the same definition of poverty commonly used by these institutions.

The most widely cited definition of poverty is be found in the World Bank (1990) and Ravallion (1994) among others, namely, "the inability to attain a minimal standard of living". In this empirical literature, the convention is to use the absolute poverty line as the most relevant poverty measure for SSA (Ali 1995:1). In this respect, absolute poverty line is defined as the cost of basic food items deemed essential to attain some recommended food energy intake. In addition, a modest allowance for non-food items thought to be crucial for living "without feeling shame" was added to the cost of food to meet Sen's "entitlement criteria". Of course, this direct approach to poverty analysis contrasts with the indirect approach of looking at poverty through social indicators such as expected life, child survival and education indicators (Pio 1994).

The most important measures used to summarize the state of poverty in the literature for several African countries, using the direct approach to poverty analysis, belong to the family 
of additively separable measures (Ali 1995:11). These include the head-count ratio $(\mathrm{H})$, the poverty-gap ratio $P(1)$, and the Foster-Greer-Thorbecke (FGT) measure $P(a)$.

The head-count ratio is defined as the proportion of the population for whom income (or consumption expenditure) is less than the poverty line. It is understood in the literature that the head-count ratio is a measure of the spread of poverty. The poverty-gap ratio is defined as the aggregate poverty deficit of the poor relative to the poverty line. It measures the depth of poverty in a given society since it depends on the distance of the poor from the poverty line. The FGT measure of poverty weighs the poverty-gap for each individual by a poverty aversion parameter prevailing in society (the parameter (a) is non-negative). The interpretation of this measure, however, is problematic. Its attraction, on the other hand, is that it gives more weight to the poorer in society. Moreover, for values zero and one of the poverty aversion parameter, the FGT measure gives rise to head-count ratio and the povertygap ratio respectively.

Despite improvements in the analysis of poverty based on both direct and indirect evidence of measuring poverty, it was shown that poverty in Africa is a much deeper phenomenon than is commonly recognized and that the increase in poverty during the second half of the 1980 s is much more dramatic than is commonly reported in the literature (Ali 1995:17). Conflicting evidence on the magnitude and behavior of poverty in SSA directs ECA's attention, concern and interest on poverty measurement in Africa. For the purpose of this seminar, we wish to flag the following interrelated issues.

1. Most of the poverty measures in Africa were based on either unknown poverty line or arbitrary chosen poverty lines. For example; Chen, Datt and Ravallion (1994) assumed five poverty lines to estimate poverty incidence curves (PIC). A PIC is generated by plotting the proportion of population (p) - on the vertical axis consuming less than a given level $\mathrm{z}$ - on the horizontal axis. Each point on the PIC gives the head-count index of poverty. Using PIC, poverty deficit curves and poverty sensitivity curves; and assuming specific value of the poverty line (which is unknown), poverty between two dates can be compared by invoking the idea of dominance. The idea of dominance permit assessments about whether poverty has increased or decreased over time or with and without some policy change, regardless of the poverty line or poverty measure selected. It is based on a comparison of cumulative income distributions at two times.

In these studies the poverty lines were defined as consumption levels per person per month in 1985 purchasing power parity (PPP) dollars. The consumption levels used were $\$ 21, \$ 30, \$ 40, \$ 50$, and $\$ 60$; whereas, their respectively computed PICs underestimated poverty in SSA (Ali 1995:9). Although it is difficult to obtain country-specific poverty lines in the absence of of detailed country studies on poverty in Africa, available household budget surveys augmented by the use of CWIQ will provide sufficient information to estimate country-specific poverty lines based on representative consumption basket for the poor in these countries. 
2. Moving from absolute measures to relative measures of poverty, poverty line used by the World Bank was arbitrarily chosen at two-thirds of the national average expenditure per capita; based on the PPP of US \$ 1 per day per person (World Bank 1996:12). The report concluded that poverty is higher in rural areas than in urban areas in all 17 countries, where data are available (World Bank 1996:13). Given the richness of the survey data, additional indicators describing the characteristics of the poor in Africa could have been extracted to inform policy; particularly indicators on gender and ethnicity. In this respect, ECA's interest and concern are not only related to improving the analytical work of estimating relative poverty lines, but also poverty comparisons between countries in the region and over time.

3. Recent empirical evidence also suggests that for the last two years Gross Domestic Product (GDP) growth in more than half of the African countries exceeded their population growth; while poverty has been increasing for the same comparable years (ECA 1997). One interesting issue to understand this non-conventional finding is to revisit the linkages between growth and poverty reduction in Africa.

Despite the lack of appropriate information required to examine growth-poverty linkages and their direction of causality, the contribution of the pattern of growth (in addition to growth) must have something to do with poverty situation in Africa. Such a proposition calls for decomposing the change in poverty into a growth component and a distribution component. Preliminary evidence, using the decomposition approach, suggests that the true depth of poverty in Africa is more than is captured by the results of the conventional procedure; based on the growth component on poverty (Ali 1995:17). The former results recommended a distinction between "secular poverty " and "incremental poverty" in dealing with poverty reduction in Africa (Ali 1995:18). Further investigation of the components of poverty at country-level would contribute to filling the lacuna in the current debate of poverty measurement; with the view of providing insights into engineering appropriate policy shocks that would reverse the current trends in the behavior of poverty in the region.

4. The current policy debate on poverty reduction is influenced by the World Bank's approach to the subject (Ali 1995:18). In this respect it is perhaps important to note that in revisting Africa's development strategy, the Bank identified two clear legs to the strategic agenda of sustainable poverty reduction (World Bank 1994). The first leg emphasized the importance of encouraging labour-intensive growth, since labour is the only asset owned by the poor. The second leg requires the provision of broad-based health, education and infrastructural services. There is less disagreement in both propositions as viable tools to alleviate poverty in Africa; assuming that the strategy embraces implicity the crucial importance of the equity dimension in the process of development. However, disagreement may arise on how to go about doing them.

5. The two legs strategic approach is also based on information generated to characterize the poor. That is, if governments are to reduce poverty or to judge how their economic 
policies affect poverty, they need to know a lot about the poor (World bank 1990:29). ECA shares the growing concern over the state of the African poverty statistics and we note that little information exists to enlighten policy formulation (Ali 1885, Azam and ECA 1996). With this grave concern in mind, ECA accorded high priority to poverty statistics in its thematic approach to poverty monitoring and analysis. Operationally, collaborative efforts with the World Bank and other development partners are underway to improve the quality of statistics at country level and to facilitate its free flow throughout Africa.

\section{Poverty Statistics:}

The main source of poverty information on African countries has been extra-continental (mainly the World Bank). Household surveys contain detailed information on the required money-metric indicators to measure poverty and to allow for easy comparisons within and across countries.

Most of the household surveys supported by the World Bank in African countries, set up under the Social Dimensions of Adjustment Programme, were established as nationally representative surveys with the objective of measuring and monitoring welfare levels of different population groups within a country. Out of the 70 national household surveys that have been carried out in Africa since the late 1980s, 38 are now stored in the World Bank's data library (World Bank 1997:4-5). This represents a wealth of statistical information. Household surveys library is considered a growing source of household survey data which is capable of providing key indicators for monitoring the impact of macro and sectoral programmes on living standards and welfare.

Currently, standardized data files have been generated from the standard survey data. These files contain a minimum set of common indicators (demographic, anthropometric and labour market) stored in a standardized format which allows for producing basic poverty reports. There are now 19 standardized datasets (World Bank 1996:61).

One of the most neglected but essential links in the statistical chain, is the absence of a regional repository and source of African poverty statistics and information. Given its geographical proximity and mandate, ECA is a logical choice to establish and maintain a regional database/archive centre in Africa. Within the existing collaborative poverty programme between ECA and the World Bank, the agreement between the two institutions is to progressively transfer the household survey library to ECA. In addition, the knowledge to create and archive the standardized poverty data files will also be transferred with the view to the ECA organizing workshops and training courses to pass on the skills to organize and document statistical surveys down to National Statistical Offices.

Moreover, the regional facility will attract research, learning and bringing together suppliers of data and users to identify data-cum-conceptual gaps, standardization of statistical definitions, concepts, and strengthening poverty network in Africa. It is to be 
noted that ECA's role, inter alia, in the recently launched AERC's collaborative project on poverty issues in Africa is to address the above mentioned bottlenecks. In addition, the forthcoming training and policy forum to be held in ECA's premise on next June 1997 will address training, networking, exchange of best practices and implementation of recommended policies in poverty reduction and other related social policy issues. As such, demand for statistics; particularly extensive use of household survey data would be increasingly promoted. Consequently, the establishment of the regional database and its increasing use will promote national ownership of poverty monitoring and analysis by African countries. As a follow up to poverty monitoring activities and through its capacitybuilding mechanism and collaborative training activities (at least three training modules have been scheduled for this year covering Anglo, Franco and Arabic zones in Africa), ECA would strengthen national statistical capacity to sustain poverty monitoring in these countries.

As part of ECA's regional connectivity programme, the regional database will be linked to ECA statistical database to facilitate free flow of information to the public domain and to disseminate poverty statistics through electronic networks. The electronic network will also link ECA to the Live Database (LDB) as well as the Country LDB (CLDB) developed by the World Bank. Indeed, collaborative work between ECA and the Bank have already been implemented at a pilot stage, since early February 1997, to establish and connect CLDB in Mozambique.

As argued in the literature, the major challenge facing poverty alleviation efforts in Africa is the lack of knowledge about the behavior and magnitude of poverty. Hence, the objective of establishing an ECA regional database on poverty represents an invaluable wealth on poverty statistics and an active indigenous centre to inform, update and improve the design of development programmes in Africa. 


\section{REFERENCES}

Ali, A.A.G. 1995. The Challenge of Poverty Alleviation in Sub-Sharan Africa, presented at the 1995 World Congress of International Economic Association, Tunis, Tunisia, 1722 December.

Azam, J - P. 1994. The Uncertain distributional Impact of Structural Adjustment in subSaharan Africa, in R. Van der Hoeven and F. Van der Kraaij (eds.) Structural

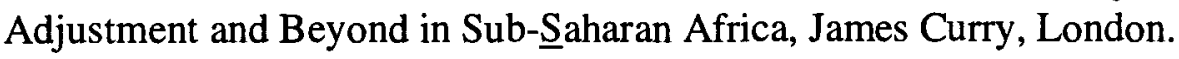

Chen, S.; Datt, G. and Ravallion, M. 1994. Is Poverty Increasing in the Developing World ? Review of Income and Wealth, Series 40, No. 4.

ECA. 1997. Economic Report for Africa, Draft Report, United Nations Economic Commission for Africa, Addis Ababa, March.

ECA. 1996. Serving Africa Better: Strategic Direction for the Economic Commission for Africa, Report No. E/ECA/CM.22/2, United Nations Economic Commission for Africa, Addis Ababa, March.

Pio, A. 1994. The Social Impact of Adjustment in Africa, in G. Cornia and G. Helleiner (eds.) From Adjustment to Development in Africa, St. Martin Press, New York.

Ravallion, M. 1994. Poverty Comparisons: Fundamentals in Pure and Applied Economics, Harwood Academic Press, Chur, Switzerland.

World Bank. 1997. Africa Household Surveys Data Bank: List of Surveys, Draft Tables, Africa Region, World Bank, Washington, April.

World Bank. 1996. Status Report on Poverty in Sub-Saharan Africa 1996: Country Profiles and patterns of Growth, Draft Report, Africa Region, World Bank, Washington,

World Bank. 1994. Africa's Development Strategy Revisited: An Overview, Africa Region, World Bank, Washington.

World Bank. 1990. World Development Report 1990, The World Bank, Washington. 

POVERTY ALLEVIATION THROUGH ECONOMIC GROWTH AND SOCIAL DEVELOPMENT: REPORT OF THE COMMITTEE ON POVERTY ALLEVIATION THROUGH ECONOMIC GROWTH AND SOCIAL DEVELOPMENT, FIRST SESSION, AND ITS FOLLOW-UP

by

Khalid Siddiqui

Economic and Social Commission for Asia and the Pacific (ESCAP) Thailand 


\title{
Poverty alleviation through economic growth and social development: Report of the Committee on Poverty Alleviation through Economic Growth and Social Development, first session, and its follow-up
}

(Item $8(a)$ of the provisional agenda)

Note by the secretariat

\begin{abstract}
Annex I
RECOMMENDATIONS OF THE EXPERT Group MEeTing ON NATIONAL POVERTY CONCEPTS AND MEASUREMENT IN THE ESCAP REGION, 15-17 SEPTEMBER 1993, BANGKOK
\end{abstract}

\section{A. Background}

The Expert Group Meeting on National Poverty Concepts and Measurement in the ESCAP Region was held at Bangkok from 15 to 17 September 1993.

It was attended by experts from nine countries: Bangladesh, China, Fiji, India, Indonesia, Nepal, Philippines, Thailand and Viet Nam. Mr. S.R. Hashim, Principal Adviser, Planning Commission, India, and Mr. Rabindra K. Shakya, Member-Secretary, National Planning Commission, Nepal, acted as Chairperson and Vice-Chairperson, respectively.

The Expert Group Meeting reviewed national concepts and definitions as well as approaches to obtaining poverty-related data for planning, implementing and monitoring poverty alleviation strategies and policies.

The following are the recommendations of the Expert Group.

\section{B. Concept of poverty}

(1) There was broad agreement in the Expert Group on the conceptualization of poverty as a state of deprivation with reference to socially accepted norms of basic human needs. The precise specification of the set of basic needs and the specification of the normative threshold level defining poverty would necessarily reflect the conditions and socio-cultural values of a society and would therefore vary from one country to another.

(2) On the issue of whether poverty should be conceptualized in absolute or relative terms, the Expert Group generally endorsed the absolute approach for application in developing countries. 


\section{Measurement of poverty}

(3) The Expert Group recognized the need for appropriate measures of poverty at different levels of disaggregation for purposes of:

(a) Obtaining an understanding of the broad dimensions of the problem which, in turn, could provide a basis for mobilization of national and international resources for poverty alleviation;

(b) Designing appropriate strategies for poverty alleviation;

(c) Identifying target communities, villages or households for designing and implementing poverty alleviation programmes;

(d) Monitoring and evaluation the progress in poverty alleviation both at the programme level and at the area, province, regional and country levels.

(4) In spite of the recognized inadequacies of income/expenditure-based measures of poverty, the Expert Group recommended their adoption for the purpose of assessing the overall magnitude of poverty and tracking changes over time. The measures should be supplemented by a few widely-accepted social indicators, such as those relating to the health and educational status of the population, differentiating, wherever possible, along the spatial and gender dimensions. The countries of the region should be encouraged and assisted to produce official estimates of poverty using those measures and indicators.

(5) In addition to the measurement of the magnitude of poverty, there was a need to identify the dominant poverty groups and monitor their poverty status in a dynamic context through micro-level studies.

(6) The Expert Group recognized the complexity of issues underlying the specification of the poverty line in terms of income/expenditure. It therefore recommended that the poverty line be viewed as a reasonable level of private purchasing power (ability to buy goods and services) with which the household would be able to fulfil its basic needs taking into account any freely provided public services. The measurement of private purchasing power should take explicit account of self-produced commodities and, in particular, not be restricted to cash income. As it would be difficult to have a uniform specification for the poverty line across countries, researchers and policy makers should exercise caution in making intercountry comparisons of poverty data based on national poverty lines.

(7) The Expert Group recognized the widespread use of nutrition norms in the specification of the poverty line but recommended that the focus should be on overall purchasing power rather than on the nutrition norm anchoring it. Such a focus on private purchasing power and the underlying bundle of goods and services would help to ensure comparability of poverty estimates across space and over time. 
(8) From the perspective of designing appropriate strategies, the Expert Group stressed the need for a clear understanding of the causes and correlates of poverty. It recommended that estimates of the proportion and number of the poor be supplemented with a comprehensive report covering the following aspects of the poor population:

(a) Composition in terms of dominant characteristics, such as distribution by social group, spatial distribution, means of livelihood, family characteristics, asset status, and access to means for coping with crises;

(b) Nutritional status;

(c) Health status: mortality, morbidity; access to and use of health services (public and private) and costs;

(d) Educational status: educational attainment, school enrolment by region, sex and age group and by economic and social classes; and reach and quality of public education services and costs;

(e) Living environment: distribution by density of settlement; living space per head and type of houses; access to safe drinking water and sanitation; access to other amenities;

(f) Social communication, awareness and participation in decision-making.

(9) The Expert Group recognised that in the identification of households to be assisted, visible characteristics matching the overall poverty profile and/or a process of consultation and consensus at the local level would be needed. That would also assist in monitoring at the programme level. Keeping this in view, the Expert Group recommended that:

(a) The county, block, village or household be adopted as the ultimate unit of analysis, depending on the particular focus of the anti-poverty programme;

(b) Innovative methods of data collection and analysis, such as those involving active community participation, be explored for possible adoption in the countries of the region.

\section{Poverty database}

(10) The Expert Group recognised the diversity among countries with regard to the availability of data for implementing the above recommendations. It recommended that countries with an inadequate database should be assisted to build an integrated data system and better utilise existing data sources. The ESCAP secretariat should assist countries in their efforts to improve poverty-related statistics, particularly by facilitating the sharing of knowledge and experience available in the region through technical publications, guidelines and meetings. The publication of a compendium of statistics focusing on poverty in the region would be a useful contribution to the promotion of awareness about poverty issues. 
(11) In the context of poverty measures based on household income/expenditure, the Expert Group recognised the role of household surveys as the principal instrument of data collection. To facilitate effective data collection on poverty, it recommended that efforts should be made to prepare a detailed regional handbook for operationalizing poverty concepts and definitions and outlining effective survey strategies and also to provide training facilities and materials.

(12) The Expert Group recognised the role that could be played by active community participation in data collection and analysis and recommended that efforts should be made by all countries in the region to introduce that approach. 



\title{
POVERTY IN TRANSITION IN EASTERN EUROPE AND THE COMMONWEALTH OF INDEPENDENT STATES
}

\author{
by
}

\author{
Wolf Scott $^{1}$ \\ Statistical Division \\ Economic Commission for Europe
}

\footnotetext{
${ }^{1}$ Consultant, Statistical Division, Economic Commission for Europe. The opinions expressed are the consultant's and not necessarily those of ECE.
} 


\section{Poverty in Transition in Eastern Europe and the Commonwealth of Independent States}

\section{Introduction}

Average life expectation among men declined in the Russian Federation between 1990 and 1995 by six years, a magnitude never before experienced in peace time since records began. It is the more startling since it affected not the very young or the very old but men in their prime of life, between 20 and 59. Such mortality is perhaps the most dramatic symptom of a deterioration in conditions in general: rapidly rising unemployment and underemployment, falling incomes, a rise in crime and violence, a further decline in already deficient diets, high levels of alcohol and tobacco consumption, conditions which affected not only the Russian Federation but to varying degrees all the countries in transition (CITs, the term used henceforth) in eastern Europe and the Commonwealth of Independent States (CIS). ${ }^{2}$

Poverty is widespread currently in the CITs, but particularly in the CIS and parts of former Yugoslavia and Albania than elsewhere. As shown below, estimates of the extent of poverty in the republics of the former Soviet Union vary from 50 to 90 per cent or more (poor persons as per cent of the total population). The point to note, however, is that the term covers a wide variety of conditions. Poverty in the CITs is sharply distinct in kind from poverty elsewhere. The principal distinction relates to the fact that in its present extreme form it is a very recent and sudden phenomenon in these countries. There was little affluence in the Soviet era but, with some exceptions as in the Central Asian republics, the Soviet system avoided destitution. Full employment, controlled prices of essential goods, a universal system of health and education, and widespread, if moderate, state benefits ensured an adequate minimum for the vast majority. Public services, and especially health services, were often of low quality compared to western Europe, but nevertheless they existed and served almost the whole population.

Collapse came with little warning, giving no time for people to adjust materially or psychologically. Moreover, it was initially collapse of an economic kind, leaving the basic social structure unchanged. The result is not only extreme poverty in the sense of a grave shortage of the means of livelihood, but the fact that it is happening to people in no way prepared for it. In this sense, poverty in the CITs is quite different from countries which have never known anything else. Where poverty is endemic, the population has have had time to develop mechanism for survival, but most of the poor of eastern Europe and the CIS have had no time to develop such mechanisms, and it is the resulting imbalance, as much as the poverty.in itself, which has caused so much hardship.

\footnotetext{
${ }^{2}$ The CIS includes in a military and economic union all the republics of the former Soviet Union except the three Baltic states Estonia, Latvia and Lithuania.
} 
Imbalance can be expressed also in other terms. Social development had in Soviet times progressed at about the same pace as economic development, depending on how either is defined. Medium levels of economic development were matched by high to medium social levels - high for example in education and many forms of cultural development, medium in health and nutrition. When economic levels declined, drastically in some of the countries, social levels in some respects tended not to follow suit, but remained what they were. The resulting imbalance is shown, in Section 3 below, in terms for example of high levels of adult literacy and advantageous levels of infant mortality in the CITs in relation to the (now relatively low) national incomes, and in comparison with other countries with about the same levels of income. As a result, poverty in the CITs, and especially in the countries of the former Soviet Union, has little in common with poverty for example in western Europe, and even less with that in Africa. ${ }^{3}$

On a positive note, the relative favourable social levels, especially in education and occupational skills, could assist in relatively speedy recovery.

An attempt has been made in this paper to describe the extent and the nature of poverty in the CITs. Almost inevitably, it has been necessary in the attempt to come to grips with concepts and definitions. In a brief Section 2, especially the relationship between poverty as defined in this paper, and human welfare more broadly, is discussed. And although Section 3 started out as a descriptive piece on poverty in transition, here too a brief statement on the extent of poverty is followed by a relatively lengthy critical assessment of methodological issues.

The lack of valid data on poverty in the majority of CITs, finally, has prompted a fourth section on data requirements.

The discussion of poverty in the CITs in this paper is bases mainly on information from the national Human Development Reports (NHDRs) produced in recent years, with the assistance of UNDP, in most of the countries in transition. The contribution of these reports to the analysis of economic and social factors in transition, despite the lack of statistical information in many of them, is hereby acknowledged.

\section{Basic concepts}

The concept of poverty is given very varied meaning in the current literature Three issues especially require discussion: the relations of poverty to human welfare (and similar terms), the distinction in concept and measurement of poverty between the national and household levels, and finally the issue of absolute versus relative measures of poverty.

\footnotetext{
${ }^{3}$ See United Nations, Report on the World Social Situation 1961 for a discussion of the measurement of relative social and economic macro levels. Also, D. V. McGranahan, E. Pizarro, C. Richard, Measurement and Aalysis of Socio-Economic Development, UNRISD, Geneva 1985.
} 
Poverty and human welfare. As defined for the purposes of this paper, human welfare (living conditions ${ }^{4}$ and similar), is a function of (i) income and/or the goods and services that can be obtained with income ${ }^{5}$, including income in both cash and kind, and (ii) benefits that in practice cannot readily be obtained with money or expressed in monetary terms (such as public services ${ }^{6}$, a state of health, educational achievement, "happiness", "capabilities for development", freedom from oppression, freedom of speech and movement). Inversely, an insufficiency in human welfare is a function of (i) a critical shortfall in income, here defined as poverty, ${ }^{7}$ as well as (ii) deficiencies in these other, non-income related benefits.

Thus human welfare is here the broader term which includes both income and nonincome benefits and conditions. Definitions vary. Some writers speak of "capabilities poverty" ${ }^{\prime 8}$ or "human welfare poverty". All aspects of human welfare are important. However, I have chosen here to be more consistent with normal usage, and therefore to associate poverty with (a lack of) income, and distinguish it from deprivation in the nonincome aspects of human welfare.

The two aspects are, of course, interrelated. The poor in the sense used here are commonly not only short of income, but typically also under-educated, underfed, in illhealth, underemployed, and they generally fail to participate in society to the same degree as their more affluent neighbours. The extent to which this is so - and it is less true in the CITs than in some other regions - is a profitable area of study, but it can be examined only if from the outset these various conditions are kept separate. A critical lack of money is one factor, ill-health, illiteracy, a scarcity of crucial public services etc. are other factors. Lumping them all together under the term poverty is unhelpful if the objective is to determine the degree of association among them. It is also unhelpful when it comes to devising remedies to help the poor and disadvantaged, since policies must vary according to whether a shortfall of money is the complaint, or female illiteracy, or a lack of trained midwives.

Poverty of nations and of households ${ }^{9}$. Depending on the purpose, poverty can be defined and measured at the national (macro-) or the household (micro-) levels. There is a conceptual distinction. A "poor" nation may contain non-poor households, and in this sense the poverty refers to an average. Concepts apart, different measures and indicators are used,

\footnotetext{
${ }^{4}$ Standard of living, although in common use, is not recommended as a term. In English, a standard suggests something to be emulated, a target to be achieved. Levels of living is the more appropriate term.

${ }^{5}$ The distinction between income and the ability to purchase goods was important in Soviet times when incomes often outran the supply of goods and services.

${ }^{6}$ Leaving aside the question whether, as is sometimes claimed, public services, as in health and education, can be given a monetary value and counted as income.

7 The Oxford dictionary defines poverty as a "want of means", Webster's as 'the state of one who lacks a usual or socially acceptable amount of money or material possessions".

${ }^{8}$ Cf. United Nations Development Programme, Human Development Report 1996, Oxford University Press, Oxford and New York, 1996. p. 109, ff. The "capability poverty" index in this report is compounded of three indicators: (i) births not attended by trained health staff. (ii) underweight children under age 5, (iii) the female illiteracy rate.

${ }^{9}$ The term 'household' is taken here to include the individuals living together in households, unless there is cause for differentiation.
} 
depending on the level. The poverty line, for example, is essentially a device to distinguish poor from non-poor households. There is in practice no obvious equivalent to poverty lines at the macro-level.

Absolute and relative poverty. Poverty, that is a critical shortfall in income, can be absolute or relative. Absolute poverty was defined (by Rowntree in 1901, but the definition has not greatly varied since) as less than the "minimum necessary income for maintenance of merely physical health". The minimum then included food, clothing, rent, fuel and essential household sundries. ${ }^{10}$ Relative poverty is defined in terms of an average or other movable standard (irrespective of absolute level), for example the ten per cent persons with the lowest incomes in a country, or those with an income of less than 50 per cent of average national household expenditure. Clearly, the poorest ten per cent in a well off country (say Switzerland) by this definition would be affluent in comparison with the ten per cent in a poor country (say the Illyrian islands), even if they might not appreciate this when comparing themselves to the more affluent in their own country. ${ }^{11}$

While, subject to problems of measurement, the concept of the relative poor is clear and unambiguous (the poorest ten or twenty per cent persons or households, in terms of defined income, in a country at a given point of time, for example), the same cannot be said about absolute poverty or an absolute poverty line. As the discussion of poverty measurement in the CITs below demonstrates, definition of an absolute standard invokes so many problems of a conceptual and practical nature that agreement on a single line is difficult to reach within any one country and the more so cross-nationally.

\section{Poverty and human welfare in countries in transition in Europe}

\section{A. The national level}

Human welfare at the level of the nation is measured in economic terms, using national accounting aggregates, such as per capita GNP, as well as in social, mainly non-monetary, terms including such items, especially important in the CITs, as physical security, including the absence of armed strife in the many forms to which some of the republics have been subjected since independence (Nagorno Karabakh, Abkhazia, Tchechenia, Southern Ossetia, the current civil war in Tajikistan, to give only a few examples), protection from environmental pollution, the provision of education and health services, or emergence of cultural and political institutions.

\footnotetext{
${ }^{10}$ B.S.Rowntree, Poverty: A Study of Town Life, Macmillan, London, 1901. Rowntree is cited in this paper for two reasons. Together with Charles Booth, he is the pioneer of poverty studies in their modern form having begun almost exactly one hundred years ago. His work moreover is exemplary in conceptual clarity, precision, in the imaginative way in which statistics are combined with non-statistical observation, and, finally, in the relation of method to purpose.

${ }^{11}$ A few of the CITs made use of the concept of subjective (conceived) as distinct from objective poverty. To obtain an estimate of subjective poverty, all. persons are asked to define the income they consider necessary to maintain an adequate level. They are poor by this definition if their income falls short of whatever they consider to be necessary.
} 
Table 1 shows for the countries of eastern Europe and the CIS ${ }^{12}$ per capita GNP in 1989 and 1995 as well as the rate of change between the two years. In 1989, only two of the countries in transition in Europe, Albania and Tajikistan, had per capita GNP below $\$ 1000$. By 1995 the situation especially in the CIS had changed dramatically. Income had dropped below $\$ 1,000$ in seven of the twelve member states. Percentage declines of per capita GNP between 1989 and 1995 vary from 17 per cent of the 1989 level in Uzbekistan to as much as 74 per cent in Georgia. The figures are rough estimates, but they probably convey the general magnitude of the actual change.

${ }^{12}$ The estimates are only appoximations, but they well describe general trends. 
Table 1

Estimated Per capita GNP 1989 and 1995 and per cent change 1989-1995

\begin{tabular}{|c|c|c|c|}
\hline . & $\begin{array}{c}1989 \\
\text { per } \\
\text { capita } \\
\text { GNP } \\
\text { US\$ }\end{array}$ & $\begin{array}{c}\% \\
\text { change } \\
1989- \\
1995\end{array}$ & $\begin{array}{c}1995 \\
\text { per } \\
\text { capita } \\
\text { GNP } \\
\text { US\$ }\end{array}$ \\
\hline Albania & 548 & -21.4 & 431 \\
\hline Bulgaria & 1675 & -23.5 & 1281 \\
\hline Croatia & 4035 & -37.5 & 2522 \\
\hline Czech & 3989 & -15.6 & 3366 \\
\hline Republic & & & \\
\hline Hungary & 4586 & -14.6 & 3917 \\
\hline Poland & 2618 & -1.5 & 2579 \\
\hline Romania & 1605 & -15.4 & 1358 \\
\hline Slovakia & 2887 & -16.3 & 2417 \\
\hline Slovenia & 8346 & -11.6 & 7378 \\
\hline FYR & $\ldots$ & -47.1 & $\ldots$ \\
\hline Macedonia $^{*}$ & & & \\
\hline Yugoslavia* & $\cdots$ & -51.0 & $\cdots$ \\
\hline Armenia & 1806 & -60.4 & 715 \\
\hline Azerbaijan & 1228 & -66.2 & 415 \\
\hline Belarus & 3156 & -38.4 & 1944 \\
\hline Georgia & 3375 & -82.4 & 594 \\
\hline Kazakstan & 2354 & -55.1 & 1057 \\
\hline Kyrgyzstan & 1121 & -47.3 & 591 \\
\hline Moldova & 2221 & -62.0 & 844 \\
\hline Russian Fed. & 4226 & -39.8 & 2544 \\
\hline Tajikistan & 792 & -60.0 & 317 \\
\hline Turkmenistan & 1684 & -0.2 & 1681 \\
\hline Ukraine & 3177 & -47.1 & 1681 \\
\hline Uzbekistan & 1163 & -18.3 & 950 \\
\hline Estonia & 4447 & -35.0 & 2891 \\
\hline Latvia & 4521 & -49.5 & 2283 \\
\hline Lithuania & 3558 & -61.3 & 1377 \\
\hline
\end{tabular}

*NMP or GMP

Sources: Economic Commission for Europe, Economic Bulletin for Europe, Vol.48, 1996, for rates of change. UNICEF, The State of the World's Children 1997, for estimates of per capita GNP, adjusted to 1989 and 1995. The estimates, per capita GNP, adjusted to 1989 and 1995. The estimates are subject to wide margins of error, but they convey the general pattern. 
The decline was much less elsewhere in eastern Europe except probably in Bosnia and Herzegovina (no figures), FYR Macedonia and Yugoslavia FR. However, even here national incomes tended to stagnate and recovery is fairly recent.

Especially in the republics of the former Soviet Union the situation behind these few, stark figures is dramatic. Production declined as political was succeeded by economic disintegration, widespread unemployment and underemployment, rapidly declining incomes, massive inflation that eroded assets and the value of welfare benefits, private and state insolvency. Many people lost, virtually overnight, their principal source of livelihood, others had their incomes drastically reduced. Mass poverty resulted, as describes below.

The impact on non-income aspects of human welfare has been more complex. Aspects that depend directly on personal incomes or government expenditure have been the most affected, while others, related to past conditions, or in some cases to current international charity, have been relatively unaffected. High cultural levels, professional skills, as well as a good all-round education leading to virtually universal literacy, carried forward from the past, have remained unchanged. The current education system, on the other hand, has suffered from the financial penury.

Much depends on the indicators used. Some are more sensitive to change than others. The consumption of the more nutritious foods, like milk and milk products, meat, fish, vegetables and fruit, and therefore of total, and especially animal, protein declined sharply because most people could no longer afford them, or the supply was disrupted. "The calorie level, on the other hand, declined much less as people maintained their consumption of bread and other cereals (Chart 1). Bread and tea, and not much else, has been the staple diet for many persons in recent years.

Chart 1. Georgia. Changing Patterns of Food Consumption. 1989-1994
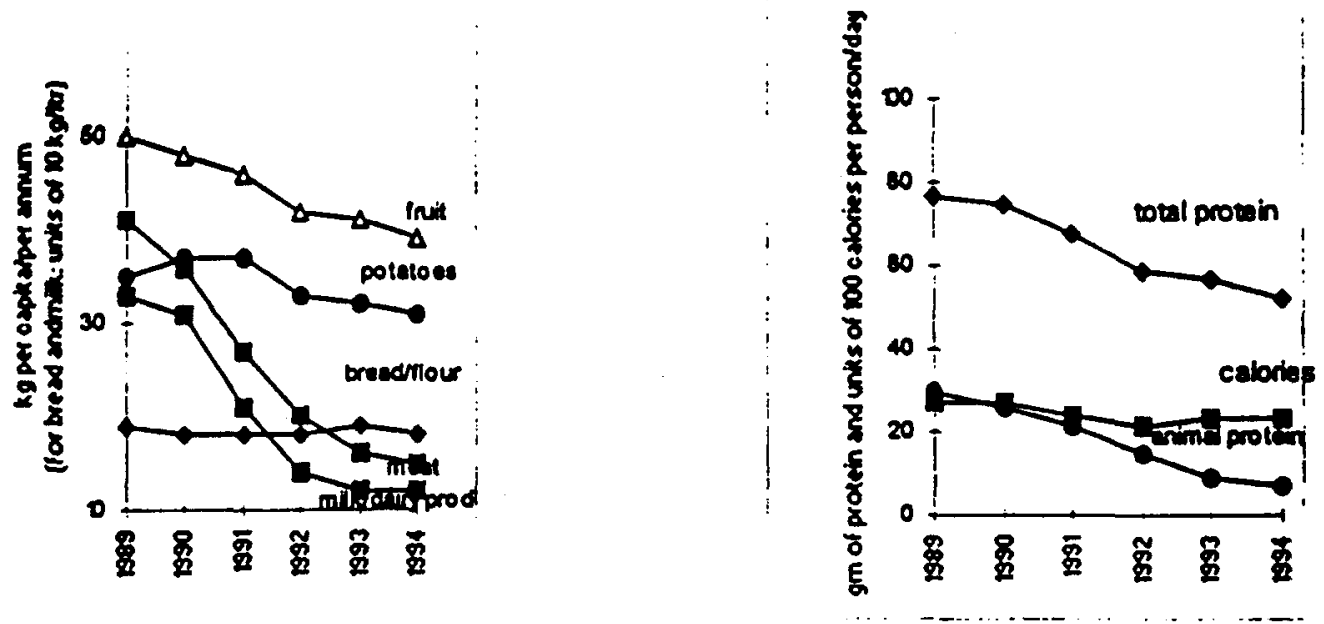
Similarly in education or health. The numbers of schools, teachers or pupils, and derivations such as enrolment ratios (commonly used indicators of current levels of education for want of something better) have remained stable in primary and secondary education, whereas the sharp decline in the condition of buildings, the absence of heating (leading to the frequent closing of schools in the winter), severe shortage of books, paper and other teaching aids, the failure to pay teachers adequate salaries, the widespread absenteeism of staff, resulting in a severe decline in the quality of education have, in the absence of statistics on these events, gone largely unrecorded.

In respect of health care services, also, the numbers of doctors or hospital beds, commonly used as indicators, are quite unrelated to reality in the ex-Soviet republics. Many doctors, without adequate pay from their medical work, prefer to work outside their profession, though remaining on the registers to be counted. Many hospital beds, similarly, continue to be counted, but often remain empty for lack of heating, meals or professional care in hospitals. In Georgia, for example, the occupation rate of hospital beds, in the absence of proper care in the hospitals, declined between 1990 and 1993 from 16 to 9 patients per bed per annum. ${ }^{13}$

As noted in Section 1, because of the very recent and precipitous character of economic decline, but also because of the complexity of social development during transition, poverty in these countries has a profoundly different image and significance from that in most countries with similar levels of national income. Whereas the CITs until recently had moderate economic development with relatively high social levels to match (in many, if not all, respects, and quality sometimes lagging behind quantity), economic collapse, has brought many of them to the economic level of developing countries, whereas social levels, in some ways unaffected by the collapse have remained high.

When, as in Table 2, CITs are compared with other countries having the same per capita GNP in respect of such indicators as infant mortality or adult literacy, the contrast is striking. CITs with under $\$ 1000$ per capita (GNP have much more favourable rates than the developing countries, an average infant mortality rate of 37 as compared with 81 in developing countries, an adult literacy rate of 98 as compares with 70 in the developing countries. ${ }^{14}$ The differences are similar in the higher income groups of countries.

\footnotetext{
${ }^{13}$ Georgia, Human Development Report 1995, p. 35.

${ }^{14}$ No counts have taken place of adult literacy in the CITs, and the figures possibly overestimate literacy,. However, the gap noted in Table 2 is on other evidence probably an accurate reflection of the real situation.
} 
Table 2

Differences in respect of Social Levels

between Countries in Transition and

others with about the same per capita GNP in 1995

\begin{tabular}{|c|c|c|c|}
\hline & $\begin{array}{c}\text { Per } \\
\text { capita } \\
\text { GNP } \\
1994 \\
\text { US\$ } \\
\end{array}$ & $\begin{array}{c}\text { Infant mortality } \\
\text { rate } \\
1995\end{array}$ & $\begin{array}{c}\text { Adult } \\
\text { literacy } \\
1995\end{array}$ \\
\hline \multicolumn{4}{|l|}{ Under $\$ 1000$ per capita } \\
\hline \multicolumn{4}{|l|}{ GNP } \\
\hline CITs & 675 & 37 & 98 \\
\hline Developing & 654 & 81 & 70 \\
\hline \multicolumn{4}{|l|}{$\$ 1000-\$ 1999$ per capita } \\
\hline \multicolumn{4}{|l|}{ GNP } \\
\hline CITs & 1362 & 31 & 98 \\
\hline Developing & 1469 & 38 & 77 \\
\hline \multicolumn{4}{|l|}{$\$ 2000-\$ 2999$ per capita } \\
\hline \multicolumn{4}{|l|}{ GNP } \\
\hline CITs & 2453 & 18 & 98 \\
\hline Developing & 2520 & 31 & 89 \\
\hline \multicolumn{4}{|l|}{$\$ 3000-\$ 3999$ per capita } \\
\hline GNP & & & \\
\hline CITs & 3520 & 11 & 99 \\
\hline Developing & 3468 & 33 & 84 \\
\hline
\end{tabular}

Source: UNICEF, The State of the World's Children, 1997

In terms of literacy and infant mortality, most of the CITs while declining economically have not declined socially. A man or woman may lose his or her income, but they do not forget how to write or read. Similarly, infant mortality - normally a sensitive indicator of general as well as child health - had by 1995 not been seriously affected by declining living conditions, probably because children were better protected from adversity than adults.

However, as noted above, some other social characteristics have shared in the overall economic decline. Thus, life expectancy differs little between the CITs and other countries with the same income levels. The sharp decline in male life expectancy in Russia was noted in the opening paragraph, reflecting the onerous condition of working-age men, trying to cope, often unsuccessfully, with economic adversity. 


\section{B. The household level}

The decline in national incomes resulted in greatly increased poverty also at household level. There is some argument as to how widespread poverty was in Soviet times. Destitution in the former Soviet Union was largely avoided by the three pillars of social security: full employment (however unproductive and often badly paid), controlled and low prices of essential goods and services including food, housing, fuel, health, education, entertainment (including circuses) and, finally, an extensive scheme of social protection through cash benefits. The 1995 NHDR for the Russian Federation states ${ }^{15}$ :

"While the command economy managed to administer a system of wages and benefits, full employment and controlled prices for goods and services ensured a minimum standard of living for the large majority of the population (in the 1980s.... 10 per cent of Russians had a per capita income below a poverty line based on the minimum consumption level)." (p.25)

It is difficult to say at this stage on what basis such calculations were made, or to assess how the provision of free or low-cost goods and services affected calculations of poverty. It is probably true that the problem in the pre-transition Soviet Union and its dependencies was not so much outright poverty in the sense that people lived below a subsistence level, but that few people were able by honest means to rise much above the minimum. Some of the central Asian republics probably had even in Soviet times more poverty than the other republics. According to the Kyrgyz HDR, the high level of poverty in 1995 is not only the consequence of the economic crisis in transition. "lt. is also a legacy of the Soviet period".

As noted, the subsequent collapse, entailing massive reduction in production as well as depreciation of money, eroded paid employment and cash benefits. For the great majority of the populations, particularly in the CIS, transition meant the collapse of their livelihood whether this depended on employment or pensions. Underemployment has been a very significant feature of transition in the CIS. While numerous people continued to be nominally employed, the time spent at the place of work, output and incomes sank to very low levels. Pensions and similar benefits, similarly, were reduced to a small fraction of their former value. Poverty, on all accounts, became widespread after 1991.

The increase in the number of households in poverty results from the overall decline in national income, but also to the distribution of incomes within a country. Where income distribution figures are available they suggest a strong degree of inequality in the sense that a disproportionately large share of total income is concentrated in relatively few hands (even if poverty is equitably distributed among the remainder). The Tbilisi figures are probably a fair example (Chart 2).

\footnotetext{
${ }^{15}$ Russian Federation, Human Development Report, 1995
} 


\section{Chart 2, Tbilisi (Georgia), Household income distribution (Lorenz curve) 1994}

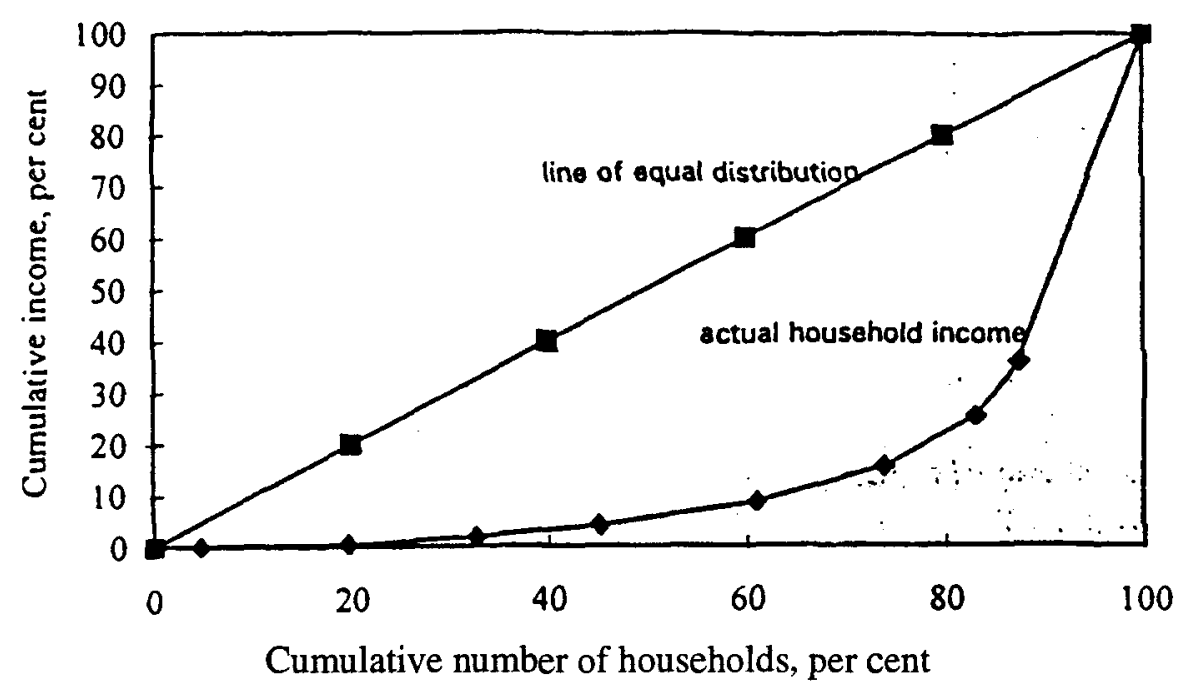

Source: Georgia, Human Development Report

Of the 22 national Human Development Reports examined, 17 attempt to define and estimate the amount of poverty at the level of the individual or household, and for the most part do so in absolute rather than relative terms: ${ }^{16}$

"In Turkmenistan, as in other post-socialist countries, the absolute approach is used because it is necessary to target the most needy categories of the population rather than all who are relatively worse than others."17

In each case, an attempt has been made to define one or more "poverty lines", and then calculate the proportion of persons or households lying below the line or lines. It is clear from the figures that poverty is widespread especially in the countries of the former Soviet Union, ranging from 21 to 90 per cent poor (as percentage of the total population, disregarding the unlikely 12 per cent in Uzbekistan). At best, the figures, summarised in Table 3, are rough estimates, depending on somewhat arbitrary judgements as to the level at which people can survive and on inadequate figures of income.

\footnotetext{
${ }^{16}$ Only the Czech Republic and Poland calculated a relative (on the model of Eurostat) as well as an absolute poverty line.

${ }^{17}$ Turkmenistan. Human Development Report, 1996, p.84.
} 
Table 3

Poverty Estimates in the National Human Development Reports 1995-1996

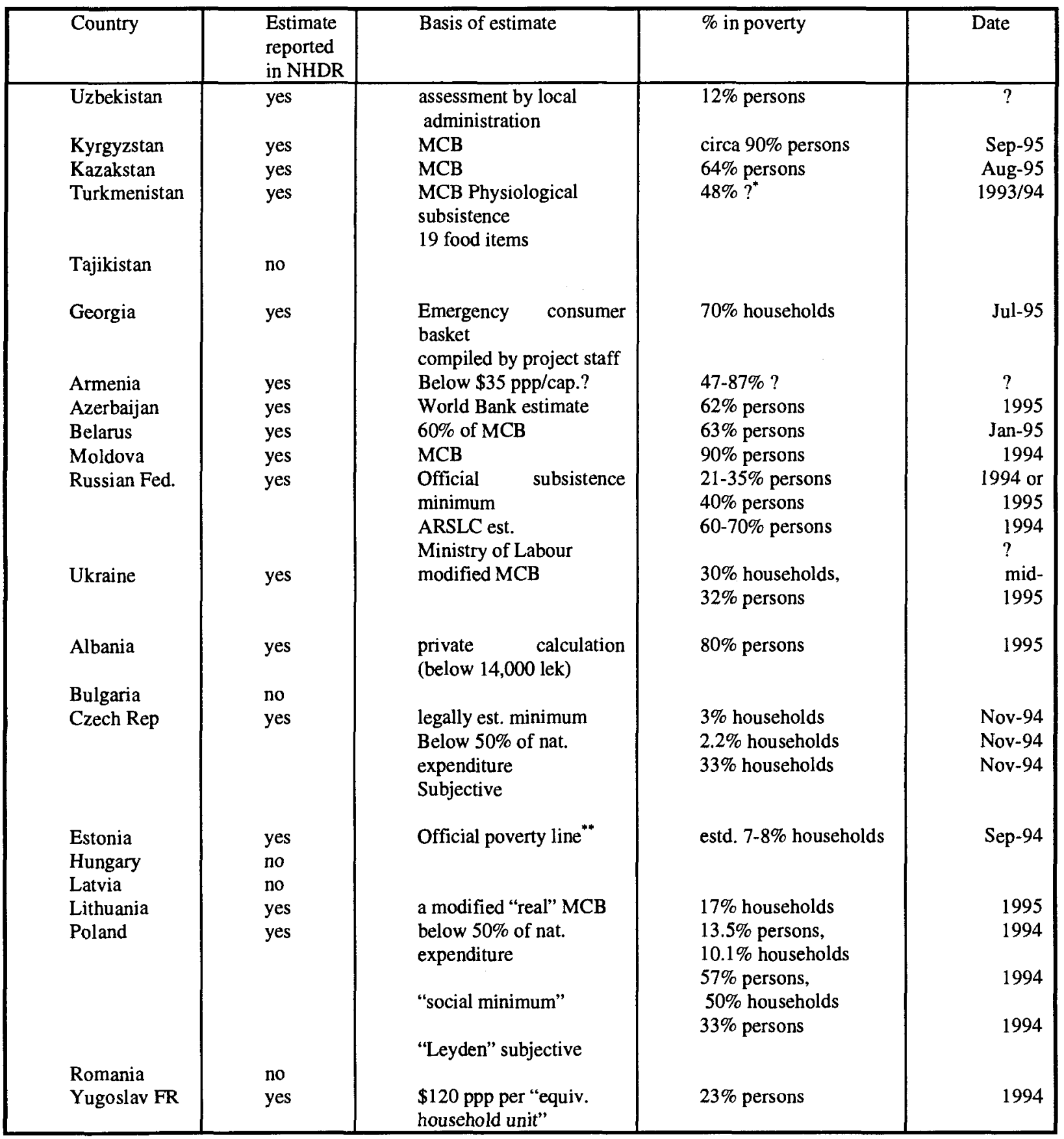

MCB: Minimum consumption basket, the least possible consumption consistent with maintenance of a normal life, as estimated separately by each government.

"It is not certain to which of the three lines the $48 \%$ applies

${ }^{* *}$ The authors of the HOR consider the estimate too low. They propose $40 \%$ as an alternative. 
The data for the Russian Federation are a good example: The official minimum subsistence line (calculated on the basis of 75 food and 124 non-food items and "several dozen" service items) was 254,000 roubles (per capita) in May 1995. Between 25 and 32 per cent of the population had incomes less than this. Other minima in use were the cost of a "food basket", estimated at 171,000 roubles, and a minimum wage of 39,000 roubles per month. According to the NHDR, the All-Russia Standard of Living Centre preferred a poverty line higher than the official minimum subsistence by some 15 per cent. Approximately 60 million persons lived below this level. A still higher line was calculated by the Research Centre of the Ministry of Labour, to encompass between 60 and 79 million people.

The figures in Table 3 and the discussion of these figures in the NHDRs are of interest in their own right, but perhaps more so for the light they throw on methodological problems relating to the poverty lines, including specification of a minimal subsistence basket or baskets, their pricing, and to estimates of the distribution of income that determine the proportion of the population below the line:

\section{Problems relating to contents and pricing of the minimal subsistence basket}

Certain problems relating to the contents of so-called minimum baskets are well known. They include culturally induced variations in minima and what is called secondary poverty (see below). As regards the former, what is acceptable as a minimum standard in one society and one set of conditions is not necessarily acceptable in another society and in different circumstances. There is often little agreement on the constituents of a minimum even within the same country and society. Is television an absolute necessity in modern society, or shoes in the summer? As noted in one report:

"Thus, the poverty line in the United States is between 10 to 17 times higher than that in India (depending on the exchange rates used, whether these are the official exchange or the purchasing power parity rates) ... although both pretend to be absolute in some sense." 18

The term secondary poverty was first used by Rowntree to denote a variation from the condition where an income would suffice if optimally spent, on essentials only. ${ }^{19}$ Secondary poverty occurs where with small incomes the pattern of expenditure is less than optimal. People may smoke and drink instead of spending their meagre income on milk and raw carrots. It is a consideration of this kind that led George Orwell to comment on a nutritionally optimal diet:

"Would it not be better if they spent more money on wholesome things like oranges and wholemeal bread or if they even, like the writer to the letter to the New.Statesman, saved on fuel and ate their carrots raw? Yes, it would, but the point is that no ordinary human being is ever going to do such a thing. The ordinary human being would rather starve than live on brown bread and raw carrots. And the particular evil is this, that the less money you have, the less inclined you feel to spend it on wholesome food. A millionaire may enjoy

${ }^{18}$ Wolf Scott. Concepts and Measurement of Poverty, UNRISD, Geneva, 1981.

${ }^{19}$ See B. S. Rowntree, Poverty and Progress: A Second Social Survey of York, Longmans, Green \& Co., London 1942. Rowntree made no use of the concept of secondary poverty in his first study. 
breakfasting off orange juice and Ryvita biscuits, an unemployed man doesn't... When you are unemployed, which is to say when you are underfed, harassed, bored and miserable, you don't want to eat wholesome food. You want something a little bit 'tasty'..."20

Marres and Van der Wiel make the same point in respect to poverty lines in Lesotho. They point out that people living on small incomes in Lesotho behave with a different rationality from those who compile the minimum budgets. They propose that 50 per cent be added to the minimum budget to allow for the satisfaction of "strongly felt needs". These include tobacco, sweets, alcohol, radios, since in practice this is where some money will go at the cost of essentials. ${ }^{21}$

Problems in the CITs relate to fiscal as well as cultural or psychological considerations. Most of the ex-Soviet countries established early in transition a minimum consumption basket (MCB), but did so on standards which increasingly impecunious governments could not afford to maintain. That is, they could not afford to pay wages or social benefits matching the MCB. For analytic purposes various ministries, international organisations and private research institutes then sometimes substituted their own, allegedly more realistic, poverty lines. Not uncommonly, countries thus constructed several standards or poverty lines and reported poverty in respect of each.

In practice, poverty lines have in many cases been determined by governments or local authorities at the level these can afford, only partly related to the needs of the poor. ${ }^{22}$ The Kyrgyz HDR 96 comments that the poverty line in Kyrgyzstan is:

“... not a figure which is fixed once and for all. Its level depends on various capacities of the economy and the state budget, and on how feasible it is to provide social support and to how many people. It is linked to the minimum consumer budget (MCB) which itself is flexible. The low end of the MCB could be set at the level below which real danger to physical human existence is bound to ensue. The high end depends on the economic conditions of the society. The richer the society, the higher the MCB and conversely..."23

And again,

"By' lowering the poverty line, the state 'frees' itself from the worry of providing social support to this portion of the population ... It is the state's profound insolvency which necessitates this step, not any ill will on its part." 24

${ }^{20}$ George Orwell, The Road to Wigan Pier, Victor Gollancz, London, 1937.

21 P.J.Th.Marres and A.C.A.van der Wiel, Poverty Eats my Blanket, Government Press, Lesotho, 1975.

${ }^{22}$ The case is cited of a public authority in California: "A welfare official ... indicated to us that that state bases its needs levels entirely on Fiscal ability. To account fort this discrepancy, many states have two standards: a needs standard and a payment standard. The needs standard ... represents the amount recognised by the state as the level required to meet basic needs. ...Due to fiscal limitations, however, the state may not pay the full amount of its needs standard, and a second, lower amount is shown as the 'payments standard', and a second, lower amount shown as the 'payment standard', is paid." (S.M.Oster, E.E.Lake, C.G.Oksman, The Definition and Measurement of Poverty, Westwood Press, Boulder, Colorado, 1878).

${ }^{23}$ Kyrgyz Republic, Human Development Report 1996, p.29.

${ }^{24}$ ibid., p.31 
Other difficulties relate to ambiguities in what are physiological necessities. The authors of the Estonian HDR note the fact that purported minimum food requirements in Lithuania are in respect of some of the items from 3 to 5 times higher than in Estonia, though presumably requirements are the same in the two countries: $:^{25}$

Table 4

Composition of Minimum Food Baskets respectively in Estonia and Lithuania ( $\mathrm{kg}$ per month)

\begin{tabular}{|l|r|r|}
\hline & $\begin{array}{r}\text { Est } \\
\text { oni } \\
\text { a }\end{array}$ & $\begin{array}{r}\text { Lithu } \\
\text { ania } \\
1993\end{array}$ \\
& 198 & \\
& 9 & \\
\hline Meat & 2.3 & 6.1 \\
Fish & nil & 1.0 \\
Cheese & 0.6 & nil \\
Milk & 9.2 & 40.5 \\
Eggs & 15 & 22.6 \\
(number) & & \\
Sugar & 1.5 & 2.1 \\
Vegetable & 0.6 & 0.6 \\
Oil & & \\
Butter & 0.3 & nil \\
Potatoes & 6.1 & 10.1 \\
Vegetables & 9.2 & 5.9 \\
Fruit & 1.5 & 4.2 \\
Bread & 7.6 & 8.4 \\
\hline
\end{tabular}

While, further, a subsistence minimum normally allows for the replacement of worn clothes, household equipment and the like, in other cases, minima were determined on the understanding that the current emergency would soon pass. Some kinds of expenditure, according to this theory, may be postponed for a time (a year or a few years) until a given emergency has passed. Clothes and household utensils can be darned and patched for a time before they wear out completely. Their replacement might be considered unnecessary in a poverty basket, in the expectation that the emergency will not last, a consideration more relevant to the CITs than to countries where destitution is virtually endemic. Thus, the Georgian HDR for 1995 identifies an "emergency basket" which makes no allowance for replacement of clothing, household utensils and similar, on the assumption that, in the hope of better times to come, households can for some time manage without such replacement. This no more than reflects the actual situation in Georgia where every scarce Lari (unit of currency) is required for essential food and fuel while Georgians hope for better days.

\footnotetext{
${ }^{25}$ Estonian Human Development Report, Table 4.3, p.38.
} 
Pricing of the basket has been another problem in conditions of rapid inflation. According to the Estonian HDR:

"When the official poverty line was established $10 \%$ of inhabitants were living below it. Though the number of poor families has decreased at a time of relatively rapid inflation and slow raising of the poverty line, this does not mean that poverty has decreased. ${ }^{, 26}$... (but simply that the line did not keep step with rising prices)

Alternatively, it was deliberate policy to let prices of the basket lag behind rampant inflation because a government, in any case, lacked the means to help the poor at the existing level of the poverty line.

\section{Measurement of the distribution of household income}

The third step, namely estimation of how many individuals or households fall below a given poverty line, also gave rise to problems, since such estimation requires valid figures of income distribution:

(a) Household income surveys (except in countries like Denmark, Finland or the Netherlands that rely on good administrative registers for this information) are the main source of income data in most countries. Surveys are not so far well established in most of the CITs, even if the situation is improving. Nor are alternative sources, such as the tax system, which sometimes provides supplementary information on incomes elsewhere, well developed in many of the CITs.

(b) Incomes in CITs are derived from a large variety of, often overlapping, irregular, sometimes marginal, if not outright illegal sources. Householders hesitate to give, and interviewers find it difficult to extract, valid information. Multiple sources of income are often ignored.

(c) For purposes of the poverty line, incomes should include income in kind as well as cash, including home-grown or donated food as well as other donations - important in the context of the CITs, where many households depend for help on national or international charitable organisations. Again, ascertaining valid information on goods and services received in kind (which involves attribution of price as well as assessment of quantities) is problematical.

(d) Variations in income over the year, for example seasonal variation in rural incomes, tend to be ignored, which could be the reason why so many households move in and out of poverty in successive annual surveys, especially where these take place in different seasons (see below).

For all these reasons, information on income is likely to be faulty. In particular, income tends to be underreported. To avoid the use of faulty income data, information on consumption expenditure, thought to be more reliable than income data, is sometimes substituted for income. This introduces a conceptual error since savings are omitted. It could

\footnotetext{
${ }^{26}$ ibid., p.40.
} 
be argued, however, that households whose expenditure is near a poverty line are unlikely to have significant savings, so that expenditure at this level is close to income. Savings apart, the use of expenditure rather than income data does not altogether get rid of errors, especially those connected with the consumption of home-grown food and other selfservices, a substantial item in most of the CITs. Expenditure surveys are very cumbersome, time-consuming and costly affairs. If, however, as is commonly the case, they are carried out for other purposes, for example, for the calculation of the weights for consumer price indices, then the data can be used also in determining the numbers below poverty lines.

Three other factors affect the validity and comparability of the data and their significance for policy purposes:

(i) Distribution of income within households. Household income may not indicate the poverty of its individual members.

(ii) Impermanence of poverty. Reported evidence in two CITs suggests that in respect of a large proportion of the poor, poverty as defined here, is not permanent. Many households crowd around the poverty line and may be in poverty at one count and out of it another time. In Poland for example the same households were examined in 1993 and 1994. Only about half of those in poverty at the time of the surveys in 1993 and 1994 were so in both years. ${ }^{27}$ A similar result was obtained from studies in the Russian Federation. ${ }^{28}$

(iii) Use of persons vs. households in the calculations. The proportion of poor is affected by whether persons or households are used in the count. As poverty is generally greater in large than in small households (or anyway in large households with children) other things being equal, the proportion of poor is to that extent greater when persons rather than households are counted.

(iv) Bunching of households around the poverty line. Because in most countries the population is densely clustered around the line (many just above or just below) even slight shifts in the poverty line, in response to one or other of the above considerations, can induce a substantial change in the estimated number of poor.

\section{The use of poverty lines and estimates of the poor}

In spite of the ambiguities that beset poverty lines it would be wrong to conclude that they are useless. Such lines have for many years greatly helped administrations, for example in the USA or India. On the other hand, it is clear in the conditions of the CITs that a valid assessment is required not only of the proportion of the population falling below a single, necessarily arbitrary, line, but in relation to several alternative lines, based on alternative assessments of minimal needs, keeping in mind also fiscal constraints.

\footnotetext{
${ }^{27}$ Poland'96: Habitat and Human Development, p. 15 ff.

${ }^{28}$ Russian Federation, Human Development Report 1995, p.26.
} 
Such cut-off points would be for analytical or policy purposes. They should not be mistaken for poverty lines in a universal or scientific sense. They have operational significance in a particular context, related to political or administrative convenience.

The important element in any calculation of poverty is a valid distribution of income which, apart from showing the number of people below given cut-off points, can be used also to calculate the depth of poverty (how far the poor are below the various poverty lines) using for example the Foster, Greer, Thorbecke coefficients. ${ }^{29}$ Annual estimates of income distributions are used, further, to monitor changes over time, and can do so more comprehensively than with single poverty lines. ${ }^{30}$

Because criteria and data sources are too varied, it is not possible to compare CITs one with another or with countries in other regions, on the basis of the poverty line data from the NHDRs (of the kind assembled in Table 3). The figures in Table 3 give support to arguments made on other grounds. These would include the hypothesis that most of the CIS countries (as well as Albania).had upwards of 50 per cent of its population in poverty. Rates in the Baltic states and Yugoslavia FR may lie between 20 and 40 per cent, in the central European states below 20 per cent. That is probably as far as the figures permit the calculation of the extent of poverty in these countries.

\section{Alternative forms of measurement}

A reasonable question, given the conceptual difficulties surrounding the poverty line and the practical problems of measuring income or expenditure, is whether human welfare at the household or individual levels can be measured by other means than poverty lines. As we saw earlier, a wide range of social data is available to measure welfare at the macro-level: infant or child mortality, life expectancy, levels of food consumption, housing conditions, pre-school enrolment, measures of environmental pollution, participation of women in public life, and the like. But this is not the case at the level of the individual household within a country, where the purpose is to classify such households as poor or non-poor. Most of the data used at macro-level are either not available at household level or, for technical reasons, are inapplicable for the purpose. ${ }^{31}$ Which is why researchers, for lack of anything better, tend to revert to household income or expenditure as their principal or unique indicator of poverty.

A few ideas have emerged from the NHDRs that could supplement income data. One of them, describes in the Estonian HDR for 1996, makes use of household assets, jointly with income. Another is the familiar concept of expenditure on food as a proportion of total consumption expenditure.

\footnotetext{
${ }^{29}$ J.Foster, J.Greer, E.Thorbecke, "A class of decomposable poverty measures", Econometrica, 1984.

${ }^{30}$ Changes in the distribution of income over time are often complex, some segments of the distribution gaining. others losing. a complexity to which single measures, such as poverty lines, or averages likes the Gini coefficient, cannot do justice.

${ }^{31}$ Households cannot be classified in terms of life expectancy, for example, or according to whether or not an infant has died in the household in the previous year.
} 
The Estonians used household surveys to ask whether households have or do not have the following items:

1- Central heating in the house or flat

2. Sufficient living space: number of rooms exceeding the number of people living in them

3. Private car

4. A summer house

5. Monthly income per household member exceeding 1,500 EK.

The material well-being index (MI), as it is called, calculated by simply adding the number of positive responses to the five items, varies from zero to five. Households with an MI of zero or 1 are called poor (49 per cent in Estonia in the survey year); they would be average with an MI of 2 (31 per cent); and economically secure with an MI of 3 or more (20 per cent).

Whether this kind of classification gives satisfactory results or not (and in which conditions and countries) is a matter of practical experience, rather than theoretical conjecture. It seems to have given satisfactory results in Estonia. A point to note, however, is that both this index, and the food coefficient, continue to make use of income or expenditure data.

\section{Characteristics of the poor}

The provision of total figures is not the sole, or even the most important, purpose of poverty assessment. The aim of Rowntree's studies in York, and of most studies of the kind since, has been to ascertain the causes of poverty as a basis for remedial action. By seeking an answer to the question who are the poor in terms of socio-economic and geographic categories and "immediate causes", it has been possible to devise policies to help the poor, or at least some of them. In the case of York at the turn of the century (the first survey of York was published in 1901) the most common causes were sickness or death of the principal wage earner, low wages (in the first survey), unemployment (in the second survey, during the great depression of the 1930s), and such impediments as alcoholism, compounded or not by the burden of large families. Rowntree is thought to have greatly influenced, through the findings of his three surveys, the state schemes of social insurance in Britain early in the century and again after the second world war.

The principal cause of poverty in the CITs, as mentioned, has been the decline of the economy following transition. The impact, however, has not been uniform on all households. Some have been more, others less, affected. Household survey data, which provided figures of income and expenditure, can be used also to identify the principal victims. A considerable amount of information is available in the NHDRs which is summarised here only very briefly.

Poverty in the CITs (defined in the NHDRs in terms of persons below the poverty line or lines) normally varied by geographic region, urban/rural, type of household distinguishing 
for example number and ages of children in a household, source of income, whether from earnings or social benefits etc. In Poland, for example, the category most in poverty were rural households with no farm of their own and living on unearned incomes (mainly pensions, presumably). In Belarus, families in direst poverty were rural families with children and only a single adult ( 89 per cent of this group were below the poverty line, as compared with a national total of 63 per cent). Of urban families with the head aged over 60 and no children only 3 per cent were below the poverty line. Pensioners clearly were better protected in Belarus (as in some other CITs) than children. In the Russian Federation, the poor were most highly concentrated in households with three or more children, those with unemployed or disabled persons, and households where pensions were the sole source of income.

Clearly, the finer the categorisation the more helpful it is for policies of intervention. With very limited resources, the government and charitable organisations perforce concentrate on the most needy. For example, in one of the CITs, large families as such were not necessarily afflicted since many of them also had more than a single earner. However, large families, with no or only a single earner, and especially those with children, were at risk. Similarly, while all pensioners in this particular country were vulnerable, following repeated devaluations of the currency that reduced pensions to three dollars or so equivalent per month, some were clearly worse off than others. Those living with their relatives or, though living alone, had relatives close at hand, could survive, while others, living entirely on their own and uncared for, were at high risk.

\section{Data needs for the measurement of poverty in countries in transition}

To measure poverty (as poverty is defined in this paper) reliably and monitor changes in poverty over time the requirements are (a) a clear definition of one or more baskets of goods corresponding to minimal subsistence in line with a country's fiscal ability, or other standards, (b) the pricing of such baskets, updated to reflect changing prices, and (c) an income distribution (or equivalent, such as a distribution of household expenditure), with income defined broadly to cover cash and non-cash sources. To measure poverty, only the lower part of the income distribution is required. Measurement of income at levels well above the poverty line, that is of households in the upper one or two deciles of the distribution, including the difficult measurement of the most affluent, is not essential. ${ }^{32}$

In countries in transition, measurement of income and its distribution (or expenditure as a substitute) poses difficult problems. Data are required in respect of each member of the household, and for the household jointly, on income from each of the many possible sources, in cash and in kind. Quality of the data depends on the ability of interviewers to elicit correct and full responses. If information is sought on both income and expenditure over matching periods, results can be compared and gross divergencies queried. Other standards can be

\footnotetext{
${ }^{32}$ It is required for measures of income distribution, such as the Gini coefficient or the ratio of extreme deciles.but not for poyerty defined as the proportion below given poverty lines
} 
applied. Thus, if reported income or expenditure is less than a stipulated absolute minimum (the poverty line adjusted for size and composition of household) by a significant margin, the respondent should be asked to explain the shortfall. It could be real in the sense that the respondent is destitute. In other cases, it will result in the respondent revising his or her earlier statements.

Total income apart, data are required to identify those below the poverty line or lines in terms of socio-economic and geographic characteristics as discussed above: geographic location, size and composition of households in terms of sex, ages, employment status, occupations and education of household members, temporary or permanent illness and disability, ethnic status, nationality - in short, any factor that by throwing light on possible causes of poverty can facilitate the search for remedies. Much depends on local conditions. Most persons recently displaced from their homes by civil armed conflict are likely to be poor, for example.

Household surveys could be used also to gather information on other factors associated with poverty. Examples are the assets (summer house, car, number of rooms, central heating) noted in the Estonian HDR, education currently received by children, state of health and access to health care services, such as immunisation. If nothing can be done about the basic causes of poverty, governments and charitable organisations can sometimes mitigate consequences, by providing low-cost health care or education specially designed to help the poor. As with all household surveys, however, there is a limit to the number of questions that can be asked without unduly fatiguing respondent and interviewer and straining the resources of those who are to analyse the results. A small amount of valid information is to be preferred to broad and superficial information. In general, given the difficulties of eliciting good income data, mentioned earlier, it is on income/expenditure data that the weight of the survey should he put.

Problems notwithstanding, the effective organisation of household income/expenditure surveys - no easy task in any environment - deserves high priority in countries in transition. 


\section{LIST OF PARTICIPANTS}




\section{COUNTRIES}

AUSTRALIA

BOTSWANA

BRAZIL
Ms. Maureen McDonald, Assistant Director Household Income and Expenditure Section Australian Bureau of Statistics (ABS) Cameron Offices, Chandler Street P.O. Box 10, Belconnen A.C.T. 2616, AUSTRALIA tel.: (61-6) 2527375 fax: (61-6) 2526870 e-mail: maureen.mcdonald@abs.gov.au

Mr. David Wilson, Head, Housing Unit

Australian Institute of Health and Welfare 6A Traeger Court, Fern Hill Park, Bruce Act, GPO Box 570

Canberra ACT 2601, AUSTRALIA

tel.: (61-6) 2441202 fax: (61-6) 2441199

e-mail: david.wilson@aihw.gov.au

Mr. Dabilani Buthali

Statistician

Central Statistical Office

Private Bag 0024

Gaborone, BOTSWANA

tel.: (267) 352200 fax: (267) 352201

e-mail: cso@is.co.za

Dr. Simon Schwartzman, Presidente

Fundacao Instituto Brasileiro de Geografía e Estadística, (IBGE)

Av. Franklin Roosevelt 166, Andar 10

20.000-000 Rio de Janeiro, R.J., BRASIL

tel.: (55-21) 2206671 fax: (55-21) 2205943

e-mail: simon@ibge.gov.br

Mr. Mariano de Matos Macedo, Director

Diretoria de Politica Social

Instituto de Pesquisa Econômica Aplicada (IPEA)

SBS Ed. BNDES, 140. andar

70076-900 Brasilia - D.F. BRAZIL

tel.: (061) 3155282 fax: (061) 2264289

e-mail: macedo@ipea.gov.br 
BRAZIL (cont.)

CANADA

CHILE
Mrs. Sonia Rocha, Senior Analyst, Instituto de Pesquisa Econômica Aplicada (IPEA) Av. Presidente Antonio Carlos 51, 17o. andar Río de Janeiro, R.J., BRASIL

tel.: (55-21) 2121183 fax: (55-21) 2401920

e-mail: srocha@ipea.gov.br

Mr. Alfonso Rodríguez Arias, Consultor Instituto de Pesquisa Econômica Aplicada (IPEA)

Ed. BNDES, 140. andar

SON 116-D-502

70076-900 Brasilia - D.F.

BRAZIL

tel.: (061) 2749590 fax: (061) 2734110

e-mail:

Mrs. Maryanne Webber

Director, Household Surveys Division

Statistics Canada

Jean Talon Bldg., 5th Floor, Section B2

Ottawa, Ontario

CANADA K1A OT6

tel.: (613) 9512899 fax: (613) 9510085

e-mail: webber@statcan.ca

Mr. Alexis Guardia, Director Nacional

Instituto Nacional de Estadística (INE)

Av. Bulnes 418, piso 3

Casilla 498, Correo 3

Santiago, CHILE

tel.: (56-2) 6961929 fax: (56-2) 6961929

e-mail: inesdadm@reuna.cl

Mrs. Sonia Araiz, Economista del Sector Salud, Departamento de Estudios Sociales, Ministerio de Planificación y Cooperación (MIDEPLAN), Ahumada 48

Santiago, CHILE

tel.: (56-2) 6722033 fax:

e-mail: 
CHILE (cont.)

SPAIN

FRANCE

INDIA
Mr. Germán Puentes, Sectorialista, Departamento de Estudios Sociales,

Ministerio de Planificación y Cooperación (MIDEPLAN)

Ahumada 48

Santiago, CHILE

tel.: (56-2) 6722033 fax: (56-2) 6729027

e-mail:

Mrs. Berta Teitelboim, Jefa,

Departamento de Información Social,

Ministerio de Planificación y Cooperación (MIDEPLAN)

Ahumada 48

Santiago, CHILE

tel.: (56-2) 6722033 fax: (56-2) 6729027

e-mail:

Mrs. Paloma Seoane, Jefe de Area de

Encuestas de Presupuestos Familiares y Condiciones de

Vida, Instituto Nacional de Estadística (INE)

Paseo La Castellana 183

28046 Madrid, ESPAŃA

tel.: (34-1) 5839264 fax: (34-1) 5839488

e-mail: pseoane@ine.es

Mr. Madior Fall, Researcher

Institut National de la Statistique

et des Etudes Economiques (INSEE)

18, Bld. Adolphe Pinard

75675 Paris (Cedex 14),

FRANCE

tel.: (33-1) 41175469 fax: (33-1) 41176317

e-mail: madior.fall@dg75-f350.insee.atlas.fr

Dr. P.D. Joshi, Joint Director, National Sample Survey

Organization, Department of Statistics

Mininstry of Planning and Prog. Implementation

Sardar Patel Bhavan

Parliament Street, New Delhi 110001, INDIA

tel.: (91-11) 3361080 fax: (91-11) 3342384

e-mail: dgcso@hub.nic.in 
INDONESIA

MEXICO

SOUTH AFRICA

TURKEY

URUGUAY
Dr. Agus Sutanto, Chief

Economic Statistics Analysis and Development Division, Central Bureau of Statistics (CBS)

8 Jalan Dr. Sutomo

P.O. Box 1003

Jakarta 1002, INDONESIA

tel.: (62-21) 3810291 fax: (62-21) 3519744

e-mail: sugito@bps.go.id

Lic. Miguel Cervera Flores, Director General de Estadística, Instituto Nacional de Estadística, Geografía e Informática (INEGI), Edificio Sede, Av. Prolongación Héroe de Nacozari No. 2003 Sur, CP 2240 Ciudad Industrial Aguascalientes, MEXICO

tel.: (491) 82480 fax: (491) 53888

e-mail: mcervera@dge.inegi.gob.mx

Dr. Rosaline Hirschowitz

Chief Director, Research and Development

Central Statistical Service (CSS)

Steyn's Arcade, 274 Schowman Street

Pretoria 0001, SOUTH AFRICA

tel.: (27-12) 3108101 fax: (27-12) 3108504

e-mail: rosh@css.pwv.gov.za

Mrs. Güzin Erdogan, Chief, Purchasing Power Parity

Division, State Institute of Statistics, Prime Ministry

Necatibey Caddesi No. 114

06100 Ankara, TURKEY

tel.: (90-312) 4251765 fax: (90-312) 4253387

e-mail:

guzin.erdogan@pascal.bsb.die.gov.tr

Mrs. Marcia Rama Regueira, Encargada de la Unidad de Indicadores Sociales

Instituto Nacional de Estadística (INE)

Rio Negro 1520, piso 4

Montevideo, URUGUAY

tel.: (598-2) 908902 fax: (598-2) 914653

e-mail: mrama@ine.gub.uy 
URUGUAY (cont.) Mrs. María Dolores Fernández, Directora, División

Estadísticas Sociodemográficas

Instituto Nacional de Estadística (INE)

Rio Negro 1520, piso 4

Montevideo,

URUGUAY

tel.: (598-2) 908902 fax: (598-2) 914653

e-mail: mdfernan@ine.gub.uy

UNITED STATES OF AMERICA
Mr. Charles T. Nelson, Assistant Division Chief for

Economic Characteristics, Housing and Household Economic Statistics Division

U.S. Bureau of the Census

Washington, DC 20233

U. S. A.

tel.: (301) 7638029 fax: (301) 7638412

e-mail: charles.t.nelson@ccmail.census.gov

\section{AGENCIES}

CELADE

ECA
Mr. Jorge Bravo, Experto en Población y Desarrollo, Area Demografía

Centro Latinoamericano de Demografía

CELADE

Casilla 91

Santiago, CHILE

tel.: (56-2) 2102007 fax: (56-2) 2080252

e-mail: jbravo@eclac.cl

Dr. Siddig A. Salih, Senior Regional Advisor on Poverty Issues

Economic Commission for Africa (ECA)

Africa Hall

P.O. Box 3001

Addis Ababa, ETHIOPIA

tel.: (251-1) 511056 fax: (251-1) 514416

e-mail: siddiga.salihatuneca@un.org 
ECLAC
Mr. Gert Rosenthal, Executive Secretary,

Economic Commission for Latin America and the Caribbean (ECLAC)

Av. Dag Hammarskjöld s/n

Casilla 179-D

Santiago, CHILE

tel.: (56-2) 2102553 fax: (56-2) 2080252

e-mail: grosenthal@eclac.cl

Mr. Pedro Sáinz, Chief, Division of Statistics and Economic Projections,

Economic Commission for Latin America and the Caribbean (ECLAC)

Av. Dag Hammarskjöld s/n, Casilla 179-D

Santiago, CHILE

tel.: (56-2) 2102633 fax: (56-2) 2102472

e-mail: psainz@eclac.cl

Mr. Juan Carlos Feres

Division of Statistics and Economic Projections,

Economic Commission for Latin America and the Caribbean (ECLAC)

Av. Dag Hammarskjöld s/n

Casilla 179-D

Santiago, CHILE

tel.: (56-2) 2102408 fax: (56-2) 2102472

e-mail: jferes@eclac.cl

Mr. Luis Beccaria

Economic Commission for Latin America and the Caribbean (ECLAC)

Av. Dag Hammarskjöld $s / n$

Casilla 179-D

Santiago,

CHILE

tel.:

e-mail: 
ECLAC (cont.)
Mr. Pascual Gerstenfeld, Principal Expert Quantitative Analysis

Social Development Division

Economic Commission for Latin America and the Caribbean (ECLAC)

Av. Dag Hammarskjöld s/n, Casilla 179-D

Santiago, CHILE

tel.: (56-2) 2102299 fax: (56-2) 2080252

e-mail: pgerstenfeld@eclac.cl

Mrs. Beverley Carlson, Social Affairs Officer

Social Development Division

Economic Commission for Latin America and the Caribbean (ECLAC)

Av. Dag Hammarskjöld $s / n$

Casilla 179-D

Santiago, CHILE

tel.: (56-2) 2102528 fax: (56-2) 2080252

e-mail: bcarlson@eclac.cl

Mr. Rubén Katzman, Director

ECLAC

Office in Montevideo

Juncal 1305 Of. 1002, CP 11000

Montevideo,

URUGUAY

tel.: (598-2) 961580 fax: (598-2) 961776

e-mail:

Mrs. Maria de la Luz Avendaño

Division of Statistics and Economic Projections,

Economic Commission for Latin America and the Caribbean (ECLAC)

Av. Dag Hammarskjöld s/n, Casilla 179-D

Santiago, CHILE

tel.: (56-2) 2102441 fax: (56-2) 2102472

e-mail: mavendano@eclac.cl 
Mr. Marcelo Ortúzar

Division of Statistics and Economic Projections, Economic Commission for Latin America and the Caribbean (ECLAC)

Av. Dag Hammarskjöld s/n, Casilla 179-D

Santiago, CHILE

tel.: (56-2) 2102449 fax: (56-2) 2102472

e-mail: mortuzar@eclac.cl

Mr. Carlos Daroch

Division of Statistics and Economic Projections,

Economic Commission for Latin America and the Caribbean (ECLAC)

Av. Dag Hammarskjöld s/n, Casilla 179-D

Santiago, CHILE

tel.: (56-2) 2102449 fax: (56-2) 2102472

e-mail: cdaroch@eclac.cl

ESCAP

Mr. M Khalid Siddiqui, Chief, Statistics Development

Section, Statistics Division, ESCAP

United Nations Building

Rajdamnern, Avenue

Bangkok 10200,

THAILAND

tel.: (66-2) 2881653 fax: (66-2) 2881082

e-mail: siddiqui.unescap@un.org

EUROSTAT

IDB
Mrs. Teresa Bento, Acting Head, Living Conditions

Statistics Unit, Statistical Office of the European

Communities, EUROSTAT

Bâtiment Jean Monnet C3/85

Rue Alcide De Gasperi

L-2920 LUXEMBOURG

tel.: (352) 4301-32056 fax: (352) 4301-34415

e-mail: teresa.bento@eurostat.cec.be

Mr. Michael McPeak, Chief

Statistics and Quantitative Analysis

Inter-American Development Bank (IDB)

1300 New York Avenue, N.W.

Washington D.C. 20577

U. S. A.

tel.: (1-202) 6232479 fax: (1-202) 6233682

e-mail: michaelm@iadb.org 
ILO

Mr. Hamid Tabatabai, Senior Economist

ILO/SAMAT

11 th floor, Karigamombe Centre

53 Samora Machel Ave.

P.O. Box 210, Harare

ZIMBABWE

tel.: 263-4-759460 fax: 263-4-759372

e-mail: tabatabai@ilo.org

ILPES

Mrs. Lais Abramo, Directora a.i.

Dirección de Desarrolly y Gestión Local

ILPES, Av. Dag Hammarskjöld s/n

Casilla 179-D, Santiago, CHILE

tel.: (56-2) 2102510 fax: (56-2) 2080252

e-mail:

PAHO/WHO

THE WORLD BANK

Mr. Edward Greene, Advisor Public Policy and Health, Pan American Health Organization/World Health Organization (PAHO/WHO)

Pan American Sanitary Bureau, Regional Office of the World Health Organization

525 Twenty-third Street, N.W., Washington, D.C. 20037-2895, USA

tel.: (202) 9743177 fax: (202) 9743675

e-mail: greeneed@paho.org

Mr. Michael Ward

Principal Economist

Development Data Group

The World Bank

1818 H Street NW,

Washington D.C. 20433,

U.S.A.

tel.: (1-202) 4736318 fax: (1-202) 5223669

e-mail: mward@worldbank.org

UNDP

Mr. Selim Jahan, Deputy Director

Human Development Report Office (HDRO)

UNDP

336 East 45th Street,

New York, N.Y. 10017, U. S. A.

tel.: (1-212) 9063699 fax: (1-212) 9063677

e-mail: selim.jahan@undp.org 
UNFPA

UNICEF

UNSD
Mr. José García-Núnéez, Regional Advisor

CST/UNFPA

Tomás de Figueroa 2451, Vitacura

Casilla 19036,

SANTIAGO

tel.: (56-2) 2066097 fax: (56-2) 2066105

e-mail: unfpachi@huelen.reuna.cl

Mr. Alberto Minujin, Regional Advisor

Regional Office for Latin America and the Caribbean

UNICEF, Transversal 38 No. 100-25, piso 3, P.O. Box 7555

Santa Fe de Bogotá D.C., COLOMBIA

tel.: (57-1) 6357211 fax: (57-1) 3101437

e-mail: aminujin@unicef.org

Ms. Joann Vanek, Chief, Social and Housing Statistics, Statistics Division (UNSD)

DC2 - 1584,

United Nations,

New York, N.Y. 10017

U. S. A.

tel.: (1-212) 9634939 fax: (1-212) 9634116

e-mail: vanek@un.org 
